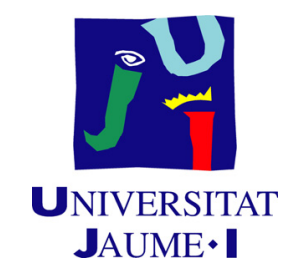

ESCUELA SUPERIOR DE TECNOLOGÍA Y CIENCIAS EXPERIMENTALES

Departamento de Química Inorgánica y Orgánica

\title{
ESCENARIOS ATMOSFÉRICOS DE CONTAMINACIÓN Y LLUVIA ÁCIDA SOBRE LA VERTIENTE MEDITERRÁNEA DEL SISTEMA IBÉRICO
}

\author{
TESIS DOCTORAL \\ Presentada por: \\ $M^{a}$ Victoria Quereda Vázquez \\ Dirigida por: \\ Dr. D. José Quereda Sala \\ Dr. D. Enrique Montón Chiva
}

INSTITUTO INTERUNIVERSITARIO DE GEOGRAFÍA

LABORATORIO DE CLIMA, UNIVERSITAT JAUME I

Castellón, 2016 

"El hombre de hoy usa y abusa de la Naturaleza como si hubiera de ser el último inquilino de este desgraciado planeta, como si detrás de él no se anunciara un futuro." Miguel Delibes Un mundo que agoniza, 1975 

A mis padres Paqui y Pepe

A mis sobrinos Víctor, Andrea y Martina,

A mi futuro marido Juanma 



\section{AGRADECIMIENTOS}

Todo el mundo, en mi entorno, se pregunta cómo una licenciada en química decide dedicar cuatro años de su vida a realizar una tesis doctoral sobre climatología y medio ambiente. Esta pregunta siempre me conduce a la misma persona: a mi padre, el Dr. D. José Quereda Sala. Desde bien niña me he sentado en las últimas filas de sus numerosas conferencias, ponencias o incluso charlas informales para escuchar atentamente como desde el inicio iba desenmarañando todas las intrigas del temido cambio climático. He crecido viendo como mi padre no se rendía nunca y jamás le ha importado nadar a contracorriente. Tengo 31 años y quizá hoy con estas palabras descubra lo mucho que lo admiro. Por él me embarqué en esta apasionante aventura, a él le debo mi pasión por el clima y especialmente por el medio ambiente y sobretodo mis ganas de compartir esta experiencia a su lado. Y para él, como no podía ser de otra manera, va mi primer agradecimiento. Gracias a mi director de tesis, mi padre, mi maestro, mi ejemplo a seguir. Gracias papá por ser tan exigente, por obligarme a dar lo mejor de mí y por dar siempre lo mejor de ti. Gracias porque durante estos cuatro años no han existido los relojes, siempre era hora de trabajar, siempre había una idea nueva o un nuevo reto que afrontar. Gracias por enseñarme desde bien pequeña lo que es ser un investigador. Quizá no sepas que cuando empecé esta tesis lo hice también con un objetivo personal. Empecé esta aventura para conseguir que estuvieras orgulloso de mi, no sé si lo he conseguido pero lo que si se es que la he acabado estando aún más orgullosa de ti. Los dos sabemos que esta singladura no ha sido fácil. El exceso de confianza le ha permitido a esta atrevida ignorante cuestionarte absolutamente todo y creo que, quizá ahí, este la magia de este trabajo. Tu gran sabiduría, tu larguísima experiencia y mi joven inconformismo han desembocado en un trabajo del que ambos estamos orgullosos. No me imagino mayor honor que después de tu dilatada trayectoria sea mi tesis, la de tu hija pequeña, la última que vayas a dirigir. Gracias Papá.

No todo ha sido fácil, trabajar codo a codo padre e hija nunca lo es. Por eso hoy hay otra persona sin la cual este trabajo no sería lo que es. Mi madre, Paqui. Gracias mamá por enseñarme a no rendirme nunca, a luchar por lo que quiero y a levantarme cuando caigo una y otra vez. Por darme ánimos cuando me fallaban las fuerzas, por saber nadar entre dos aguas y conseguir que padre e hija hayan podido entenderse y sacar adelante este trabajo. Mi madre, mi amiga, mi ángel, gracias por ser como eres y porque todo lo que yo soy te lo debo a ti. Gracias por ser el espejo en el que siempre me voy a querer mirar. Me faltan páginas para agradecerte TODO lo que has hecho por mí. No existen palabras en el mundo para expresar lo que 
significas para mí así que aunque se queden cortas te diré las mismas que te digo cada noche: te quiero mami.

En tercer lugar quiero expresar mi agradecimiento al Dr. D. Enrique Montón Chiva, mi codirector de tesis pero ante todo mi amigo. Gracias por tus sabios consejos, tu apoyo incondicional y tus sabias correcciones. Gracias porque desde que empecé esta andadura tu disponibilidad hacia mi trabajo ha sido absoluta, nunca han existido las horas o los fines de semana, siempre has estado ahí para apoyarme. Gracias.

No puedo olvidarme en estas líneas de agradecer el esfuerzo a mi informático personal, mi hermano, Pepe. Gracias por estar 24 horas al día disponible para emergencias informáticas. Por no desesperarte cuando esta torpe bloqueaba todos los ordenadores de casa o perdía un documento y tenías que estar horas buscando como recuperar mi trabajo. Gracias.

A mi hermana, Paqui, gracias por apoyarme en todo, por ayudarme a entenderme con mi director, nuestro padre, como solo una hermana mayor sabe hacer.

A Víctor, Andrea y Martina, mis sobrinos, porque en sus sonrisas siempre encuentro la calma. Porque solo vosotros sabéis hacer que me olvide del mundo. Os quiero.

A mi ángel de la guarda, desde el cielo me acompañas a cada paso y me das fuerzas para enfrentarme a todo, gracias abuelita, no imaginarías cuánto me faltas.

A Juan y Manolita por su cariño y apoyo incondicionales. Gracias de todo corazón.

Finalmente quiero darle las gracias a Juanma, mi compañero, mi amigo, mi futuro marido. Gracias por tus abrazos que paran mi mundo y me permiten respirar cuando todo se desmorona. Por tus ánimos, por confiar en mí como solo tú sabes hacerlo. Gracias por perdonar todo el tiempo que esta tesis nos ha mantenido separados, por el tiempo que te merecías y no te he podido dedicar, por entender lo importante que esto era para mí y compartir conmigo este proyecto. Te quiero. Siempre juntos.

A todos, esta tesis también es vuestra, jmuchas gracias! 


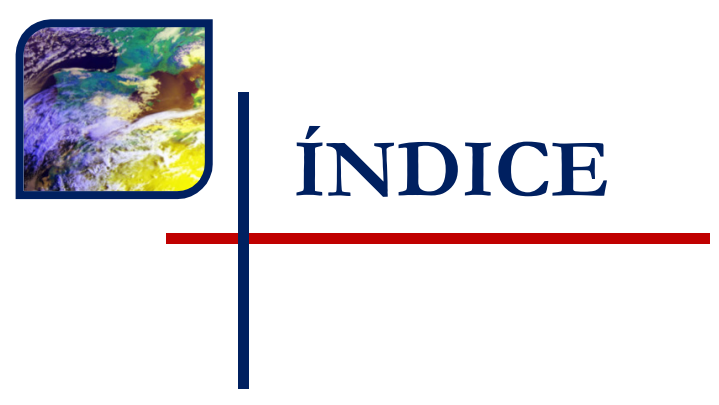





\section{ÍNDICE}

CAPÍTULO PRIMERO: ANTECEDENTES, FUNDAMENTOS CIENTÍFICOS Y

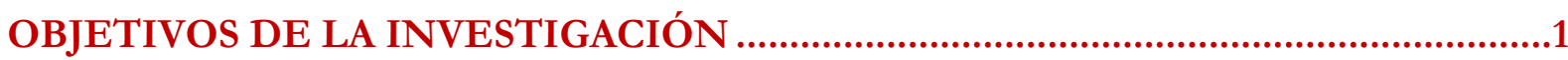

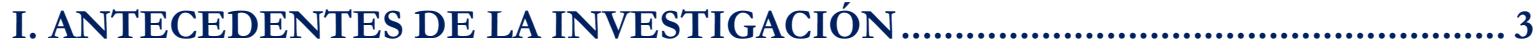

II. EVOLUCIÓN HISTÓRICA DE LA PROBLEMÁTICA AMBIENTAL EN LA REGIÓN MEDITERRÁNEA: VERTIENTE DEL SISTEMA IBÉRICO ................... 4

III. DAÑOS OBSERVADOS SOBRE LAS MASAS FORESTALES .............................13

IV. FUNDAMENTOS CIENTÍFICOS DE LA TESIS ...........................................15

V. OBJETIVOS PRINCIPALES DE LA INVESTIGACIÓN ..................................19

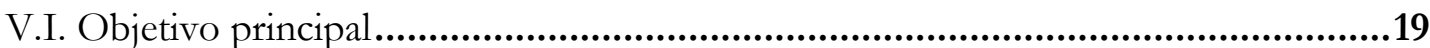

V.II. Objetivo complementario .................................................................................19

VI. HIPÓTESIS, METODOLOGÍA Y PLAN DE TRABAJO ....................................21

CAPÍTULO SEGUNDO: EL ESCENARIO ATMOSFÉRICO SOBRE LA VERTIENTE MEDITERRÁNEA DEL SISTEMA IBÉRICO.................................. 25

I. EL CONOCIMIENTO DEL ESCENARIO ATMOSFÉRICO REGIONAL Y SU

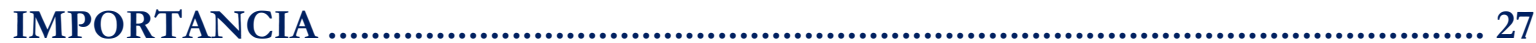

II. LA CAPA DE MEZCLA: DEFINICIÓN Y METODOLOGÍAS DE CÁLCULO. 29

II.I. Metodología aplicada para la determinación de la altura de la capa de mezcla en el

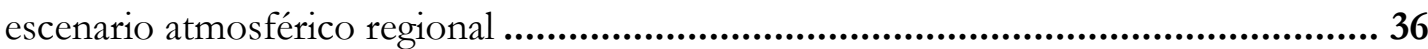

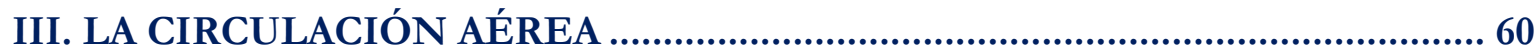

III.I. Configuración de la circulación aérea en el límite de la capa de mezcla ................ 64

IV. CONCLUSIONES SOBRE EL ESCENARIO ATMOSFÉRICO REGIONAL....71 


\section{LA ATMÓSFERA COMO MEDIO RECEPTOR DE CONTAMINANTES}

GASEOSOS

II.I. Clasificación del poder dispersor de la atmósfera (clases de estabilidad Pasquill-

Gifford-Turner) 78

III. TIPOS DE PENACHOS EN FUNCIÓN DE LA ESTRATIFICACIÓN ATMOSFÉRICA.

III.I. El gradiente vertical de temperatura: $\partial \mathrm{T} / \partial \mathrm{z}$ 79

III.II. El gradiente vertical de velocidad del viento: $\partial \mathrm{u} / \partial \mathrm{z}$. 87

\section{CÁlCULO DE LA SOBREELEVACIÓN DEL PENACHO DE HUMOS EN

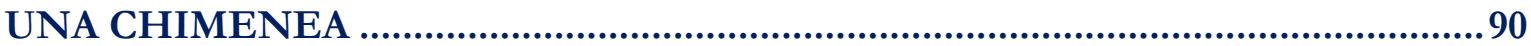

IV.I. Aproximación semiempírica al cálculo de la sobreelevación de un penacho..........92

IV.II. Fórmula de Briggs generalizada ................................................................. 94

IV.III. Aplicación y verificación de las expresiones generalizadas de Briggs para el cálculo de la sobreelevación del penacho de la CT de Andorra ...

\section{MODELO GAUSSIANO DE DISPERSIÓN ATMOSFÉRICA DE}

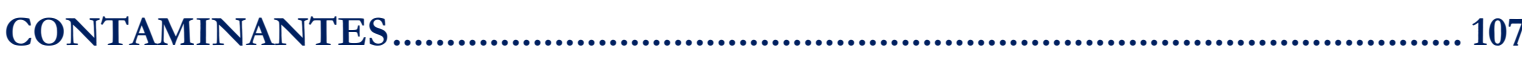

V.I. Modelo de Pasquill para la dispersión de contaminantes emitidos por una fuente puntual

V.II. Cálculo de los coeficientes de dispersión de Gauss

V.III. Corrección al Modelo de Pasquill para la dispersión de contaminantes emitidos bajo una capa de inversión térmica.

V.IV. Aplicación y verificación del modelo gaussiano de dispersión de contaminantes de Pasquill 
VI. CONCLUSIONES SOBRE LA MODELIZACIÓN GAUSSIANA DEL PENACHO 130

CAPÍTULO CUARTO: LA IDENTIFICACIÓN DE LAS SITUACIONES DE IMPACTOS SEVEROS DE DIÓXIDO DE AZUFRE

II. EPISODIOS SOBRE EL VALOR LÍMITE MÁXIMO DE INMISIÓN DE SO 139 III. LA CONCENTRACIÓN GEOGRÁFICA Y ESTACIONAL DE LA CONTAMINACIÓN

IV. LA CONFIGURACIÓN ATMOSFÉRICA EN LAS SITUACIONES DE PICOS SEVEROS DE INMISIÓN DE $\mathrm{SO}_{2}$

IV.I Las situaciones del 2000 143

IV.II Las situaciones del 2001 150

IV.III La situaciones del 2004 155

IV.IV Las situaciones más recientes de altos valores de inmisión 159

V. CONCLUSIONES Y SÍNTESIS DE LA ESTRUCTURA ATMOSFÉRICA EN LAS SITUACIONES DE IMPACTO SEVERO DE CONTAMINACIÓN. 175

CAPÍTULO QUINTO: LAS SITUACIONES ATMOSFÉRICAS DE ACIDIFICACIÓN Y SU IMPACTO 179

I. METODOLOGÍA DE IDENTIFICACIÓN 181

II. SITUACIONES ATMOSFÉRICAS DE ACIDIFICACIÓN. 185

III. SITUACIONES DE NEUTRALIZACIÓN DE LLUVIA ÁCIDA 194

IV. CONCLUSIONES SOBRE LA CALIDAD DEL AIRE 204 
CAPÍTULO SEXTO: ANÁLISIS DEL VALOR DE ACIDEZ Y DEL CONTENIDO DE AZUFRE DE LOS SUELOS EN LAS COMARCAS DE ELS PORTS DE

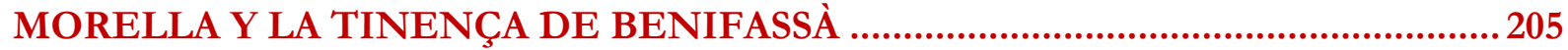

I. OBJETIVO DE LA ANALÍTICA DE SUELOS DESARROLLADA..................... 207

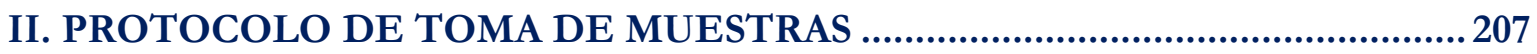

III. TÉCNICAS DE LA ANALÍTICA PRACTICADA.......................................... 210

III.I. Determinación de azufre ........................................................................... 210

III.II. Determinación del pH en muestras sólidas ................................................... 210

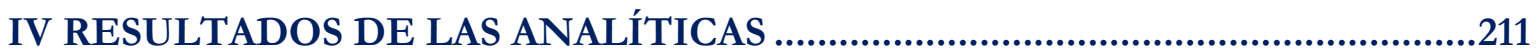

IV.I. Resultados Informe $\mathrm{n}^{\mathrm{o}} \mathrm{C} 123180$ (monte Carrascales) .......................................211

IV.II. Resultados Informe $\mathrm{n}^{\mathrm{o}} \mathrm{C} 130577$ (monte Pereroles) …..................................... 212

V. CONCLUSIONES SOBRE EL ESTADO EDAFOLÓGICO DE LA REGIÓN

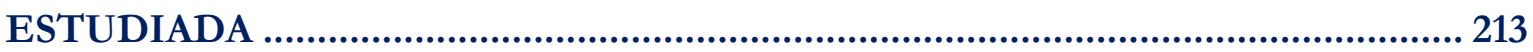

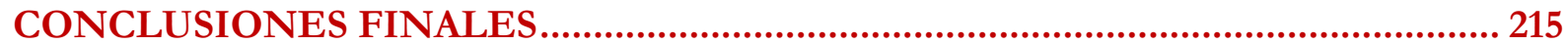

CONCLUSIONES FINALES Y FUTURAS LÍNEAS DE INVESTIGACIÓN ........ 217

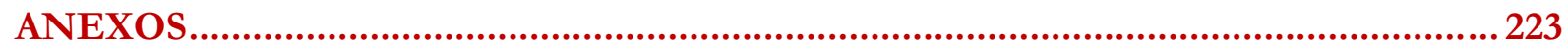

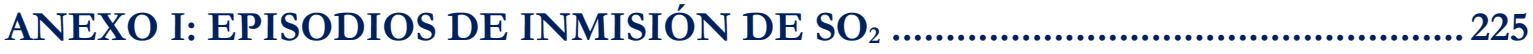

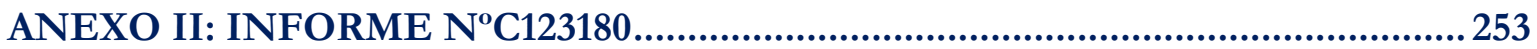

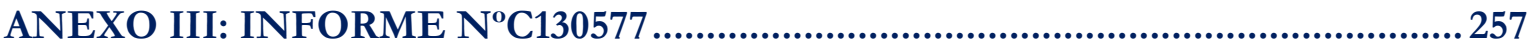

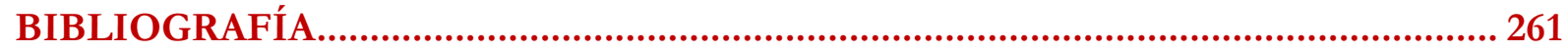

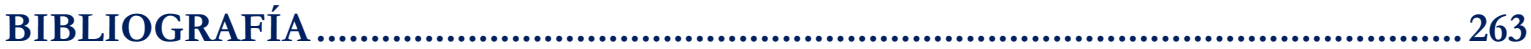

Referencias Bibliográficas ................................................................................. 263

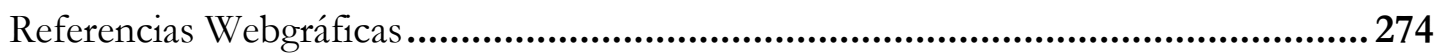

Legislación: Decretos y Directivas...........................................................................2275 


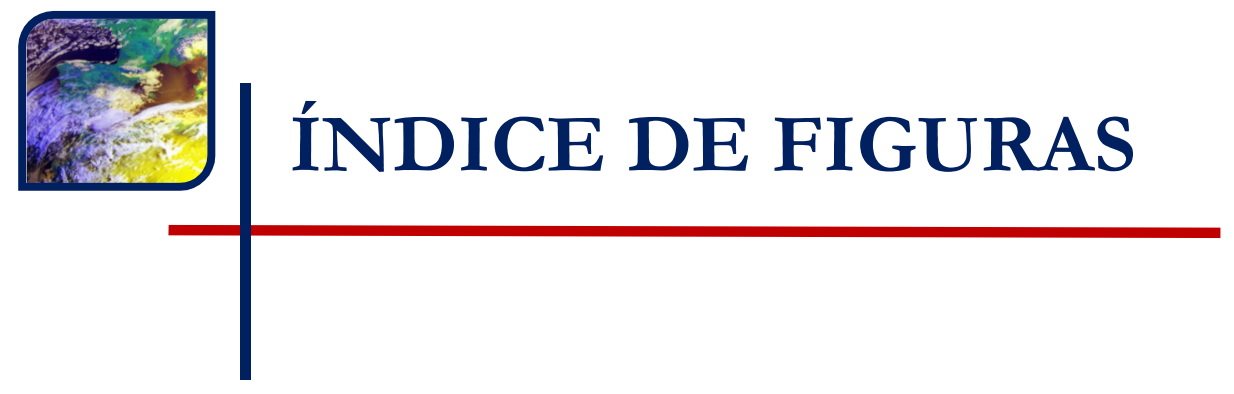





\section{ÍNDICE DE FIGURAS}

Figura 1: Central Térmica de Andorra (Teruel). Fuente propia, imagen tomada el 15 de diciembre del 2013.

Figura 2: La imagen es evocadora de que la opinión pública impute daños ecológicos a la CT desde el primer momento y de que el chorro de humos se compare a un penacho-misil lanzado a grandes distancias. Fuente propia, imagen tomada el 30 de noviembre del 2013

Figura 3: La situación atmosférica mostraba una gran inestabilidad durante los días 6 a 11 de mayo del 1985, período de experimentación del NILU. Fuente: http://www.wetterzentrale.de/topkarten/fsreaeur.html.

Figura 4: Penacho emitido por la central térmica de Andorra en condiciones de inestabilidad. Fuente propia, imagen tomada el 14 de diciembre del 2013.

Figura 5: Árbol afectado por la patología ungulina, "Fotomitoxis pinícola", y fracturado posteriormente por el viento. Monte Bobalar de Castellfort, 1998. Fuente: archivo del Laboratorio de Climatología de la Universitat Jaume I.

Figura 6: Infección de muérdago, "Viscum álbum", sobre un árbol caído en la vertiente del Barranc del Molar, monte Bobalar de Castellfort, 1998. Fuente: archivo del Laboratorio de Climatología de la Universitat Jaume I.

Figura 7: Principales masas forestales estudiadas en la vertiente mediterránea del sistema ibérico durante los diversos proyectos (2005-2012). Fuente: archivo del Laboratorio de Climatología de la Universitat Jaume I.

Figura 8: La circulación aérea regional en el nivel superior de la capa activa (1200-1450 metros). Estaciones de la CT de Andorra, Torre Miró y monte Caro. Fuente: archivo del Laboratorio de Climatología de la Universitat Jaume I.

Figura 9: Evolución del crecimiento forestal en los montes de Carrascales y Pereroles. Las curvas dendrocronológicas muestran la superación o estabilización del declive en el crecimiento forestal. Fuente: Elaboración propia, Laboratorio de Climatología de la Universitat Jaume I.

Figura 10: Mapa en relieve de la región de Els Ports de Morella (Castellón) y de la reserva natural de Els Ports de Tortosa-Beseit (Massís del Caro, Tarragona). La nítida 
alineación aerodinámica desde la CT a Coratxar, permite una excelente modelización gaussiana del penacho. Fuente: elaboración propia, Laboratorio de Climatología de la Universitat Jaume I.

Figura 11: Analizador de lluvia ácida, marca Kimoto, modelo AR-106. Fuente: archivo del Laboratorio de Climatología de la Universitat Jaume I.

Figura 12: Sistema de recepción de imágenes procedentes de satélites geoestacionarios (MSG) y orbitales (NOAA). Estación de Climatología, Universitat Jaume I. Fuente: archivo del Laboratorio de Climatología de la Universitat Jaume I.

Figura 13: Mapa geográfico del Bajo Aragón y de la vertiente mediterránea del Sistema Ibérico. Fuente: Cartografía del IGN, Mapa Topográfico Nacional, hojas 520, 521, 545 y 546....24

Figura 14: Capa de inversión sobre la reserva natural de Tortosa-Beseit. Imagen tomada desde la cima del Monte Caro (1447 metros). Fuente: archivo del Laboratorio de Climatología de la Universitat Jaume I.

Figura 15: Mapa en relieve de la región ibérica estudiada con la ubicación de las estaciones automáticas de Fredes (1235 metros), Torre Miró (1256 metros) y monte Caro (1447 metros), pertenecientes a la red meteorológica de la Universitat Jaume I. Fuente: elaboración propia, Laboratorio de Climatología, Universitat Jaume I

Figura 16: Estación meteorológica del pico Fredes (1235 metros) y observatorio forestal. Fuente: archivo del Laboratorio de Climatología de la Universitat Jaume I.

Figura 17: Estación meteorológica de la cima del monte Caro (1447 metros). Fuente: archivo del Laboratorio de Climatología de la Universitat Jaume I.

Figura 18: Radiosondeo de Zaragoza aeropuerto del 25 de octubre del 2015. Altura de la capa de mezcla (LCLP o NCA) a 882,8 hPa (1150 metros), (Mixing ratio 7,87 g/Kg). Este nivel (LCLP) marca el techo de la capa de mezcla, en coincidencia con la capa de inversión. Fuente: http://weather.uwyo.edu/upperair/sounding.html.

Figura 19: Información sobre los índices asociados al radiosondeo de Zaragoza aeropuerto del 25 de octubre del 2015. Fuente: http://weather.uwyo.edu/upperair/sounding.html. 
Figura 20: Esquema de las capas inferiores de la Troposfera: capa geográfica y capa libre. Fuente: archivo del Laboratorio de Climatología de la Universitat Jaume I.

Figura 21: Imagen de la CT. El penacho se eleva hasta la altura de 1150 metros (LCLP a $882,8 \mathrm{hPa}$ ). La cizalla del viento en superficie queda reflejada en la dirección contraria de las columnas de vapor. Fuente propia, imagen tomada el 25 de octubre del 2015 a las 13 horas.

Figura 22: Análisis topográfico de la región Calanda-Coratxar (Pobla de Benifassà). Fuente: elaboración propia, Laboratorio de Climatología, Universitat Jaume I.

Figura 23: El penacho emitido por la chimenea de la CT se difunde linealmente sin ascenso apreciable. Fuente propia, imagen tomada el 30 de noviembre del 2013 a las 14 horas. 42

Figura 24: Mapa de presión en superficie del 30 de noviembre del 2013 a las 12 horas. Fuente: http://www.wetterzentrale.de/topkarten/tkfaxbraar.html.

Figura 25: Registros de la torre meteorológica de la CT y del observatorio de Fredes del 30 de noviembre del 2013. Fuente: datos proporcionados por la CT y la red meteorológica universitaria. Elaboración propia, Laboratorio de Climatología, Universitat Jaume I.

Figura 26: Mapa de presión en superficie del 20 de noviembre del 2015 a las 12 horas. Fuente: http://www.wetterzentrale.de/topkarten/tkfaxbraar.html.

Figura 27: Registros del observatorio de Fredes y de la torre meteorológica de la CT del 20 de noviembre del 2015. Fuente: datos proporcionados por la CT y la red meteorológica universitaria. Elaboración propia, Laboratorio de Climatología de la Universitat Jaume I.

Figura 28: El penacho emitido por la chimenea de la CT se difunde linealmente sin ascenso apreciable. Fuente propia, imagen tomada el 20 de noviembre del 2015 a las 13 horas. .46

Figura 29: La capa de inversión y la cizalla en la velocidad del viento determinan las ondas de Kelvin-Helmhotz sobre Valderrobres. Fuente propia, imagen tomada el 20 de noviembre del 2015 a las 18 horas.

Figura 30: El ascenso vertical del penacho, con viento en calma y dirección opuesta a la de superficie, se detiene en el nivel de la capa de inversión alta (1350 metros aprox.). Las torres de emisión de vapor muestran la capa de inversión baja entre 1050 y 1080 metros. Fuente propia, imagen tomada el 2 de septiembre del 2013 a las 14 horas. 
Figura 31: Radiosondeo del día 2 de septiembre del 2013. Fuente: http://weather.uwyo.edu/upperair/sounding.html.

Figura 32: Reanálisis a $850 \mathrm{hPa}$ del 2 de septiembre del 2013. La notable dorsal a 850 $\mathrm{hPa}$ es la causa de la gran inversión térmica de subsidencia. Fuente: http://www.wetterzentrale.de/topkarten/fsreaeur.html.

Figura 33: Radiosondeo del 14 de diciembre del 2013. Fuente: http://weather.uwyo.edu/upperair/sounding.html.

Figura 34: Imagen del penacho de la CT. La columna ascendente del fluido es atrapada en el nivel de condensación ascendente y mezclada en el estrato situado sobre la base de la inversión (1150-1200 metros). Fuente propia, imagen tomada el 14 de diciembre del 2013 a las 14 horas.

Figura 35: Promedio de los radiosondeos invernales durante el mes de febrero del 2013 en Zaragoza aeropuerto. Fuente: radiosondeos de la Universidad de Wyoming. Elaboración propia, Laboratorio de Climatología de la Universitat Jaume I.

Figura 36: Promedio de los radiosondeos invernales durante el mes de febrero del 2015 en Zaragoza aeropuerto. Fuente: radiosondeos de la Universidad de Wyoming. Elaboración propia, Laboratorio de Climatología de la Universitat Jaume I.

Figura 37: Radiosondeo de Zaragoza aeropuerto del 24 de octubre del 2015. Fuente: http://weather.uwyo.edu/upperair/sounding.html.

Figura 38: Imagen de la CT, la elevación vertical del penacho hasta los 1200 metros o altura del LCLP puede evaluarse sobre la escala de los 343 metros de la altura de la chimenea. Fuente propia, imagen tomada el 24 de octubre del 2015.

Figura 39: Radiosondeo de Zaragoza aeropuerto del 19 de marzo del 2011. La capa de inversión aparece nítida sobre los 875 hPa. Fuente: http://weather.uwyo.edu/upperair/sounding.html.

Figura 40: Capa de inversión sobre la reserva natural de Tortosa-Beseit. Imagen tomada desde la cima del monte Caro (1447 metros) el 19 de marzo del 2011 a las 12 horas. El LCLP se sitúa a 867,7 hPa (1300 metros). Fuente: Quereda, 2012: 149. 
Figura 41: Temperaturas medias mensuales y gradientes en las estaciones de Fredes y del monte Caro (2008-2015). Fuente: elaboración propia, Laboratorio de Climatología de la Universitat Jaume I.

Figura 42: La disimetría e inclinación de los pinares (Pinus sylvestris) en la zona cacuminal del monte Caro (1447 metros, Reserva Natural de Tortosa-Beseit). Fuente: archivo del Laboratorio de Climatología de la Universitat Jaume I.

Figura 43: Localización de los principales observatorios anemocinemográficos utilizados en este estudio. Fuente: archivo del Laboratorio de Climatología de la Universitat Jaume I.

Figura 44: Topografía de la superficie isobárica de 700 hPa (2000-2014). Fuente: NCEP Reanalysis, NOAA/OAR/ESRL PSD, Boulder, Colorado, USA, http://www.esrl.noaa.gov/psd.

Figura 45: Topografía de la superficie isobárica de 850 hPa (2000-2014). Fuente: NCEP Reanalysis, NOAA/OAR/ESRL PSD, Boulder, Colorado, USA, http://www.esrl.noaa.gov/psd.

Figura 46: La topografía de la superficie isobárica a nivel de 925 hPa (2000-2014) muestra la fuerte influencia de la cuenca de bajas presiones del Mediterráneo. Fuente: NCEP Reanalysis, NOAA/OAR/ESRL PSD, Boulder, Colorado, USA, http://www.esrl.noaa.gov/psd.

Figura 47: La rosa anual de los vientos del anemocinemógrafo de la CT de Andorra, Teruel (1992/2010), muestra el acusado predominio de los vientos procedentes del sector W y WNW. Fuente: datos proporcionados por la CT. Elaboración propia, Laboratorio de Climatología de la Universitat Jaume I.

Figura 48: Rosa anual de inmisiones de $\mathrm{SO}_{2}\left(\mu \mathrm{g} / \mathrm{m}^{3}\right)$ en Coratxar según la dirección del viento (2014/2015). El eje NNW se muestra absolutamente clave en los mayores valores de inmisión. Fuente: Red Valenciana de Vigilancia y Control de la Contaminación Atmosférica. Elaboración propia, Laboratorio de Climatología de la Universitat Jaume I.

Figura 49: Rosas estacionales de las inmisiones de $\mathrm{SO}_{2}$ en función de la dirección del viento en Coratxar (2014/2015). Fuente: Red Valenciana de Vigilancia y Control de la Contaminación Atmosférica. Elaboración propia, Laboratorio de Climatología de la Universitat Jaume I. 
Figura 50: Rosa anual de vientos y umbrales de los picos de las inmisiones de $\mathrm{SO}_{2}$ en Coratxar (2000). La totalidad de los picos de inmisión de $\mathrm{SO}_{2}$ aparece vinculada a ventilaciones del NNW, con alguna mínima presencia en vientos del Norte. Fuente: Red Valenciana de Vigilancia y Control de la Contaminación Atmosférica. Elaboración propia, Laboratorio de Climatología de la Universitat Jaume I.

Figura 51: Rosa de vientos del período nocturno durante el mes de enero (2003-2012), en la cima del monte Caro a 1447 metros, $850 \mathrm{hPa}$. Fuente: red meteorológica universitaria. Elaboración propia, Laboratorio de Climatología de la Universitat Jaume I.

Figura 52: Rosa de vientos durante los meses de invierno (2014-2015) en Fredes, 1235 metros. Fuente: red meteorológica universitaria. Elaboración propia, Laboratorio de Climatología de la Universitat Jaume I.

Figura 53: Estructura de la troposfera: capa geográfica y capa libre. Fuente: Quereda, 2005: 25

Figura 54: Curva de estado con inversión térmica. Fuente: elaboración propia, Laboratorio de Climatología de la Universitat Jaume I.

Figura 55: Penacho serpenteante ascendente en condiciones de inestabilidad. Fuente: elaboración propia, Laboratorio de Climatología de la Universitat Jaume I.

Figura 56: Penacho tubular en condiciones de estabilidad. Fuente: elaboración propia, Laboratorio de Climatología de la Universitat Jaume I.

Figura 57: Condiciones de estabilidad relativa. Fuente: elaboración propia, Laboratorio de Climatología de la Universitat Jaume I.

Figura 58: Penacho cónico en condiciones neutras. Fuente: elaboración propia, Laboratorio de Climatología de la Universitat Jaume I.

Figura 59: Penacho antifumigante emitido sobre una capa de inversión térmica. Fuente: elaboración propia, Laboratorio de Climatología de la Universitat Jaume I.

Figura 60: Penacho fumigante emitido bajo una capa de inversión térmica. Fuente: elaboración propia, Laboratorio de Climatología de la Universitat Jaume I.

Figura 61: Diagrama termodinámico con los diferentes tipos de estabilidad atmosférica. Fuente: elaboración propia, Laboratorio de Climatología de la Universitat Jaume I. 
Figura 62: Gradiente medio de la velocidad del viento con la altura. Fuente: Quereda et al., 2012: 56 .

Figura 63: Esquema sobreelevación del penacho. Fuente: elaboración propia, Laboratorio de Climatología de la Universitat Jaume I.

Figura 64: Sobreelevación del penacho de humos de la CT. Fuente propia, imagen tomada el 15 de diciembre del 2013 a las 12 horas.

Figura 65: Sobreelevación del penacho de humos de la CT. Fuente propia, imagen tomada el 14 de diciembre del 2013 a las 12 horas.

Figura 66: Sobreelevación del penacho de humos de la CT. Fuente propia, imagen tomada el 24 de octubre del 2015 a las 12 horas.

Figura 67: Sobreelevación del penacho de humos de la CT. Fuente propia, imagen tomada el 25 de octubre del 2015 a las 12 horas.

Figura 68: Sobreelevación del penacho de humos de la CT. Fuente propia, imagen tomada el 2 de septiembre del 2013 a las 12 horas.

Figura 69: Esquema del modelo gaussiano de dispersión de contaminantes. Fuente: http://www.bvsde.paho.org/cursoa_meteoro/lecc6/lecc6_4.html.

$\begin{array}{llll}\text { Figura } & \text { 70: Distribución gaussiana. } & \text { Fuente: }\end{array}$ http://www.bvsde.paho.org/cursoa_meteoro/lecc6/lecc6_4.html.....

Figura 71: Esquema cambio origen coordenadas. Fuente: http://www.bvsde.paho.org/cursoa_meteoro/lecc6/lecc6_4.html.

Figura 72: Esquema del efecto de reflexión del suelo. Fuente: Puigcerver y Carrascal, 2008: 148 .

Figura 73: Esquema para la simplificación de las expresiones del modelo gaussiano. Fuente: http://www.bvsde.paho.org/cursoa_meteoro/lecc6/lecc6_4.html.

Figura 74: Esquema de la reflexión de contaminantes provocada por una capa de inversión térmica. Fuente: elaboración propia, Laboratorio de Climatología de la Universitat Jaume I. 
Figura 75: Esquema de la dispersión del penacho en condiciones de inversión térmica. Fuente: Masters y Ela, 2008: 483.

Figura 76: Radiosondeo de Zaragoza aeropuerto del 13 de enero del 2012 a las 12 horas. Fuente: http://weather.uwyo.edu/upperair/sounding.html.

Figura 77: Temperaturas registradas en las estaciones de Fredes (1235 metros) y del monte Caro (1447 metros) durante los días 11-15 de enero del 2012. Fuente: elaboración propia, Laboratorio de Climatología de la Universitat Jaume I

Figura 78: Radiosondeo de Zaragoza aeropuerto del 7 de enero del 2013 a las 12 horas. Fuente: http://weather.uwyo.edu/upperair/sounding.html.

Figura 79: Temperaturas registradas en las estaciones de Fredes (1235 metros) y del monte Caro (1447 metros) durante el día 7 de enero del 2013. Fuente: elaboración propia, Laboratorio de Climatología de la Universitat Jaume I.

Figura 80: Radiosondeo de Zaragoza aeropuerto del 23 de febrero del 2012 a las 12 horas. Fuente: http://weather.uwyo.edu/upperair/sounding.html.

Figura 81: Temperaturas registradas en las estaciones de Fredes (1235 metros) y del monte Caro (1447 metros) durante el día 23 de febrero del 2012. Fuente: elaboración propia, Laboratorio de Climatología de la Universitat Jaume I.

Figura 82: Radiosondeo de Zaragoza aeropuerto del 19 de diciembre del 2014 a las 00 horas. Fuente: http://weather.uwyo.edu/upperair/sounding.html.

Figura 83: Temperaturas registradas en las estaciones de Fredes (1235 metros) y del monte Caro (1447 metros) durante el día 19 de diciembre del 2014. Fuente: elaboración propia, Laboratorio de Climatología de la Universitat Jaume I.

Figura 84: Estaciones de la Red de Vigilancia y Control de la Contaminación Atmosférica de la Generalitat Valenciana y rosas aerodinámicas de la red meteorológica universitaria. Fuente: archivo del Laboratorio de Climatología de la Universitat Jaume I.

Figura 85: Ejemplo de imagen NOAA-HRPT del 25 de junio del 2010 que muestra un espectacular transporte de aerosol africano sobre la Cuenca Occidental del Mediterráneo. Fuente: archivo del Laboratorio de Climatología de la Universitat Jaume I. 
Figura 86: Picos de inmisión diarios de $\mathrm{SO}_{2}\left(\mu \mathrm{g} / \mathrm{m}^{3}\right)$ en la estación de Coratxar (20002015). La línea roja marca el umbral máximo diario permitido por la normativa $\left(125 \mu \mathrm{g} / \mathrm{m}^{3}\right)$, la línea verde marca el 75\% de dicho umbral. Fuente: Red Valenciana de Vigilancia y Control de la Contaminación Atmosférica. Elaboración propia, Laboratorio de Climatología de la Universitat Jaume I.

Figura 87: Picos de inmisión horarios de $\mathrm{SO}_{2}\left(\mu \mathrm{g} / \mathrm{m}^{3}\right)$ en la estación de Coratxar (20002015). La línea roja marca el umbral máximo horario permitido por la normativa $\left(350 \mu \mathrm{g} / \mathrm{m}^{3}\right)$, la línea verde marca el 75\% de dicho umbral. Fuente: Red Valenciana de Vigilancia y Control de la Contaminación Atmosférica. Elaboración propia, Laboratorio de Climatología de la Universitat Jaume I.

Figura 88: Distribución geográfica de los episodios horarios de impactos severos de $\mathrm{SO}_{2}$ (>75\% del umbral máximo permitido) durante el periodo 2000-2015. Fuente: Red Valenciana de Vigilancia y Control de la Contaminación Atmosférica. Elaboración propia, Laboratorio de Climatología de la Universitat Jaume I.

Figura 89: Distribución mensual de los episodios (diarios y horarios) de inmisión severa de $\mathrm{SO}_{2}$ (Coratxar, 2000-2015). Los episodios con inmisión severa (>75\% del umbral máximo permitido) se vinculan al otoño y al invierno, si bien los picos horarios pueden acontecer en todos los meses. Fuente: Red Valenciana de Vigilancia y Control de la Contaminación Atmosférica. Elaboración propia, Laboratorio de Climatología de la Universitat Jaume I.

Figura 90: Radiosondeo de Zaragoza aeropuerto del 8 de enero del 2000 a las 00 horas. Fuente: http://weather.uwyo.edu/upperair/sounding.html.

Figura 91: Reanálisis a $850 \mathrm{hPa}$ del 8 de enero del 2000. Fuente: http://www.wetterzentrale.de/topkarten/fsreaeur.html.

Figura 92: Radiosondeo de Zaragoza aeropuerto del 11 de enero del 2000 a las 12 horas. La situación atmosférica muestra la persistencia de una notable inversión térmica a los 890925 hPa. Fuente: http://weather.uwyo.edu/upperair/sounding.html.....

Figura 93: Reanálisis a $500 \mathrm{hPa}$ del 12 de enero del 2000. Fuente: http://www.wetterzentrale.de/topkarten/fsreaeur.html.

Figura 94: Radiosondeo de Zaragoza aeropuerto del 17 de diciembre del 2000 a las 12 horas. Fuente: http://weather.uwyo.edu/upperair/sounding.html. 
Figura 95: Mapa de superficie del 17 de diciembre del 2000 a las 00 horas. Fuente: http://www.wetterzentrale.de/topkarten/tkfaxbraar.htm.

Figura 96: Radiosondeo de Zaragoza aeropuerto del 13 de septiembre del 2001 a las 12 horas. Fuente: http://weather.uwyo.edu/upperair/sounding.html.

Figura 97: Reanálisis a $850 \mathrm{hPa}$ del 13 de septiembre del 2001. Fuente: http://www.wetterzentrale.de/topkarten/fsreaeur.html.

Figura 98: Radiosondeo de Zaragoza aeropuerto del 26 de octubre del 2001 a las 12 horas. Fuente: http://weather.uwyo.edu/upperair/sounding.html.

Figura 99: Reanálisis a $850 \mathrm{hPa}$ del 26 de octubre del 2001. Fuente: http://www.wetterzentrale.de/topkarten/fsreaeur.html.

Figura 100: Radiosondeo de Zaragoza aeropuerto del 6 de enero del 2004 a las 00 horas. Fuente: http://weather.uwyo.edu/upperair/sounding.html.

Figura 101: Reanálisis a $850 \mathrm{hPa}$ del 6 de enero del 2004. Fuente: http://www.wetterzentrale.de/topkarten/fsreaeur.html.

Figura 102: Radiosondeo de Zaragoza aeropuerto del 5 de febrero del 2004 a las 12 horas. Fuente: http://weather.uwyo.edu/upperair/sounding.html.

Figura 103: Reanálisis a $850 \mathrm{hPa}$ del 5 de febrero del 2004. Fuente: http://www.wetterzentrale.de/topkarten/ fsreaeur.html.

Figura 104: Radiosondeo de Zaragoza aeropuerto del 1 de diciembre del 2007 a las 00 horas. Fuente: http://weather.uwyo.edu/upperair/sounding.html.

Figura 105: Reanálisis a $850 \mathrm{hPa}$ del 1 de diciembre del 2007. Fuente: http://www.wetterzentrale.de/topkarten/fsreaeur.html.

Figura 106: Registros de temperatura en los observatorios del monte Caro (1447 metros) y del pico Fredes (1235 metros) durante los días 1-15 de diciembre del 2007. Los picos horarios de contaminación sobrevienen cuando la capa de inversión se halla bajo ese nivel de alturas sobre la región. Fuente: elaboración propia, Laboratorio de Climatología de la Universitat Jaume I. 
Figura 107: Registros de temperatura en los observatorios del monte Caro (1447 metros) y del pico Fredes (1235 metros) en enero del 2012. Los episodios de contaminación se operan en momentos en que la capa de inversión cubre ese nivel de alturas sobre la región. Fuente: elaboración propia, Laboratorio de Climatología de la Universitat Jaume I

Figura 108: Los registros de la temperatura del aire en la torre meteorológica de la CT muestran, en régimen diario, la notable estabilidad e inversión térmica durante el 13 de enero del 2012. Fuente: datos proporcionados por la CT, elaboración propia, Laboratorio de Climatología de la Universitat Jaume I.

Figura 109: Radiosondeo de Zaragoza aeropuerto del 13 de enero del 2012 a las 12 horas. Fuente: http://weather.uwyo.edu/upperair/sounding.html.

Figura 110: Reanálisis a $500 \mathrm{hPa}$ del 13 de enero del 2012. Fuente: http://www.wetterzentrale.de/topkarten/fsreaeur.html.

Figura 111: Registros de la temperatura, durante los días 1-10 del mes de enero del 2013, en los observatorios del monte Caro (1447 metros) y del pico Fredes (1235 metros). Fuente: elaboración propia, Laboratorio de Climatología de la Universitat Jaume I.

Figura 112: Radiosondeo de Zaragoza aeropuerto del 7 de enero del 2013 a las 12 horas. Fuente: http://weather.uwyo.edu/upperair/sounding.html.

Figura 113: Reanálisis a $850 \mathrm{hPa}$ del 7 de enero del 2013. Fuente: http://www.wetterzentrale.de/topkarten/fsreaeur.html.

Figura 114: Evolución térmica en los observatorios del monte Caro (1447 metros) y Fredes (1235 metros) entre el 8 y el 17 de noviembre del 2015. Fuente: elaboración propia, Laboratorio de Climatología de la Universitat Jaume I.

Figura 115: Radiosondeo de Zaragoza aeropuerto del 24 de marzo del 2015 a las 00 horas. Fuente: http://weather.uwyo.edu/upperair/sounding.html.

Figura 116: Mapa de superficie correspondiente al día 24 de marzo del 2015. Fuente: http://www.wetterzentrale.de/topkarten/tkfaxbraar.html

Figura 117: Radiosondeo de Zaragoza aeropuerto del 5 de junio del 2015 a las 12 horas. Fuente: http://weather.uwyo.edu/upperair/sounding.html. 
Figura 118: Mapa de presión de superficie del día 5 de junio del 2015. Fuente: http://www.wetterzentrale.de/topkarten/tkfaxbraar.html.

Figura 119: Control y calibrado del analizador automático de $\mathrm{pH}$ y conductividad en agua de lluvia, marca Kimoto, modelo AR-106 (Estación de Torre Miró, Morella). Fuente: archivo del Laboratorio de Climatología de la Universitat Jaume I.

Figura 120: Ubicación del analizador Kimoto en el altiplano de Torre Miró (1256 metros). La rosa de vientos de Coratxar, refleja los flujos aéreos dominantes sobre la vertiente mediterránea del Sistema Ibérico en el nivel de 1200 metros. Fuente: archivo del Laboratorio de Climatología de la Universitat Jaume I.

Figura 121: Valor del pH en el agua de lluvia precipitada en Torre Miró (2005-2014). Fuente: elaboración propia, Laboratorio de Climatología de la Universitat Jaume I.

Figura 122: Situación en superficie del día 1 de enero del 2006. El campo bárico muestra la afluencia de flujos del NW. Fuente: Instituto Nacional de Meteorología, INM.

Figura 123: Imagen NOAA del 1 de enero del 2006. Fuente: archivo del Laboratorio de Climatología de la Universitat Jaume I.

Figura 124: Valores de pH y conductividad en el agua de lluvia durante los días 4 y 5 de enero del 2006. Fuente: elaboración propia, Laboratorio de Climatología de la Universitat Jaume I.

Figura 125: Situación en superficie del día 4 de enero del 2006. Fuente: http://www.wetterzentrale.de/topkarten/tkfaxbraar.htm.

Figura 126: Radiosondeo de Zaragoza aeropuerto del 4 de enero del 2006 a las 00 horas. Fuente: http://weather.uwyo.edu/upperair/sounding.html.

Figura 127: Registros de $\mathrm{pH}$ y conductividad en el agua de lluvia durante los días 13 y 14 de febrero del 2008. Fuente: elaboración propia, Laboratorio de Climatología de la Universitat Jaume I

Figura 128: Situación atmosférica a 850 hPa el día 14 de febrero del 2008. Nítida advección de aire frío en altura, nivel de $850 \mathrm{hPa}$ Fuente: http://www.wetterzentrale.de/topkarten/fsreaeur.html. 
Figura 129: Radiosondeo de Zaragoza el día 14 de febrero del 2008 a las 00 horas. Fuente: http://weather.uwyo.edu/upperair/sounding.html.

Figura 130: Evolución térmica $(T)$ y del punto de rocío $\left(T_{d}\right)$ en la estación de Torre Miró durante los días 13, 14 y 15 de febrero del 2008. Fuente: elaboración propia, Laboratorio de Climatología de la Universitat Jaume I.

Figura 131: Régimen aéreo del día 14 de febrero del 2008 sobre la cima de Torre Miró (1256 metros). Fuente: elaboración propia, Laboratorio de Climatología de la Universitat Jaume I

Figura 132: Situación atmosférica a $850 \mathrm{hPa}$ del 4 de agosto del 2012. Aerosol africano sobre la Cuenca occidental del Mediterráneo y frontólisis sobre el NW de la Península Ibérica. Fuente: http://www.wetterzentrale.de/topkarten/fsreaeur.html.

Figura 133: Análisis del agua de lluvia precipitada en Torre Miró durante el día 4 de agosto del 2012. Fuente: elaboración propia, Laboratorio de Climatología de la Universitat Jaume I.

Figura 134: Imagen NOAA-AVHRR, VIS, correspondiente al día 4 de agosto del 2012. Fuente: archivo del Laboratorio de Climatología de la Universitat Jaume I.

Figura 135: Situación atmosférica a 850 hPa del día 9 de septiembre del 2012. Fuente: http://www.wetterzentrale.de/topkarten/fsreaeur.html.

Figura 136: Registro de valores de $\mathrm{pH}$ durante el día 9 de septiembre del 2012. Fuente: elaboración propia, Laboratorio de Climatología de la Universitat Jaume I.

Figura 137: Imagen NOAA-AVHRR, VIS, correspondiente al día 9 de septiembre del 2012. Fuente: archivo del Laboratorio de Climatología de la Universitat Jaume I.

Figura 138: Imagen NOAA-19 HRPT del día 20 de abril del 2016. Fuente: archivo del Laboratorio de Climatología de la Universitat Jaume I

Figura 139: Notable carga de tierra sobre la Cuenca Occidental del Mediterráneo. Imagen NOAA-19 HRPT del 27 de abril del 2016. Fuente: archivo del Laboratorio de Climatología de la Universitat Jaume I.

Figura 140: La imagen muestra la notable persistencia del aerosol que todavía cubre la Cuenca Occidental del Mediterráneo a finales del mes de abril. Imagen NOAA-19 HRPT del 
día 29 de abril del 2016. Fuente: archivo del Laboratorio de Climatología de la Universitat Jaume I

Figura 141: Mapa topográfico del monte de los Carrascales. La vertiente explorada corresponde a la orilla derecha del Barranco de Torre Segura, en cuyas aguas circulantes se efectuaron determinaciones de pH. Fuente: mapa topográfico nacional, MTN50, Hoja N545, Morella.

Figura 142: Masa forestal del monte Pereroles. Fuente: mapa topográfico nacional, MTN50. Hoja No520, Penyarroya de Tastavins.

Figura 143: Litología de la zona. Fuente: Mapa litológico de España. Instituto Geológico y Minero de España. Hoja Nº2.

Figura 144: Tipología de los suelos explorados, rendzinas. Fuente: archivo del Laboratorio de Climatología de la Universitat Jaume I.

Figura 145: Zonas de análisis edafológico y de aguas. Fuente: mapa militar de España, escala 1:400000. Hoja: Teruel 4-3. 


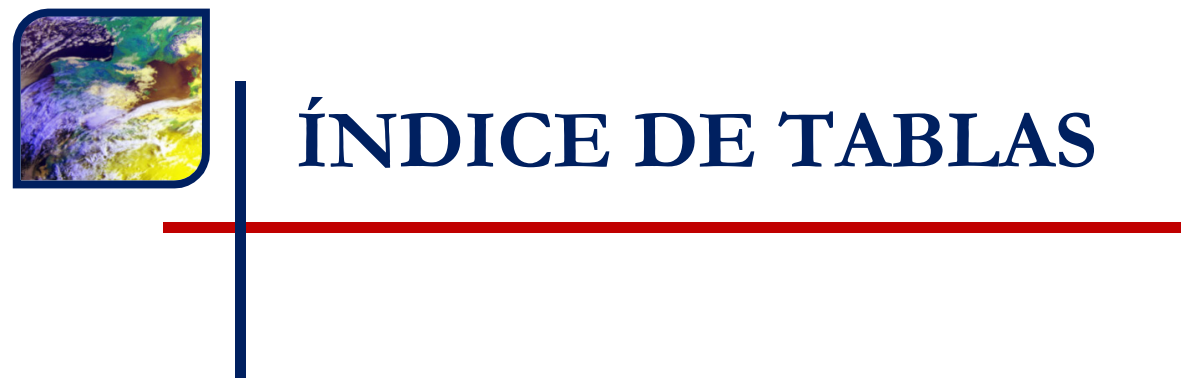





\section{ÍNDICE DE TABLAS}

Tabla 1: Rango de valores de la longitud de Monin-Obukhov. Fuente: Barthelmie, 1999: 42.

Tabla 2: Registro del sondeo de Zaragoza del 2 de septiembre del 2013. Se destacan en negrita los valores que evidencian la presencia de la inversión térmica. Fuente: http://weather.uwyo.edu/upperair/sounding.html.

Tabla 3: Registro del radiosondeo en Zaragoza del 14 de diciembre del 2013. Se destacan en negrita los dos niveles de inversión. Fuente: http://weather.uwyo.edu/upperair/sounding.html.

Tabla 4: Tabla de categorías de dispersión de Pasquill (1961) que incluye las modificaciones sugeridas por Gifford (1961) y Turner (1970). Fuente: Puigcerver y Carrascal, 2008: 137.

Tabla 5: Valores de n. Fuente: Puigcerver y Carrascal, 2008: 131.

Tabla 6: Resumen de las variables que afectan al cálculo de la sobreelevación del penacho. Fuente: elaboración propia, Laboratorio de Climatología de la Universitat Jaume I...... 91

Tabla 7: Parámetros de la fuente de emisión. Fuente: datos proporcionados por la CT de Andorra.

Tabla 8: Parámetros meteorológicos correspondientes a la jornada del 15 de diciembre del 2013. Datos extraídos del registro del radiosondeo de Zaragoza del 15 de diciembre del 2013 a las 12 horas. Fuente: http://weather.uwyo.edu/upperair/sounding.html.

Tabla 9: Parámetros meteorológicos correspondientes a la jornada del 14 de diciembre del 2013. Datos extraídos del registro del radiosondeo de Zaragoza del 14 de diciembre del 2013 a las 12 horas. Fuente: http://weather.uwyo.edu/upperair/sounding.html.

Tabla 10: Parámetros meteorológicos correspondientes a la jornada del 24 de octubre del 2015. Datos extraídos del registro del radiosondeo de Zaragoza del 24 de octubre del 2015 a las 12 horas. Fuente: http://weather.uwyo.edu/upperair/sounding.html.

Tabla 11: Parámetros meteorológicos correspondientes a la jornada del 25 de octubre del 2015. Datos extraídos del registro del radiosondeo de Zaragoza del 25 de octubre del 2015 a las 12 horas. Fuente: http://weather.uwyo.edu/upperair/sounding.html. 
Tabla 12: Parámetros meteorológicos correspondientes a la jornada del 2 de septiembre del 2013. Datos extraídos del registro del radiosondeo de Zaragoza del 2 de septiembre del 2013 a las 12 horas. Fuente: http://weather.uwyo.edu/upperair/sounding.html.

Tabla 13: Valores de los coeficientes de dispersión para un medio rural. Fuente: Puigcerver y Carrascal, 2008: 151

Tabla 14: Valores de los coeficientes de dispersión para un medio urbano. Fuente: Puigcerver y Carrascal, 2008: 151

Tabla 15: Expresiones para el cálculo de los coeficientes de dispersión en un medio rural. Fuente: Castro, 2004: 128.

Tabla 16: Expresiones para el cálculo de los coeficientes de dispersión en un medio urbano. Fuente: Castro, 2004: 128.

Tabla 17: Parámetros de la fuente de emisión. Fuente: datos proporcionados por la CT de Andorra.

Tabla 18: Parámetros meteorológicos correspondientes a la jornada del 13 de enero del 2012. Datos extraídos del registro del radiosondeo de Zaragoza del 13 de enero del 2012 a las 12 horas. Fuente: http://weather.uwyo.edu/upperair/sounding.html.

Tabla 19: Parámetros meteorológicos correspondientes a la jornada del 7 de enero del 2013. Datos extraídos del registro del radiosondeo de Zaragoza del 7 de enero del 2013 a las 12 horas. Fuente: http://weather.uwyo.edu/upperair/sounding.html.

Tabla 20: Parámetros meteorológicos correspondientes a la jornada del 23 de febrero del 2012. Datos extraídos del registro del radiosondeo de Zaragoza del 23 de febrero del 2012 a las 12 horas. Fuente: http://weather.uwyo.edu/upperair/sounding.html.

Tabla 21: Parámetros meteorológicos correspondientes a la jornada del 19 de diciembre del 2014. Datos extraídos del registro del radiosondeo de Zaragoza del 19 de diciembre del 2014 a las 00 horas. Fuente: http://weather.uwyo.edu/upperair/sounding.html.

Tabla 22: Episodios de mayor inmisión de $\mathrm{SO}_{2}$ en Coratxar durante el año 2000. Fuente: Red Valenciana de Vigilancia y Control de la Contaminación Atmosférica, http://www.habitatge.gva.es. 
Tabla 23: Radiosondeo de Zaragoza aeropuerto del 8 de enero del 2000 a las 00 horas. Fuente: http:/ /weather.uwyo.edu/upperair/sounding.html.

Tabla 24: Radiosondeo de Zaragoza aeropuerto del 11 de enero del 2000 a las 12 horas. Fuente: http://weather.uwyo.edu/upperair/sounding.html.

Tabla 25: Registro del radiosondeo de Zaragoza del 17 de diciembre del 2000 a las 12 horas. Fuente: http://weather.uwyo.edu/upperair/sounding.html.

Tabla 26: Episodios de mayor inmisión de $\mathrm{SO}_{2}$ en Coratxar durante el año 2001. Fuente: Red Valenciana de Vigilancia y Control de la Contaminación Atmosférica, http://www.habitatge.gva.es.

Tabla 27: Registro del radiosondeo de Zaragoza aeropuerto del 13 de septiembre del 2001 a las 12 horas. Fuente: http://weather.uwyo.edu/upperair/sounding.html.

Tabla 28: Registro del radiosondeo de Zaragoza aeropuerto del 26 de octubre del 2001 a las 12 horas. Fuente: http://weather.uwyo.edu/upperair/sounding.html.

Tabla 29: Episodios de mayor inmisión de $\mathrm{SO}_{2}$ registrados en Coratxar durante el año 2004. Fuente: Red Valenciana de Vigilancia y Control de la Contaminación Atmosférica, http://www.habitatge.gva.es.

Tabla 30: Registro del radiosondeo de Zaragoza del 6 de enero del 2004 a las 00 horas. Fuente: http://weather.uwyo.edu/upperair/sounding.html.

Tabla 31: Radiosondeo de Zaragoza del 5 de febrero del 2004 a las 00 horas. Fuente: http://weather.uwyo.edu/upperair/sounding.html.

Tabla 32: Tabla resumen de episodios horarios de mayor inmisión de $\mathrm{SO}_{2}$ durante el periodo 2007-2015. Fuente: Red Valenciana de Vigilancia y Control de la Contaminación Atmosférica, http://www.habitatge.gva.es.

Tabla 33: Tabla resumen de episodios horarios de mayor inmisión de $\mathrm{SO}_{2}$ durante el año 2012. Fuente: Red Valenciana de Vigilancia y Control de la Contaminación Atmosférica, http://www.habitatge.gva.es.

Tabla 34: Registro del radiosondeo de Zaragoza del 13 de enero del 2012 a las 12 horas. Fuente: http://weather.uwyo.edu/upperair/sounding.html. 165 
Tabla 35: Tabla resumen de episodios horarios de mayor inmisión de $\mathrm{SO}_{2}$ durante el año 2013. Fuente: Red Valenciana de Vigilancia y Control de la Contaminación Atmosférica, http://www.habitatge.gva.es.

Tabla 36: Tabla resumen de episodios horarios de mayor inmisión de $\mathrm{SO}_{2}$ durante el año 2015. Fuente: Red Valenciana de Vigilancia y Control de la Contaminación Atmosférica, http://www.habitatge.gva.es.

Tabla 37: Registro correspondiente al radiosondeo de Zaragoza del día 24 de marzo del 2015 a las 00 horas. Fuente: http://weather.uwyo.edu/upperair/sounding.html.

Tabla 38: Tabla de análisis químico del agua de lluvia, promedio de los valores analizados durante el 18 de septiembre del 1993 y el 1 de junio del 1994. Fuente: Quereda et al., 1996.

Tabla 39: Resultados informe $\mathrm{n}^{\circ}$ C123180, monte Carrascales. Fuente: informe $\mathrm{n}^{\circ}$ C123180, ITC

Tabla 40: Resultados del informe $\mathrm{n}^{\circ}$ C130577, monte Pereroles. Fuente: informe $\mathrm{n}^{\circ}$ C130577, ITC

Tabla 41: Episodios horarios de inmisión de $\mathrm{SO}_{2}(>75 \%$ del umbral permitido) en Coratxar en el año 2000. Fuente: RVVCCA.

Tabla 42: Episodios horarios de inmisión de $\mathrm{SO}_{2}(>75 \%$ del umbral permitido) en Coratxar en el año 2001. Fuente: RVVCCA.

Tabla 43: Episodios horarios de inmisión de $\mathrm{SO}_{2}(>75 \%$ del umbral permitido) en Coratxar en el año 2002. Fuente: RVVCCA.

Tabla 44: Episodios horarios de inmisión de $\mathrm{SO}_{2}(>75 \%$ del umbral permitido) en Coratxar en el año 2003. Fuente: RVVCCA.

Tabla 45: Episodios horarios de inmisión de $\mathrm{SO}_{2}(>75 \%$ del umbral permitido) en Coratxar en el año 2004. Fuente: RVVCCA.

Tabla 46: Episodios horarios de inmisión de $\mathrm{SO}_{2}(>75 \%$ del umbral permitido) en Coratxar en el año 2005. Fuente: RVVCCA. 
Tabla 47: Episodios horarios de inmisión de $\mathrm{SO}_{2}(>75 \%$ del umbral permitido) en Coratxar en el año 2006. Fuente: RVVCCA.

Tabla 48: Episodios horarios de inmisión de $\mathrm{SO}_{2}(>75 \%$ del umbral permitido) en Coratxar en el año 2007. Fuente: RVVCCA.

Tabla 49: Episodios diarios de inmisión de $\mathrm{SO}_{2}(>75 \%$ del umbral permitido) en Coratxar en el año 2000. Fuente: RVVCCA..

Tabla 50: Episodios diarios de inmisión de $\mathrm{SO}_{2}(>75 \%$ del umbral permitido) en Coratxar en el año 2001. Fuente: RVVCCA.

Tabla 51: Episodios diarios de inmisión de $\mathrm{SO}_{2}(>75 \%$ del umbral permitido) en Coratxar en el año 2002. Fuente: RVVCCA.

Tabla 52: Episodios diarios de inmisión de $\mathrm{SO}_{2}(>75 \%$ del umbral permitido) en Coratxar en el año 2004. Fuente: RVVCCA......

Tabla 53: Episodios diarios de inmisión de $\mathrm{SO}_{2}(>75 \%$ del umbral permitido) en Coratxar en el año 2005. Fuente: RVVCCA.

Tabla 54: Episodios diarios de inmisión de $\mathrm{SO}_{2}(>75 \%$ del umbral permitido) en Coratxar en el año 2006. Fuente: RVVCCA.

Tabla 55: Episodios diarios de inmisión de $\mathrm{SO}_{2}(>75 \%$ del umbral permitido) en Coratxar en el año 2007. Fuente: RVVCCA......

Tabla 56: Episodios horarios de inmisión de $\mathrm{SO}_{2}(>75 \%$ del umbral permitido) en Vallibona en el año 2000. Fuente: RVVCCA.

Tabla 57: Episodios horarios de inmisión de $\mathrm{SO}_{2}(>75 \%$ del umbral permitido) en Vallibona en el año 2001. Fuente: RVVCCA.

Tabla 58: Episodios horarios de inmisión de $\mathrm{SO}_{2}(>75 \%$ del umbral permitido) en Vallibona en el año 2002. Fuente: RVVCCA.

Tabla 59: Episodios horarios de inmisión de $\mathrm{SO}_{2}(>75 \%$ del umbral permitido) en Vallibona en el año 2003. Fuente: RVVCCA.

Tabla 60: Episodios horarios de inmisión de $\mathrm{SO}_{2}(>75 \%$ del umbral permitido) en Vallibona en el año 2004. Fuente: RVVCCA. 
Tabla 61: Episodios horarios de inmisión de $\mathrm{SO}_{2}(>75 \%$ del umbral permitido) en Vallibona en el año 2005. Fuente: RVVCCA.

Tabla 62: Episodios horarios de inmisión de $\mathrm{SO}_{2}(>75 \%$ del umbral permitido) en Vallibona en el año 2006. Fuente: RVVCCA

Tabla 63: Episodios horarios de inmisión de $\mathrm{SO}_{2}(>75 \%$ del umbral permitido) en Vallibona en el año 2007. Fuente: RVVCCA.

Tabla 64: Episodios diarios de inmisión de $\mathrm{SO}_{2}(>75 \%$ del umbral permitido) en Vallibona en el año 2000. Fuente: RVVCCA

Tabla 65: Episodios diarios de inmisión de $\mathrm{SO}_{2}(>75 \%$ del umbral permitido) en Vallibona en el año 2001. Fuente: RVVCCA

Tabla 66: Episodios diarios de inmisión de $\mathrm{SO}_{2}(>75 \%$ del umbral permitido) en Vallibona en el año 2002. Fuente: RVVCCA

Tabla 67: Episodios diarios de inmisión de $\mathrm{SO}_{2}(>75 \%$ del umbral permitido) en Vallibona en el año 2003. Fuente: RVVCCA.

Tabla 68: Episodios diarios de inmisión de $\mathrm{SO}_{2}(>75 \%$ del umbral permitido) en Vallibona en el año 2004. Fuente: RVVCCA. 244

Tabla 69: Episodios diarios de inmisión de $\mathrm{SO}_{2}$ (> 75\% del umbral permitido) en Vallibona en el año 2005. Fuente: RVVCCA.

Tabla 70: Episodios horarios de inmisión de $\mathrm{SO}_{2}(>75 \%$ del umbral permitido) en Morella en el año 2000. Fuente: RVVCCA.

Tabla 71: Episodios horarios de inmisión de $\mathrm{SO}_{2}(>75 \%$ del umbral permitido) en Morella en el año 2001. Fuente: RVVCCA. .245

Tabla 72: Episodios horarios de inmisión de $\mathrm{SO}_{2}(>75 \%$ del umbral permitido) en Morella en el año 2002. Fuente: RVVCCA.

Tabla 73: Episodios horarios de inmisión de $\mathrm{SO}_{2}(>75 \%$ del umbral permitido) en Morella en el año 2003. Fuente: RVVCCA.

Tabla 74: Episodios horarios de inmisión de $\mathrm{SO}_{2}(>75 \%$ del umbral permitido) en Morella en el año 2004. Fuente: RVVCCA. 
Tabla 75: Episodios horarios de inmisión de $\mathrm{SO}_{2}(>75 \%$ del umbral permitido) en Morella en el año 2005. Fuente: RVVCCA.

Tabla 76: Episodios horarios de inmisión de $\mathrm{SO}_{2}(>75 \%$ del umbral permitido) en Morella en el año 2006. Fuente: RVVCCA.

Tabla 77: Episodios horarios de inmisión de $\mathrm{SO}_{2}(>75 \%$ del umbral permitido) en Morella en el año 2007. Fuente: RVVCCA.

Tabla 78: Episodios diarios de inmisión de $\mathrm{SO}_{2}(>75 \%$ del umbral permitido) en Morella en el año 2000. Fuente: RVVCCA.

Tabla 79: Episodios diarios de inmisión de $\mathrm{SO}_{2}(>75 \%$ del umbral permitido) en Morella en el año 2002. Fuente: RVVCCA. 249

Tabla 80: Episodios diarios de inmisión de $\mathrm{SO}_{2}(>75 \%$ del umbral permitido) en Morella en el año 2003. Fuente: RVVCCA.

Tabla 81: Episodios diarios de inmisión de $\mathrm{SO}_{2}(>75 \%$ del umbral permitido) en Morella en el año 2004. Fuente: RVVCCA.

Tabla 82: Episodios horarios de inmisión de $\mathrm{SO}_{2}(>75 \%$ del umbral permitido) en Zorita en el año 2000. Fuente: RVVCCA. .250

Tabla 83: Episodios horarios de inmisión de $\mathrm{SO}_{2}(>75 \%$ del umbral permitido) en Zorita en el año 2001. Fuente: RVVCCA. 250

Tabla 84: Episodios horarios de inmisión de $\mathrm{SO}_{2}(>75 \%$ del umbral permitido) en Zorita en el año 2002. Fuente: RVVCCA. 250

Tabla 85: Episodios horarios de inmisión de $\mathrm{SO}_{2}(>75 \%$ del umbral permitido) en Zorita en el año 2003. Fuente: RVVCCA.

Tabla 86: Episodios horarios de inmisión de $\mathrm{SO}_{2}(>75 \%$ del umbral permitido) en Zorita en el año 2004. Fuente: RVVCCA.

Tabla 87: Episodios horarios de inmisión de $\mathrm{SO}_{2}(>75 \%$ del umbral permitido) en Zorita en el año 2005. Fuente: RVVCCA.

Tabla 88: Episodios horarios de inmisión de $\mathrm{SO}_{2}(>75 \%$ del umbral permitido) en Zorita en el año 2006. Fuente: RVVCCA. 
Tabla 89: Episodios horarios de inmisión de $\mathrm{SO}_{2}(>75 \%$ del umbral permitido) en

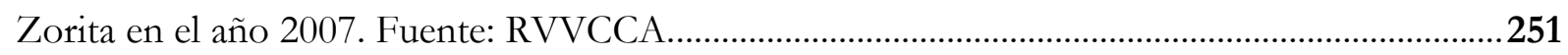


CAPÍTULO PRIMERO

ANTECEDENTES, FUNDAMENTOS

CIENTÍFICOS Y OBJETIVOS DE LA

INVESTIGACIÓN 



\section{ANTECEDENTES DE LA INVESTIGACIÓN}

El tema de investigación propuesto tiene su fundamento en los estudios que los miembros del Instituto Interuniversitario de Geografía (IIG), Laboratorio de Climatología, sede de la Universitat Jaume I, desarrollaron durante el periodo 1995-2004 sobre el estado de las masas forestales en la vertiente mediterránea del Sistema Ibérico. De estos estudios se desprendía la existencia de una evidente degradación de las masas forestales, especialmente acusada en algunas zonas, y que podría constituir un grave riesgo medioambiental. Degradación cuyo origen, inicialmente atribuido a las adversidades climáticas, pronto se focalizará, con mayor o menor virulencia, en las emisiones de gases contaminantes procedentes de la central térmica de Andorra (Teruel).

La degradación forestal de Els Ports, detectada por primera vez en el año 1980, se interpretó como un claro efecto de la contaminación ambiental. Desde entonces la muerte de un gran número de pinos de esta comarca, situada en el interior de Castellón y limítrofe con Teruel y Tarragona, dio lugar a una encendida controversia. Informes y contrainformes se sucedieron a lo largo de los años sin resultados totalmente concluyentes y ello probablemente porque no se puede hablar de un único factor. Esta multifactorialidad tiene como principal protagonista el innegable papel que juega el escenario atmosférico regional donde tales emisiones se inyectan y difunden.

En el continente europeo el reconocimiento de que los efectos fitotóxicos sobre masas forestales puedan ser debidos a la contaminación atmosférica es un hecho relativamente reciente. Este hecho tuvo lugar hacia finales de los años setenta cuando se observaron extensas masas forestales afectadas en Checoslovaquia, Alemania, Rusia y Noruega.

En España, como ya se ha señalado, será en 1980 cuando comenzará a asociarse la degradación forestal de las comarcas de El Maestrazgo y Els Ports, en las provincias de Castellón, Tarragona y Teruel, a los efectos fitotóxicos de la contaminación ambiental. 


\section{EVOLUCIÓN HISTÓRICA DE LA PROBLEMÁTICA} AMBIENTAL EN LA REGIÓN MEDITERRÁNEA: VERTIENTE DEL SISTEMA IBÉRICO

Hasta finales de los años sesenta la región mediterránea se caracterizaba por ser una zona dedicada principalmente a actividades básicas, agricultura y ganadería, y con muy pocos núcleos urbanos. Sin embargo, es a partir de este periodo y sobre todo durante los años setenta cuando se observa un cambio radical en este panorama. Asistimos en estos momentos a un acelerado desarrollo turístico que llevará aparejado un cambio brutal en el paisaje, ganando cada vez más espacios para el asentamiento de núcleos urbanos y provocando los primeros impactos ambientales: escasez de recursos hídricos y salinización.

No obstante, el mayor problema medioambiental a que se enfrentará la región mediterránea será la instalación de toda una serie de centrales térmicas y refinerías, consecuencia directa del acelerado proceso de industrialización experimentado en ese periodo. Proceso que en la vertiente mediterránea del Sistema Ibérico culminará con la puesta en marcha entre 1979 y 1980 de la central térmica de ENDESA en Andorra (Teruel) (Fig. 1).

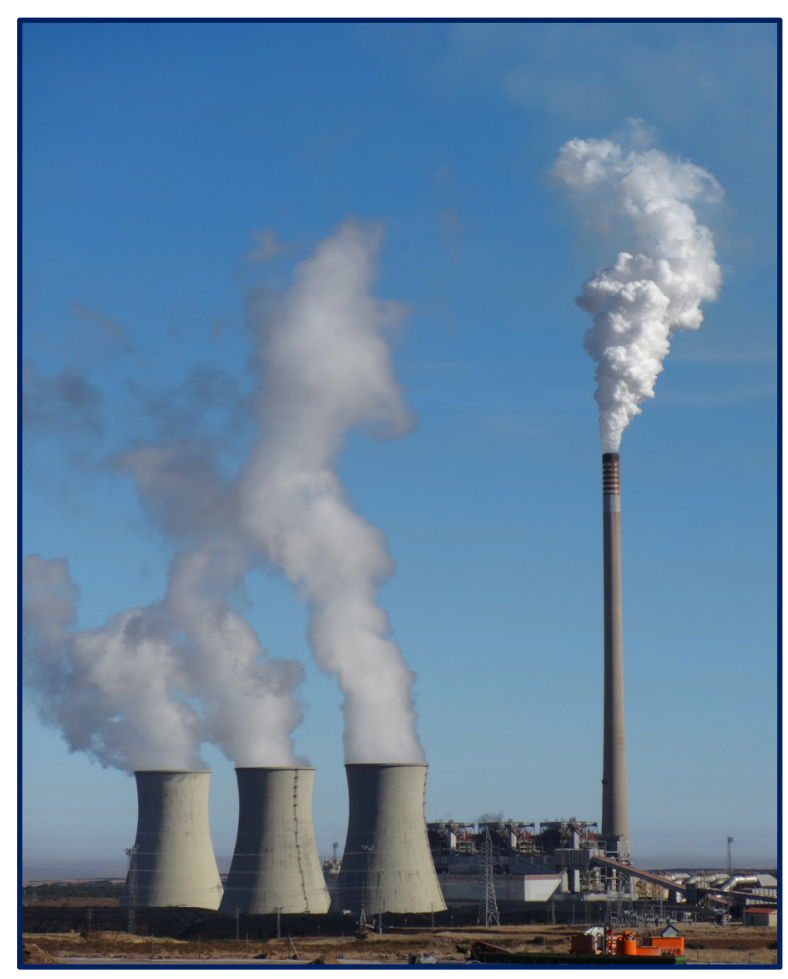

Figura 1: Central Térmica de Andorra (Teruel). Fuente propia, imagen tomada el 15 de diciembre del 2013.

Página | 4 
Este intenso proceso de industrialización de la vertiente mediterránea del Sistema Ibérico estaba basado principalmente en la explotación del carbón extraído en la cuenca minera de Andorra entre los años 1950 y 1970 y cuya principal consumidora era la central térmica de Escatrón, Zaragoza.

La central térmica de Escatrón fue planificada por ENDESA con la idea de ir ejecutándola por grupos, de manera que durante los años 1953, 1955 y 1958 se pusieron en marcha los tres primeros grupos de 50000, 60000 y $62500 \mathrm{kWh}$ respectivamente. Sin embargo, nunca se llegó a construir la cuarta fase. Ello fue paradójicamente debido al aumento de la demanda de energía eléctrica que hubo en España en la década de los años setenta. A medida que se hacía imprescindible un aumento de la producción energética, las centrales térmicas de la Aliaga (Teruel) y la misma de Escatrón (Zaragoza) empezaron a mostrar su incapacidad para absorber la producción de carbón de la zona. Así pues, ante la evidencia de que dichas centrales se estaban quedando paulatinamente obsoletas, surgió la necesidad de construir nuevas instalaciones productoras de energía que abasteciesen al sistema eléctrico nacional.

Es en este marco cuando se empieza a construir en 1979 la central térmica de ENDESA en Andorra (Teruel) que utilizará como materia prima los carbones extraídos de las cuencas mineras turolenses. Estas cuencas mineras cercanas constituyen la mayor reserva de España de lignitos, aunque su elevado contenido en azufre $(\sim 7 \%)$ será el detonante de toda la problemática ambiental que ha envuelto a esta central desde que se puso en funcionamiento por primera vez. A partir de este momento todos los daños que se observarán en las masas forestales de la zona serán atribuidos al alto contenido en azufre de los humos procedentes de la central térmica de Andorra comparados popularmente a un penacho-misil (Fig. 2). 


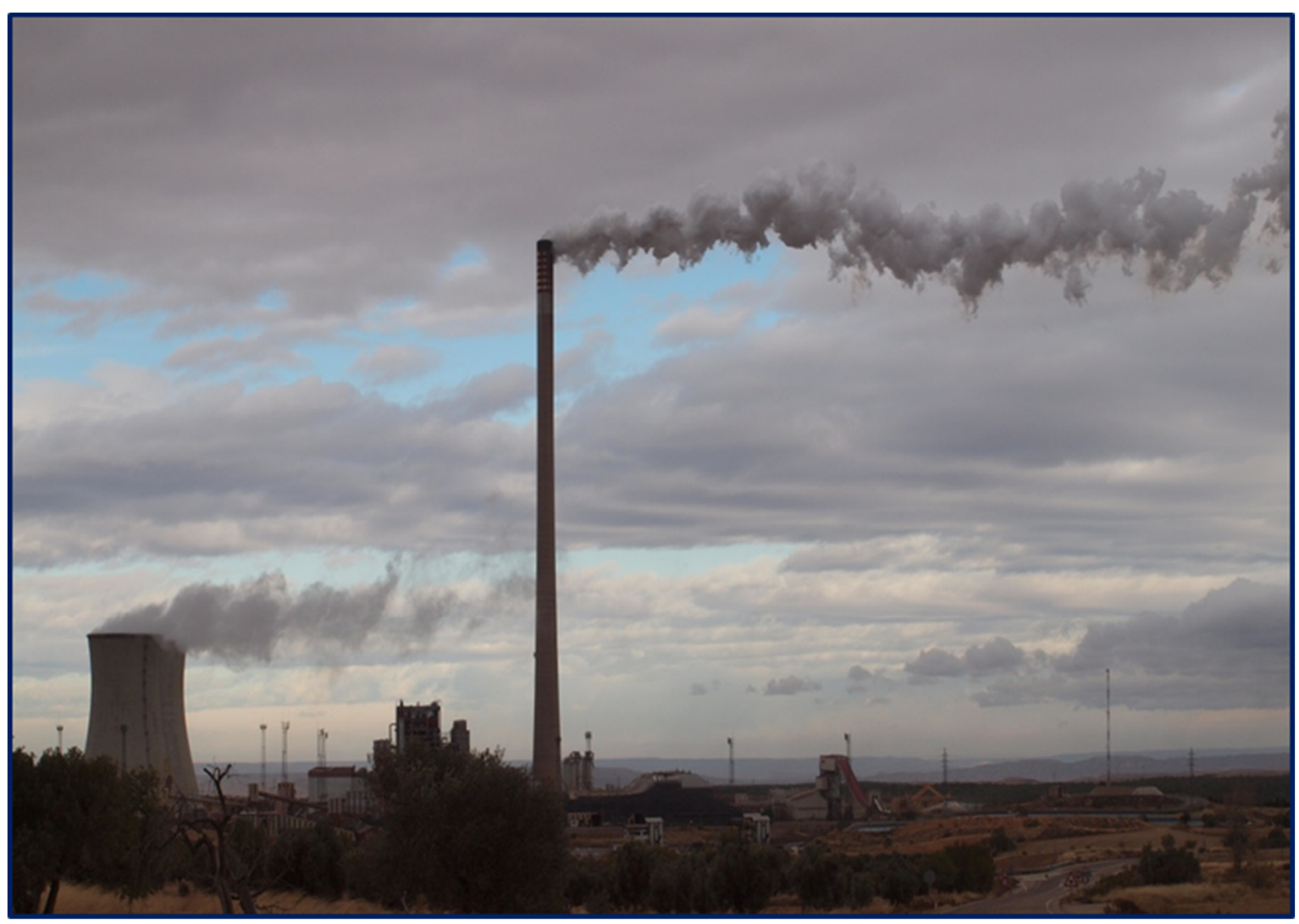

Figura 2: La imagen es evocadora de que la opinión pública impute daños ecológicos a la CT desde el primer momento y de que el chorro de humos se compare a un penacho-misil lanzado a grandes distancias. Fuente propia, imagen tomada el 30 de noviembre del 2013.

Las instalaciones de la central térmica de Andorra, desde ahora CT, ocupan una zona de 300 hectáreas y se encuentran a una altitud de 600 metros sobre el nivel del mar. Su puesta en marcha fue en noviembre de 1979, con un único grupo de generación de 350 MW de potencia. Posteriormente, en enero de 1980, se procedió a la puesta en marcha de otros dos grupos más, de 350 MW cada uno, proporcionando así una potencia total de 1,05 GW. Cada grupo dispone de caldera, turboalternador y torre de refrigeración independiente de 107 metros de altura. Por otro lado, los tres grupos comparten el parque de carbones y caliza, el sistema de evacuación de cenizas y escorias y el sistema de alimentación de agua para la refrigeración que proviene de la presa de Calanda. Posteriormente, a partir del año 2000, se construye, en diversas fases, la planta de desulfuración de gases para intentar paliar los posibles efectos nocivos causados por el penacho de humos altamente contaminantes que la central emite.

La central destaca principalmente por las características de su imponente chimenea de 343 metros. Esta estructura fue diseñada para que las emisiones se realicen en el exterior de la capa geográfica, situada en la baja troposfera, favoreciendo así la dispersión de los Página | 6 
contaminantes atmosféricos hacia capas altas de la atmósfera y disminuyendo por tanto el impacto ambiental sobre la región. No obstante, y como veremos a lo largo de los 6 capítulos que componen este trabajo de investigación, el comportamiento del penacho de humos muestra la complejidad de los procesos atmosféricos regionales y evidencia la multitud de factores que intervienen en la modelización de la dispersión de los contaminantes atmosféricos.

El combustible utilizado por la central consiste principalmente en lignito negro y carbones bituminosos de la localidad de Andorra y de áreas cercanas. Estos carbones nacionales son de muy baja calidad por su alto contenido en azufre (hasta un 7\%). Este hecho, junto con la cada vez más exigente legislación ambiental, ha hecho necesario que sean mezclados con carbones de importación para obtener una mezcla con menor contenido de azufre. Además, desde 1988 se han adoptado toda una serie de medidas con la finalidad de minimizar el impacto ambiental como, por ejemplo, incluir un proceso de lavado que permite reducir el contenido de azufre en casi un 40\%. Medidas ambientales que culminaron con el inicio de la construcción, en el año 2000, de la novedosa y específica planta de desulfuración de gases, una de las mayores en su género en todo el mundo, con la finalidad de reducir el contenido de azufre de las emisiones en más de un $90 \%$.

Casi coincidente con la puesta en marcha de la central se detecta una paulatina degradación de las coníferas en algunas zonas del Maestrazgo. Ante la gran controversia y problemática ambiental surgida con la aparición de los primeros daños, los primeros estudios forestales no se hicieron esperar. Es en 1984 cuando los resultados iniciales confirman la existencia en los pinos del hongo de la tristeza y parecen atestiguar la relación causa-efecto con la actividad de la CT. Entre estos estudios iniciales los del ICONA (Instituto para la Conservación de la Naturaleza) muestran en principio su conformidad con esa causalidad. No obstante, los sucesivos estudios realizados irán adoptando una posición más cautelar (ICONA, 1984 a, 1984 b, 1986, 1988 a, 1988 b y 1991). Esta nueva postura menos contundente a la hora de apuntar a la CT como única responsable de la contaminación es debida principalmente a las mediciones realizadas sobre el $\mathrm{pH}$ del agua de lluvia. Los valores medios obtenidos experimentalmente son de 5,4, es decir, valores de $\mathrm{pH}$ normal del agua de lluvia, muy distantes de los valores atribuidos a la existencia del fenómeno de lluvia ácida. Estos resultados serán también avalados por la existencia comarcal de líquenes, considerados, en esos años, como bioindicadores de contaminación al ser especies muy sensibles a cualquier tipo de alteración del medio (Barreno et al., 1990, 1991, 1992 a, 1992 b y 1993). 
En medio de un estado de crispación popular y de campañas encarnizadas contra la CT, la comisión de seguimiento (creada en 1984) pidió a un organismo ajeno totalmente a la cuestión, el NILU (Instituto Noruego de Investigación Atmosférica), un informe científico para intentar poner fin al problema y averiguar el origen de los daños observados. Las conclusiones alcanzadas fueron que la difusión del penacho de humos se efectuaba principalmente en una dirección este y con impacto máximo entre los 5 y los $15 \mathrm{~km}$ de la central y que, por lo tanto, no resultaba probable que afectara a la zona del Maestrazgo. No obstante, el informe final del NILU dejó una ventana abierta al afirmar que no era posible descartar totalmente esos daños en masas forestales del Maestrazgo (NILU, 1985 a, 1985 b, 1987 a y 1987 b). Sin embargo, el resultado de este informe parece condicionado por la específica estructura atmosférica bajo la que se realizaron las experiencias, en plena primavera, y por el breve periodo de experimentación del equipo en la zona. Las experimentaciones, realizadas siempre bajo las mismas condiciones climáticas, obviaban las diferentes situaciones climáticas que afectan a la zona durante el año y que, como veremos a lo largo de este trabajo de investigación, resultan de gran relevancia a la hora de establecer conclusiones sobre los impactos ambientales debidos a contaminantes atmosféricos.

Así pues, la situación atmosférica de neta inestabilidad, predominante durante el periodo de experimentación del NILU, explicaba perfectamente los resultados obtenidos mediante el seguimiento del hexafluoruro de azufre $\left(\mathrm{SF}_{6}\right)$, gas no tóxico, utilizado como trazador durante las experimentaciones (Fig. 3).

Página $\mid 8$ 


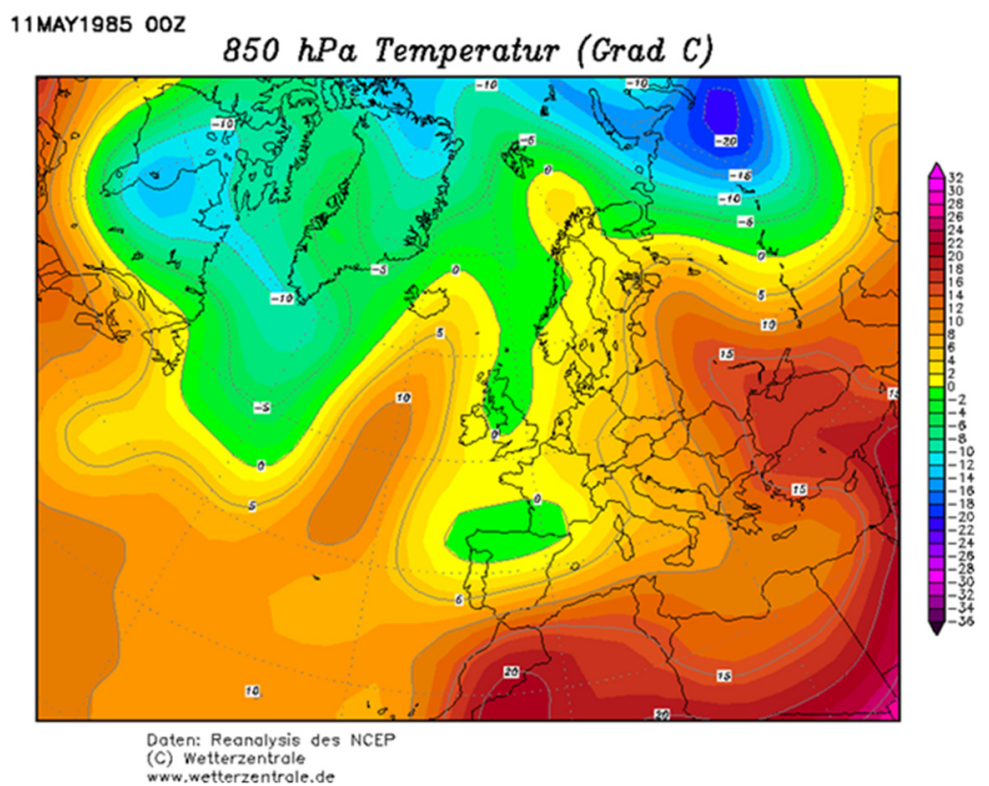

O8MAY1985 00Z

850 hPa Temperatur (Grad C)

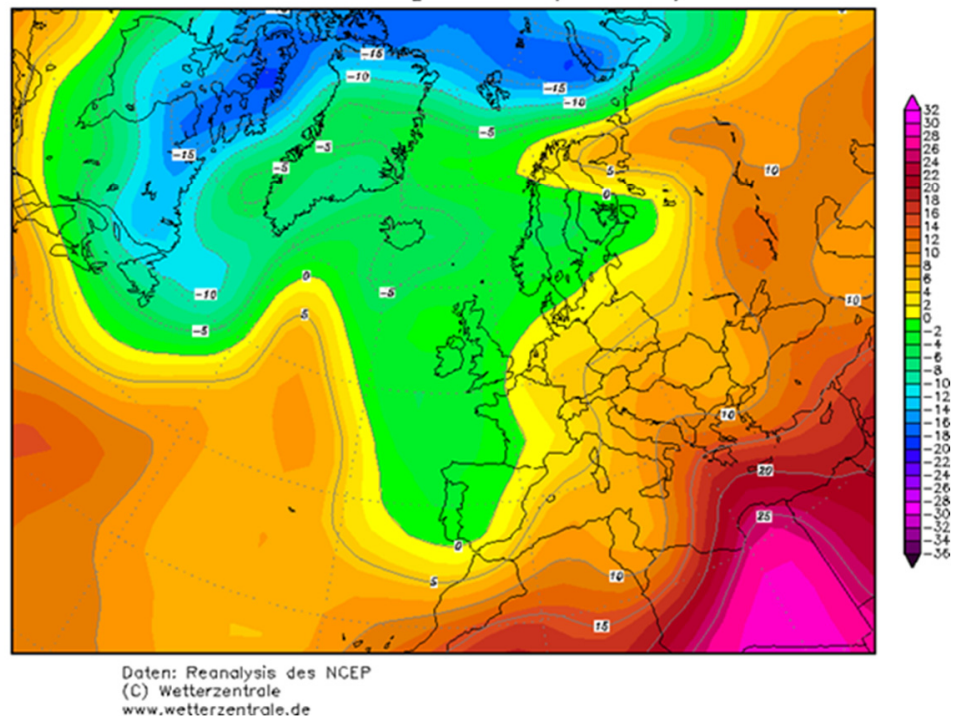

Figura 3: La situación atmosférica mostraba una gran inestabilidad durante los días 6 a 11 de mayo del 1985, período de experimentación del NILU. Fuente: http://www.wetterzentrale.de/topkarten/fsreaeur.html.

Estas situaciones atmosféricas de inestabilidad determinan un ascenso vertical del aire que se extiende hasta que una capa de inversión térmica o el nivel de equilibrio lo detienen. El proceso arrastra así los contaminantes gaseosos, favoreciendo la dispersión de estos hacia las capas más altas de la atmósfera (Fig. 4). 


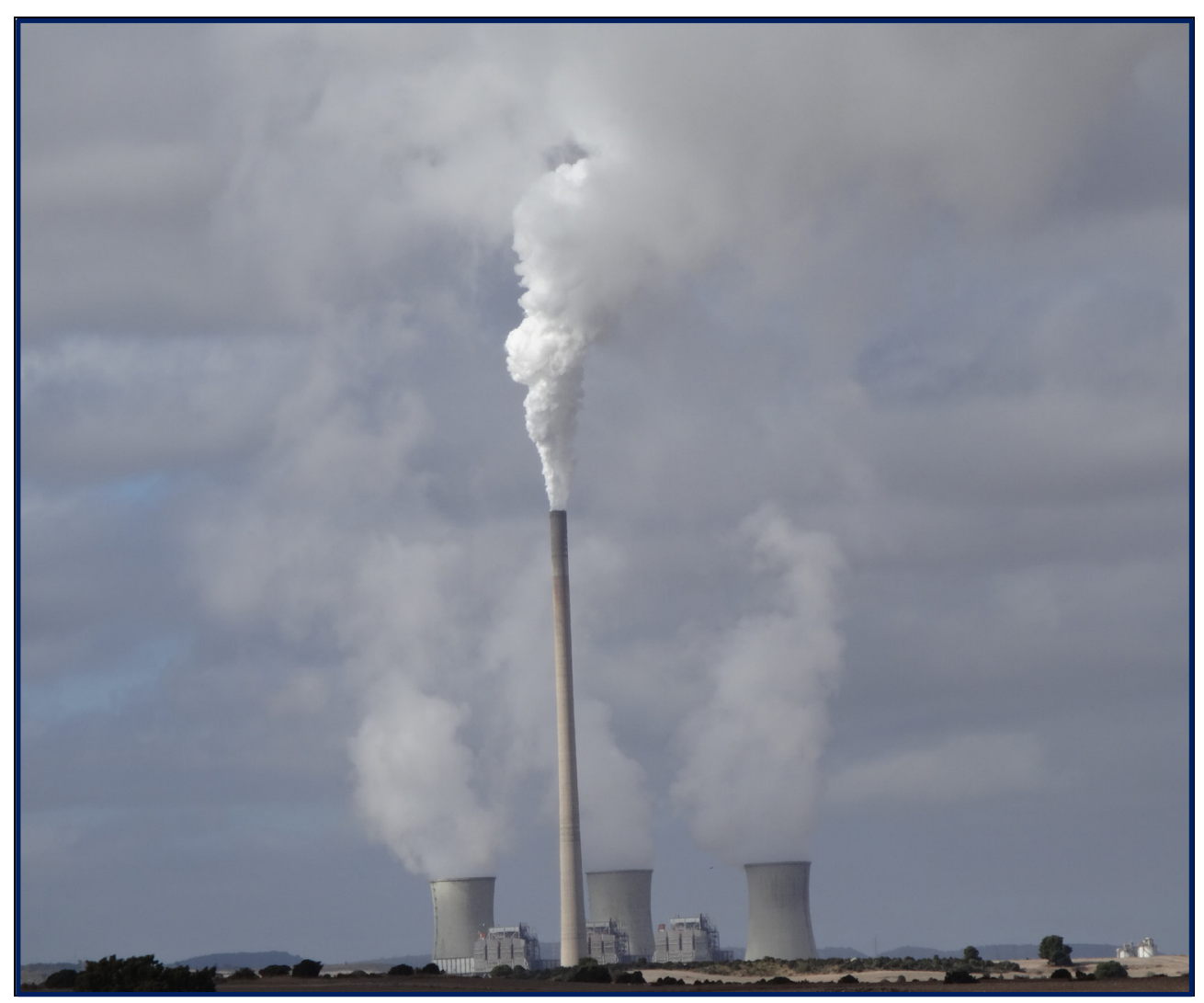

Figura 4: Penacho emitido por la central térmica de Andorra en condiciones de inestabilidad. Fuente propia, imagen tomada el 14 de diciembre del 2013.

La validez de estos informes sigue siendo cuestionada y ni siquiera los organismos oficiales parecen ponerse por fin de acuerdo. Unos, como el ICONA, siguen atribuyendo los daños ecológicos a la contaminación por azufre (ICONA, 1991). Sin embargo, el Ministerio extrae unas conclusiones totalmente diferentes después de analizar durante 8 años las inmisiones en la zona (AMBIO, 1984-1992). De este análisis se deduce que las 22 estaciones que fueron objeto de estudio presentaban valores medios que respetaban los niveles de contraste establecidos por la normativa vigente en aquel momento.

En 1992, la problemática medioambiental del Mediterráneo dio un giro radical tras la publicación de los resultados del Proyecto MECAPIP de la UE. El proyecto MECAPIP tenía como objetivo principal el estudio del origen y evolución de las circulaciones atmosféricas responsables de la dispersión y de los procesos de transformación de los contaminantes atmosféricos sobre la Península Ibérica (Millán et al., 1993, 1997 y 2000).

Se pretendía así completar los estudios realizados hasta el momento y obtener resultados concluyentes que permitieran entender los ciclos de contaminantes observados Página | 10 
sobre la costa mediterránea. Según las conclusiones alcanzadas en el proyecto y en palabras de Millán Millán Muñoz (Director del CEAM desde su creación, en julio de 1991, y hasta el momento de su jubilación, en febrero de 2012):

- "En su conjunto, se puede considerar que estos mecanismos conforman un 'gran reactor fotoquímico natural' que opera a lo largo de las costas mediterráneas casi todos los días desde la primavera al otoño. Durante varios meses puede generar niveles de ozono superiores a los legislados por la UE.

- Así mismo, parte de los contaminantes emitidos en las costas pueden penetrar, a lo largo de pasos naturales, hacia el interior de la península durante el día y quedar dentro del alcance de las circulaciones que se desarrollan sobre el centro de la península el día siguiente" (Millán, 2009: 36).

En medio de este agitado panorama científico, e incluso político, la Mancomunidad de El Maestrat-Els Ports, encarga un Dictamen Científico a la Universitat Jaume I. Es en este momento cuando se crea la Comisión Interuniversitaria, coordinada por la Universitat Jaume I. Comisión que, tras un estudio exhaustivo de todo lo publicado hasta la fecha concerniente al tema y las propias observaciones realizadas sobre el terreno, emitió su informe en 1994. Esta comisión integrada por investigadores de distintas universidades españolas y de todas las ramas de conocimiento implicadas en el tema (geólogos, biólogos, climatólogos, etc.) llevó a cabo un extenso estudio de campo sobre el terreno relativo al deterioro de las masas forestales de la comarca y la problemática de la contaminación ambiental.

Tras el periodo de observación y la revisión de los más de 140 estudios publicados sobre el tema, la Comisión emitió las siguientes conclusiones (Conde et al., 1993):

a) Los daños observados en las masas forestales no son de carácter general sino localizado y, además, de origen incierto ya que pueden ser atribuidos a causas diversas que no han sido suficientemente estudiadas y que pueden interaccionar entre sí. Por ello, el dictamen establece que se debe estudiar rigurosamente la influencia relativa de los factores bióticos y abióticos que, conjunta o individualmente, pueden causar daños en la vegetación y determinar cuáles de estos daños son realmente causados por la contaminación. Así pues, se hace hincapié en la multitud de factores que intervienen en la degradación observada en las masas forestales y especialmente en que sus efectos son acumulativos, resultando muy complicado atribuir los efectos observados en la vegetación a un único origen. 
b) Esta contaminación no es solo atribuible a las inmisiones de dióxido de azufre. Tal como señala M. Millán, el ozono fotooxidante puede ser incluso más perjudicial para la vegetación que el SO 2 (Millán y Sanz, 1993).

Por otra parte, el dictamen remarca la importancia que tienen los picos de inmisión de $\mathrm{SO}_{2}$ frente a los valores medios $\mathrm{y}$, consecuentemente, la necesidad de una normativa de contaminantes especial aplicada a la cuenca mediterránea.

c) Los resultados no son concluyentes ni fiables para atribuir exclusivamente a las emisiones de la CT de Andorra los daños observados en las masas forestales de la zona de estudio. Para obtener unas conclusiones verdaderamente exhaustivas sería necesario un estudio mucho más complejo y prolongado en el tiempo, con el fin de abarcar todos los factores implicados y profundizar en el indiscutible papel que juega el sistema atmosférico en la dispersión de contaminantes atmosféricos.

d) En consecuencia, se establece que sería necesario disponer de una red de estaciones meteorológicas adecuada para poder llevar a cabo rigurosamente la caracterización del escenario meteorológico regional y su innegable influencia en la dispersión de contaminantes atmosféricos.

En consecuencia, y dada su trascendental importancia, el objetivo de la presente investigación será el estudio de los escenarios atmosféricos de contaminación sobre la vertiente mediterránea del Sistema Ibérico. En ella, supliendo las carencias observacionales señaladas, ya ha sido posible contar con la estación de radiosondeos de Zaragoza aeropuerto (desde 1992) y con la red meteorológica universitaria (desde 2003), diseñada sobre vértices orográficos a tales efectos.

Finalmente, debe ser destacado que, tras todo este largo panorama de investigaciones y los sucesivos informes presentados por los diferentes organismos anteriormente citados, se acuerda el 23 de marzo de 1994 un convenio de colaboración entre la Generalitat Valenciana y la Empresa Nacional de Electricidad (ENDESA).

Fruto de este convenio será la creación en diciembre de 1994 de tres nuevas estaciones de control de inmisiones en Morella, Villafranca y Coratxar y la implantación de toda una serie de medidas de mejora de procesos técnicos de la CT que culmina con los sistemas de 
desulfuración comenzados a instalar en el año 2000 y sus subsiguientes adaptaciones y mejoras en años posteriores.

\section{DAÑOS OBSERVADOS SOBRE LAS MASAS FORESTALES}

En primer lugar es necesario destacar que, si bien las afecciones y degradaciones que se observaron en las masas forestales de las comarcas del Maestrat y els Ports son comunes a las que pueden verse en cualquier otra comarca de España, diferían de éstas en la magnitud y concentración. Esta mayor virulencia de las plagas, aunque no constituya una consecuencia directa y exclusiva de la contaminación atmosférica, sí que puede ser para algunos expertos consecuencia de la mayor debilidad que ésta provocó en las especies vegetales. Una virulencia que determinaba, a nivel de 1989-1991, un estado fitosanitario grave en necrosis y defoliaciones (TECMENA S. L., 1990, 1991, 1992).

Entre las plagas observadas podemos destacar:

- Hongos infecciosos como los causantes de la tristeza del pino (Thyriopsis halepensis) o "ungulina" (Fomitopsis pinicola) que absorbe la savia de los arboles provocando su secado (Fig. 5).

- Infecciones de muérdago (Viscum álbum) que invade rápidamente el árbol debilitándolo y llegando a producir su muerte (Fig. 6).

- El hongo Kabatina juniperi que en formaciones de enebro produce una elevada y generalizada mortandad.

- Oruga procesionaria (Thaumatopea pityiocampa), aunque abundante en los primeros años de estudio, las medidas adoptadas para el control de esta plaga provocaron una sensible reducción. 


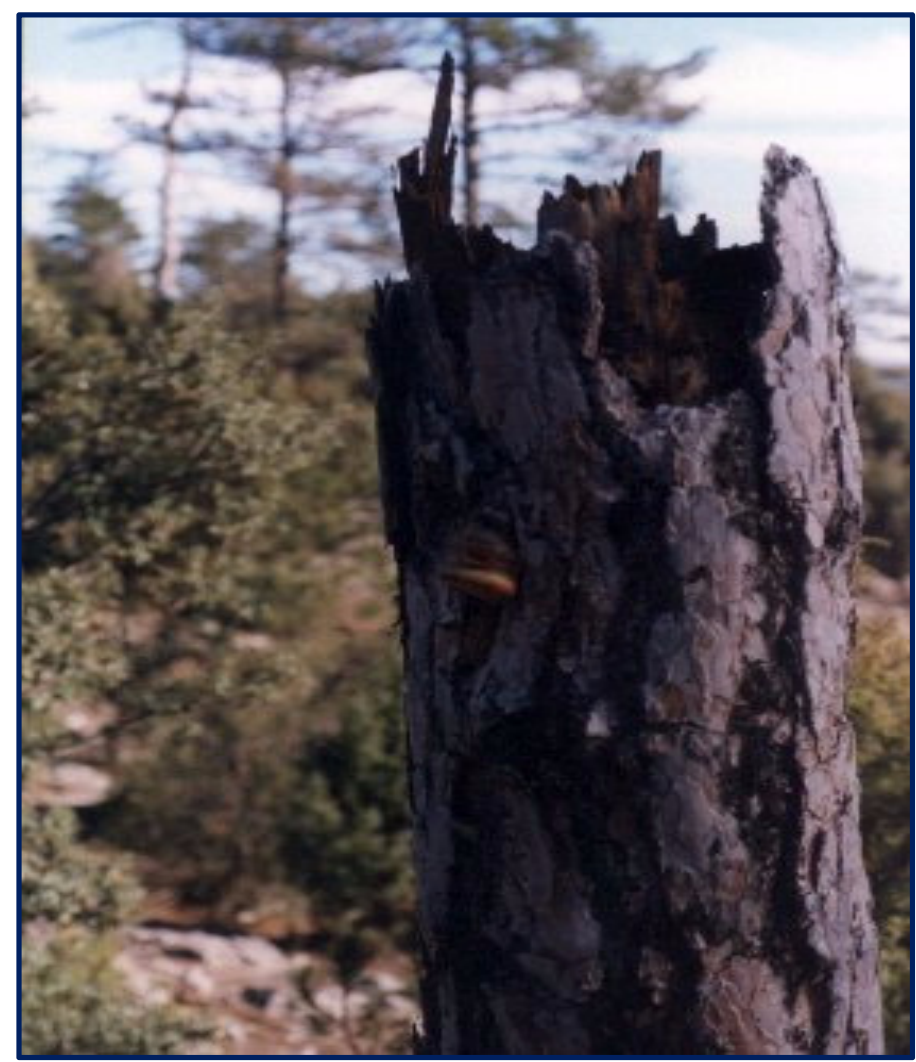

Figura 5: Árbol afectado por la patología ungulina, "Fotomitoxis pinícola", y fracturado posteriormente por el viento. Monte Bobalar de Castellfort, 1998. Fuente: archivo del Laboratorio de Climatología de la Universitat Jaume I.

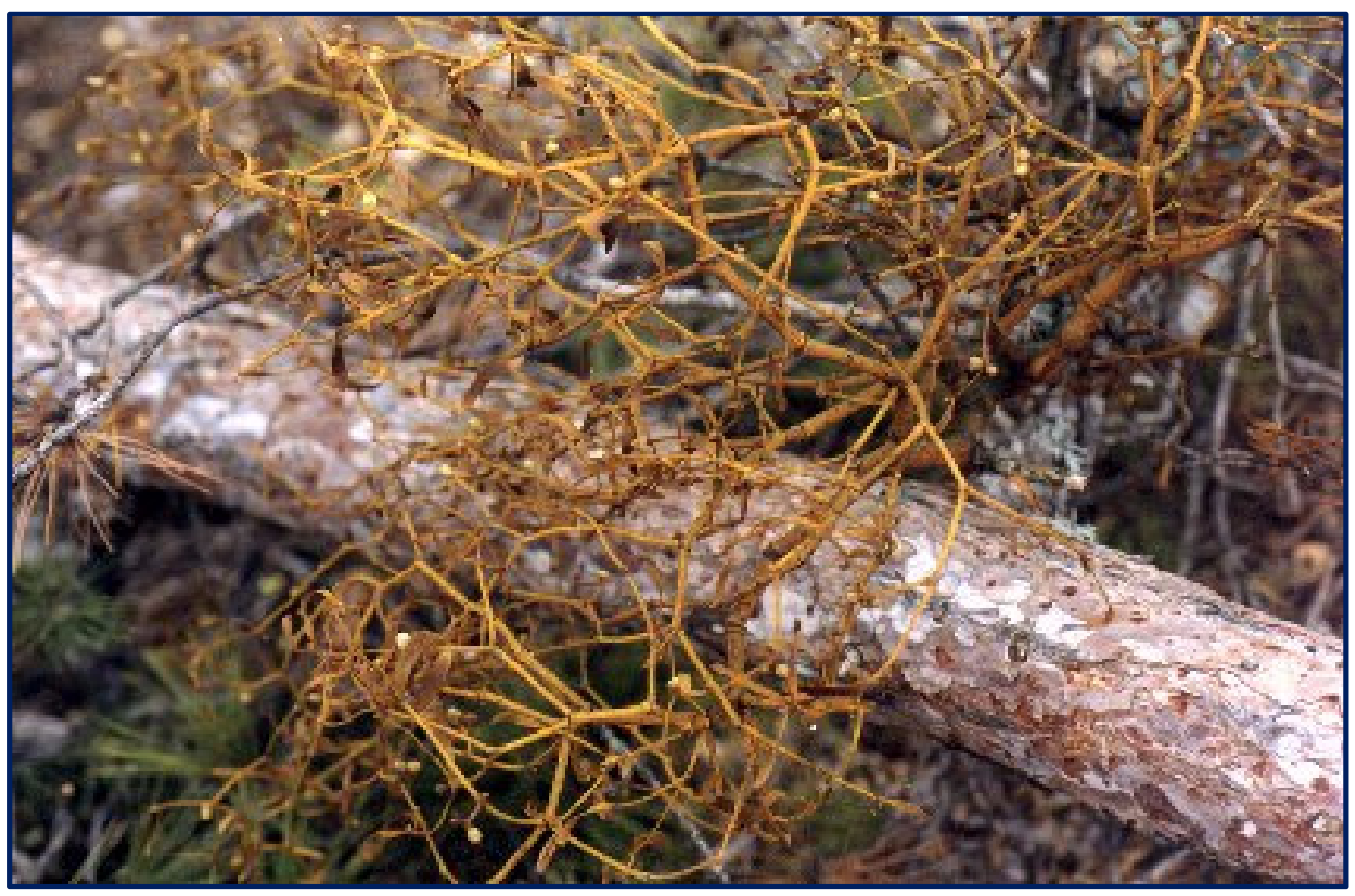

Figura 6: Infección de muérdago, "Viscum álbum", sobre un árbol caído en la vertiente del Barranc del Molar, monte Bobalar de Castellfort, 1998. Fuente: archivo del Laboratorio de Climatología de la Universitat Jaume I.

Página | 14 


\section{FUNDAMENTOS CIENTÍFICOS DE LA TESIS}

La tesis desarrollada tiene su fundamento científico en los trabajos dendrocronológicos realizados en el marco del contrato Universitat Jaume I-APF-ENDESA (1995-2004), y más recientemente en el proyecto sobre “Avaluació global i seguiment de la qualitat de l'aire en relació al seu impacte en el creixement forestal de les comarques de Els Ports de Morella (Castelló) i de la Reserva Natural de Els Ports de Tortosa-Beseit (Massís del Caro, Tarragona)”. Este trabajo de investigación más reciente se desarrolló entre los años 2005-2012, como continuación y complemento de los estudios anteriores que la Comisión InteruniversitariaENDESA había realizado sobre el análisis del estado de los bosques en Els Ports-Maestrazgo y la influencia de la CT, ubicada en Andorra (Teruel), en el deterioro de los mismos. Trabajo en el que tuve la ocasión de participar durante el disfrute de las dos becas de colaboración que me fueron concedidas en los cursos 2005-2006 y 2007-2008 y que me introdujeron ya en la problemática ambiental objeto de mi tesis doctoral. Durante estas colaboraciones mi dedicación se centró especialmente en la analítica edafológica y de aguas, cuyas conclusiones han sido posteriormente desarrollas y aparecen en los capítulos V y VI del presente trabajo de investigación.

Los estudios realizados por el Instituto Interuniversitario de Geografía (IIG), en el marco de este contrato, se basaron en una rigurosa investigación dendrocronológica sobre las masas forestales de Pinus nigra Arn en la vertiente mediterránea del Sistema Ibérico. Esta investigación se llevó a cabo sobre veintidós masas forestales de las comarcas de Els Ports de Morella (Castellón) y de la reserva natural de Els Ports de Tortosa-Beseit (Massís del Caro, Tarragona). Específicamente fueron: Sierra de Gúdar, Mosqueruela (Barranco de Orduño, Pinar Ciego, Los Lores), Bellena, Peñarroya, Vallivana, Castellfort, Morella, Vilafranca-La Iglesuela (Sierra Palomita), Monte de Fontanals (Vistabella-Penyagolosa), Fredes (Pla del rei), Castell de Cabres, Pereroles, Herbés, Monte Carlares, La Mina, Cassetes Velles (Massís del Caro) y en el alto Senia, Barranc de la Fou (Fig. 7). 


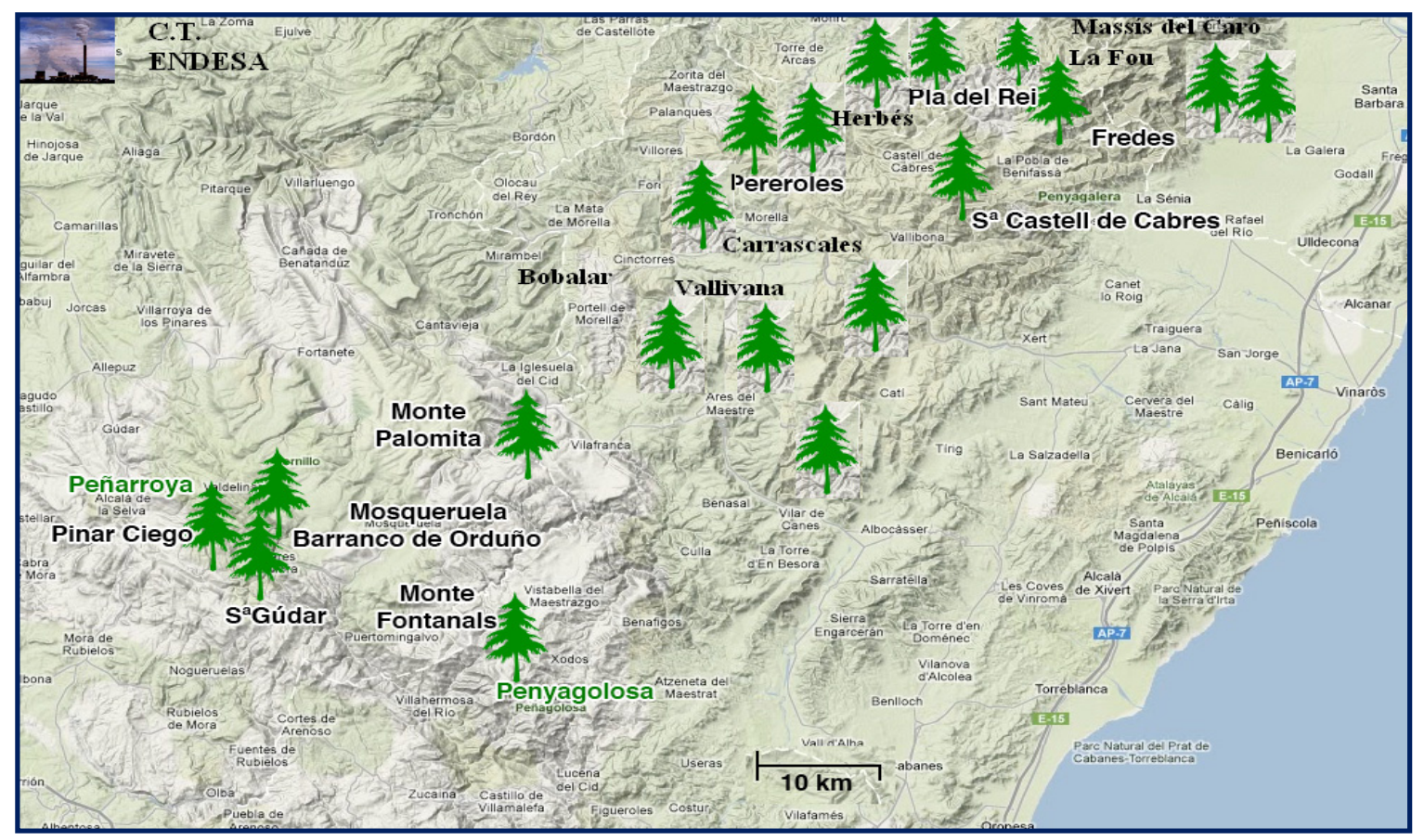

Figura 7: Principales masas forestales estudiadas en la vertiente mediterránea del sistema ibérico durante los diversos proyectos (2005-2012). Fuente: archivo del Laboratorio de Climatología de la Universitat Jaume I.

La ubicación de los puntos donde se tomaron las muestras no es aleatoria sino que responde al trazado del eje aerodinámico de la zona, auténtico vector de transporte y dispersión de los contaminantes gaseosos emitidos por la CT (Fig. 8).

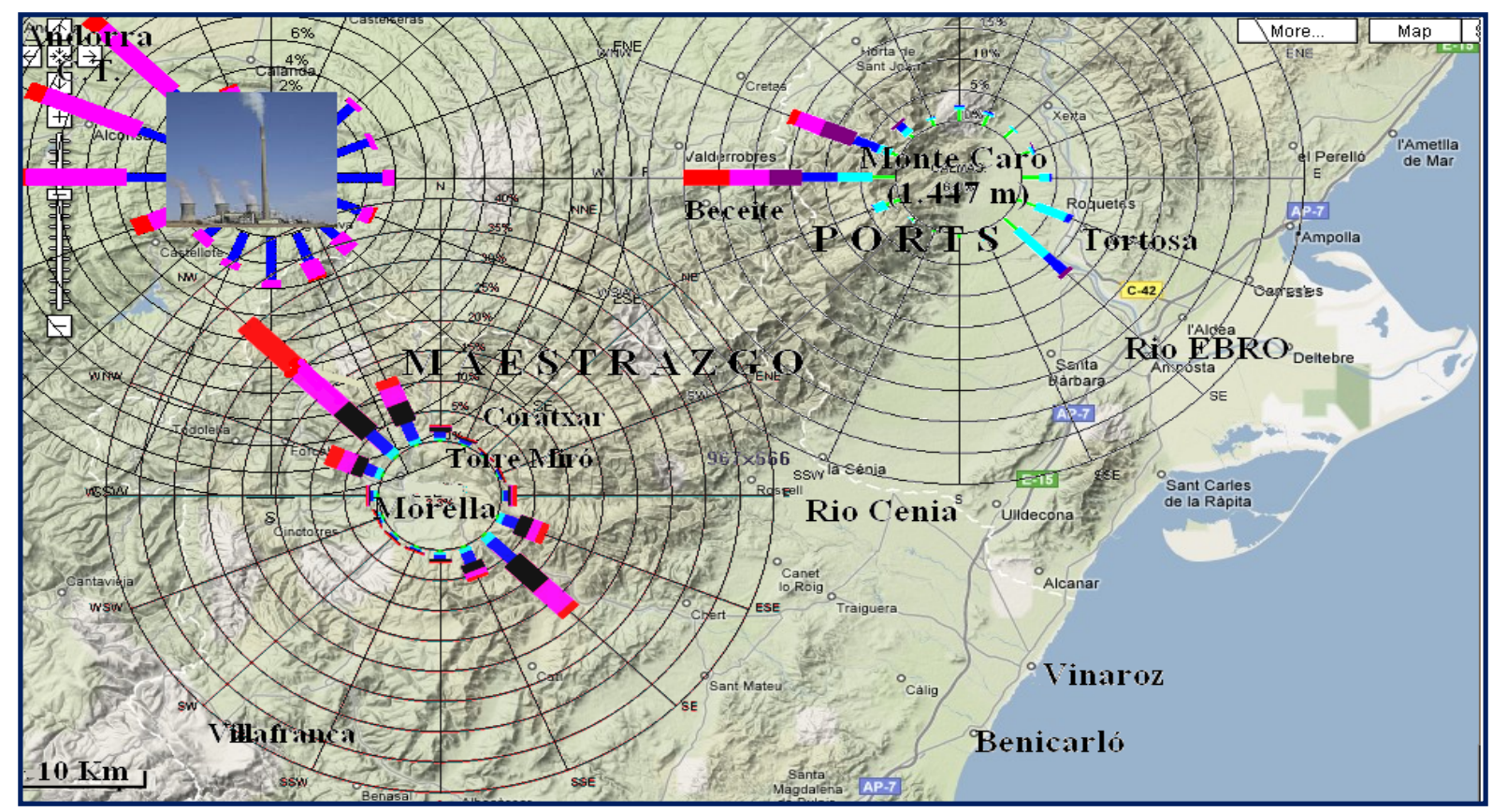

Figura 8: La circulación aérea regional en el nivel superior de la capa activa (1200-1450 metros). Estaciones de la CT de Andorra, Torre Miró y monte Caro. Fuente: archivo del Laboratorio de Climatología de la Universitat Jaume I.

Página | 16 
Las cerca de 1100 series dendrocronológicas obtenidas mostraron declives localizados de crecimiento que podrían ser atribuidos al impacto de la contaminación atmosférica. Contaminación muy condicionada por las complejas y variables situaciones atmosféricas regionales inherentes a la dispersión de contaminantes atmosféricos. Es precisamente la importancia de estas condiciones atmosféricas, capaces de magnificar en gran medida los impactos ambientales debidos a contaminantes gaseosos, la que condicionó la construcción de la imponente chimenea de emisión de gases de la CT de Andorra. Sin embargo, sólo una rigurosa caracterización del escenario meteorológico regional, determinante de los modelos de dispersión atmosférica de los contaminantes, puede atestiguar si realmente esta grandiosa chimenea cumple su cometido. Actualmente, contamos con medios técnicos y de observación muy superiores a los intuitivos existentes en 1980-1990 que nos permitirán llevar a cabo esa necesaria caracterización del escenario meteorológico regional.

En el momento actual parece juicioso sintetizar los procesos observados y conclusiones más relevantes obtenidas. Una síntesis encaminada al objeto de plantear, en el marco de la investigación doctoral propuesta: "Escenarios atmosféricos de contaminación y lluvia ácida sobre la vertiente mediterránea del Sistema Ibérico", una nueva metodología investigadora que permita explicar los resultados obtenidos sobre el grado de afección forestal y su causalidad. Surge así el objetivo meteorológico para establecer la evidencia científica entre los valores de contaminación y acidificación del medio y los daños forestales observados.

Un medio donde la acidificación, provocada fundamentalmente por los procesos de lluvia ácida, podría explicar los daños fitotóxicos observados en determinadas masas forestales. Hipótesis compartida hoy en día por la mayoría de investigadores que afirman que los principales daños forestales se deben a la acidificación de los suelos (Johnson y Siccama, 1983).

Los contaminantes una vez introducidos en las plantas provocan graves alteraciones en su metabolismo. No obstante, algunos suelos son capaces de neutralizar en mayor o menor grado la acidificación actuando como tampón o "buffer", justificando así las diferencias observadas en la degradación de las distintas masas forestales estudiadas.

En síntesis, un objetivo cuya principal contribución es la mejor preservación del ecosistema, a través de su pilar básico que es el medio forestal. En el momento actual, a más de diez años de la entrada en escena de las medidas de desulfuración que ENDESA viene 
aplicando en su CT de Andorra, la presente investigación supone asimismo el seguimiento y evaluación de la eficiencia de los protocolos ambientales adoptados.

Durante el transcurso de la presente investigación, se ha tratado de analizar la evolución del crecimiento forestal en las zonas de máxima afección: el monte Carrascales (Ares-Morella) y el monte Pereroles (Torre Miró-Morella). Para ello se ha continuado la investigación dendrocronológica iniciada ya en los anteriores trabajos de investigación llevados a cabo en el seno del Instituto Interuniversitario de Geografía (Escrig, 1999 y Mollà, 2007). Los resultados dendrocronológicos muestran que tanto la evolución del monte Carrascales como el de Pereroles han superado la tendencia altamente negativa que registraban en el horizonte del año 2002. La evolución del crecimiento parece remontar, en los últimos años, la situación de declive registrada desde comienzos de la década de 1980. La figura 9 muestra la evolución reciente del crecimiento forestal en las series del monte de Pereroles y de Carrascales (Morella). El desarrollo del crecimiento en el espesor de los anillos no parece acusar impactos adversos.

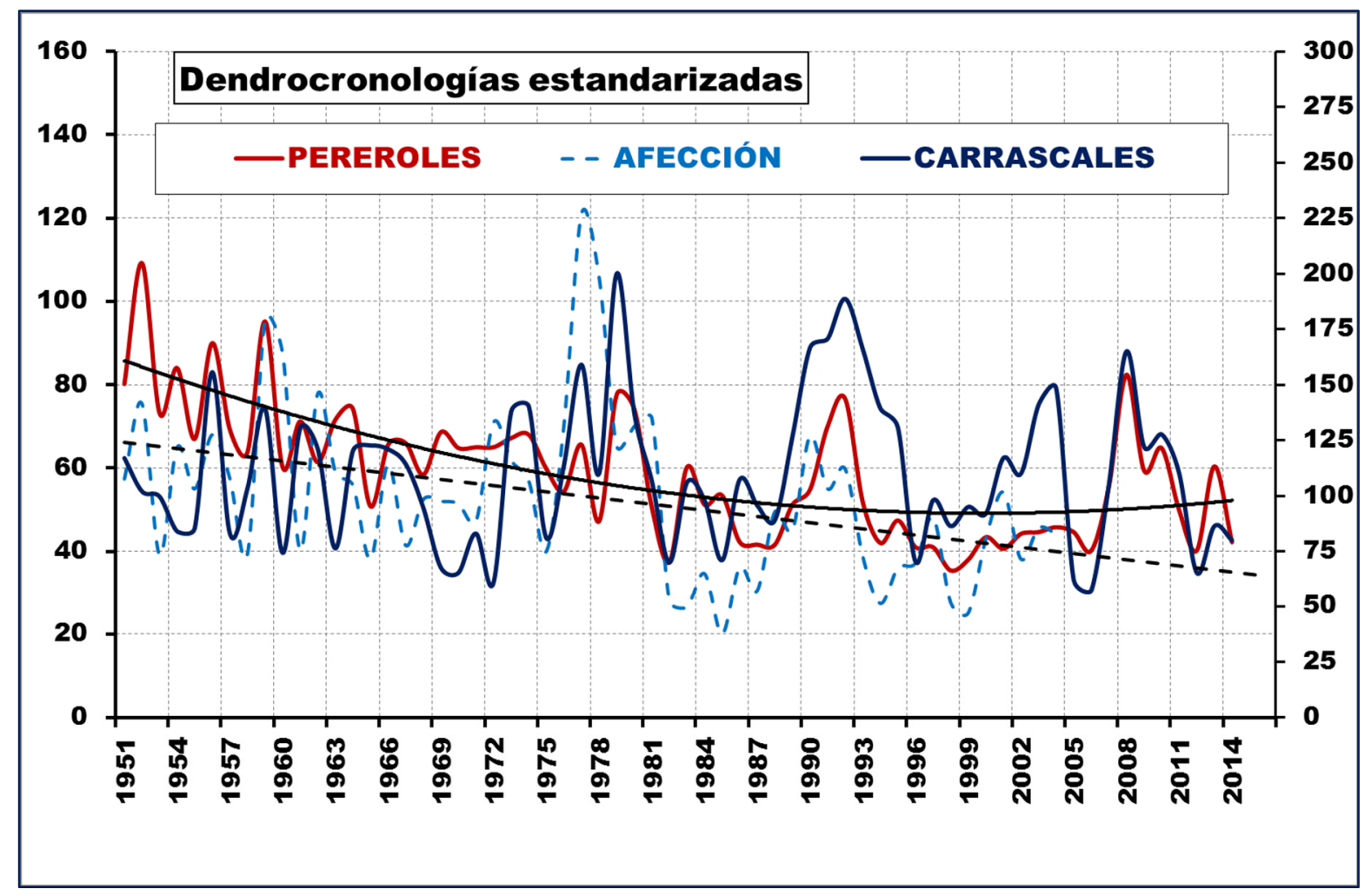

Figura 9: Evolución del crecimiento forestal en los montes de Carrascales y Pereroles. Las curvas dendrocronológicas muestran la superación o estabilización del declive en el crecimiento forestal. Fuente: Elaboración propia, Laboratorio de Climatología de la Universitat Jaume I. 


\section{OBJETIVOS PRINCIPALES DE LA INVESTIGACIÓN}

A tenor de los trabajos desarrollados, fundamento de la tesis propuesta "Escenarios atmosféricos de contaminación y lluvia ácida sobre la vertiente mediterránea del Sistema Ibérico", los dos objetivos principales de la investigación son:

\section{V.I. Objetivo principal}

El objetivo principal de la investigación es el reconocimiento de los modelos de escenario atmosférico que, sin menoscabo del valor de las emisiones contaminantes de la zona, actúan como potenciadores de los valores de inmisión y de riesgo ambiental. Modelos de situación atmosférica, condicionantes del transporte y dispersión de los penachos portadores de contaminantes atmosféricos, que deben de servir como guías para una mejor y más eficaz gestión del medio-ambiente. Todo ello con referencia a un territorio que, desde 1980, viene mostrando señales de alerta entre dos grandes fuentes de emisión: la CT de Andorra (Teruel) al oeste y la gran vía de transporte litoral mediterráneo emisora de gases precursores del ozono. Una zona donde esas señales han determinado la instalación de una densa red de vigilancia de calidad del aire ENDESA y GVA (Generalitat Valenciana).

\section{V.II. Objetivo complementario}

Asimismo, la investigación desarrollada parte de la base de que la CT de ENDESA ha instalado una de las más eficientes tecnologías en DGC (Desulfuración de Gases de Combustión). Ello, si bien permite un mayor y mejor control primario sobre el principal foco regional de emisión de contaminantes, no garantiza a priori que se cumplan siempre las normas de calidad del aire. No obstante, es cierto que las medidas relativas al $\mathrm{SO}_{2}$ permiten actualmente considerar que los niveles registrados en la zona se encuentran por debajo de los límites establecidos en la normativa vigente. Asimismo, el análisis de la tendencia de los datos, proporcionados por los informes anuales de la GVA sobre "Evaluación de la calidad del aire en la Comunidad Valenciana", muestra igualmente que no parece probable que se vayan a superar los límites legales establecidos (Real Decreto 102/2011, BOE 29 de enero de 2011

1 http:// http://www.habitatge.gva.es/web/calidad-ambiental/red-valenciana-de-vigilancia-y-control-dela-contaminacion-atmosferica 
relativo a la mejora de la calidad del aire). En consecuencia, el objetivo complementario de la investigación, será verificar la eficacia regional de las medidas de desulfuración de la CT de Andorra (Teruel).

Unos objetivos que se insertan plenamente dentro de las tres consideraciones básicas que ha fijado la directiva (UE) 2015/2193 del Parlamento Europeo y del Consejo, en 25 de noviembre de 2015, sobre la limitación de las emisiones a la atmósfera de determinados agentes contaminantes procedentes de las instalaciones de combustión:

I. La Decisión no 1386/2013/UE del Parlamento Europeo y del Consejo («el Programa de Medio Ambiente») reconoce que las emisiones de agentes contaminantes del aire se han reducido considerablemente en las últimas décadas, pero, al mismo tiempo, los niveles de contaminación atmosférica siguen siendo problemáticos en muchas partes de Europa, y los ciudadanos de la Unión continúan estando expuestos a contaminantes atmosféricos que pueden poner en peligro su salud y bienestar. De acuerdo con el Programa de Medio Ambiente, los ecosistemas siguen padeciendo una deposición excesiva de nitrógeno y azufre, asociada a las emisiones del transporte, a prácticas agrarias insostenibles y a la generación de electricidad. Los niveles de contaminación atmosférica en muchas zonas de la Unión siguen estando por encima de los límites fijados por la Unión, y las normas de calidad del aire de la Unión siguen incumpliendo los objetivos establecidos por la Organización Mundial de la Salud.

II. Para garantizar un medio ambiente saludable para todos, el Programa de Medio Ambiente aboga por que las medidas que se adopten a nivel local se complementen con una política adecuada, tanto a nivel nacional como de la Unión. Exige, en particular, que se intensifiquen los esfuerzos para cumplir plenamente la legislación sobre calidad del aire de la Unión y que se determinen acciones y objetivos estratégicos para después de 2020 .

III. Estudios científicos han demostrado que la contaminación atmosférica acorta en ocho meses de media la vida de los ciudadanos de la Unión. 


\section{HIPÓTESIS, METODOLOGÍA Y PLAN DE TRABAJO}

La tesis desarrollada compete a la verificación del determinante papel que las situaciones atmosféricas juegan en la potenciación o inhibición de los procesos de inmisión de los contaminantes atmosféricos y que, por ello, constituye uno de los dominios claves del estudio ambiental. Un dominio donde la construcción de la colosal chimenea de la CT de Andorra (Teruel), elevada a 343 metros, ya es un claro exponente de la trascendencia que adquieren los escenarios atmosféricos en sus emisiones. En este orden de verificaciones ha sido clave la metodología de la modelización gaussiana del penacho de humos emitido por la chimenea de la CT de Andorra (Teruel). Metodología de difusión y dispersión atmosférica que ha podido ser testeada sobre la extraordinaria base de datos que ha supuesto la Red de Vigilancia y Control de la Contaminación Atmosférica de la Generalitat Valenciana, creada por Decreto 161/2003 del Consell de la Generalitat. Los registros de esta red utilizados en la investigación, corresponden esencialmente a la estación de observación de Coratxar (La Pobla de Benifassà, 1200 metros), situada en pleno eje aerodinámico de la demarcación territorial de Andorra a Els Ports de Morella (Castellón) y de la Reserva Natural de Els Ports de TortosaBeseit (Massís del Caro, Tarragona) (Fig. 10).

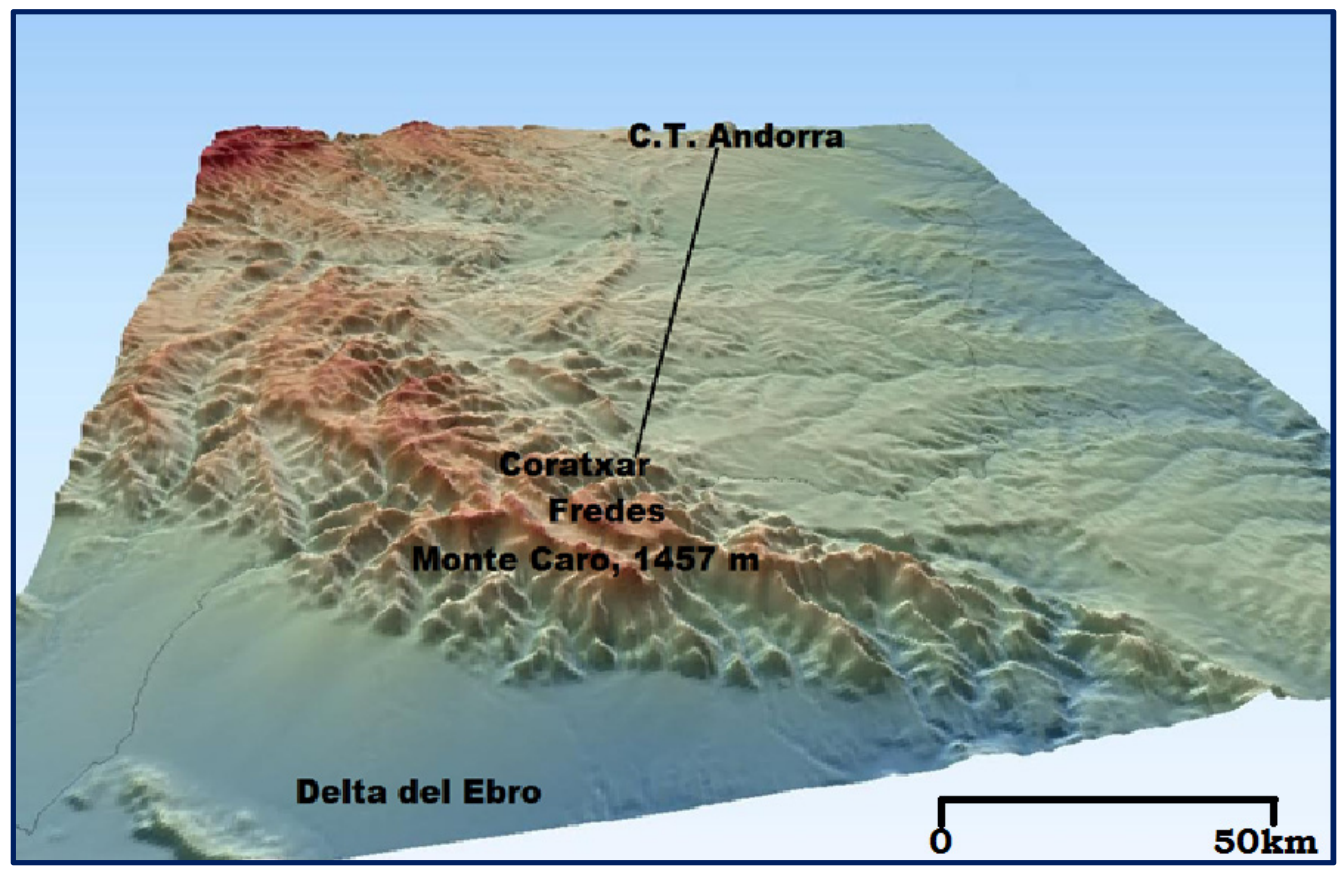

Figura 10: Mapa en relieve de la región de Els Ports de Morella (Castellón) y de la reserva natural de Els Ports de Tortosa-Beseit (Massís del Caro, Tarragona). La nítida alineación aerodinámica desde la CT a Coratxar, permite una excelente modelización gaussiana del penacho. Fuente: elaboración propia, Laboratorio de Climatología de la Universitat Jaume I. 
Esta metodología de dispersión, y por ende de calidad del aire, se ha completado con el control del pH en el agua de lluvia. Control que ha sido realizado mediante un analizador automático de lluvia ácida marca Kimoto, modelo AR-106 (Fig. 11). Analizador que desde 2006 ha venido registrando el pH en el agua de lluvia en el alto de Torre Miró (Morella, 1256 metros).

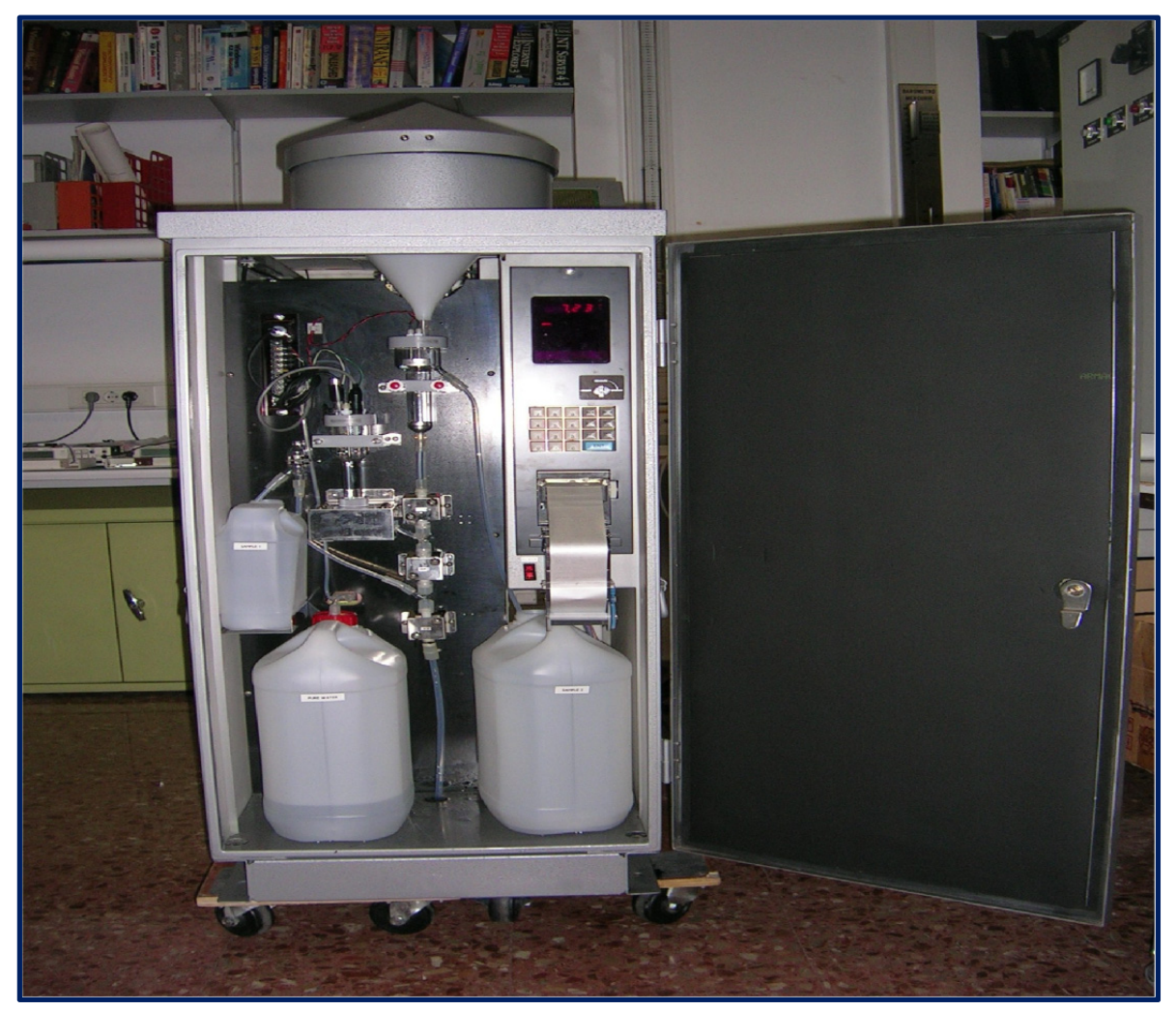

Figura 11: Analizador de lluvia ácida, marca Kimoto, modelo AR-106. Fuente: archivo del Laboratorio de Climatología de la Universitat Jaume I.

El criterio para la identificación de los períodos críticos de inmisiones de $\mathrm{SO}_{2}$ se ha basado en la aplicación de los umbrales críticos señalados en la actual legislación y normativa europea (Real Decreto 102/2011, BOE 29 de enero de 2011), así como en la adopción de umbrales situados tan sólo al $75 \%$ de esos niveles de daño y riesgo ambiental. Esta disminución de los umbrales máximos alcanza su justificación en que todo el referente normativo todavía dista mucho de haber establecido científicamente las relaciones de los valores fijados con los daños observados en las masas forestales o la salud humana.

Una vez identificados estos periodos críticos se ha procedido a aplicar la metodología meteorológica basada en el análisis de la situación atmosférica durante los períodos críticos detectados. Este análisis comprende la estructura térmica vertical de la atmósfera mostrada por Página | 22 
los radiosondeos de Zaragoza aeropuerto. Este análisis de la estructura térmica vertical de la atmósfera ha contado con la importante aportación de la red meteorológica de la Universitat Jaume I, iniciada en el año 2003 y completada en el 2006. Los observatorios del monte Caro (Tortosa, Tarragona, 1447 metros), Fredes (Castellón, 1235 metros) y Torre Miró (Morella, Castellón, 1256 metros) han resultado, por su ubicación dentro de la región estudiada, fundamentales en la presente investigación. Observatorios que, especialmente en la capa de 900 a $850 \mathrm{hPa}$, han constituido un sondeo permanente en ese nivel crítico en las emisiones de la CT, además de permitirnos caracterizar el modelo de circulación atmosférica. Todo ello aplicado a unas situaciones definidas por los umbrales críticos de inmisión y configuradas sinópticamente en los reanálisis (NCAR, National Center for Atmospheric Research, Boulder). Cartografía completada con la imaginería de satélites meteorológicos recibida diariamente en el Laboratorio de Climatología de la Universitat Jaume I. Esta imaginería, procedente principalmente de los satélites NOAA y MSG, permite el acceso a la información en tiempo real del estado atmosférico y de los subsistemas básicos mar y superficies continentales (Fig. 12).

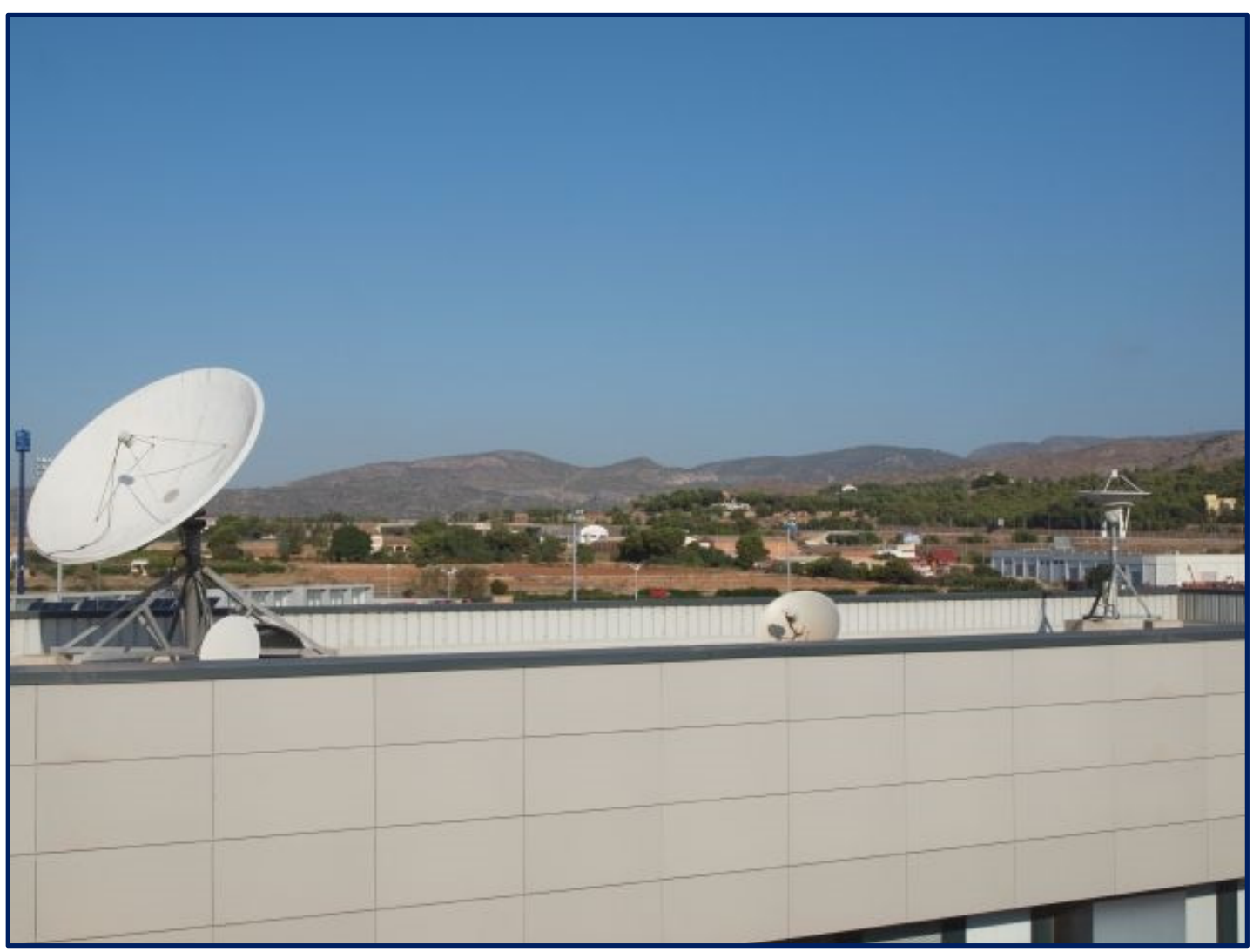

Figura 12: Sistema de recepción de imágenes procedentes de satélites geoestacionarios (MSG) y orbitales (NOAA). Estación de Climatología, Universitat Jaume I. Fuente: archivo del Laboratorio de Climatología de la Universitat Jaume I. 
En la figura 13 se aprecia el marco geográfico donde se desarrolla la presente investigación. La nítida expresión gráfica de la geografía regional, entre Andorra y los relieves ibérico-catalánides, ilustra el alto valor que los factores geográficos desempeñan en los procesos ambientales estudiados.

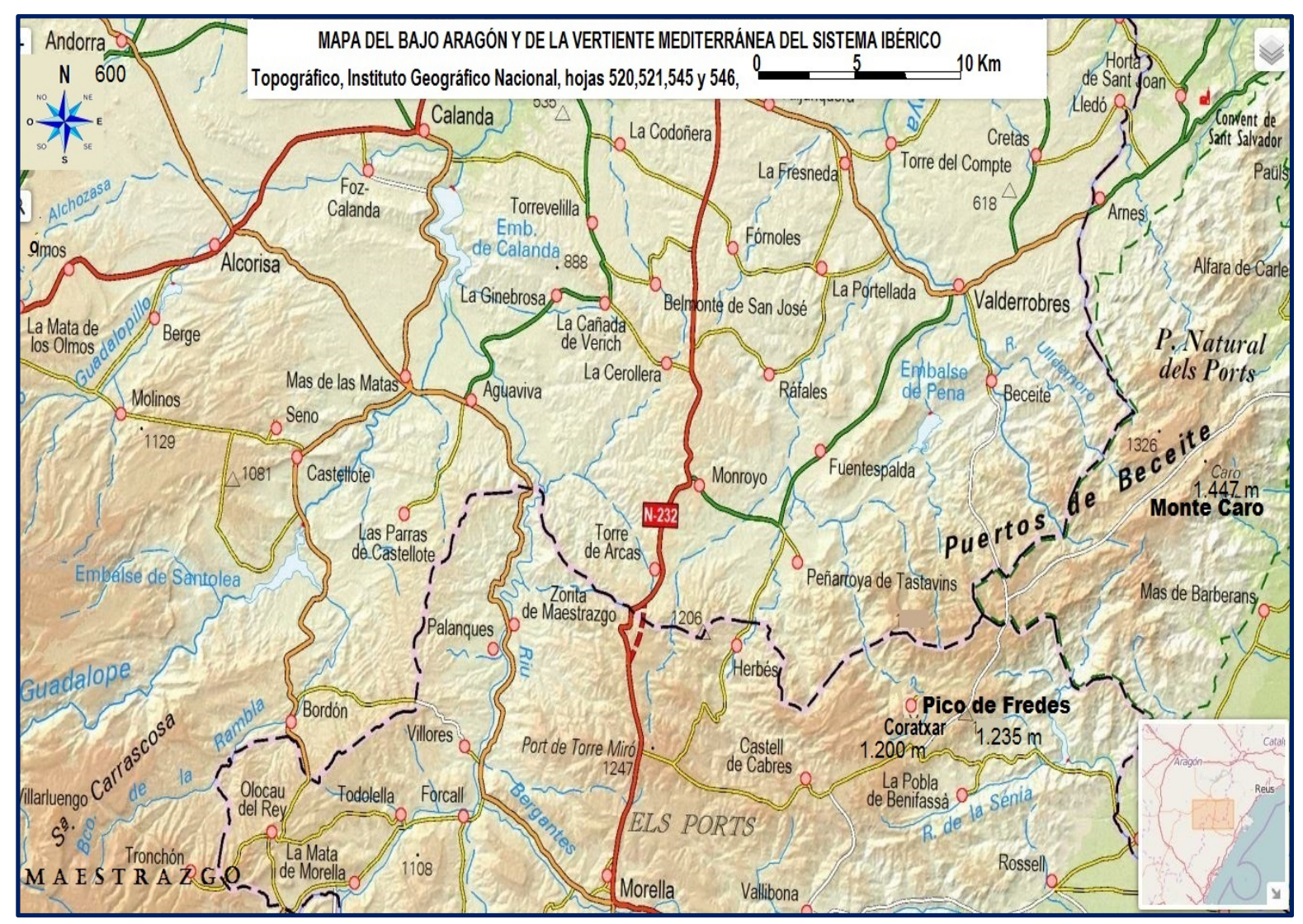

Figura 13: Mapa geográfico del Bajo Aragón y de la vertiente mediterránea del Sistema Ibérico. Fuente: Cartografía del IGN, Mapa Topográfico Nacional, hojas 520, 521, 545 y 546. 
EL ESCENARIO ATMOSFÉRICO SOBRE LA VERTIENTE MEDITERRÁNEA DEL SISTEMA IBÉRICO 



\section{EL CONOCIMIENTO DEL ESCENARIO ATMOSFÉRICO REGIONAL Y SU IMPORTANCIA}

Como ya se ha evidenciado a lo largo del primer capítulo del presente trabajo, la comprensión del escenario atmosférico constituye un condicionante indispensable para el estudio de los impactos ambientales provocados por contaminantes gaseosos. "No en balde es el medio en el que se inyectan, transforman, difunden y precipitan los contaminantes atmosféricos y, por ello, constituye uno de los dominios claves del estudio ambiental" (Quereda et al., 2014: 107). Su vital importancia es aún más acusada en una región como la mediterránea en la cual el escenario atmosférico presenta una serie de singularidades que hacen que su estudio resulte más complejo que el de otras regiones de la zona templada europea, donde las situaciones atmosféricas de inestabilidad son predominantes.

La región litoral mediterránea se caracteriza principalmente por el predominio de situaciones de estabilidad atmosférica. Situaciones en las que aparece una estratificación atmosférica estable donde los movimientos ascendentes del aire están considerablemente restringidos. Esta característica del escenario atmosférico regional influye en el movimiento y dispersión de los contaminantes del aire en la atmósfera y es, precisamente, la que va a provocar, en situaciones de gran estabilidad, la existencia de episodios de contaminación más o menos acusados en la zona mediterránea. La inhibición de los movimientos ascendentes del aire provoca que los contaminantes gaseosos queden confinados cerca de la superficie terrestre, impidiendo su dispersión vertical y agudizando, como veremos más adelante, los impactos ambientales. Por el contrario, en situaciones de inestabilidad atmosférica o neutras, como es más frecuente en el resto de regiones de la zona templada, las circulaciones verticales de aire aumentan, arrastrando así los contaminantes gaseosos y favoreciendo su dispersión hacia capas atmosféricas más altas. Son pues situaciones mucho más favorables desde el punto de vista medioambiental, si soslayamos la potenciación del proceso de lluvia ácida.

Siendo la estabilidad atmosférica el tipo de escenario predominante en nuestra región, su estudio será uno de los ejes de este trabajo. En este sentido consideraremos especialmente las situaciones en las que la estabilidad resulta extrema. Ellas vienen condicionadas por cuanto que se invierte la disminución general de la temperatura con la altura en la troposfera y aparece lo que se conoce como una inversión térmica. Durante los procesos de inversión se forma una capa de aire más cálido que impide que los contaminantes emitidos por debajo de ella la 
atraviesen. Podemos decir que la flotabilidad de los contaminantes gaseosos quedará interrumpida por la capa de inversión regional que se comporta como una "tapadera" de la capa activa o de mezcla.

Es por ello fundamental intentar delimitar el alcance de esta capa activa o de mezcla (San José et al., 1984). Esta capa constituye la zona más baja de la troposfera, en contacto con la superficie terrestre, donde la estructura atmosférica, generalmente inestable o indiferente, hace posible la dispersión vertical de los contaminantes hasta alcanzar esa "tapadera" provocada por la capa de inversión (Fig. 14). Precisamente, esta capa recibe su nombre de la enorme influencia que tiene sobre ella la turbulencia, tanto térmica como dinámica, que la cercanía de la superficie terrestre provoca dando lugar a un efecto de "mezclado" de los componentes atmosféricos. No obstante, no existe un único término para referirnos a esta capa, de manera que en la amplia bibliografía existente podemos encontrar referencias a ella como: capa límite planetaria, capa geográfica, capa activa, capa convectiva o en términos ingleses: PBL (Planetary Boundary Layer), ABL (Atmospheric Boundary Layer), CBL (Convective Boundary Layer) y ML (Mixing Layer).

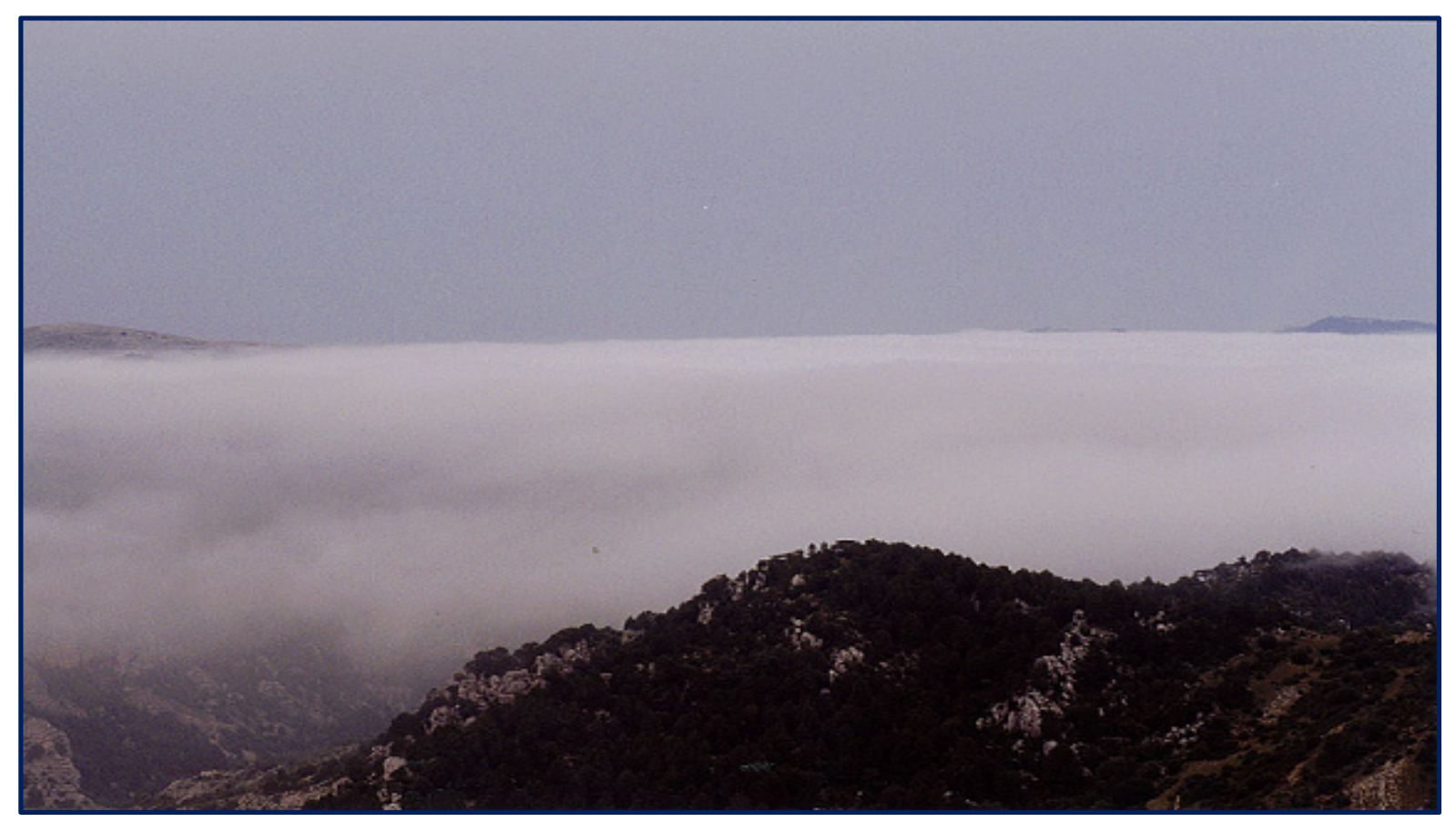

Figura 14: Capa de inversión sobre la reserva natural de Tortosa-Beseit. Imagen tomada desde la cima del Monte Caro (1447 metros). Fuente: archivo del Laboratorio de Climatología de la Universitat Jaume I. 


\section{LA CAPA DE MEZCLA: DEFINICIÓN Y METODOLOGÍAS DE CÁLCULO}

La capa de mezcla podría definirse como "el estrato de aire en el que la turbulencia atmosférica originada por desequilibrios térmicos o mecánicos, produce una intensificación de los movimientos caóticos del aire, favoreciendo el fenómeno de difusión y transporte de energía y materia hasta un nivel delimitado normalmente por la presencia de una discontinuidad térmica, a partir de la cual, el comportamiento de la atmósfera no está sujeto a dichos intercambios turbulentos" (Núñez, 2004: 10). Su delimitación es tarea imprescindible aunque ardua ya que no es un límite fijo sino que presenta variaciones dependiendo principalmente su altura de la clase de estabilidad, de la velocidad del viento, de la radiación solar y de la orografía. No obstante, fijar este límite superior es indispensable en el estudio de la dispersión de los contaminantes atmosféricos ya que define el volumen de aire en el cual éstos podrán dispersarse (Pey, 2007). Este límite superior de la capa de mezcla está caracterizado por dos rasgos: por ser el nivel en el que el viento real es igual al viento geostrófico y por venir asociado a condiciones de inversión térmica (Irwin, 1985; Stull, 1988 y Crespi et al., 1995).

En nuestra región mediterránea las distintas caracterizaciones realizadas a lo largo de los años han establecido que, a modo de promedio, esta capa de mezcla se extendería hasta los 800-900 milibares, es decir, su límite superior quedaría comprendido entre los 1000 y los 2000 metros de altura (NILU, 1987 b; Millán y Sanz, 1993 y Quereda, 1985). En el caso de las emisiones contaminantes, estas diferencias de altitud serán determinantes en los procesos de dispersión de las mismas. Por ello, nuestro estudio pretende establecer este importante nivel en la escala regional de la vertiente mediterránea del Sistema Ibérico a través de un análisis minucioso de los registros atmosféricos disponibles.

No en balde, como veremos en el capítulo siguiente, el espesor de la capa activa o de mezcla es el parámetro fundamental para la aplicación de los modelos gaussianos de dispersión de contaminantes. En este orden de investigaciones, la única estación regional de radiosondeos disponible para este fin es la del aeropuerto de Zaragoza (AEMET). Aunque distante $85 \mathrm{~km}$ de Andorra, los registros sobre el nivel de los $900 \mathrm{hPa}$ son generalmente válidos. Asimismo, y afortunadamente, estos datos han podido ser completados, desde 2003, con los obtenidos en 
los observatorios de Torre Miró (Morella, Castellón), del pico Fredes (Tinença de Benifassà, Castellón) y de la cima del monte Caro (Tortosa, Tarragona) (Fig. 15).

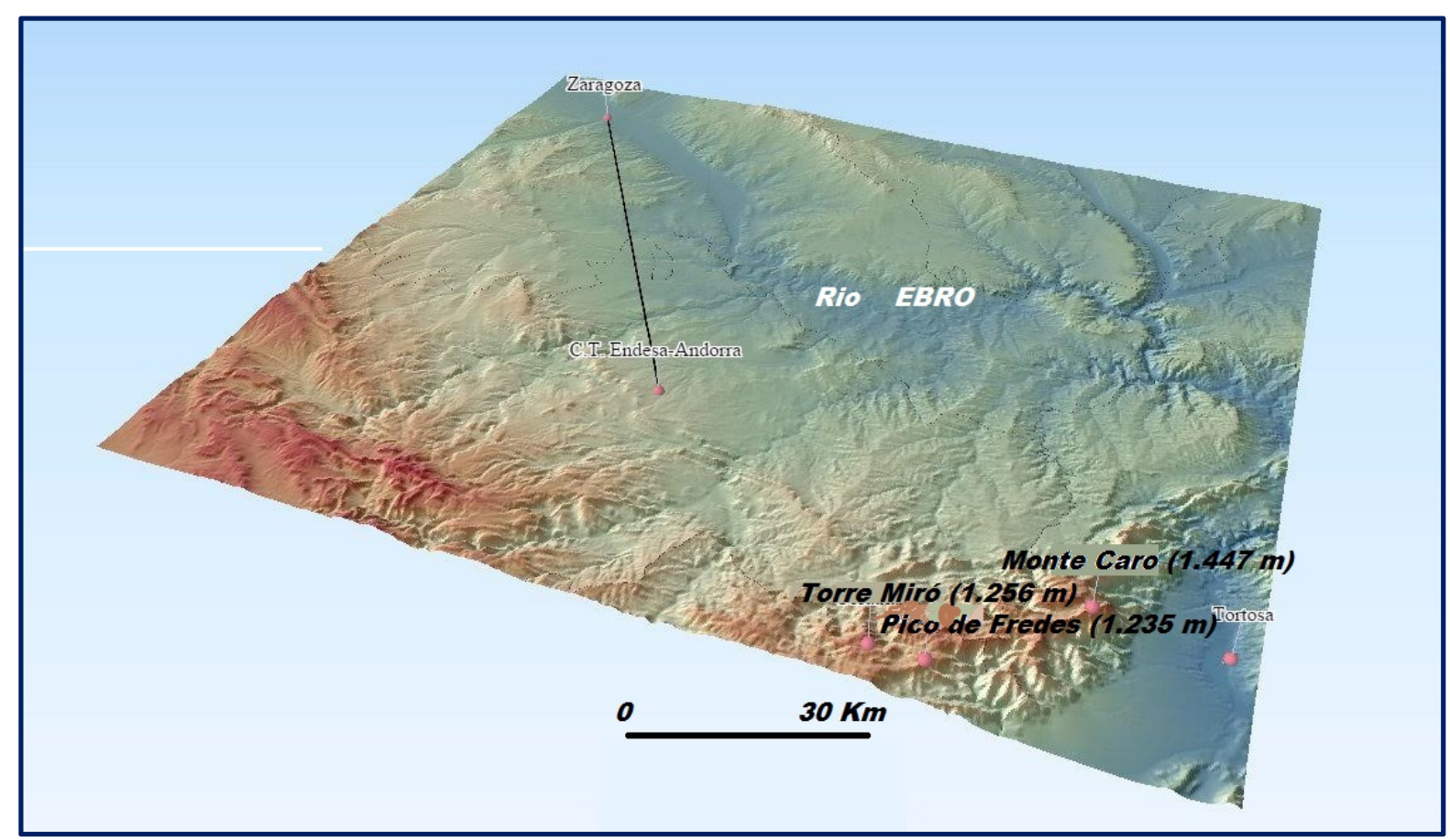

Figura 15: Mapa en relieve de la región ibérica estudiada con la ubicación de las estaciones automáticas de Fredes (1235 metros), Torre Miró (1256 metros) y monte Caro (1447 metros), pertenecientes a la red meteorológica de la Universitat Jaume I. Fuente: elaboración propia, Laboratorio de Climatología, Universitat Jaume I.

Estas estaciones automáticas pertenecen a nuestra red meteorológica de la Universitat Jaume I y se hallan ubicadas en cimas o torres orográficas, Torre Miró a 1256 metros, el pico Fredes a 1235 metros (Fig. 16) y el observatorio del Caro a 1447 metros de altura (Fig. 17). 


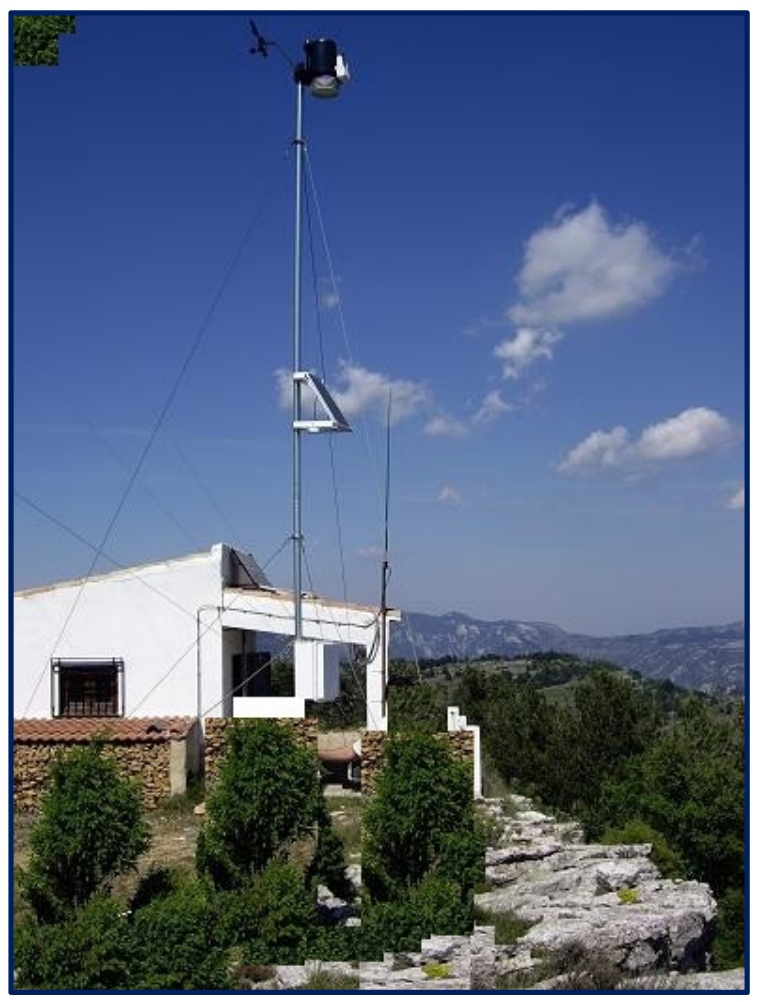

Figura 16: Estación meteorológica del pico Fredes (1235 metros) y observatorio forestal. Fuente: archivo del Laboratorio de Climatología de la Universitat Jaume I.

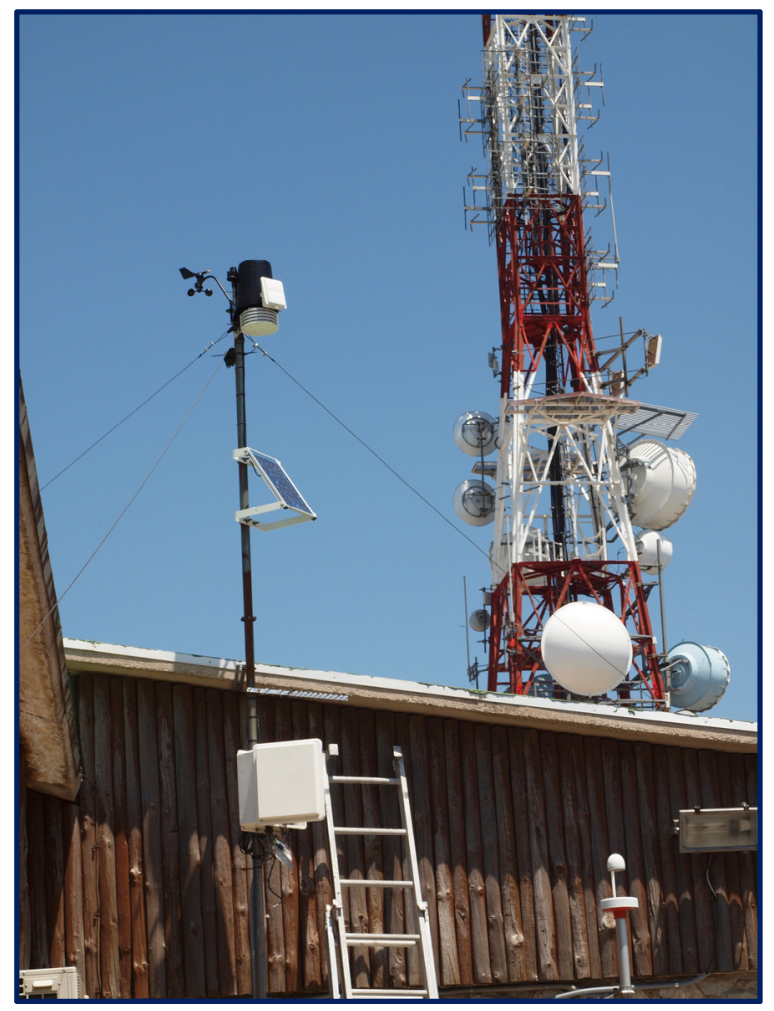

Figura 17: Estación meteorológica de la cima del monte Caro (1447 metros). Fuente: archivo del Laboratorio de Climatología de la Universitat Jaume I. 
A través de sus datos, en ese nivel crítico sobre los $900 \mathrm{hPa}$, hemos tratado de salvar esa gran dificultad para definir la capa de mezcla regional mediante el establecimiento de su límite superior. Ante las grandes variaciones del espesor de la capa de mezcla dependiente, como ya se ha señalado, de la clase de estabilidad, de la velocidad del viento, de la radiación solar y de la orografía, es de suma importancia la determinación diaria del espesor de la misma en un lugar y tiempo determinado. Ello, junto con el inventario de emisiones y el monitoreo atmosférico, constituye una información básica para la modelización de la dispersión y la subsecuente toma de decisiones en una política medioambiental responsable. La evaluación del impacto ambiental y el análisis de sus consecuencias es una herramienta indispensable para una correcta planificación en el desarrollo sostenible.

Esta importancia ha dado como consecuencia el desarrollo de toda una serie de técnicas para determinar con la mayor exactitud posible el espesor de la capa de mezcla. Estas técnicas, tanto teóricas como experimentales, abarcan desde las más sencillas hasta las más complejas expresiones matemáticas. De entre todos los métodos existentes, los radiosondeos constituyen hoy en día una de las técnicas más empleadas para establecer la estructura vertical de la capa de mezcla. De este modo, siempre y cuando puedan realizarse medidas en altura, el espesor de la capa de mezcla puede estimarse mediante la detección del nivel de la capa de inversión o del nivel de condensación ascendente. Ello sin soslayar las dificultades que presenta contar con tales sondeos de altura o en globo cautivo. Unas medidas o registros de altura que enfatizan las grandes dificultades de la determinación del espesor de esta capa.

Así, el método más simple sobre sondeos para el cálculo de la altura de la capa de mezcla, siempre en condiciones de estabilidad, es el de Holzworth (Holzworth, 1972). Este método calcula la altura de la capa de mezcla dos veces al día (mañana y tarde) a partir de los radiosondeos diarios. La altura de la capa de mezcla sería el punto de intersección de la adiabática seca con la curva de estado. El origen de la adiabática seca sería la temperatura del aire en la superficie terrestre $\left(\mathrm{T}_{\mathrm{s}}\right)$ (ocasionalmente en la mañana con la $\mathrm{T}_{\min }$ se añade un incremento experimental entre 1 y $3{ }^{\circ} \mathrm{C}$ para compensar el efecto de calor del suelo o el urbano de las ciudades). La limitación del método radica, precisamente, en esa estimación de la $\mathrm{T}_{\mathrm{s}} \mathrm{y}$ que tan sólo puede aplicarse en situaciones de estabilidad homogénea en la capa de mezcla. Una limitación que torna más significativa la utilización de un método diferente al propuesto por Holzworth y basado en el denominado LCLP (Lifted Convective Level Pressure), en español NCA (Nivel de Condensación Ascendente). Dicho nivel, medido en hPa, marca el Página | 32 
techo de la capa de mezcla. El LCLP se localiza en la intersección de la adiabática seca, con origen en el promedio de la curva de estado en los 500 metros inferiores, con la equisaturada $\left(\mathrm{MLMR}^{2}, \mathrm{~g} / \mathrm{Kg}\right.$ ), con origen en la media de la $\mathrm{MIXR}^{3}$ en los 500 metros inferiores (Universidad de $\mathrm{W}_{\text {yoming }}{ }^{4}$ ). A lo largo del presente estudio se emplearán los datos proporcionados por la Universidad de Wyoming, que ofrece los diagramas de los radiosondeos diarios de un gran número de estaciones mundiales junto con sus respectivos registros numéricos de variables meteorológicas. En la figura 18 se refleja la aplicación gráfica para el cálculo del LCLP sobre uno de los radiosondeos de Zaragoza (25 de octubre del 2015) proporcionados por la Universidad de Wyoming.

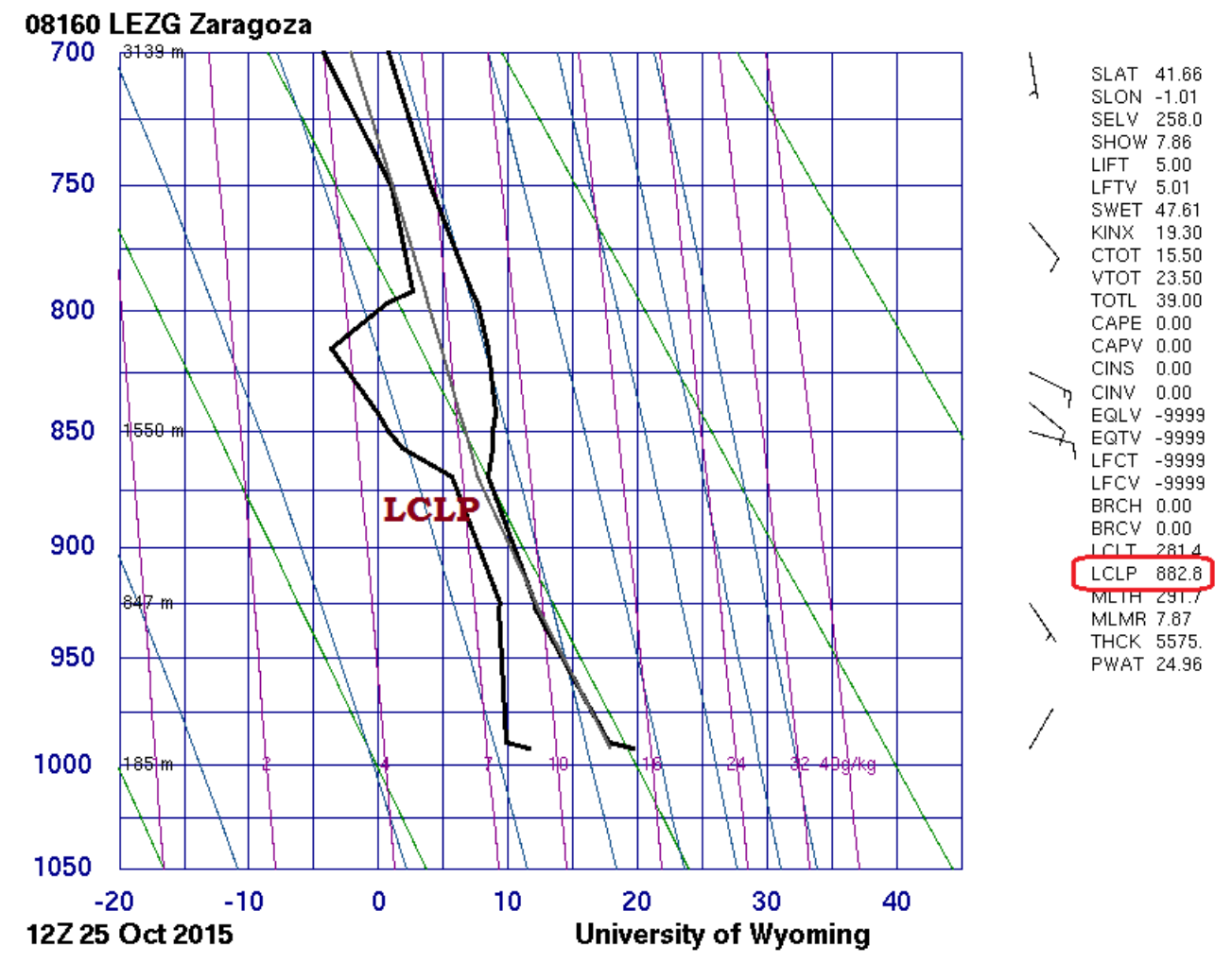

Figura 18: Radiosondeo de Zaragoza aeropuerto del 25 de octubre del 2015. Altura de la capa de mezcla (LCLP o NCA) a 882,8 hPa (1150 metros), (Mixing ratio 7,87 g/Kg). Este nivel (LCLP) marca el techo de la capa de mezcla, en coincidencia con la capa de inversión. Fuente: http://weather.uwyo.edu/upperair/sounding.html.

${ }^{2}$ MLMR o Mixing Ratio of the Mean mixed layer es el promedio de la MIXR (Mixing Ratio) en los 500 metros más bajos de la atmósfera.

${ }^{3}$ MIXR (Mixing Ratio o Razón de Mezcla) es la cantidad total de vapor de agua que puede contener el aire a una temperatura dada, por la relación de peso, antes de alcanzar la saturación. Se define como el cociente entre la masa de vapor de agua y la masa de aire seco y se expresa en $\mathrm{g} / \mathrm{kg}$. Es casi igual numéricamente a la humedad específica, pero siempre es ligeramente mayor.

${ }^{4}$ Universidad de Wyoming (http://weather.uwyo.edu/upperair/sounding.html) 
Del mismo modo, junto a los radiosondeos diarios, la Universidad de Wyoming ofrece sus registros e índices numéricos en los que se incluye el valor del LCLP, calculado gráficamente mediante el método anteriormente citado (Fig. 19). Dicho valor será empleado en los capítulos posteriores para establecer la altura de la capa de mezcla.

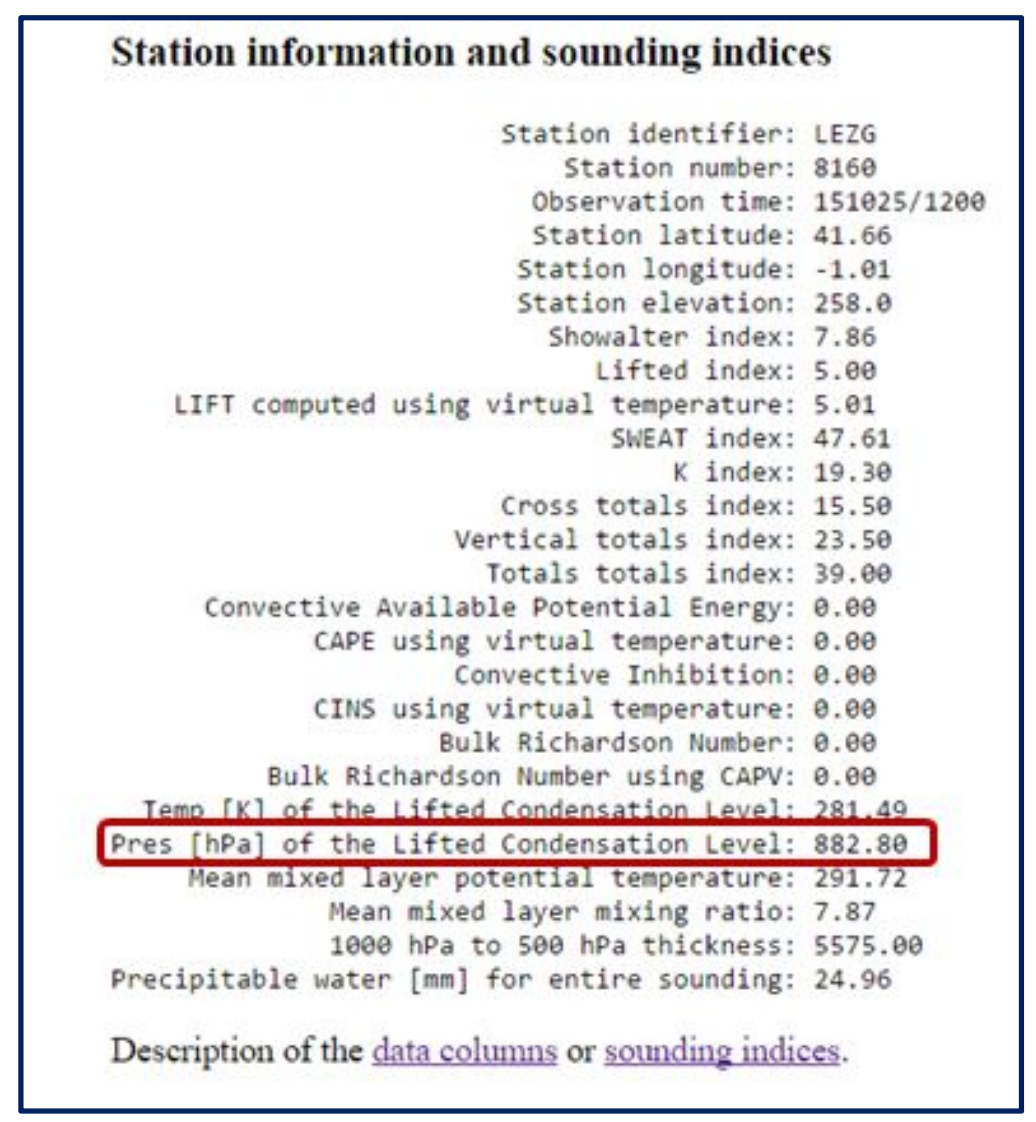

Figura 19: Información sobre los índices asociados al radiosondeo de Zaragoza aeropuerto del 25 de octubre del 2015. Fuente: http://weather.uwyo.edu/upperair/sounding.html.

El mismo ejemplo anterior (Fig. 18) muestra la proximidad del LCLP con la base de una inversión térmica evidenciando como, con carácter general, la altura de la capa de mezcla viene determinada también por las inversiones térmicas. Estas actúan como superficies de separación entre la masa de aire que se halla formando la capa de mezcla y la que se halla por encima de ella (Fig. 20). 


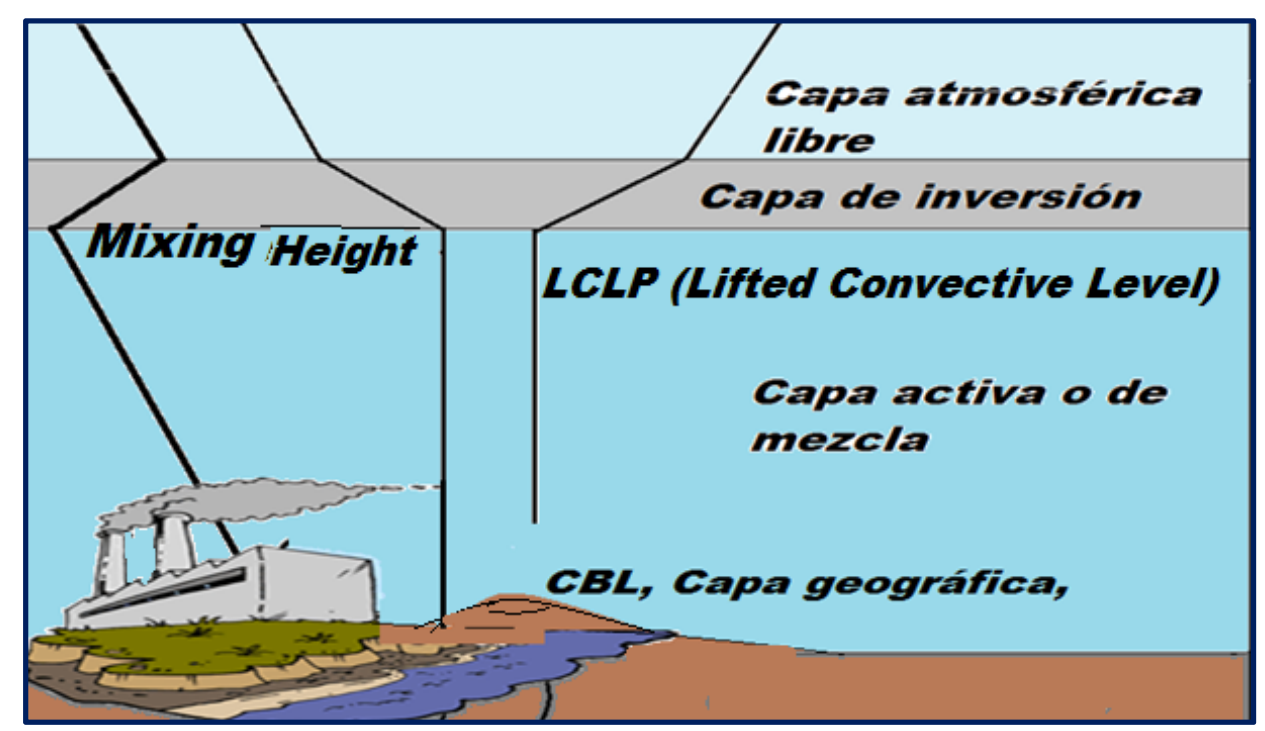

Figura 20: Esquema de las capas inferiores de la Troposfera: capa geográfica y capa libre. Fuente: archivo del Laboratorio de Climatología de la Universitat Jaume I.

La figura 21 ilustra los procesos atmosféricos que tienen lugar bajo la estructura atmosférica registrada por el sondeo correspondiente al día 25 de octubre del 2015. El penacho se eleva hasta la altura del LCLP (1150 metros, $882,8 \mathrm{hPa})$, coincidente con la base de la inversión térmica.

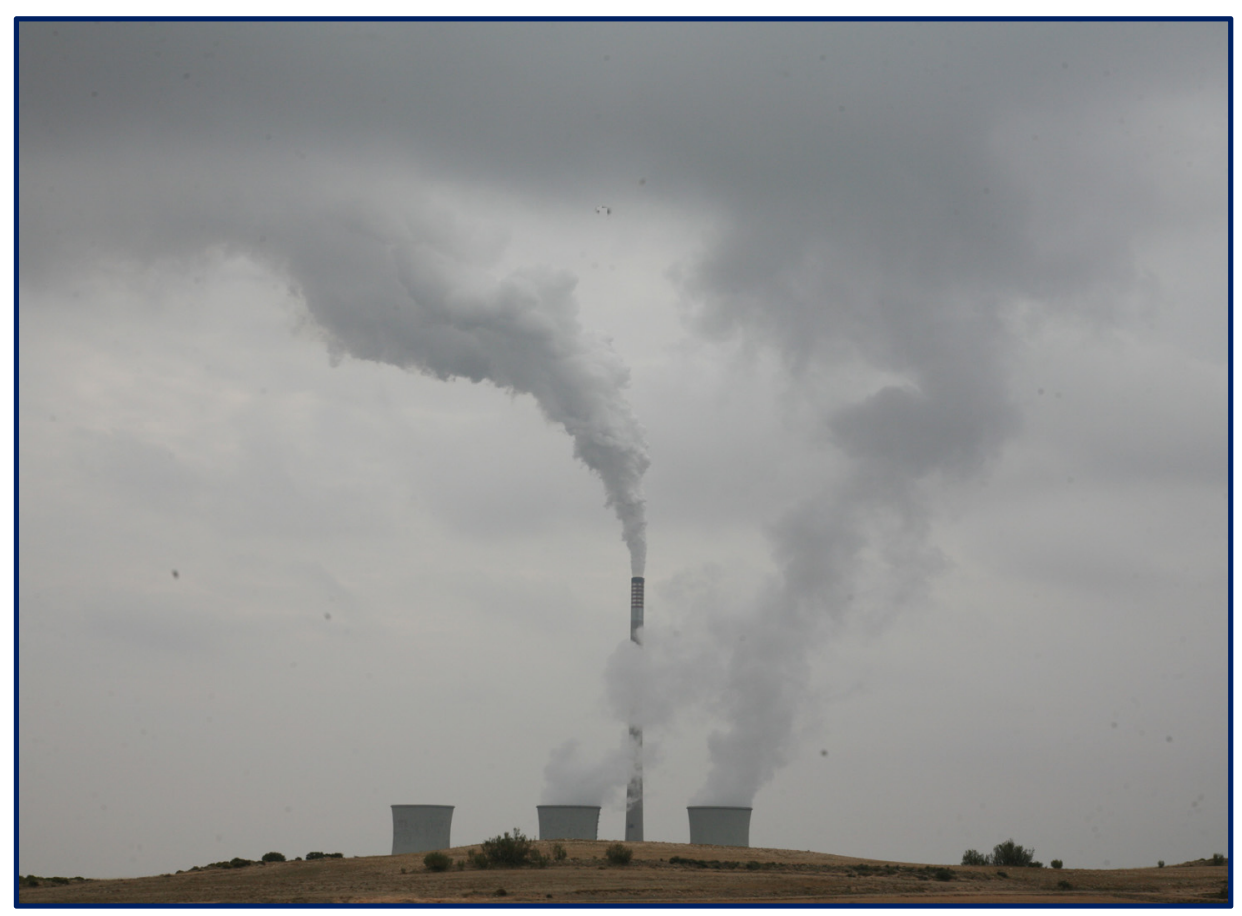

Figura 21: Imagen de la CT. El penacho se eleva hasta la altura de 1150 metros (LCLP a 882,8 hPa). La cizalla del viento en superficie queda reflejada en la dirección contraria de las columnas de vapor. Fuente propia, imagen tomada el 25 de octubre del 2015 a las 13 horas. 


\section{II.I. Metodología aplicada para la determinación de la altura de la capa de mezcla en el escenario atmosférico regional}

El espesor de la capa de mezcla sufre grandes oscilaciones en su valor debido a los cambios continuos que la superficie terrestre ejerce sobre él como consecuencia de la actividad solar. Así, la capa de mezcla presenta variaciones tanto de carácter estacional como de carácter diurno y nocturno.

Durante la noche, y especialmente en invierno, la inversión térmica radiativa de superficie determina que la capa de mezcla no supere los 400-500 metros de altura. Esto es lo que se conoce como capa de inversión térmica baja. Durante el día, en cambio, la actividad de turbulencia térmica provoca que el espesor de la capa de mezcla aumente. Este fenómeno se produce en cuatro etapas claramente diferenciadas (Núñez, 2004: 19):

I) Destrucción de la inversión radiativa nocturna a primeras horas de la mañana y comienzo de una débil capa de mezcla mientras se destruye, paulatinamente, el estrato estable nocturno.

II) Formación de una capa de mezcla de gran espesor en horas centrales del día, delimitada frecuentemente por la presencia de una inversión térmica en altura.

III) Pérdida o disminución de la inestabilidad como consecuencia del desequilibrio térmico que tiene lugar al atardecer.

IV) Finalmente, formación de una nueva inversión térmica radiativa que irá profundizándose e intensificándose a lo largo de la noche.

Consecuentemente, a tenor de la altura de boca de la chimenea, 939 metros (chimenea de 343 metros situada a 596 metros sobre el nivel del mar), las emisiones de la CT suelen realizarse en un estrato atmosférico que se halla sobre esas inversiones bajas, y donde los efectos de la superficie ya aparecen bastante debilitados. Fuera de estos períodos, vinculados a la formación de esa inversión radiativa baja, los efectos de la turbulencia térmica y dinámica de superficie se dejan sentir a mayores alturas. Alturas que vienen determinadas generalmente por la capa de inversión alta.

Por todo ello, la metodología aplicada en el escenario regional (capítulos III y IV) ha estado basada en el análisis de la estructura atmosférica registrada por los sondeos de Zaragoza aeropuerto. Estos registros, aunque distantes, han permitido establecer dos parámetros Página | 36 
fundamentales para el cálculo de la altura de la capa de mezcla: el LCLP (Lifted Convective Level Pressure) y el nivel de las capas de inversión térmica. El LCLP, como ya se ha mencionado, se calcula a través de la equisaturada MLMR, Mean mixed layer, que tiene su origen en el valor medio de la MIXR (Mixing ratio, $\mathrm{g} / \mathrm{Kg}$ ) en los 500 metros superficiales. La capa de inversión se observa en los estratos con una ruptura del gradiente térmico de enfriamiento.

Complementariamente, los registros numéricos de los sondeos, obtenidos de la base de datos de la Universidad de Wyoming, han aportado los valores de los flujos de calor y humedad $(\omega \theta$ y $\omega \mathrm{q})$, temperatura potencial, equivalente y virtual (THTA, THTE y THTV), así como la fuerza del viento (SKNT). Unos registros que, como ya se ha mencionado, han podido completarse, a partir de 2003, con los obtenidos en la red meteorológica universitaria, especialmente en las estaciones de altura de Torre Miró, Fredes y cima del monte Caro. De este modo ha sido posible obtener el valor de la altura de la capa de mezcla (Mixing Height), en cuyo seno deja sentir sus efectos la constante turbulencia térmica y dinámica de la fuente de emisiones de la CT. Un parámetro fundamental para la modelización gaussiana de las emisiones contaminantes.

En este escenario regional, los radiosondeos y los registros de la red meteorológica universitaria y de la torre de la CT desprenden que, durante el invierno y especialmente durante la noche, existe normalmente una capa de inversión baja determinada por la inversión radiativa superficial. Este límite constituido por la capa de estabilidad superficial es netamente rebasado por los penachos de emisión de la CT, emitidos a gran altitud, con elevada temperatura y a gran velocidad. No obstante, sobre esta capa de inversión superficial, ya en niveles superiores, puede aparecer la capa de inversión general provocada por la compresión subsidente y tangencial del aire superior sobre las capas de aire inferiores. "El movimiento subsidente puede tener velocidades muy variadas, desde sólo unos 25 metros por día hasta 1 $\mathrm{km}$ en el mismo intervalo temporal. La subsidencia general a menudo no alcanza el suelo, en especial de día, pues la capa límite o fronteriza, definida por una intensa turbulencia, convectiva y friccional, lo impide" (Martín y Olcina, 1996: 117). Cuando estos efectos de subsidencia son muy acusados, esta capa de inversión puede descender hasta niveles próximos a 1000-1100 metros. Estas son las ocasiones en que el penacho, si bien se expande sobre la capa de inversión radiativa superficial, se encuentra obstaculizado en su ascenso por la capa de 
inversión general de subsidencia (Fig. 22). Un obstáculo que aparece reforzado cuando el flujo del viento es intensificado por la compresión y adquiere una fuerza superior a los $50 \mathrm{~km} / \mathrm{h}$.

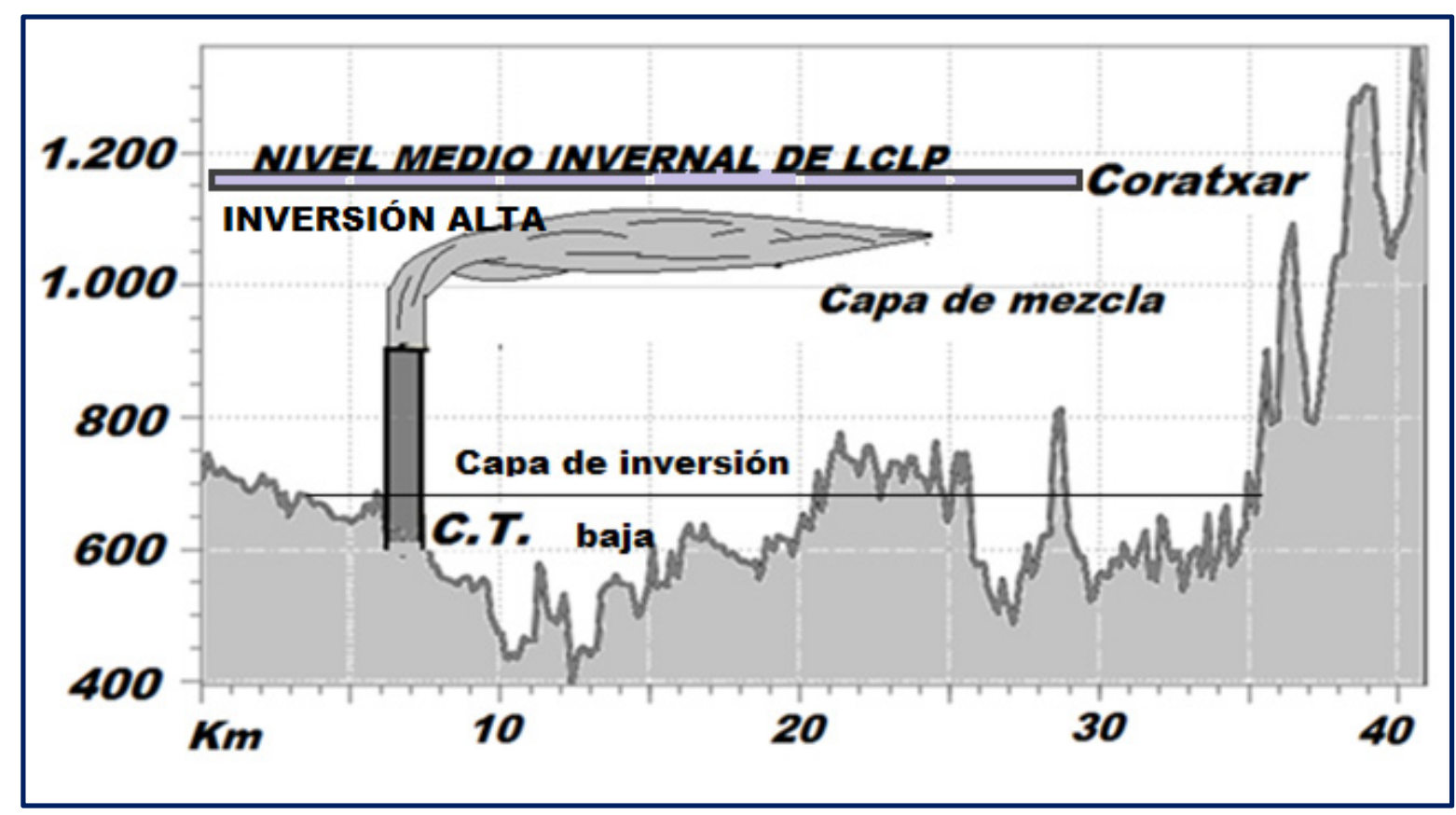

Figura 22: Análisis topográfico de la región Calanda-Coratxar (Pobla de Benifassà). Fuente: elaboración propia, Laboratorio de Climatología, Universitat Jaume I.

En síntesis, la determinación de la altura de la capa de mezcla ha sido realizada sobre la base de los registros de los radiosondeos de Zaragoza, con los valores del LCLP y la altura de las inversiones térmicas. Unos registros que han sido complementados con los realizados en la red meteorológica universitaria. No obstante, en las situaciones en las que no se dispone de dichos registros de radiosondeos, la altura de la capa de mezcla podría ser verificada o ponderada mediante la teoría de la semejanza y el cálculo del parámetro conocido como la longitud de Monin-Obukhov. Bajo su expresión se determina la magnitud de los efectos de flotación en los flujos turbulentos de superficie. Esta magnitud o longitud (L) de MoninObukhov representa el límite donde la flotabilidad, causada por la turbulencia térmica y dinámica de la superficie, se equipara con los efectos dinámicos o fuerzas tangenciales del viento. Esta formulación es definida (Arya, 2001) como:

$$
L=-\frac{\overline{\boldsymbol{\theta}_{v}} \boldsymbol{u}_{*}{ }^{3}}{\boldsymbol{k g}\left(\overline{\boldsymbol{w}^{\prime} \boldsymbol{\theta}^{\prime}{ }_{v}}\right)_{s}}
$$


Donde:

$\boldsymbol{u}_{*}$ es la velocidad de fricción o fuerza capaz de elevar partículas gaseosas y sólidas del suelo. Un parámetro básico utilizado para medir la turbulencia. Cuando el valor de la velocidad de fricción es elevado implica una mayor turbulencia y una mejor mezcla. En la práctica, la velocidad de fricción $\boldsymbol{u}_{*}$, en $\mathrm{cm} / \mathrm{s}$, es aproximadamente una décima parte de la velocidad del flujo a 2 metros y se puede calcular mediante la siguiente expresión propuesta por Businger (Businger et al., 1971 y Businger, 1973):

$$
\boldsymbol{u}_{*}=V_{s} \frac{k}{\ln \left(\frac{Z}{Z_{0}}\right)}
$$

Junto al valor de este parámetro fundamental de la velocidad de fricción, las restantes variables para calcular la longitud de Monin-Obukhov son:

g es la gravedad

$\overline{\boldsymbol{\theta}_{\boldsymbol{v}}}$ es la temperatura media potencial virtual

K es la constante de Von Karman (cuyo valor es 0,4)

$\left(\overline{\boldsymbol{w}^{\prime} \boldsymbol{\theta}_{\boldsymbol{v}}^{\prime}}\right)_{S}$ es el flujo medio de la temperatura potencial virtual de la superficie y viene dado por:

$$
\overline{\omega^{\prime} \theta_{v}^{\prime}}=\overline{\omega^{\prime} \theta^{\prime}}+0,61 \bar{T} \overline{\omega^{\prime} q^{\prime}}
$$

Donde:

$\overline{\omega^{\prime} \mathrm{q}^{\prime}}$ es el flujo medio de la humedad específica

$\overline{\omega^{\prime} \theta^{\prime}}$ es el flujo medio de la temperatura potencial

$\bar{T}$ es la temperatura media absoluta

Como consecuencia de la inversión que experimenta el flujo de calor, la longitud de Monin-Obukhov (L) es una magnitud negativa durante el día y positiva durante la noche, dado que el flujo de la temperatura virtual es positivo durante el día, mientras que es típicamente negativo durante la noche. 
Es importante destacar que la expresión 1 tiene su fundamento en la formulación original de Monin y Obukhov de 1954 (Hanna et al., 1982):

$$
L=-\frac{u_{*}{ }^{3}}{k \cdot\left(g / T_{a}\right) \cdot\left(H / \rho \cdot C_{p}\right)}
$$

En esta expresión original $\left(H / \rho \cdot C_{p}\right)$ representa el flujo cinemático de calor que sale desde la superficie y $\left(g / T_{a}\right)$ la variable de flotabilidad, siendo $T_{a}$ la temperatura superficial. El signo negativo respondía al criterio de los autores para que el valor de $\mathrm{L}$ fuera positivo en situaciones de estabilidad $(\mathrm{H}<0)$ y negativo en las de inestabilidad $(\mathrm{H}>0)$.

Dicha expresión original (4) tuvo que ser modificada posteriormente hasta obtener la expresión que se emplea en la actualidad (1) ya que en ella el término del flujo turbulento no tenía en cuenta el efecto del vapor de agua presente en el aire (Castro et al., 1991).

Así pues, el rango de valores que puede adoptar la longitud de Obukhov (L), parámetro utilizado para definir la estabilidad atmosférica, aparece en la tabla 1:

Tabla 1: Rango de valores de la longitud de Monin-Obukhov. Fuente: Barthelmie, 1999: 42.

\begin{tabular}{|c|c|}
\hline Clase de Estabilidad & Rango \\
\hline Muy estable & $0<\mathrm{L}<200 \mathrm{~m}$ \\
\hline Estable & $200<\mathrm{L}<1000 \mathrm{~m}$ \\
\hline Neutra & $1000<\mathrm{L}<-1000 \mathrm{~m}$ \\
\hline Inestable & $-1000<\mathrm{L}<-200 \mathrm{~m}$ \\
\hline Muy inestable & $-200<\mathrm{L}<0 \mathrm{~m}$ \\
\hline
\end{tabular}

Como hemos dicho, esta longitud de Obukhov viene a significar el nivel o altura, sobre el foco de emisión, en que la flotación por turbulencia se equipara a la fuerza tangencial del viento, viento real o geostrófico. Así, su valor permitiría estimar la altura de la capa de mezcla. Una altura de la capa de mezcla que puede ser calculada mediante el algoritmo siguiente (Zilitinkevich, 1972, 1975 y Businger y Arya, 1974):

Página | 40 


$$
H=k\left(u_{*} \cdot \frac{L}{f}\right)^{1 / 2}
$$

Donde:

H es la altura de la capa de mezcla en metros

K es la constante de Von Karman

$u_{*}$ es la velocidad de fricción del viento

L es la longitud de Monin-Obukhov

f es el parámetro de Coriolis que se calcula mediante la velocidad de rotación de la Tierra $(\Omega)$ y la latitud del lugar $(\varphi)$ :

$$
f=2 \cdot \Omega \cdot \sin (\varphi)
$$

No obstante, no es fácil disponer de las dos variables fundamentales. Así acontece, especialmente, en el caso del flujo cinemático de calor $\left(H / \rho \cdot C_{p}\right)$. El cálculo de este valor requiere datos de registro de la velocidad vertical y turbulencia del viento. "Estos parámetros solo pueden ser obtenidos directamente mediante prolongadas medidas de turbulencia que resultan muy complicadas en la práctica. De este modo, cuando estas medidas no están disponibles se debe recurrir a otros métodos para estimarlos" (Nieuwstadt, 1978: 235). Por ello el NILU, en su campaña de mayo de 1985, se vio obligado a utilizar los datos obtenidos de radiosondas, ponderando una combinación de datos observados y estimados, ciertamente muy dispares. Máxime en cuanto que los mismos registros de la torre meteorológica de la CT a 10, 25 y 60 metros de altura resultaron no fiables y difíciles de interpretar (NILU, 1987 a y 1987 b).

Por ello, en ausencia de radiosondeos regionales, hemos recurrido a los registros de la red meteorológica universitaria. Unos registros que nos han permitido aproximar la altura de la capa de mezcla mediante un riguroso análisis de los gradientes térmicos y de humedad existentes entre la CT y los niveles de 1235 metros (Fredes) y 1447 metros (Caro). 
Análisis que está justificado en la linealidad o proporcionalidad que establece la ley de Fourier sobre el flujo de energía (J) con la siguiente expresión basada en el gradiente térmico $(\partial \mathrm{T} / \partial \mathrm{z})$ y en la conductividad térmica $(\mathrm{k})$ :

$$
J=k \cdot\left(\frac{\partial T}{\partial z}\right)
$$

Un caso significativo de la utilización del análisis de los gradientes térmicos para la estimación de la altura de la capa de mezcla en carencia de radiosondeo, fue el de la situación reflejada en la figura 23, correspondiente al día 30 de noviembre del 2013.

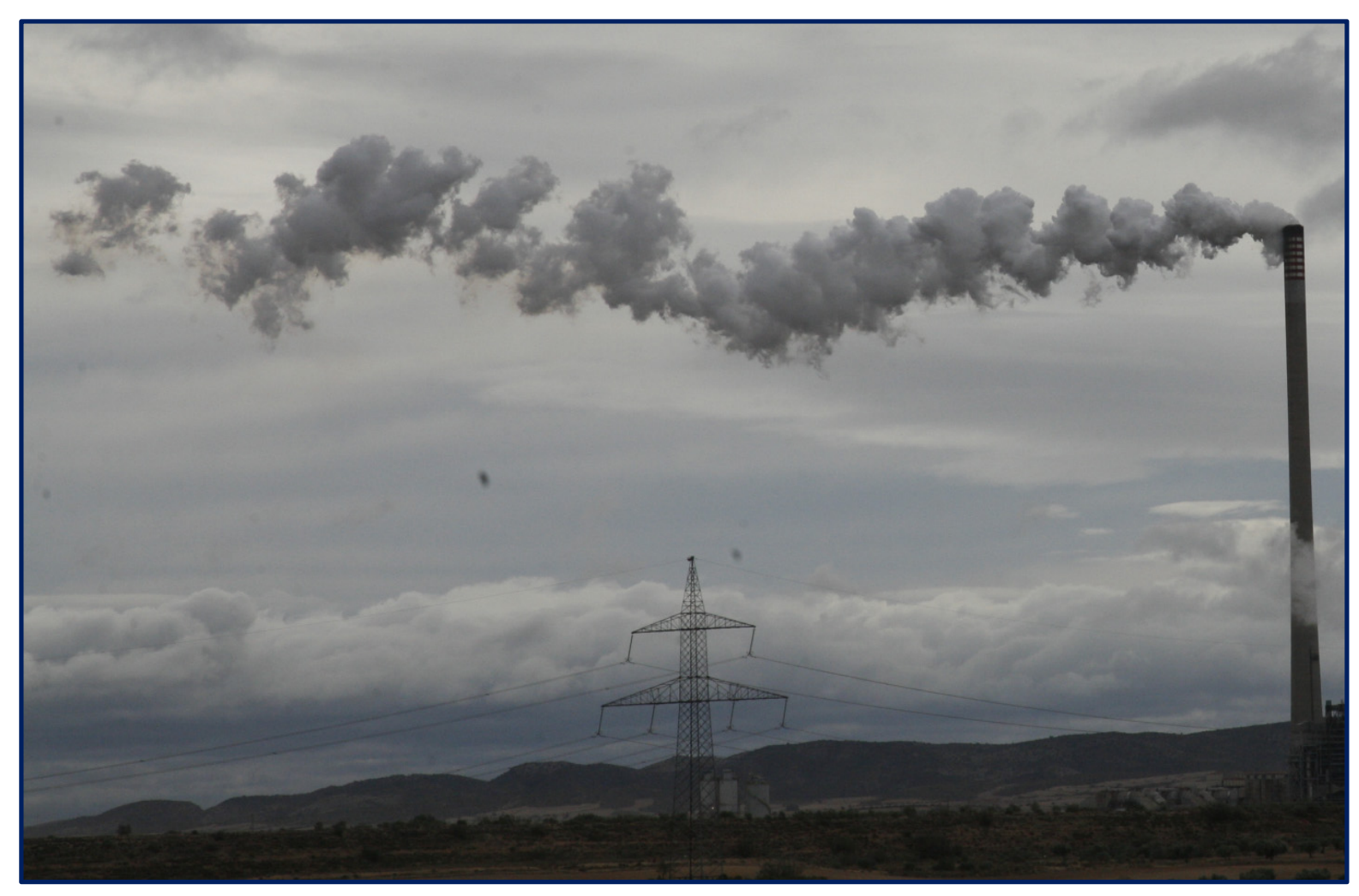

Figura 23: El penacho emitido por la chimenea de la CT se difunde linealmente sin ascenso apreciable. Fuente propia, imagen tomada el 30 de noviembre del 2013 a las 14 horas.

La fotografía muestra, tanto por la base de la formación nubosa como por el penacho tubular, que el nivel de condensación ascendente y el límite de inversión de la capa de mezcla se alcanza a escasa altura sobre la superficie. El mapa de presión en superficie (Fig. 24) muestra la existencia de un notable anticiclón sobre la Península Ibérica, con $1028 \mathrm{mb}$. 


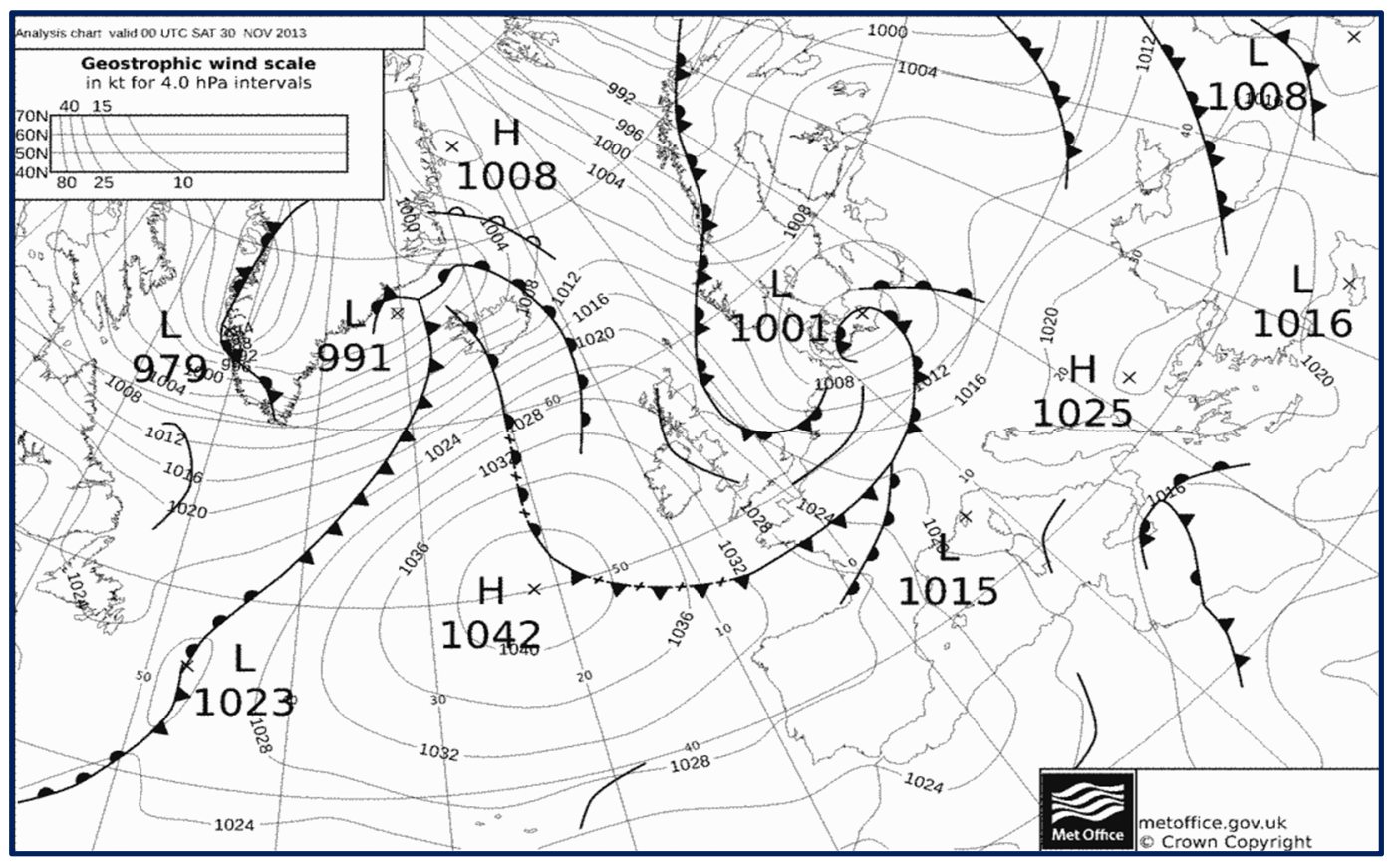

Figura 24: Mapa de presión en superficie del 30 de noviembre del 2013 a las 12 horas. Fuente: http://www.wetterzentrale.de/topkarten/tkfaxbraar.htm.

Una situación que permite entrever la existencia de una gran capa de inversión a niveles inferiores a los 1000-1100 metros, ya que la red regional, con registros sobre los 1235 metros (estación de Fredes), no la detecta (Fig. 25).

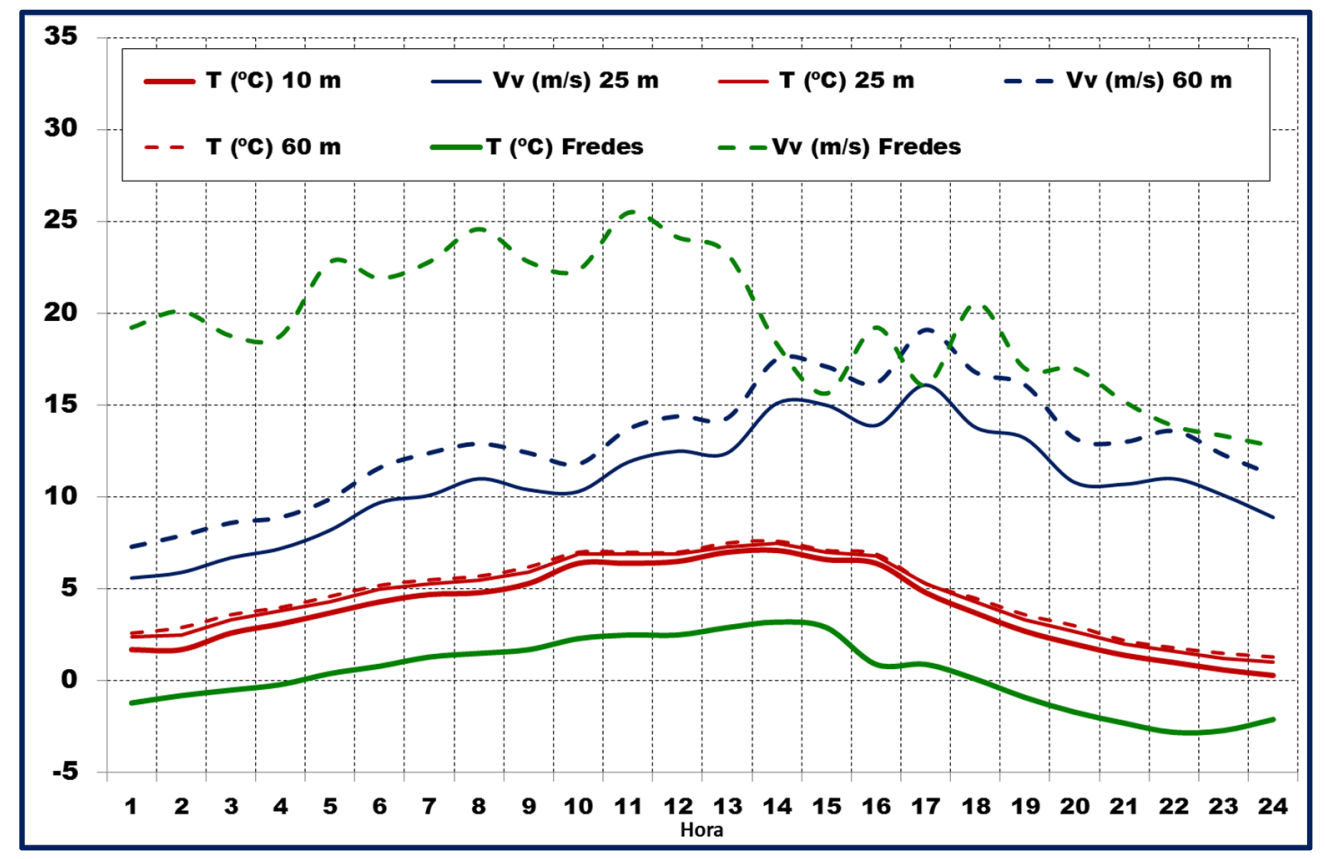

Figura 25: Registros de la torre meteorológica de la CT y del observatorio de Fredes del 30 de noviembre del 2013. Fuente: datos proporcionados por la CT y la red meteorológica universitaria. Elaboración propia, Laboratorio de Climatología, Universitat Jaume I. 
Sobre la base de estos registros, y en ausencia de radiosondeo, los gradientes térmicos medidos en la torre, entre 610 y 660 metros, dan un valor debilísimo o nulo $\left(0\right.$ a $\left.0,001{ }^{\circ} \mathrm{C} / \mathrm{m}\right)$ mientras que en el estrato entre 660 y 1235 metros (Fredes), el gradiente térmico continúa débil con $0,005^{\circ} \mathrm{C} / \mathrm{m}$. Sin embargo, entre el nivel de 1235 metros y el de los 1447 metros (cima del Caro) este gradiente se exagera notablemente a $0,02{ }^{\circ} \mathrm{C} / \mathrm{m}$. Ello permite considerar que las condiciones de estabilidad pueden estar marcando un nivel de inversión por debajo de los 1235 metros. En consecuencia, la altura de mezcla se situará muy próxima al nivel de coronación de la chimenea (943 metros). Este valor justifica la evolución del penacho observada durante esta jornada como se puede comprobar en la figura 23.

Una situación atmosférica idéntica se operó el 20 de noviembre del 2015. Igualmente no disponemos de radiosondeo en Zaragoza para esta jornada, si bien el mapa de presión en superficie (Fig. 26) vuelve a mostrar la existencia de un notable anticiclón sobre la Península Ibérica, con $1032 \mathrm{mb}$.

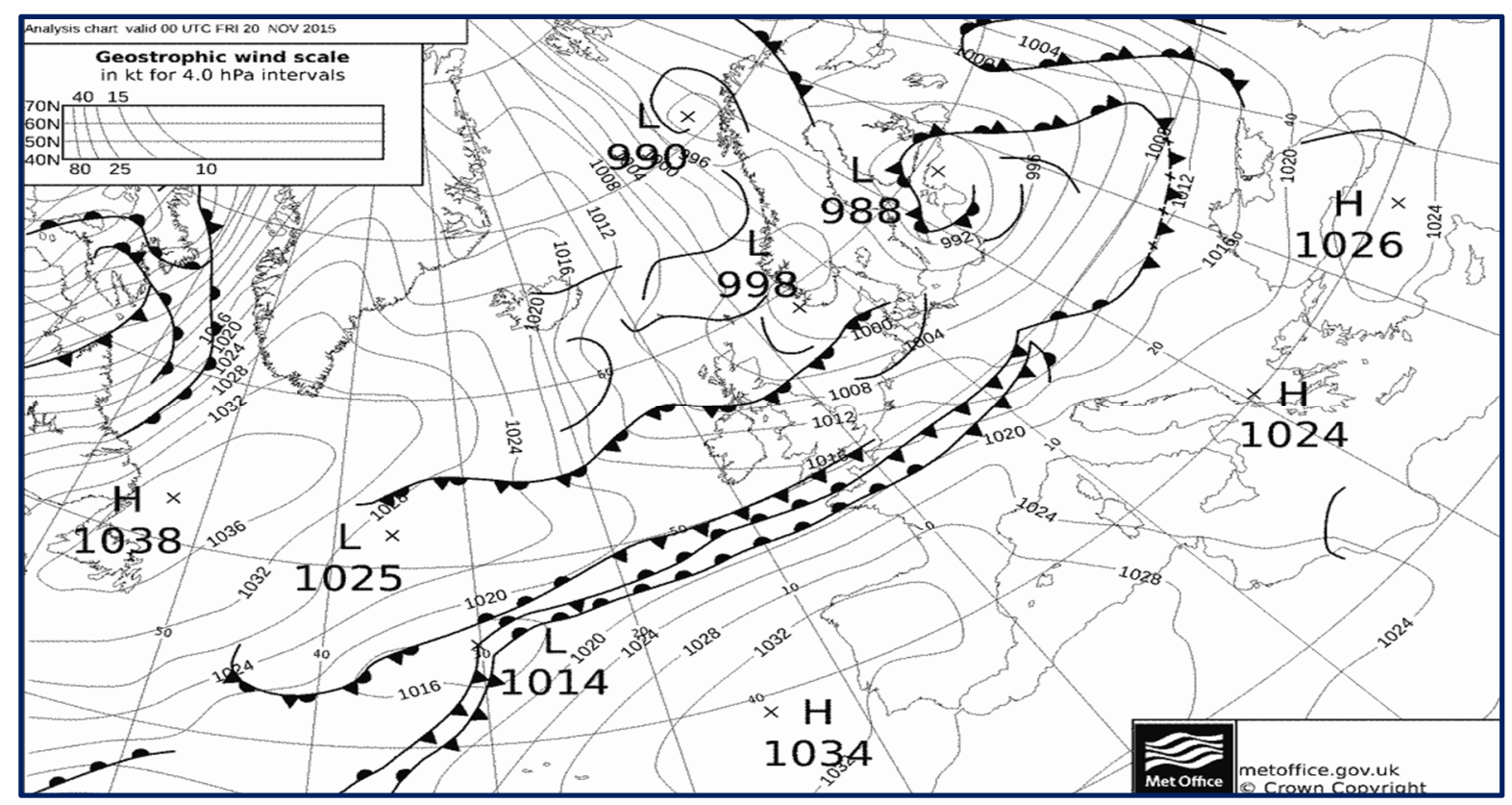

Figura 26: Mapa de presión en superficie del 20 de noviembre del 2015 a las 12 horas. Fuente: http://www.wetterzentrale.de/topkarten/tkfaxbraar.htm.

Este campo barométrico permite entrever la existencia de una gran capa de inversión a niveles inferiores a los 1100 metros, ya que, al igual que en el caso anterior, la red regional con el observatorio del pico Fredes, sobre los 1235 metros, no la detecta. Dicho observatorio de Fredes registraba, durante la primera mitad del día, temperaturas idénticas a las de la torre 
meteorológica de la CT a 10 metros de altura. Ya en las horas centrales del día, los registros de la torre meteorológica de la CT (10-60 metros) muestran un gran estrato de inversión en superficie. Un estrato que parece culminar a un nivel de 1000 metros, ya que el gradiente térmico 600-1235 metros es débil $\left(0,003{ }^{\circ} \mathrm{C} / \mathrm{m}\right)$, en neto contraste con la exageración $(0,02$ ${ }^{\circ} \mathrm{C} / \mathrm{m}$ ) hasta los 1447 metros. Simultáneamente a ese perfil térmico vertical, la aerodinámica está configurada por vientos débiles y moderados a 60 metros de altura. Unas fuerzas que, entre las 16 y las 20 horas, suponen una fuerte cizalla con los valores de $15 \mathrm{~m} / \mathrm{s}$ registrados en el observatorio de Fredes (Fig. 27).

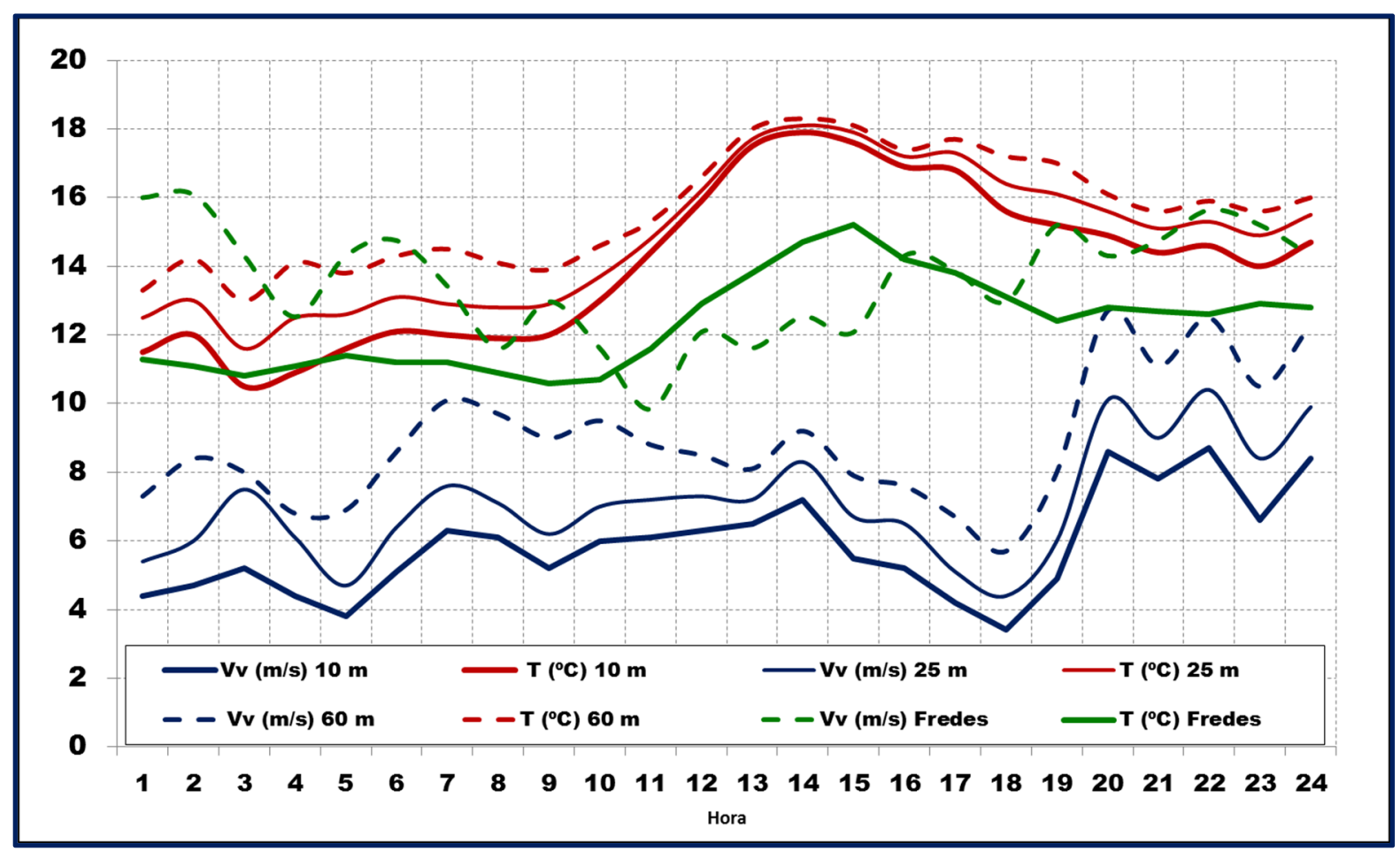

Figura 27: Registros del observatorio de Fredes y de la torre meteorológica de la CT del 20 de noviembre del 2015. Fuente: datos proporcionados por la CT y la red meteorológica universitaria. Elaboración propia, Laboratorio de Climatología de la Universitat Jaume I.

Bajo estas condiciones atmosféricas, y tal y como muestra la figura 28, la elevación del penacho sería detenida por la capa de inversión que, a tenor de las temperaturas de la torre meteorológica de la CT y del observatorio de Fredes, en esas horas centrales del día, se establecería en un nivel próximo a los 1000 metros de altura. La homogeneidad de la capa de mezcla, delimitada por la capa de inversión, se traduce en la idéntica evolución que muestran los distintos penachos tanto de las torres bajas de refrigeración como de la chimenea. 


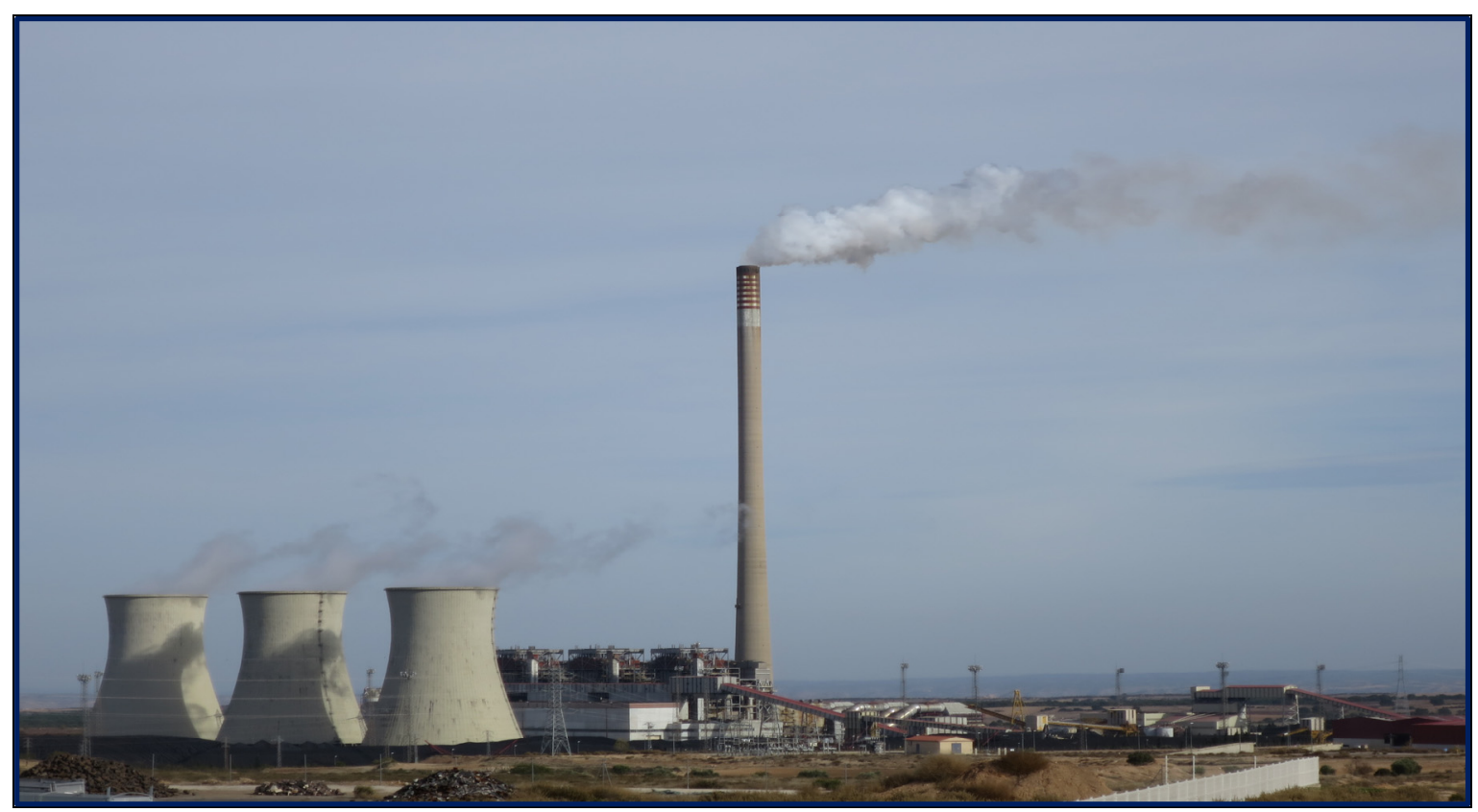

Figura 28: El penacho emitido por la chimenea de la CT se difunde linealmente sin ascenso apreciable. Fuente propia, imagen tomada el 20 de noviembre del 2015 a las 13 horas.

Las ondas de Kelvin-Helmholtz $(\mathrm{KH})$, observadas en la figura 29, evidencian la existencia de la capa de inversión que separa dos masas de aire de diferente densidad. Estas ondas se generan debido a que las dos masas de aire separadas por la capa de inversión se mueven a velocidades muy diferentes. La capa superior está regida por vientos de $55 \mathrm{~km} / \mathrm{h}$ y la inferior por vientos de tan solo $18 \mathrm{~km} / \mathrm{h}$. Ello crea una turbulencia que da origen a formaciones de ondas. La imagen, tomada a las 18 horas del día 20 de noviembre del 2015 en Valderrobres, a orillas del rio Matarraña, a $35 \mathrm{~km}$ de la CT de Andorra, muestra las incipientes ondas de Kelvin-Helmholtz en el estrato de inversión 900-1000 metros donde se inyecta el penacho de la CT, coadyuvando a la cizalladura de temperatura y densidad de esa capa. 


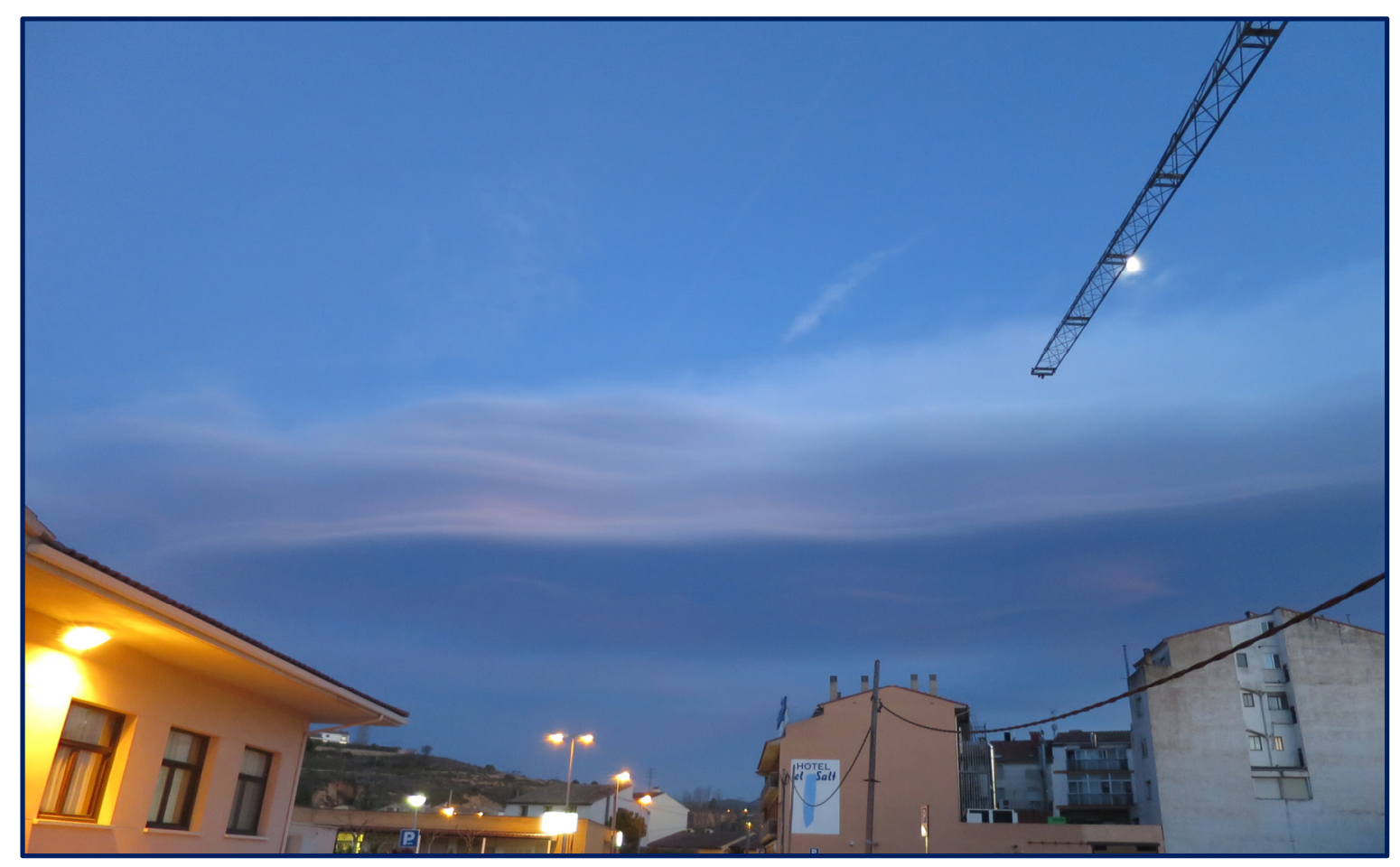

Figura 29: La capa de inversión y la cizalla en la velocidad del viento determinan las ondas de Kelvin-Helmholtz sobre Valderrobres. Fuente propia, imagen tomada el 20 de noviembre del 2015 a las 18 horas.

Todas estas situaciones muestran que la capa de inversión actúa como límite de la capa de mezcla. Un límite que puede también situarse a gran altura. Tal es la evolución del penacho en la jornada del día 2 de septiembre del 2013 (Fig. 30). 


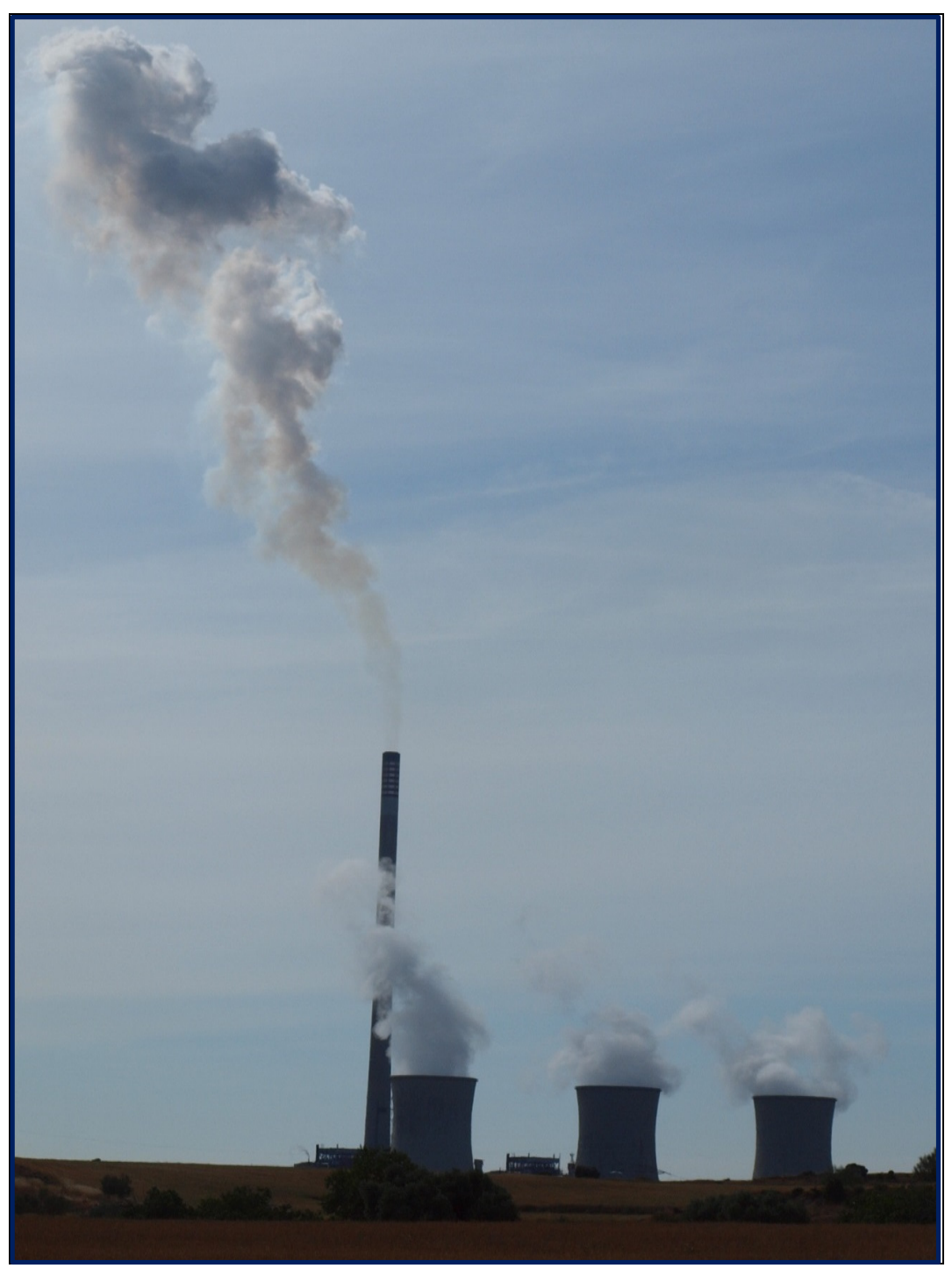

Figura 30: El ascenso vertical del penacho, con viento en calma y dirección opuesta a la de superficie, se detiene en el nivel de la capa de inversión alta (1350 metros aprox.). Las torres de emisión de vapor muestran la capa de inversión baja entre 1050 y 1080 metros. Fuente propia, imagen tomada el 2 de septiembre del 2013 a las 14 horas.

El penacho de humos asciende, más o menos verticalmente, hasta el techo de la capa de mezcla que el nivel de la capa de inversión alta sitúa sobre los 1350 metros en el radiosondeo de Zaragoza para esta jornada (Fig. 31). 


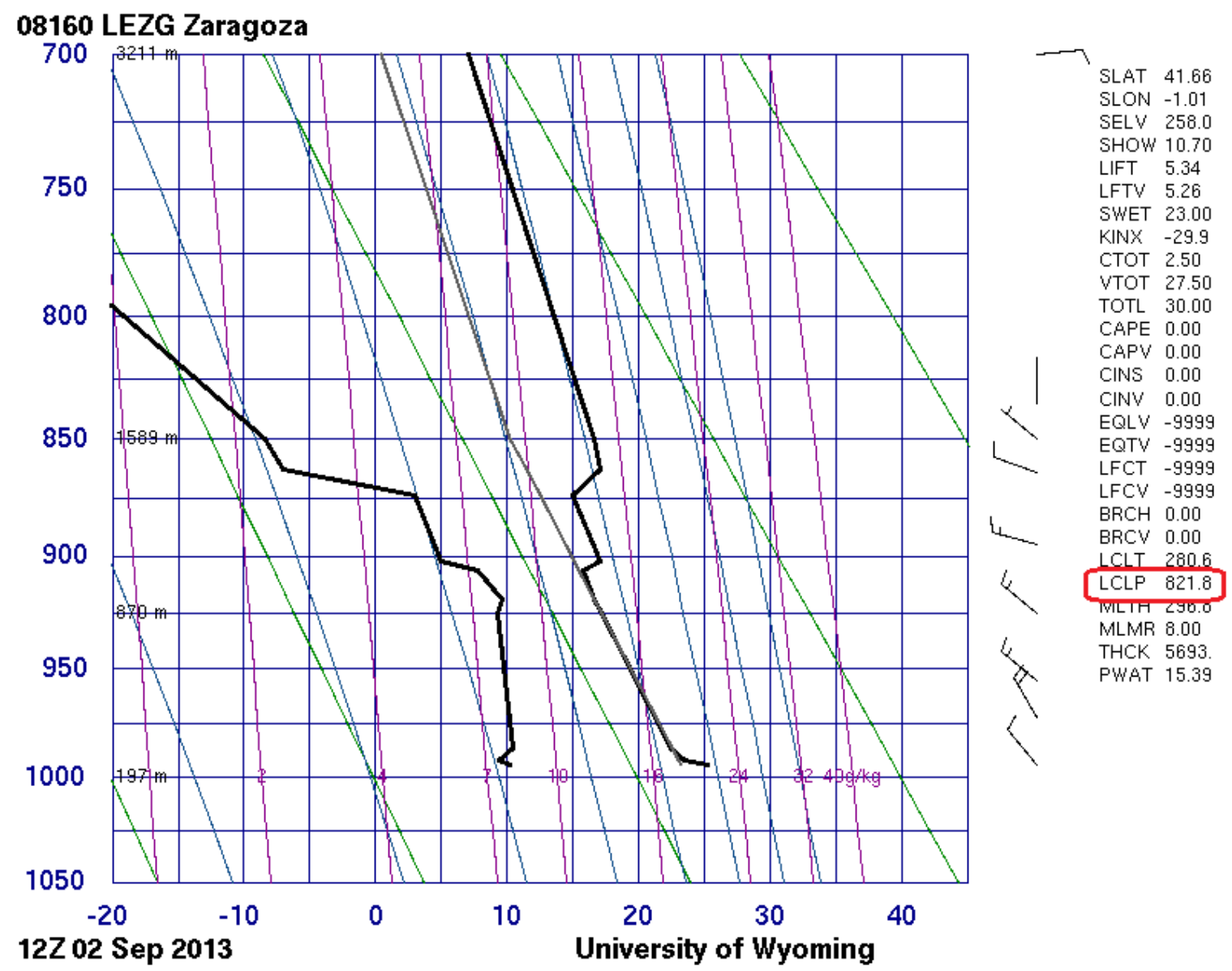

Figura 31: Radiosondeo del día 2 de septiembre del 2013. Fuente: http://weather.uwyo.edu/upperair/sounding.html.

En el mapa de presión, correspondiente a esta jornada del 2 de septiembre del 2013, se aprecia con claridad la dorsal de aire cálido que provoca la compresión por subsidencia del aire, dando lugar al descenso de altura de la capa de inversión térmica sobre la Península Ibérica (Fig. 32). 


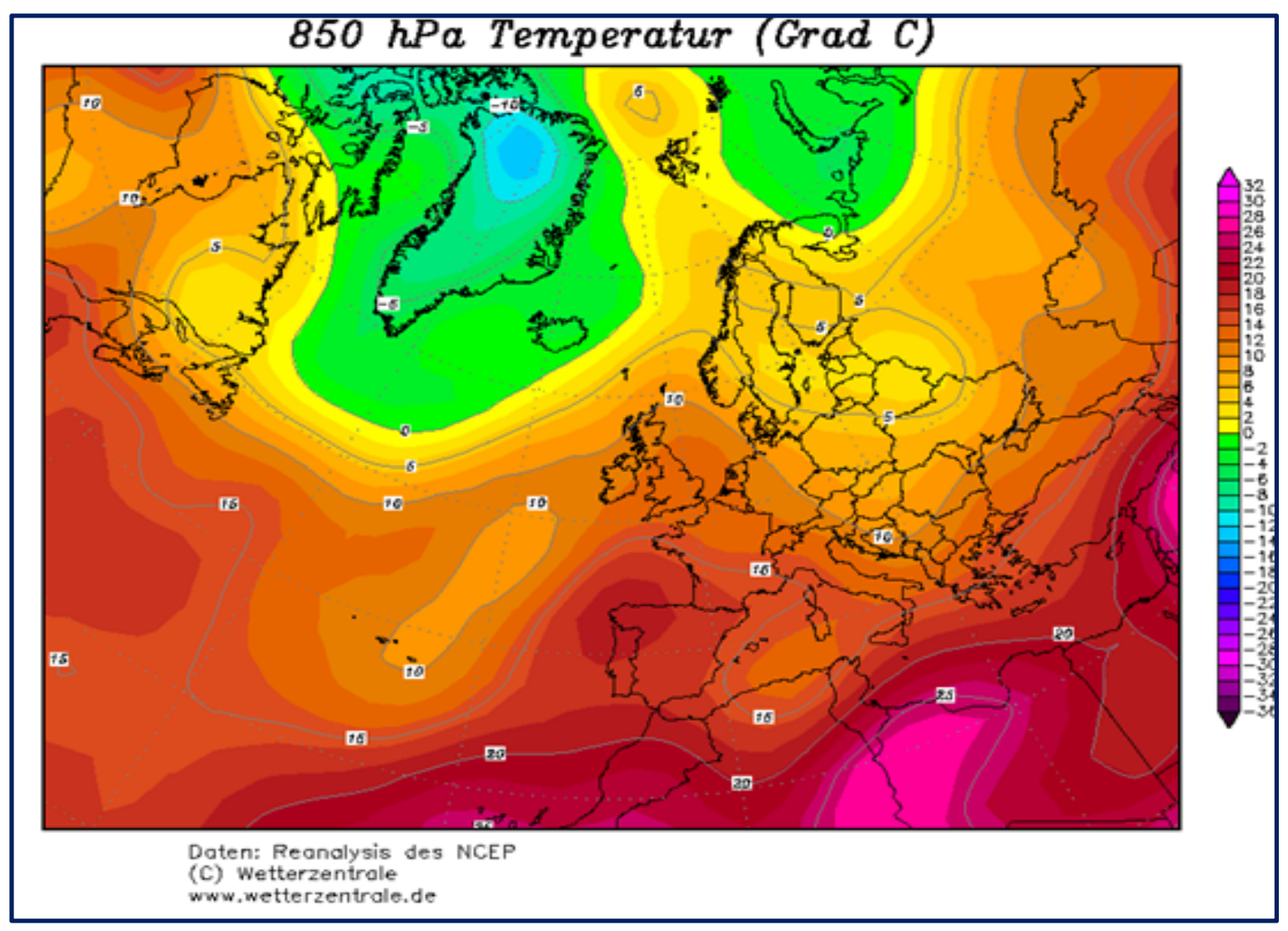

Figura 32: Reanálisis a $850 \mathrm{hPa}$ del 2 de septiembre del 2013. La notable dorsal a 850 hPa es la causa de la gran inversión térmica de subsidencia. Fuente: http://www.wetterzentrale.de/topkarten/fsreaeur.html.

En el registro numérico del radiosondeo se aprecian con claridad los dos niveles de inversión térmica. La más superficial, a 1047 metros aproximadamente y con escaso desarrollo, es atravesada por el penacho de gases. La capa de inversión superior, sobre los 1350 metros de altura, actúa como barrera bloqueando la dispersión (Tabla 2). 
Tabla 2: Registro del sondeo de Zaragoza del 2 de septiembre del 2013. Se destacan en negrita los valores que evidencian la presencia de la inversión térmica. Fuente: http://weather.uwyo.edu/upperair/sounding.html.

\begin{tabular}{|c|c|c|c|c|c|c|c|c|}
\hline PRES & HGHT & TEMP & DWPT & RELH & MIXR & DRCT & SKNT & THTA \\
\hline $\mathbf{h P a}$ & $\mathbf{m}$ & ${ }^{\mathbf{0}} \mathbf{C}$ & $\mathbf{}^{\mathbf{0}}$ & $\mathbf{0}$ & $\mathbf{g} / \mathbf{k g}$ & $\mathbf{d e g}$ & $\mathbf{k n o t}$ & $\mathbf{K}$ \\
\hline 994,0 & 258 & 25,2 & 10,2 & 39 & 7,92 & 320 & 12 & 298,9 \\
\hline 992,0 & 275 & 23,4 & 9,4 & 41 & 7,51 & 327 & 11 & 297,2 \\
\hline 988,0 & 310 & 22,7 & 10,1 & 45 & 7,89 & 340 & 10 & 296,9 \\
\hline 986,0 & 327 & 22,4 & 10,4 & 47 & 8,09 & 339 & 11 & 296,7 \\
\hline 972,0 & 449 & 21,2 & 10,1 & 49 & 8,06 & 330 & 18 & 296,8 \\
\hline 955,0 & 599 & 19,8 & 9,8 & 52 & 8,02 & 310 & 14 & 296,8 \\
\hline 925,0 & 870 & 17,2 & 9,2 & 59 & 7,95 & 310 & 14 & 296,9 \\
\hline 922,0 & 898 & 16,9 & 9,4 & 61 & 8,09 & 310 & 14 & 296,9 \\
\hline 919,0 & 926 & 16,6 & 9,6 & 63 & 8,23 & 307 & 14 & 296,8 \\
\hline $\mathbf{9 0 6 , 0}$ & $\mathbf{1 0 4 7}$ & $\mathbf{1 5 , 8}$ & $\mathbf{7 , 8}$ & $\mathbf{5 9}$ & $\mathbf{7 , 3 8}$ & $\mathbf{2 9 5}$ & $\mathbf{1 6}$ & $\mathbf{2 9 7 , 2}$ \\
\hline $\mathbf{9 0 2 , 0}$ & $\mathbf{1 0 8 4}$ & $\mathbf{1 7 , 0}$ & $\mathbf{5 , 0}$ & $\mathbf{4 5}$ & $\mathbf{6 , 1 0}$ & $\mathbf{2 9 2}$ & $\mathbf{1 6}$ & $\mathbf{2 9 8 , 8}$ \\
\hline 895,0 & 1151 & 16,5 & 4,5 & 45 & 5,93 & 285 & 17 & 299,0 \\
\hline 874,0 & 1352 & 15,0 & 3,0 & 44 & 5,46 & 288 & 14 & 299,4 \\
\hline $\mathbf{8 6 4 , 0}$ & $\mathbf{1 4 5 0}$ & $\mathbf{1 6 , 8}$ & $\mathbf{- 6 , 1}$ & $\mathbf{2 0}$ & $\mathbf{2 , 8 2}$ & $\mathbf{2 9 0}$ & $\mathbf{1 2}$ & $\mathbf{3 0 2 , 3}$ \\
\hline $\mathbf{8 6 3 , 0}$ & $\mathbf{1 4 6 0}$ & $\mathbf{1 7 , 0}$ & $\mathbf{- 7 , 0}$ & $\mathbf{1 9}$ & $\mathbf{2 , 6 3}$ & $\mathbf{2 9 1}$ & $\mathbf{1 2}$ & $\mathbf{3 0 2 , 6}$ \\
\hline
\end{tabular}

No obstante, tal y como hemos podido observar en esta jornada, es preciso resaltar que estas capas de inversión térmica, claves en la delimitación de la capa de mezcla, no son techos rígidos. Ello sucede por cuanto que en el seno de estas capas de inversión tiene lugar cierto intercambio de aire. En este proceso de intercambio una parte del penacho de humos puede ser atrapado, o incluso llegar a atravesar la capa de inversión (si es de poco espesor), empujado por el tirón térmico y dinámico de la fuente de emisión.

Un proceso que vuelve a ser reflejado en la situación del 14 de diciembre del 2013. El radisondeo muestra la existencia de dos capas de inversión. La inversión baja se desarrolla en el espesor de los 300-400 metros inferiores y no afecta a las emisiones de la chimenea de la CT. Por el contrario, la capa de inversión alta tiene su base sobre los $906 \mathrm{hPa}$ (1147 metros), en coincidencia con el LCLP. El penacho es atrapado en el nivel de condensación ascendente y mezclado con el estrato situado sobre la base de la inversión (Figs. 33 y 34). 


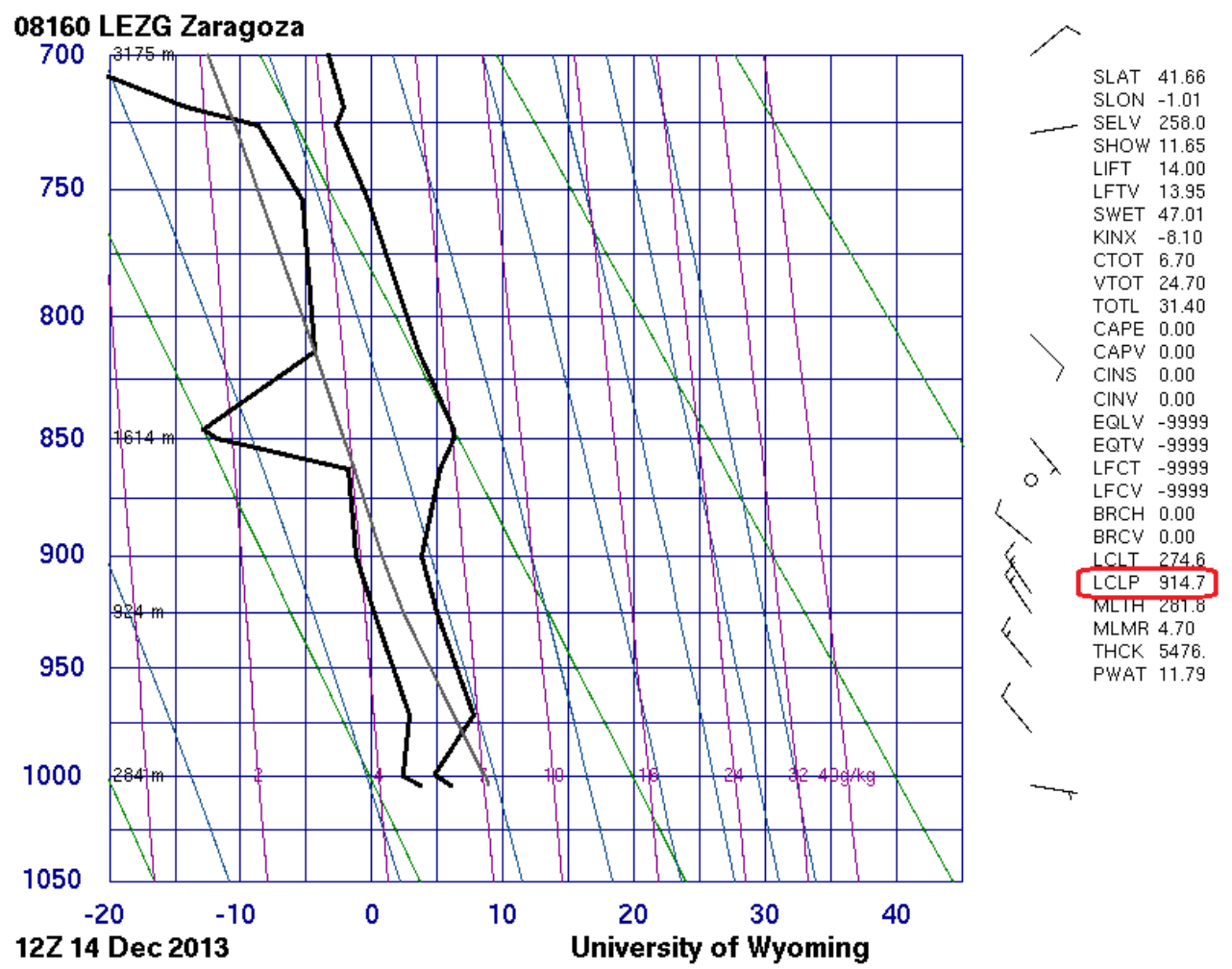

Figura 33: Radiosondeo del 14 de diciembre del 2013. Fuente: http://weather.uwyo.edu/upperair/sounding.html.

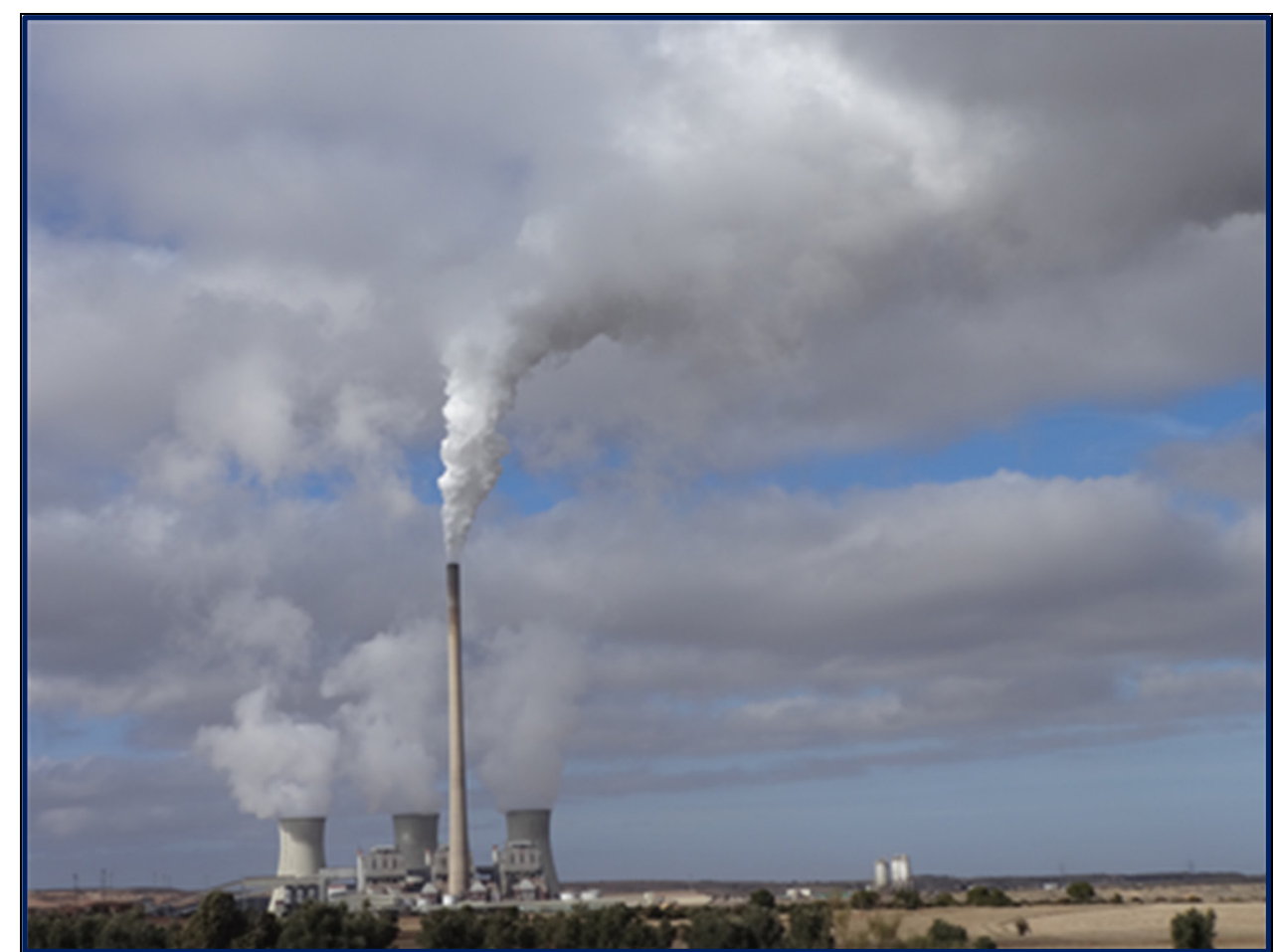

Figura 34: Imagen del penacho de la CT. La columna ascendente del fluido es atrapada en el nivel de condensación ascendente y mezclada en el estrato situado sobre la base de la inversión (1150-1200 metros). Fuente propia, imagen tomada el 14 de diciembre del 2013 a las 14 horas.

Página $\mid 52$ 
Tal y como muestra la figura anterior, correspondiente al día 14 de diciembre del 2013, este nivel de la coronación de la chimenea de la CT se hallaría en el seno de una capa de inversión cuya base puede situarse en 1150-1200 metros, de acuerdo a los registros del radiosondeo (Tabla 3).

Tabla 3: Registro del radiosondeo en Zaragoza del 14 de diciembre del 2013. Se destacan en negrita los dos niveles de inversión. Fuente: http://weather.uwyo.edu/upperair/sounding.html.

\begin{tabular}{|c|c|c|c|c|c|c|c|c|c|c|}
\hline PRES & HGHT & TEMP & DWPT & RELH & MIXR & DRCT & SKNT & THTA & THTE & THTV \\
\hline $\mathrm{hPa}$ & $\mathrm{m}$ & ${ }^{\circ} \mathrm{C}$ & ${ }^{\circ} \mathrm{C}$ & $\%$ & $\mathrm{~g} / \mathrm{kg}$ & $\operatorname{deg}$ & knot & $\mathbf{K}$ & K & $\mathbf{K}$ \\
\hline 1004,0 & 258 & 6,0 & 3,7 & 85 & 4,99 & 100 & 4 & 278,8 & 292,7 & 279,7 \\
\hline 1000,0 & 284 & 5,0 & 2,4 & 83 & 4,57 & 100 & 1 & 278,1 & 290,9 & 278,9 \\
\hline 998,0 & 300 & 4,8 & 2,4 & 84 & 4,58 & 87 & 2 & 278,1 & 290,8 & 278,9 \\
\hline 979,0 & 458 & 6,9 & 2,8 & 75 & 4,79 & 320 & 10 & 281,8 & 295,2 & 282,6 \\
\hline 971,0 & 526 & 7,8 & 2,9 & 71 & 4,88 & 320 & 12 & 283,3 & 297,2 & 284,2 \\
\hline 949,0 & 714 & 6,5 & 1,6 & 71 & 4,56 & 320 & 17 & 283,8 & 296,8 & 284,6 \\
\hline 925,0 & 924 & 5,0 & 0,2 & 71 & 4,22 & 325 & 15 & 284,4 & 296,5 & 285,1 \\
\hline 916,0 & 1004 & 4,6 & $-0,3$ & 71 & 4,10 & 325 & 14 & 284,8 & 296,6 & 285,5 \\
\hline 900,0 & 1147 & 3,8 & $-1,2$ & 70 & 3,91 & 314 & 12 & 285,4 & 296,7 & 286,1 \\
\hline 894,0 & 1202 & 4,0 & $-1,3$ & 68 & 3,91 & 310 & 11 & 286,2 & 297,5 & 286,9 \\
\hline 867,0 & 1452 & 5,0 & $-1,7$ & 62 & 3,90 & 0 & 0 & 289,8 & 301,3 & 290,5 \\
\hline 863,0 & 1490 & 5,2 & $-1,8$ & 61 & 3,90 & 33 & 1 & 290,3 & 301,9 & 291,0 \\
\hline 850,0 & 1614 & 6,2 & $-11,8$ & 26 & 1,83 & 140 & 6 & 292,6 & 298,3 & 292,9 \\
\hline 846,0 & 1653 & 6,2 & $-12,8$ & 24 & 1,70 & 140 & 6 & 293,0 & 298,4 & 293,3 \\
\hline 814,0 & 1967 & 3,6 & $-4,4$ & 56 & 3,40 & 140 & 10 & 293,5 & 303,8 & 294,1 \\
\hline 807,0 & 2037 & 3,2 & $-4,5$ & 57 & 3,41 & 135 & 12 & 293,8 & 304,1 & 294,4 \\
\hline
\end{tabular}

Los episodios analizados hasta el momento muestran la metodología seguida para definir la altura de la capa límite, especialmente durante los grandes episodios regionales de contaminación. Una metodología que, tal y como reiteramos, requiere datos obtenidos mediante radiosondeos de altura o sondeos en globo cautivo para capas de aire muy próximas a la superficie.

Asimismo, es especialmente marcado el carácter estacional que presentan las configuraciones de las curvas de estado. La altura de la capa de mezcla alrededor del nivel de $900 \mathrm{hPa}$, es decir sobre los 1000 metros de altura aproximadamente, aparece muy vinculada a la estación invernal. Así, la figura 35 muestra la estructura térmica vertical a través de los sondeos realizados en el aeropuerto de Zaragoza durante el mes de febrero del 2013. La capa de inversión a $880 \mathrm{hPa}$ viene a marcar nítidamente el límite más elevado de dispersión de los 
contaminantes, si bien puede observarse que esta capa límite puede oscilar entre los 935 y los $880 \mathrm{hPa}(650-1150$ metros).

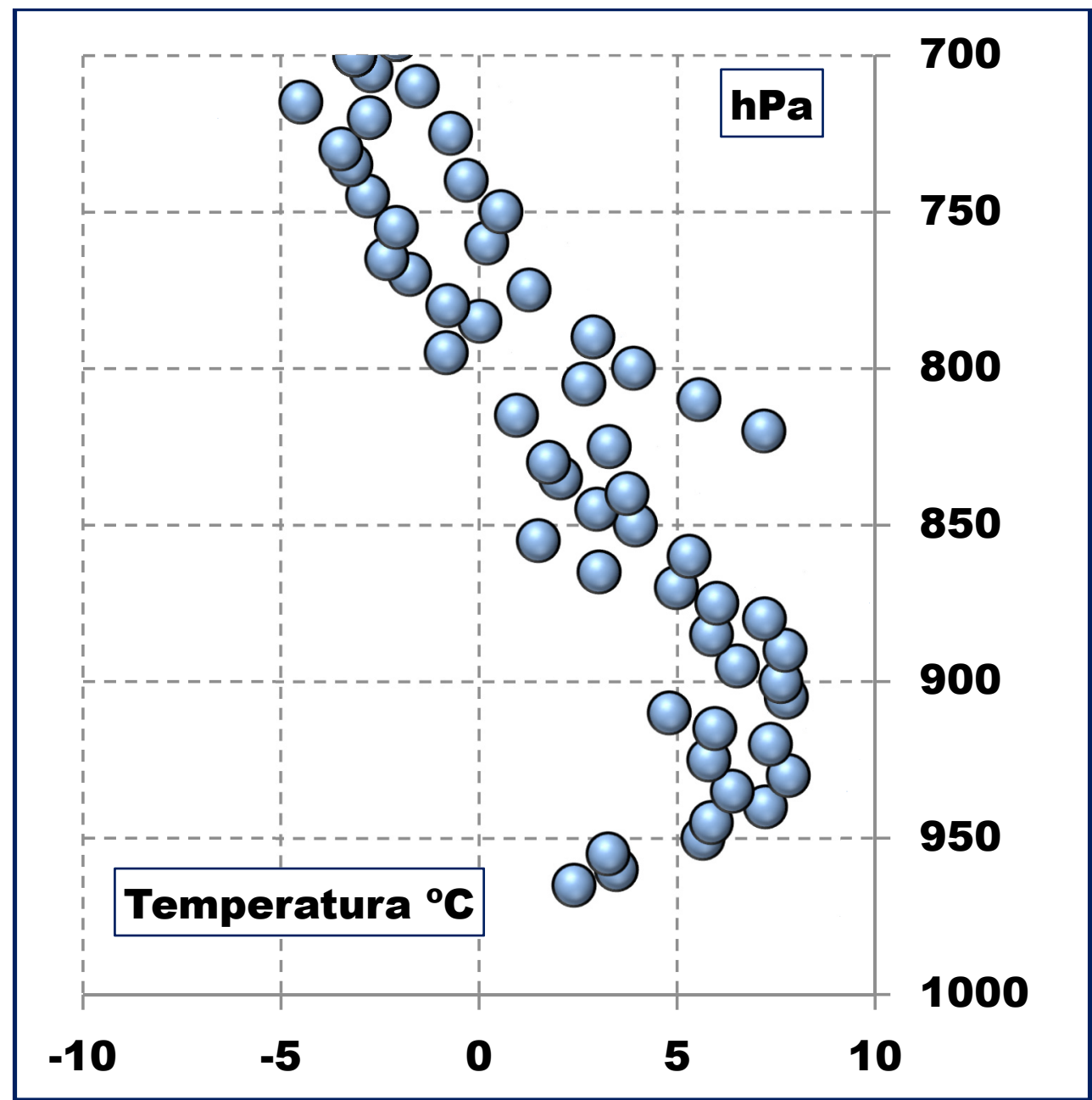

Figura 35: Promedio de los radiosondeos invernales durante el mes de febrero del 2013 en Zaragoza aeropuerto. Fuente: radiosondeos de la Universidad de Wyoming. Elaboración propia, Laboratorio de Climatología de la Universitat Jaume I.

Esta gran constancia estacional de la estructura atmosférica regional durante los meses invernales vuelve a verse reflejado en los promedios del mes de febrero del 2015 (Fig. 36).

Página | 54 


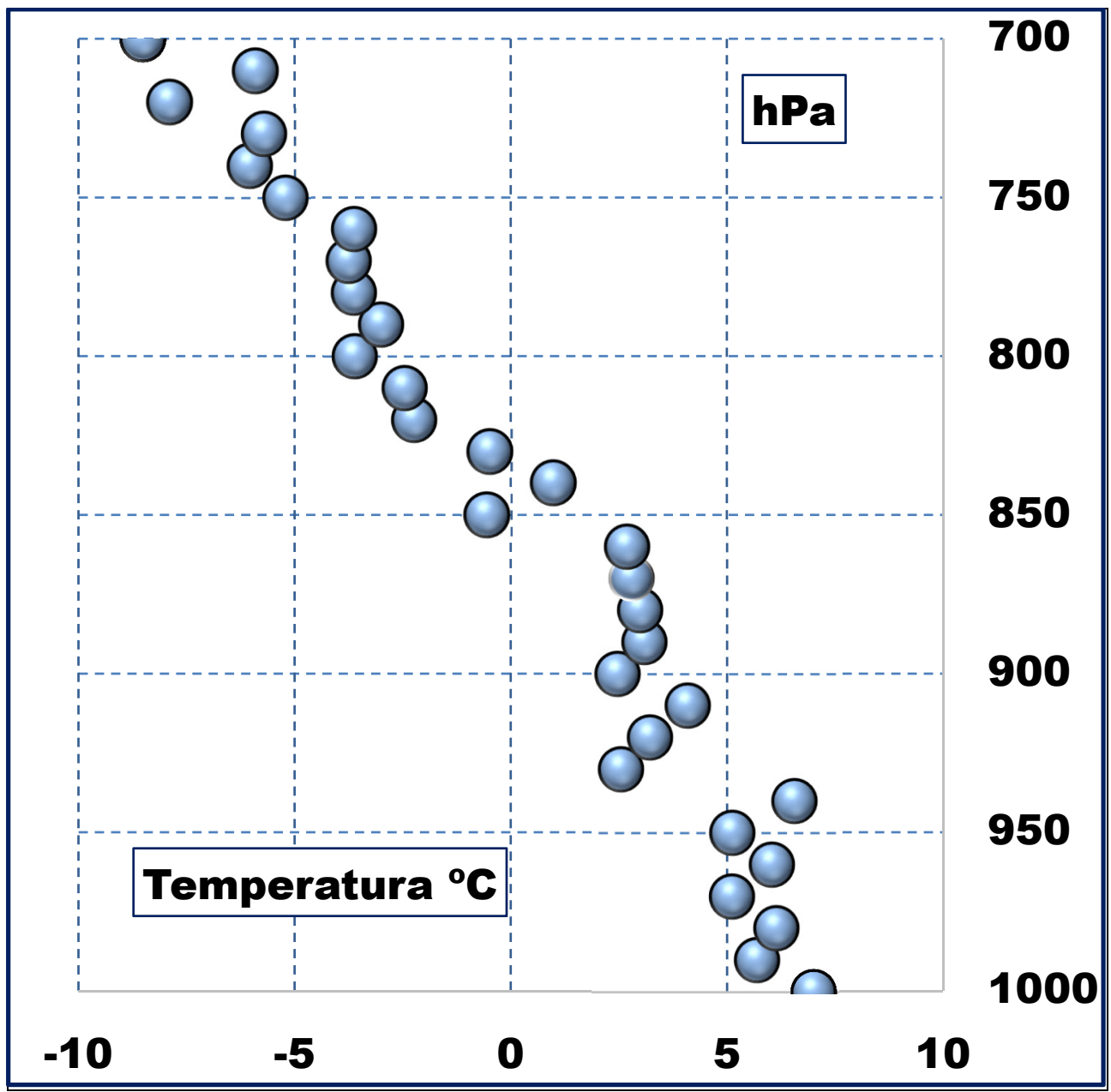

Figura 36: Promedio de los radiosondeos invernales durante el mes de febrero del 2015 en Zaragoza aeropuerto. Fuente: radiosondeos de la Universidad de Wyoming. Elaboración propia, Laboratorio de Climatología de la Universitat Jaume I.

La capa de inversión regional o límite de la capa geográfica aparece sobre los 900-860 $\mathrm{hPa}$, marcando nítidamente la zona atmosférica de oscilación del límite más elevado de dispersión de los contaminantes. Este ha sido el nivel promedio del LCLP de los años 2014 y 2015 con un valor de $877 \mathrm{hPa}$ (1200 metros). Los niveles inferiores aparecen notoriamente influidos por los efectos termoconvectivos invernales de la superficie. Así, las condiciones de irradiación y las de la circulación regional determinan básicamente dos niveles de inversión. La inversión baja aparece oscilando al nivel de los $940 \mathrm{hPa}$, mientras que entre los 900 y los 860 $\mathrm{hPa}$ aparece un frecuente nivel de inversión que marca el límite superior de la capa de mezcla. Ambas capas de inversión adquieren una gran importancia ambiental por cuanto que constituyen las tapaderas de la contaminación que las fuentes o focos de superficie emiten. Especialmente en los casos de contaminación ambiental producida por chimeneas altas $(>100$ metros) que suelen rebasar el nivel superficial de inversión baja o local. 
Nuevamente el caso determinado por la estructura atmosférica reflejada en la figura 37 (24 de octubre del 2015) muestra una configuración típica de la estructura térmica vertical con el LCLP situado a $877 \mathrm{hPa}$ (1200 metros de altura).

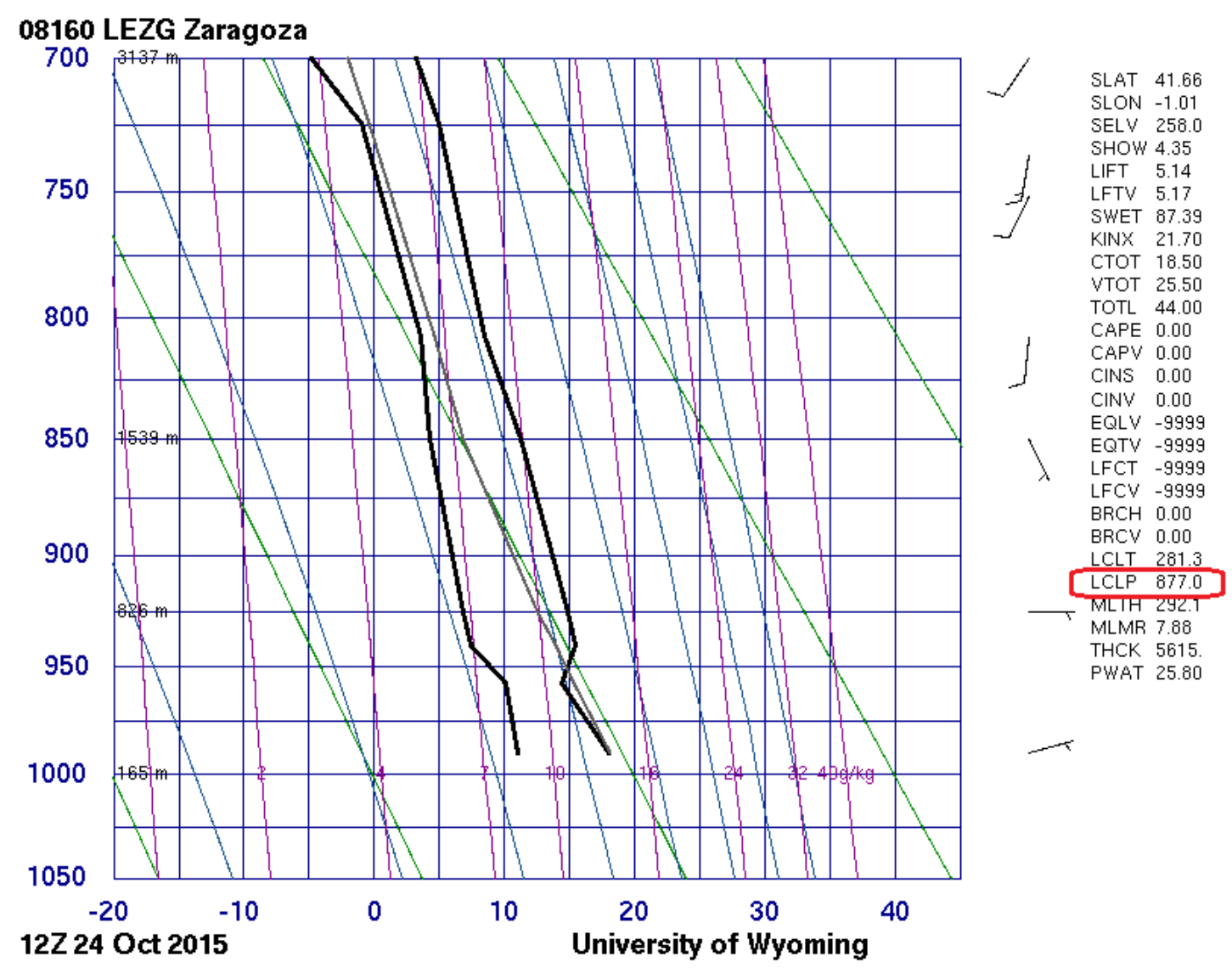

Figura 37: Radiosondeo de Zaragoza aeropuerto del 24 de octubre del 2015. Fuente: http://weather.uwyo.edu/upperair/sounding.html.

En la figura 38 se aprecia como bajo estas condiciones atmosféricas el penacho de la CT se eleva verticalmente hasta los 1200 metros o altura del LCLP.

Página | 56 


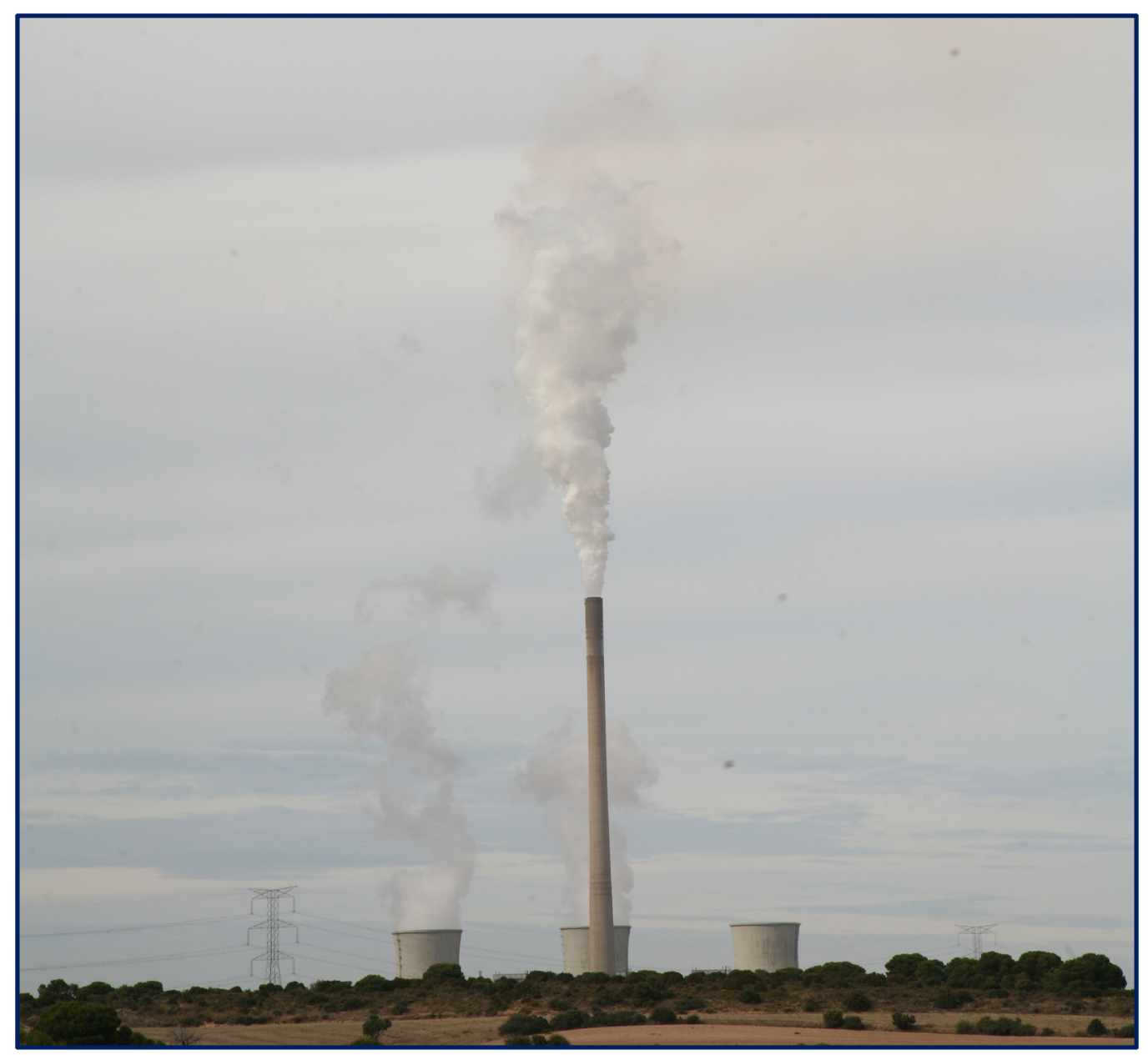

Figura 38: Imagen de la CT, la elevación vertical del penacho hasta los 1200 metros o altura del LCLP puede evaluarse sobre la escala de los 343 metros de la altura de la chimenea. Fuente propia, imagen tomada el 24 de octubre del 2015.

De este modo, si bien los promedios mensuales de los sondeos permiten apreciar la estructura media de la atmósfera, son los sondeos diarios de la estructura atmosférica los que mejor permiten apreciar la importancia de esta capa activa o de mezcla a los efectos ambientales de la región. Tal y como muestra la figura 39, correspondiente al día 19 de marzo del 2011, la capa de inversión más elevada o altura máxima de la capa de mezcla, en situaciones invernales, suele situarse a nivel de los 1200 metros. Esta capa culminaría una estructura de gran estabilidad y mezcla en los niveles inferiores. 


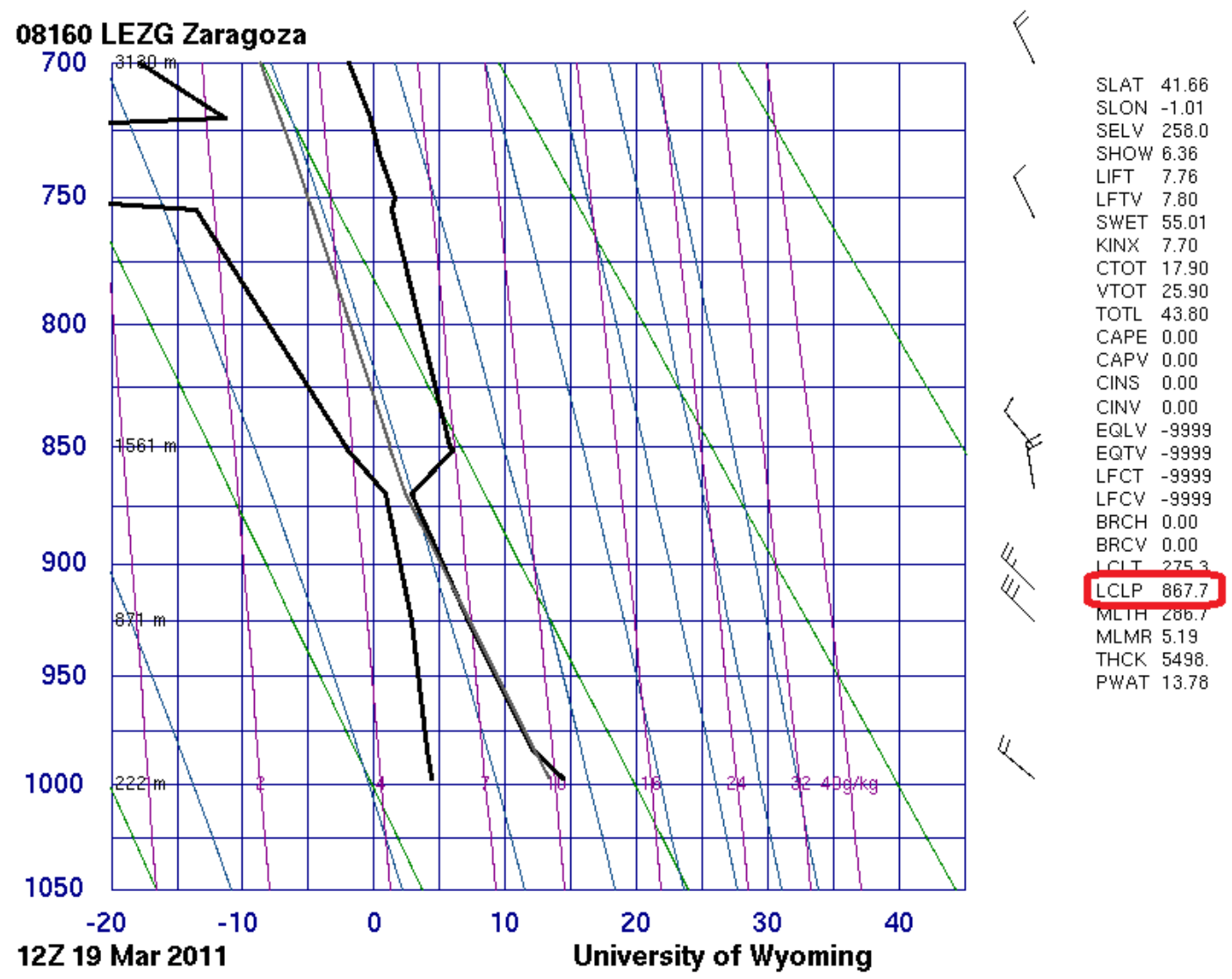

Figura 39: Radiosondeo de Zaragoza aeropuerto del 19 de marzo del 2011. La capa de inversión aparece nítida sobre los 875 hPa. Fuente: http://weather.uwyo.edu/upperair/sounding.html.

La determinación del nivel de estas inversiones presenta así un gran interés en las ocasiones en que tal proceso se desarrolla. Determinación para la cual se dispone, junto a los radiosondeos, de la red meteorológica universitaria. Si bien esta red meteorológica no refleja toda la estructura térmica vertical de la capa baja de la atmósfera, si puede mostrar el comportamiento de la capa atmosférica entre el nivel del mar y los niveles de 1250 y 1450 metros y, consecuentemente, el importante papel que los factores geográficos pueden desempeñar en los procesos de dispersión de contaminantes (Fig. 40).

Página | 58 


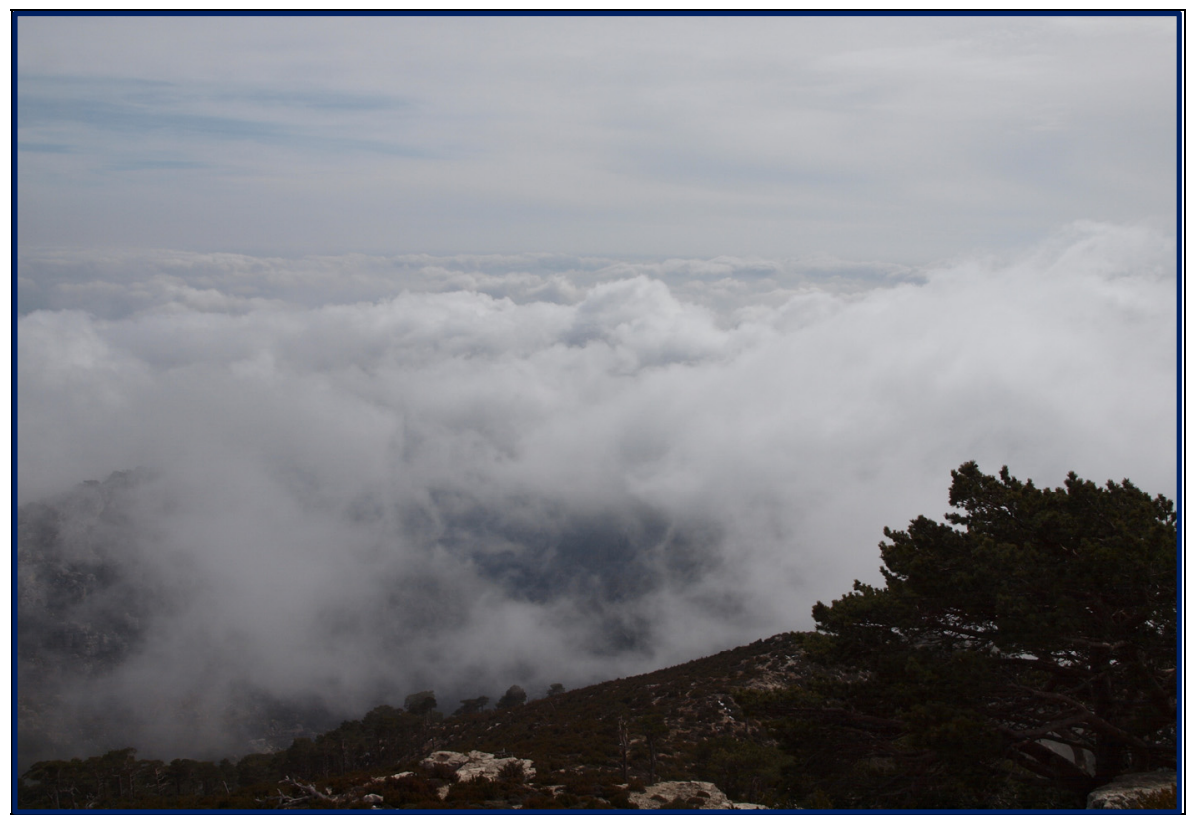

Figura 40: Capa de inversión sobre la reserva natural de Tortosa-Beseit. Imagen tomada desde la cima del monte Caro (1447 metros) el 19 de marzo del 2011 a las 12 horas. El LCLP se sitúa a 867,7 hPa (1300 metros). Fuente: Quereda, 2012: 149.

El gradiente térmico medio anual, entre el valor de la temperatura en el pico de Fredes (1235 metros) y en el monte Caro (1447 metros), arroja un valor de $0,07{ }^{\circ} \mathrm{C} / \mathrm{m}$. Un notable gradiente térmico medio que muestra la importancia de los procesos térmicos en ese nivel crítico de la capa de mezcla regional (Fig. 41).

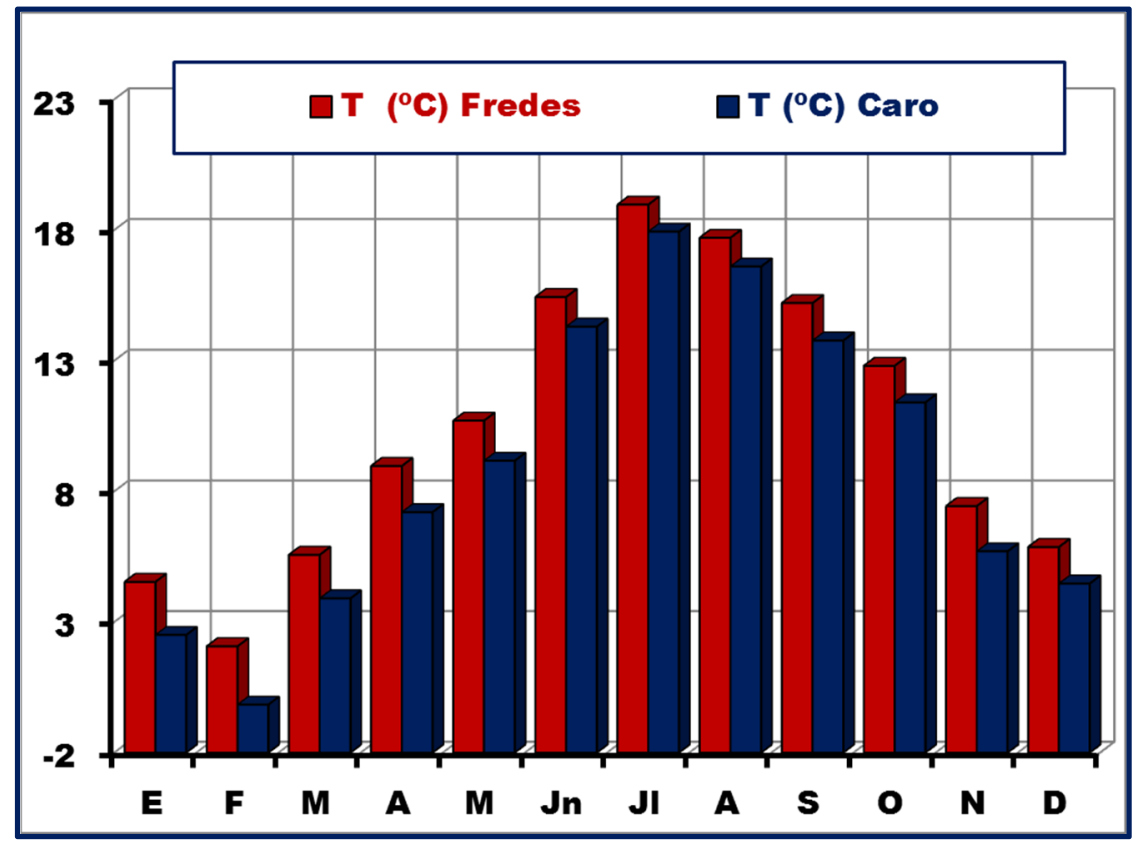

Figura 41: Temperaturas medias mensuales y gradientes en las estaciones de Fredes y del monte Caro (2008-2015). Fuente: elaboración propia, Laboratorio de Climatología de la Universitat Jaume I. 


\section{LA CIRCULACIÓN AÉREA}

En el seno de estas estructuras atmosféricas viene a actuar un vector básico de la difusión y dispersión. Este vector, de naturaleza aerodinámica, viene caracterizado por el sistema de circulación aérea (Quereda y Obiol, 1986; Quereda et al., 1992 y Quereda y Montón, 1996). Una circulación aérea que junto a su papel difusor de contaminantes adquiere también una gran trascendencia bioclimática, pudiendo afectar más o menos severamente al crecimiento de los árboles. En la figura 42 podemos apreciar "las formas tumbadas y en banderola que presentan los pinares de la zona cacuminal del monte Caro sobre los 1400 metros de altura. El stress mecánico y fisiológico que los vientos del oeste provocan se traduce en la fuerte disimetría e inclinación de los pinos hacia el lado oriental"' (Quereda et al., 2004: 398).

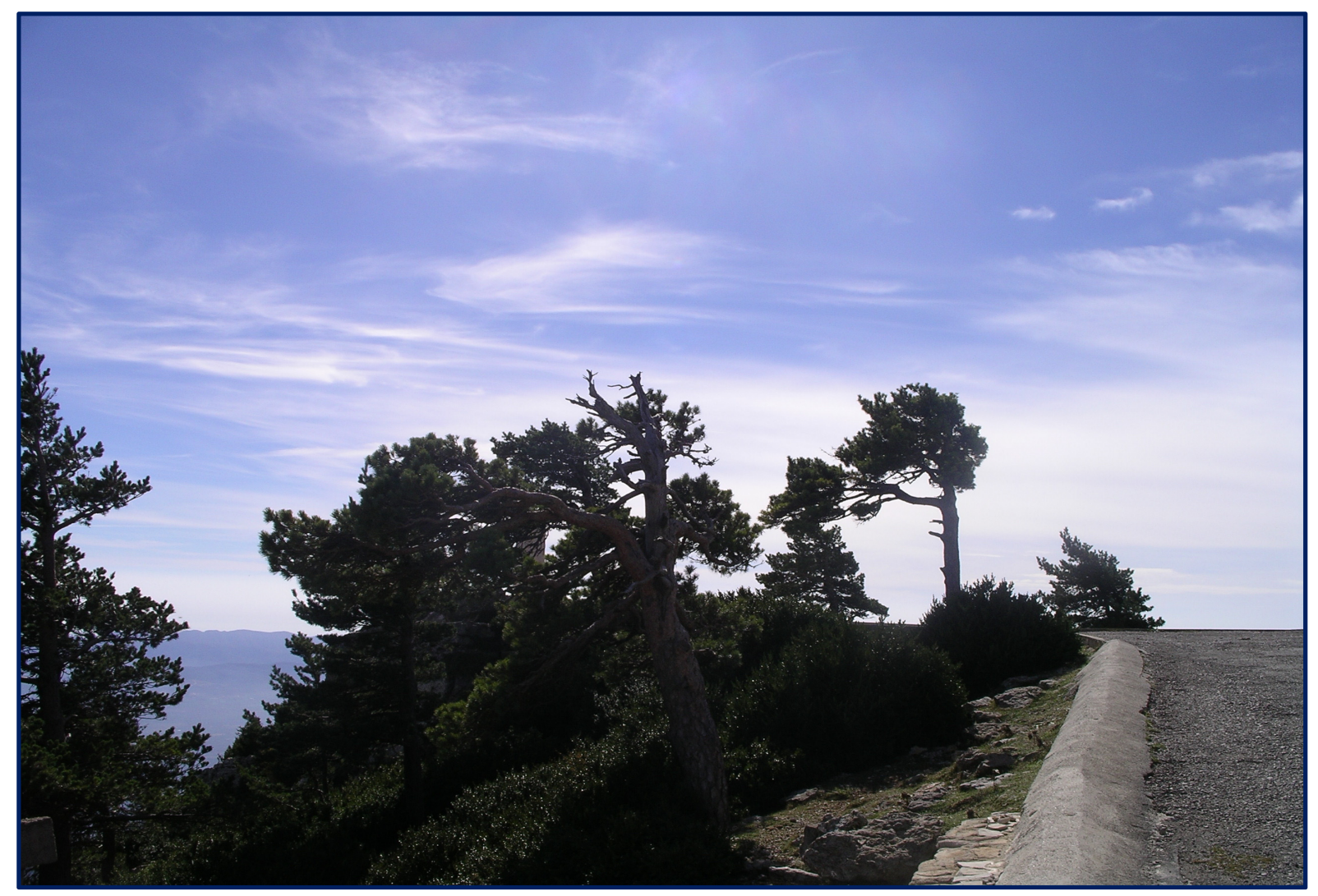

Figura 42: La disimetría e inclinación de los pinares (Pinus sylvestris) en la zona cacuminal del monte Caro (1447 metros, Reserva Natural de Tortosa-Beseit). Fuente: archivo del Laboratorio de Climatología de la Universitat Jaume I.

Para el estudio de la circulación aérea regional, los miembros del Laboratorio de Climatología hemos contado con los registros proporcionados por los observatorios de la red meteorológica universitaria con tres anemocinemógrafos estratégicamente situados. Estos observatorios (Fredes, Torre Miró y monte Caro) han permitido caracterizar la circulación Página | 60 
aérea sobre la vertiente mediterránea del Sistema Ibérico, completando la información de la rosa de vientos de la propia CT (Fig. 43).

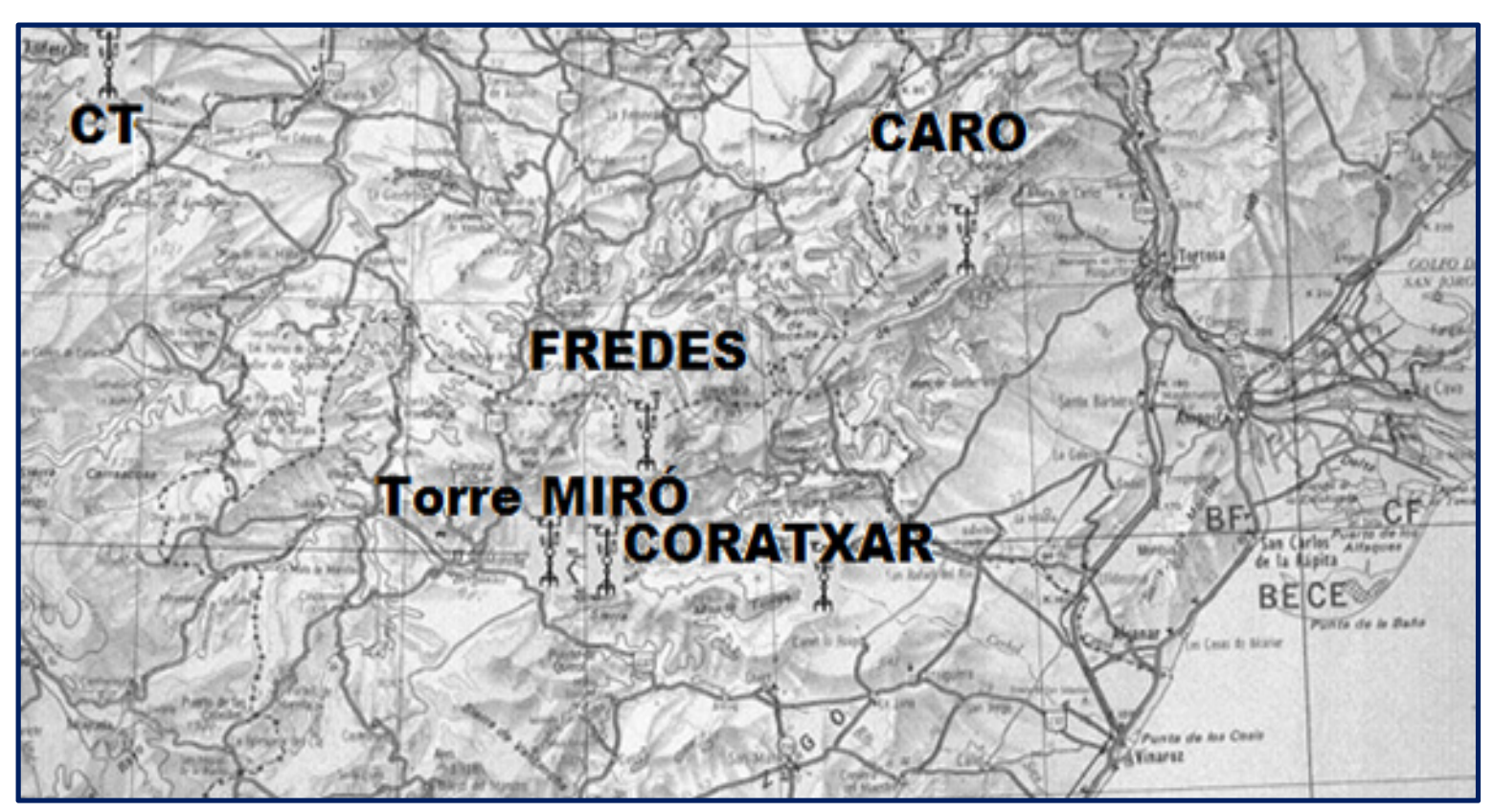

Figura 43: Localización de los principales observatorios anemocinemográficos utilizados en este estudio. Fuente: archivo del Laboratorio de Climatología de la Universitat Jaume I.

De los datos extraídos de estos observatorios se desprende que la circulación aérea regional está sometida a una doble influencia: los elementos de la circulación general de la atmósfera (CGA) y los de la circulación atmosférica regional (CAR). La circulación general de la atmósfera es aquella que afecta a las capas medias y altas de la atmósfera sobre los 3000-4000 metros de altura y se representa en los mapas sinópticos de 300-500 hPa. En cambio, la circulación atmosférica regional es aquella que afecta a los niveles atmosféricos inferiores y viene representada en los mapas de $850 \mathrm{hPa}$ y de superficie. Como se muestra en la figura $44 \mathrm{el}$ campo de presión a $700 \mathrm{hPa}$ determina que la orientación general de los vientos de altura sea zonal y geostrófica (Quereda et al., 2012). 


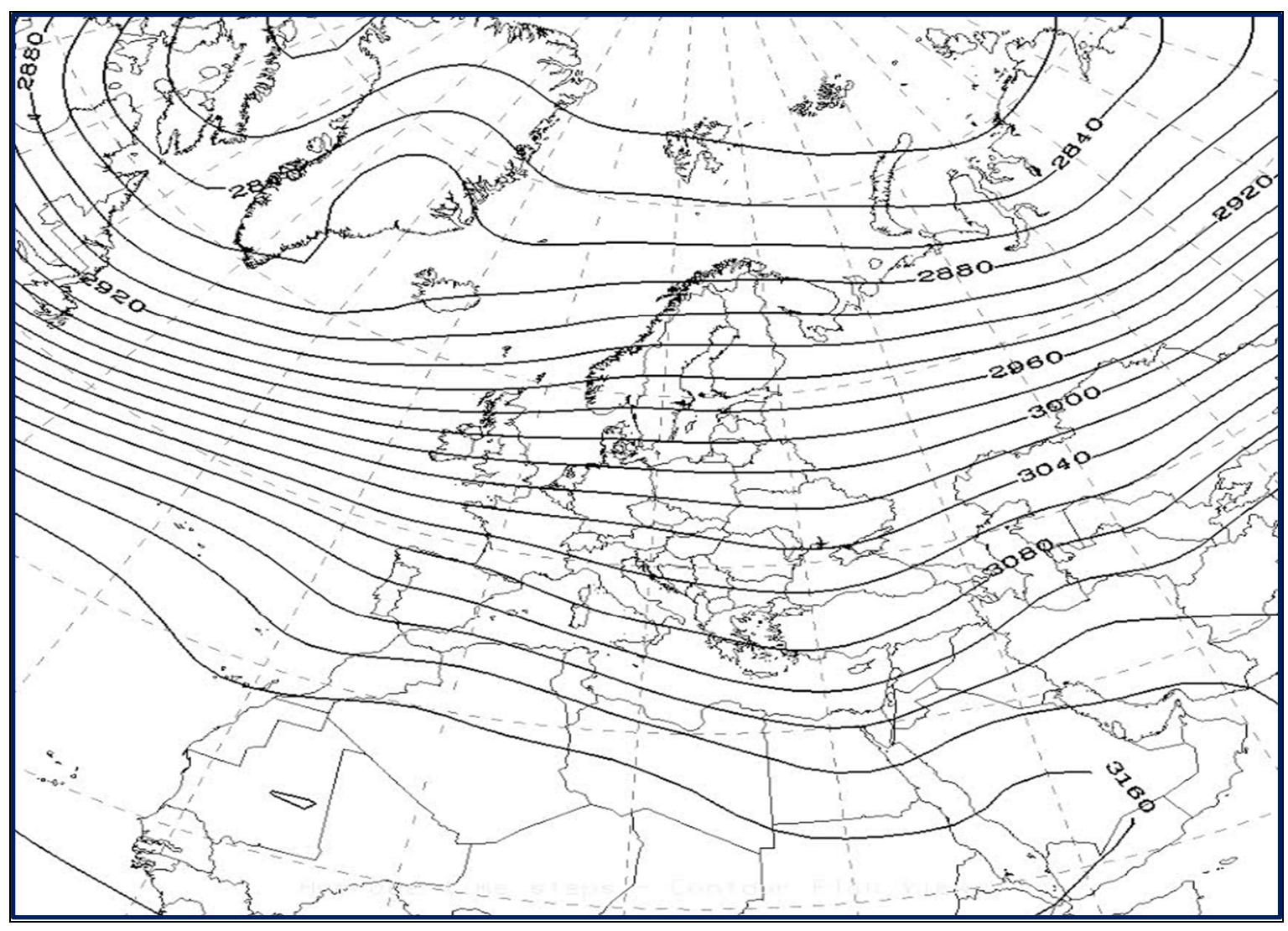

Figura 44: Topografía de la superficie isobárica de 700 hPa (2000-2014). Fuente: NCEP Reanalysis, NOAA/OAR/ESRL PSD, Boulder, Colorado, USA, http://www.esrl.noaa.gov/psd.

No obstante, es el campo barométrico de $850 \mathrm{hPa}$ el que empieza a mostrar los factores convectivos de superficie, insinuando ya la circulación atmosférica regional. En la figura 45 se aprecia claramente la desviación de las isohipsas sobre la Cuenca Occidental del Mediterráneo.

Página | 62 


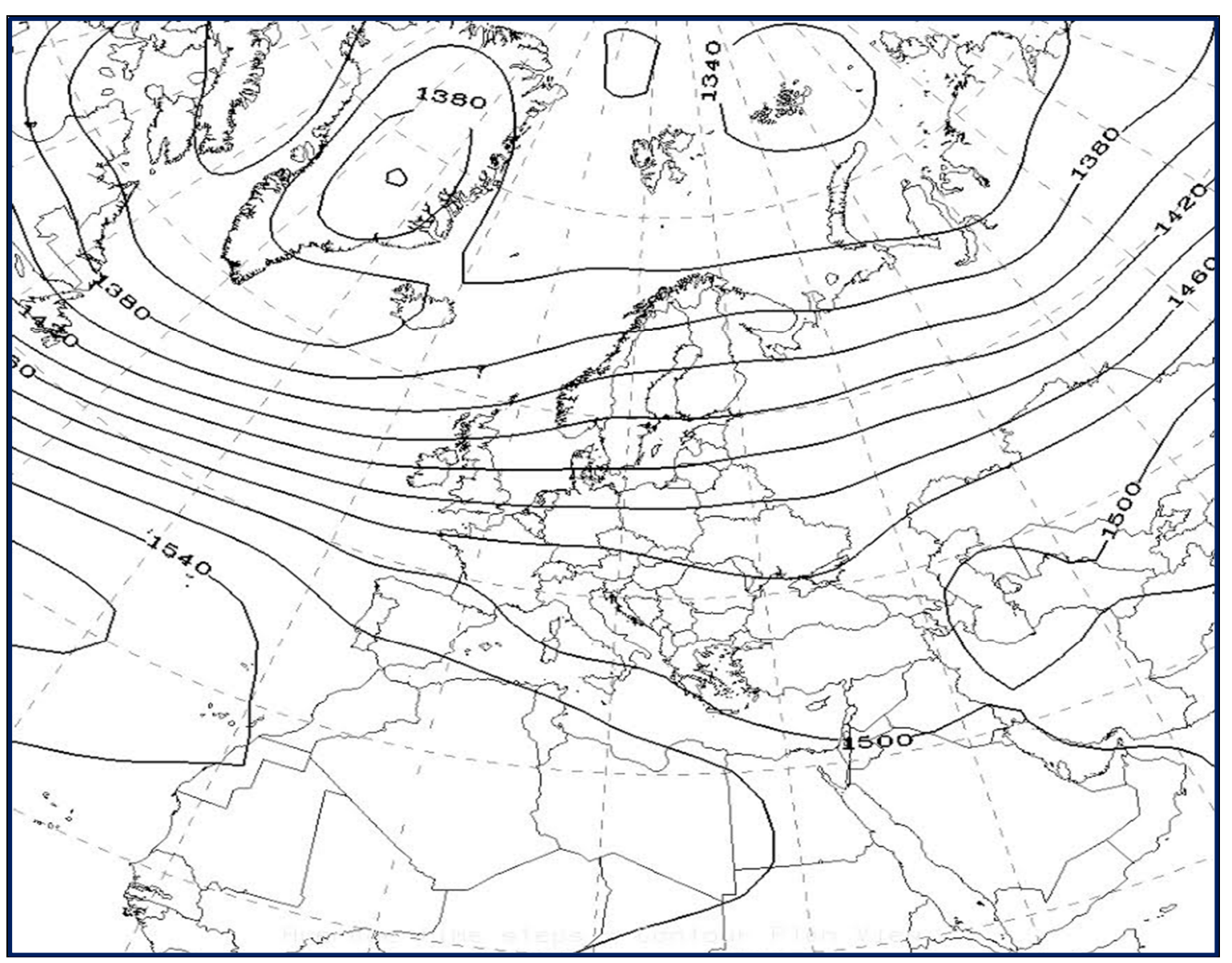

Figura 45: Topografía de la superficie isobárica de $850 \mathrm{hPa}$ (2000-2014). Fuente: NCEP Reanalysis, NOAA/OAR/ESRL PSD, Boulder, Colorado, USA, http://www.esrl.noaa.gov/psd.

A partir de los $850 \mathrm{hPa}$, y a medida que descendemos de nivel, los vientos geostróficos de la circulación atmosférica regional son gradualmente afectados tanto por el efecto de la cubeta marina como por la orografía de esta vertiente regional de Sistema Ibérico (Quereda et al., 2009). De este modo, los flujos de vientos, inicialmente del oeste, sufren una torsión dando lugar a flujos rectores del noroeste en el nivel de la capa de mezcla. Esta desviación que sufren los flujos de vientos, consecuencia de su paso hacia el fondo de la cubeta marina e influidos simultáneamente por la orografía ibérica, es más acusada cuanto más nos aproximamos a la zona costera mediterránea. Como podemos apreciar en la figura 46, que muestra el mapa de presión atmosférica a $925 \mathrm{hPa}$, los vientos dejan de ser zonales y acusan los factores del relieve y de la cuenca mediterránea. Una circulación superficial que ya, con frecuencia, resulta alterada por células de vientos locales o brisas (Quereda, 1987 y Quereda y Torres, 1989). 


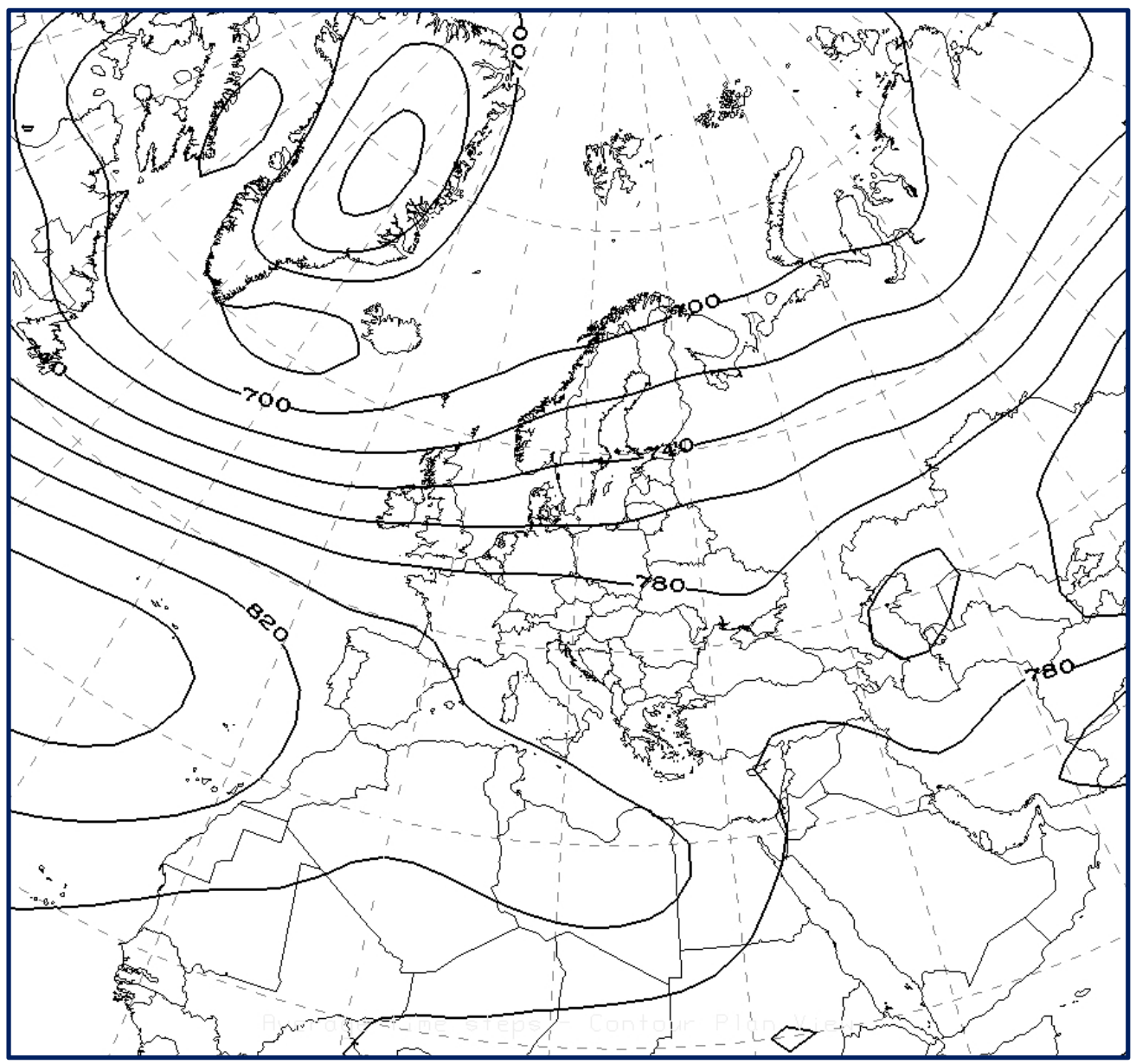

Figura 46: La topografía de la superficie isobárica a nivel de $925 \mathrm{hPa}(2000-2014)$ muestra la fuerte influencia de la cuenca de bajas presiones del Mediterráneo. Fuente: NCEP Reanalysis, NOAA/OAR/ESRL PSD, Boulder, Colorado, USA, http://www.esrl.noaa.gov/psd.

\section{III.I. Configuración de la circulación aérea en el límite de la}

\section{capa de mezcla}

La configuración de la circulación aérea en el límite de la capa de mezcla se manifiesta en las distintas rosas de los vientos obtenidas en nuestra red meteorológica universitaria, ubicada entre los 1000 y los 1500 metros de altura. Esta red nos ha permitido estudiar y caracterizar el modelo de flujo de la circulación atmosférica en esos niveles altos. Unos niveles situados en el estrato atmosférico donde suele oscilar el límite de la capa de mezcla.

La estación más occidental de las analizadas es la ubicada en el observatorio de la propia CT de Andorra. Los registros extraídos de dicha estación y representados en la figura 47 evidencian como la circulación aérea muestra un acusado predominio de vientos del sector W a 
NW. Este sector, excluidas las calmas, concentra el 70\% de las frecuencias incluyendo el flujo de WSW. Un sector que además registra las mayores velocidades. Así, el 70\% de los vientos con fuerza superior a los $21 \mathrm{~km} / \mathrm{h}$ y prácticamente todos aquellos con fuerza superior a 50 $\mathrm{km} / \mathrm{h}$ están comprendidos en este sector.

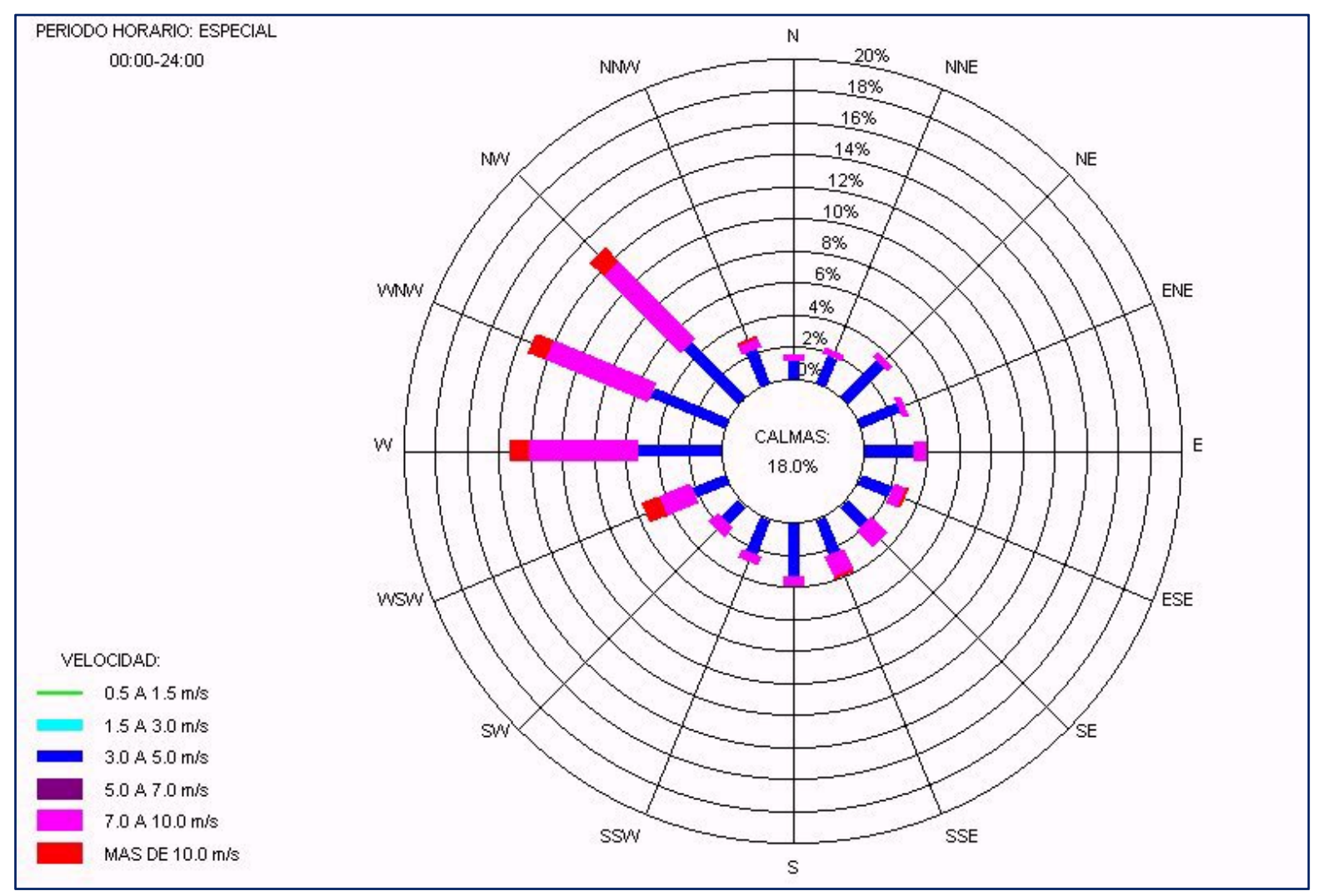

Figura 47: La rosa anual de los vientos del anemocinemógrafo de la CT de Andorra, Teruel (1992/2010), muestra el acusado predominio de los vientos procedentes del sector W y WNW. Fuente: datos proporcionados por la CT. Elaboración propia, Laboratorio de Climatología de la Universitat Jaume I.

En la rosa de los vientos anterior junto al predominio de estos vientos fuertes del oeste se puede apreciar un pequeño porcentaje de vientos débiles del este, principalmente debidos a un régimen de brisas de verano. Estos registros han sido obtenidos por el anemocinemógrafo que está situado a 60 metros de altura sobre la superficie. Este gran predominio, tanto en dirección como en fuerza de los vientos del NW y NNW, se mantiene sobre toda la región analizada de la vertiente mediterránea del Sistema Ibérico.

La configuración aérea así definida, desde su origen territorial como hemos visto en la rosa de Andorra y extendida por todo el territorio del Maestrazgo y de la Reserva Natural de Tortosa, viene a explicar la procedencia de las inmisiones de $\mathrm{SO}_{2}$ en la estación de Coratxar, a 
1200 metros de altura. Los registros de inmisión de $\mathrm{SO}_{2}$ (red de vigilancia atmosférica de la GVA) representados en función de la dirección del viento en la rosa de inmisiones de Coratxar (Fig. 48), muestran el neto predominio de los flujos del NNW en las magnitudes de la citada inmisión. Si bien los vientos que soplan sobre Coratxar comportan algún porcentaje de origen oriental o marino, su aportación en $\mathrm{SO}_{2}$ es mínima.

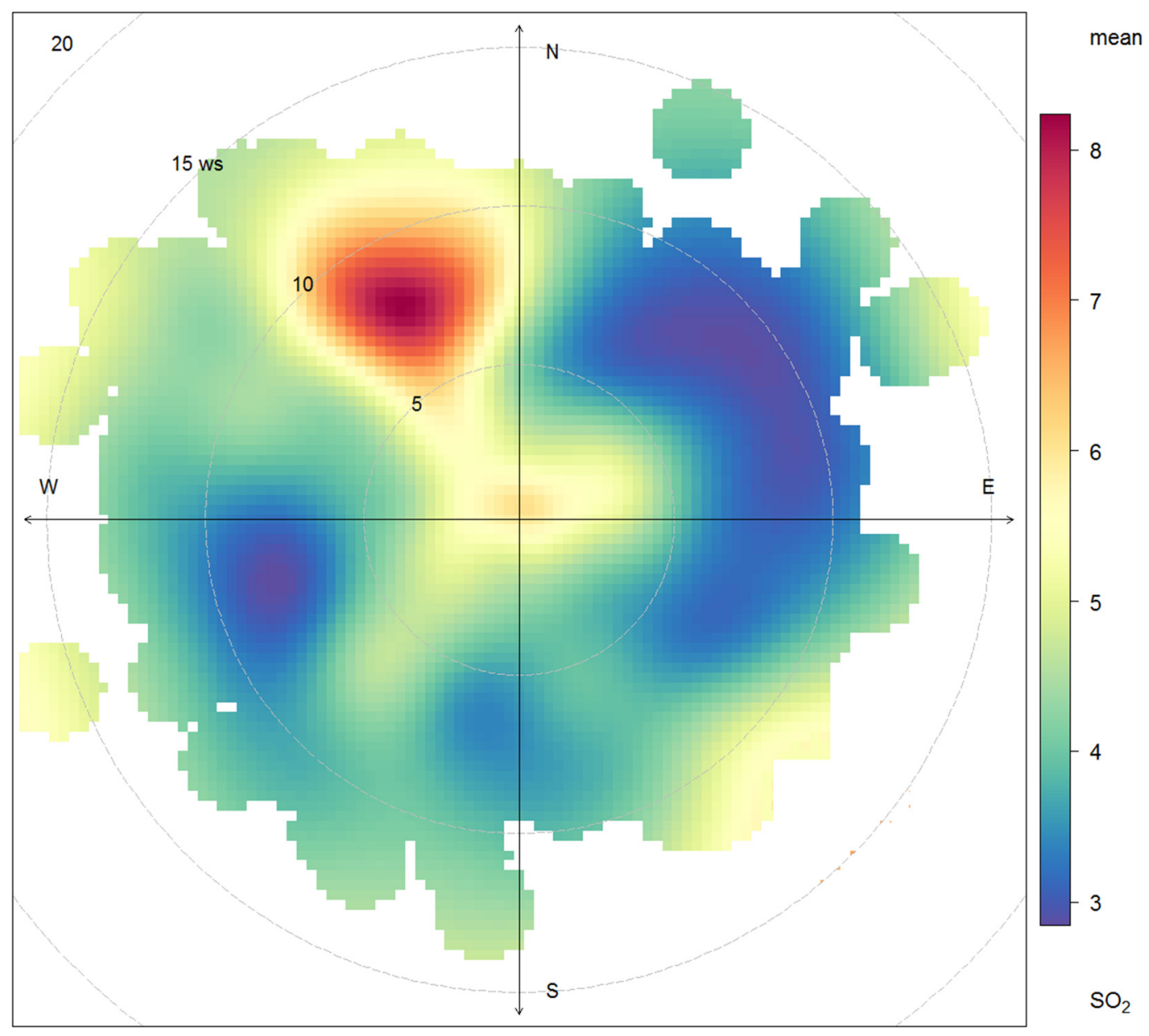

Figura 48: Rosa anual de inmisiones de $\mathrm{SO}_{2}\left(\mu \mathrm{g} / \mathrm{m}^{3}\right)$ en Coratxar según la dirección del viento (2014/2015). El eje NNW se muestra absolutamente clave en los mayores valores de inmisión. Fuente: Red Valenciana de Vigilancia y Control de la Contaminación Atmosférica. Elaboración propia, Laboratorio de Climatología de la Universitat Jaume I.

En la figura 49 se han representado las inmisiones estacionales de $\mathrm{SO}_{2}$ en Coratxar en función de la dirección del viento. Todas las grandes inmisiones de $\mathrm{SO}_{2}$ aparecen vinculadas a los flujos del NW y NNW. Los promedios de 2014 y 2015 muestran que las estaciones de otoño y de invierno han concentrado los mayores valores de inmisión.

Página | 66 


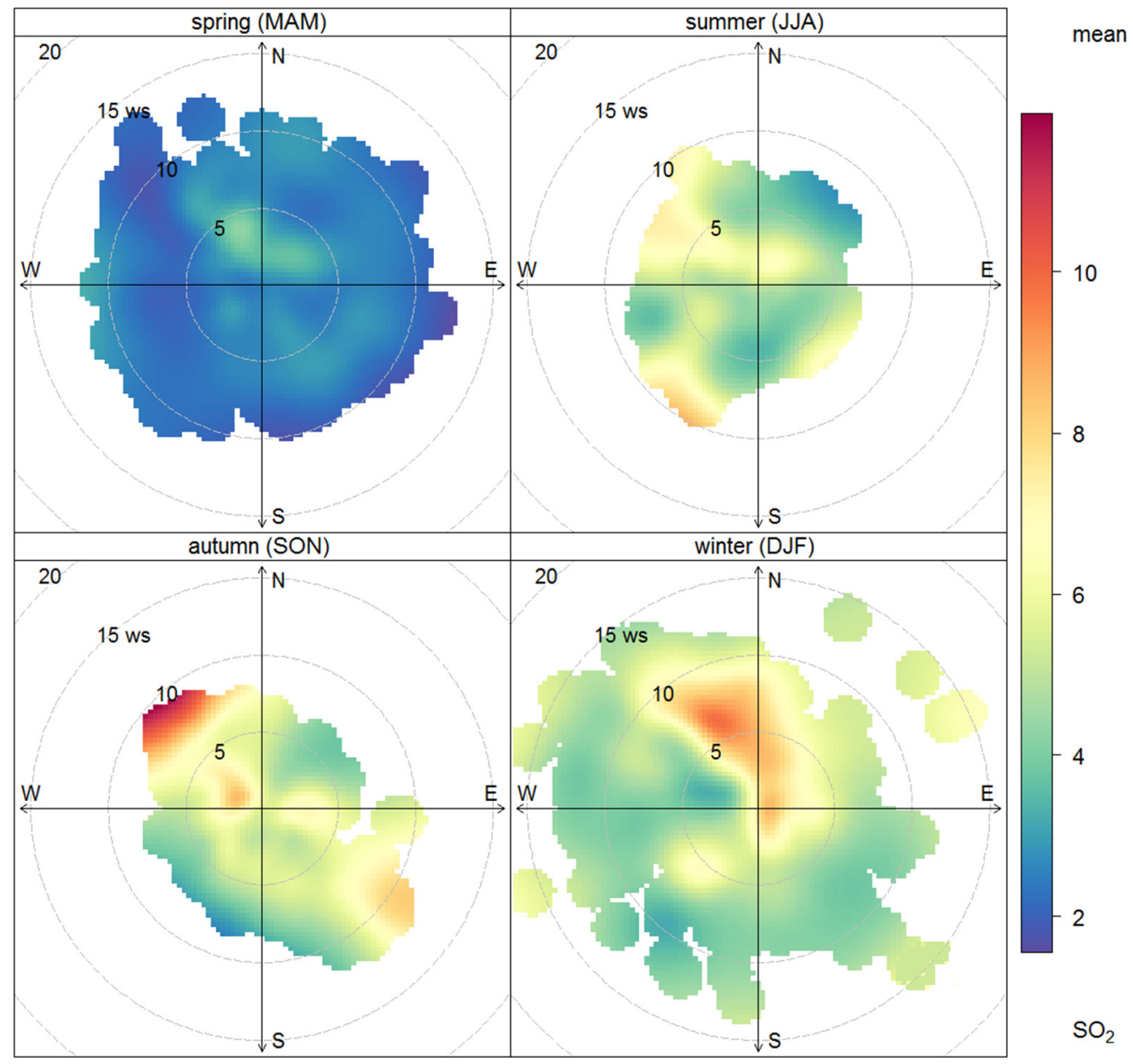

Figura 49: Rosas estacionales de las inmisiones de $\mathrm{SO}_{2}$ en función de la dirección del viento en Coratxar (2014/2015). Fuente: Red Valenciana de Vigilancia y Control de la Contaminación Atmosférica. Elaboración propia, Laboratorio de Climatología de la Universitat Jaume I.

La figura 50, representativa de la aerodinámica de los picos de inmisión, muestra una configuración idéntica. No obstante, los valores de inmisión representados corresponden al año 2000, antes de la plena actividad de los procesos de desulfuración. Ello, al mismo tiempo que muestra esa concentración de los picos sobre los vectores NW y NNW, refleja los altos valores de inmisión existentes en aquellos años. 


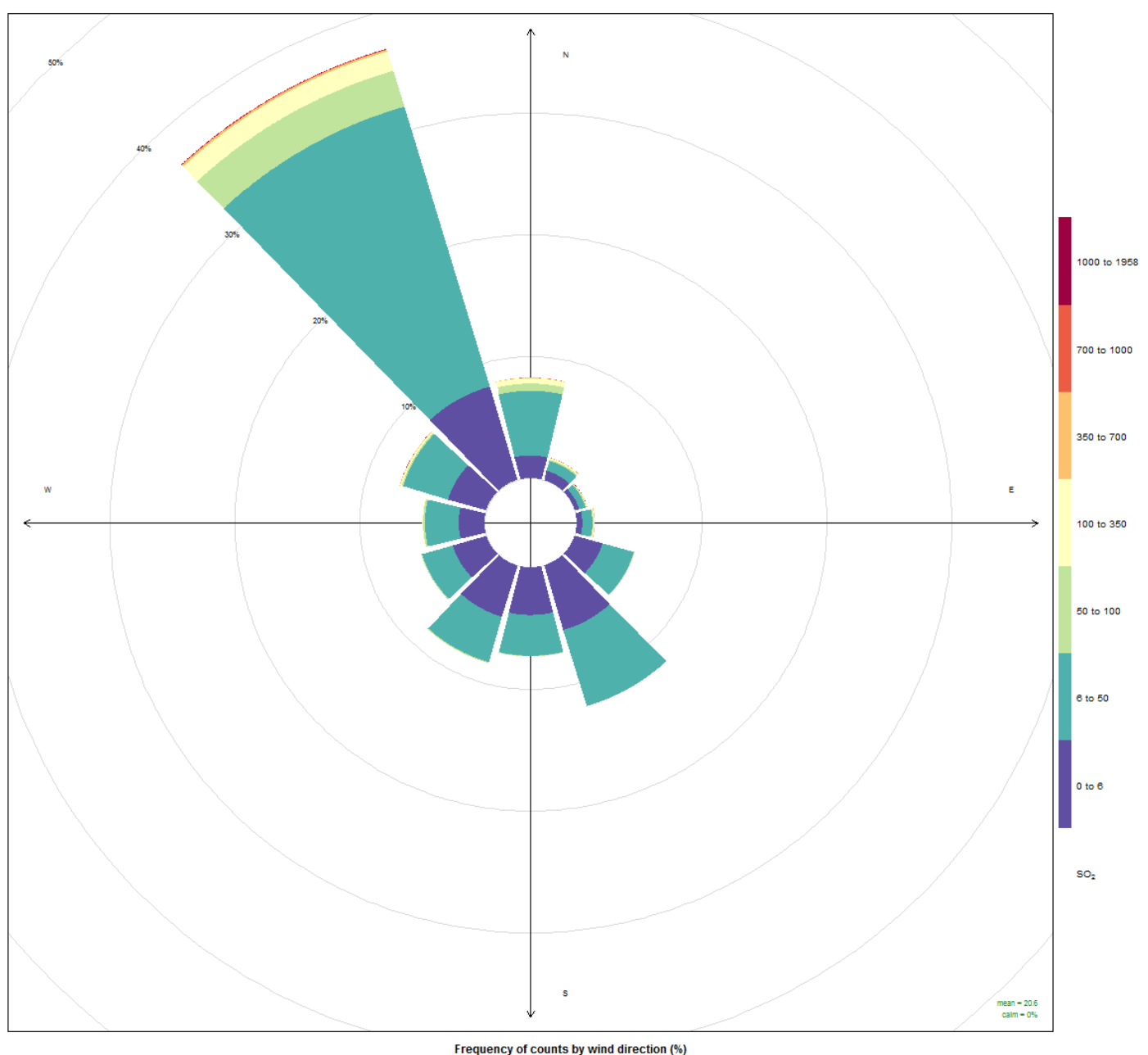

Figura 50: Rosa anual de vientos y umbrales de los picos de las inmisiones de $\mathrm{SO}_{2}$ en Coratxar (2000). La totalidad de los picos de inmisión de $\mathrm{SO}_{2}$ aparece vinculada a ventilaciones del NNW, con alguna mínima presencia en vientos del Norte. Fuente: Red Valenciana de Vigilancia y Control de la Contaminación Atmosférica. Elaboración propia, Laboratorio de Climatología de la Universitat Jaume I.

Esta circulación predominante del NW aparece nítidamente caracterizada también en las rosas de vientos del monte Caro (Fig. 51) y de Fredes (Fig. 52).

Página | 68 
En la figura 51, correspondiente a la rosa de vientos del monte Caro, los registros aéreos nocturnos muestran la débil influencia de las brisas orientales. Al mismo tiempo, el eje aerodinámico muestra que estamos sobre el límite de la capa de mezcla donde el viento es geostrófico.

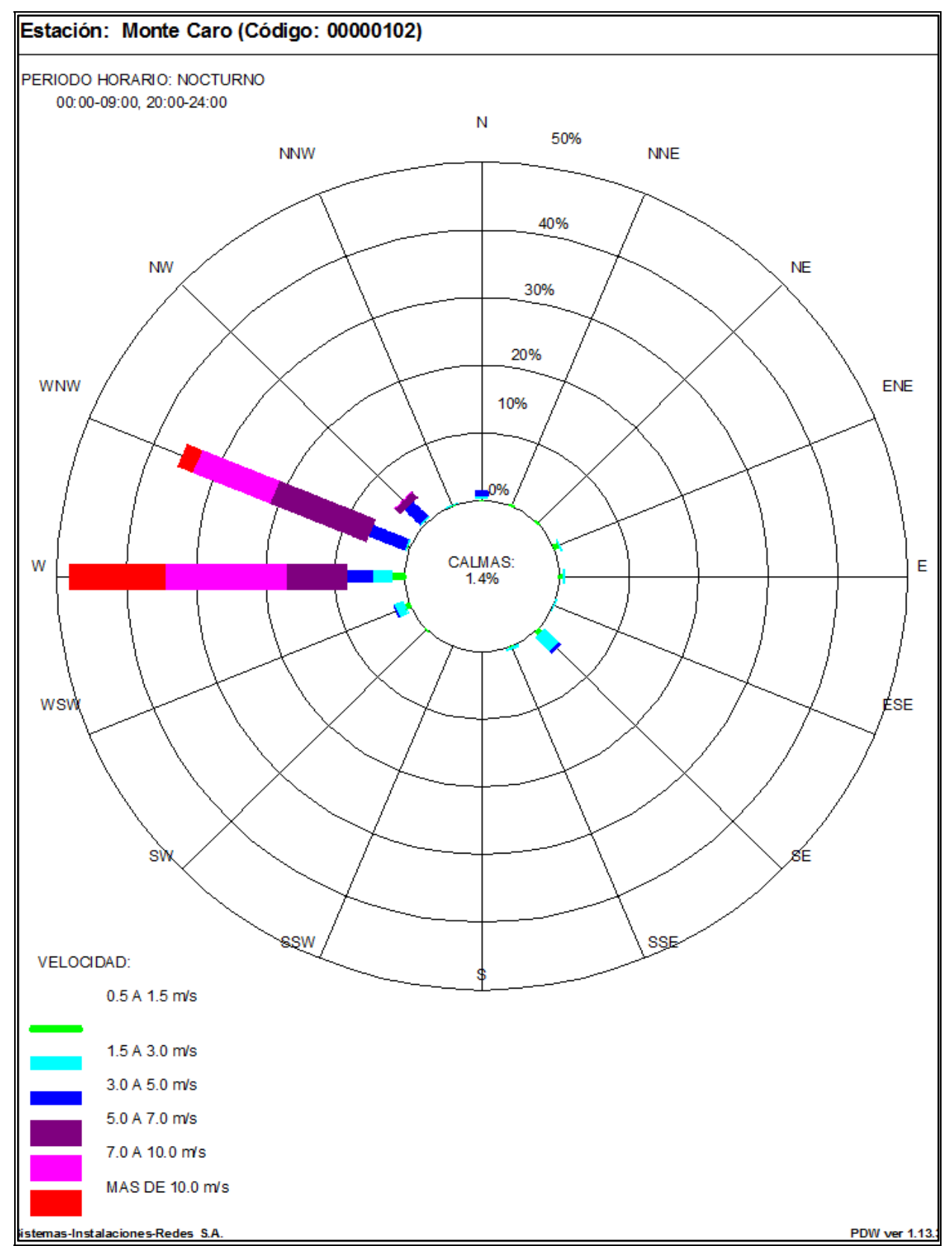

Figura 51: Rosa de vientos del período nocturno durante el mes de enero (2003-2012), en la cima del monte Caro a 1447 metros, 850 hPa. Fuente: red meteorológica universitaria. Elaboración propia, Laboratorio de Climatología de la Universitat Jaume I. 


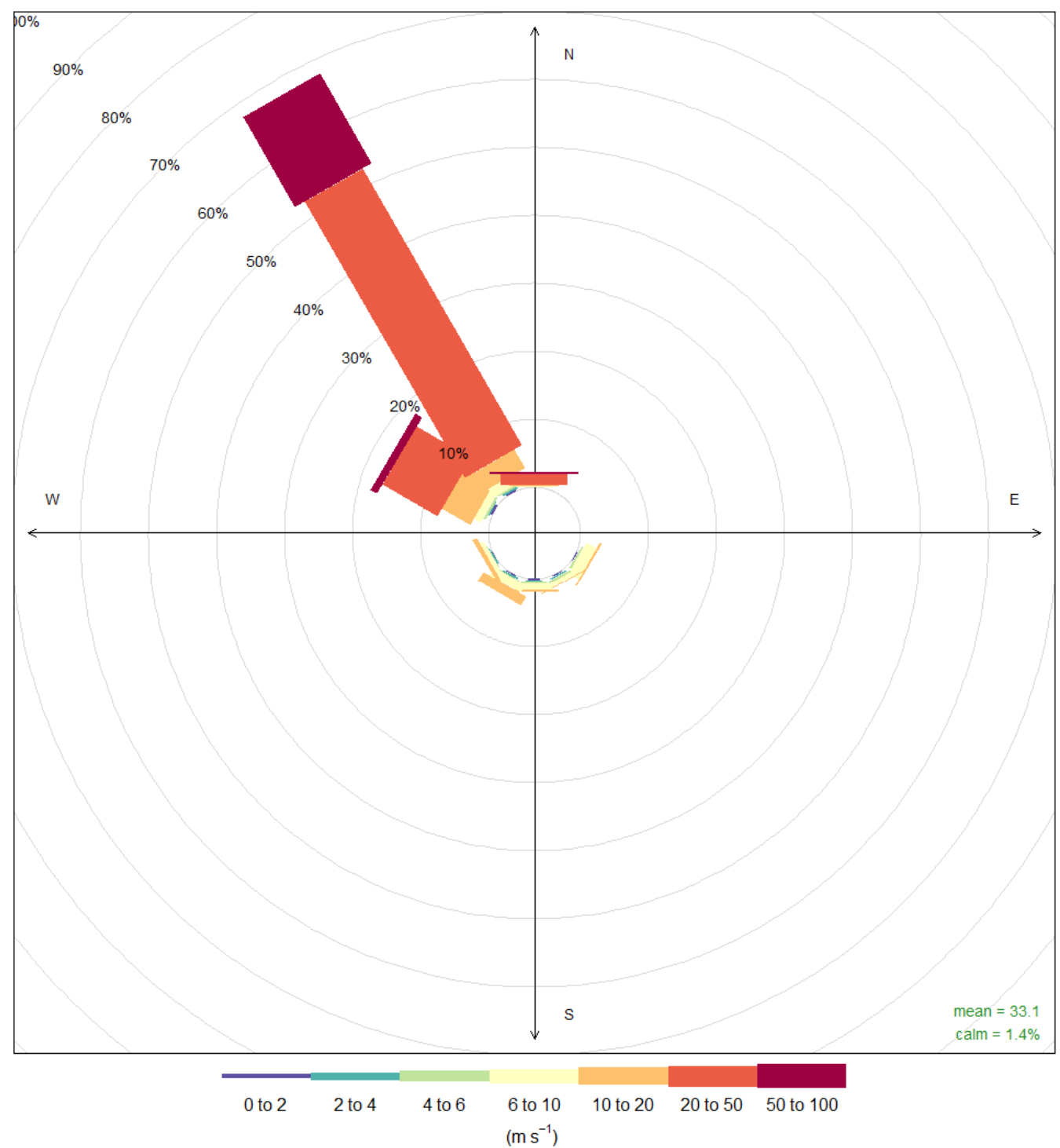

Frequency of counts by wind direction (\%)

Figura 52: Rosa de vientos durante los meses de invierno (2014-2015) en Fredes, 1235 metros. Fuente: red meteorológica universitaria. Elaboración propia, Laboratorio de Climatología de la Universitat Jaume I.

Los vientos son esencialmente geostróficos a 1447 metros (monte Caro) y ya con una ligera inflexión NNW en Fredes (1235 metros). Unos niveles que marcan los oscilantes límites de la capa de mezcla.

Página | 70 


\section{CONCLUSIONES SOBRE EL ESCENARIO ATMOSFÉRICO REGIONAL}

Los numerosos análisis efectuados han permitido configurar la específica estructura térmica vertical de la atmósfera regional y definir la capa de mezcla en la que son difundidos los contaminantes atmosféricos. Así, como hemos podido constatar a lo largo del presente capítulo tras un riguroso análisis de los registros meteorológicos, la altura máxima de la capa activa regional viene netamente delimitada por la configuración cuasi geostrófica o geostrófica de los flujos aerodinámicos de la cima del pico Fredes y del monte Caro respectivamente. Esta configuración geostrófica señala el límite hasta donde los efectos de la turbulencia termodinámica de la superficie se dejan sentir. Las rosas aéreas, obtenidas a partir de los registros de la red meteorológica universitaria desde el año 2003, junto a los radiosondeos de Zaragoza aeropuerto, la única estación disponible sobre la región de la vertiente mediterránea del Sistema Ibérico, han permitido precisar ese parámetro clave de la meteorología ambiental y de la dispersión de contaminantes.

Como complemento de esos registros, el nivel de la capa de mezcla ha sido definido por la presencia de la capa de inversión y a través del cálculo del LCLP. Así pues, los registros de los radiosondeos analizados nos han permitido situar el valor medio del LCLP en los meses invernales de los años 2014 y 2015 en 877 hPa (1200 metros), 35 metros por debajo del observatorio universitario ubicado en la cima del pico Fredes (1235 metros). Asimismo, durante los meses de julio y agosto de 2014 y 2015 el valor de la LCLP se ha situado en 781 hPa (2150 metros), casi mil metros más elevado que durante el invierno. Ello explica que las situaciones estivales sean las que permiten una mayor dispersión de los contaminantes con menor impacto regional. La aplicación en los modelos de sobreelevación y dispersión de penachos (capítulo III) será determinante para verificar su papel.

Por otro lado, paralelamente a esa oscilación estacional de alturas del LCLP, se operan las del nivel de las capas de inversión. En efecto, tal como hemos definido, la capa límite atmosférica o capa de mezcla representa el estrato de aire sujeto a la influencia de la superficie terrestre. Sin embargo, dado que en invierno el gradiente térmico es más elevado que la variación de la razón de mezcla, la inversión térmica se forma antes de alcanzar el nivel de condensación ascendente. En consecuencia, la determinación de la altura de la capa de mezcla la hemos realizado sobre la altura de la capa de inversión. Consecuentemente, la variación en 
magnitud de esta influencia terrestre determina que la capa de mezcla presente grandes oscilaciones de espesor, tanto estacional como diurno. Así pues, podemos concluir que:

1. En invierno y durante la noche la inversión térmica de superficie, situada a niveles atmosféricos bajos, determina que la capa de mezcla no rebase los 400/500 metros de altura.

2. Fuera de estos periodos, tiene lugar una inversión térmica alta, asociada a fenómenos de subsidencia y que se produce a niveles atmosféricos más elevados.

3. Dado que la altura de la chimenea es de 343 metros y se sitúa a 596 metros sobre el nivel del mar, las emisiones de la CT se producen generalmente en un estrato atmosférico que se sitúa fuera de los efectos de las inversiones bajas y de la influencia de la superficie terrestre.

4. En las situaciones en las que se producen inversiones térmicas altas, el comportamiento de los contaminantes atmosféricos vendrá determinado principalmente por la altura a la que aparezca la capa de inversión térmica. Una capa que, como hemos definido, viene a delimitar el mayor o menor volumen atmosférico en el que se inyectan y difunden las emisiones contaminantes. Estos procesos se analizarán con detenimiento en los capítulos III y IV del presente estudio. 
CAPÍTULO TERCERO

MODELIZACIÓN GAUSSIANA DEL PENACHO 



\section{INTRODUCCIÓN}

A lo largo del capítulo precedente se ha efectuado un análisis de la estructura atmosférica regional. Una estructura térmica vertical esencialmente caracterizada por las situaciones de estabilidad. Dentro de esta estructura se ha definido muy especialmente la de la capa de mezcla en la que son difundidos los contaminantes atmosféricos. Una capa de mezcla cuyo espesor medio varia estacionalmente entre los $877 \mathrm{hPa}$ (1200 metros) en invierno y los $781 \mathrm{hPa}$ (2150 metros) en verano, favoreciendo en este caso la dispersión de los contaminantes.

La capa de mezcla así diseñada cubre un territorio alineado sobre el eje orográfico del valle del Ebro y el Sistema Ibérico. El techo de este escenario atmosférico viene a coincidir con el nivel donde el viento real coincide con el geostrófico. Un nivel que señala la altura máxima donde todavía puede percibirse algún efecto termodinámico de la turbulencia engendrada en superficie. En el seno de esta capa de mezcla, el eje aerodinámico viene constituido por los flujos del WNW. Unos flujos que, en el nivel medio de $900 \mathrm{hPa}$ donde se efectúan principalmente las emisiones de la CT, muestran un predominio casi absoluto de las frecuencias. Estos ejes aerodinámicos de la dispersión aérea, desde la misma CT, vienen a confluir, libres de obstáculos orográficos, sobre las cimas de El Maestrazgo. En síntesis, toda una configuración de escenario atmosférico que constituye el marco ideal para una modelización gaussiana del penacho procedente de la CT. Modelización de sobreelevación y dispersión de penachos que será determinante para verificar el importante papel que el escenario atmosférico regional juega en la gestión ambiental de la zona. Consecuentemente, en el presente capítulo se sintetiza, en primer lugar, el marco teórico en el que se fundamenta el cálculo de la concentración de contaminantes que llega a un determinado punto más o menos alejado de la fuente emisora. En segundo lugar, se analizan algunos de los modelos semiempíricos existentes para llevar a cabo el cálculo de la sobreelevación del penacho de humos emitido por una chimenea. En tercer lugar, se describe el modelo gaussiano de Pasquill de dispersión de contaminantes del penacho, protocolo matemático empleado para la evaluación del impacto ambiental producido por los contaminantes gaseosos emitidos por chimeneas.

Finalmente, todas las expresiones más o menos teóricas analizadas en el presente capítulo son contrastadas con casos reales. Para corroborar los valores de sobreelevación 
obtenidos de manera teórica se cotejan con fotografías de la evolución real del penacho de humos de la CT de Andorra. Por otra parte, los registros de inmisión de $\mathrm{SO}_{2}$ de la estación de Coratxar se utilizan para evaluar los resultados obtenidos tras la aplicación del modelo gaussiano de Pasquill a diferentes situaciones en las que se han registrado picos significativos de inmisión de $\mathrm{SO}_{2}$ en Coratxar.

\section{LA ATMÓSFERA COMO MEDIO RECEPTOR DE CONTAMINANTES GASEOSOS}

En primer lugar se va a abordar el cálculo de la concentración de contaminantes que llega a un determinado punto más o menos alejado de la fuente emisora. La concentración de contaminantes en un determinado punto dependerá en gran medida de la capacidad de la atmósfera para dispersarlos es decir, de la turbulencia atmosférica (Puigcerver y Carrascal, 2008 y Gallego et al., 2012).

La turbulencia puede definirse como un cambio brusco de la velocidad y dirección de los vientos que se aprecia en una capa atmosférica próxima al suelo y de espesor variable. El grado de turbulencia depende de diversos factores tales como la velocidad del viento, la rugosidad del terreno (vegetación, edificios...), el gradiente vertical de temperatura, etc. "Es precisamente la intensidad de esta turbulencia el rasgo esencial que permite distinguir en la troposfera la existencia, a unos 2000 o 4000 metros de altura, de la llamada capa geográfica que experimenta los efectos turbulentos con más intensidad que la capa superior llamada capa límite (Fig. 53). Esta capa geográfica o de fricción tiene una extraordinaria importancia tanto en los procesos climáticos como en los de difusión y contaminación ambiental” (Quereda, 2005: 53).

Página | 76 


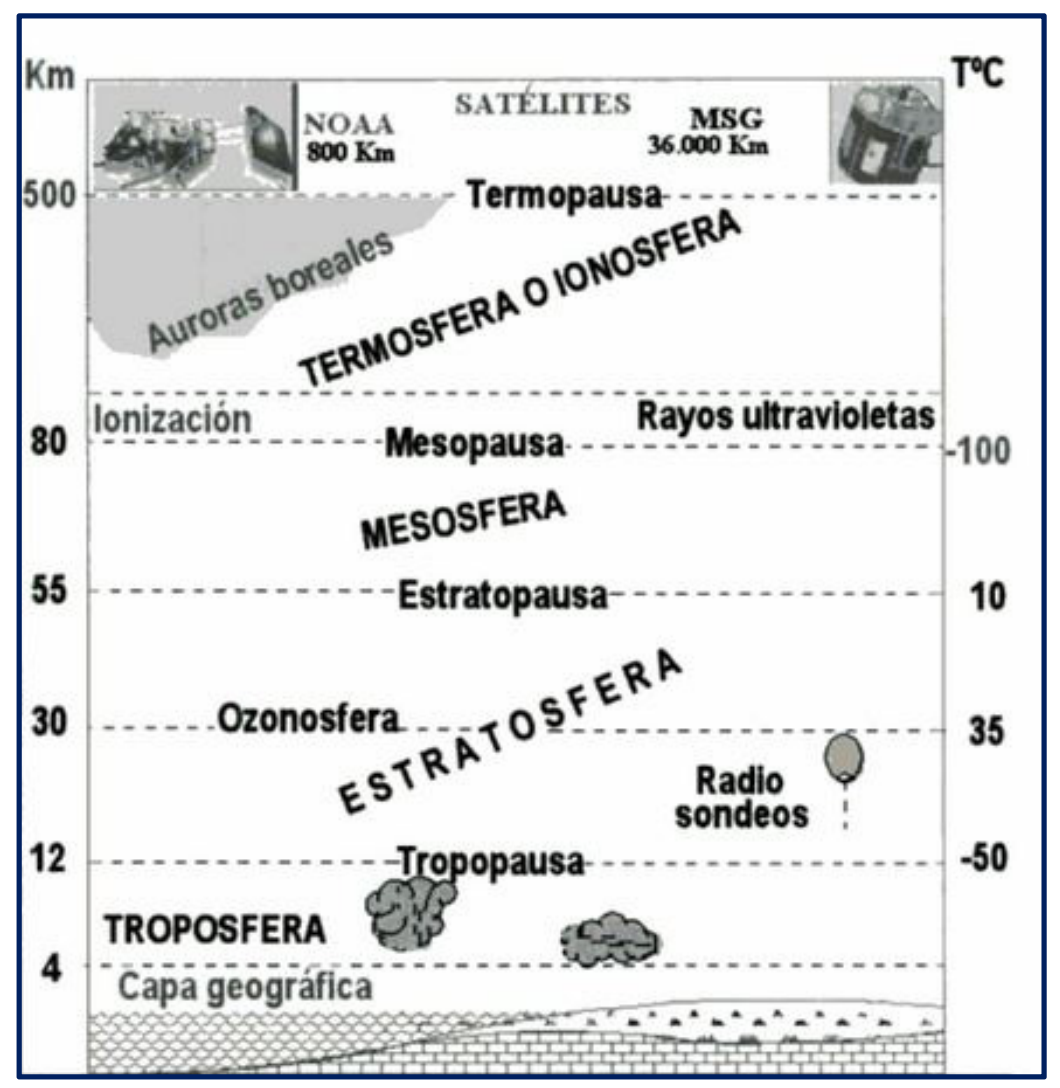

Figura 53: Estructura de la troposfera: capa geográfica y capa libre. Fuente: Quereda, 2005: 25.

Podemos distinguir dos tipos de turbulencia:

1. La turbulencia térmica: debida principalmente a la inestabilidad térmica del aire. La causa principal de este tipo de turbulencia es el calentamiento del suelo que tiene su origen en el fenómeno de la convección, mecanismo natural de transmisión del calor en la atmósfera.

2. La turbulencia mecánica: debida principalmente al rozamiento del aire con las irregularidades del terreno. De manera que cuanto más irregular sea la superficie (mayor rugosidad) y mayor sea la velocidad del viento, el grado de turbulencia será más elevado.

Aunque para obtener unos resultados lo más exactos posible se debería disponer de medidas reales de la intensidad de la turbulencia, esto en la práctica resulta considerablemente complicado tanto instrumental como conceptualmente. Por ello es habitual emplear modelos propuestos por diferentes autores para poder clasificar las diferentes situaciones atmosféricas en función de la turbulencia. 


\section{II.I. Clasificación del poder dispersor de la atmósfera (clases de estabilidad Pasquill-Gifford-Turner)}

Una de las clasificaciones más empleadas es la propuesta por Pasquill y modificada posteriormente por Gifford y por Turner (Pasquill, 1961; Gifford, 1961 y Turner, 1970). Esta clasificación va a depender de dos factores principalmente, por un lado de la radiación solar neta (turbulencia térmica) y por el otro de la velocidad del viento (turbulencia mecánica) (Tabla 4). De este modo, la estabilidad atmosférica o poder dispersor ${ }^{5}$ de la atmósfera queda dividido en seis categorías A, B, C, D, E y F, siendo la categoría A la más inestable y turbulenta y la categoría F la más estable y, por ello, menos turbulenta (Turner y Schulze, 2007).

Tabla 4: Tabla de categorías de dispersión de Pasquill (1961) que incluye las modificaciones sugeridas por Gifford (1961) y Turner (1970). Fuente: Puigcerver y Carrascal, 2008: 137.

\begin{tabular}{|c|c|c|c|c|c|}
\hline \multirow{2}{*}{$\begin{array}{c}\text { Velocidad del } \\
\text { viento } \\
\mathrm{m} / \mathrm{s}\end{array}$} & \multicolumn{3}{c}{ Día } & \multicolumn{2}{c|}{ Noche } \\
\cline { 2 - 6 } & $\begin{array}{c}\text { Fuerte } \\
\mathrm{h}>60^{\circ}\end{array}$ & $\begin{array}{c}\text { Moderada } \\
35^{\circ}<\mathrm{h}<60^{\circ}\end{array}$ & $\begin{array}{c}\text { Débil } \\
15^{\circ}<\mathrm{h}<35^{\circ}\end{array}$ & $\begin{array}{c}\text { Nubladosidad } \\
\geq 4 / 8\end{array}$ & $\begin{array}{c}\text { Despejado } \\
\leq 3 / 8\end{array}$ \\
\hline$<2$ & A & A-B & B & F & F \\
\hline $2-3$ & A-B & B & C & E & F \\
\hline $3-5$ & B & B-C & C & D & E \\
\hline $5-6$ & C & C-D & D & D & D \\
\hline$>6$ & C & D & D & D & D \\
\hline
\end{tabular}

La intensidad de la "turbulencia afecta, esencialmente, al valor del gradiente térmico medio del aire, que en la troposfera es de $0,6{ }^{\circ} \mathrm{C} / 100 \mathrm{~m}$. En efecto, los movimientos de difusión turbulenta se traducen en rupturas y zig-zags en la curva de estado o curva de la estructura térmica vertical de la troposfera en cada momento y lugar”' (Quereda, 2005: 54).

De este modo, la diferencia entre el gradiente adiabático seco y el gradiente térmico real de cada día (curva de estado) puede utilizarse para definir la clase de estabilidad y, por ello, para conocer la intensidad de la turbulencia y sus efectos sobre la dispersión de contaminantes gaseosos en la atmósfera.

5 "Por desgracia, Pasquill cometió un lapsus terminológico al llamar "stability classes" a sus categorías. Lo que el método pretende, y en buena parte logra, es estimar el poder dispersor de la atmósfera, que tiene alguna relación (aunque no unívoca) con su estabilidad estática y ninguna con la estabilidad hidrodinámica. Se debe evitar, pues, hablar de estabilidad en este contexto, aunque tal inexactitud está ampliamente difundida" (Puigcerver y Carrascal, 2008: 135).

Página $\mid 78$ 


\section{TIPOS DE PENACHOS EN FUNCIÓN DE LA ESTRATIFICACIÓN ATMOSFÉRICA}

Como ya se ha mencionado anteriormente, la dispersión de los contaminantes gaseosos de un penacho emitido por una chimenea se va a producir en la capa geográfica o de fricción. Capa que viene caracterizada por dos parámetros básicos: el gradiente vertical de temperatura y el gradiente vertical de velocidad del viento.

\section{III.I. El gradiente vertical de temperatura: $\partial \mathrm{T} / \partial \mathrm{z}$}

La dispersión vertical de los contaminantes gaseosos está condicionada por las variaciones que experimenta la temperatura a medida que ascendemos en la atmósfera. En función del gradiente térmico que tengamos cada día, el aire puede resultar estable, actuando por tanto en contra de la dispersión y la disolución de contaminantes o, por el contrario, será inestable dando lugar a una rápida mezcla vertical de los contaminantes y mejorando por ello la calidad del aire.

Este gradiente se produce como consecuencia de complejas interacciones producidas por factores meteorológicos que caracterizan a la troposfera inferior. Generalmente se produce una disminución de la temperatura con la altura (gradiente de signo negativo), de manera que cuanto mayor sea este gradiente térmico con respecto al gradiente adiabático $\operatorname{seco}^{6}\left(\sim 1^{\circ} \mathrm{C} / 100\right.$ m) mayor será la inestabilidad atmosférica y viceversa. Sin embargo, existen situaciones en las que la temperatura aumenta con la altitud (gradiente de signo positivo), es lo que se conoce como inversión térmica (Fig. 54). Como ya se ha visto en los capítulos anteriores, estas situaciones son de especial importancia en el estudio de la dispersión de contaminantes ya que limitan la circulación vertical de éstos. Ello determina un mayor impacto ambiental de las emisiones gaseosas contaminantes producidas bajo estas circunstancias.

${ }^{6}$ Siempre que una porción de aire seco ascienda o descienda en la atmósfera, experimentará una variación de temperatura de $1{ }^{\circ} \mathrm{C}$ por cada 100 metros, independientemente de cuál sea su temperatura inicial o de la temperatura del aire circundante. Este gradiente de temperatura es lo que se conoce como gradiente adiabático seco $\left(\partial \mathrm{T} / \partial \mathrm{z}\right.$ aire $\left.\mathrm{seco}=\Gamma_{\mathrm{S}} \sim 1^{\circ} \mathrm{C} / 100 \mathrm{~m}\right)$ 


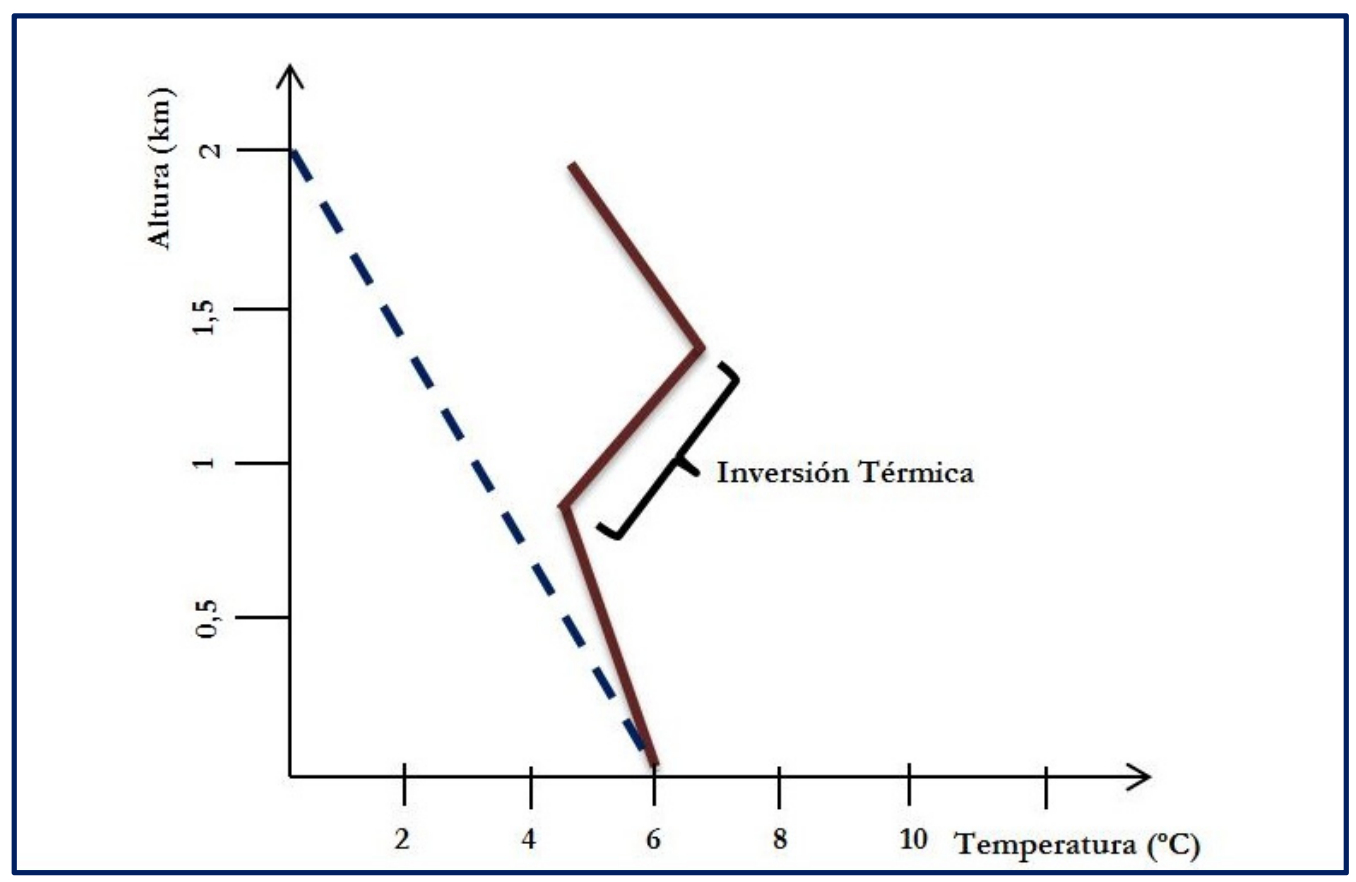

Figura 54: Curva de estado con inversión térmica. Fuente: elaboración propia, Laboratorio de Climatología de la Universitat Jaume I.

Así, dependiendo de la estratificación atmosférica, podemos clasificar los diferentes tipos de penacho en cuatro grupos significativos (Puigcerver y Carrascal, 2008; Espert y López, 1998; De Visscher, 2013; Beychok, 2005 y Quereda, 2005):

1. Penacho en atmósfera inestable: Las condiciones de inestabilidad por lo general favorecen la dispersión de contaminantes, minimizando a su vez el impacto ambiental de las emisiones contaminantes. La inestabilidad absoluta tiene lugar cuando el gradiente de temperatura real $\left(\Gamma_{\mathrm{t}}\right)$ es superior al gradiente adiabático seco $\left(\Gamma_{\mathrm{s}}=1{ }^{\circ} \mathrm{C} / 100 \mathrm{~m}\right)$. De esta manera, cualquier parcela de aire (o de gas contaminante) que ascienda en la atmósfera se enfriará más lentamente que el aire que la rodea. Así, a una altura determinada, la parcela de aire ascendente permanecerá más caliente (menos densa) que el aire a su alrededor por lo que continuará ascendiendo. En estas circunstancias, la dispersión vertical de los contaminantes hacia capas altas de la atmósfera se favorece, formándose un penacho ascendente y serpenteante (debido a la turbulencia del aire) (Fig. 55). 


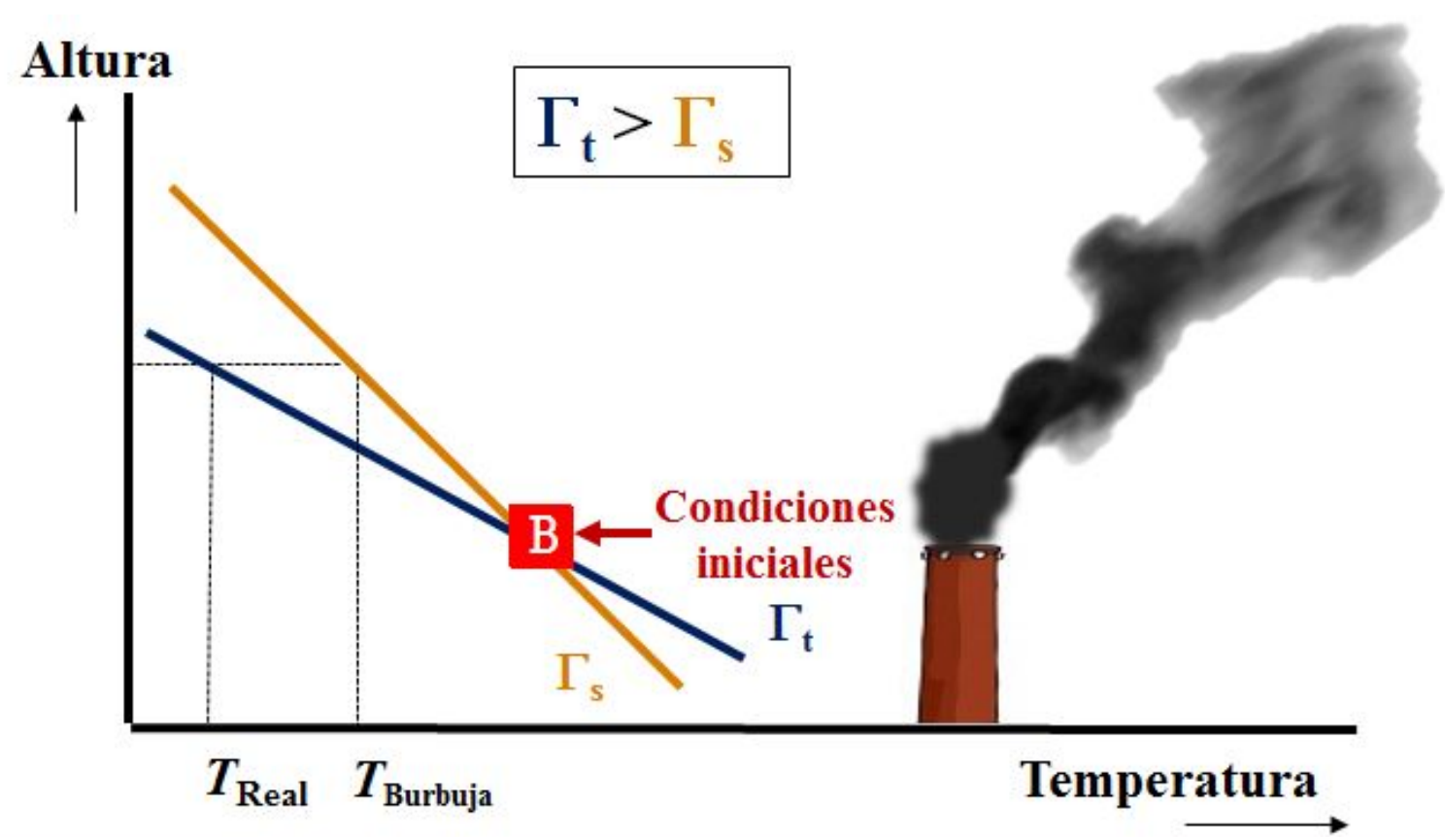

Figura 55: Penacho serpenteante ascendente en condiciones de inestabilidad. Fuente: elaboración propia, Laboratorio de Climatología de la Universitat Jaume I.

2. Penacho en atmósfera estable: Tiene lugar cuando el gradiente térmico real (curva de estado, $\left.\Gamma_{\mathrm{t}}\right)$ es inferior al gradiente adiabático seco $\left(\Gamma_{\mathrm{s}}=1{ }^{\circ} \mathrm{C} / 100 \mathrm{~m}\right)$. Concretamente, "se considera que, atendidos hechos térmicos, las condiciones atmosféricas resultan de estabilidad absoluta cuando el gradiente real o gradiente térmico estático en la vertical registra valor inferior a $0,5{ }^{\circ} \mathrm{C} / 100 \mathrm{~m}$ " (Gil y Olcina, 1997: 137). En estos casos de estabilidad absoluta, cualquier parcela de aire que ascienda se enfriará más rápidamente que el aire que la rodea de manera que, a una altura determinada, su temperatura será inferior al aire de su alrededor por lo que, al ser más densa, tenderá a descender a la altura del punto de origen. Estas situaciones dificultan la dispersión vertical de los contaminantes emitidos por chimeneas, formando un penacho tubular que puede extenderse a grandes distancias del foco emisor (Fig. 56). 


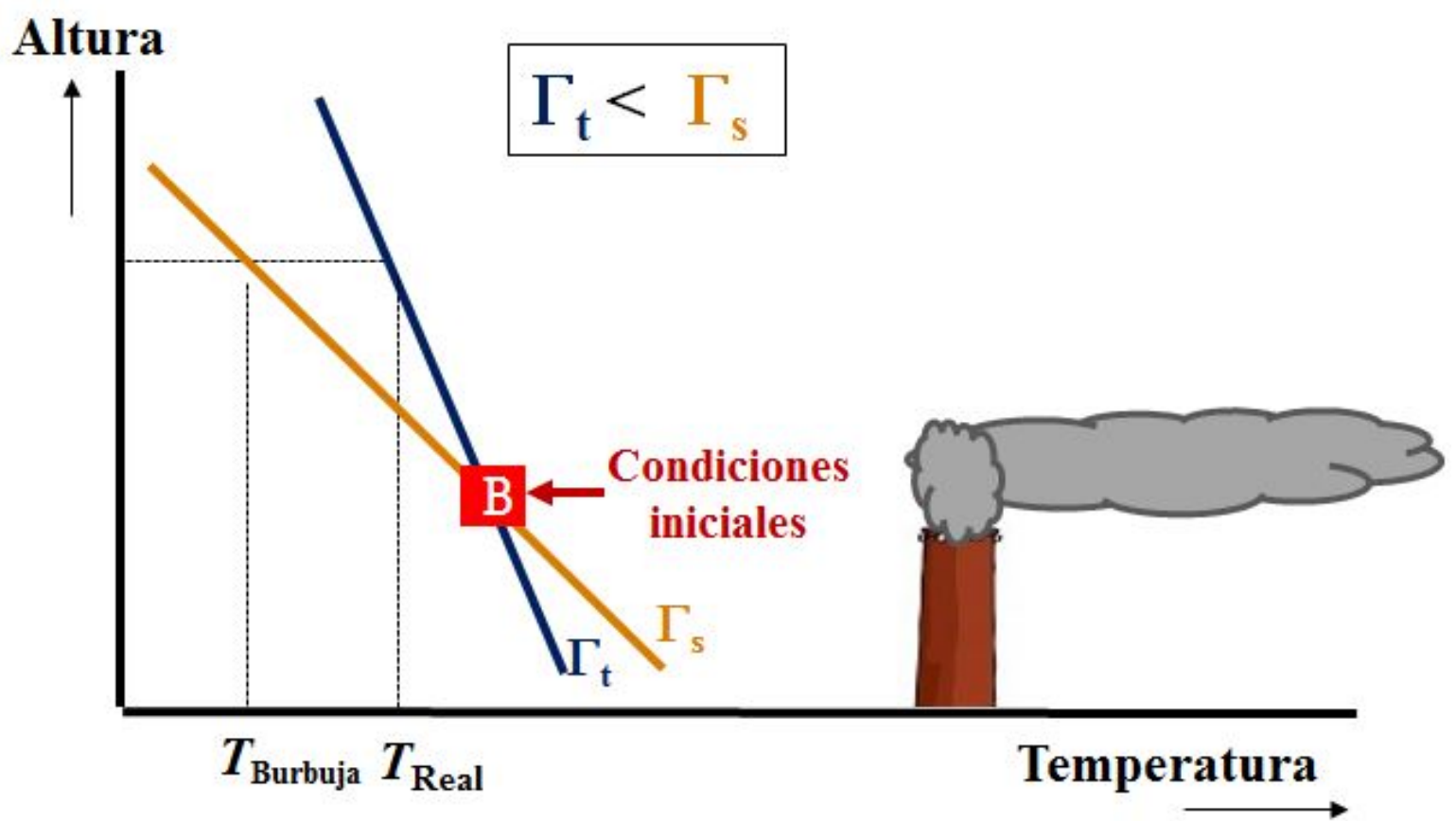

Figura 56: Penacho tubular en condiciones de estabilidad. Fuente: elaboración propia, Laboratorio de Climatología de la Universitat Jaume I.

En este punto de nuestro análisis conviene destacar la existencia de situaciones de estabilidad o inestabilidad relativas o condicionadas. "A diferencia de la estabilidad o inestabilidad absolutas, la estabilidad o inestabilidad relativas no pueden deducirse de la sola referencia al gradiente térmico estático en la vertical; para llegar a conclusiones se hace preciso examinar el juego conjunto del gradiente térmico estático en la vertical $\left(\Gamma_{\mathrm{t}}\right)$ y de los gradientes dinámicos, ya sea el adiabático $\left(\Gamma_{\mathrm{s}}\right)$ o el pseudoadiabático $\left(\Gamma_{\mathrm{h}}\right)$, o la sucesión de ambos” (Gil y Olcina, 1997: 138). Así pues, en estas situaciones la dispersión y morfología del penacho pueden ser modificadas a tenor de la magnitud de la razón de mezcla y de la dinámica aérea. Esta combinación de factores puede determinar que el nivel de condensación ascendente (NCA/LCLP) se sitúe en niveles bajos y que la relación de gradientes se establezca entre el gradiente adiabático húmedo o saturado $\left(\Gamma_{\mathrm{h}}\right)$ y el gradiente térmico real $\left(\Gamma_{\mathrm{t}}\right)$. "En este caso la evolución atmosférica, su estabilidad o inestabilidad, vendrá asociada a la humedad relativa existente ya que la condensación es un proceso muy desestabilizador. En efecto, una partícula de aire que al ascender alcanzase la saturación e incorporase el calor liberado por la condensación, seguiría enfriándose según la adiabática saturada con menor gradiente que la adiabática seca" (Quereda, 2005: 71). De este modo, si tras la condensación el gradiente térmico real $\left(\Gamma_{\mathrm{t}}\right)$ se sitúa a la izquierda del gradiente adiabático húmedo $\left(\Gamma_{\mathrm{h}}\right)$, la inestabilidad ascendente se manifiesta y se produce lo que se conoce como inestabilidad relativa. Es decir, Página | 82 
en estas situaciones si el aire está seco habrá estabilidad, pero si llega a alcanzar la saturación las condiciones serán de inestabilidad. "En suma, las situaciones de estabilidad relativa se plantean cuando el gradiente en la vertical $\left(\Gamma_{\mathrm{t}}\right)$ conoce valores entre $0,5^{\circ} \mathrm{C} / 100 \mathrm{~m}$ y $1{ }^{\circ} \mathrm{C} / 100 \mathrm{~m}$ " (Gil y Olcina, 1997: 138)(Fig. 57).

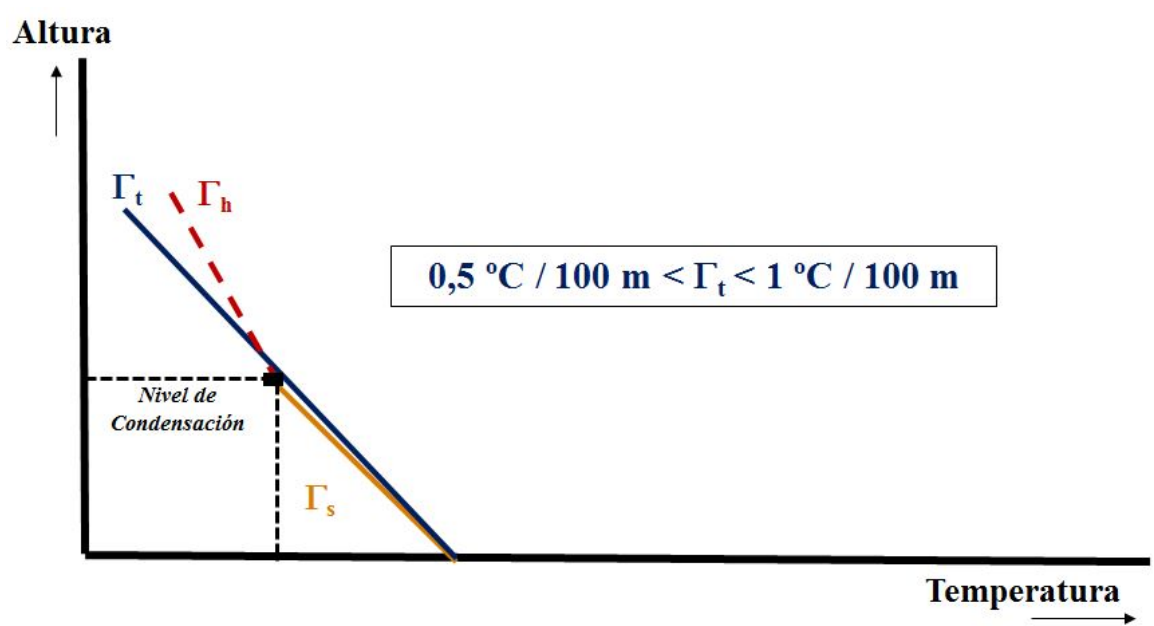

Figura 57: Condiciones de estabilidad relativa. Fuente: elaboración propia, Laboratorio de Climatología de la Universitat Jaume I.

3. Penacho en condiciones de estabilidad neutra o indiferente: Tiene lugar cuando el gradiente térmico real (curva de estado, $\left.\Gamma_{\mathrm{t}}\right)$ es igual al gradiente adiabático seco $\left(\Gamma_{\mathrm{s}}\right)$. En estos casos una parcela de aire que se vea obligada a ascender por cualquier causa se enfriará en la misma medida que el aire que la rodea. Así, la dispersión vertical no se verá ni favorecida ni suprimida, dando lugar a un penacho con una morfología cónica (Fig. 58).

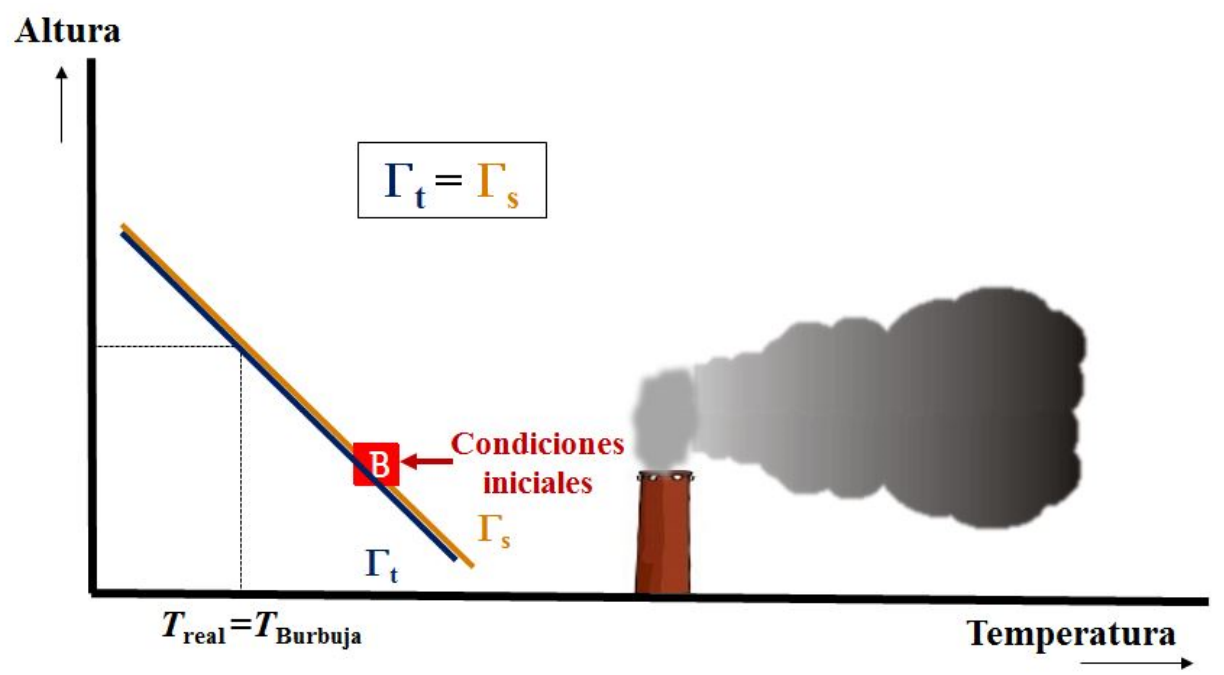

Figura 58: Penacho cónico en condiciones neutras. Fuente: elaboración propia, Laboratorio de Climatología de la Universitat Jaume I. 
4. Penacho en condiciones de inversión térmica: Tiene lugar cuando el gradiente térmico real (curva de estado, $\Gamma_{\mathrm{t}}$ ) es positivo, es decir, la temperatura del aire aumenta con la altura y se consideran situaciones de extrema estabilidad atmosférica. En estos casos, la diferencia entre el gradiente térmico real $\left(\Gamma_{\mathrm{t}}\right)$ y el gradiente adiabático seco $\left(\Gamma_{\mathrm{s}}\right)$ es tan grande que la dispersión vertical de contaminantes queda prácticamente anulada, por lo que se magnifica en gran medida el impacto ambiental de las emisiones contaminantes de chimeneas (Hufty, 1984). Se forma una especie de "tapadera" que bloquea el movimiento ascendente de los contaminantes gaseosos e impide su dispersión vertical. Así, “todo penacho que entre en una capa de inversión tiende a quedarse contenido en el interior de dicha capa y experimentará muy poca dispersión a menos que posea suficiente empuje para penetrar y atravesar la capa de inversión" (Beychok, 2005: 12). Este tipo de situaciones provocan la acumulación de contaminantes a nivel de superficie y crean situaciones de alarma y alto riesgo medioambiental. Existen diversos tipos de inversiones térmicas de los cuales podemos destacar:

4.1. Inversión térmica por radiación o de superficie (inversiones bajas): causadas por el enfriamiento nocturno de la superficie terrestre. Al enfriarse la superficie de la Tierra también lo hacen las capas de aire que se encuentran en contacto con ella. Así, la temperatura de estas capas de aire inferiores es más fría que la de las capas superiores por lo que se crea una inversión térmica. La característica principal de este tipo de inversiones es que suelen tener lugar en las noches claras de invierno, se producen cerca de la superficie terrestre y son de muy corta duración ya que al llegar la mañana tienden a desaparecer. Sin embargo, "conviene destacar que las inversiones térmicas no resultan sólo de mecanismos de superficie, como los citados, o incluso de contacto de una masa de aire con una corriente marina fría, sino que obedecen también a mecanismos de altitud; así, por ejemplo, la presencia de una cresta de aire tropical en niveles altos, o un fenómeno de subsidencia que crea línea de inversión” (Gil y Olcina, 1997: 133).

\subsection{Inversión térmica por subsidencia o hundimiento (inversiones altas): provocadas} por el calentamiento producido por la compresión de masas de aire que descienden en zonas de altas presiones (anticiclones). Las características de este tipo de inversiones las hacen más peligrosas desde el punto de vista medioambiental ya que, al contrario que las inversiones por radiación, éstas al ir asociadas a fenómenos anticiclónicos pueden

Página | 84 
durar días o incluso meses. Son más frecuentes en verano y, además, se producen a más altura por lo que muchas chimeneas contaminantes, incluso las altas como es el caso de la de la CT de Andorra, emiten por debajo de este tipo de capas de inversión. Una capa de inversión generalmente vinculada a la vecindad de la subsidencia tropical como consecuencia climática de la situación regional (Gil, 2009).

Consecuentemente, en este tipo de situaciones de inversión térmica es muy importante la altura de las chimeneas para poder predecir el impacto ambiental que producirán sus emisiones. De nuevo podemos encontrar dos situaciones muy diferentes:

\section{a) Chimeneas que emiten por encima de una capa de inversión térmica:}

Cuando la capa de inversión queda por debajo del foco emisor se crea una "barrera" que evita la caída de los contaminantes a la superficie terrestre y favorece considerablemente su dispersión hacia las capas altas de la atmósfera. Se forma un penacho de flotación o antifumigante, caracterizado por una capa de mezcla sobre la capa de inversión (Fig. 59). Tiene lugar cuando las condiciones son inestables sobre una capa de inversión, es decir, cuando el gradiente térmico pasa de positivo a negativo. En estos casos el impacto ambiental a nivel de superficie de las emisiones gaseosas se minimiza considerablemente.

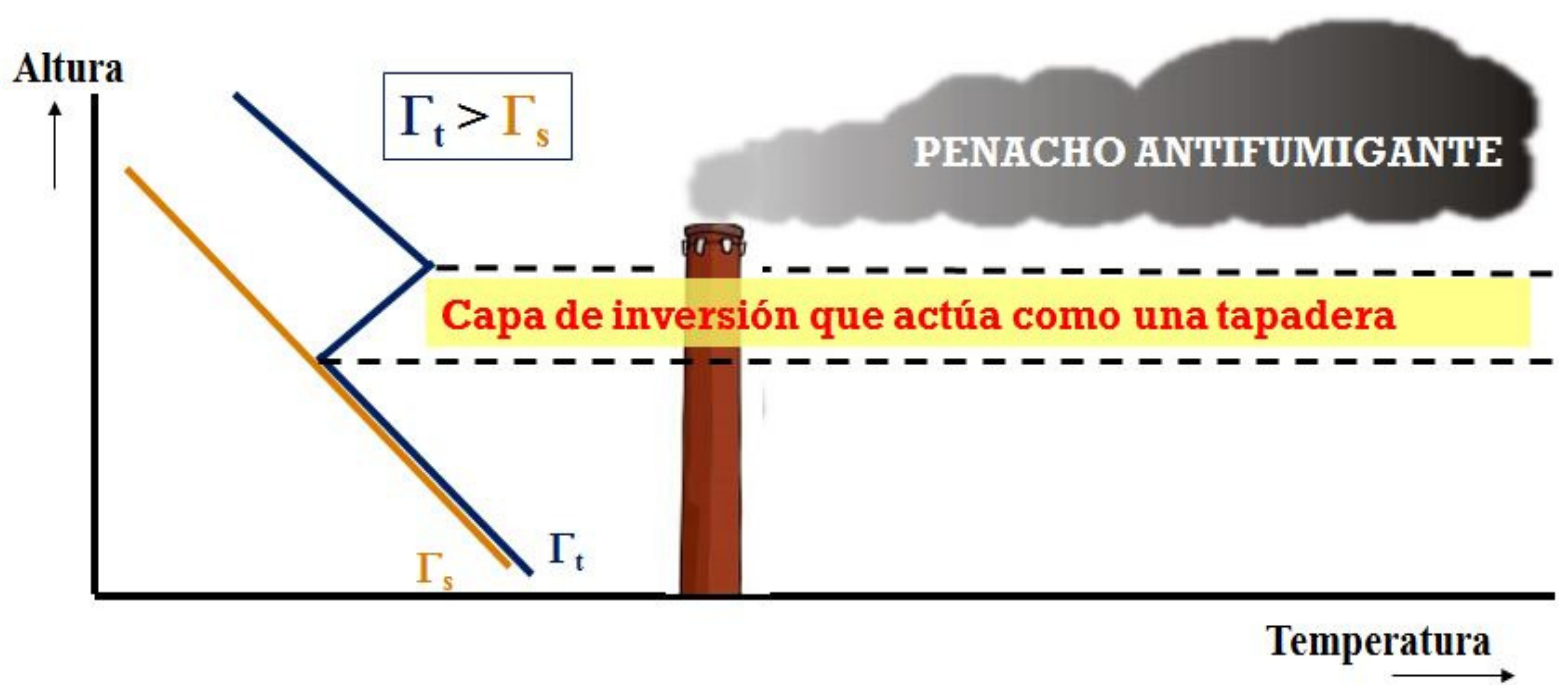

Figura 59: Penacho antifumigante emitido sobre una capa de inversión térmica. Fuente: elaboración propia, Laboratorio de Climatología de la Universitat Jaume I. 


\section{b) Chimeneas que emiten por debajo de una capa de inversión térmica:}

La capa de inversión aparece en esta ocasión a más altura, formando una eficaz barrera que impide la dispersión de contaminantes en la atmósfera y favorece su deposición en el suelo. Este tipo de penacho recibe el nombre de fumigante. En estas situaciones es cuando se agudizan los problemas de lluvia ácida y contaminación de suelos, debido a la elevada concentración de contaminantes que queda retenida bajo la "tapadera" formada por la capa de inversión térmica (Fig. 60). Por este motivo, en los últimos años se ha insistido en la construcción de lo que se conoce como chimeneas altas ( $>100$ metros) para poder superar, en la medida de lo posible, los niveles de inversión térmica. Sin embargo, esta propuesta trae consigo ciertos inconvenientes ya que los contaminantes emitidos por este tipo de chimeneas de gran altura no siempre salvan la inversión. En estos casos los contaminantes pueden dispersarse horizontalmente a grandes distancias, provocando impactos ambientales inesperados en zonas muy alejadas del foco emisor tal y como acontece, ocasionalmente, en la región ibérica con las emisiones de la CT de Andorra.

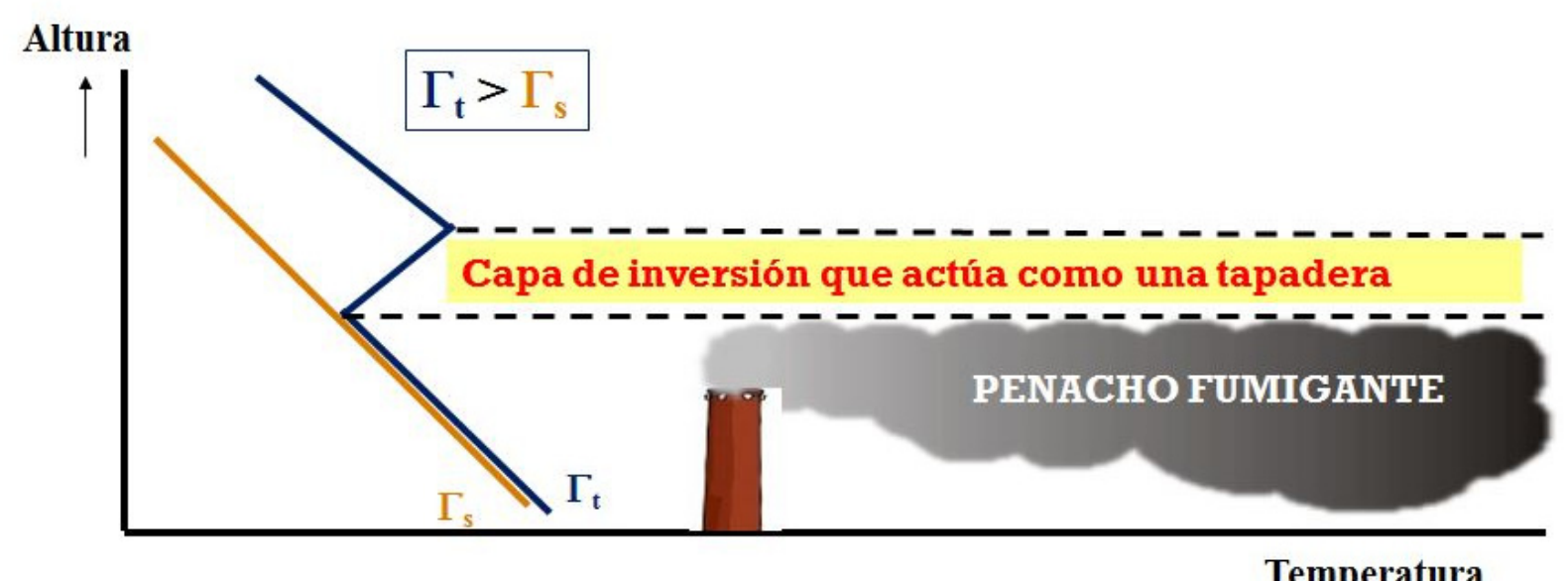

Figura 60: Penacho fumigante emitido bajo una capa de inversión térmica. Fuente: elaboración propia, Laboratorio de Climatología de la Universitat Jaume I.

En síntesis, y como se ha visto, las situaciones de inversión térmica son las más problemáticas ya que pueden provocar graves episodios de contaminación. La magnitud de su efecto sobre la dispersión de contaminantes dependerá de factores como:

- La altura de la capa de inversión respecto a la altura del foco de emisión de contaminantes.

Página | 86 
- El espesor de la capa de inversión.

- El gradiente de temperaturas existente entre la base y el vértice de la capa de inversión.

Como se ha visto, la diferencia entre el gradiente adiabático seco y el gradiente real de temperatura permite conocer el grado de turbulencia de la atmósfera. Por ello, dicho gradiente de temperatura puede ser empleado para definir las clases de estabilidad de Pasquill.

La figura 61 muestra las posibles condiciones atmosféricas, desde la inestabilidad hasta la extrema estabilidad (inversión térmica), así como su correspondencia con la clasificación del poder dispersor de la atmósfera de Pasquill.

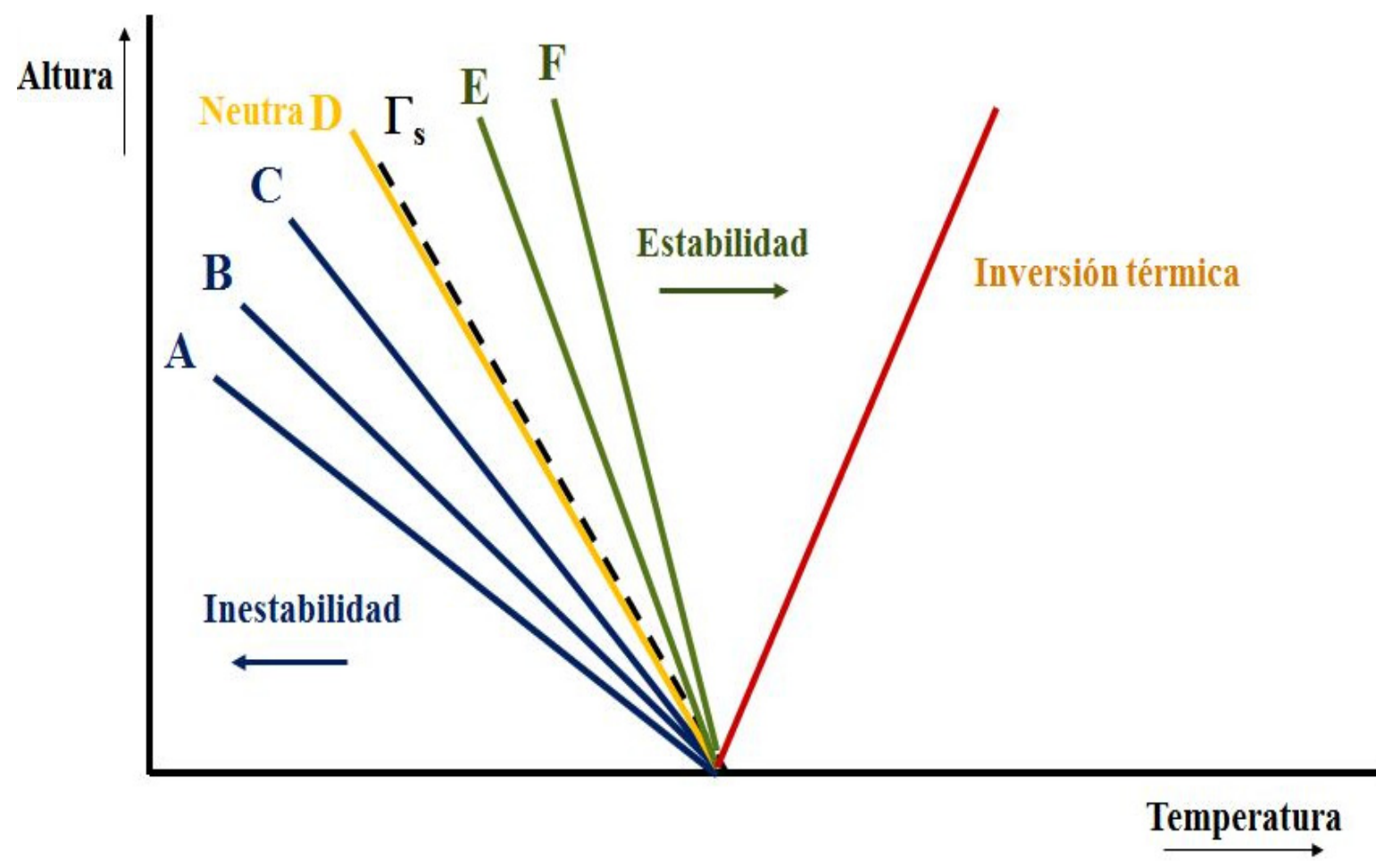

Figura 61: Diagrama termodinámico con los diferentes tipos de estabilidad atmosférica. Fuente: elaboración propia, Laboratorio de Climatología de la Universitat Jaume I.

\section{III.II. El gradiente vertical de velocidad del viento: $\partial u / \partial z$}

La velocidad del viento está íntimamente relacionada tanto con la dilución de contaminantes en un penacho como con la altura que alcanza éste al ser emitido por la boca de la chimenea. Así, a mayor velocidad del viento tendremos una menor elevación, provocando 
que el penacho se sitúe más cercano al suelo y produciendo así impactos ambientales más intensos y a más corta distancia del foco emisor.

Resulta evidente que lo más adecuado sería disponer de medidas reales del viento a la altura de la boca de la chimenea. No obstante, esto no suele ocurrir y habitualmente disponemos de los valores de anemómetros situados en niveles inferiores a la altura real de la emisión. Por ello es necesaria la utilización de un método generalizado que permita obtener una correlación entre la velocidad del viento y la altitud, es decir un perfil de velocidades del viento.

La determinación de la forma del perfil de velocidades del viento resulta de nuevo una tarea compleja, debido a que depende de diversos factores como la estratificación atmosférica (grado de turbulencia) y la rugosidad del terreno (rozamiento con la superficie terrestre) (Davenport, 1963). Como tendencia general, los vientos de altura poseen una velocidad mayor que los vientos a nivel de superficie. En otras palabras, la velocidad del viento, por lo general, aumenta con la altitud (Fig. 62).

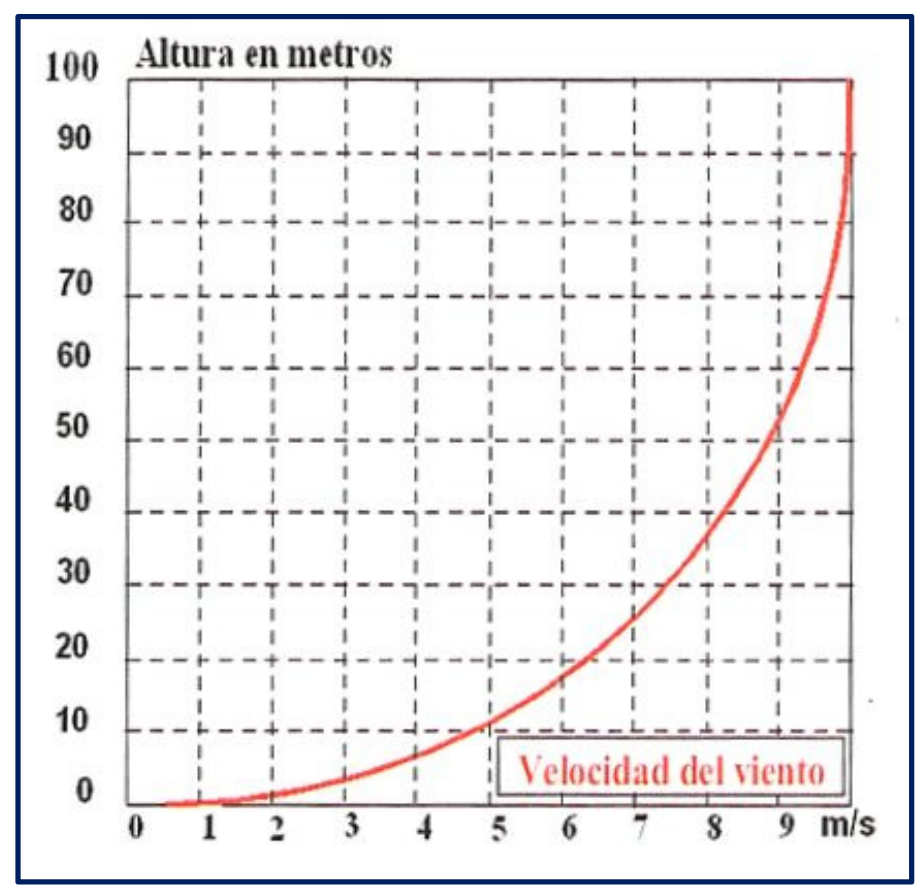

Figura 62: Gradiente medio de la velocidad del viento con la altura. Fuente: Quereda et al., 2012: 56.

De nuevo en la bibliografía encontramos diversas vías para llevar a cabo este cálculo. En el presente trabajo de investigación emplearemos el ajuste potencial empírico propuesto por Hellmann en 1915, ya que es el más empleado en meteorología de la contaminación. Así 
tenemos que la velocidad del viento, a la altura de la boca de la chimenea, será (Villarrubia, 2012):

$$
U_{h}=U_{10}\left(\frac{H}{10}\right)^{n}
$$

Donde:

$\mathrm{U}_{\mathrm{h}}=$ velocidad del viento en la boca de la chimenea.

$\mathrm{U}_{10}=$ velocidad del viento a 10 metros de altura.

$\mathrm{H}=$ altura de la chimenea

El exponente $\mathrm{n}$ es función de la estratificación atmosférica y de la rugosidad del terreno. $\mathrm{Al}$ ser un exponente obtenido experimentalmente aparece en la bibliografía con valores ligeramente diferentes. En el presente estudio se adoptará la clasificación formulada por Irwin en 1979 que emplea las siete categorías atmosféricas propuestas por Pasquill. Éstas resultan de gran utilidad a la hora de realizar los cálculos de la velocidad del viento en función de la altura geométrica de la chimenea objeto de estudio. Los valores de n en función de las clases de estabilidad y de la rugosidad del terreno aparecen en la tabla 5.

Tabla 5: Valores de n. Fuente: Puigcerver y Carrascal, 2008: 131.

Clase Estabilidad Pasquill-Gifford

\begin{tabular}{|c|c|c|c|c|c|c|}
\hline Entorno & A & B & C & D & E & F \\
\hline Urbano (rugosidad grande) & 0,15 & 0,15 & 0,20 & 0,25 & 0,40 & 0,60 \\
\hline Rural (rugosidad pequeña) & 0,07 & 0,07 & 0,10 & 0,15 & 0,35 & 0,55 \\
\hline
\end{tabular}




\section{CÁlCULO DE LA SOBREELEVACIÓN DEL PENACHO DE HUMOS EN UNA CHIMENEA}

El cálculo de la sobreelevación del penacho de humos en una chimenea constituye un tema central en todos los procesos de contaminación atmosférica. Un tema complejo, ya que para calcular la concentración de contaminantes en zonas más o menos alejadas del foco de emisión es imprescindible tener en cuenta diversos factores no siempre bien conocidos. En estos cálculos, el primer paso, y de especial relevancia, es determinar la sobreelevación del penacho de humos emitido por la chimenea. Dicha sobreelevación viene determinada por la diferencia existente entre la altura efectiva de la chimenea $\mathrm{H}_{\mathrm{e}}$ (altura a la cual el penacho adquiere una disposición horizontal) y su altura geométrica H (Fig. 63). Así:

$$
\mathrm{H}+\Delta \mathrm{H}=\mathrm{H}_{\mathrm{e}}
$$

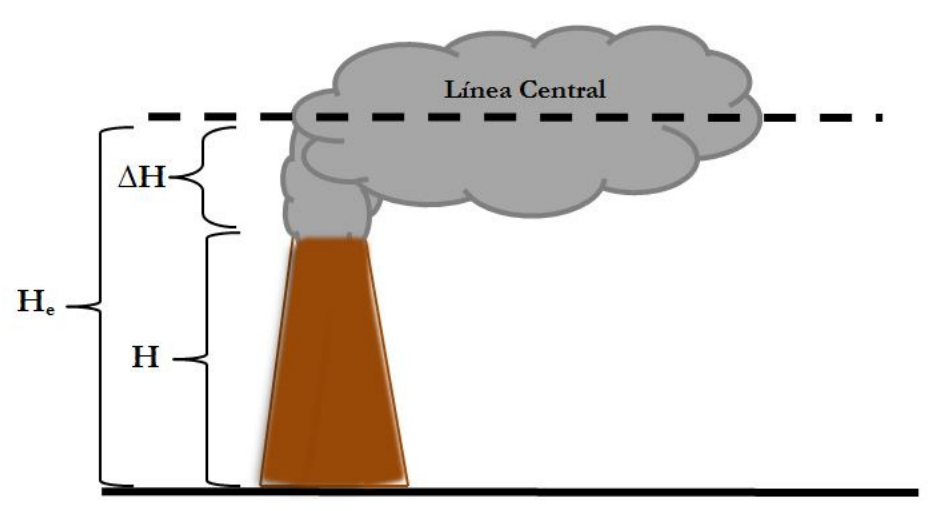

Figura 63: Esquema sobreelevación del penacho. Fuente: elaboración propia, Laboratorio de Climatología de la Universitat Jaume I.

Esta diferencia de alturas es debida fundamentalmente a dos factores (Oliver, 2015):

- La diferencia de temperaturas entre los gases emitidos (generalmente más cálidos) y el aire ambiente (elevación por flotabilidad).

- La diferencia entre la velocidad de salida de los gases emitidos y la velocidad del viento (elevación por empuje). 
Factores convectivos que condicionan las tres fases claramente diferenciadas que aparecen en la evolución de un penacho (Espert y López, 1998):

Fase 1: El penacho asciende de manera prácticamente vertical, debido fundamentalmente a la propia velocidad de salida con la que es expulsado de la chimenea y a su diferencia de temperatura con el aire que lo rodea. A medida que los gases ascienden van perdiendo temperatura y velocidad hasta alcanzar unas condiciones de presión y temperatura similares a las del aire ambiente. Por ello, el impulso que les hace ascender también disminuye llegando así a la segunda fase del penacho.

Fase 2 (transición): El penacho se curva paulatinamente, hasta adquirir una morfología progresivamente horizontal, como consecuencia de la acción del viento y de la pérdida del empuje de salida inicial.

Fase 3: El penacho es dominado por el aire ambiente y carece, por tanto, de movimiento propio. Su dispersión y morfología dependen en este caso de las características del flujo de aire que lo arrastra. Es en esta fase cuando adquieren especial importancia las condiciones atmosféricas (capas de inversión térmica, velocidad del viento, estratificación atmosférica...) así como los obstáculos mecánicos cercanos a la fuente de emisión (edificios, accidentes orográficos...).

Sintetizando todo lo tratado en este capítulo, podemos resumir en la tabla 6 el conjunto de variables que afectan al cálculo de la sobreelevación del penacho de humos emitido por una chimenea y, por tanto, al cálculo de la concentración de contaminantes en un determinado punto más o menos alejado del foco de emisión.

Tabla 6: Resumen de las variables que afectan al cálculo de la sobreelevación del penacho. Fuente: elaboración propia, Laboratorio de Climatología de la Universitat Jaume I.

\begin{tabular}{|c|c|c|}
$\begin{array}{c}\text { Características del foco } \\
\text { emisor }\end{array}$ & $\begin{array}{c}\text { Características de la } \\
\text { chimenea }\end{array}$ & $\begin{array}{c}\text { Características } \\
\text { meteorológicas y } \\
\text { topográficas de la zona }\end{array}$ \\
\hline Caudal de gases emitidos & $\begin{array}{c}\text { Altura geométrica de la } \\
\text { chimenea }\end{array}$ & Velocidad del viento \\
\hline \multirow{2}{*}{$\begin{array}{c}\text { Tamaño y porcentaje de las } \\
\text { partículas emitidas }\end{array}$} & $\begin{array}{c}\text { Tiro disponible en la chimenea } \\
\text { gases en la boca de la chimenea }\end{array}$ & Temperatura del aire exterior \\
\cline { 2 - 3 } & $\begin{array}{c}\text { Diámetro de salida de la } \\
\text { chimenea }\end{array}$ & $\begin{array}{c}\text { Características topográficas } \\
\text { (rugosidad, obstáculos, etc.) }\end{array}$ \\
\hline
\end{tabular}




\section{IV.I. Aproximación semiempírica al cálculo de la sobreelevación de un penacho}

Como ya se ha visto, existen multitud de parámetros que influyen directamente en la trayectoria y sobreelevación de un penacho y esto hace extremadamente complicado el cálculo teórico de su valor.

En la bibliografía existen más de un centenar de fórmulas y modelos tanto teóricos como empíricos para realizar estos cálculos, dando resultados generalmente muy discrepantes. Las primeras expresiones utilizadas para calcular la sobreelevación del penacho de humos de una chimenea datan de 1950 y fueron desarrolladas por Bosanquet, Carey y Halton (Bosanquet et al., 1950). Es en los últimos 30 años cuando más progresos se han realizado en este tipo de modelización. No obstante, no existe un consenso claro sobre qué método o autor ofrece mejores resultados. De todas las expresiones existentes para el cálculo de la sobreelevación de emisiones calientes, las más utilizadas son las siguientes (Espert y López, 1998):

Fórmula de Concawe (Brummage et al., 1966)

$$
\Delta H=5,53 \cdot \frac{Q_{H}^{1 / 2}}{U_{H}^{3 / 4}}
$$

Donde:

$\mathrm{Q}_{\mathrm{H}}=$ Potencia calorífica de la emisión $(\mathrm{Mw})$

$\mathrm{U}_{\mathrm{h}}=$ Velocidad del viento a la altura de la boca de la chimenea $(\mathrm{m} / \mathrm{s})$

Esta expresión, basada en un método de regresión múltiple, fue obtenida mediante la realización de experiencias en una central de potencia reducida y con mediciones de sobreelevación del penacho inferiores a 500 metros. Por ello los resultados que se obtienen al aplicarla son más fiables cuando se estudian casos de baja sobreelevación (<200 metros), apareciendo márgenes de error superiores a medida que aumenta dicha sobreelevación. Este modelo consiguió bastante aceptación en Europa, especialmente en la industria del petróleo. 
Fórmula de Lucas, Moore y Spurr (Lucas et al., 1963)

$$
\Delta H=\alpha \cdot \frac{Q_{H}^{1 / 4}}{U_{H}}
$$

El coeficiente $\alpha$ depende de la altura de la chimenea de manera que:

$$
\alpha=475+(2 / 3) \cdot(\mathrm{H}-100)
$$

Esta expresión, desarrollada a partir de medidas experimentales realizadas en dos centrales térmicas del Reino Unido, posee en este país una elevada aceptación.

\section{Fórmula de Briggs simplificada}

En 1965 Briggs realizó un profundo estudio de los diferentes modelos y expresiones existentes para cálculo de la sobrelevación del penacho de humos de una chimenea (Briggs, 1965). Así, tras varios años, es en 1969 cuando publicó su primer modelo conocido como "las ecuaciones de Briggs" (Briggs, 1969). Las expresiones inicialmente propuestas fueron modificadas posteriormente por el propio autor en 1971 y en 1972. De este modo surgieron las que hoy se conocen como "fórmulas de Briggs generalizadas" (Briggs, 1972, 1973 y 1974) y que han conseguido una gran aceptación hasta el punto de ser las recomendadas tanto por la EPA (Environmental Protection Agency) como por la administración española. Por ello estas expresiones serán la que se empleen posteriormente en los cálculos de la sobrelevación del penacho de humos emitido por la CT de Andorra.

La expresión original de Briggs fue obtenida mediante el análisis de las mediciones experimentales realizadas en 15 focos de emisión diferentes y de ella se obtiene la sobreelevación del penacho en función de la distancia $\mathrm{x}$, medida horizontalmente respecto del foco emisor.

$$
\Delta H=3,24 \cdot x^{2 / 3} \frac{Q_{H}^{1 / 3}}{U_{H}}
$$


Para poder calcular la sobrelevación máxima que alcanza el penacho de humos emitido por una chimenea debemos establecer la distancia $\mathrm{x}_{\mathrm{m}}$ a la cual termina la sobreelevación y el penacho queda estabilizado. Así tenemos dos alternativas a la hora de realizar los cálculos (Espert y López, 1998):

Fórmula de Briggs I, donde $\mathrm{x}_{\mathrm{m}}=2000$ metros que se corresponde con la distancia a la que se efectuaron las mediciones de Briggs:

$$
\Delta H=514,32 \cdot \frac{Q_{H}^{1 / 3}}{U_{H}}
$$

Fórmula de Briggs II, que considera que la distancia a la cual se alcanza la máxima sobreelevación es igual a diez veces la altura de la chimenea $\left(\mathrm{x}_{\mathrm{m}}=10 \cdot \mathrm{H}\right)$ :

$$
\Delta H=15,04 \cdot H^{2 / 3} \frac{Q_{H}^{1 / 3}}{U_{H}}
$$

Como se puede apreciar, ninguna de las expresiones reseñadas tiene en cuenta el tipo de situación atmosférica que, como ya se ha señalado anteriormente, es un factor que influye considerablemente en la sobreelevación del penacho y por ello en la dispersión de los contaminantes emitidos. Para minimizar este importante error, y como ya se ha mencionado, Briggs llevó a cabo durante varios años una serie de revisiones y modificaciones de sus ecuaciones. Así, en 1972, llegó a obtener una expresión generalizada en la que se tiene en consideración los distintos tipos de atmósfera y que, por tanto, ofrece resultados más exactos.

\section{IV.II. Fórmula de Briggs generalizada}

Para la obtención de las expresiones de Briggs generalizadas para cada tipo de estratificación atmosférica (Hanna et al., 1982; Briggs, 1975; Briggs, 1982; Puigcerver y Carrascal, 2008 y Espert y López, 1998) se introducirá el factor de flotabilidad F. Este factor es equivalente a la potencia calorífica $\mathrm{Q}_{\mathrm{H}}$, empleada en la fórmula simplificada, y representa la flotabilidad propia de los gases emitidos como consecuencia de la velocidad de salida y la diferencia de temperatura con el aire ambiente. 
Dicho factor se expresa de la siguiente manera:

$$
F\left(m^{4} / s^{3}\right)=g V_{s} \frac{D_{s}^{2}}{4} \frac{T_{s}-T_{a}}{T_{s}}
$$

Donde:

$\mathrm{g}=$ aceleración de la gravedad

$\mathrm{V}_{\mathrm{s}}=$ velocidad de salida de los gases

$\mathrm{T}_{\mathrm{s}}=$ temperatura de salida de los gases

$\mathrm{T}_{\mathrm{a}}=$ temperatura ambiente

$\mathrm{D}_{\mathrm{s}}=$ diámetro interior de la boca de la chimenea

Para poder considerar los efectos de la estratificación atmosférica y así tener en cuenta cómo afecta la turbulencia atmosférica a la sobreelevación del penacho, se define el parámetro de estabilidad S:

$$
S\left(s^{-2}\right)=\frac{g}{T_{a}}\left(\Gamma+\frac{\partial T}{\partial z}\right)
$$

Donde:

$\mathrm{g}=$ aceleración de la gravedad

$\mathrm{T}_{\mathrm{a}}=$ temperatura ambiente

$\Gamma=$ Gradiente adiabático seco

$\partial \mathrm{T} / \partial \mathrm{z}=$ Gradiente térmico real

Es importante destacar que el signo del gradiente de temperatura indica si la atmósfera es estable o inestable. Sin embargo, "para el cálculo del parámetro de estabilidad debe emplearse el valor absoluto de este gradiente, ya que las expresiones de Briggs emplean raíces cuadradas y cubicas que no podrían resolverse si dicho parámetro fuera negativo" (Beychok, 2005: 105). 
Una vez definidos los parámetros anteriores, Briggs establece las siguientes expresiones generales para el cálculo de la sobrelevación máxima del penacho de humos en función de las condiciones atmosféricas:

\section{Atmósfera inestable o neutra (Clases de estabilidad A-D):}

Las expresiones propuestas por Briggs en función del valor del parámetro de flotabilidad en condiciones atmosféricas inestables o neutras son:

$$
\begin{aligned}
& \text { Si } \mathrm{F}<55 \mathrm{~m}^{4} \mathrm{~s}^{-3} \Rightarrow \mathrm{x}_{\mathrm{m}}=49 \cdot \mathrm{F}^{5 / 8} \Rightarrow \Delta H=21,43 \frac{F^{\frac{3}{4}}}{U_{h}} \\
& \text { Si F } \geq 55 \mathrm{~m}^{4} \mathrm{~s}^{-3} \Rightarrow \mathrm{x}_{\mathrm{m}}=119 \cdot \mathrm{F}^{2 / 5} \Rightarrow \Delta H=38,7 \frac{F^{\frac{3}{5}}}{U_{h}}
\end{aligned}
$$

\section{Atmósfera estable con viento (Clases de estabilidad E-F):}

Para condiciones atmosféricas estables con viento Briggs propone la siguiente expresión:

$$
\Delta H=2,6\left(\frac{F}{U_{h} S}\right)^{1 / 3}
$$

\section{Atmósfera estable con viento en calma $\left(U_{h}<1 \mathrm{~m} / \mathrm{s}\right)($ Clases de estabilidad E-F):}

Para condiciones atmosféricas estables con viento en calma, en las que el penacho asciende verticalmente hasta que se anula su fuerza ascensional, Briggs propone emplear la siguiente expresión:

$$
\Delta H=5,0 \frac{F^{1 / 4}}{S^{3 / 8}}
$$




\section{IV.III. Aplicación y verificación de las expresiones} generalizadas de Briggs para el cálculo de la sobreelevación del penacho de la CT de Andorra

Las expresiones generalizadas propuestas por Briggs para el cálculo de la sobreelevación del penacho se han aplicado a diferentes situaciones reales. Con ello se pretende contrastar y, en su caso, corroborar los resultados obtenidos teóricamente con imágenes fotográficas tomadas in situ en las cercanías de la propia CT de Andorra.

Para la realización de los cálculos se han empleado los siguientes parámetros básicos de emisión de la chimenea de la CT de Andorra (Tabla 7):

Tabla 7: Parámetros de la fuente de emisión. Fuente: datos proporcionados por la CT de Andorra.

\begin{tabular}{|c|c|}
\hline \multicolumn{2}{|c|}{ Parámetros característicos de la chimenea } \\
\hline $\mathbf{V}_{\mathbf{s}}$ & $26,4 \mathrm{~m} / \mathrm{s}$ \\
\hline $\mathbf{T}_{\mathbf{s}}$ & $348 \mathrm{~K}$ \\
\hline $\mathbf{D}_{\mathbf{s}}$ & $9,54 \mathrm{~m}$ \\
\hline $\mathbf{H}$ & $343 \mathrm{~m}$ \\
\hline
\end{tabular}

La primera de las situaciones analizadas corresponde al 15 de diciembre del 2013. Durante esta jornada el registro del radiosondeo de Zaragoza aeropuerto ofrecía los siguientes parámetros meteorológicos necesarios para la aplicación de las expresiones de Briggs (Tabla 8):

Tabla 8: Parámetros meteorológicos correspondientes a la jornada del 15 de diciembre del 2013. Datos extraídos del registro del radiosondeo de Zaragoza del 15 de diciembre del 2013 a las 12 horas. Fuente: http://weather.uwyo.edu/upperair/sounding.html.

\begin{tabular}{|c|c|}
\hline \multicolumn{2}{|c|}{ Parámetros meteorológicos } \\
\hline $\mathbf{T}_{\mathrm{a}}$ & $276 \mathrm{~K}$ \\
\hline $\mathbf{U}_{343}$ & $3 \mathrm{~m} / \mathrm{s}$ \\
\hline$\partial \mathbf{T} / \partial \mathbf{z}$ & $0,003^{\circ} \mathrm{C} / \mathrm{m}$ \\
\hline
\end{tabular}

Bajo estas condiciones atmosféricas, el factor de flotabilidad (Exp. 16) y el parámetro de estabilidad (Exp. 17) se pueden calcular de la siguiente manera:

$$
\begin{gathered}
F=g V_{s} \frac{D_{s}^{2}}{4} \frac{T_{s}-T_{a}}{T_{s}}=9,8 \cdot 26,4 \cdot \frac{9,54^{2}}{4} \cdot \frac{348-276}{348}=1217,9 \mathrm{~m}^{4} / \mathrm{s}^{3} \\
S=\frac{g}{T_{a}}\left(\Gamma+\frac{\partial T}{\partial z}\right)=\frac{9,8}{276}(0,01+0,003)=0,00046 \mathrm{~s}^{-2}
\end{gathered}
$$


La situación atmosférica durante esta jornada era estable con viento, por lo que podemos calcular la sobreelevación del penacho de humos aplicando la expresión propuesta por Briggs (Exp. 20):

$$
\Delta H=2,6 \cdot\left(\frac{F}{U_{h} S}\right)^{1 / 3}=2,6 \cdot\left(\frac{1217,9}{3 \cdot 0,00046}\right)^{1 / 3}=249,4 \mathrm{~m}
$$

Esta sobreelevación se suma a la altura geométrica de la propia chimenea para calcular la altura efectiva de las emisiones.

$$
\mathrm{H}_{\mathrm{e}}=\mathrm{H}+\Delta \mathrm{H}=343+249,4=592,4 \mathrm{~m}
$$

En la figura 64 se muestra la evolución del penacho de humos durante dicha jornada.

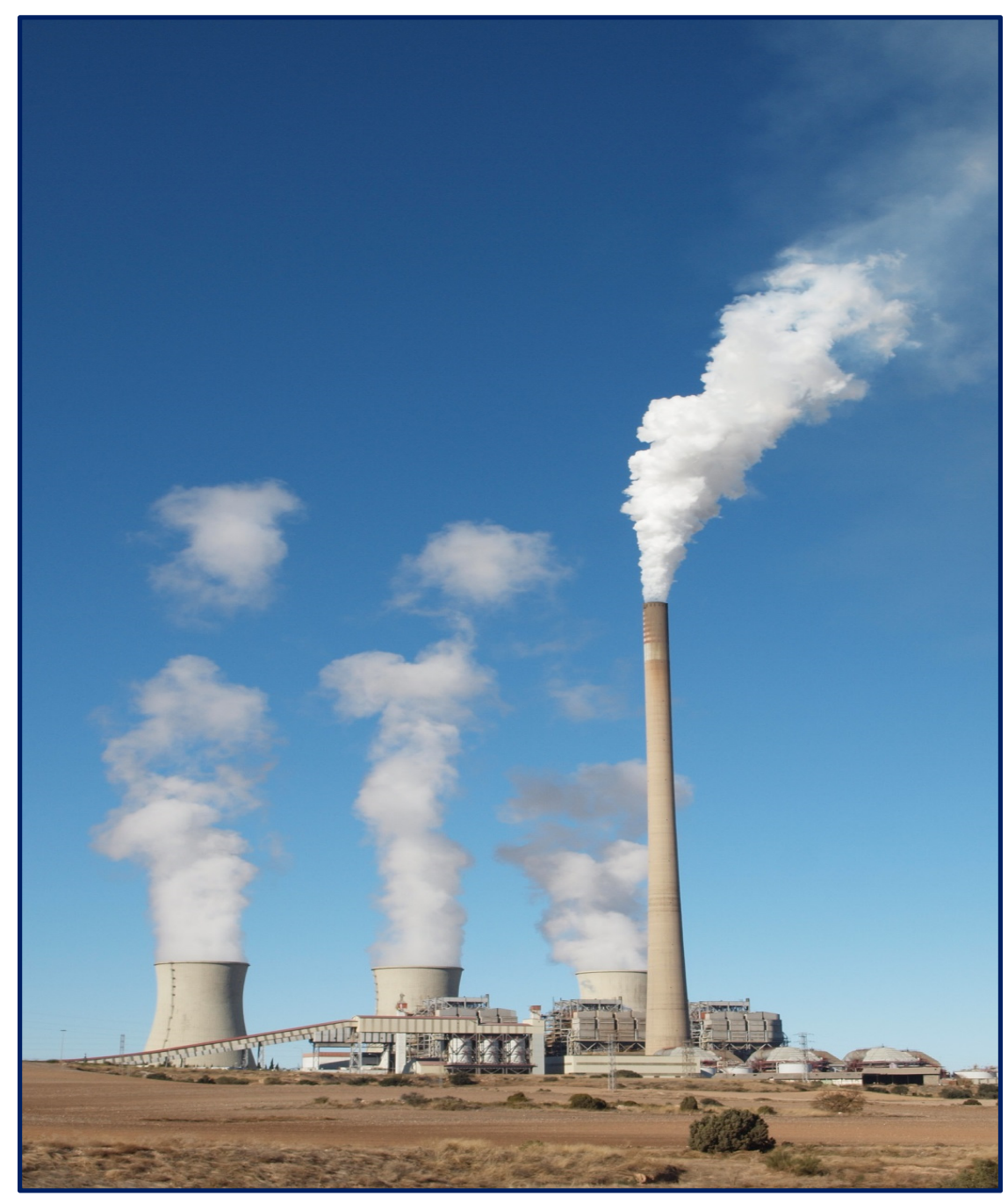

Figura 64: Sobreelevación del penacho de humos de la CT. Fuente propia, imagen tomada el 15 de diciembre del 2013 a las 12 horas.

Página | 98 
La imagen correspondiente a la evolución del penacho en la jornada del día 15 de diciembre del 2013 muestra una gran conformidad con los cálculos realizados. La sobreelevación del penacho o máximo ascenso provocado por el tirón termodinámico de salida de los gases, calculado mediante las expresiones de Briggs, alcanza un valor de aproximadamente 250 metros. Esta sobreelevación, junto con la altura geométrica de la propia chimenea (343 metros), hace que la altura efectiva de la fuente de emisión se sitúe cerca de los 600 metros sobre la superficie. Este nivel calculado de manera teórica es perfectamente apreciable en la imagen fotográfica tomada durante dicha jornada.

La siguiente situación analizada corresponde al 14 de diciembre del 2013. Los parámetros meteorológicos extraídos del registro del radiosondeo de Zaragoza aeropuerto se muestran en la tabla 9:

Tabla 9: Parámetros meteorológicos correspondientes a la jornada del 14 de diciembre del 2013. Datos extraídos del registro del radiosondeo de Zaragoza del 14 de diciembre del 2013 a las 12 horas. Fuente: http://weather.uwyo.edu/upperair/sounding.html.

\begin{tabular}{|c|c|}
\hline \multicolumn{2}{|c|}{ Parámetros meteorológicos } \\
\hline $\mathbf{T}_{\mathrm{a}}$ & $278 \mathrm{~K}$ \\
\hline $\mathbf{U}_{343}$ & $7 \mathrm{~m} / \mathrm{s}$ \\
\hline$\partial \mathbf{T} / \partial \mathbf{z}$ & $0,00036^{\circ} \mathrm{C} / \mathrm{m}$ \\
\hline
\end{tabular}

Con estos parámetros meteorológicos se calcula el factor de flotabilidad (Exp. 16) y el parámetro de estabilidad (Exp. 17):

$$
\begin{gathered}
F=g V_{s} \frac{D_{s}^{2}}{4} \frac{T_{s}-T_{a}}{T_{S}}=9,8 \cdot 26,4 \cdot \frac{9,54^{2}}{4} \cdot \frac{348-278}{348}=1184,1 \mathrm{~m}^{4} / \mathrm{s}^{3} \\
S=\frac{g}{T_{a}}\left(\Gamma+\frac{\partial T}{\partial z}\right)=\frac{9,8}{278}(0,01+0,00036)=0,00036 \mathrm{~s}^{-2}
\end{gathered}
$$

A continuación se calcula la sobreelevación del penacho de humos aplicando la expresión propuesta por Briggs para una situación atmosférica estable con viento (Exp. 20):

$$
\Delta H=2,6 \cdot\left(\frac{F}{U_{h} S}\right)^{1 / 3}=2,6 \cdot\left(\frac{1184,1}{7 \cdot 0,00036}\right)^{1 / 3}=202,1 \mathrm{~m}
$$

Finalmente se suma la altura geométrica de la chimenea con el fin de calcular la altura efectiva de las emisiones.

$$
\mathrm{H}_{\mathrm{e}}=\mathrm{H}+\Delta \mathrm{H}=343+202,1=545,1 \mathrm{~m}
$$


En la figura 65 se muestra la evolución del penacho de humos durante dicha jornada.

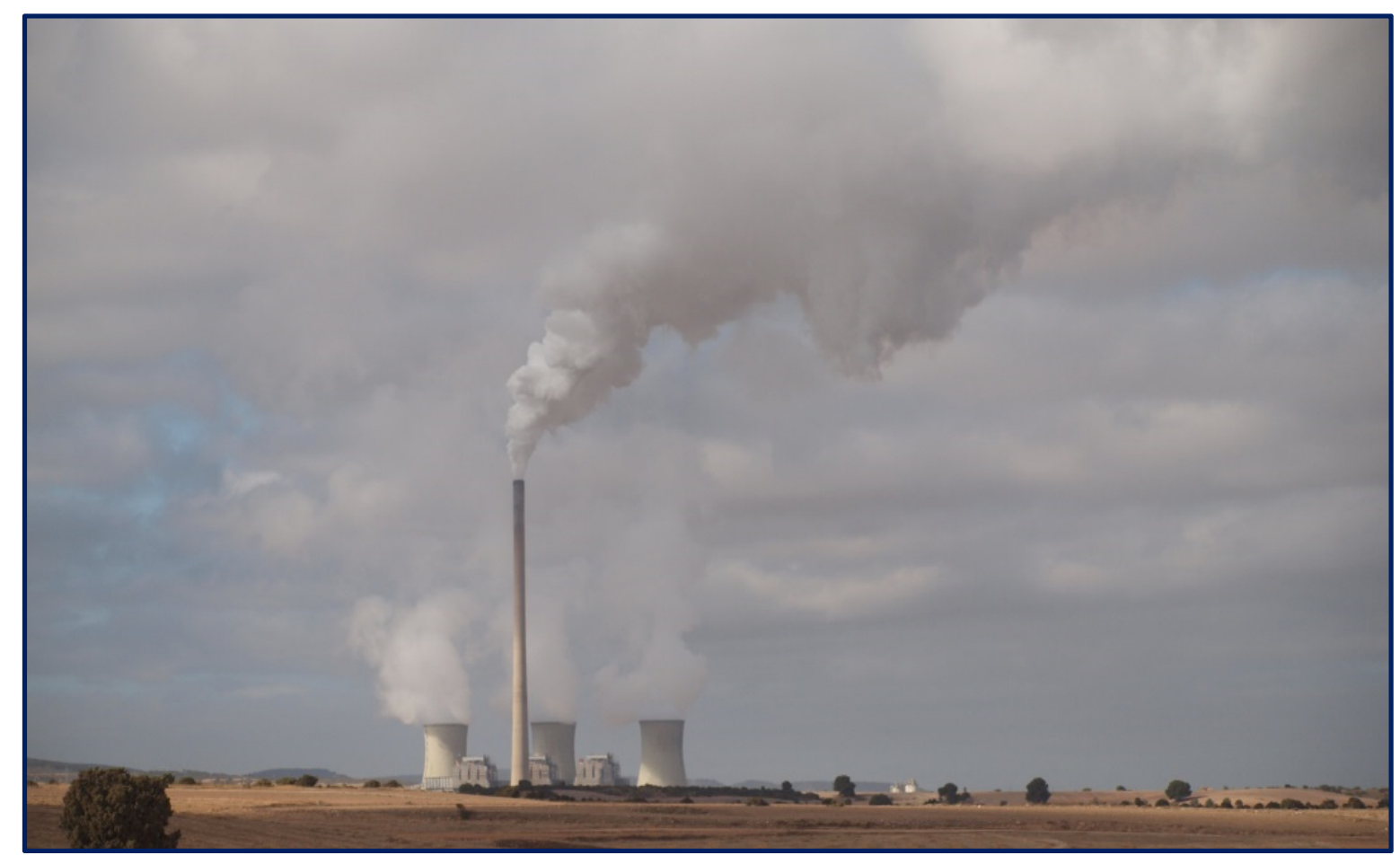

Figura 65: Sobreelevación del penacho de humos de la CT. Fuente propia, imagen tomada el 14 de diciembre del 2013 a las 12 horas.

Los cálculos de sobreelevación del penacho, en las horas centrales del día 14 de diciembre del 2013, se corresponden con la evolución reflejada en las imágenes fotográficas tomadas durante dicha jornada. La sobreelevación del penacho $(\Delta \mathrm{H})$ calculada mediante las expresiones de Briggs ofrece un valor de 202 metros sobre la boca de la chimenea. Ello determina que la altura efectiva de emisiones $\left(\mathrm{H}_{\mathrm{e}}\right)$ se sitúe a 541 metros sobre la superficie. A partir de ese nivel, el penacho se alinea con el viento dominante y se propaga con su misma dirección y velocidad. Durante su propagación, el penacho se abre como consecuencia de la turbulencia atmosférica y convectiva provocada al alcanzar el nivel del LCLP situado, como es bien visible en la imagen por el techo de nubosidad, a escasos metros 200 metros del nivel de emisión.

La siguiente situación analizada corresponde al 24 de octubre del 2015. Del registro del radiosondeo de Zaragoza aeropuerto se han tomado los parámetros meteorológicos de esta jornada (Tabla 10): 
Tabla 10: Parámetros meteorológicos correspondientes a la jornada del 24 de octubre del 2015. Datos extraídos del registro del radiosondeo de Zaragoza del 24 de octubre del 2015 a las 12 horas. Fuente: http://weather.uwyo.edu/upperair/sounding.html.

\begin{tabular}{|c|c|}
\hline \multicolumn{2}{|c|}{ Parámetros meteorológicos } \\
\hline $\mathbf{T}_{\mathbf{a}}$ & $287 \mathrm{~K}$ \\
\hline $\mathbf{U}_{343}$ & $1,5 \mathrm{~m} / \mathrm{s}$ \\
\hline$\partial \mathbf{T} / \partial \mathbf{z}$ & $0,0039^{\circ} \mathrm{C} / \mathrm{m}$ \\
\hline
\end{tabular}

Con estos datos se ha calculado el factor de flotabilidad (Exp. 16) y el parámetro de estabilidad (Exp. 17):

$$
\begin{gathered}
F=g V_{s} \frac{D_{s}^{2}}{4} \frac{T_{s}-T_{a}}{T_{s}}=9,8 \cdot 26,4 \cdot \frac{9,54^{2}}{4} \cdot \frac{348-287}{348}=1031,85 \mathrm{~m}^{4} / \mathrm{s}^{3} \\
S=\frac{g}{T_{a}}\left(\Gamma+\frac{\partial T}{\partial z}\right)=\frac{9,8}{287}(0,01+0,0039)=0,00047 \mathrm{~s}^{-2}
\end{gathered}
$$

Al tratarse de una situación atmosférica estable con viento se ha aplicado la expresión 20 propuesta por Briggs para obtener la sobreelevación del penacho de humos:

$$
\Delta H=2,6 \cdot\left(\frac{F}{U_{h} S}\right)^{1 / 3}=2,6 \cdot\left(\frac{1031,85}{1,5 \cdot 0,00047}\right)^{1 / 3}=295,2 \mathrm{~m}
$$

La altura efectiva de las emisiones se ha obtenido mediante la suma de la altura de la chimenea y la sobreelevación previamente calculada:

$$
\mathrm{H}_{\mathrm{e}}=\mathrm{H}+\Delta \mathrm{H}=343+295,2=638,2 \mathrm{~m}
$$

En la figura 66 se muestra la evolución del penacho de humos durante dicha jornada. 


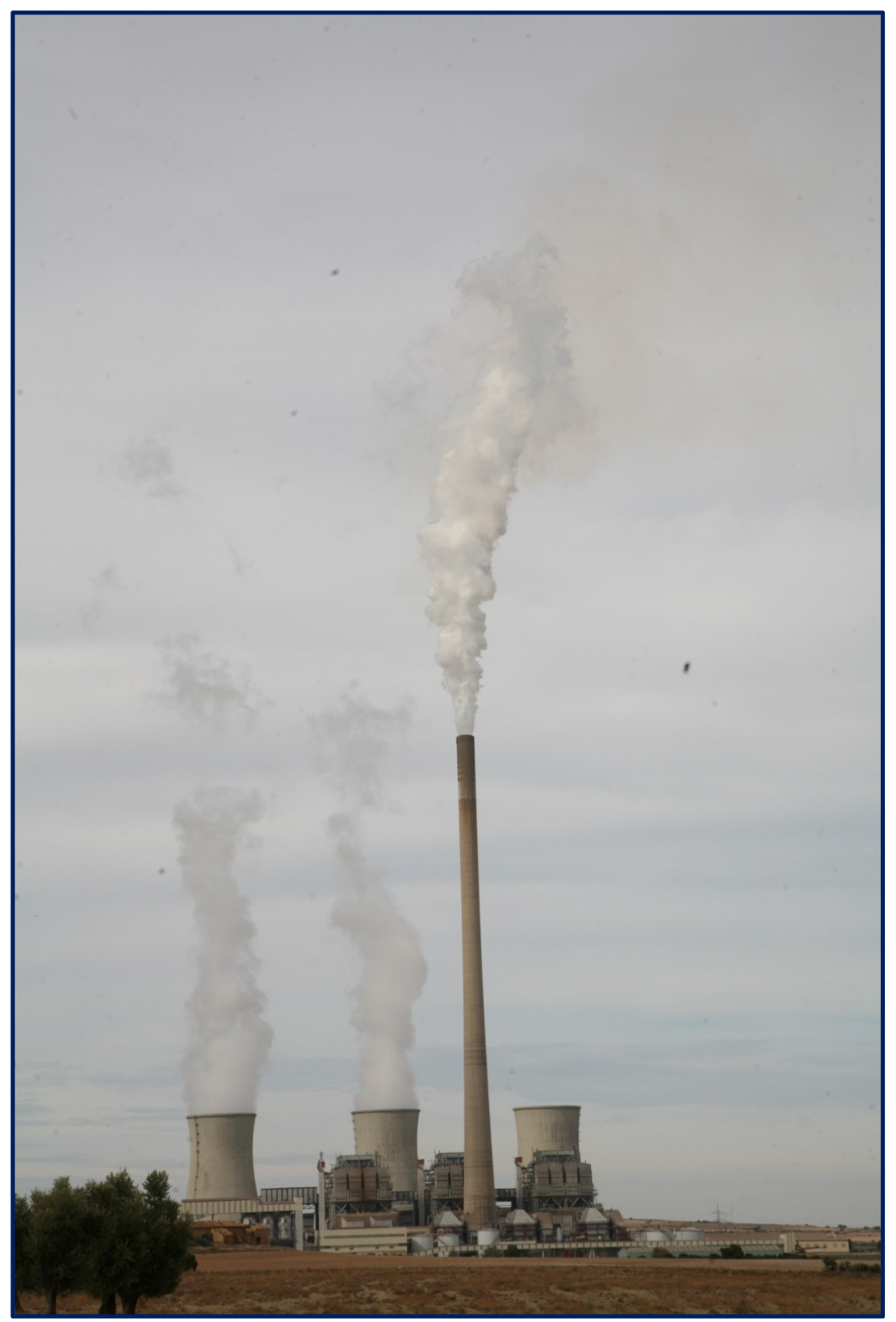

Figura 66: Sobreelevación del penacho de humos de la CT. Fuente propia, imagen tomada el 24 de octubre del 2015 a las 12 horas.

La notable sobreelevación $(\Delta \mathrm{H})$ obtenida mediante las expresiones de Briggs, próxima a los 300 metros, queda perfectamente reflejada en el gran ascenso vertical que puede apreciarse en la imagen fotográfica tomada durante la jornada del 24 de octubre del 2015. Esta elevación provocada como consecuencia del tirón termodinámico ofrece una altura efectiva de la chimenea $\left(\mathrm{H}_{\mathrm{e}}\right)$ de 638 metros sobre la superficie regional. Un nivel que sitúa la dispersión y difusión de contaminantes sobre el eje del viento dominante en un nivel notable de espesor de la capa de mezcla. 
La siguiente situación analizada corresponde al 25 de octubre del 2015. En la tabla 11 se sintetizan los parámetros meteorológicos extraídos del registro del radiosondeo de Zaragoza aeropuerto para esta jornada (Tabla 11):

Tabla 11: Parámetros meteorológicos correspondientes a la jornada del 25 de octubre del 2015. Datos extraídos del registro del radiosondeo de Zaragoza del 25 de octubre del 2015 a las 12 horas. Fuente: http://weather.uwyo.edu/upperair/sounding.html.

\begin{tabular}{|c|c|}
\hline \multicolumn{2}{|c|}{ Parámetros meteorológicos } \\
\hline $\mathbf{T}_{\mathbf{a}}$ & $284,4 \mathrm{~K}$ \\
\hline $\mathbf{U}_{343}$ & $2,5 \mathrm{~m} / \mathrm{s}$ \\
\hline$\partial \mathbf{T} / \partial \mathbf{z}$ & $0,007^{\circ} \mathrm{C} / \mathrm{m}$ \\
\hline
\end{tabular}

Bajo estas condiciones atmosféricas, el factor de flotabilidad (Exp. 16) y el parámetro de estabilidad (Exp. 17) se pueden calcular de la siguiente manera:

$$
\begin{gathered}
F=g V_{s} \frac{D_{s}^{2}}{4} \frac{T_{s}-T_{a}}{T_{s}}=9,8 \cdot 26,4 \cdot \frac{9,54^{2}}{4} \cdot \frac{348-284,4}{348}=1075,8 \mathrm{~m}^{4} / \mathrm{s}^{3} \\
S=\frac{g}{T_{a}}\left(\Gamma+\frac{\partial T}{\partial z}\right)=\frac{9,8}{284,4}(0,01+0,007)=0,00059 \mathrm{~s}^{-2}
\end{gathered}
$$

Aplicando la expresión propuesta por Briggs (Exp. 20) para situaciones atmosféricas estables con viento se puede calcular la sobreelevación del penacho de humos:

$$
\Delta H=2,6 \cdot\left(\frac{F}{U_{h} S}\right)^{1 / 3}=2,6 \cdot\left(\frac{1075,8}{2,5 \cdot 0,00059}\right)^{1 / 3}=234 \mathrm{~m}
$$

Esta sobreelevación se suma a la altura geométrica de la propia chimenea para calcular la altura efectiva de las emisiones.

$$
\mathrm{H}_{\mathrm{e}}=\mathrm{H}+\Delta \mathrm{H}=343+234=577 \mathrm{~m}
$$

En la figura 67 se muestra la evolución del penacho de humos durante dicha jornada. 


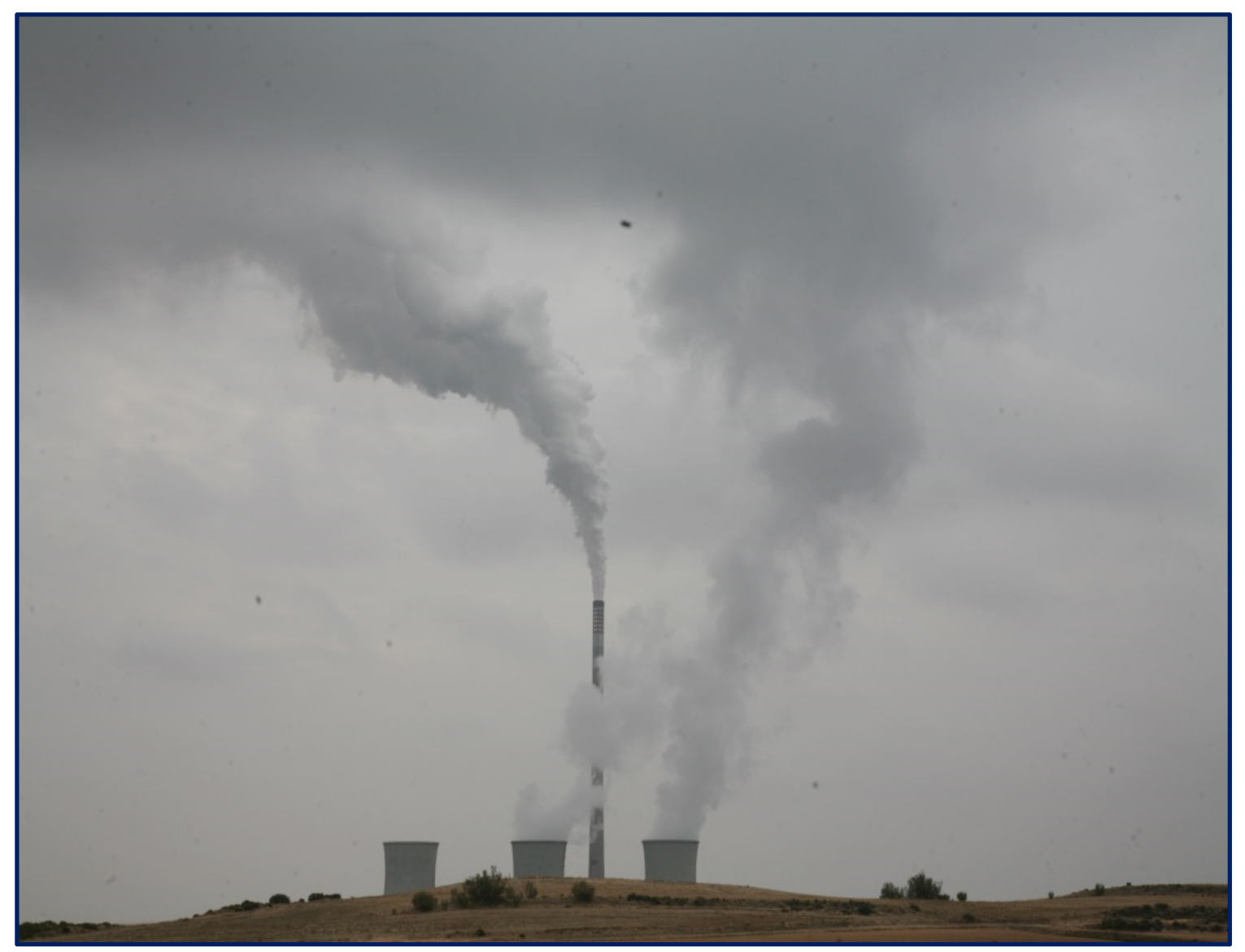

Figura 67: Sobreelevación del penacho de humos de la CT. Fuente propia, imagen tomada el 25 de octubre del 2015 a las 12 horas.

Las imágenes de evolución del penacho en la jornada del día 25 de octubre del 2015 son altamente expresivas de la significación de los cálculos teóricos realizados mediante la aplicación de las expresiones propuestas por Briggs. La sobreelevación provocada por el tirón termodinámico de salida de los gases $(\Delta \mathrm{H})$ alcanza un valor de 234 metros. Esta altura aparece nítidamente reflejada en la imagen de la evolución del penacho tomada durante dicha jornada. La altura efectiva $\left(\mathrm{H}_{\mathrm{e}}\right)$ durante esta jornada se situaría a 577 metros sobre la superficie. A partir de ese nivel, la evolución seguida se corresponde con la succión ascendente provocada por el nivel de condensación ascendente (NCA/LCLP) que limita la altura de la capa de mezcla en esos momentos. 
La siguiente situación analizada corresponde al 2 de septiembre del 2013. Los parámetros meteorológicos correspondientes a esta jornada se muestran en la tabla 12:

Tabla 12: Parámetros meteorológicos correspondientes a la jornada del 2 de septiembre del 2013. Datos extraídos del registro del radiosondeo de Zaragoza del 2 de septiembre del 2013 a las 12 horas. Fuente: http://weather.uwyo.edu/upperair/sounding.html.

\begin{tabular}{|c|c|}
\hline \multicolumn{2}{|c|}{ Parámetros meteorológicos } \\
\hline $\mathbf{T}_{\mathrm{a}}$ & $289,6 \mathrm{~K}$ \\
\hline $\mathbf{U}_{343}$ & $7 \mathrm{~m} / \mathrm{s}$ \\
\hline$\partial \mathbf{T} / \partial \mathbf{z}$ & $0,0004^{\circ} \mathrm{C} / \mathrm{m}$ \\
\hline
\end{tabular}

Para calcular la sobreelevación del penacho de humos, se ha calculado previamente el factor de flotabilidad (Exp. 16) y el parámetro de estabilidad (Exp. 17):

$$
\begin{gathered}
F=g V_{s} \frac{D_{s}^{2}}{4} \frac{T_{s}-T_{a}}{T_{s}}=9,8 \cdot 26,4 \cdot \frac{9,54^{2}}{4} \cdot \frac{348-289,6}{348}=987,87 \mathrm{~m}^{4} / \mathrm{s}^{3} \\
S=\frac{g}{T_{a}}\left(\Gamma+\frac{\partial T}{\partial z}\right)=\frac{9,8}{289,6}(0,01+0,0004)=0,00035 \mathrm{~s}^{-2}
\end{gathered}
$$

Tratándose de una situación estable con viento se ha calculado la sobreelevación del penacho de humos aplicando la expresión propuesta por Briggs para este tipo de condiciones atmosféricas (Exp. 20):

$$
\Delta H=2,6 \cdot\left(\frac{F}{U_{h} S}\right)^{1 / 3}=2,6 \cdot\left(\frac{987,87}{7 \cdot 0,00035}\right)^{1 / 3}=192,1 \mathrm{~m}
$$

Finalmente se ha calculado la altura efectiva de las emisiones:

$$
\mathrm{H}_{\mathrm{e}}=\mathrm{H}+\Delta \mathrm{H}=343+192,1=535,1 \mathrm{~m}
$$

En la figura 68 se muestra la evolución del penacho de humos a las 12 horas de dicha jornada. 


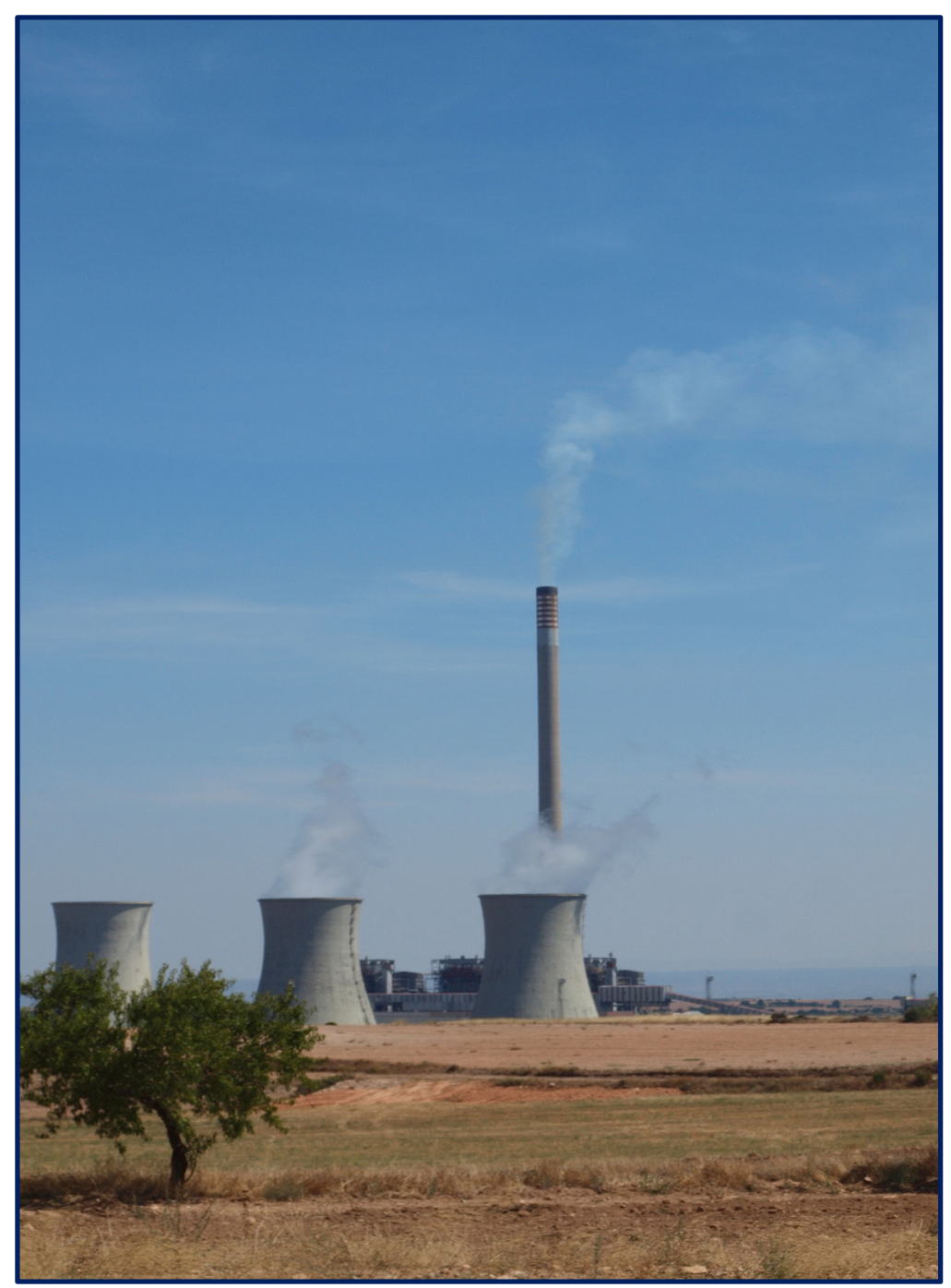

Figura 68: Sobreelevación del penacho de humos de la CT. Fuente propia, imagen tomada el 2 de septiembre del 2013 a las 12 horas.

La imagen fotográfica tomada en las inmediaciones de la CT permite verificar los cálculos realizados. En la figura 68 se aprecia nítidamente como el penacho asciende hasta un nivel aproximado de unos 200 metros, en coincidencia con el valor de 192 metros obtenido mediante la aplicación de las expresiones de Briggs. En la imagen también se puede apreciar como este ascenso, debido a la propia flotabilidad de los gases como consecuencia de su elevada temperatura y al empuje conferido por la propia chimenea, se detiene por encima de los 192 metros aproximadamente. En este momento el penacho pierde su tirón termodinámico inicial y empieza a regirse tanto por la velocidad como por la dirección del viento dominante. La sobreelevación alcanzada da lugar a una altura efectiva de emisión de 535 metros sobre la superficie. 


\section{MODELO GAUSSIANO DE DISPERSIÓN ATMOSFÉRICA DE CONTAMINANTES}

Una vez definidas las expresiones para el cálculo de la sobreelevación que alcanzará el penacho de humos emitido por una chimenea, en el presente apartado se abordará el cálculo de la concentración de contaminante que se obtendrá en un determinado punto más o menos alejado de la fuente emisora.

Los modelos gaussianos de dispersión atmosférica de contaminantes son los más comúnmente empleados en el campo de la contaminación atmosférica. Estos modelos ajustan la distribución tridimensional de concentraciones de contaminantes del penacho emitido por una fuente puntual a una gaussiana, de manera que la concentración máxima de contaminantes estará situada en el eje del penacho (Fig. 69 y Fig. 70).

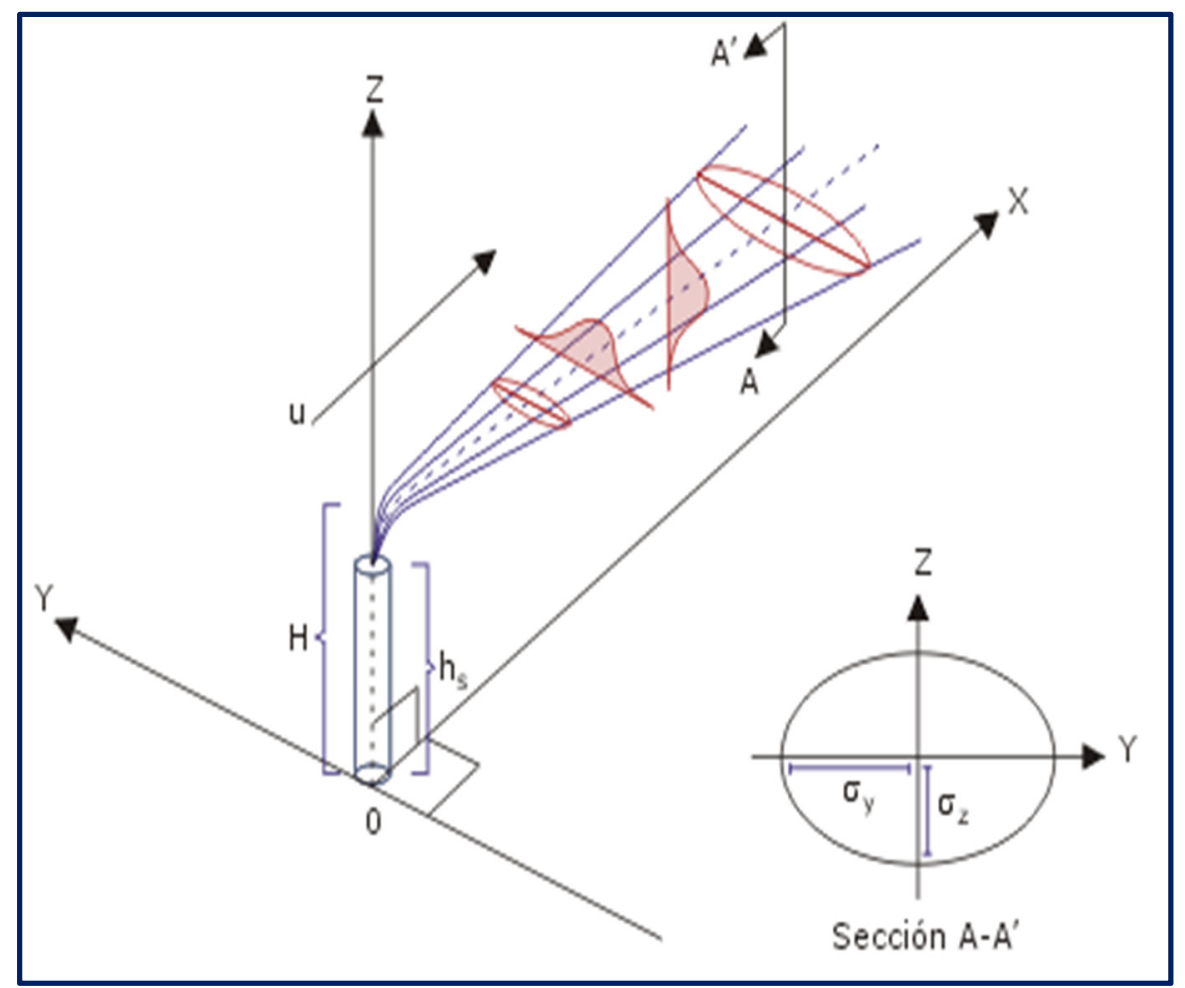

Figura 69: Esquema del modelo gaussiano de dispersión de contaminantes. Fuente: http://www.bvsde.paho.org/cursoa_meteoro/lecc6/lecc6_4.html. 


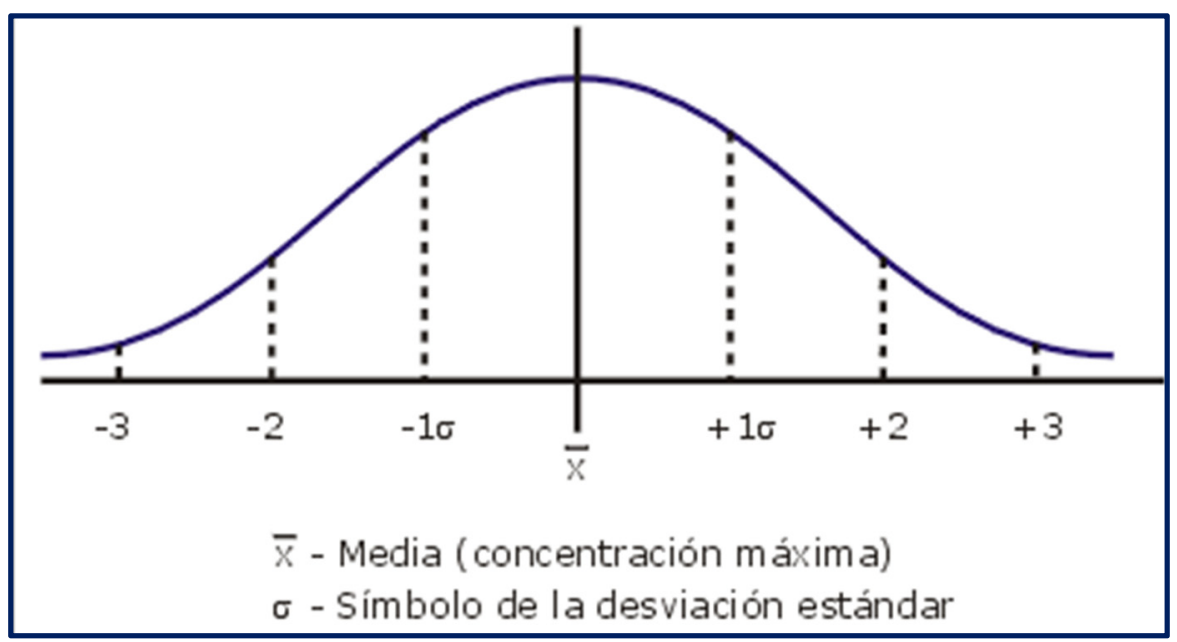

Figura 70: Distribución gaussiana. Fuente: http://www.bvsde.paho.org/cursoa_meteoro/lecc6/lecc6_4.html.

La expresión fundamental de estos modelos es la siguiente (Puigcerver y Carrascal, 2008; Beychok, 2005; Espert y López, 1998 y Briggs, 1982):

$$
C(x, y, z)=\frac{G}{2 \pi \sigma_{y} \sigma_{z} u_{h}} \exp \left(-\frac{y^{2}}{2 \sigma_{y}^{2}}\right) \exp \left(-\frac{z^{2}}{2 \sigma_{z}^{2}}\right)
$$

Donde:

$\mathbf{C}(\mathbf{x}, \mathbf{y}, \mathbf{z})=$ Concentración en el punto de coordenadas $(\mathrm{x}, \mathrm{y}, \mathrm{z})$, suponiendo un eje de coordenadas con origen en el $(0,0,0)$ y el eje x siguiendo la dirección del viento medio (u).

$\mathbf{G}=$ Caudal másico de contaminante emitido.

$\mathbf{U}_{\mathbf{h}}=$ Velocidad del viento en la boca de la chimenea.

$\boldsymbol{\sigma}_{\boldsymbol{y}} \boldsymbol{y} \boldsymbol{\sigma}_{\boldsymbol{z}}=$ Desviaciones estándar de las distribuciones gaussianas de concentraciones en el penacho según el eje y y z respectivamente.

Las condiciones que presupone el modelo teórico para las cuales es aplicable la expresión anterior son:

- Condiciones meteorológicas estacionarias

- Turbulencia atmosférica homogénea

- Vientos medios constantes y superiores a $2 \mathrm{~m} / \mathrm{s}$ 
Dentro de los diferentes modelos de dispersión gaussianos que se han desarrollado a lo largo del tiempo, el más ampliamente utilizado es sin duda el modelo propuesto por Pasquill en 1959 (Pasquill, 1979 y Pasquill y Smith, 1983) y será, por tanto, el empleado en los cálculos posteriores del presente capítulo.

\section{V.I. Modelo de Pasquill para la dispersión de} contaminantes emitidos por una fuente puntual

La expresión anterior considera una fuente emisora situada en el origen de coordenadas $(0,0,0)$. No obstante, y como ya hemos mencionado, se debe considerar también tanto la altura real de la chimenea como la sobreelevación experimentada por el penacho.

Por ello se deben adaptar las fórmulas al nuevo origen de coordenadas $\left(0,0, \mathrm{H}_{\mathrm{e}}\right)$ (Fig. 71).

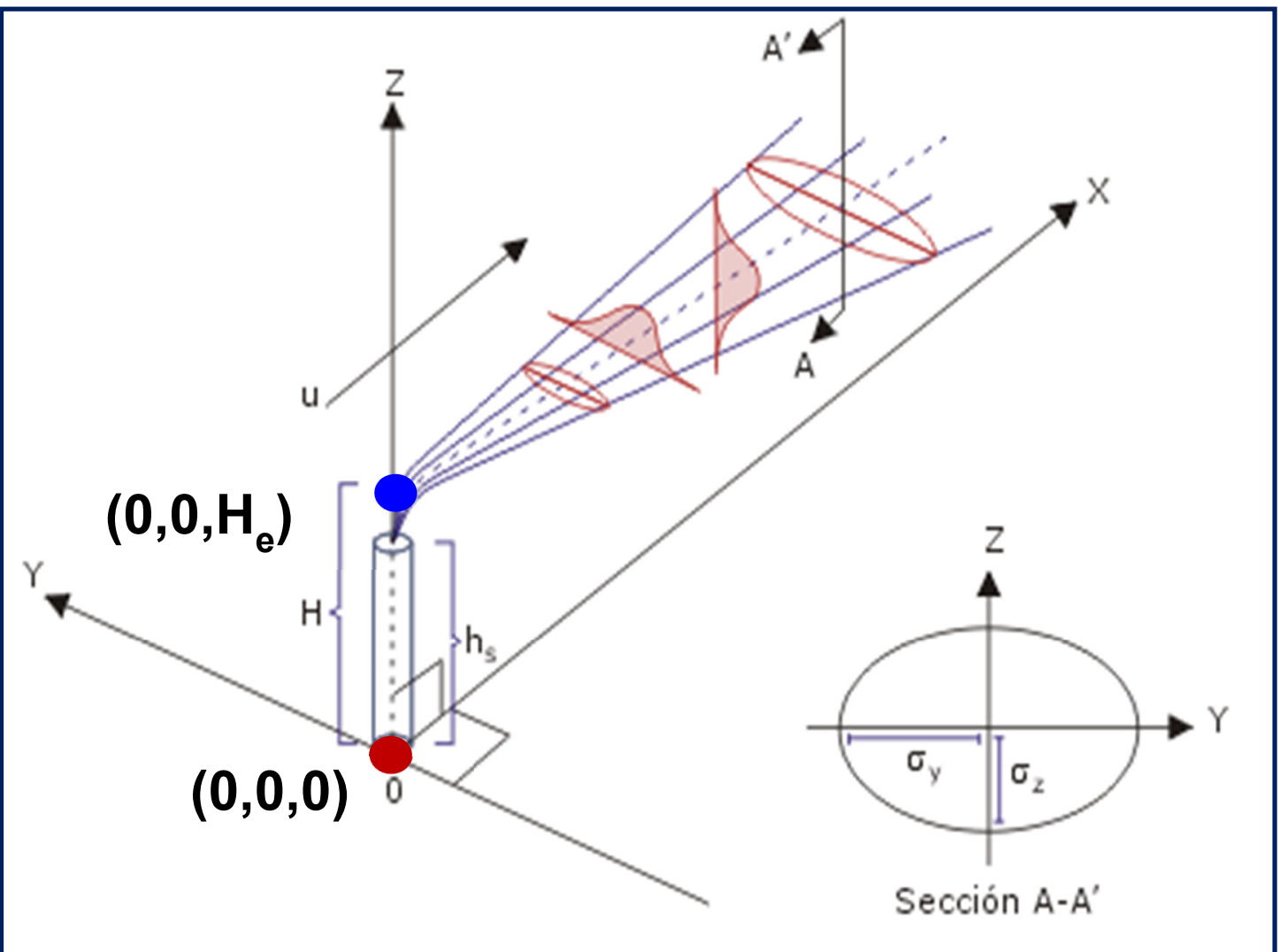

Figura 71: Esquema cambio origen coordenadas. Fuente: http://www.bvsde.paho.org/cursoa_meteoro/lecc6/lecc6_4.html. 
De este modo, la expresión resultante tiene la forma:

$$
C(x, y, z)=\frac{G}{2 \pi \sigma_{y} \sigma_{z} u_{h}} \exp \left(-\frac{y^{2}}{2 \sigma_{y}^{2}}\right) \exp \left(-\frac{\left(z-H_{e}\right)^{2}}{2 \sigma_{z}^{2}}\right)
$$

Por otra parte, en la expresión anterior, también es imprescindible tener en cuenta el efecto del suelo que se produce cuando a lo largo de su recorrido, y debido a su apertura vertical, el penacho alcanza el suelo con su borde inferior. En este momento se produce una reflexión de parte de los contaminantes contenidos en el penacho. Esta reemisión de contaminantes por parte del suelo provoca un aumento de la concentración en una zona determinada del penacho. Este fenómeno puede apreciarse en la figura 72 (zona con sombreado más oscuro):

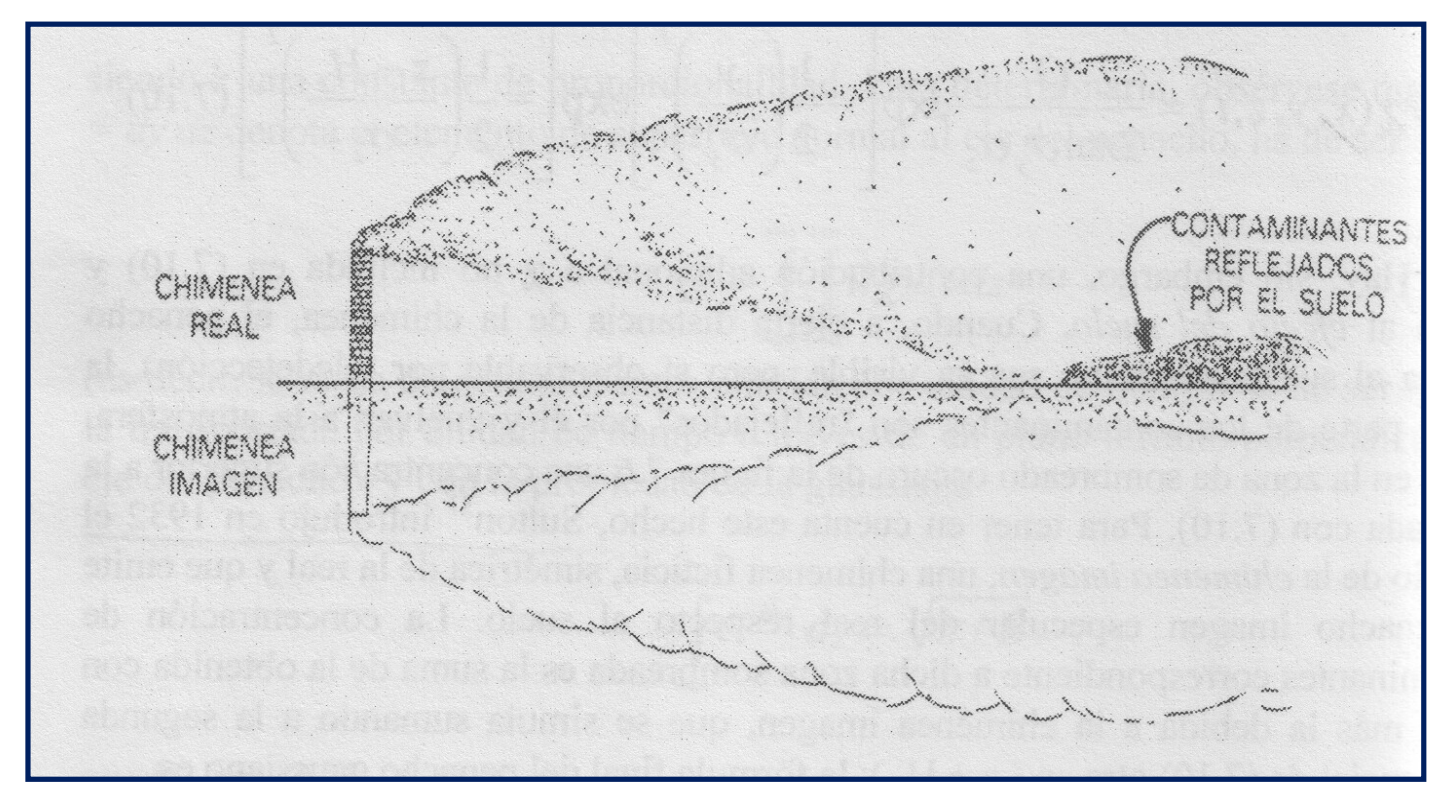

Figura 72: Esquema del efecto de reflexión del suelo. Fuente: Puigcerver y Carrascal, 2008: 148.

El efecto del suelo fue considerado por Sutton en 1932 (Puigcerver y Carrascal, 2008). Sutton introdujo en el esquema una chimenea imagen ficticia, totalmente simétrica a la real, pero que, como se aprecia en la figura 72 , queda invertida, de manera que el penacho ficticio sería la imagen especular de nuestro penacho real. Así pues, tendremos que adaptar de nuevo la expresión, considerando que la concentración de contaminantes será el resultado de la suma de los penachos de ambas chimeneas: 


$$
C\left(x, y, z, H_{e}\right)=\frac{G}{2 \pi \sigma_{y} \sigma_{z} u_{h}} \exp \left(-\frac{y^{2}}{2 \sigma_{y}^{2}}\right)\left\{\exp \left(-\frac{\left(z-H_{e}\right)^{2}}{2 \sigma_{z}^{2}}\right)+\exp \left(-\frac{\left(z+H_{e}\right)^{2}}{2 \sigma_{z}^{2}}\right)\right\}
$$

Una vez consideradas todas las contribuciones que afectan al cálculo de la concentración de contaminantes, y ante la complejidad de la expresión obtenida, vamos a simplificarla adaptándola exclusivamente a la situación que nos interesa para realizar los cálculos del presente capítulo.

Para evaluar el impacto ambiental producido por una chimenea interesa conocer la concentración de contaminantes que llega a nivel del suelo, donde $z=0$. De manera que:

$$
C\left(x, y, 0, H_{e}\right)=\frac{G}{\pi \sigma_{y} \sigma_{z} u_{h}} \exp \left\{-\left(\frac{y^{2}}{2 \sigma_{y}^{2}}+\frac{H_{e}^{2}}{2 \sigma_{z}^{2}}\right)\right\}
$$

Además, nos interesa conocer las situaciones de máximo impacto. Como se ha mencionado anteriormente, la máxima concentración de contaminantes se obtiene a lo largo del eje del penacho sobre el suelo (Fig. 73), pudiendo así simplificar la expresión, considerando $\mathrm{y}=0$. De manera que:

$$
C\left(x, 0,0, H_{e}\right)=\frac{G}{\pi \sigma_{y} \sigma_{z} u_{h}} \exp \left(-\frac{H_{e}^{2}}{2 \sigma_{z}^{2}}\right)
$$

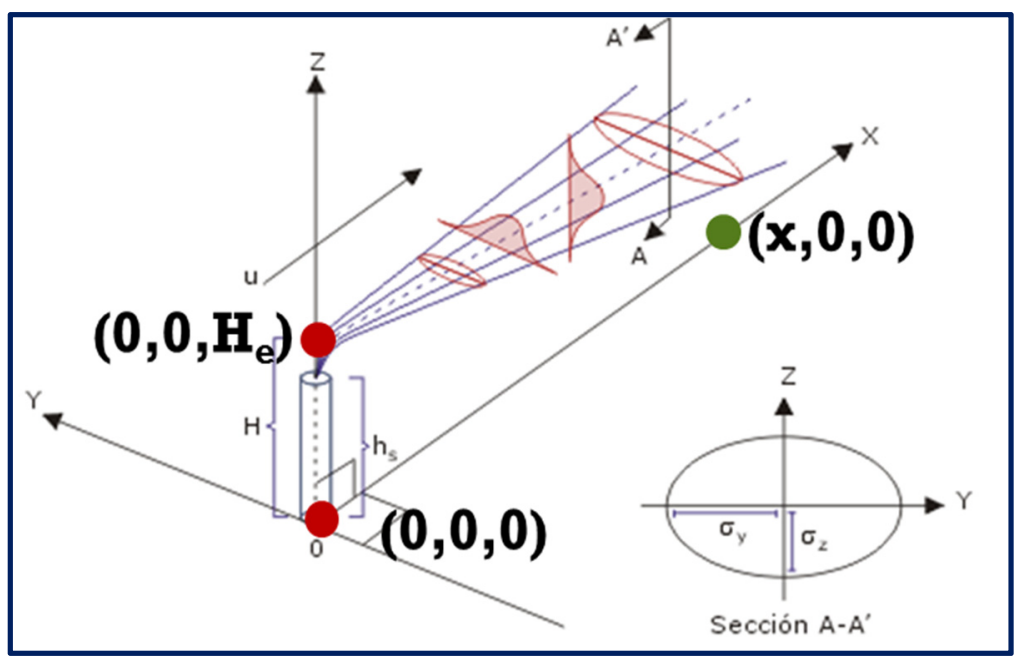

Figura 73: Esquema para la simplificación de las expresiones del modelo gaussiano. Fuente: http://www.bvsde.paho.org/cursoa_meteoro/lecc6/lecc6_4.html. 


\section{V.II. Cálculo de los coeficientes de dispersión de Gauss}

Finalmente, para poder realizar los cálculos correspondientes, solo nos resta obtener los valores de los coeficientes de dispersión $\sigma_{y} y \sigma_{z}$. Este punto de nuevo provoca cierta controversia, existiendo varios modelos para el cálculo de dichos coeficientes (Draxler, 1976; Green et al., 1980; Briggs, 1973...). Aunque resulta difícil definir cuál de todos los modelos es el más exacto o riguroso, actualmente las fórmulas propuestas por Briggs (1973) son de nuevo las más empleadas y, por tanto, las que se utilizarán en el presente capítulo. De este modo, los coeficientes se definen de la siguiente manera (Puigcerver y Carrascal, 2008; Hanna et al., 1982 y Castro, 2004):

$$
\sigma_{y, z}=m x(1+n x)^{p}
$$

Donde $\mathrm{m}, \mathrm{n}$ y $\mathrm{p}$ dependerán de las clases de estabilidad atmosférica propuestas por Pasquill (Tablas 13 y 14). Cabe resaltar que el propio Briggs aconseja no utilizar estas expresiones para distancias mayores de $10 \mathrm{~km}$. No obstante, en la práctica, es habitual emplearlas a distancias muy superiores. En las tablas 13 y 14 aparecen los valores de m, n y p propuestos por Briggs en función del tipo de estabilidad, tanto para zonas rurales como urbanas:

Tabla 13: Valores de los coeficientes de dispersión para un medio rural. Fuente: Puigcerver y Carrascal, $2008: 151$.

\begin{tabular}{|c|c|c|c|c|c|c|}
\hline \multirow{2}{*}{ Clase PGT } & \multicolumn{5}{c|}{$\boldsymbol{\sigma}_{\mathbf{y}}$} & \multicolumn{3}{|c|}{$\boldsymbol{\sigma}_{\mathbf{z}}$} \\
\cline { 2 - 7 } & $\mathbf{m}$ & $\mathbf{n}$ & $\mathbf{p}$ & $\mathbf{m}$ & $\mathbf{n}$ & $\mathbf{p}$ \\
\hline $\mathbf{A}$ & 0,22 & 0,0001 & $-0,5$ & 0,20 & 0 & 1 \\
\hline $\mathbf{B}$ & 0,16 & 0,0001 & $-0,5$ & 0,12 & 0 & 1 \\
\hline $\mathbf{C}$ & 0,11 & 0,0001 & $-0,5$ & 0,08 & 0,0002 & $-0,5$ \\
\hline $\mathbf{D}$ & 0,08 & 0,0001 & $-0,5$ & 0,06 & 0,0015 & $-0,5$ \\
\hline $\mathbf{E}$ & 0,06 & 0,0001 & $-0,5$ & 0,03 & 0,0003 & -1 \\
\hline $\mathbf{F}$ & 0,04 & 0,0001 & $-0,5$ & 0,016 & 0,0003 & -1 \\
\hline
\end{tabular}


Tabla 14: Valores de los coeficientes de dispersión para un medio urbano. Fuente: Puigcerver y Carrascal, $2008: 151$.

\begin{tabular}{|c|c|c|c|c|c|c|}
\hline \multirow{2}{*}{ Clase PGT } & \multicolumn{5}{|c|}{$\boldsymbol{\sigma}_{\mathbf{y}}$} & \multicolumn{3}{|c|}{$\boldsymbol{\sigma}_{\mathbf{z}}$} \\
\cline { 2 - 7 } & $\mathbf{m}$ & $\mathbf{n}$ & $\mathbf{p}$ & $\mathbf{m}$ & $\mathbf{n}$ & $\mathbf{p}$ \\
\hline A-B & 0,32 & 0,0004 & $-0,5$ & 0,24 & 0,001 & 0,5 \\
\hline $\mathbf{C}$ & 0,22 & 0,0004 & $-0,5$ & 0,20 & 0,0000 & 1 \\
\hline $\mathbf{D}$ & 0,16 & 0,0004 & $-0,5$ & 0,14 & 0,0003 & $-0,5$ \\
\hline E-F & 0,11 & 0,0004 & $-0,5$ & 0,08 & 0,00015 & $-0,5$ \\
\hline
\end{tabular}

Aplicando dichos valores al cálculo de $\sigma_{y} y \sigma_{z}$ obtenemos las expresiones siguientes (Tablas 15 y 16):

Tabla 15: Expresiones para el cálculo de los coeficientes de dispersión en un medio rural. Fuente: Castro, $2004: 128$.

\begin{tabular}{|c|c|c|}
\hline Clase de estabilidad PGT & $\sigma_{\mathrm{y}}$ & $\sigma_{\mathrm{z}}$ \\
\hline A & $0,22 \times(1+0,0001 \mathrm{x})^{-0,5}$ & $0,20 \mathrm{x}$ \\
\hline B & $0,16 \times(1+0,0001 \mathrm{x})^{-0,5}$ & $0,12 \mathrm{x}$ \\
\hline C & $0,11 \times(1+0,0001 \mathrm{x})^{-0,5}$ & $0,08 \times(1+0,0002 \mathrm{x})^{-0,5}$ \\
\hline D & $0,08 \times(1+0,0001 \times)^{-0,5}$ & $0,06 \times(1+0,0015 \mathrm{x})^{-0,5}$ \\
\hline E & $0,06 \times(1+0,0001 \times)^{-0,5}$ & $0,03 \times(1+0,0003 \mathrm{x})^{-1}$ \\
\hline F & $0,04 \times(1+0,0001 \times)^{-0,5}$ & $0,016 \times(1+0,0003 \times)^{-1}$ \\
\hline
\end{tabular}

Tabla 16: Expresiones para el cálculo de los coeficientes de dispersión en un medio urbano. Fuente: Castro, $2004: 128$.

\begin{tabular}{|c|c|c|}
\hline Clase de estabilidad PGT & $\sigma_{\mathrm{y}}$ & $\sigma_{\mathrm{z}}$ \\
\hline A-B & $0,32 \times(1+0,0004 \mathrm{x})^{-0,5}$ & $0,24 \times(1+0,001 \mathrm{x})^{-0,5}$ \\
\hline C & $0,22 \times(1+0,0004 \mathrm{x})^{-0,5}$ & $0,20 \mathrm{x}$ \\
\hline D & $0,16 \times(1+0,0004 \mathrm{x})^{-0,5}$ & $0,14 \times(1+0,0003 \mathrm{x})^{-0,5}$ \\
\hline E-F & $0,11 \times(1+0,0004 \mathrm{x})^{-0,5}$ & $0,08 \times(1+0,00015 \mathrm{x})^{-0,5}$ \\
\hline
\end{tabular}




\section{V.III. Corrección al Modelo de Pasquill para la dispersión de contaminantes emitidos bajo una capa de inversión térmica}

La expresión general del modelo gaussiano de Pasquill debe modificarse cuando trabajamos bajo unas condiciones atmosféricas de inversión térmica ya que, como ya se ha mencionado, afectan notablemente a la dispersión de los contaminantes emitidos. Como se ha descrito en el capítulo precedente, cuando un penacho de humos emitido por una chimenea alcanza una capa de inversión térmica ésta actúa a modo de tapadera, impidiendo la dispersión vertical de los contaminantes que quedan confinados bajo esta barrera. Así pues, cuando un penacho de humos se eleva e impacta contra una capa de inversión, los contaminantes "rebotan" y se reflejan del mismo modo que ocurre cuando impactan con la superficie terrestre (efecto de reflexión del suelo de Sutton) (Fig. 74).

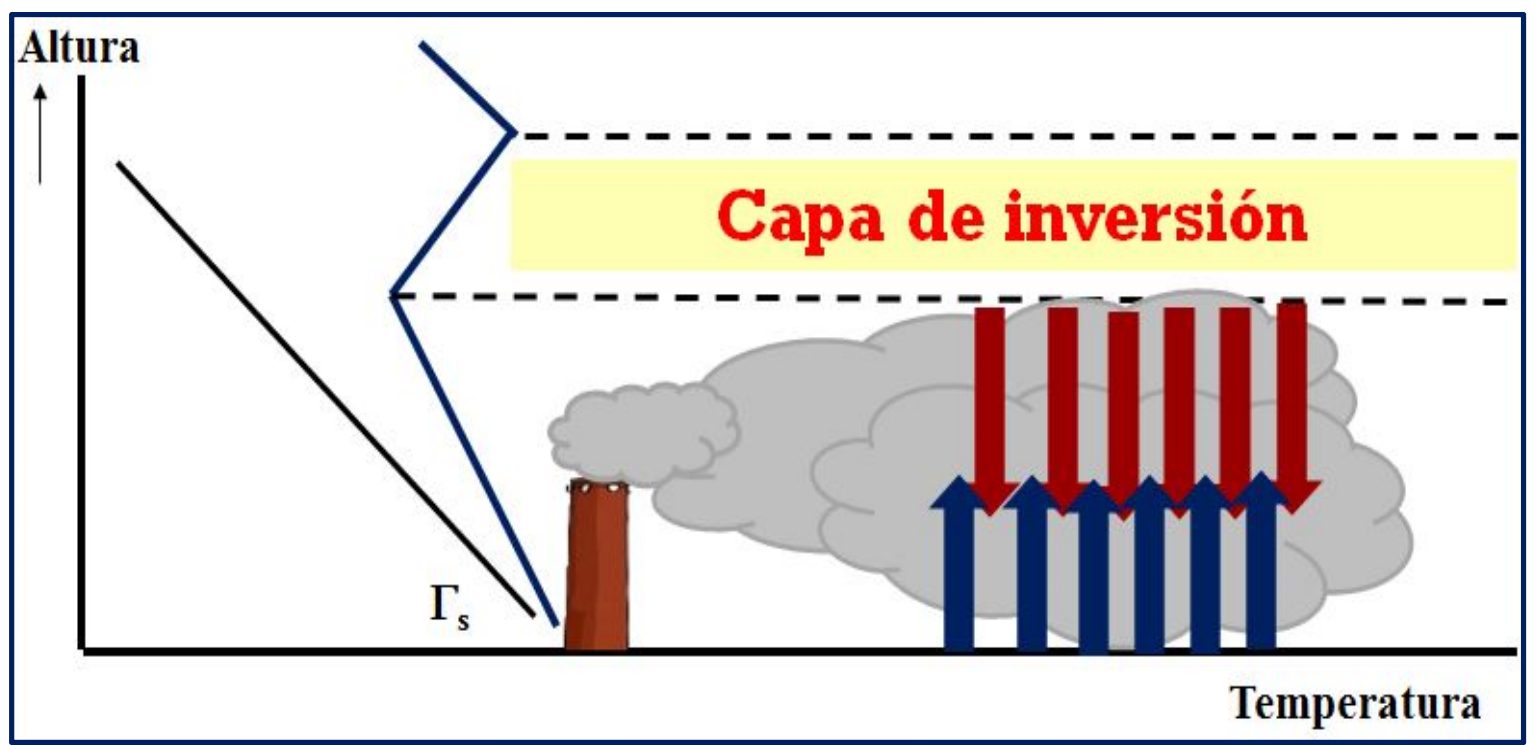

Figura 74: Esquema de la reflexión de contaminantes provocada por una capa de inversión térmica. Fuente: elaboración propia, Laboratorio de Climatología de la Universitat Jaume I.

De este modo, el cálculo de la concentración de contaminantes bajo estas condiciones resulta muy complejo ante la necesidad de considerar todas la múltiples reflexiones. Sin embargo, es posible simplificar los cálculos si únicamente consideramos distancias lejanas en la dirección del viento. A estas distancias se considera que el aire ya está completamente mezclado bajo la capa de inversión y las concentraciones resultan uniformes desde la superficie terrestre hasta el límite inferior de la capa de inversión. Varios modelos y adaptaciones se han propuesto para calcular el impacto ambiental producido por penachos emitidos en este tipo de 
situaciones de inversión térmica. Uno de los modelos más ampliamente utilizados es el propuesto por Pasquill en 1961 y ampliado por Turner en 1970 (Beychok, 2005; De Visscher, 2013; Masters y Ela, 2008). Este modelo considera que la expresión gaussiana de dispersión (Exp. 22) puede aplicarse para distancias que van desde la fuente emisora hasta una distancia $\mathrm{x}_{\mathrm{L}}$ a la cual la capa de mezcla (definida como la distancia desde el suelo hasta la base de la capa de inversión térmica) es igual a:

Altura de la capa de mezcla, $\mathrm{L}=\mathrm{H}_{\mathrm{e}}+2,5 \cdot \sigma_{\mathrm{z}}$

\section{Donde:}

$\mathrm{H}_{\mathrm{e}}=$ Altura efectiva de la chimenea

$\sigma_{\mathrm{z}}=$ Coeficiente de dispersión vertical

Para distancias superiores, la expresión 22 debe ser modificada para poder calcular la concentración de contaminantes a nivel de suelo bajo los efectos de una capa de inversión térmica. La expresión propuesta posee validez para situaciones en las que la distancia entre el receptor en la dirección del viento y la fuente emisora es superior a dos veces la distancia $\mathrm{x}_{\mathrm{L}}$, siendo $\mathrm{x}_{\mathrm{L}}$ la distancia donde el penacho de humos interacciona por primera vez con el límite inferior de la capa de inversión (Fig. 75):

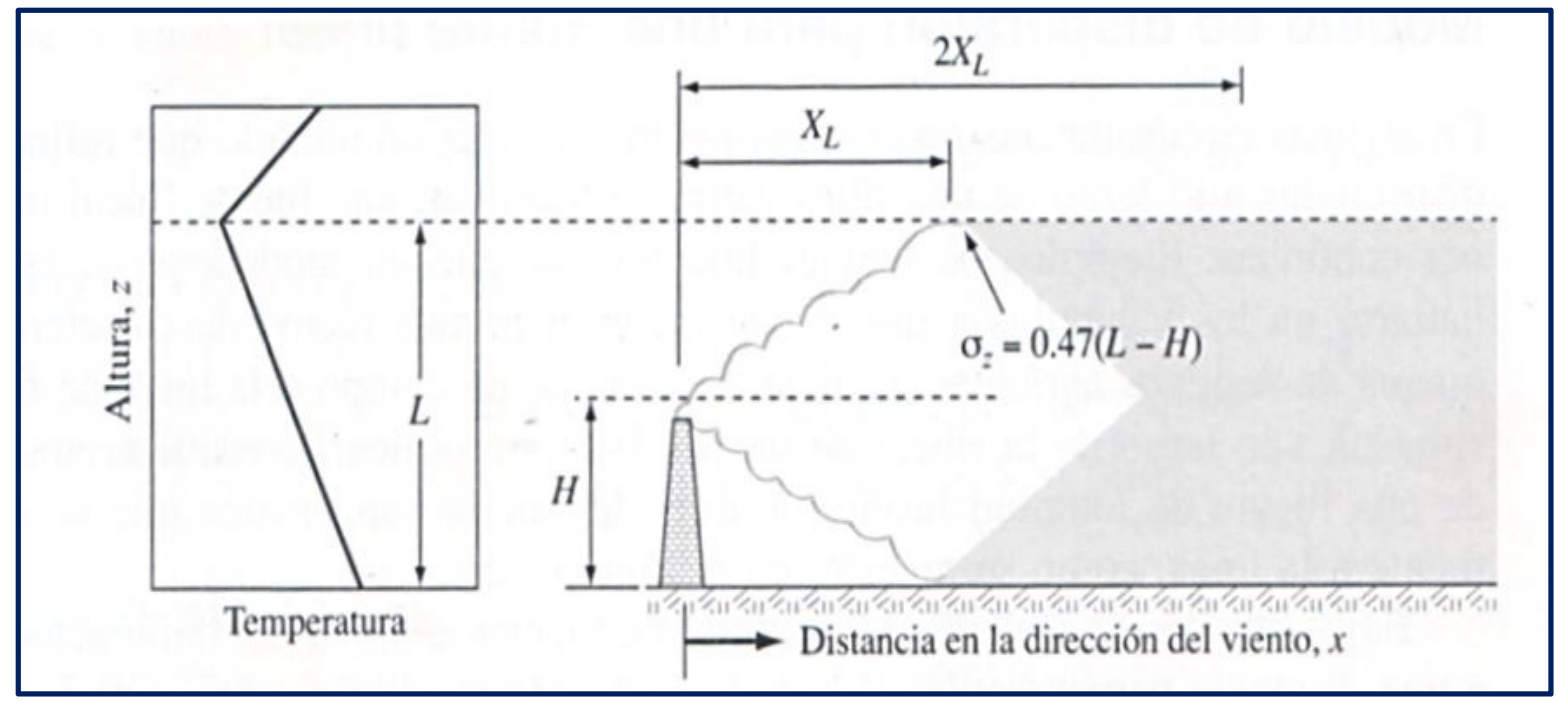

Figura 75: Esquema de la dispersión del penacho en condiciones de inversión térmica. Fuente: Masters y Ela, $2008: 483$. 
La expresión para estos casos queda de la siguiente manera:

$$
C(x, 0)=\frac{\mathrm{G}}{(2 \pi)^{\frac{1}{2}} \cdot L \cdot \sigma_{y} \cdot U_{H}} \quad \text { para } x \geq 2 x_{L}
$$

Donde:

$\mathrm{L}=$ Altura del límite inferior de la capa de inversión (m).

$\mathrm{x}_{\mathrm{L}}=$ Distancia en la dirección del viento a la cual se produce la primera interacción entre el penacho y la capa de inversión.

Como ya se ha dicho, esta expresión posee validez únicamente para distancias superiores a $2 \mathrm{x}_{\mathrm{L}}$. Para distancias inferiores a $\mathrm{x}_{\mathrm{L}}$ podemos emplear la expresión general del modelo gaussiano de Pasquill. Ahora bien, para distancias intermedias, es decir, para distancias entre $\mathrm{x}_{\mathrm{L}}$ y $2 \mathrm{x}_{\mathrm{L}}$, necesitaremos hacer una interpolación entre los resultados obtenidos con ambas expresiones para las distancias $\mathrm{x}_{\mathrm{L}}$ y $2 \mathrm{x}_{\mathrm{L}}$ respectivamente. Sin embargo, esto no será necesario cuando apliquemos las expresiones al caso concreto de estudio del presente trabajo de investigación ya que siempre nos encontraremos a distancias superiores a $2 \mathrm{x}_{\mathrm{L}}$.

\section{V.IV. Aplicación y verificación del modelo gaussiano de dispersión de contaminantes de Pasquill}

Al igual que hemos realizado con la verificación de las ecuaciones de Briggs para el cálculo de la sobreelevación del penacho emitido por la chimenea de la CT, hemos procedido a validar los resultados obtenidos mediante la modelización de impactos o concentración de $\mathrm{SO}_{2}$. Esta validación se ha efectuado a través de la comparación del resultado teórico con el valor de las inmisiones registradas en la estación de Coratxar (Red de Vigilancia Atmosférica de la GVA). Los episodios analizados corresponden a situaciones de estabilidad, especialmente aquellas con presencia de inversión térmica, las paradigmáticas de impacto ambiental, como se analiza en el capítulo IV, con eje de vientos procedentes del sector W-WNW-NW.

Para la realización de los cálculos se han empleado los siguientes parámetros básicos de emisión de la chimenea de la CT de Andorra (Tabla 17): 
Tabla 17: Parámetros de la fuente de emisión. Fuente: datos proporcionados por la CT de Andorra.

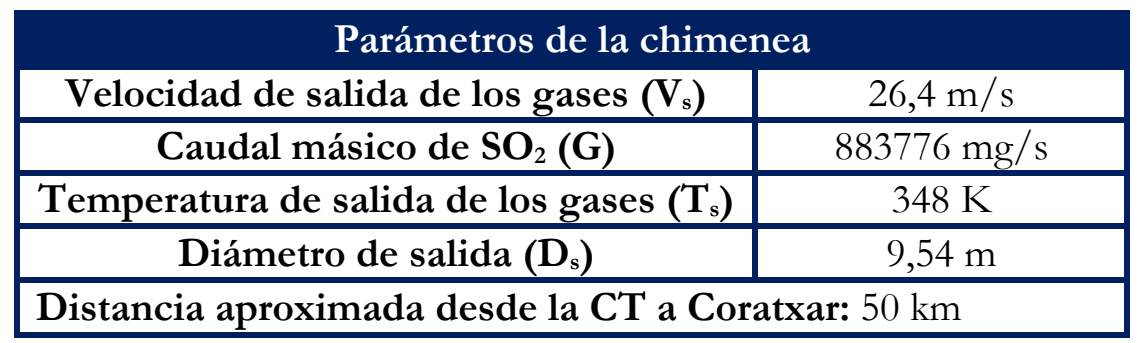

El primer episodio analizado, y exponente de la alta eficacia del modelo para la previsión de impactos de $\mathrm{SO}_{2}$, es el acontecido el 13 de enero del 2012. Durante esta jornada, en la que se registró un pico de inmisión de $254 \mu \mathrm{g} / \mathrm{m}^{3}$ de $\mathrm{SO}_{2}$ a las 13 horas, el registro del radiosondeo de Zaragoza aeropuerto ofrecía los siguientes parámetros meteorológicos (Tabla 18):

Tabla 18: Parámetros meteorológicos correspondientes a la jornada del 13 de enero del 2012. Datos extraídos del registro del radiosondeo de Zaragoza del 13 de enero del 2012 a las 12 horas. Fuente: http://weather.uwyo.edu/upperair/sounding.html.

\begin{tabular}{|c|c|}
\hline \multicolumn{2}{|c|}{ Parámetros meteorológicos } \\
\hline $\mathbf{T}_{\mathbf{a}}$ & $271 \mathrm{~K}$ \\
\hline $\mathbf{U}_{343}$ & $5 \mathrm{~m} / \mathrm{s}$ \\
\hline$\partial \mathbf{T} / \partial \mathbf{z}$ & $0,02^{\circ} \mathrm{C} / \mathrm{m}$ \\
\hline LsONDEO & $396 \mathrm{~m}$ sobre la superficie de Andorra \\
\hline Clase de estabilidad & $\mathrm{F}$ (medio rural) \\
\hline
\end{tabular}

Bajo estas condiciones atmosféricas el factor de flotabilidad (Exp. 16) y el parámetro de estabilidad (Exp. 17) se pueden calcular de la siguiente manera:

$$
\begin{gathered}
F=g V_{s} \frac{D_{s}^{2}}{4} \frac{T_{s}-T_{a}}{T_{s}}=9,8 \cdot 26,4 \cdot \frac{9,54^{2}}{4} \cdot \frac{348-271}{348}=1302,5 \mathrm{~m}^{4} / \mathrm{s}^{3} \\
S=\frac{g}{T_{a}}\left(\Gamma+\frac{\partial T}{\partial z}\right)=\frac{9,8}{271}(0,01+0,02)=0,0011 \mathrm{~s}^{-2}
\end{gathered}
$$

La situación atmosférica durante esta jornada era estable con viento, por lo que podemos calcular la sobreelevación del penacho de humos aplicando la expresión propuesta por Briggs (Exp. 20):

$$
\Delta H=2,6 \cdot\left(\frac{F}{U_{h} S}\right)^{1 / 3}=2,6 \cdot\left(\frac{1302,5}{5 \cdot 0,0011}\right)^{1 / 3}=160,86 \mathrm{~m}
$$


Esta sobreelevación se suma a la altura geométrica de la propia chimenea para calcular la altura efectiva de las emisiones.

$$
\mathrm{H}_{\mathrm{e}}=\mathrm{H}+\Delta \mathrm{H}=343+160,86=503,86 \mathrm{~m}
$$

Aunque el penacho podría ascender, según el modelo teórico de Briggs, 161 metros aproximadamente, el radiosondeo de Zaragoza (Fig. 76) muestra que la capa de inversión térmica se sitúa muy próxima a la cima de la chimenea (396 metros).

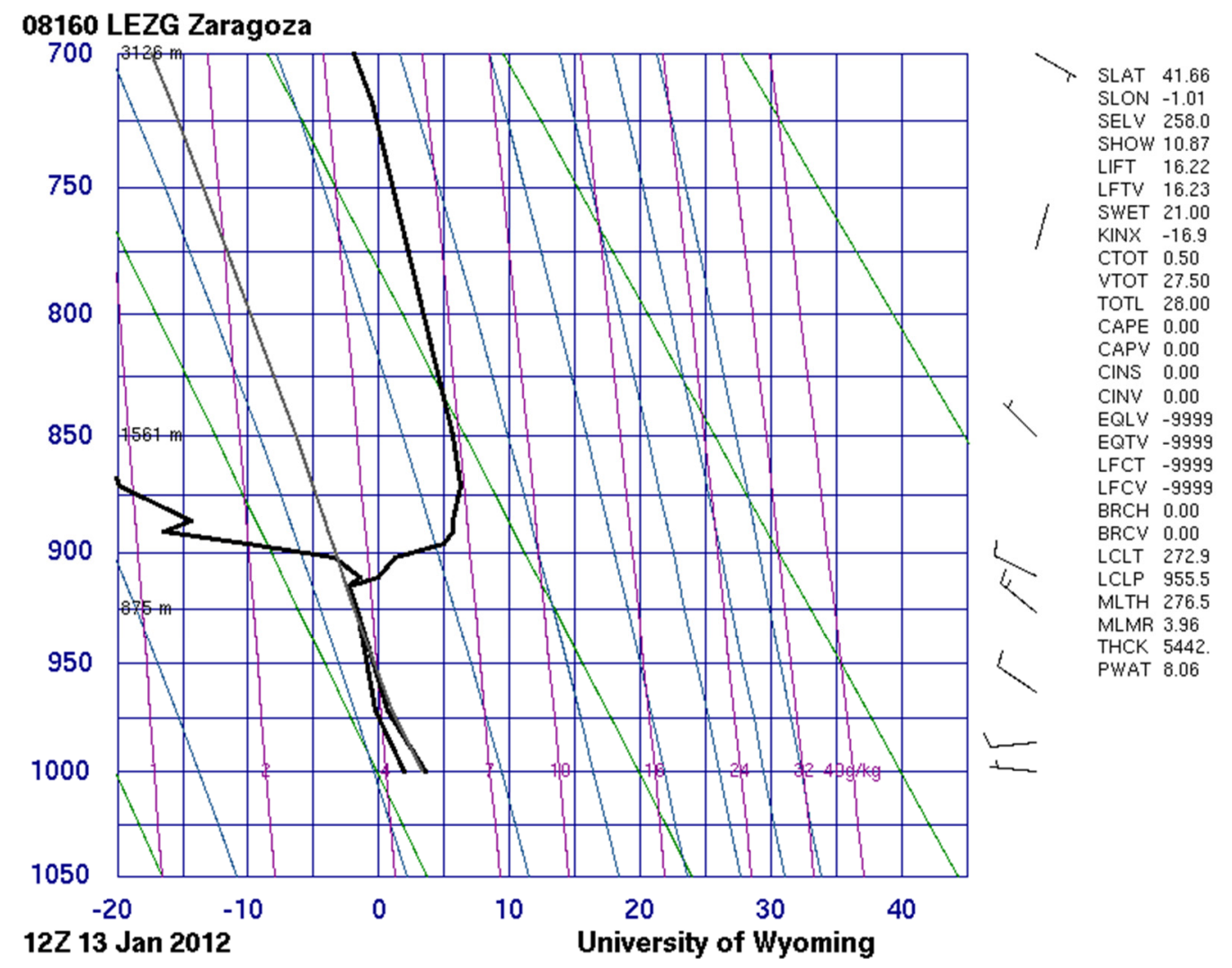

Figura 76: Radiosondeo de Zaragoza aeropuerto del 13 de enero del 2012 a las 12 horas. Fuente: http://weather.uwyo.edu/upperair/sounding.html.

Esta capa de inversión bloquea el ascenso y la dispersión de los contaminantes emitidos. El espesor atmosférico donde se difunden los contaminantes no permite gran dispersión, por ello es necesario aplicar la corrección del modelo gaussiano de Pasquill para situaciones de inversión térmica.

Bajo estas condiciones atmosféricas, y considerando un medio rural, podemos estimar, mediante la aplicación de las expresiones propuestas por Briggs, el valor de los coeficientes de dispersión necesarios para la aplicación del modelo gaussiano:

Página | 118 


$$
\begin{gathered}
\sigma_{z}=m x(1+n x)^{p}=0,016 \cdot 50000 \cdot(1+0,0003 \cdot 50000)^{-1}=50 m \\
\sigma_{y}=m x(1+n x)^{p}=0,04 \cdot 50000 \cdot(1+0,0001 \cdot 50000)^{-0,5}=816,5 m
\end{gathered}
$$

Con los parámetros meteorológicos registrados y las características propias de la emisión podemos estimar la concentración de $\mathrm{SO}_{2}$ que alcanzaría la estación de Coratxar mediante la aplicación del modelo gaussiano de Pasquill, corregido para situaciones de inversión térmica:

$$
C=\frac{\mathrm{G}}{(2 \pi)^{\frac{1}{2}} \cdot L \cdot \sigma_{y} \cdot U_{H}}=\frac{883776}{(2 \pi)^{\frac{1}{2}} \cdot 396 \cdot 816,5 \cdot 5}=0,218 \frac{\mathrm{mg}}{\mathrm{m}^{3}}=218 \frac{\mu \mathrm{g}}{\mathrm{m}^{3}}
$$

El pico registrado en la estación de Coratxar fue de $254 \mu \mathrm{g} / \mathrm{m}^{3}$ y el valor, calculado mediante la aplicación del modelo gaussiano, ha sido de $218 \mu \mathrm{g} / \mathrm{m}^{3}$. La diferencia entre el valor calculado y el medido es de un 14\%. El flujo aéreo, en las horas centrales del día, variaba sensiblemente entre Zaragoza, con una gran constancia de $290^{\circ} \mathrm{N}$ (registro del radiosondeo de Zaragoza aeropuerto), y Coratxar con $340^{\circ} \mathrm{N}$ con vientos débiles (registro de la estación de Coratxar). Parámetros en el seno de una situación de gran estabilidad y capa de inversión térmica como puede apreciarse nítidamente en la figura 77, donde aparecen representadas las temperaturas registradas en las estaciones de Fredes (1235 metros) y del monte Caro (1447 metros) durante los días 11-15 de enero del 2012. 


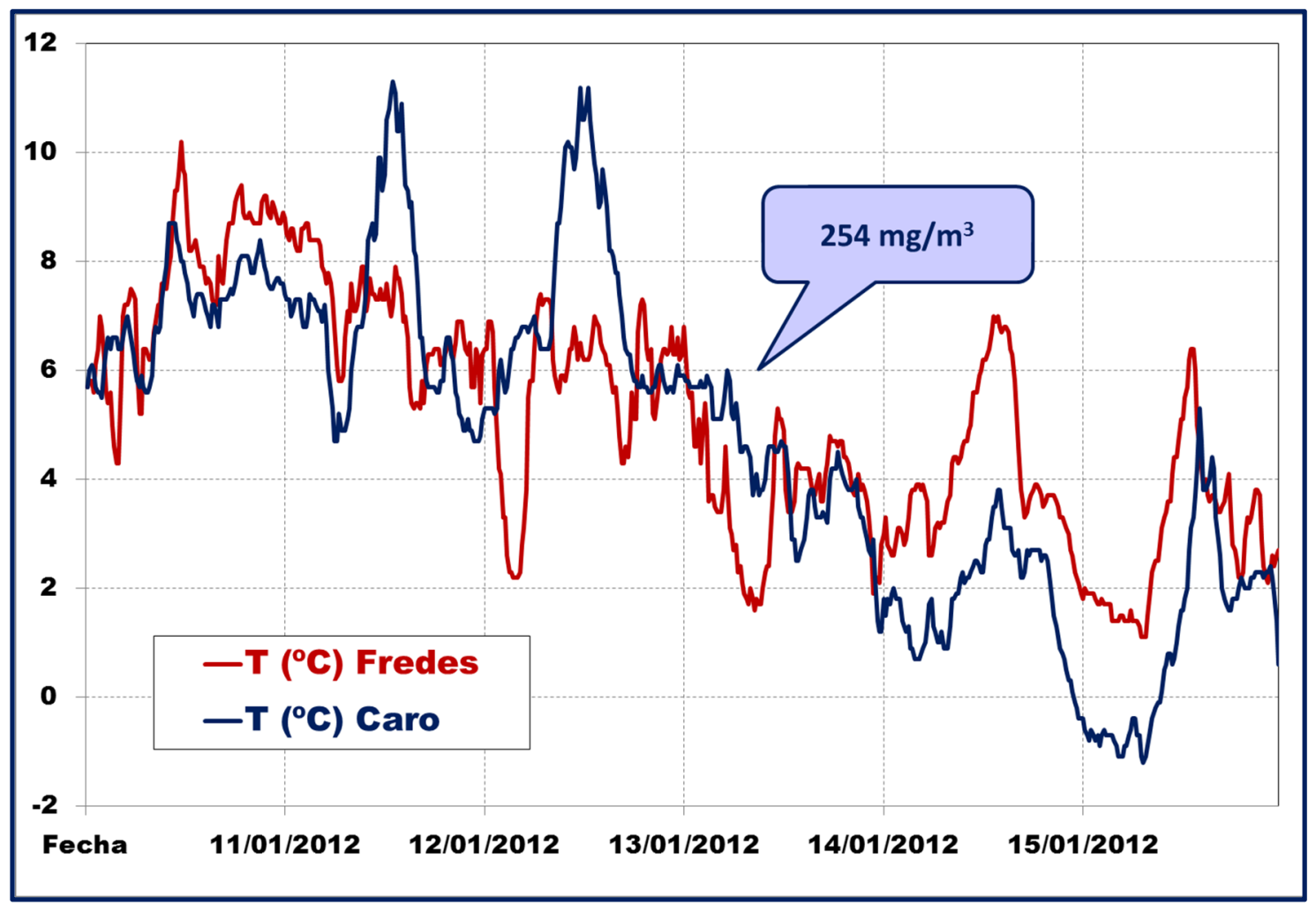

Figura 77: Temperaturas registradas en las estaciones de Fredes (1235 metros) y del monte Caro (1447 metros) durante los días 1115 de enero del 2012. Fuente: elaboración propia, Laboratorio de Climatología de la Universitat Jaume I.

El segundo episodio analizado corresponde al 7 de enero del 2013. Durante esta jornada, en la cual se registraron en Coratxar tres picos de inmisión de $\mathrm{SO}_{2}$ de $106 \mu \mathrm{g} / \mathrm{m}^{3}$ (10 horas), $236 \mu \mathrm{g} / \mathrm{m}^{3}$ (22 horas) y $115 \mu \mathrm{g} / \mathrm{m}^{3}$ (23 horas), los registros de los radiosondeos de Zaragoza aeropuerto ofrecían los siguientes parámetros meteorológicos (Tabla 19):

Tabla 19: Parámetros meteorológicos correspondientes a la jornada del 7 de enero del 2013. Datos extraídos del registro del radiosondeo de Zaragoza del 7 de enero del 2013 a las 12 horas. Fuente: http://weather.uwyo.edu/upperair/sounding.html.

\begin{tabular}{|c|c|}
\hline \multicolumn{2}{|c|}{ Parámetros meteorológicos } \\
\hline $\mathbf{T}_{\mathbf{a}}$ & $282,4 \mathrm{~K}$ \\
\hline $\mathbf{U}_{343}$ & $5,5 \mathrm{~m} / \mathrm{s}$ \\
\hline$\partial \mathbf{T} / \partial \mathbf{z}$ & $0,015^{\circ} \mathrm{C} / \mathrm{m}$ \\
\hline $\mathbf{L}_{\text {sondeo }}$ & $369 \mathrm{~m}$ sobre la superficie de Andorra \\
\hline Clase de estabilidad & $\mathrm{F}$ (medio rural) \\
\hline
\end{tabular}

Con estos parámetros el factor de flotabilidad y el parámetro de estabilidad se pueden calcular aplicando las expresiones 16 y 17 respectivamente:

$$
F=g V_{s} \frac{D_{s}^{2}}{4} \frac{T_{s}-T_{a}}{T_{s}}=9,8 \cdot 26,4 \cdot \frac{9,54^{2}}{4} \cdot \frac{348-282,4}{348}=1109,7 \mathrm{~m}^{4} / \mathrm{s}^{3}
$$




$$
S=\frac{g}{T_{a}}\left(\Gamma+\frac{\partial T}{\partial z}\right)=\frac{9,8}{282,4}(0,01+0,015)=0,00087 s^{-2}
$$

Utilizando la expresión propuesta por Briggs (Exp. 20) para una situación atmosférica estable con viento se obtiene la sobreelevación del penacho de humos:

$$
\Delta H=2,6 \cdot\left(\frac{F}{U_{h} S}\right)^{1 / 3}=2,6 \cdot\left(\frac{1109,7}{5,5 \cdot 0,00087}\right)^{1 / 3}=159,7 \mathrm{~m}
$$

A continuación se suma la sobreelevación obtenida a la altura geométrica de la propia chimenea para averiguar la altura efectiva de las emisiones.

$$
\mathrm{H}_{\mathrm{e}}=\mathrm{H}+\Delta \mathrm{H}=343+159,7=502,7 \mathrm{~m}
$$

Según el modelo teórico de Briggs el penacho podría elevarse 160 metros aproximadamente sobre la chimenea. Sin embargo, el radiosondeo de Zaragoza (Fig. 78) muestra que la capa de inversión térmica se sitúa muy próxima a la boca de la chimenea (369 metros). 


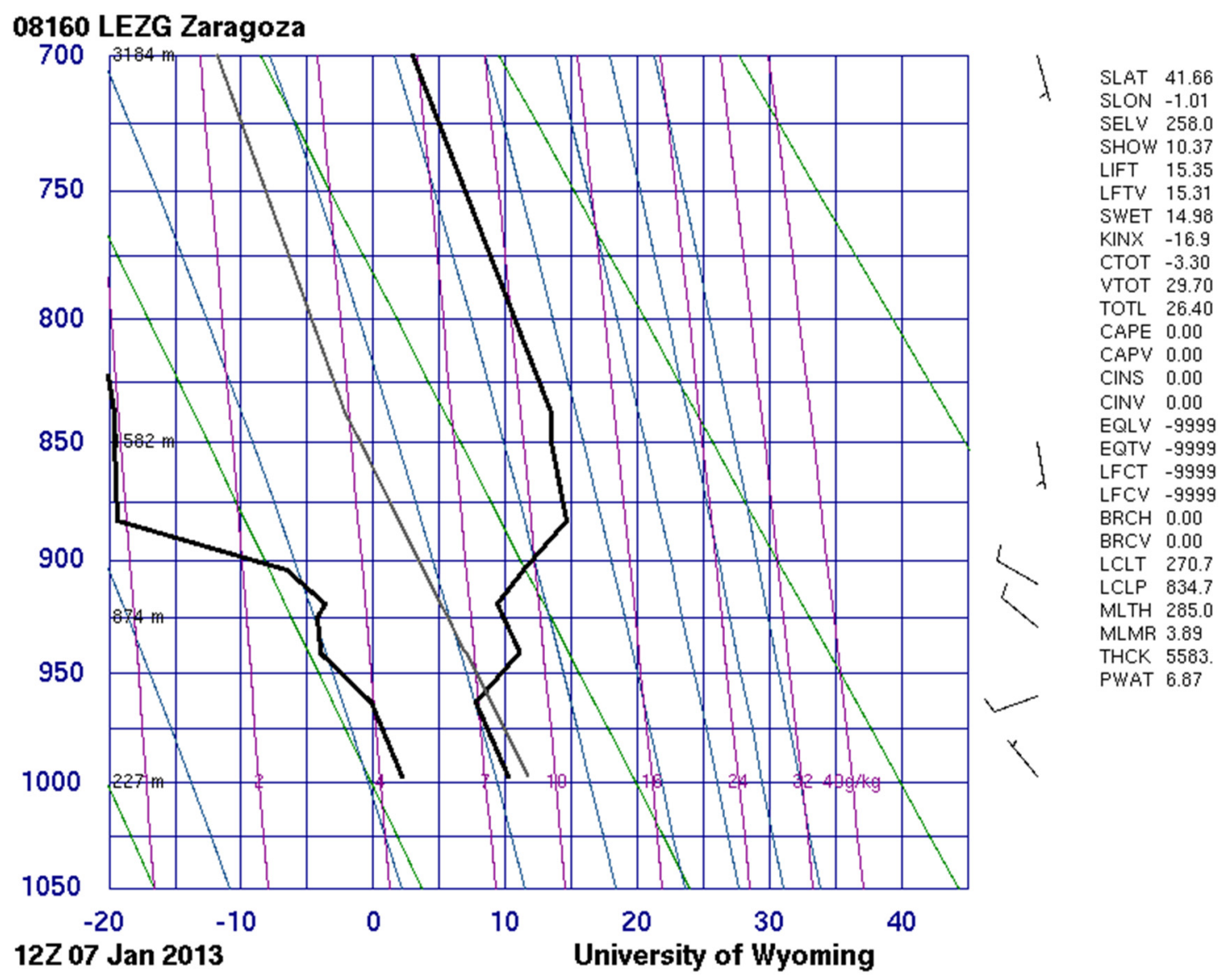

Figura 78: Radiosondeo de Zaragoza aeropuerto del 7 de enero del 2013 a las 12 horas. Fuente: http://weather.uwyo.edu/upperair/sounding.html.

El penacho se emitiría, por tanto, bajo la influencia de esta capa de inversión que limitaría su ascenso y dispersión, haciendo necesario aplicar la corrección del modelo gaussiano de Pasquill para situaciones de inversión térmica.

Considerando un medio rural y unas condiciones atmosféricas estables los coeficientes de dispersión se pueden estimar mediante la aplicación de las expresiones propuestas por Briggs.

$$
\begin{gathered}
\sigma_{z}=m x(1+n x)^{p}=0,016 \cdot 50000 \cdot(1+0,0003 \cdot 50000)^{-1}=50 m \\
\sigma_{y}=m x(1+n x)^{p}=0,04 \cdot 50000 \cdot(1+0,0001 \cdot 50000)^{-0,5}=816,5 m
\end{gathered}
$$

Aplicando el modelo gaussiano de Pasquill, corregido para situaciones de inversión térmica, se puede estimar la concentración de $\mathrm{SO}_{2}$ que alcanzaría la estación de Coratxar: 


$$
C=\frac{\mathrm{G}}{(2 \pi)^{\frac{1}{2}} \cdot L \cdot \sigma_{y} \cdot U_{H}}=\frac{883776}{(2 \pi)^{\frac{1}{2}} \cdot 369 \cdot 816,5 \cdot 5,5}=0,213 \frac{\mathrm{mg}}{\mathrm{m}^{3}}=213 \frac{\mu \mathrm{g}}{\mathrm{m}^{3}}
$$

Bajo los parámetros atmosféricos existentes en las horas centrales del día, con flujos medios de $287-300^{\circ} \mathrm{N}$, el valor de inmisión calculado es de $213 \mu \mathrm{g} / \mathrm{m}^{3}$ y los registrados en la red de vigilancia (Coratxar) fueron de $106 \mu \mathrm{g} / \mathrm{m}^{3}$ (10 horas), $236 \mu \mathrm{g} / \mathrm{m}^{3}$ (22 horas) y 115 $\mu \mathrm{g} / \mathrm{m}^{3}$ (23 horas). Esta alternancia de picos de inmisión se muestra acorde con las oscilaciones de la capa de inversión a lo largo del día, evidenciada por el cruce de las curvas de temperatura registradas en los observatorios de Fredes y del Caro (Fig. 79).

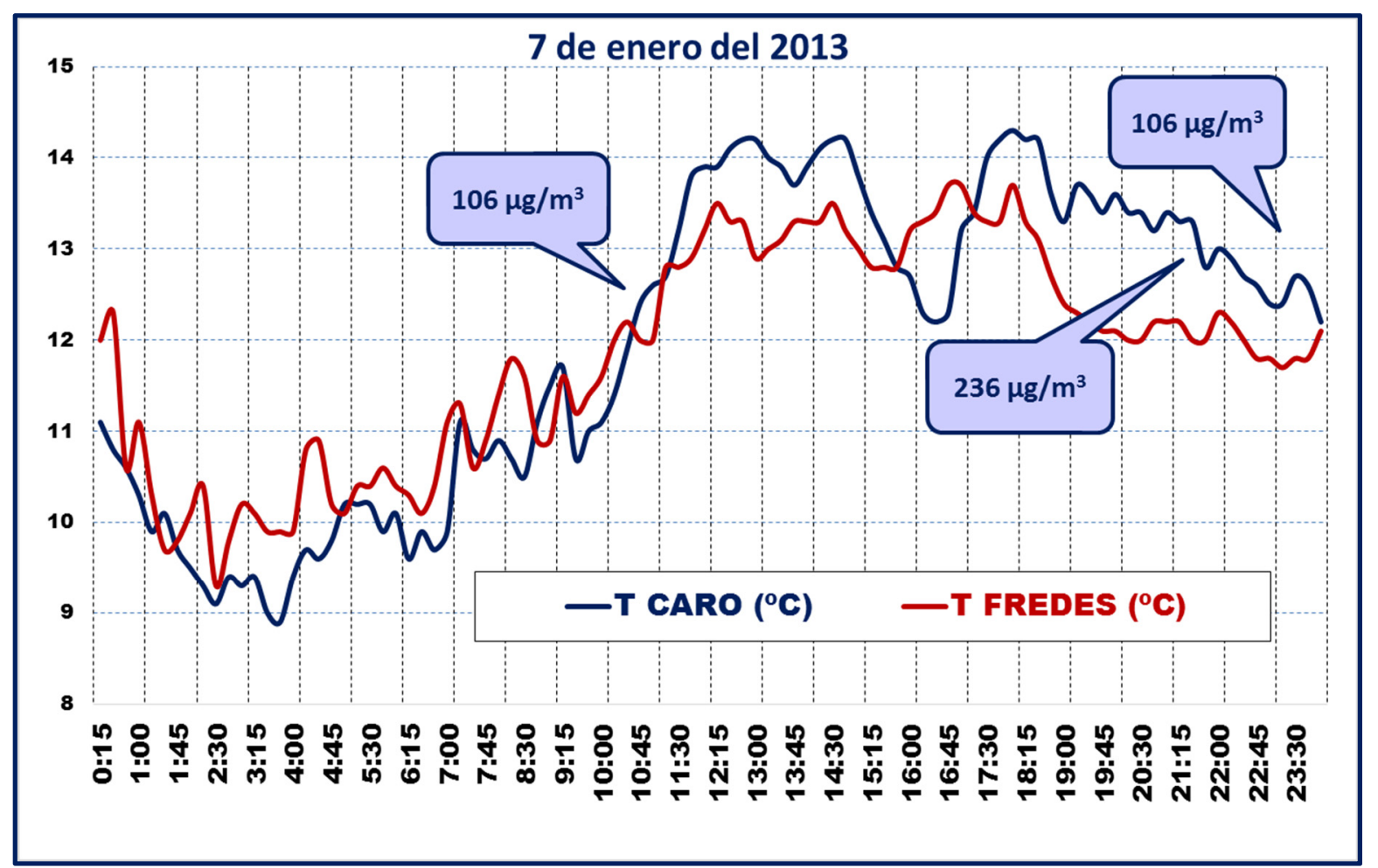

Figura 79: Temperaturas registradas en las estaciones de Fredes (1235 metros) y del monte Caro (1447 metros) durante el día 7 de enero del 2013. Fuente: elaboración propia, Laboratorio de Climatología de la Universitat Jaume I.

No obstante, existe una apreciable diferencia entre el valor del pico calculado con los parámetros meteorológicos del radiosondeo de las 12 horas $\left(213 \mu \mathrm{g} / \mathrm{m}^{3}\right)$ y el registrado en Coratxar a las 10 horas $\left(106 \mu \mathrm{g} / \mathrm{m}^{3}\right)$. La causa de esta discrepancia radica en la diferencia entre el valor de la velocidad del viento, $5,5 \mathrm{~m} / \mathrm{s}$ (radiosondeo de Zaragoza), aplicado en los cálculos y el viento registrado en los observatorios de Fredes y del Caro, 15-16 m/s (registros de la red universitaria). Esta notable diferencia en la velocidad hace evidente que el viento en la boca de la chimenea para esta jornada debía ser considerablemente mayor que el registrado por el 
radiosondeo y justificaría, por tanto, el margen de error del resultado obtenido al aplicar el modelo gaussiano.

El tercer episodio analizado corresponde a la jornada del 23 de febrero del 2012 en la cual se registró un pico de inmisión en Coratxar de $114 \mu \mathrm{g} / \mathrm{m}^{3}$ de $\mathrm{SO}_{2}$ a las 10 horas. Este pico de inmisión se produjo bajo los siguientes parámetros meteorológicos extraídos del registro del radiosondeo de Zaragoza aeropuerto (Tabla 20):

Tabla 20: Parámetros meteorológicos correspondientes a la jornada del 23 de febrero del 2012. Datos extraídos del registro del radiosondeo de Zaragoza del 23 de febrero del 2012 a las 12 horas. Fuente: http://weather.uwyo.edu/upperair/sounding.html.

\begin{tabular}{|c|c|}
\hline \multicolumn{2}{|c|}{ Parámetros meteorológicos } \\
\hline $\mathbf{T}_{\mathrm{a}}$ & $280,4 \mathrm{~K}$ \\
\hline $\mathbf{U}_{343}$ & $11,5 \mathrm{~m} / \mathrm{s}$ \\
\hline$\partial \mathbf{T} / \partial \mathbf{z}$ & $0,027^{\circ} \mathrm{C} / \mathrm{m}$ \\
\hline $\mathbf{L}_{\text {sONDEO }}$ & $449 \mathrm{~m}$ sobre la superficie de Andorra \\
\hline Clase de estabilidad & $\mathrm{F}$ (medio rural) \\
\hline
\end{tabular}

El factor de flotabilidad (Exp. 16) y el parámetro de estabilidad (Exp. 17) se pueden calcular de la siguiente manera:

$$
\begin{gathered}
F=g V_{s} \frac{D_{s}^{2}}{4} \frac{T_{s}-T_{a}}{T_{s}}=9,8 \cdot 26,4 \cdot \frac{9,54^{2}}{4} \cdot \frac{348-280,4}{348}=1143,5 \mathrm{~m}^{4} / \mathrm{s}^{3} \\
S=\frac{g}{T_{a}}\left(\Gamma+\frac{\partial T}{\partial z}\right)=\frac{9,8}{280,4}(0,01+0,027)=0,0013 \mathrm{~s}^{-2}
\end{gathered}
$$

Nuevamente nos encontramos con una situación atmosférica estable con viento, por lo que podemos calcular la sobreelevación que alcanzará el penacho de humos mediante la expresión propuesta por Briggs (Exp. 20):

$$
\Delta H=2,6 \cdot\left(\frac{F}{U_{h} S}\right)^{1 / 3}=2,6 \cdot\left(\frac{1143,5}{11,5 \cdot 0,0013}\right)^{1 / 3}=110,37 \mathrm{~m}
$$

La altura efectiva de las emisiones para esta jornada se puede calcular sumando esta sobreelevación a la altura geométrica de la chimenea de la CT.

$$
\mathrm{H}_{\mathrm{e}}=\mathrm{H}+\Delta \mathrm{H}=343+110,37=453,37 \mathrm{~m}
$$


El radiosondeo de Zaragoza para esta jornada (Fig. 80) muestra una capa de inversión térmica situada a una altura de 449 metros sobre la superficie de Andorra que se situaría muy próxima a la altura efectiva de las emisiones calculada mediante el modelo teórico.

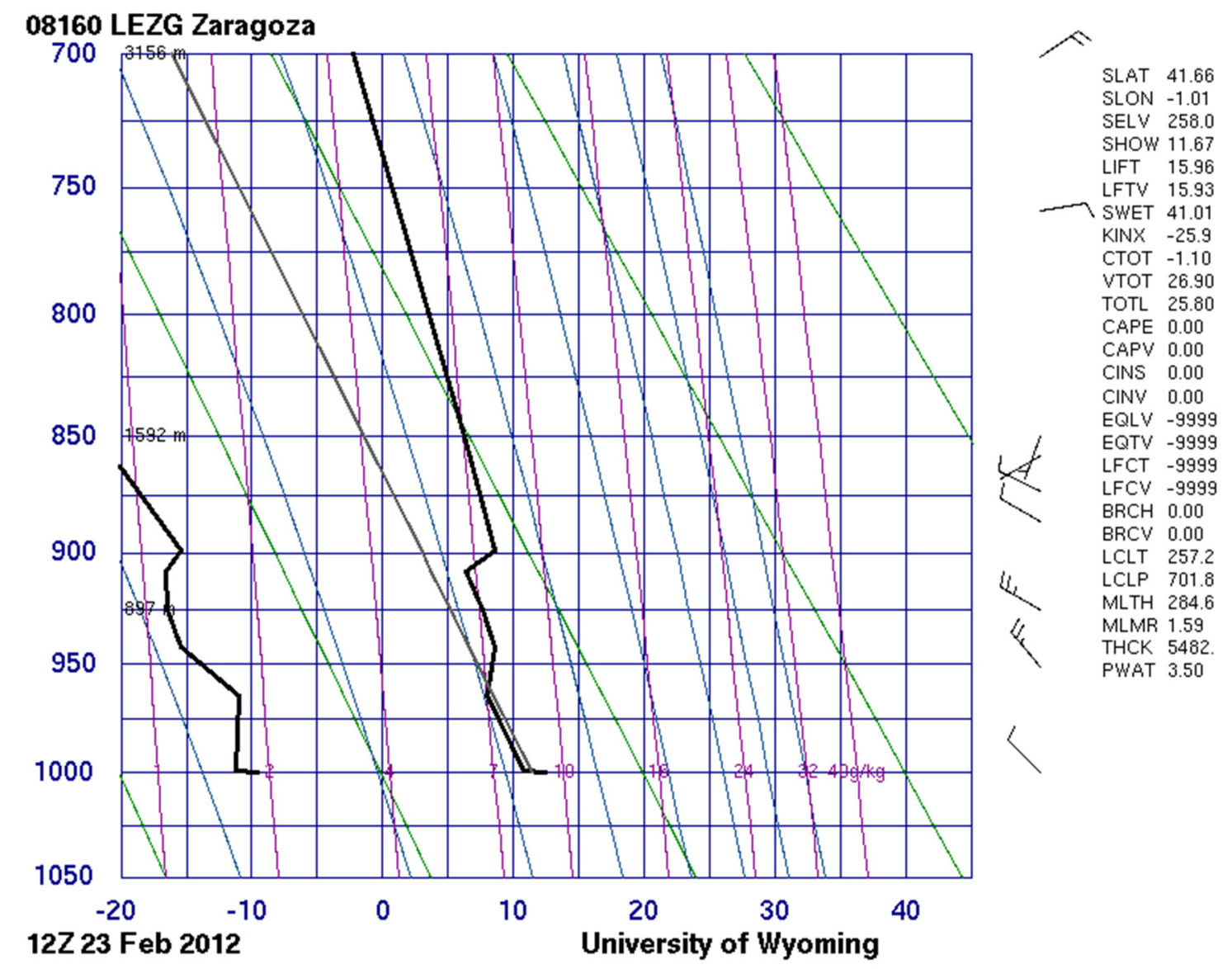

Figura 80: Radiosondeo de Zaragoza aeropuerto del 23 de febrero del 2012 a las 12 horas. Fuente: http://weather.uwyo.edu/upperair/sounding.html.

El ascenso del penacho, y por tanto la dispersión de los contaminantes gaseosos emitidos, se produciría por debajo de esta capa de inversión térmica. Así pues, para poder calcular la concentración real de $\mathrm{SO}_{2}$ que llegaría hasta Coratxar se ha aplicado la corrección del modelo gaussiano de Pasquill para situaciones de inversión térmica.

En primer lugar se ha calculado el valor de los coeficientes de dispersión necesarios para la aplicación del modelo gaussiano de dispersión de contaminantes:

$$
\begin{gathered}
\sigma_{z}=m x(1+n x)^{p}=0,016 \cdot 50000 \cdot(1+0,0003 \cdot 50000)^{-1}=50 m \\
\sigma_{y}=m x(1+n x)^{p}=0,04 \cdot 50000 \cdot(1+0,0001 \cdot 50000)^{-0,5}=816,5 m
\end{gathered}
$$


Finalmente, se ha calculado el valor de la concentración de inmisión de $\mathrm{SO}_{2}$ en la estación de Coratxar mediante la aplicación del modelo gaussiano de Pasquill, corregido para situaciones de inversión térmica:

$$
C=\frac{\mathrm{G}}{(2 \pi)^{\frac{1}{2}} \cdot L \cdot \sigma_{y} \cdot U_{H}}=\frac{883776}{(2 \pi)^{\frac{1}{2}} \cdot 449 \cdot 816,5 \cdot 11,5}=0,0836 \frac{\mathrm{mg}}{\mathrm{m}^{3}}=83,6 \frac{\mu \mathrm{g}}{\mathrm{m}^{3}}
$$

El valor de inmisión calculado por el modelo ha dado $83,6 \mu \mathrm{g} / \mathrm{m}^{3}$, mientras que el registro de la red de vigilancia (Coratxar) mostraba $114 \mu \mathrm{g} / \mathrm{m}^{3}$, ambos valores difieren en un $27 \%$. Esa discrepancia viene explicada, tal como hemos reiterado, por la aplicación de unos valores meteorológicos tomados del radiosondeo de Zaragoza, de acuerdo con el criterio seguido en toda la modelización. De nuevo, la figura 81 muestra las condiciones atmosféricas reales de la capa de inversión mediante las curvas de temperatura registradas en los observatorios de Fredes (1235 metros) y del Caro (1447 metros). Esta incipiente capa de inversión térmica estaría situada por debajo de los 1200 metros y sería determinante del pico de inmisión registrado.

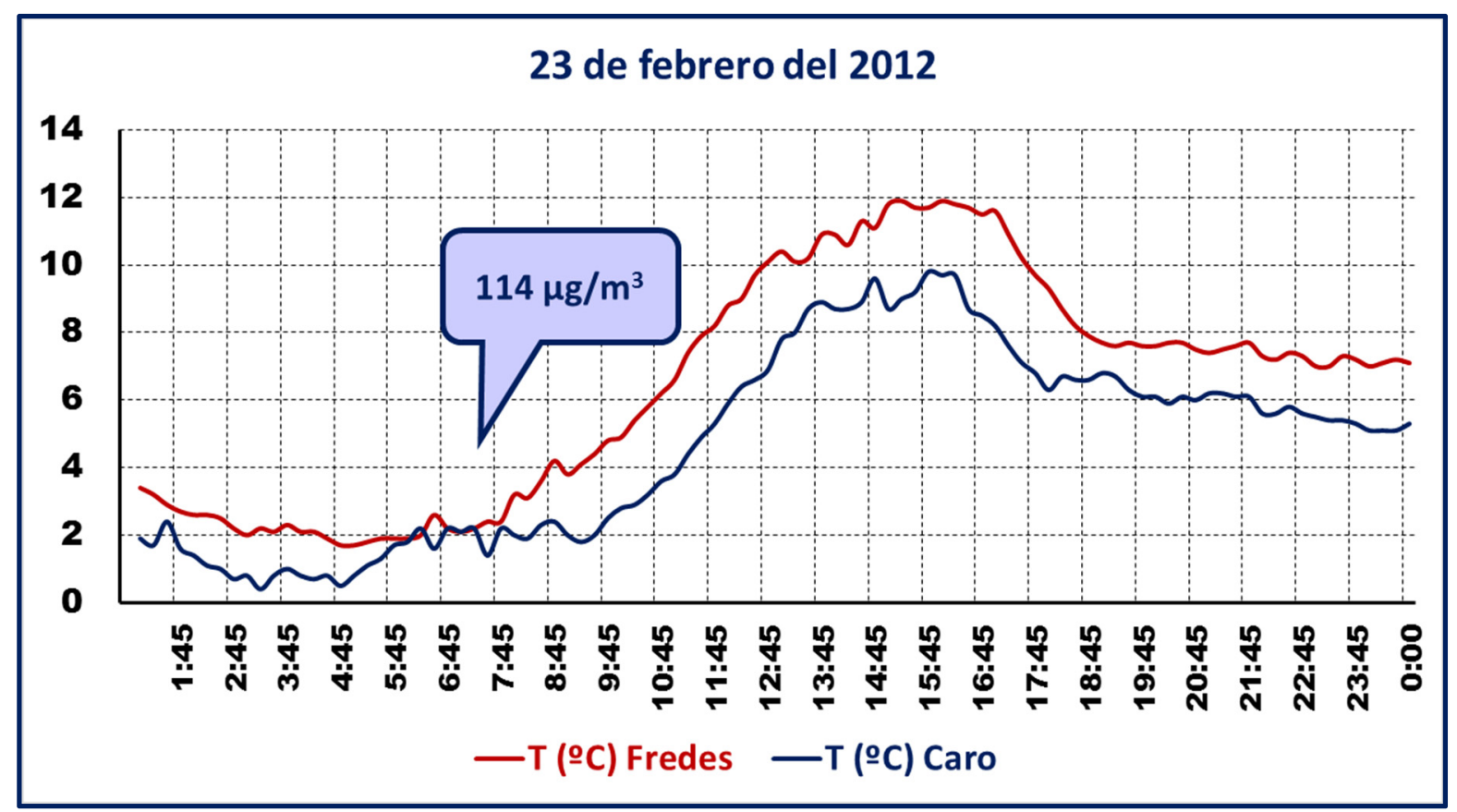

Figura 81: Temperaturas registradas en las estaciones de Fredes (1235 metros) y del monte Caro (1447 metros) durante el día 23 de febrero del 2012. Fuente: elaboración propia, Laboratorio de Climatología de la Universitat Jaume I.

El cuarto episodio analizado corresponde al día 19 de diciembre del 2014. Durante esta jornada, en la cual se registraron en Coratxar dos picos de inmisión de $\mathrm{SO}_{2}$ de $111 \mu \mathrm{g} / \mathrm{m}^{3}$ 
(5 horas) y $107 \mu \mathrm{g} / \mathrm{m}^{3}$ (1 horas), el registro del radiosondeo de Zaragoza aeropuerto reflejaba los siguientes parámetros meteorológicos (Tabla 21):

Tabla 21: Parámetros meteorológicos correspondientes a la jornada del 19 de diciembre del 2014. Datos extraídos del registro del radiosondeo de Zaragoza del 19 de diciembre del 2014 a las 00 horas. Fuente: http://weather.uwyo.edu/upperair/sounding.html.

\begin{tabular}{|c|c|}
\hline \multicolumn{2}{|c|}{ Parámetros meteorológicos } \\
\hline $\mathbf{T}_{\mathbf{a}}$ & $281,2 \mathrm{~K}$ \\
\hline $\mathbf{U}_{343}$ & $10 \mathrm{~m} / \mathrm{s}$ \\
\hline$\partial \mathbf{T} / \partial \mathbf{z}$ & $0,014^{\circ} \mathrm{C} / \mathrm{m}$ \\
\hline $\mathbf{L}_{\text {sONDEO }}$ & $540 \mathrm{~m}$ sobre la superficie de Andorra \\
\hline Clase de estabilidad & $\mathrm{F}$ (medio rural) \\
\hline
\end{tabular}

Con estos parámetros se ha procedido a calcular el factor de flotabilidad (Exp. 16) y el parámetro de estabilidad (Exp. 17):

$$
\begin{gathered}
F=g V_{s} \frac{D_{s}^{2}}{4} \frac{T_{s}-T_{a}}{T_{s}}=9,8 \cdot 26,4 \cdot \frac{9,54^{2}}{4} \cdot \frac{348-281,2}{348}=1129,96 \mathrm{~m}^{4} / \mathrm{s}^{3} \\
S=\frac{g}{T_{a}}\left(\Gamma+\frac{\partial T}{\partial z}\right)=\frac{9,8}{281,2}(0,01+0,014)=0,000836 \mathrm{~s}^{-2}
\end{gathered}
$$

Dado que se trata de una situación atmosférica estable con viento, se ha calculado la sobreelevación del penacho de humos (Exp. 20):

$$
\Delta H=2,6 \cdot\left(\frac{F}{U_{h} S}\right)^{1 / 3}=2,6 \cdot\left(\frac{1129,96}{10 \cdot 0,000836}\right)^{1 / 3}=133,43 \mathrm{~m}
$$

Sumando esta sobreelevación a la altura geométrica de la propia chimenea se ha obtenido la altura efectiva de las emisiones.

$$
H_{e}=H+\Delta H=343+133,43=476,43 m
$$

Aunque el penacho podría ascender, según el modelo teórico de Briggs, 133 metros aproximadamente, el radiosondeo de Zaragoza (Fig. 82) muestra que la capa de inversión térmica se sitúa por encima de la boca de la chimenea (540 metros). 


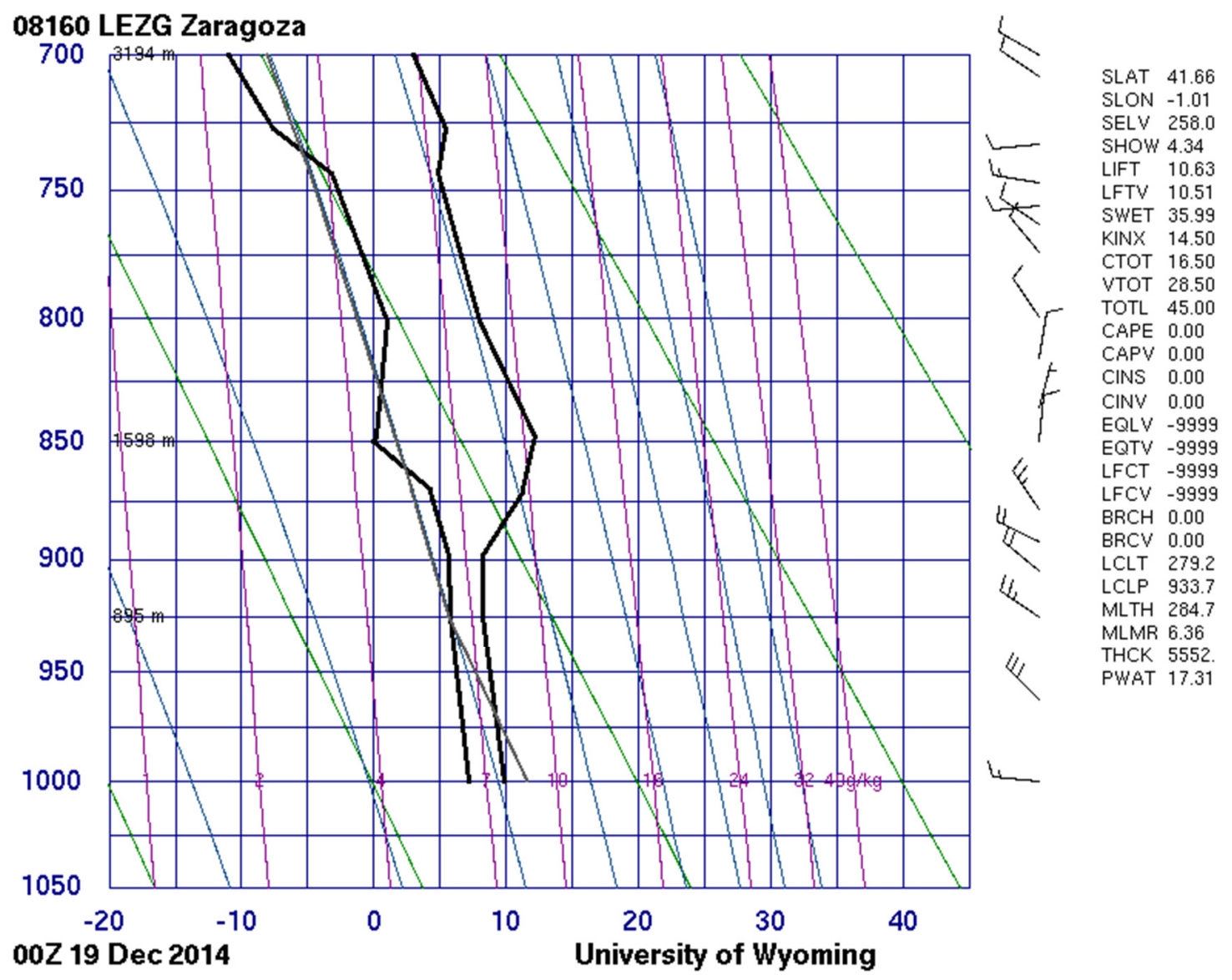

Figura 82: Radiosondeo de Zaragoza aeropuerto del 19 de diciembre del 2014 a las 00 horas. Fuente: http://weather.uwyo.edu/upperair/sounding.html.

Esta capa de inversión condicionaría el ascenso y dispersión del penacho y, por ende, su emisión que se produciría por debajo de ella. Por ello se ha aplicado la corrección del modelo gaussiano de Pasquill para situaciones de inversión térmica.

Con estas condiciones atmosféricas, y mediante la utilización de las expresiones formuladas por Briggs, se ha obtenido el valor de los coeficientes de dispersión necesarios para la aplicación del modelo gaussiano:

$$
\begin{gathered}
\sigma_{z}=m x(1+n x)^{p}=0,016 \cdot 50000 \cdot(1+0,0003 \cdot 50000)^{-1}=50 m \\
\sigma_{y}=m x(1+n x)^{p}=0,04 \cdot 50000 \cdot(1+0,0001 \cdot 50000)^{-0,5}=816,5 m
\end{gathered}
$$

Consecuentemente, la concentración de $\mathrm{SO}_{2}$ que alcanzaría la estación de Coratxar, calculada mediante la corrección del modelo gaussiano de Pasquill para situaciones de inversión térmica, sería la siguiente: 


$$
C=\frac{\mathrm{G}}{(2 \pi)^{\frac{1}{2}} \cdot L \cdot \sigma_{y} \cdot U_{H}}=\frac{883776}{(2 \pi)^{\frac{1}{2}} \cdot 540 \cdot 816,5 \cdot 10}=0,08 \frac{\mathrm{mg}}{\mathrm{m}^{3}}=80 \frac{\mu \mathrm{g}}{\mathrm{m}^{3}}
$$

El valor de inmisión calculado por el modelo ha dado $80 \mu \mathrm{g} / \mathrm{m}^{3}$ y el registro de la red de vigilancia mostraba $107 \mu \mathrm{g} / \mathrm{m}^{3}$ y $111 \mu \mathrm{g} / \mathrm{m}^{3}$. Ambos valores difieren en un 25-28\%. Discrepancia que responde a la variación de los parámetros meteorológicos que podría existir entre Zaragoza (radiosondeo) y el foco de emisión situado en Andorra. De nuevo la figura 83 muestra, mediante las curvas de temperatura registradas en los observatorios de Fredes y del monte Caro, la capa de inversión formada entre ambos niveles que explica perfectamente los dos picos de inmisión registrados en Coratxar.

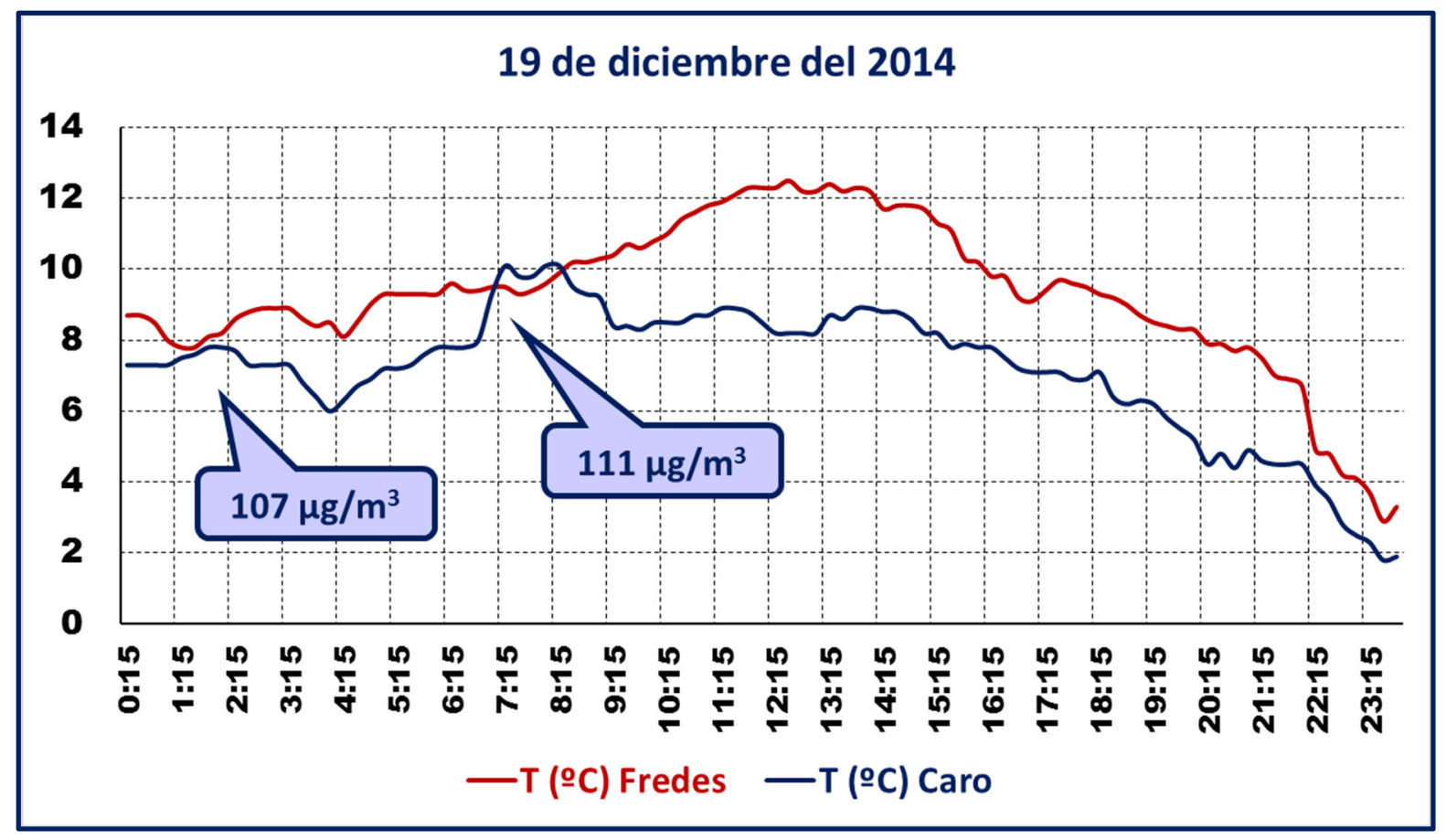

Figura 83: Temperaturas registradas en las estaciones de Fredes (1235 metros) y del monte Caro (1447 metros) durante el día 19 de diciembre del 2014. Fuente: elaboración propia, Laboratorio de Climatología de la Universitat Jaume I. 


\section{CONCLUSIONES SOBRE LA MODELIZACIÓN GAUSSIANA DEL PENACHO}

En la introducción del presente capítulo hemos enfatizado que la configuración atmosférica regional, y especialmente de la capa de mezcla, constituye un escenario ideal para la modelización gaussiana de las emisiones emitidas por la CT. Este es el modelo de dispersión, difusión y concentración de inmisiones desarrollado en el presente capítulo. Un objetivo que ha sido fundamentado sobre las formulaciones del modelo gaussiano. No obstante, este desarrollo teórico nos ha permitido aprehender el importante papel que el escenario atmosférico regional juega en la potenciación o inhibición de los impactos medioambientales vinculados a la calidad del aire. Esta aprehensión, objetivo esencial de nuestra tesis, se ha podido alcanzar mediante la validación del modelo gaussiano de dispersión de contaminantes de Pasquill. Para ello se ha partido de la validación previa de las expresiones propuestas por Briggs para el cálculo de la sobreelevación de los penachos, verificando así sus efectos sobre las inmisiones de $\mathrm{SO}_{2}$.

En cuanto a las expresiones propuestas por Briggs para el cálculo de la sobreelevación, su validación ha sido desarrollada mediante la comparación con las imágenes fotográficas de sobreelevación y difusión del penacho de la CT. Estas imágenes corresponden al archivo fotográfico realizado en nuestros trabajos de campo durante los años 2013-2016. En todos los casos observados, la sobrelevación del penacho y altura efectiva de la emisión, mostrada por las imágenes fotográficas, ha manifestado la validez de las ecuaciones aplicadas.

$\mathrm{Al}$ igual que hemos realizado con la verificación de las ecuaciones de sobreelevación del penacho, hemos procedido a validar los resultados obtenidos en la aplicación del modelo gaussiano de dispersión de contaminantes de Pasquill para la modelización de impactos o concentración de inmisión de $\mathrm{SO}_{2}$. Esta validación se ha efectuado mediante la comparación del resultado teórico con el valor de las inmisiones registradas en la estación de Coratxar (Red de Vigilancia Atmosférica de la GVA). En todos los casos analizados correspondientes a diferentes situaciones reales, los resultados han sido altamente satisfactorios. Las diferencias máximas entre la magnitud de la inmisión calculada y la registrada no han superado un $28 \%$. Unas diferencias que es muy posible que deban de imputarse más a variaciones momentáneas de carga y, especialmente, a la aplicación de registros meteorológicos obtenidos en un radiosondeo efectuado a considerable distancia que a deficiencias del modelo. Si bien, en capas Página | 130 
atmosféricas próximas o superiores a los $900 \mathrm{hPa}$ las diferencias son mucho menos acusadas que en niveles más superficiales.

La validez del modelo viene reforzada por su correspondencia con los datos meteorológicos registrados en estaciones del pico Fredes y del monte Caro de la red universitaria. Este control continuo de la capa atmosférica entre 1235 y 1447 metros ha permitido verificar que todas las situaciones de impactos se producían en momentos en que la capa de inversión térmica se situaba por debajo de los 1200 metros. 

LA IDENTIFICACIÓN DE LAS SITUACIONES DE IMPACTOS SEVEROS DE DIÓXIDO DE AZUFRE 



\section{METODOLOGÍA DE IDENTIFICACIÓN}

La identificación de las situaciones de impactos severos de $\mathrm{SO}_{2}$ ha podido ser realizada mediante el análisis de la extraordinaria base de datos que nos ha proporcionado la Red de Vigilancia y Control de la Contaminación Atmosférica de la Generalitat Valenciana. Esta red fue creada por Decreto 161/2003 del Consell de la Generalitat a partir de una serie de estaciones iniciales. Los registros de esta red, analizados durante el período de dieciséis años (2000-2015), corresponden a las estaciones de observación de Coratxar (La Pobla de Benifassà, 1200 metros), Morella (1153 metros), Vallibona (1235 metros) y Zorita (619 metros). La selección de estas estaciones, en el ámbito territorial de Els Ports de Morella (Castellón) y de la Reserva Natural de Els Ports de Tortosa-Beseit (Massís del Caro, Tarragona), ha sido realizada por su ubicación en pleno eje aerodinámico de los flujos procedentes de la CT de Andorra (Fig. 84).

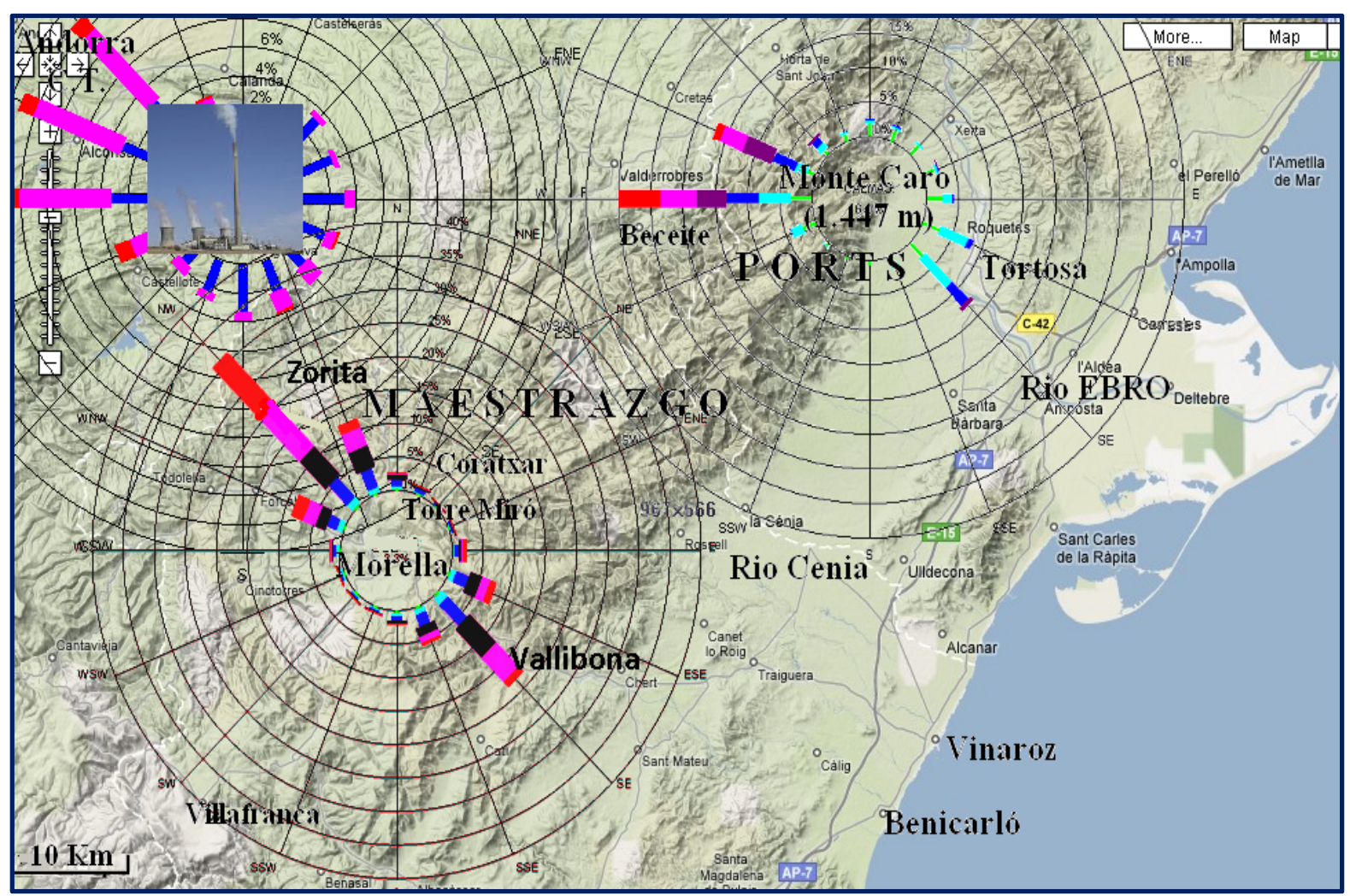

Figura 84: Estaciones de la Red de Vigilancia y Control de la Contaminación Atmosférica de la Generalitat Valenciana y rosas aerodinámicas de la red meteorológica universitaria. Fuente: archivo del Laboratorio de Climatología de la Universitat Jaume I.

La identificación de los períodos críticos de inmisiones ha estado definida por la aplicación de los umbrales límite señalados en la actual legislación y normativa europea (Real 
Decreto 102/2011, BOE 29 de enero del 2011). A partir del año 2008, con los sistemas de desulfuración de la CT actuando ya a pleno rendimiento, se ha modificado el criterio de identificación de los periodos críticos. Así pues, la analítica se ha realizado sobre aquellos períodos horarios o diarios con un valor umbral que, al menos, haya superado el $75 \%$ de esos niveles de daño y riesgo ambiental definidos por la legislación de la UE.

La metodología meteorológica ha consistido en el análisis de las situaciones atmosféricas, objetivo de la presente tesis, durante esos períodos críticos de $\mathrm{SO}_{2}$ registrados en el período 2000-2015. Estas situaciones serán completadas, en el Capítulo V, con las que simultáneamente han aparecido vinculadas a medidas de fuerte acidificación en el agua de lluvia. En síntesis, este análisis meteorológico ha sido realizado mediante cuatro técnicas:

La primera de estas técnicas, de escala sinóptica, ha consistido en la identificación previa de las distintas situaciones a través de los reanálisis a 500 y $850 \mathrm{hPa}$ del NCEP (National

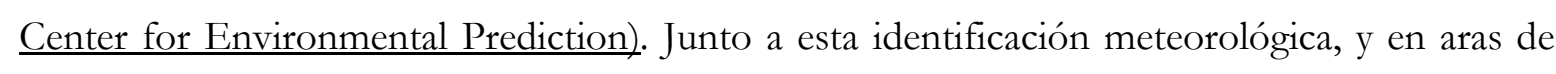
una mejor definición de los escenarios atmosféricos, la metodología aplicada ha contado con la técnica de imaginería de satélites meteorológicos del Laboratorio de Climatología de la

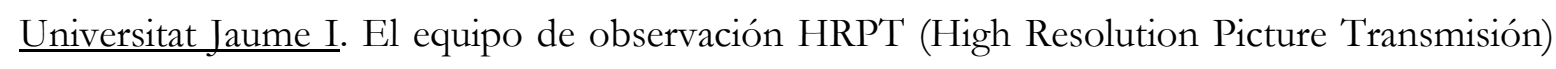
realiza la recepción de los datos digitales con una resolución espacial de $1 \mathrm{~km}$, especialmente del satélite NOAA. Esta imaginería proporciona, a través de visiones multiespectrales, el acceso a los datos actualizados permanentemente de las condiciones atmosféricas y de los subsistemas básicos mar y superficies continentales (Fig. 85).

Página | 136 


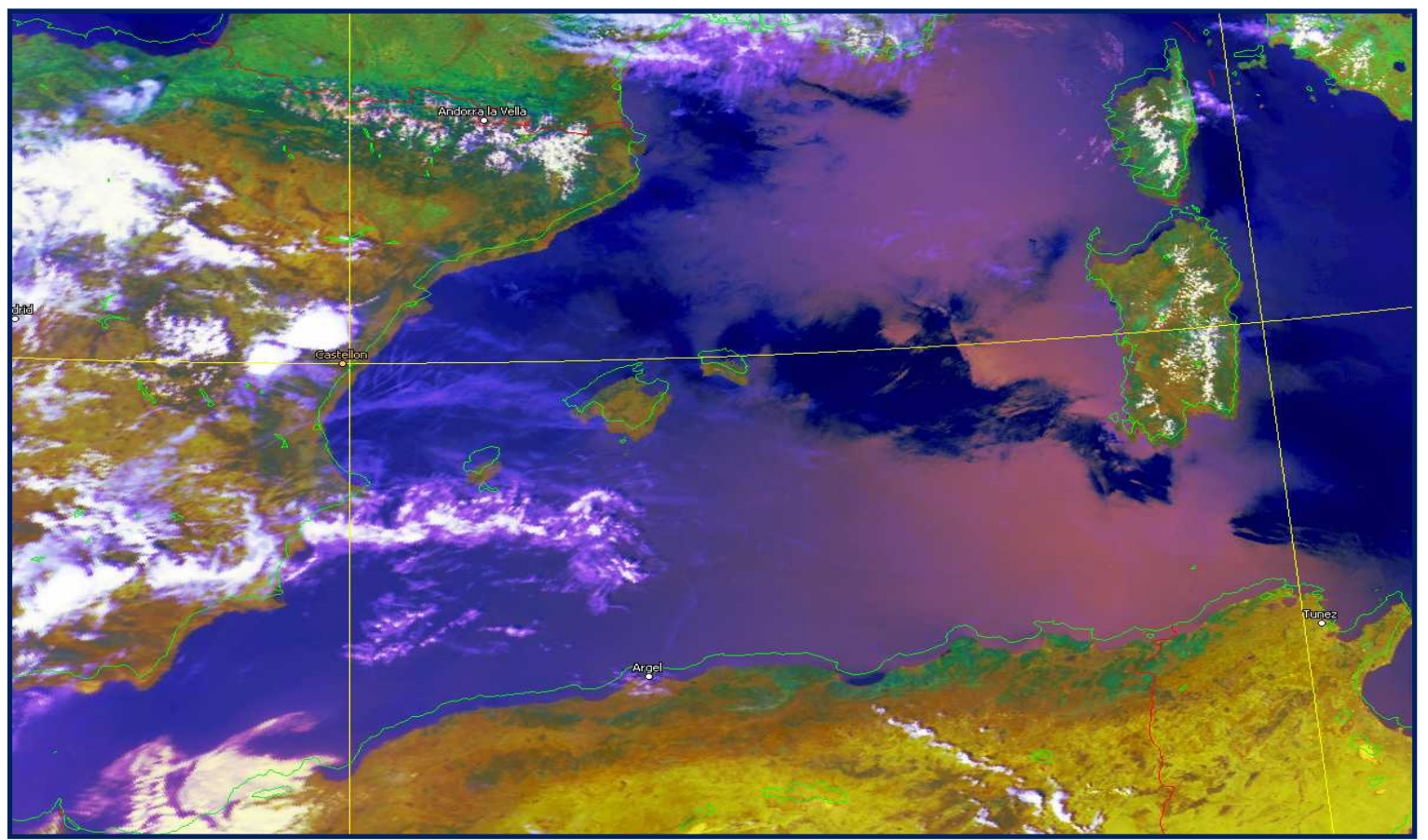

Figura 85: Ejemplo de imagen NOAA-HRPT del 25 de junio del 2010 que muestra un espectacular transporte de aerosol africano sobre la Cuenca Occidental del Mediterráneo. Fuente: archivo del Laboratorio de Climatología de la Universitat Jaume I.

El análisis meteorológico ha comprendido igualmente el empleo de dos herramientas de aplicación in situ o de mesoescala. La primera de ellas ha sido la observación de la estructura térmica vertical de la atmósfera mostrada por los radiosondeos de Zaragoza aeropuerto (AEMET), el más próximo a la zona de estudio. La segunda, aplicable desde el año 2003, ha consistido en el análisis de los registros meteorológicos de la capa activa, hasta 1500 metros de altura, a través de la red meteorológica de la Universitat Jaume I. Esta red meteorológica universitaria, ubicada sobre vértices orográficos, cuenta con las estaciones del monte Caro (1447 metros, Tortosa, Tarragona), pico de Fredes (1235 metros, Fredes, Castellón) y Torre Miró (1256 metros, Morella, Castellón) y ha permitido el análisis térmico y aerodinámico en ese nivel (1250-1450 metros) crítico para los procesos estudiados. Todos ellos correspondientes a las situaciones sinópticas cartografiadas en los reanálisis (NCAR, National Center for Atmospheric Research, Boulder).

Finalmente, será posible verificar el grado de estabilidad de las distintas situaciones atmosféricas a través del análisis de dos índices termodinámicos de estabilidad: el índice de Showalter y el Lifted Index. No obstante, siempre se debe tener presente que la caracterización de la estabilidad, o inestabilidad, realizada en el presente capítulo se refiere a la capa de mezcla (nivel inferior de la troposfera), mientras que estos índices termodinámicos de estabilidad se 
aplican a un espesor mucho mayor, entre 0 y $500 \mathrm{hPa}$, pudiendo ocasionalmente diferir los resultados.

El índice de Showalter nos da "una medida de la inestabilidad potencial de la atmósfera en el estrato entre 850 y 500 hPa” (Domínguez, 2009: 24). Su definición es:

$$
\text { Showalter Index }\left({ }^{\circ} \mathrm{C}\right)=\mathrm{SI}=\mathrm{T}_{500}-\mathrm{T}_{\text {Parcela }}
$$

Se obtiene mediante la diferencia entre la $\mathrm{T}_{500}$ (temperatura ambiente en el nivel de los $500 \mathrm{hPa}$, dada por el radiosondeo) y la $\mathrm{T}_{\text {Parcela }}$ (temperatura que alcanzaría en el nivel de 500 hPa una parcela de aire que se elevase adiabáticamente desde el nivel de $850 \mathrm{hPa}$ hasta el nivel de condensación, LCLP, y desde allí hasta los 500 hPa por la adiabática saturada).

El Lifted Index, definido por Galway en 1956, nos da una "medida de la inestabilidad potencial de la atmósfera entre la superficie y el nivel de 500 hPa" (Domínguez, 2009: 24). Su definición es:

$$
\text { Lifted Index }\left({ }^{\circ} \mathrm{C}\right)=\mathrm{LI}=\mathrm{T}_{500}-\mathrm{T}_{\text {Parcela }}
$$

Se obtiene mediante la diferencia entre la $T_{500}$ (temperatura ambiente en el nivel de los $500 \mathrm{hPa}$, dada por el radiosondeo) y la $\mathrm{T}_{\text {Parcela }}$ (temperatura que alcanzaría en el nivel de 500 hPa una parcela de aire que se elevase adiabáticamente desde la superficie hasta el nivel de condensación, LCLP, y desde allí hasta los $500 \mathrm{hPa}$ por la adiabática saturada).

Ambos índices aparecen calculados en la leyenda de los radiosondeos proporcionados por la Universidad de Wyoming (SHOW y LIFT) y se emplearán como medida de la estabilidad hasta $500 \mathrm{hPa}$, teniendo en cuenta que en ambos índices los valores positivos y superiores a 3 indican estabilidad, que es ya muy acusada con valores mayores de 6 . 


\section{EPISODIOS SOBRE EL VALOR LÍMITE MÁXIMO DE INMISIÓN DE $\mathrm{SO}_{2}$}

Como ya se ha señalado, el análisis de las situaciones atmosféricas de severa inmisión de $\mathrm{SO}_{2}$ ha sido realizado sobre los períodos con registro de inmisiones superiores a los valores umbrales señalados en la actual normativa europea (Real Decreto 102/2011, BOE 29 de enero del 2011). Este valor límite horario de $350 \mu \mathrm{g} / \mathrm{m}^{3}$ y diario de $125 \mu \mathrm{g} / \mathrm{m}^{3}$ ha sido aplicado a la serie de inmisiones registradas entre el año 2000 y el 2015 en las estaciones de Zorita (619 metros), Vallibona (1235 metros), Morella (1153 metros) y Coratxar (1200 metros).

En las figuras 86 y 87 aparecen representados los valores de inmisión de $\mathrm{SO}_{2}$, diarios y horarios respectivamente, registrados en la estación de Coratxar durante el periodo 2000-2015.

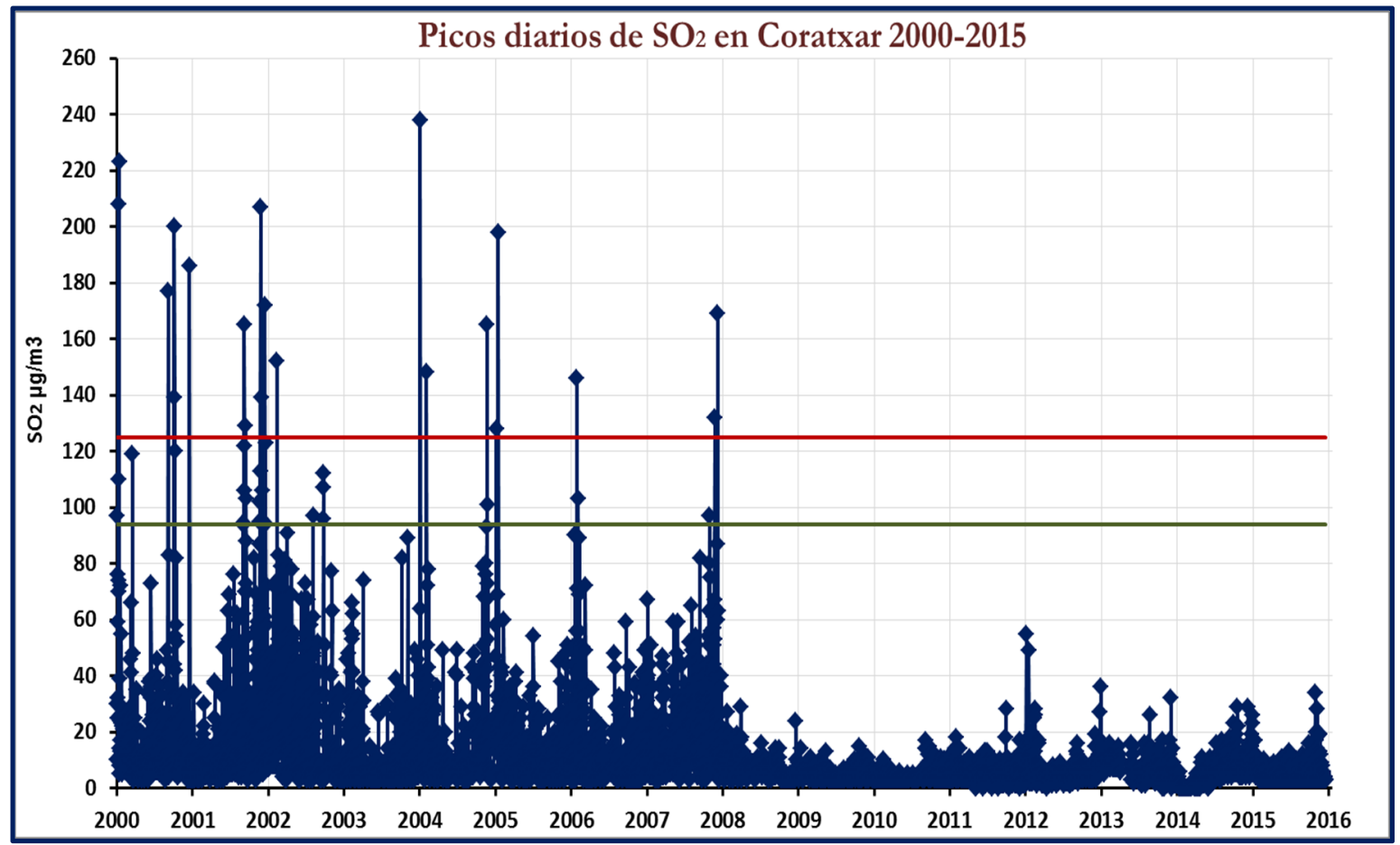

Figura 86: Picos de inmisión diarios de $\mathrm{SO}_{2}\left(\mu \mathrm{g} / \mathrm{m}^{3}\right)$ en la estación de Coratxar (2000-2015). La línea roja marca el umbral máximo diario permitido por la normativa $\left(125 \mu \mathrm{g} / \mathrm{m}^{3}\right)$, la línea verde marca el $75 \%$ de dicho umbral. Fuente: Red Valenciana de Vigilancia y Control de la Contaminación Atmosférica. Elaboración propia, Laboratorio de Climatología de la Universitat Jaume I.

El valor límite horario, tal y como muestra la figura 87 , incluso superó la tolerancia de 24 ocasiones anuales en los años 2000 y 2001 en la estación de Coratxar. Además, como se aprecia en el gráfico, hasta 2007 se registraron picos de alta inmisión con valores que superaron los fijados por la normativa vigente. 


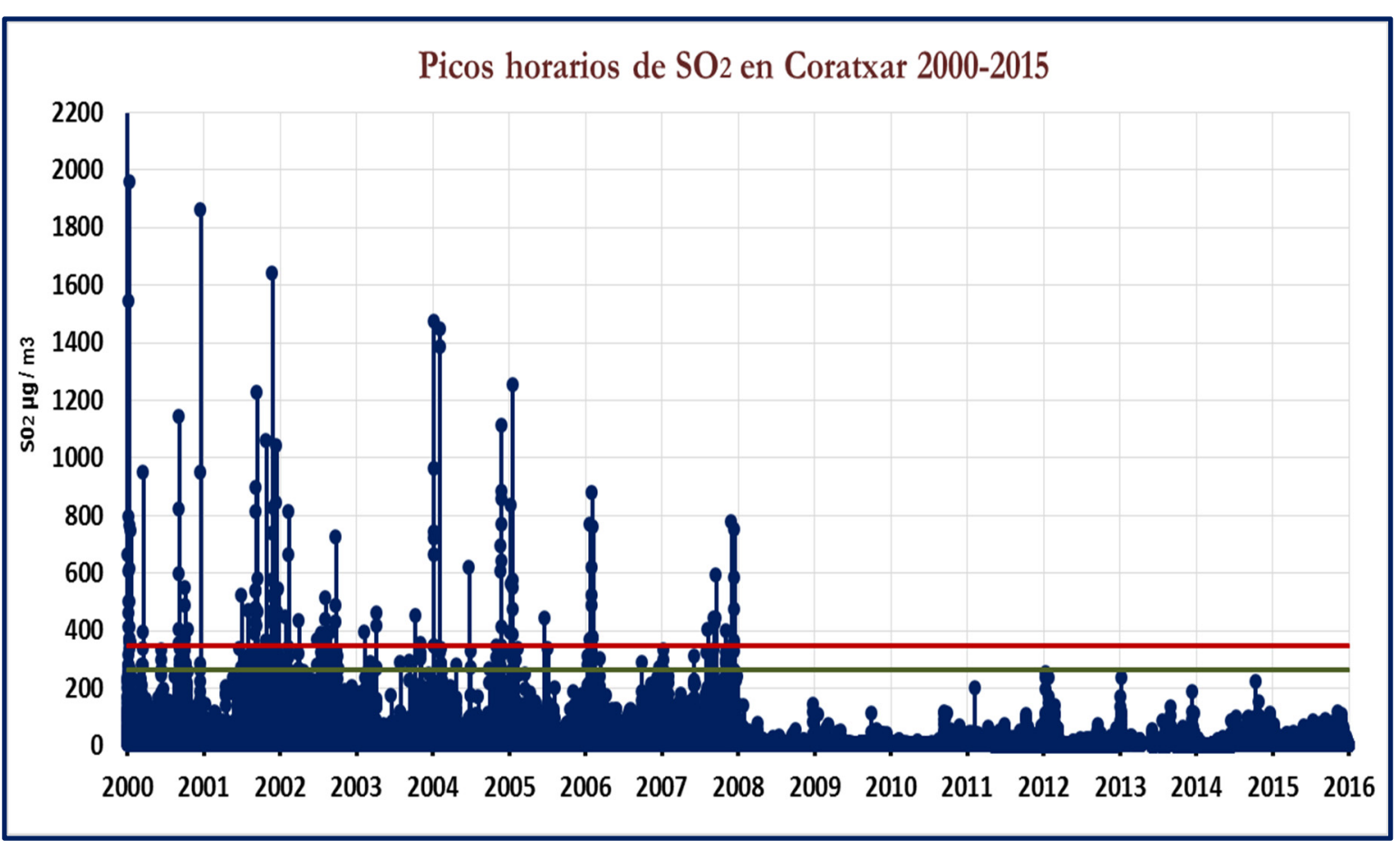

Figura 87: Picos de inmisión horarios de $\mathrm{SO}_{2}\left(\mu \mathrm{g} / \mathrm{m}^{3}\right)$ en la estación de Coratxar (2000-2015). La línea roja marca el umbral máximo horario permitido por la normativa $\left(350 \mu \mathrm{g} / \mathrm{m}^{3}\right)$, la línea verde marca el $75 \%$ de dicho umbral. Fuente: Red Valenciana de Vigilancia y Control de la Contaminación Atmosférica. Elaboración propia, Laboratorio de Climatología de la Universitat Jaume I.

No obstante, tal y como se refleja en las figuras 86 y 87, la sensible reducción de las inmisiones, tras la introducción de los actuales sistemas de desulfuración en la CT, ha impedido identificar situaciones que respondan a esos criterios de valor límite normativo a partir del año 2008. Consecuentemente, a partir de ese año, y al objeto de verificar la caracterización atmosférica en el período más reciente, la analítica de períodos críticos la hemos situado con un valor umbral que, al menos, haya superado el $75 \%$ de esos niveles de daño y riesgo ambiental definidos por la legislación de la UE. Umbrales que, al margen de aumentar la base analítica, alcanzan su justificación en que todo el referente normativo todavía dista mucho de haber establecido científicamente las relaciones de los valores fijados con los daños observados en las masas forestales o la salud humana. Afirmación especialmente sostenible en ámbitos como la Cuenca Occidental del Mediterráneo, donde una complicada orografía puede favorecer el desarrollo de episodios con fuertes impactos fitotóxicos de escala muy localizada. 


\section{LA CONCENTRACIÓN GEOGRÁFICA Y ESTACIONAL DE LA CONTAMINACIÓN}

Bajo estos criterios hemos procedido a establecer los períodos críticos de inmisión registrados y que han constituido la base de datos para el análisis meteorológico. Un análisis que nos ha permitido el establecimiento de las situaciones atmosféricas vinculadas a procesos de contaminación severa. Los períodos críticos diarios y horarios $(>75 \%$ del umbral máximo permitido) registrados en las 4 estaciones de referencia aparecen en el anexo I. Resulta evidente que la configuración estadística de la serie ya permite establecer marcos meteorológicos característicos.

Los mayores impactos, en número de episodios horarios, se registran en Coratxar (48\%) y Vallibona (33\%). En esos territorios se registra el 81\% de los episodios de contaminación. Las estaciones de Morella y Zorita tan sólo reúnen el 19\% del total (Fig. 88). Esa localización geográfica ya es expresiva de su alineación con la dinámica aérea y con menores obstáculos orográficos. Una alineación que ha permitido establecer, como hemos visto en el capítulo III, un excelente eje para la modelización gaussiana del penacho de la CT.

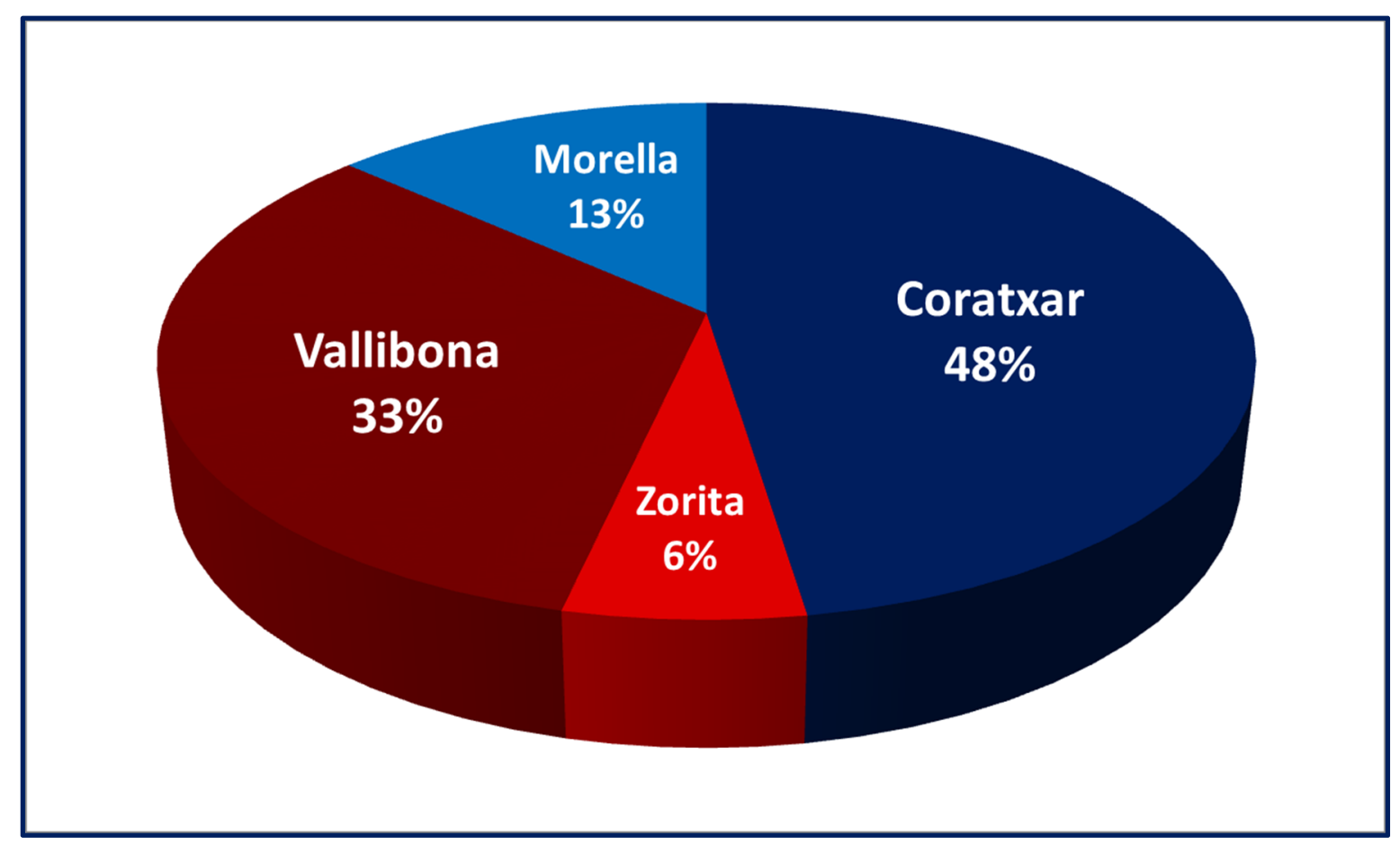

Figura 88: Distribución geográfica de los episodios horarios de impactos severos de $\mathrm{SO}_{2}$ ( $>75 \%$ del umbral máximo permitido) durante el periodo 2000-2015. Fuente: Red Valenciana de Vigilancia y Control de la Contaminación Atmosférica. Elaboración propia, Laboratorio de Climatología de la Universitat Jaume I. 
Complementariamente a esa distribución espacial, la distribución temporal de esos episodios de picos horarios y diarios de contaminación muestra una concentración mayor en los meses de otoño e invierno. Una concentración que es más significativa en los episodios diarios que en los horarios, algo más coyunturales. La figura 89 revela que en los picos diarios, registrados en la estación de Coratxar, los episodios de contaminación representan un 86\% del total, concentrado en los meses de septiembre a enero. Una concentración temporal que viene a ser expresiva de su vinculación con períodos fríos en los que la interacción de factores geográficos y atmosféricos se intensifica. Como consecuencia de esa interacción se asiste a la frecuente formación de inversiones térmicas de irradiación, limitadas en su nivel superior por la circulación atmosférica regional.

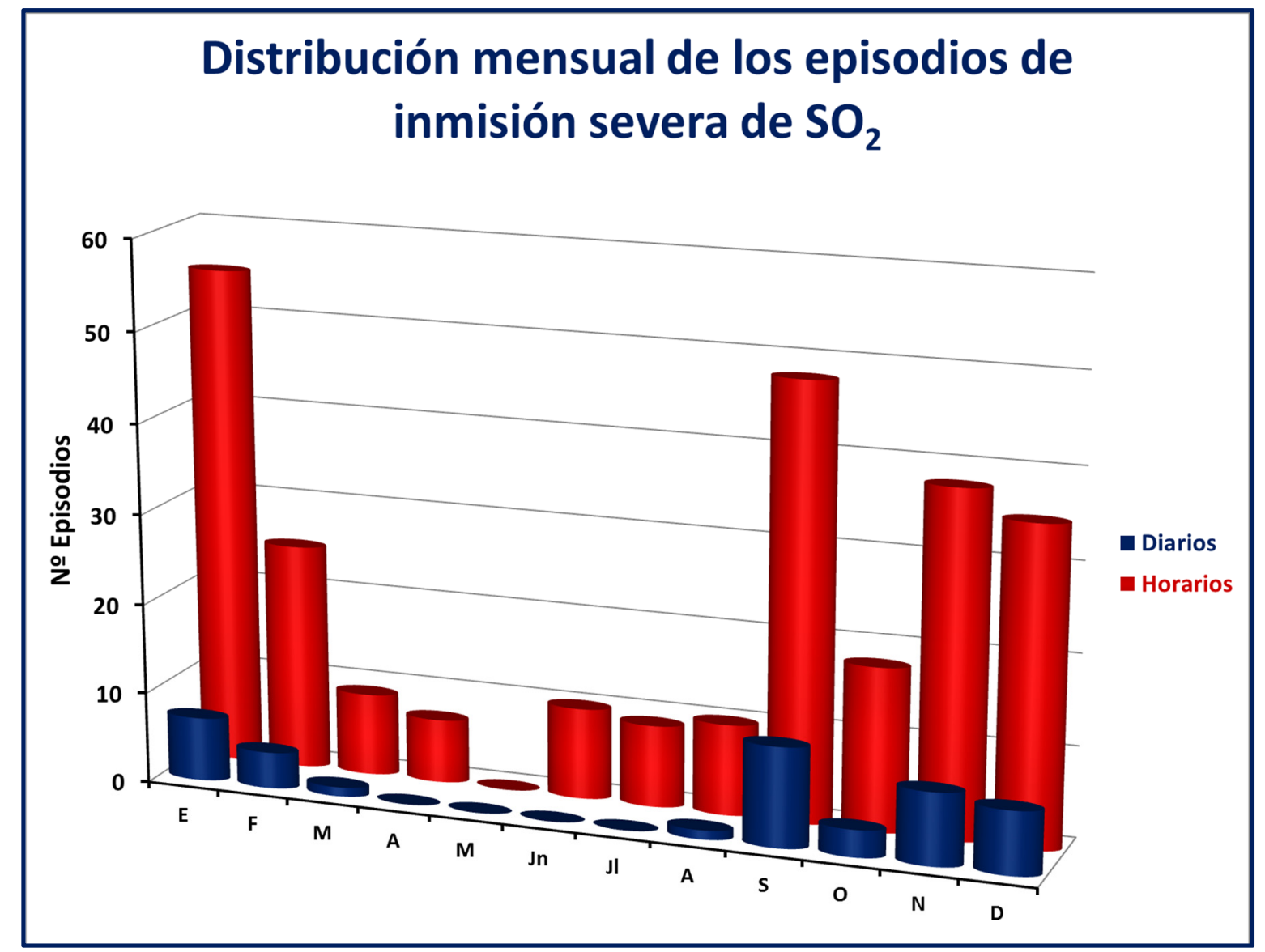

Figura 89: Distribución mensual de los episodios (diarios y horarios) de inmisión severa de $\mathrm{SO}_{2}$ (Coratxar, 2000-2015). Los episodios con inmisión severa (>75\% del umbral máximo permitido) se vinculan al otoño y al invierno, si bien los picos horarios pueden acontecer en todos los meses. Fuente: Red Valenciana de Vigilancia y Control de la Contaminación Atmosférica. Elaboración propia, Laboratorio de Climatología de la Universitat Jaume I. 


\section{LA CONFIGURACIÓN ATMOSFÉRICA EN LAS SITUACIONES DE PICOS SEVEROS DE INMISIÓN DE $\mathrm{SO}_{2}$}

En este orden analítico, hemos procedido a establecer la configuración atmosférica durante las situaciones con mayor severidad en los picos horarios y diarios de inmisión. Las situaciones diarias aquí analizadas corresponden a valores de inmisión superiores a los 200 $\mu \mathrm{g} / \mathrm{m}^{3}$ (valor normativo límite $125 \mu \mathrm{g} / \mathrm{m}^{3}$ ), mientras que las grandes situaciones de picos horarios son aquellas que han registrado más de $1000 \mu \mathrm{g} / \mathrm{m}^{3}$ (valor normativo límite 350 $\mu \mathrm{g} / \mathrm{m}^{3}$ ). Bajo este riguroso criterio de inmisión, y dado que los valores diarios son resultado de acumulación horaria, la identificación y análisis de tales situaciones vinculadas a las grandes inmisiones, ha sido realizada, básicamente, sobre picos horarios. De este modo, han sido identificados y analizados, como paradigmáticos, los grandes episodios con valores de inmisión horaria entre 1000 y $2000 \mu \mathrm{g} / \mathrm{m}^{3}$. Significativamente los valores extremos han correspondido a la estación de Coratxar. Esta estación ha servido de referencia ya que junto con la de Vallibona, ubicada en su proximidad, registran, como hemos visto, el $81 \%$ de los episodios.

\section{IV.I Las situaciones del 2000}

En conjunto, las situaciones de severa inmisión en el año 2000 superaron, con 32 episodios, las 24 ocasiones permitidas al año por la normativa. Una superación de la normativa que pudo suponer graves impactos forestales. Los principales episodios de inmisión de $\mathrm{SO}_{2}$ durante el año 2000 aparecen reflejados en la tabla 22:

Tabla 22: Episodios de mayor inmisión de $\mathrm{SO}_{2}$ en Coratxar durante el año 2000. Fuente: Red Valenciana de Vigilancia y Control de la Contaminación Atmosférica, http://www.habitatge.gva.es.

\begin{tabular}{|c|c|c|c|}
\hline Fecha & Hora & Pico horario & Pico diario \\
\hline $08 / 01 / 2000$ & $20 \mathrm{~h}$ & $1542 \mu \mathrm{g} / \mathrm{m}^{3}$ & $208 \mu \mathrm{g} / \mathrm{m}^{3}$ \\
\hline $12 / 01 / 2000$ & $2 \mathrm{~h}$ & $1958 \mu \mathrm{g} / \mathrm{m}^{3}$ & $223 \mu \mathrm{g} / \mathrm{m}^{3}$ \\
\hline $17 / 12 / 2000$ & $7 \mathrm{~h}$ & $1861 \mu \mathrm{g} / \mathrm{m}^{3}$ & $186 \mu \mathrm{g} / \mathrm{m}^{3}$ \\
\hline
\end{tabular}


Estas situaciones con altísimos valores horarios de inmisión, de hasta $1958 \mu \mathrm{g} / \mathrm{m}^{3}$ y $1861 \mu \mathrm{g} / \mathrm{m}^{3}$ en Coratxar, se configuraron bajo unos parámetros atmosféricos característicos. El primero de estos episodios aconteció el día 8 de enero. En el radiosondeo de Zaragoza aeropuerto del 8 de enero del 2000 a las 00 horas (Fig. 90) la situación atmosférica muestra una notable inversión térmica entre los 960 y los $900 \mathrm{hPa}$. Como se puede comprobar en el registro de dicho sondeo (Tabla 23), la base se establecería sobre los 536 metros y el techo se situaría a los 1070 metros. La base de esta potente inversión, $\Delta \mathrm{T}=6^{\circ} \mathrm{C}$, coincide con el nivel del LCLP.

Tabla 23: Radiosondeo de Zaragoza aeropuerto del 8 de enero del 2000 a las 00 horas. Fuente: http://weather.uwyo.edu/upperair/sounding.html.

\begin{tabular}{|c|c|c|c|c|c|c|c|c|c|c|}
\hline PRES & HGHT & TEMP & DWPT & RELH & MIXR & DRCT & SKNT & THTA & THTE & THTV \\
\hline $\mathrm{hPa}$ & $\mathrm{m}$ & ${ }^{\circ} \mathrm{C}$ & ${ }^{\circ} \mathrm{C}$ & $\%$ & $\mathrm{~g} / \mathrm{kg}$ & deg & knot & K & K & K \\
\hline 998,0 & 258 & 1,0 & 0,3 & 95 & 3,93 & 100 & 3 & 274,3 & 285,1 & 275,0 \\
\hline 996,0 & 274 & 0,8 & $-4,2$ & 69 & 2,82 & 96 & 3 & 274,3 & 282,2 & 274,7 \\
\hline 973,0 & 462 & $-0,7$ & $-1,5$ & 94 & 3,54 & 48 & 5 & 274,6 & 284,4 & 275,2 \\
\hline 964,0 & 536 & 0,0 & $-1,7$ & 88 & 3,52 & 29 & 5 & 276,0 & 285,9 & 276,6 \\
\hline 954,0 & 621 & 4,0 & 0,0 & 75 & 4,03 & 8 & 6 & 280,9 & 292,3 & 281,6 \\
\hline 947,0 & 681 & 4,4 & 0,5 & 76 & 4,21 & 353 & 6 & 281,9 & 293,9 & 282,6 \\
\hline 945,0 & 698 & 4,2 & 0,5 & 77 & 4,22 & 349 & 7 & 281,9 & 293,8 & 282,6 \\
\hline 925,0 & 873 & 5,6 & $-0,4$ & 65 & 4,03 & 305 & 8 & 285,0 & 296,7 & 285,7 \\
\hline 922,0 & 900 & 5,6 & $-1,4$ & 61 & 3,76 & 307 & 8 & 285,3 & 296,2 & 285,9 \\
\hline 903,0 & 1070 & 5,8 & $-1,2$ & 61 & 3,90 & 322 & 7 & 287,2 & 298,6 & 287,9 \\
\hline 850,0 & 1563 & 3,0 & $-3,0$ & 65 & 3,62 & 5 & 6 & 289,3 & 300,0 & 289,9 \\
\hline
\end{tabular}




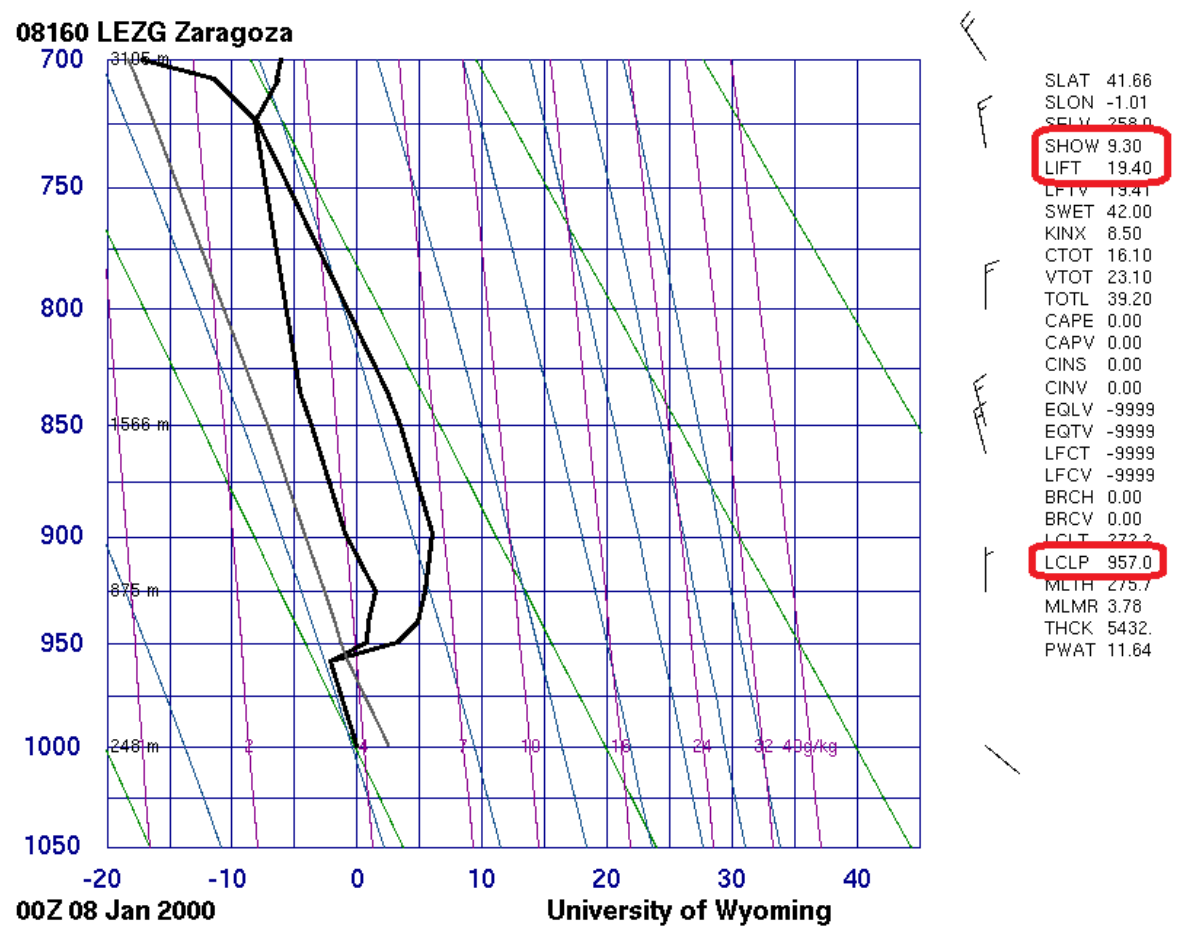

Figura 90: Radiosondeo de Zaragoza aeropuerto del 8 de enero del 2000 a las 00 horas. Fuente: http://weather.uwyo.edu/upperair/sounding.html.

En la figura 91, el reanálisis a $850 \mathrm{hPa}$ muestra la existencia de una dorsal de aire cálido a los 1500 metros de altitud.

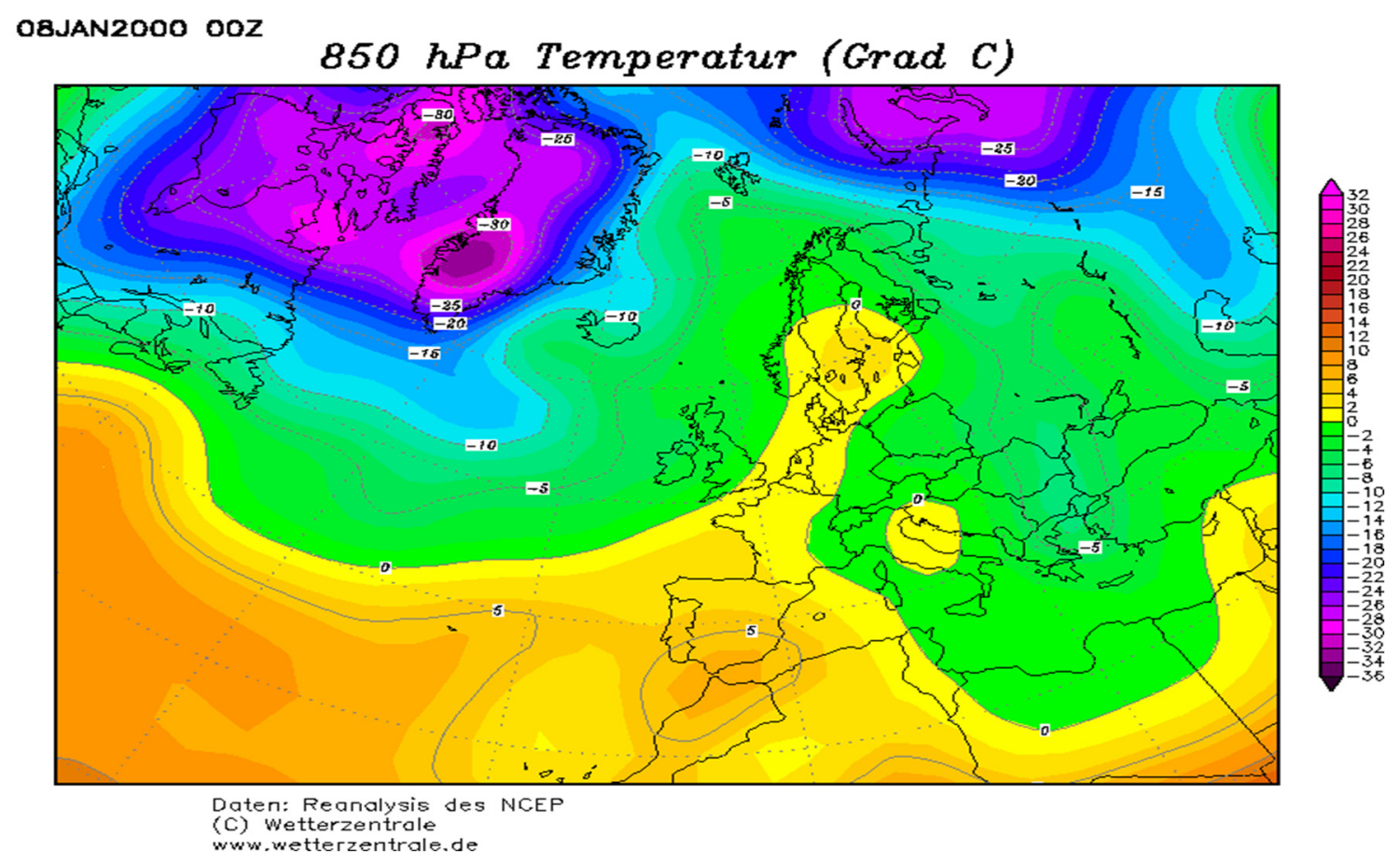

Figura 91: Reanálisis a 850 hPa del 8 de enero del 2000. Fuente: http://www.wetterzentrale.de/topkarten/fsreaeur.html. 
Una configuración atmosférica semejante perduraba en la jornada del 11 de enero y preparaba el escenario para el gran episodio de inmisión que tuvo lugar el día $\mathbf{1 2}$ de enero, con un pico de $1958 \mu \mathrm{g} / \mathrm{m}^{3}$. Como puede apreciarse en el radiosondeo de Zaragoza aeropuerto del 11 de enero del 2000 a las 12 horas (Fig. 92) y en el registro de valores de dicho sondeo (Tabla 24), la situación atmosférica muestra la presencia de una notable inversión térmica a los 890$925 \mathrm{hPa}$. La base de la inversión se sitúa próxima al nivel de los 934 metros.

Tabla 24: Radiosondeo de Zaragoza aeropuerto del 11 de enero del 2000 a las 12 horas. Fuente: http://weather.uwyo.edu/upperair/sounding.html.

\begin{tabular}{|c|c|c|c|c|c|c|c|c|c|c|}
\hline PRES & HGHT & TEMP & DWPT & RELH & MIXR & DRCT & SKNT & THTA & THTE & THTV \\
\hline $\mathbf{h P a}$ & $\mathbf{m}$ & ${ }^{\mathbf{}} \mathbf{C}$ & $\mathbf{~}^{\mathbf{C}}$ & $\mathbf{0}$ & $\mathbf{g} / \mathbf{k g}$ & $\mathbf{d e g}$ & $\mathbf{k n o t}$ & $\mathbf{K}$ & $\mathbf{K}$ & $\mathbf{K}$ \\
\hline 1006,0 & 258 & 4,0 & $-5,0$ & 52 & 2,63 & 290 & 6 & 276,7 & 284,2 & 277,1 \\
\hline 1004,0 & 275 & 4,0 & $-14,0$ & 26 & 1,30 & 292 & 7 & 276,8 & 280,7 & 277,1 \\
\hline 1000,0 & 308 & 3,6 & $-10,4$ & 35 & 1,74 & 295 & 8 & 276,8 & 281,8 & 277,0 \\
\hline 959,0 & 645 & 0,8 & $-7,2$ & 55 & 2,33 & 308 & 16 & 277,2 & 283,9 & 277,6 \\
\hline 951,0 & 712 & 0,5 & $-7,8$ & 54 & 2,25 & 310 & 17 & 277,6 & 284,1 & 278,0 \\
\hline 933,0 & 865 & $-0,1$ & $-9,1$ & 51 & 2,07 & 296 & 11 & 278,5 & 284,5 & 278,9 \\
\hline 925,0 & 934 & 0,2 & $-9,8$ & 47 & 1,97 & 290 & 9 & 279,5 & 285,3 & 279,8 \\
\hline 909,0 & 1074 & 0,4 & $-8,6$ & 51 & 2,21 & 323 & 8 & 281,1 & 287,6 & 281,5 \\
\hline 896,0 & 1190 & 1,2 & $-12,8$ & 34 & 1,60 & 350 & 7 & 283,1 & 287,9 & 283,4 \\
\hline 892,0 & 1226 & 1,4 & $-10,6$ & 40 & 1,92 & 359 & 6 & 283,7 & 289,4 & 284,0 \\
\hline 876,0 & 1371 & 0,6 & $-7,4$ & 55 & 2,51 & 33 & 5 & 284,3 & 291,7 & 284,7 \\
\hline
\end{tabular}




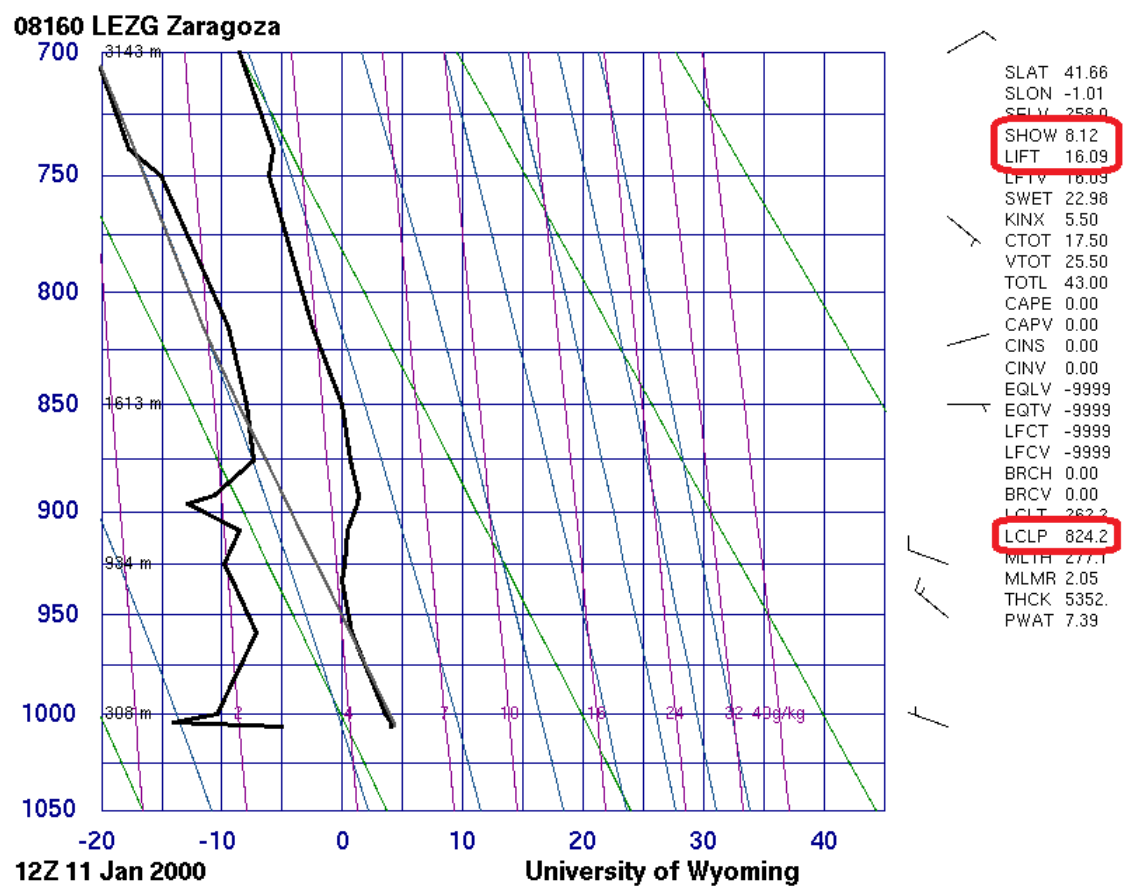

Figura 92: Radiosondeo de Zaragoza aeropuerto del 11 de enero del 2000 a las 12 horas. La situación atmosférica muestra la persistencia de una notable inversión térmica a los 890-925 hPa. Fuente: http://weather.uwyo.edu/upperair/sounding.html.

En la figura 93, en el reanálisis a $500 \mathrm{hPa}$ del 12 de enero del 2000, se aprecia con claridad que la dorsal de aire cálido existente a $850 \mathrm{hPa}$ se intensifica hasta los $500 \mathrm{hPa}$, bajo una potente estructura anticiclónica sobre la Península Ibérica.

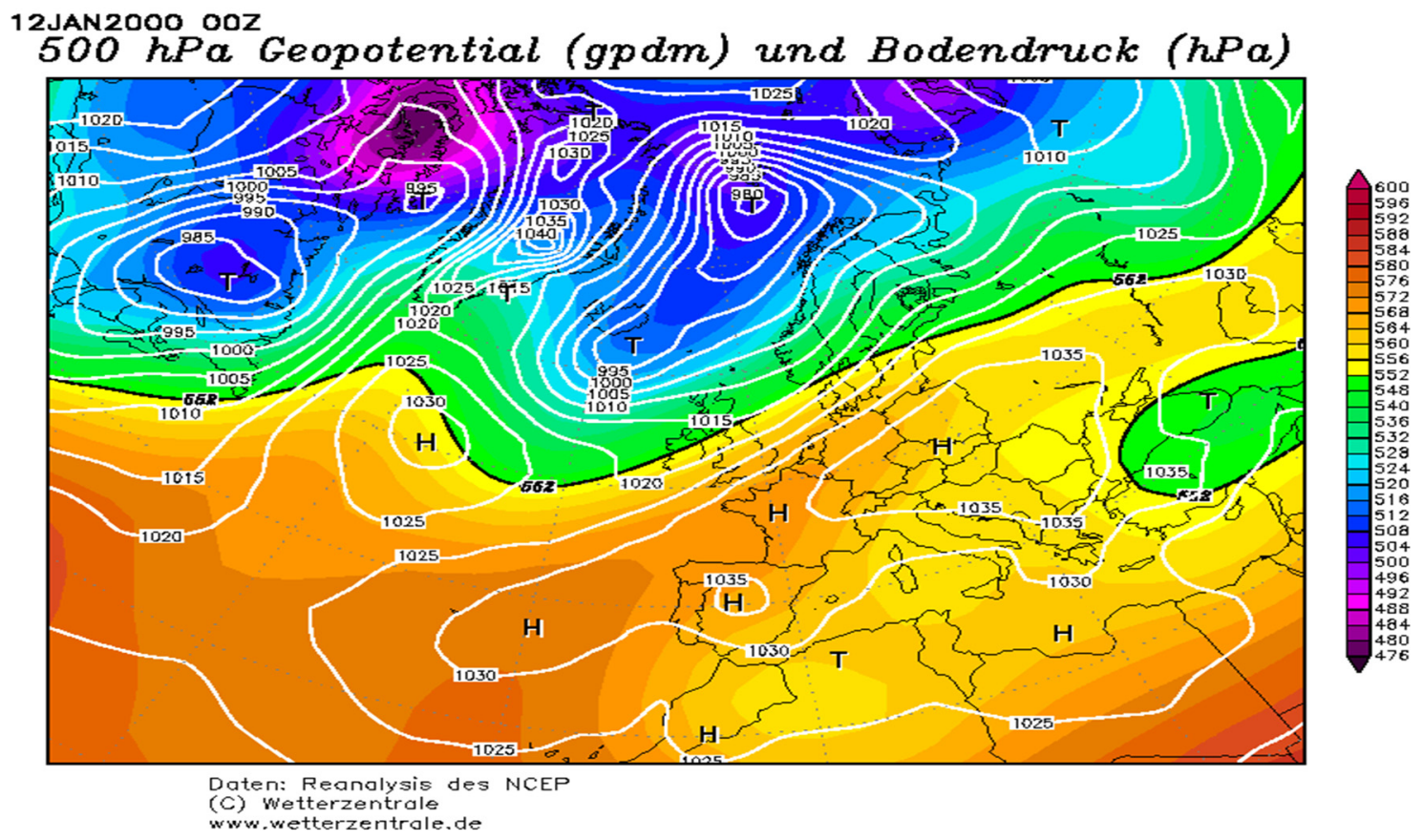

Figura 93: Reanálisis a $500 \mathrm{hPa}$ del 12 de enero del 2000. Fuente: http://www.wetterzentrale.de/topkarten/fsreaeur.html. 
El tercero de los grandes episodios de inmisión del año 2000 aconteció el 17 de diciembre a las 7 horas, con $1861 \mu \mathrm{g} / \mathrm{m}^{3}$. Como se puede comprobar en el radiosondeo de Zaragoza y en el registro de dicha jornada (Fig. 94 y Tabla 25), la capa de inversión aparece ya a nivel de los 506 metros y se extiende hasta los 929 metros, si bien sobre ella aparece una estructura atmosférica de gran estabilidad que detiene los movimientos de ascenso aéreo.

No obstante, el débil gradiente térmico $\left(\Gamma_{\mathrm{t}}=0,003{ }^{\circ} \mathrm{C} / \mathrm{m}\right)$ hasta los 1063 metros es indicativo de que esta capa estable de inversión podría ascender sobre los 1000 metros.

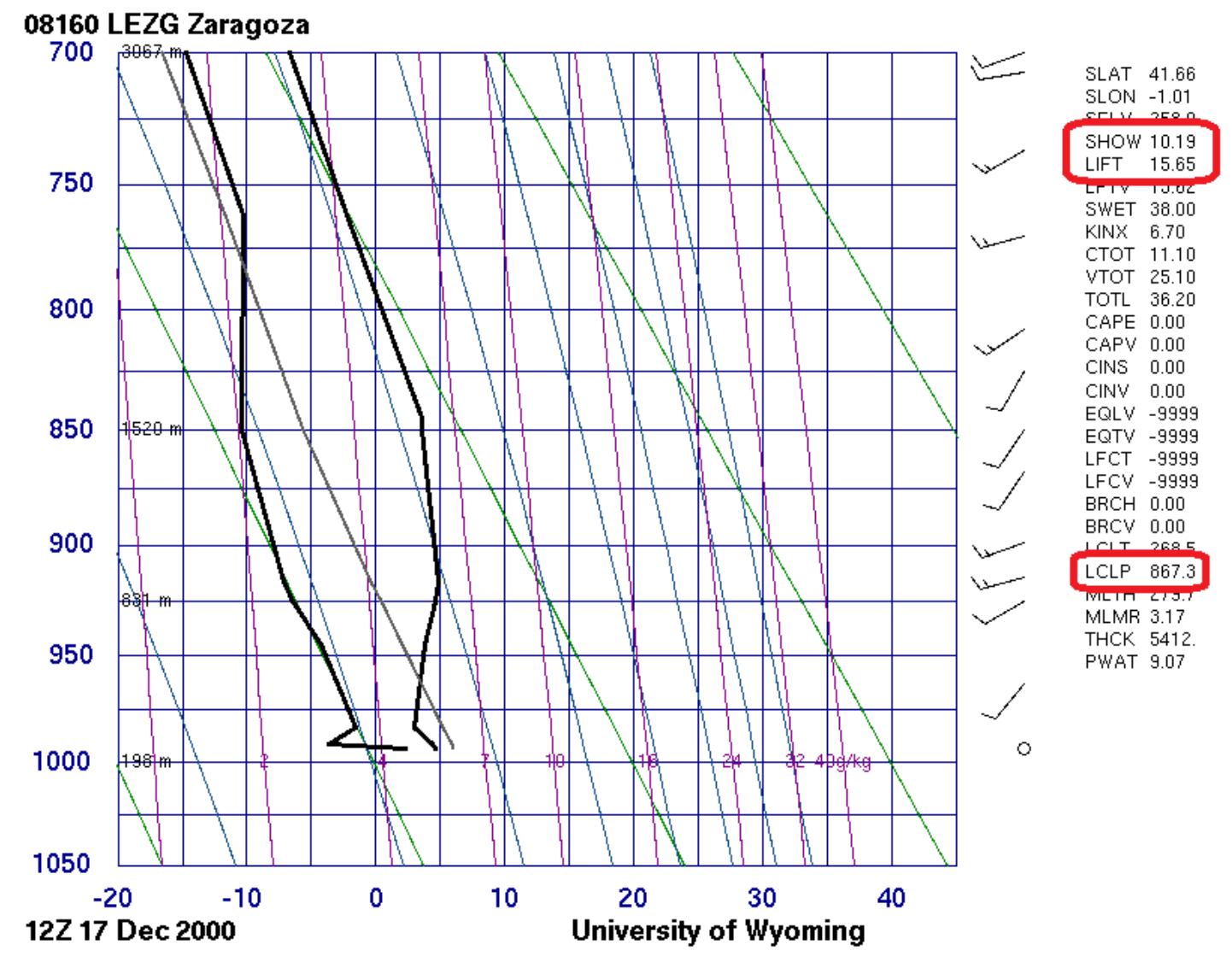

Figura 94: Radiosondeo de Zaragoza aeropuerto del 17 de diciembre del 2000 a las 12 horas. Fuente: http://weather.uwyo.edu/upperair/sounding.html. 
Tabla 25: Registro del radiosondeo de Zaragoza del 17 de diciembre del 2000 a las 12 horas. Fuente: http://weather.uwyo.edu/upperair/sounding.html.

\begin{tabular}{|c|c|c|c|c|c|c|c|c|c|c|}
\hline PRES & HGHT & TEMP & DWPT & RELH & MIXR & DRCT & SKNT & THTA & THTE & THTV \\
\hline $\mathbf{h P a}$ & $\mathbf{m}$ & ${ }^{\mathbf{o}} \mathbf{C}$ & $\mathbf{{ } ^ { \mathbf { C } }}$ & $\mathbf{\%}$ & $\mathbf{g} / \mathbf{k g}$ & $\mathbf{d e g}$ & $\mathbf{k n o t}$ & $\mathbf{K}$ & $\mathbf{K}$ & $\mathbf{K}$ \\
\hline 993,0 & 258 & 4,6 & 2,3 & 85 & 4,57 & 0 & 0 & 278,3 & 291,0 & 279,1 \\
\hline 991,0 & 274 & 4,4 & $-3,6$ & 56 & 2,97 & 351 & 1 & 278,3 & 286,7 & 278,8 \\
\hline 983,0 & 340 & 3,0 & $-1,6$ & 72 & 3,47 & 314 & 3 & 277,5 & 287,3 & 278,1 \\
\hline 963,0 & 506 & 3,4 & $-3,0$ & 63 & 3,21 & 220 & 10 & 279,6 & 288,7 & 280,1 \\
\hline 945,0 & 658 & 3,8 & $-4,2$ & 56 & 2,98 & 229 & 11 & 281,5 & 290,1 & 282,0 \\
\hline 925,0 & 831 & 4,6 & $-6,4$ & 45 & 2,57 & 240 & 12 & 284,0 & 291,6 & 284,4 \\
\hline 916,0 & 911 & 4,8 & $-7,2$ & 41 & 2,44 & 252 & 14 & 285,0 & 292,2 & 285,4 \\
\hline 914,0 & 929 & 4,8 & $-7,3$ & 41 & 2,43 & 255 & 14 & 285,1 & 292,4 & 285,6 \\
\hline 899,0 & 1063 & 4,5 & $-8,0$ & 40 & 2,34 & 250 & 16 & 286,2 & 293,2 & 286,6 \\
\hline 868,0 & 1349 & 3,9 & $-9,5$ & 37 & 2,15 & 215 & 11 & 288,5 & 295,1 & 288,9 \\
\hline
\end{tabular}

El mapa de superficie correspondiente a esta jornada (Fig. 95) muestra una situación atmosférica presidida por un notable anticiclón.

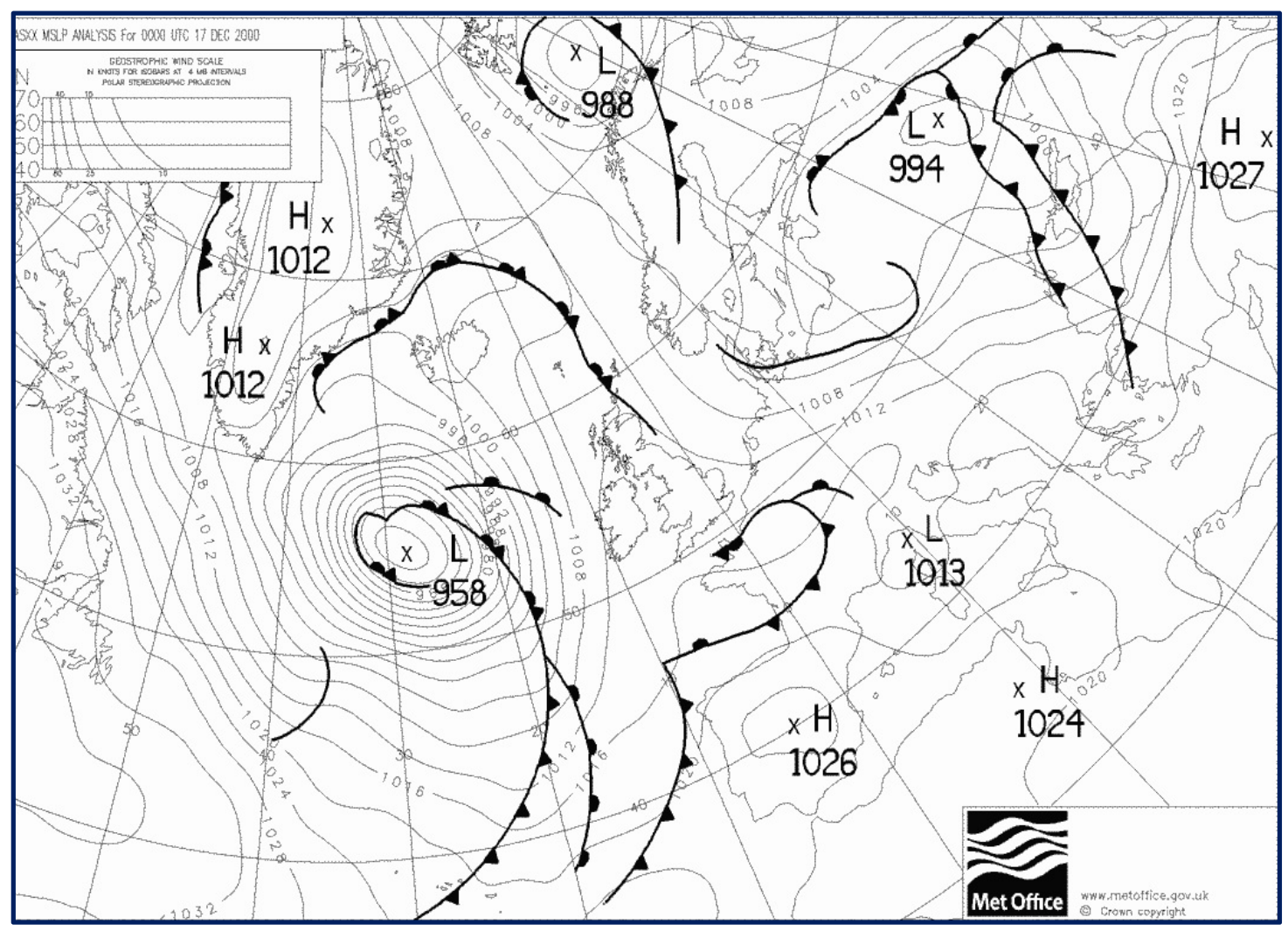

Figura 95: Mapa de superficie del 17 de diciembre del 2000 a las 00 horas. Fuente:

http://www.wetterzentrale.de/topkarten/tkfaxbraar.htm. 


\section{IV.II Las situaciones del 2001}

El año 2001 registró tres grandes episodios (Tabla 26):

Tabla 26: Episodios de mayor inmisión de $\mathrm{SO}_{2}$ en Coratxar durante el año 2001. Fuente: Red Valenciana de Vigilancia y Control de la Contaminación Atmosférica, http://www.habitatge.gva.es.

\begin{tabular}{|c|c|c|c|}
\hline \multicolumn{1}{|c|}{ Fecha } & Hora & Pico Horario & Pico diario \\
\hline $13 / 09 / 2001$ & $7 \mathrm{~h}$ & $1225 \mu \mathrm{g} / \mathrm{m}^{3}$ & $129 \mu \mathrm{g} / \mathrm{m}^{3}$ \\
\hline $26 / 10 / 2001$ & $7 \mathrm{~h}$ & $1059 \mu \mathrm{g} / \mathrm{m}^{3}$ & $82 \mu \mathrm{g} / \mathrm{m}^{3}$ \\
\hline $26 / 11 / 2001$ & $3 \mathrm{~h}$ & $1639 \mu \mathrm{g} / \mathrm{m}^{3}$ & $207 \mu \mathrm{g} / \mathrm{m}^{3}$ \\
\hline
\end{tabular}

De estos episodios, careciendo de sondeo para la situación de mayor inmisión del 26 de noviembre, analizamos la configuración atmosférica existente el 13 de septiembre. Esta situación se operó bajo los siguientes parámetros atmosféricos representados en el radiosondeo de Zaragoza aeropuerto del 13 de septiembre del 2001 (Fig. 96 y Tabla 27). La capa de inversión extendida entre los 897 y los $871 \mathrm{hPa}$ (1106-1358 metros) señala la notable estabilidad y detención de los movimientos ascendentes del aire.

Tabla 27: Registro del radiosondeo de Zaragoza aeropuerto del 13 de septiembre del 2001 a las 12 horas. Fuente: http://weather.uwyo.edu/upperair/sounding.html.

\begin{tabular}{|c|c|c|c|c|c|c|c|c|c|c|}
\hline PRES & HGHT & TEMP & DWPT & RELH & MIXR & DRCT & SKNT & THTA & THTE & THTV \\
\hline $\mathbf{h P a}$ & $\mathbf{m}$ & ${ }^{\mathbf{0}} \mathbf{C}$ & ${ }^{\mathbf{o}} \mathbf{C}$ & $\mathbf{0}$ & $\mathbf{g} / \mathbf{k g}$ & $\mathbf{d e g}$ & $\mathbf{k n o t}$ & $\mathbf{K}$ & $\mathbf{K}$ & $\mathbf{K}$ \\
\hline 990,0 & 258 & 23,0 & 6,0 & 33 & 5,96 & 320 & 8 & 297,0 & 314,8 & 298,1 \\
\hline 925,0 & 843 & 17,8 & 0,8 & 32 & 4,40 & 260 & 4 & 297,5 & 310,9 & 298,3 \\
\hline 918,0 & 908 & 17,4 & 1,4 & 34 & 4,63 & 259 & 5 & 297,7 & 311,8 & 298,6 \\
\hline 897,0 & 1106 & 18,4 & 4,4 & 40 & 5,88 & 256 & 9 & 300,8 & 318,6 & 301,8 \\
\hline 896,0 & 1115 & 18,2 & 4,2 & 39 & 5,80 & 256 & 9 & 300,6 & 318,2 & 301,7 \\
\hline 890,0 & 1173 & 18,6 & 2,7 & 35 & 5,24 & 255 & 10 & 301,6 & 317,6 & 302,6 \\
\hline 871,0 & 1358 & 19,8 & $-2,2$ & 23 & 3,75 & 264 & 11 & 304,7 & 316,6 & 305,4 \\
\hline 850,0 & 1567 & 18,2 & $-0,8$ & 28 & 4,26 & 275 & 13 & 305,2 & 318,6 & 306,0 \\
\hline 831,0 & 1758 & 16,6 & $-1,1$ & 30 & 4,25 & 280 & 15 & 305,5 & 318,8 & 306,3 \\
\hline 777,0 & 2327 & 11,8 & $-2,2$ & 38 & 4,21 & 283 & 20 & 306,2 & 319,5 & 307,0 \\
\hline 738,0 & 2752 & 8,0 & $-6,0$ & 36 & 3,31 & 285 & 23 & 306,6 & 317,2 & 307,2 \\
\hline
\end{tabular}




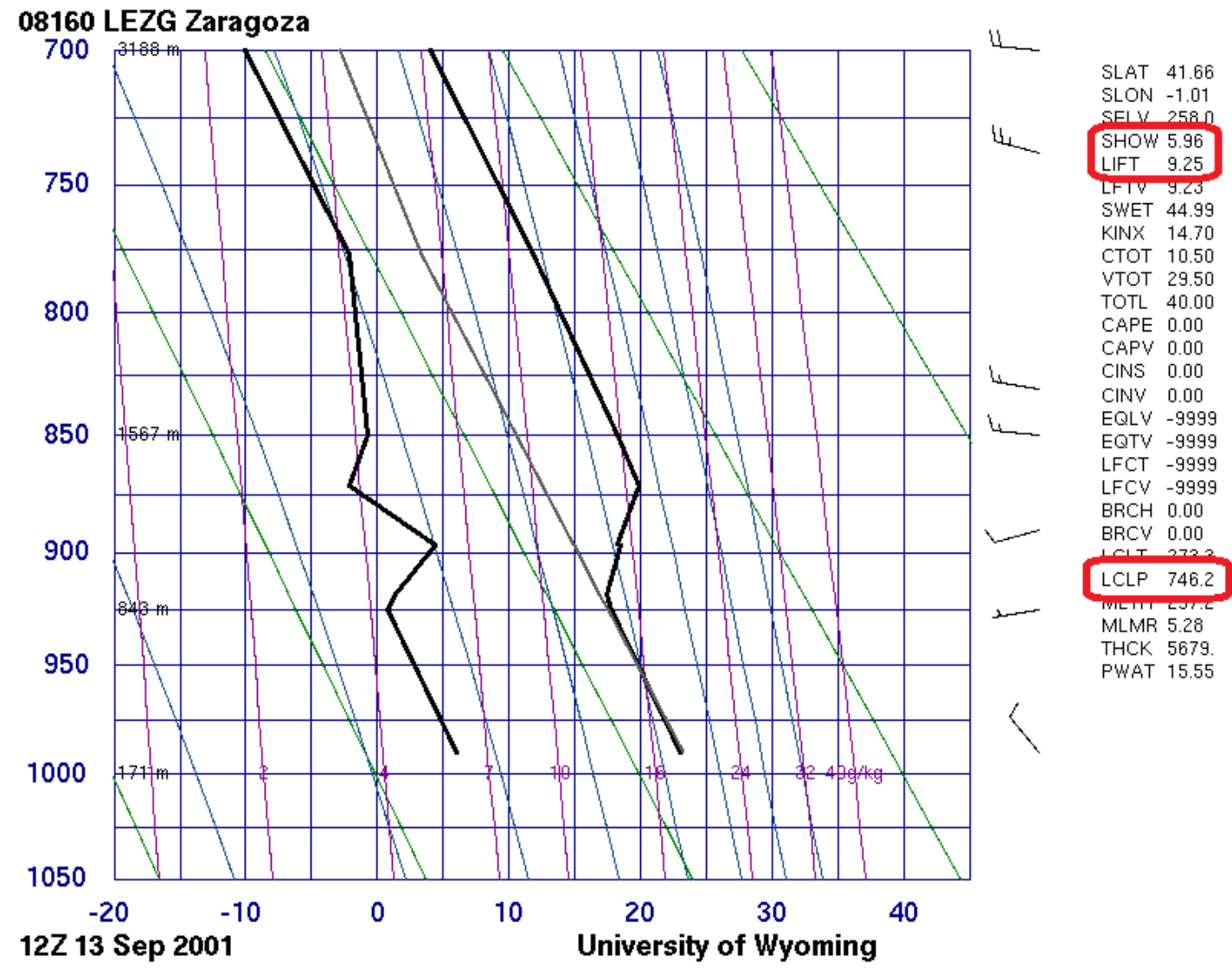

Figura 96: Radiosondeo de Zaragoza aeropuerto del 13 de septiembre del 2001 a las 12 horas. Fuente: http://weather.uwyo.edu/upperair/sounding.html.

En el reanálisis a $850 \mathrm{hPa}$ de dicha jornada (Fig. 97), la situación atmosférica aparece configurada por una notabilísima dorsal de aire cálido a los 1500 metros de altitud. Esta dorsal engendra por subsidencia la notable inversión térmica regional que, como hemos visto en la tabla del registro del radiosondeo (Tabla 27), se registra desde los 1106 metros. 
13SEP200100Z

850 hPa Temperatur (Grad C)
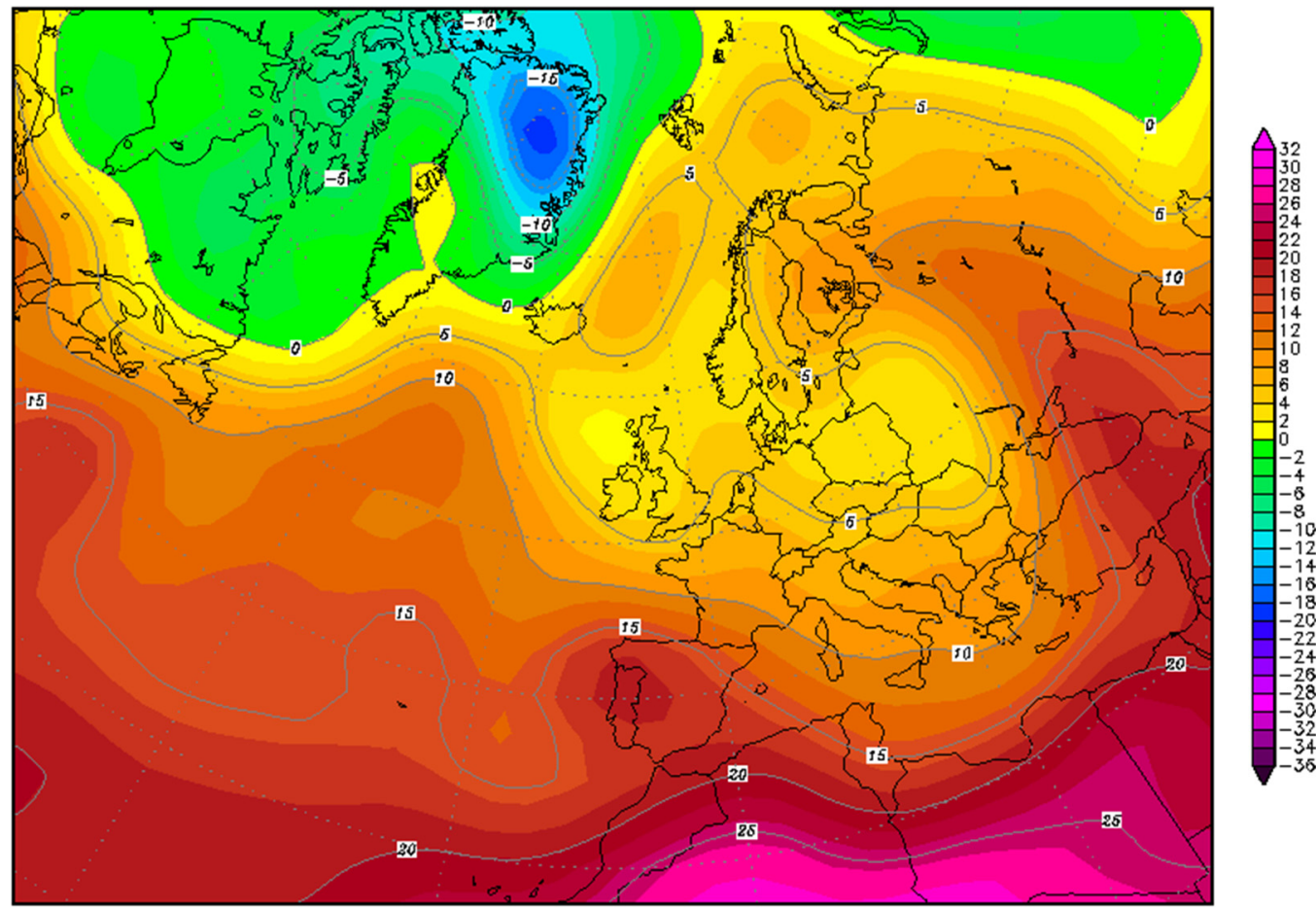

Daten: Reanalysis des NCEP

(C) Wetterzentrale

www.wetterzentrale.de

Figura 97: Reanálisis a 850 hPa del 13 de septiembre del 2001. Fuente: http://www.wetterzentrale.de/topkarten/fsreaeur.html.

Esta configuración atmosférica, de alto impacto de contaminación, coincide con la que aconteció el día 26 de octubre del 2001. En el radiosondeo de Zaragoza aeropuerto (Fig. 98), así como en el registro del mismo (Tabla 28), se puede apreciar como existe una importante capa de inversión térmica. Esta capa, formada a un nivel desde los 647 metros y extendida hasta los 918 metros, podría extenderse en realidad hasta los 1000 metros de altura aproximadamente. El debilísimo gradiente térmico $\left(\Gamma_{\mathrm{t}}=0,005{ }^{\circ} \mathrm{C} / \mathrm{m}\right)$ permite esta extrapolación. Dicho nivel coincide con el nivel de emisiones de la chimenea de la CT de manera que la gran estabilidad detiene la dispersión de los contaminantes emitidos. 
Tabla 28: Registro del radiosondeo de Zaragoza aeropuerto del 26 de octubre del 2001 a las 12 horas. Fuente: http://weather.uwyo.edu/upperair/sounding.html.

\section{PRES HGHT TEMP DWPT RELH MIXR DRCT SKNT THTA THTE THTV}

\begin{tabular}{|c|c|c|c|c|c|c|c|c|c|c|}
\hline $\mathbf{h P a}$ & $\mathbf{m}$ & ${ }^{\mathbf{0}} \mathbf{C}$ & ${ }^{\mathbf{0}} \mathbf{C}$ & $\mathbf{0}$ & $\mathbf{g} / \mathbf{k g}$ & $\mathbf{d e g}$ & $\mathbf{k n o t}$ & $\mathbf{K}$ & $\mathbf{K}$ & $\mathbf{K}$ \\
\hline 994,0 & 258 & 12,4 & 12,1 & 98 & 8,99 & 120 & 2 & 286,0 & 311,2 & 287,6 \\
\hline 993,0 & 266 & 12,0 & 7,3 & 73 & 6,50 & 121 & 2 & 285,7 & 304,1 & 286,8 \\
\hline 964,0 & 515 & 9,2 & 9,2 & 100 & 7,63 & 160 & 5 & 285,3 & 306,7 & 286,6 \\
\hline 949,0 & 647 & 12,0 & 8,3 & 78 & 7,29 & 181 & 6 & 289,4 & 310,3 & 290,7 \\
\hline 925,0 & 863 & 13,2 & 7,2 & 67 & 6,93 & 215 & 8 & 292,8 & 313,0 & 294,0 \\
\hline 919,0 & 918 & 13,4 & 7,4 & 67 & 7,07 & 218 & 8 & 293,6 & 314,2 & 294,8 \\
\hline 880,0 & 1281 & 11,5 & 3,8 & 59 & 5,76 & 240 & 11 & 295,2 & 312,3 & 296,3 \\
\hline 878,0 & 1300 & 11,4 & 3,7 & 59 & 5,70 & 255 & 11 & 295,3 & 312,2 & 296,4 \\
\hline 850,0 & 1572 & 10,0 & 1,0 & 54 & 4,86 & 255 & 12 & 296,6 & 311,2 & 297,5 \\
\hline 825,0 & 1819 & 7,8 & 0,8 & 61 & 4,94 & 254 & 12 & 296,8 & 311,7 & 297,7 \\
\hline 803,0 & 2042 & 7,6 & $-9,4$ & 29 & 2,35 & 254 & 13 & 298,9 & 306,3 & 299,3 \\
\hline 724,0 & 2888 & 4,0 & $-27,0$ & 8 & 0,58 & 251 & 14 & 303,9 & 306,0 & 304,1 \\
\hline 712,0 & 3023 & 3,8 & $-23,2$ & 12 & 0,83 & 250 & 14 & 305,2 & 308,0 & 305,3 \\
\hline 700,0 & 3161 & 2,6 & $-22,4$ & 14 & 0,91 & 250 & 14 & 305,3 & 308,4 & 305,5 \\
\hline 636,0 & 3917 & $-2,9$ & $-23,9$ & 18 & 0,88 & 255 & 16 & 307,6 & 310,6 & 307,7 \\
\hline 618,0 & 4144 & $-4,5$ & $-24,3$ & 20 & 0,87 & 275 & 15 & 308,2 & 311,2 & 308,4 \\
\hline 551,0 & 5049 & $-11,1$ & $-26,1$ & 28 & 0,83 & 247 & 17 & 310,7 & 313,6 & 310,9 \\
\hline 546,0 & 5119 & $-11,4$ & $-27,9$ & 24 & 0,71 & 245 & 17 & 311,2 & 313,7 & 311,3 \\
\hline 529,0 & 5362 & $-12,3$ & $-34,3$ & 14 & 0,40 & 249 & 16 & 312,9 & 314,4 & 313,0 \\
\hline 500,0 & 5790 & $-16,1$ & $-37,1$ & 15 & 0,32 & 255 & 15 & 313,4 & 314,5 & 313,4 \\
\hline
\end{tabular}




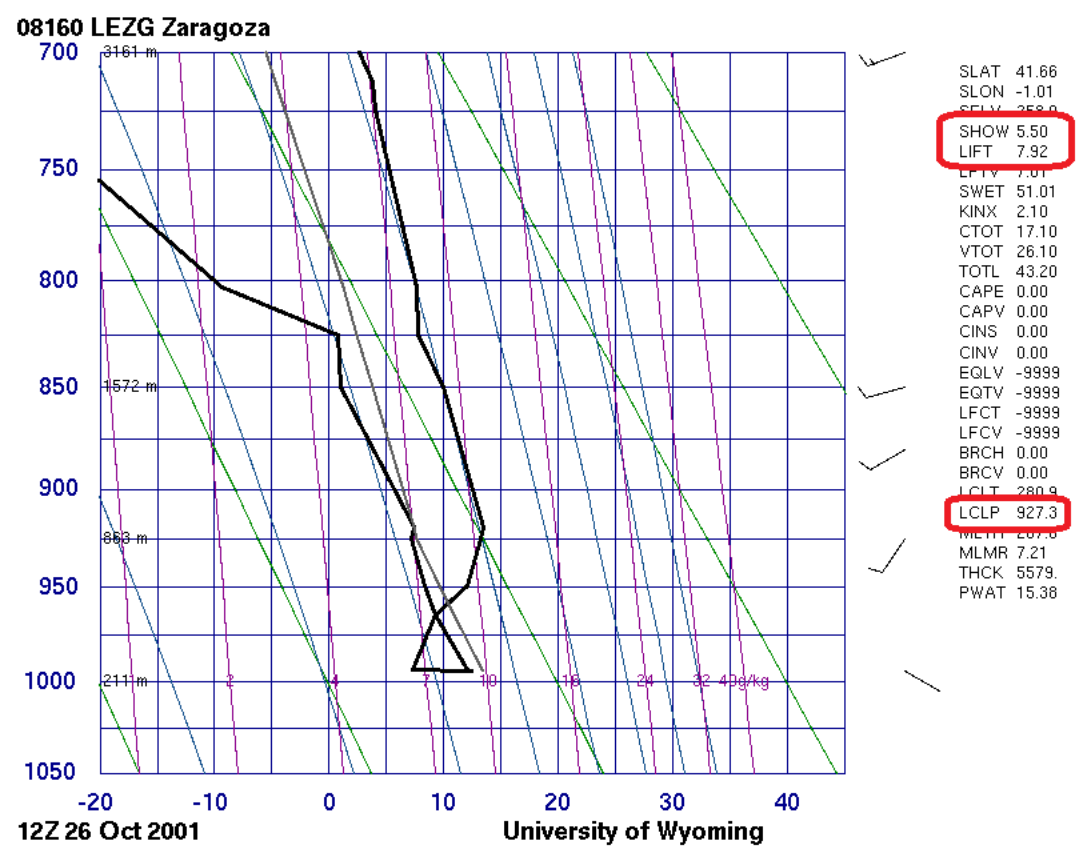

Figura 98: Radiosondeo de Zaragoza aeropuerto del 26 de octubre del 2001 a las 12 horas. Fuente: http://weather.uwyo.edu/upperair/sounding.html.

Del mismo modo que en situaciones anteriores de fuerte inmisión, el mapa de presión a $850 \mathrm{hPa}$ de esta jornada evidencia el potente anticiclón subsidente que comprime el aire agudizando los efectos de la inversión térmica (Fig. 99).

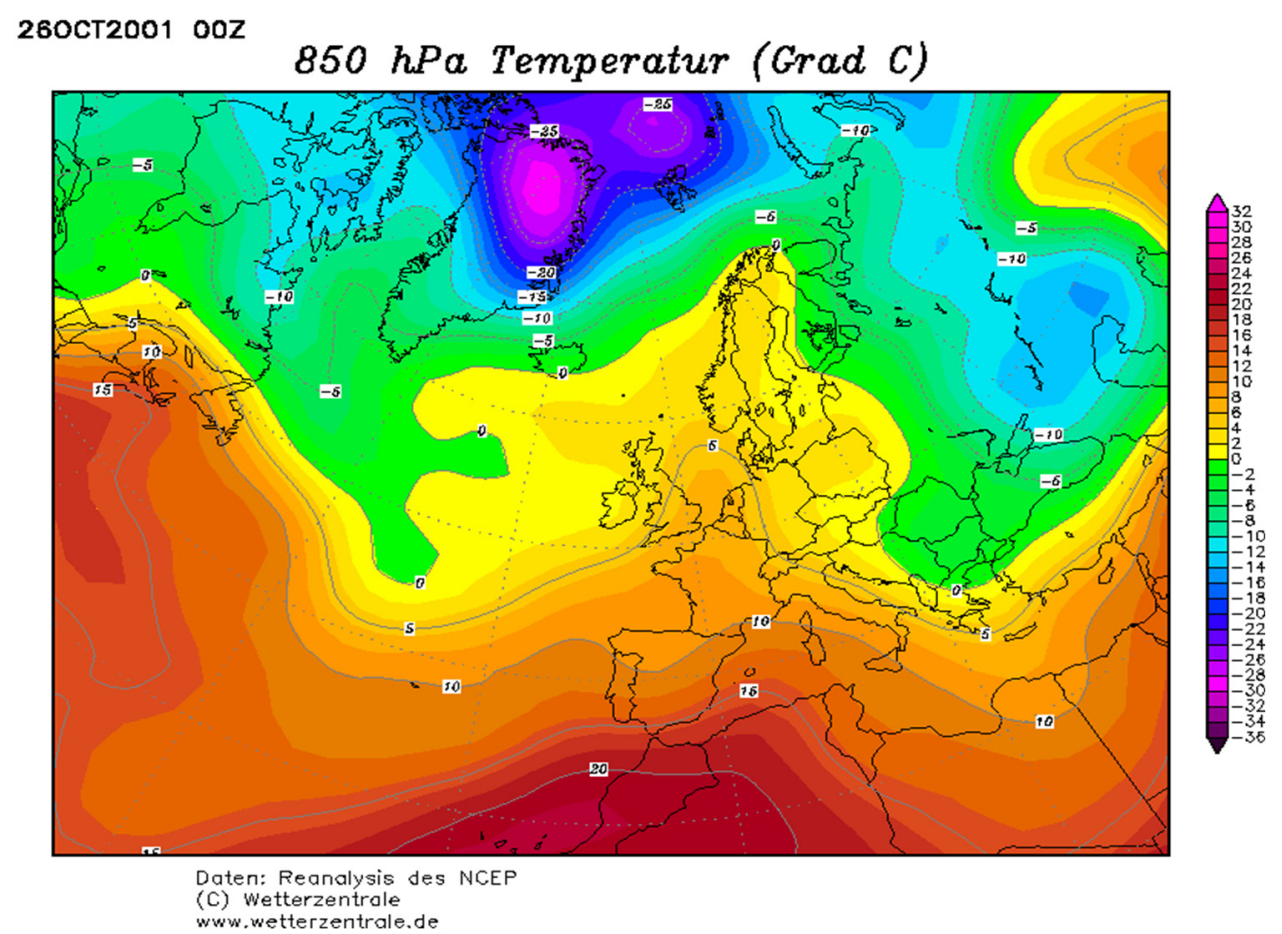

Figura 99: Reanálisis a 850 hPa del 26 de octubre del 2001. Fuente: http://www.wetterzentrale.de/topkarten/fsreaeur.html.

Página | 154 


\section{IV.III La situaciones del 2004}

El año 2004 registró dos grandes episodios de fuerte inmisión tanto horaria como diaria (Tabla 29):

Tabla 29: Episodios de mayor inmisión de $\mathrm{SO}_{2}$ registrados en Coratxar durante el año 2004. Fuente: Red Valenciana de Vigilancia y Control de la Contaminación Atmosférica, http://www.habitatge.gva.es.

\begin{tabular}{|c|c|c|c|}
\hline Fecha & Hora & Pico Horario & Pico Diario \\
\hline $06 / 01 / 2004$ & $3 \mathrm{~h}$ & $1473 \mu \mathrm{g} / \mathrm{m}^{3}$ & $238 \mu \mathrm{g} / \mathrm{m}^{3}$ \\
\hline \multirow{2}{*}{$05 / 02 / 2004$} & $7 \mathrm{~h}$ & $1387 \mu \mathrm{g} / \mathrm{m}^{3}$ & \multirow{2}{*}{$148 \mu \mathrm{g} / \mathrm{m}^{3}$} \\
\hline & $8 \mathrm{~h}$ & $1447 \mu \mathrm{g} / \mathrm{m}^{3}$ & \\
\hline
\end{tabular}

La situación del 6 de enero del 2004, de altísima inmisión en Coratxar, con 1473 $\mu \mathrm{g} / \mathrm{m}^{3}$, se operó bajo los siguientes parámetros atmosféricos representados en el radiosondeo de Zaragoza aeropuerto del 6 de enero del 2004 a las 00 horas (Fig. 100 y Tabla 30). La situación atmosférica muestra una notable inversión térmica que, a los efectos de las emisiones procedentes de la CT, tiene su base en los $925 \mathrm{hPa}$ y se eleva hasta los $864 \mathrm{hPa}(842-1408$ metros).

Tabla 30: Registro del radiosondeo de Zaragoza del 6 de enero del 2004 a las 00 horas. Fuente: http://weather.uwyo.edu/upperair/sounding.html.

\begin{tabular}{|c|c|c|c|c|c|c|c|c|c|}
\hline PRES & HGHT & TEMP & DWPT & RELH & MIXR & DRCT & SKNT & THTA & THTE \\
\hline $\mathrm{hPa}$ & $\mathrm{m}$ & ${ }^{\circ} \mathrm{C}$ & ${ }^{\circ} \mathrm{C}$ & $\%$ & $\mathrm{~g} / \mathrm{kg}$ & deg & knot & K & K \\
\hline 993,0 & 258 & 1,8 & 0,5 & 91 & 4,01 & 0 & 0 & 275,5 & 286,6 \\
\hline 985,0 & 324 & 4,6 & 1,6 & 81 & 4,38 & 350 & 1 & 278,9 & 291,2 \\
\hline 964,0 & 501 & 7,8 & 1,8 & 66 & 4,54 & 324 & 4 & 283,9 & 296,9 \\
\hline 944,0 & 674 & 7,4 & 1,4 & 66 & 4,51 & 299 & 6 & 285,2 & 298,1 \\
\hline 925,0 & 842 & 7,4 & $-0,6$ & 57 & 3,98 & 275 & 9 & 286,9 & 298,4 \\
\hline 874,0 & 1312 & 10,0 & $-9,0$ & 25 & 2,22 & 280 & 9 & 294,3 & 301,2 \\
\hline 864,0 & 1408 & 11,6 & $-18,4$ & 11 & 1,04 & 284 & 9 & 296,9 & 300,3 \\
\hline 850,0 & 1544 & 11,0 & $-16,0$ & 13 & 1,30 & 290 & 8 & 297,7 & 301,9 \\
\hline 847,0 & 1573 & 10,8 & $-16,0$ & 14 & 1,30 & 285 & 9 & 297,7 & 301,9 \\
\hline 798,0 & 2066 & 6,8 & $-16,2$ & 18 & 1,36 & 280 & 9 & 298,6 & 303,0 \\
\hline 720,0 & 2899 & 0,0 & $-22,0$ & 17 & 0,92 & 272 & 10 & 300,0 & 303,1 \\
\hline 707,0 & 3044 & $-0,1$ & $-32,4$ & 7 & 0,36 & 270 & 10 & 301,5 & 302,8 \\
\hline 700,0 & 3124 & $-0,1$ & $-38,1$ & 4 & 0,21 & 260 & 10 & 302,3 & 303,1 \\
\hline
\end{tabular}




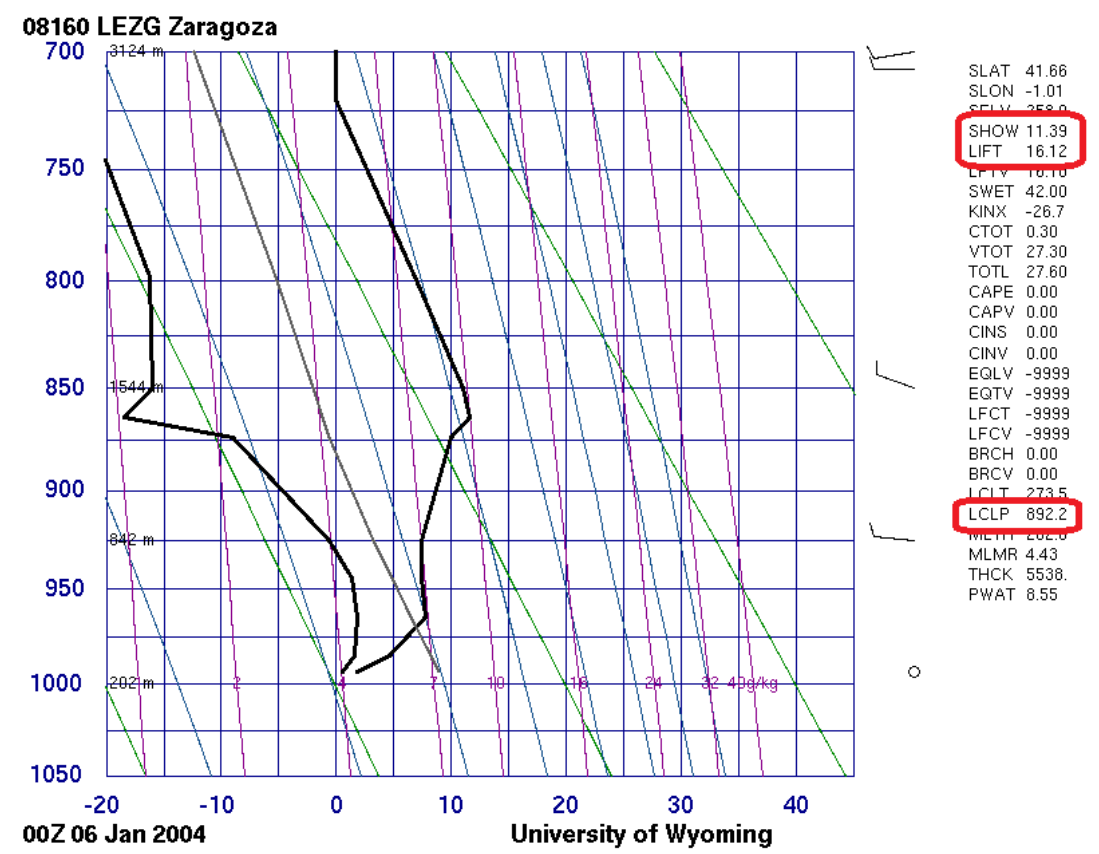

Figura 100: Radiosondeo de Zaragoza aeropuerto del 6 de enero del 2004 a las 00 horas. Fuente: http://weather.uwyo.edu/upperair/sounding.html.

En el reanálisis a $850 \mathrm{hPa}$ de esta jornada (Fig. 101) se observa la situación atmosférica que aparece configurada por una notable dorsal de aire cálido, sobre la vertiente mediterránea, a los 1500 metros de altitud.

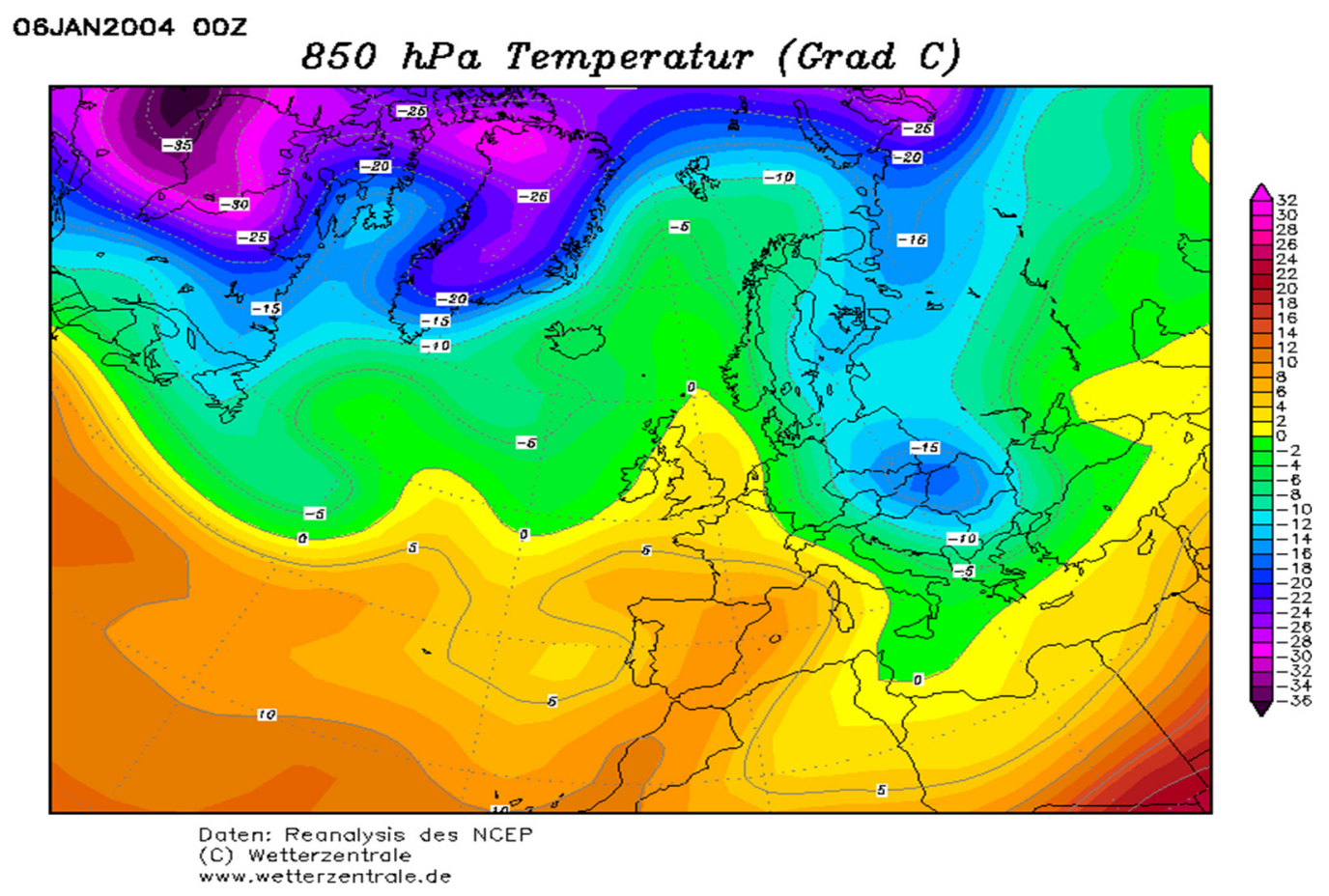

Figura 101: Reanálisis a 850 hPa del 6 de enero del 2004. Fuente: http://www.wetterzentrale.de/topkarten/fsreaeur.html.

Página | 156 
También en 2004 la situación del $\mathbf{5}$ de febrero de altísima inmisión en Coratxar, con dos picos horarios de $\mathrm{SO}_{2}$ de 1447 y $1387 \mu \mathrm{g} / \mathrm{m}^{3}$, entre las 7 y las 8 horas, se operó bajo los siguientes parámetros atmosféricos representados en el radiosondeo de Zaragoza aeropuerto del 5 de febrero del 2004 a las 12 horas (Fig. 102 y Tabla 31). Nuevamente se puede observar una situación atmosférica que muestra una notable inversión térmica y, consecuentemente, un techo de emisiones. Esta capa de inversión se extiende desde los $951 \mathrm{hPa}$ hasta los $915 \mathrm{hPa}$ (731-1055 metros).

Tabla 31: Radiosondeo de Zaragoza del 5 de febrero del 2004 a las 00 horas. Fuente: http://weather.uwyo.edu/upperair/sounding.html.

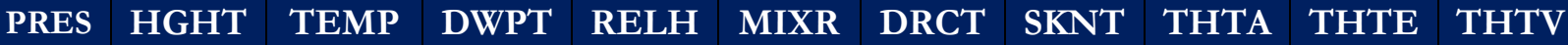

\begin{tabular}{|c|c|c|c|c|c|c|c|c|c|c|}
\hline $\mathbf{h P a}$ & $\mathbf{~} \mathbf{m}$ & ${ }^{\mathbf{o}} \mathbf{C}$ & ${ }^{\mathbf{o}} \mathbf{C}$ & $\mathbf{\%}$ & $\mathbf{g} / \mathbf{k g}$ & $\mathbf{d e g}$ & $\mathbf{k n o t}$ & $\mathbf{K}$ & $\mathbf{K}$ & $\mathbf{K}$ \\
\hline 1008,0 & 258 & 7,0 & 6,9 & 99 & 6,23 & 290 & 2 & 279,5 & 296,7 & 280,6 \\
\hline 1005,0 & 281 & 7,0 & 2,5 & 73 & 4,58 & 292 & 2 & 279,8 & 292,6 & 280,5 \\
\hline 1000,0 & 320 & 6,6 & 3,6 & 81 & 4,98 & 295 & 3 & 279,8 & 293,6 & 280,6 \\
\hline 954,0 & 705 & 4,2 & 2,6 & 89 & 4,86 & 258 & 10 & 281,1 & 294,8 & 281,9 \\
\hline 951,0 & 731 & 6,2 & 4,2 & 87 & 5,46 & 255 & 10 & 283,4 & 298,8 & 284,3 \\
\hline 944,0 & 792 & 10,8 & 7,9 & 82 & 7,13 & 258 & 11 & 288,7 & 309,0 & 289,9 \\
\hline 939,0 & 837 & 12,6 & 6,6 & 67 & 6,55 & 260 & 11 & 290,9 & 309,9 & 292,1 \\
\hline 925,0 & 963 & 14,0 & 6,0 & 59 & 6,38 & 265 & 13 & 293,6 & 312,3 & 294,8 \\
\hline 915,0 & 1055 & 14,6 & 3,6 & 48 & 5,44 & 270 & 12 & 295,1 & 311,3 & 296,1 \\
\hline 859,0 & 1586 & 11,2 & $-0,7$ & 44 & 4,26 & 300 & 9 & 296,9 & 309,8 & 297,7 \\
\hline 850,0 & 1674 & 10,6 & $-1,4$ & 43 & 4,08 & 290 & 8 & 297,2 & 309,6 & 298,0 \\
\hline 837,0 & 1802 & 9,4 & $-1,6$ & 46 & 4,08 & 286 & 9 & 297,3 & 309,7 & 298,0 \\
\hline 827,0 & 1902 & 9,8 & $-8,2$ & 27 & 2,50 & 282 & 9 & 298,7 & 306,6 & 299,2 \\
\hline 778,0 & 2402 & 7,4 & $-22,3$ & 10 & 0,83 & 265 & 11 & 301,4 & 304,2 & 301,6 \\
\hline
\end{tabular}




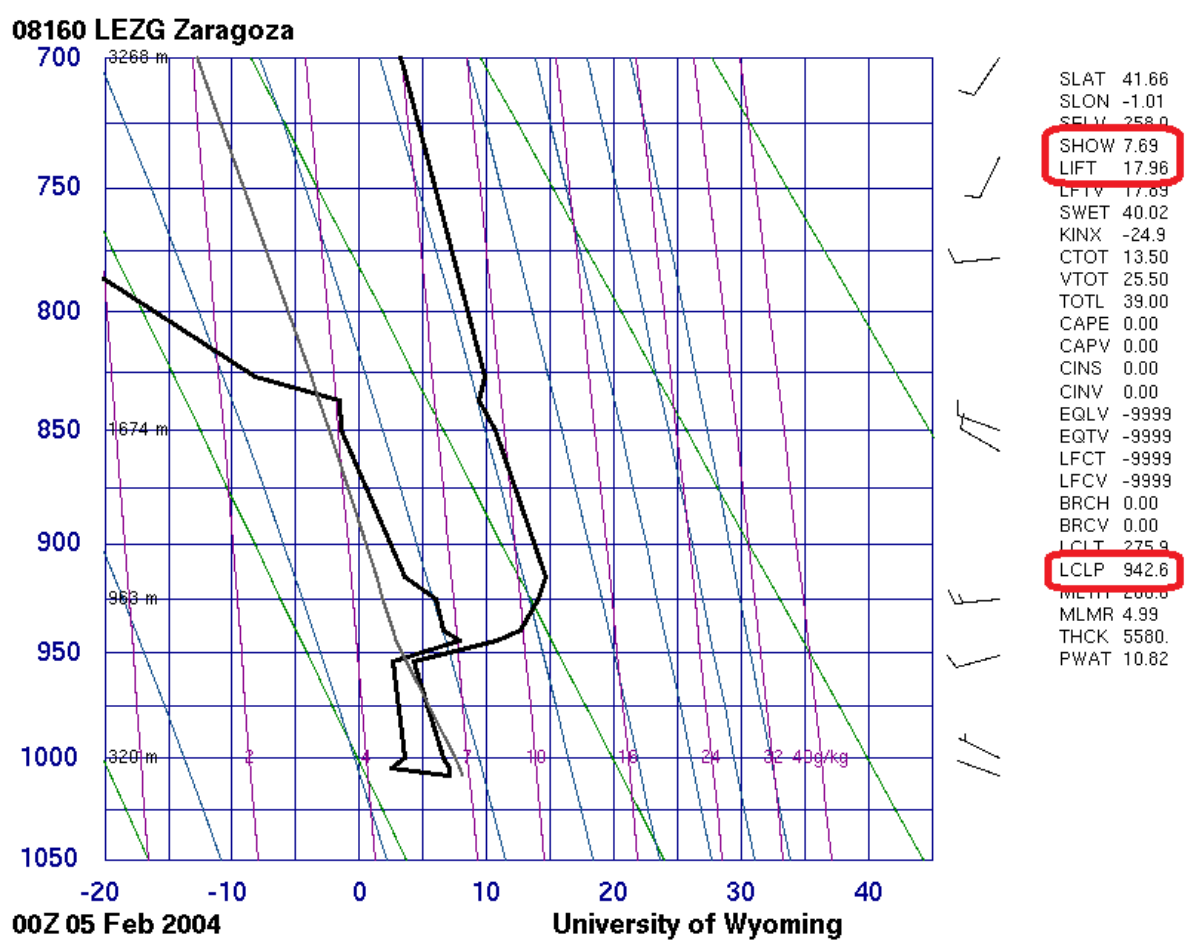

Figura 102: Radiosondeo de Zaragoza aeropuerto del 5 de febrero del 2004 a las 12 horas. Fuente: http://weather.uwyo.edu/upperair/sounding.html.

En el reanálisis a 850 hPa del 5 de febrero del 2004 (Fig. 103), la situación atmosférica aparece configurada por una notable dorsal de aire cálido sobre la vertiente mediterránea a los 1500 metros de altitud.

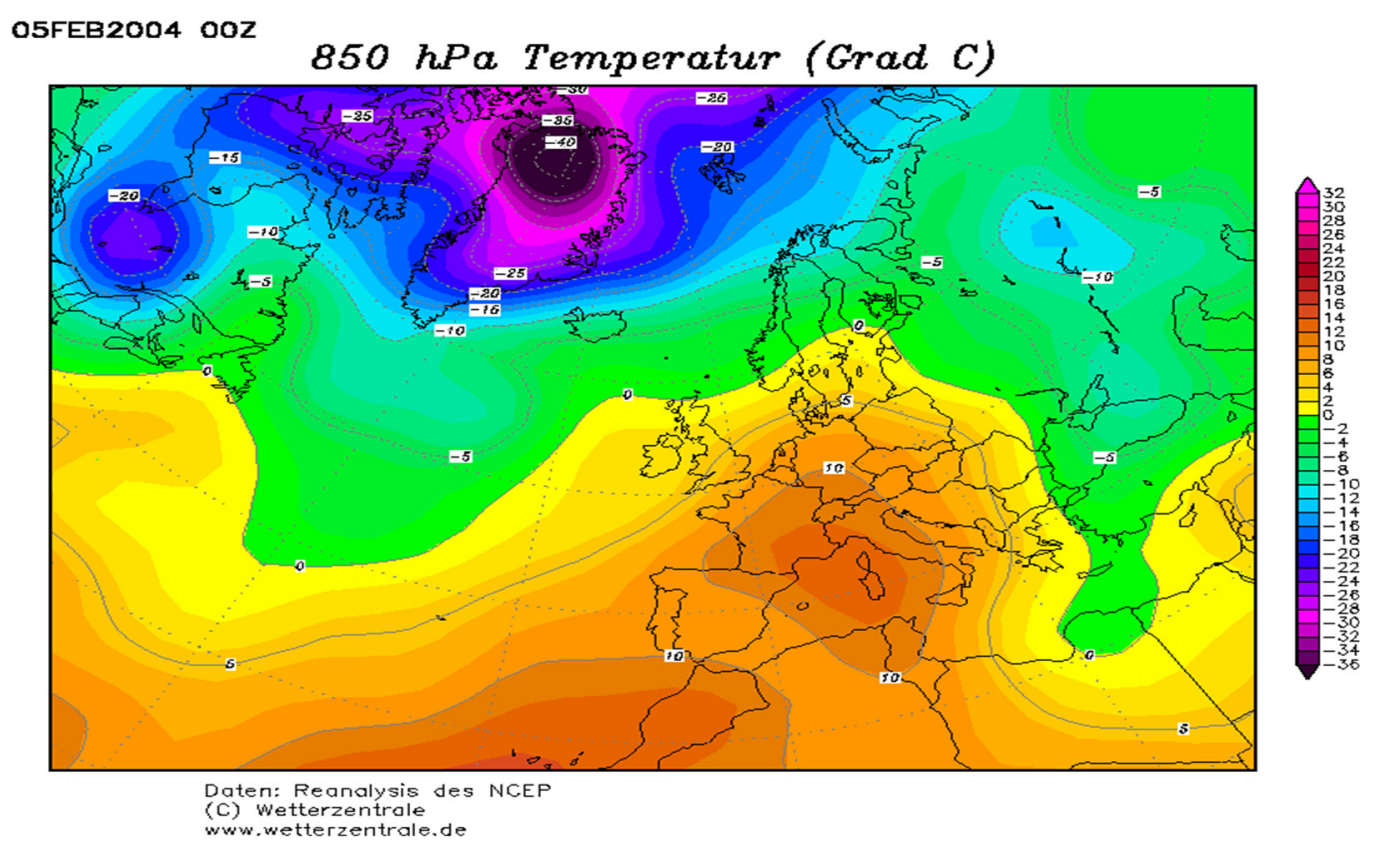

Figura 103: Reanálisis a 850 hPa del 5 de febrero del 2004. Fuente: http://www.wetterzentrale.de/topkarten/fsreaeur.html.

Página | 158 


\section{IV.IV Las situaciones más recientes de altos valores de inmisión}

Estas mismas configuraciones atmosféricas aparecen en los picos de inmisión más recientes, aunque ya bajo la plena actividad de los sistemas de desulfuración de la CT. Ello se traduce en picos de inmisión considerablemente más bajos.

Desde 2007 las situaciones con episodios de mayor inmisión de $\mathrm{SO}_{2}$ han sido las siguientes (Tabla 32):

Tabla 32: Tabla resumen de episodios horarios de mayor inmisión de $\mathrm{SO}_{2}$ durante el periodo 2007-2015. Fuente: Red Valenciana de Vigilancia y Control de la Contaminación Atmosférica, http://www.habitatge.gva.es.

\begin{tabular}{|c|c|c|c|}
\hline Año & Fecha & Hora & Pico $\mathrm{SO}_{2}\left(\mu \mathrm{g} / \mathrm{m}^{3}\right)$ \\
\hline \multirow{5}{*}{2007} & $01 / 12 / 2007$ & $0 \mathrm{~h}$ & 776 \\
\hline & $14 / 12 / 2007$ & $9 \mathrm{~h}$ & 751 \\
\hline & $19 / 09 / 2007$ & $8 \mathrm{~h}$ & 592 \\
\hline & $15 / 12 / 2007$ & $2 \mathrm{~h}$ & 584 \\
\hline & $14 / 12 / 2007$ & $7 \mathrm{~h}$ & 472 \\
\hline \multirow{5}{*}{2012} & $13 / 01 / 2012$ & $13 \mathrm{~h}$ & 254 \\
\hline & $25 / 01 / 2012$ & $20 \mathrm{~h}$ & 236 \\
\hline & $13 / 01 / 2012$ & $21 \mathrm{~h}$ & 234 \\
\hline & $13 / 01 / 2012$ & $14 \mathrm{~h}$ & 197 \\
\hline & $25 / 01 / 2012$ & $21 \mathrm{~h}$ & 172 \\
\hline 2014 & $11 / 10 / 2014$ & $7 \mathrm{~h}$ & 224 \\
\hline 2011 & $06 / 02 / 2011$ & $3 \mathrm{~h}$ & 200 \\
\hline \multirow{6}{*}{2013} & $07 / 01 / 2013$ & $22 \mathrm{~h}$ & 236 \\
\hline & $12 / 12 / 2013$ & $23 \mathrm{~h}$ & 186 \\
\hline & $04 / 01 / 2013$ & $10 \mathrm{~h}$ & 170 \\
\hline & $04 / 01 / 2013$ & $11 \mathrm{~h}$ & 134 \\
\hline & $07 / 01 / 2013$ & $23 \mathrm{~h}$ & 115 \\
\hline & $07 / 01 / 2013$ & $10 \mathrm{~h}$ & 106 \\
\hline \multirow{3}{*}{2015} & $10 / 11 / 2015$ & $9 \mathrm{~h}$ & 119 \\
\hline & $15 / 11 / 2015$ & $3 \mathrm{~h}$ & 114 \\
\hline & $01 / 12 / 2015$ & $1 \mathrm{~h}$ & 107 \\
\hline
\end{tabular}

Como podemos apreciar en la tabla anterior, en diciembre del año 2007 se produjeron los mayores picos horarios de inmisión de $\mathrm{SO}_{2}$ del periodo 2007-2015. El episodio de mayor inmisión registrado en la estación de Coratxar corresponde al día 1 de diciembre del 2007. En el radiosondeo correspondiente a esta jornada (Fig. 104) queda evidenciada la capa de 
inversión térmica formada a nivel de los $900 \mathrm{hPa}$. Esta capa constituye una tapadera que bloquea los movimientos verticales del aire y con ello limita la posibilidad de que los contaminantes gaseosos sean dispersados.

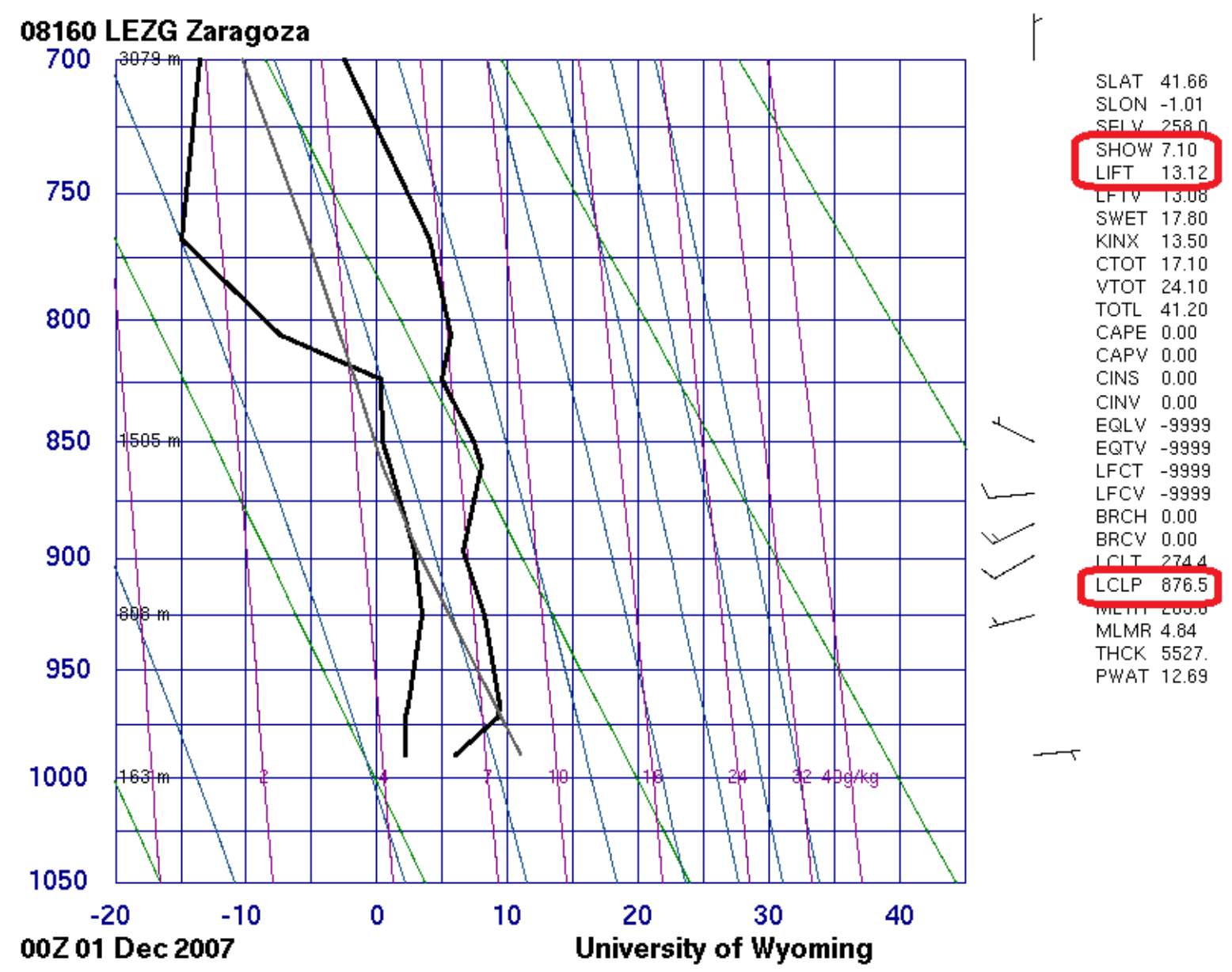

Figura 104: Radiosondeo de Zaragoza aeropuerto del 1 de diciembre del 2007 a las 00 horas. Fuente: http://weather.uwyo.edu/upperair/sounding.html.

Del mismo modo, si analizamos el mapa de presión correspondiente a la misma jornada (Fig. 105), se aprecia nítidamente como una dorsal de aire cálido se instala sobre la Península Ibérica, determinando altas presiones y procesos de subsidencia que refuerzan las capas de inversión térmica altas. 


\section{$01 \mathrm{DEC2007} \mathrm{00Z}$}

\section{$850 \mathrm{hPa}$ Temperatur (Grad C)}
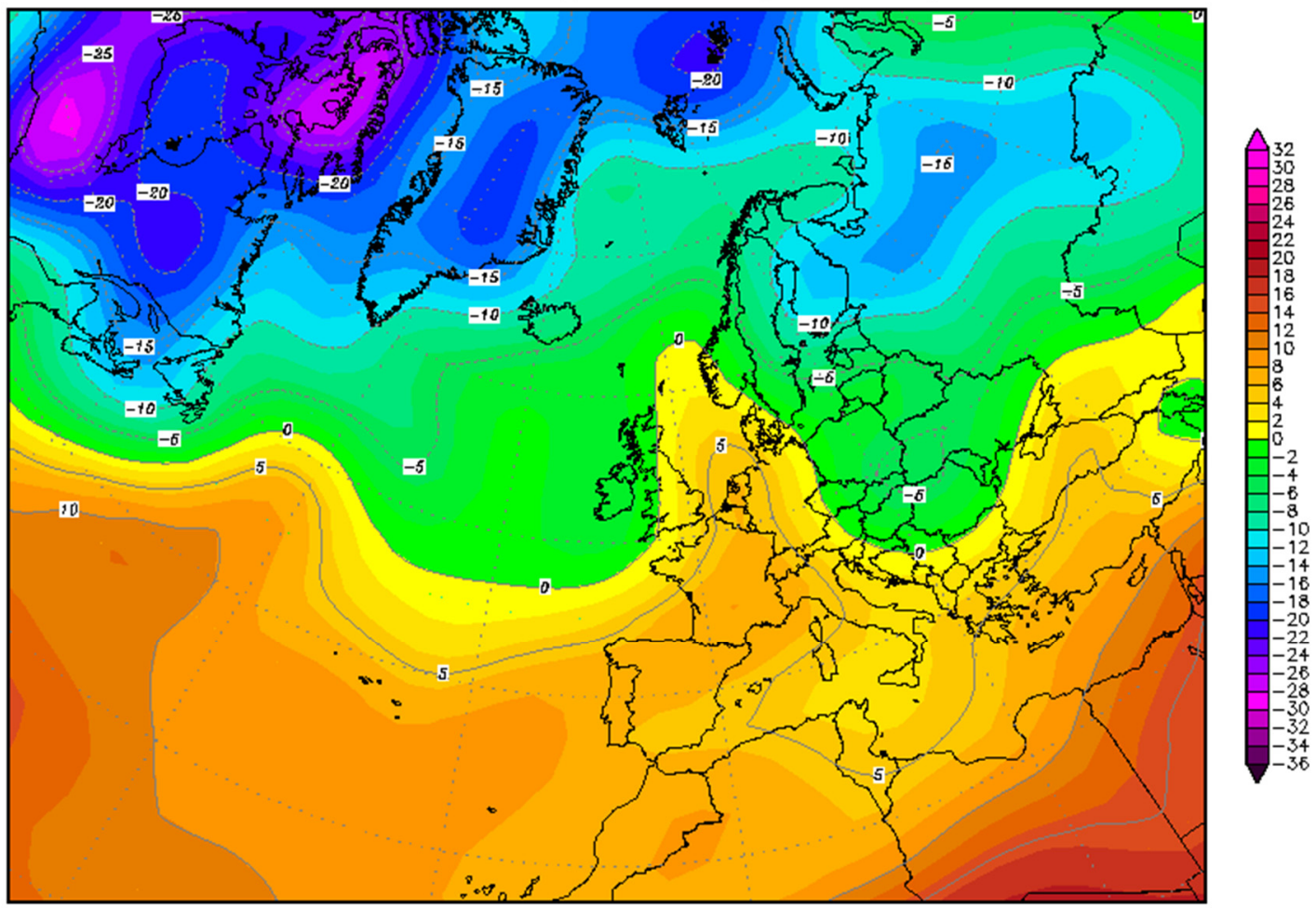

Daten: Reanalysis des NCEP

(C) Wetterzentrole

www, wetterzentrale, de

Figura 105: Reanálisis a 850 hPa del 1 de diciembre del 2007. Fuente: http://www.wetterzentrale.de/topkarten/fsreaeur.html.

La significativa capa de inversión térmica que bloquea la dispersión de contaminantes ha podido ser especialmente estudiada en nuestra región mediante los registros de la red meteorológica universitaria. El análisis de los registros de temperatura de las estaciones situadas en el monte Caro, a 1447 metros de altura, y los de la estación del pico Fredes, situado por debajo de la cima del Caro, a una altura de 1235 metros, nos van a permitir identificar las situaciones de clara inversión térmica.

Si comparamos la evolución de las curvas de temperaturas máximas de ambas estaciones podemos comprobar como los picos altos de contaminación acontecieron en aquellos momentos en los que la curva del monte Caro, estación situada a mayor altura, cruza y supera la curva de la estación de Fredes. Este cruce de ambas curvas evidencia claramente la presencia de una inversión térmica a ese nivel que actúa como techo de las emisiones de la CT. 
En la figura 106 podemos apreciar este fenómeno en las curvas de temperaturas máximas de ambas estaciones durante el mes de diciembre de 2007, mes en el que como hemos visto tuvieron lugar los mayores picos horarios de inmisión en los últimos diez años.

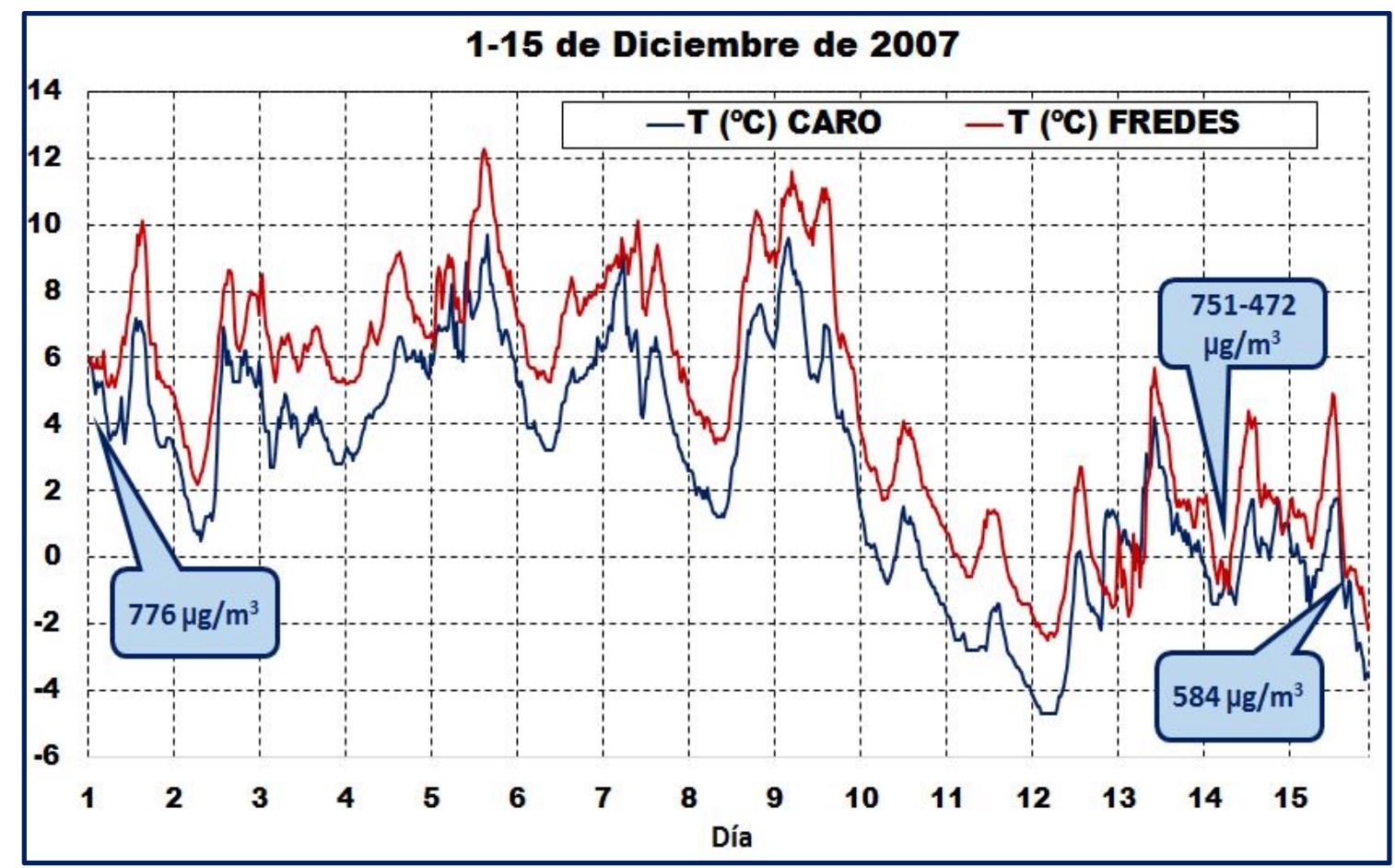

Figura 106: Registros de temperatura en los observatorios del monte Caro (1447 metros) y del pico Fredes (1235 metros) durante los días 1-15 de diciembre del 2007. Los picos horarios de contaminación sobrevienen cuando la capa de inversión se halla bajo ese nivel de alturas sobre la región. Fuente: elaboración propia, Laboratorio de Climatología de la Universitat Jaume I.

Si pasamos ahora a analizar las situaciones sobrevenidas durante el año 2012, año en el que se detectaron también diversos picos horarios de contaminación por $\mathrm{SO}_{2}$ podemos comprobar en la tabla 33 que todas estas situaciones tuvieron lugar durante el mes de enero:

Tabla 33: Tabla resumen de episodios horarios de mayor inmisión de $\mathrm{SO}_{2}$ durante el año 2012. Fuente: Red Valenciana de Vigilancia y Control de la Contaminación Atmosférica, http://www.habitatge.gva.es.

\begin{tabular}{|l|c|c|c|}
\hline \multirow{4}{*}{ Año } & Fecha & Hora & Pico $\mathrm{SO}_{2}\left(\boldsymbol{\mu g} / \mathrm{m}^{3}\right)$ \\
\hline \multirow{4}{*}{2012} & $13 / 01 / 2012$ & $13 \mathrm{~h}$ & $\mathbf{2 5 4}$ \\
\cline { 2 - 4 } & $25 / 01 / 2012$ & $20 \mathrm{~h}$ & $\mathbf{2 3 6}$ \\
\cline { 2 - 4 } & $13 / 01 / 2012$ & $21 \mathrm{~h}$ & $\mathbf{2 3 4}$ \\
\cline { 2 - 4 } & $13 / 01 / 2012$ & $14 \mathrm{~h}$ & $\mathbf{1 9 7}$ \\
\cline { 2 - 4 } & $25 / 01 / 2012$ & $21 \mathrm{~h}$ & $\mathbf{1 7 2}$ \\
\hline
\end{tabular}


De nuevo, si observamos el gráfico de evolución de las temperaturas máximas en las estaciones del Caro y Fredes durante el mes de enero del 2012, observamos nítidamente como estos episodios de inmisión se operaron en momentos en los que ambas curvas se cruzaban (Fig. 107).

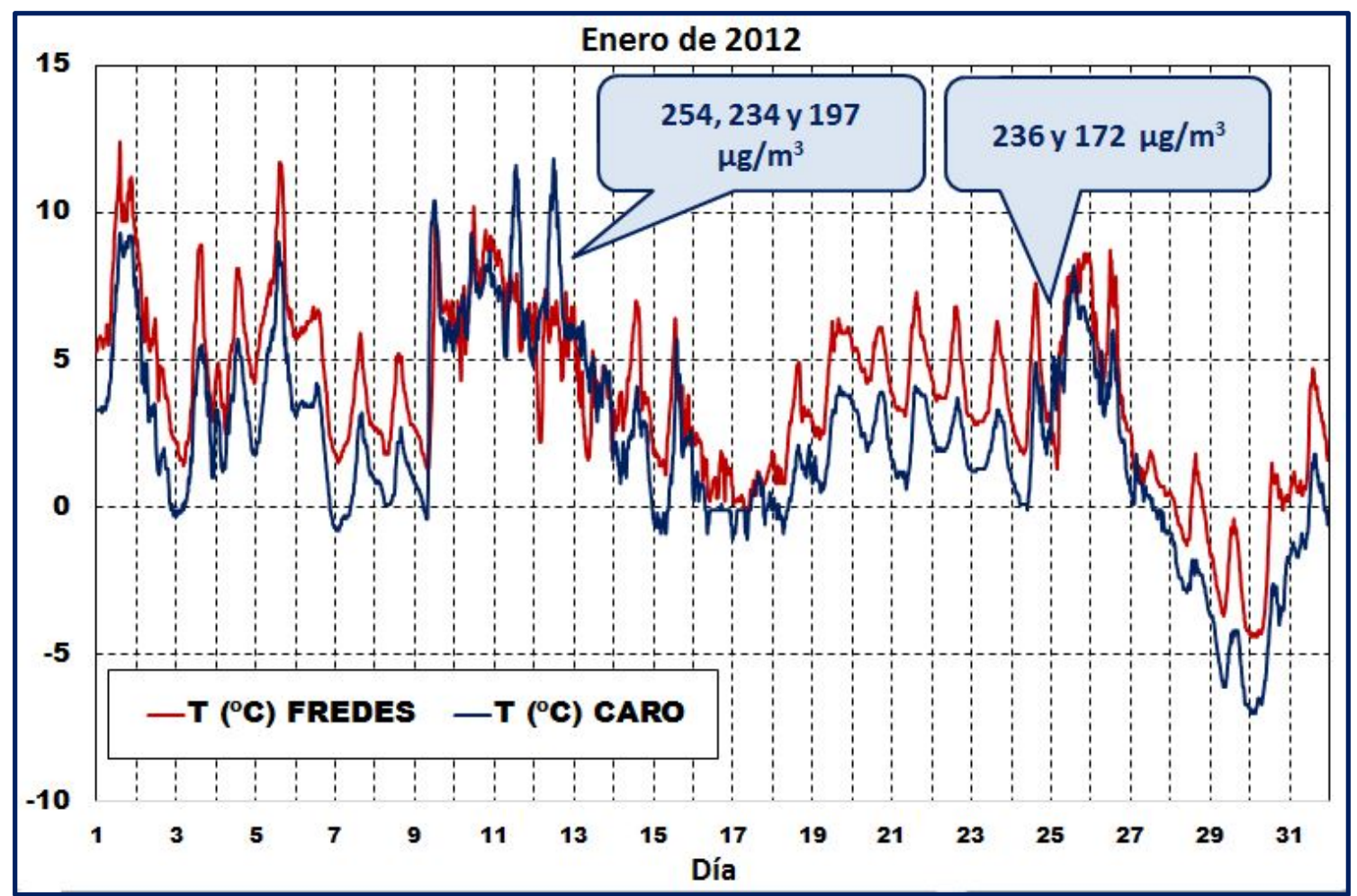

Figura 107: Registros de temperatura en los observatorios del monte Caro (1447 metros) y del pico Fredes (1235 metros) en enero del 2012. Los episodios de contaminación se operan en momentos en que la capa de inversión cubre ese nivel de alturas sobre la región. Fuente: elaboración propia, Laboratorio de Climatología de la Universitat Jaume I.

Otra evidencia de la presencia de esta capa de inversión, inductora de los episodios de mayor contaminación, la encontramos en los registros de temperatura y humedad del aire de la propia CT. La chimenea de la central cuenta con registros a dos alturas diferentes, a 10 metros y a 60 metros. En la figura 108 aparecen representados dichos registros para el día $\mathbf{1 3}$ de enero del 2012 mostrando la notable estabilidad e inversión térmica presentes durante esta jornada. 


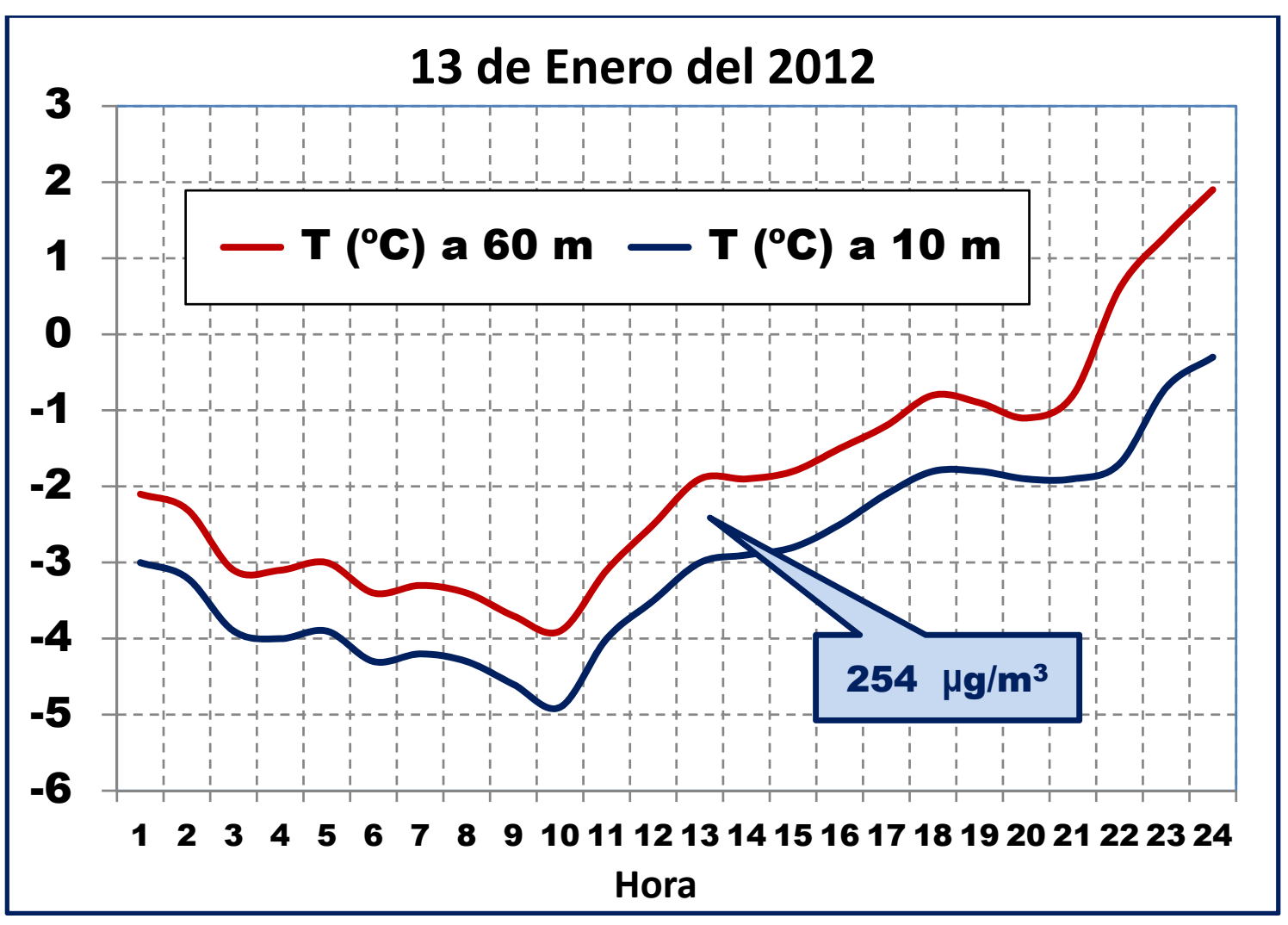

Figura 108: Los registros de la temperatura del aire en la torre meteorológica de la CT muestran, en régimen diario, la notable estabilidad e inversión térmica durante el 13 de enero del 2012. Fuente: datos proporcionados por la CT, elaboración propia, Laboratorio de Climatología de la Universitat Jaume I.

Analizamos ahora con mayor detenimiento esta jornada del 13 de enero que registró el mayor pico de inmisión del año 2012. Esta situación ya ha sido estudiada anteriormente en el capítulo III (Apartado V. IV) con el objetivo de validar el modelo gaussiano de dispersión de contaminantes de Pasquill. El estado atmosférico en esa fecha determinó que el pico horario de inmisión alcanzase un valor de $254 \mu \mathrm{g} / \mathrm{m}^{3}$. Aunque no supera la normativa establecida, tal pico emerge sobre un valor medio anual de tan solo $10 \mu \mathrm{g} / \mathrm{m}^{3}$. Durante esta jornada, y como muestran tanto el radiosondeo de Zaragoza aeropuerto (Fig. 109) como el registro del mismo (Tabla 34), aparece claramente una pronunciada inversión térmica a nivel de los $911 \mathrm{hPa}$, representativa, como ya hemos visto, de este tipo de situaciones. La estructura de la atmósfera muestra la extraordinaria estabilidad y calma que provoca la notabilísima inversión térmica entre 911 y 871 hPa (996-1362 metros). La base de la inversión se sitúa a tan sólo 996 metros, a nivel de la boca de la chimenea de la CT. 
Tabla 34: Registro del radiosondeo de Zaragoza del 13 de enero del 2012 a las 12 horas. Fuente: http://weather.uwyo.edu/upperair/sounding.html.

\begin{tabular}{|c|c|c|c|c|c|c|c|c|c|c|}
\hline PRES & HGHT & TEMP & DWPT & RELH & MIXR & DRCT & SKNT & THTA & THTE & THTV \\
\hline $\mathrm{hPa}$ & $\mathrm{m}$ & ${ }^{\circ} \mathbf{C}$ & ${ }^{\circ} \mathbf{C}$ & $\%$ & $\mathrm{~g} / \mathrm{kg}$ & deg & knot & K & K & K \\
\hline 1000,0 & 258 & 3,6 & 1,9 & 89 & 4,41 & 275 & 7 & 276,8 & 288,9 & 277,5 \\
\hline 986,0 & 370 & 2,2 & 0,8 & 91 & 4,14 & 265 & 10 & 276,4 & 287,9 & 277,1 \\
\hline 971,0 & 492 & 0,6 & $-0,3$ & 94 & 3,87 & 291 & 11 & 276,1 & 286,8 & 276,7 \\
\hline 963,0 & 558 & 0,2 & $-0,5$ & 95 & 3,84 & 305 & 11 & 276,3 & 287,0 & 277,0 \\
\hline 926,0 & 866 & $-1,6$ & $-1,7$ & 100 & 3,67 & 310 & 14 & 277,5 & 287,8 & 278,1 \\
\hline 925,0 & 875 & $-1,7$ & $-1,7$ & 100 & 3,67 & 310 & 14 & 277,6 & 287,8 & 278,2 \\
\hline 915,0 & 961 & $-2,3$ & $-2,4$ & 99 & 3,52 & 300 & 11 & 277,8 & 287,7 & 278,4 \\
\hline 911,0 & 996 & 0,0 & $-1,4$ & 90 & 3,81 & 296 & 10 & 280,5 & 291,3 & 281,2 \\
\hline 910,0 & 1005 & 0,1 & $-1,6$ & 88 & 3,75 & 295 & 10 & 280,8 & 291,4 & 281,4 \\
\hline 902,0 & 1076 & 1,2 & $-3,4$ & 71 & 3,31 & 298 & 9 & 282,6 & 292,1 & 283,1 \\
\hline 896,0 & 1130 & 5,0 & $-10,0$ & 33 & 2,01 & 300 & 9 & 287,0 & 293,1 & 287,4 \\
\hline 891,0 & 1176 & 5,6 & $-16,4$ & 19 & 1,20 & 301 & 8 & 288,1 & 291,9 & 288,3 \\
\hline 886,0 & 1222 & 5,6 & $-14,4$ & 22 & 1,42 & 303 & 8 & 288,6 & 293,0 & 288,8 \\
\hline 871,0 & 1362 & 6,2 & $-19,8$ & 14 & 0,92 & 308 & 6 & 290,6 & 293,6 & 290,8 \\
\hline 850,0 & 1561 & 5,6 & $-21,4$ & 12 & 0,82 & 315 & 4 & 292,0 & 294,7 & 292,1 \\
\hline 774,0 & 2317 & 2,2 & $-27,6$ & 9 & 0,52 & 15 & 1 & 296,3 & 298,0 & 296,4 \\
\hline 718,0 & 2924 & $-0,5$ & $-32,5$ & 7 & 0,35 & 93 & 3 & 299,7 & 300,9 & 299,8 \\
\hline 700,0 & 3126 & $-1,9$ & $-24,9$ & 15 & 0,73 & 120 & 4 & 300,4 & 302,8 & 300,5 \\
\hline 679,0 & 3368 & $-4,1$ & $-13,1$ & 50 & 2,06 & 126 & 6 & 300,5 & 307,1 & 300,9 \\
\hline 643,0 & 3796 & $-7,3$ & $-24,3$ & 24 & 0,84 & 138 & 9 & 301,6 & 304,4 & 301,8 \\
\hline 636,0 & 3879 & $-8,0$ & $-24,0$ & 26 & 0,87 & 140 & 10 & 301,7 & 304,7 & 301,9 \\
\hline 610,0 & 4199 & $-10,8$ & $-22,9$ & 36 & 1,00 & 125 & 10 & 302,1 & 305,5 & 302,3 \\
\hline 595,0 & 4390 & $-12,4$ & $-22,2$ & 44 & 1,09 & 150 & 11 & 302,4 & 306,1 & 302,6 \\
\hline 583,0 & 4547 & $-13,8$ & $-21,6$ & 52 & 1,17 & 140 & 11 & 302,6 & 306,5 & 302,8 \\
\hline 562,0 & 4828 & $-16,2$ & $-20,6$ & 69 & 1,33 & 175 & 14 & 302,9 & 307,3 & 303,1 \\
\hline 558,0 & 4883 & $-16,7$ & $-20,4$ & 73 & 1,36 & 174 & 14 & 303,0 & 307,5 & 303,2 \\
\hline 539,0 & 5143 & $-18,7$ & $-22,6$ & 71 & 1,16 & 172 & 13 & 303,6 & 307,5 & 303,8 \\
\hline 529,0 & 5282 & $-19,5$ & $-25,9$ & 57 & 0,88 & 170 & 13 & 304,3 & 307,3 & 304,4 \\
\hline 509,0 & 5568 & $-21,1$ & $-32,7$ & 34 & 0,48 & 185 & 14 & 305,6 & 307,4 & 305,7 \\
\hline 500,0 & 5700 & $-21,9$ & $-35,9$ & 27 & 0,36 & 175 & 13 & 306,3 & 307,6 & 306,3 \\
\hline
\end{tabular}




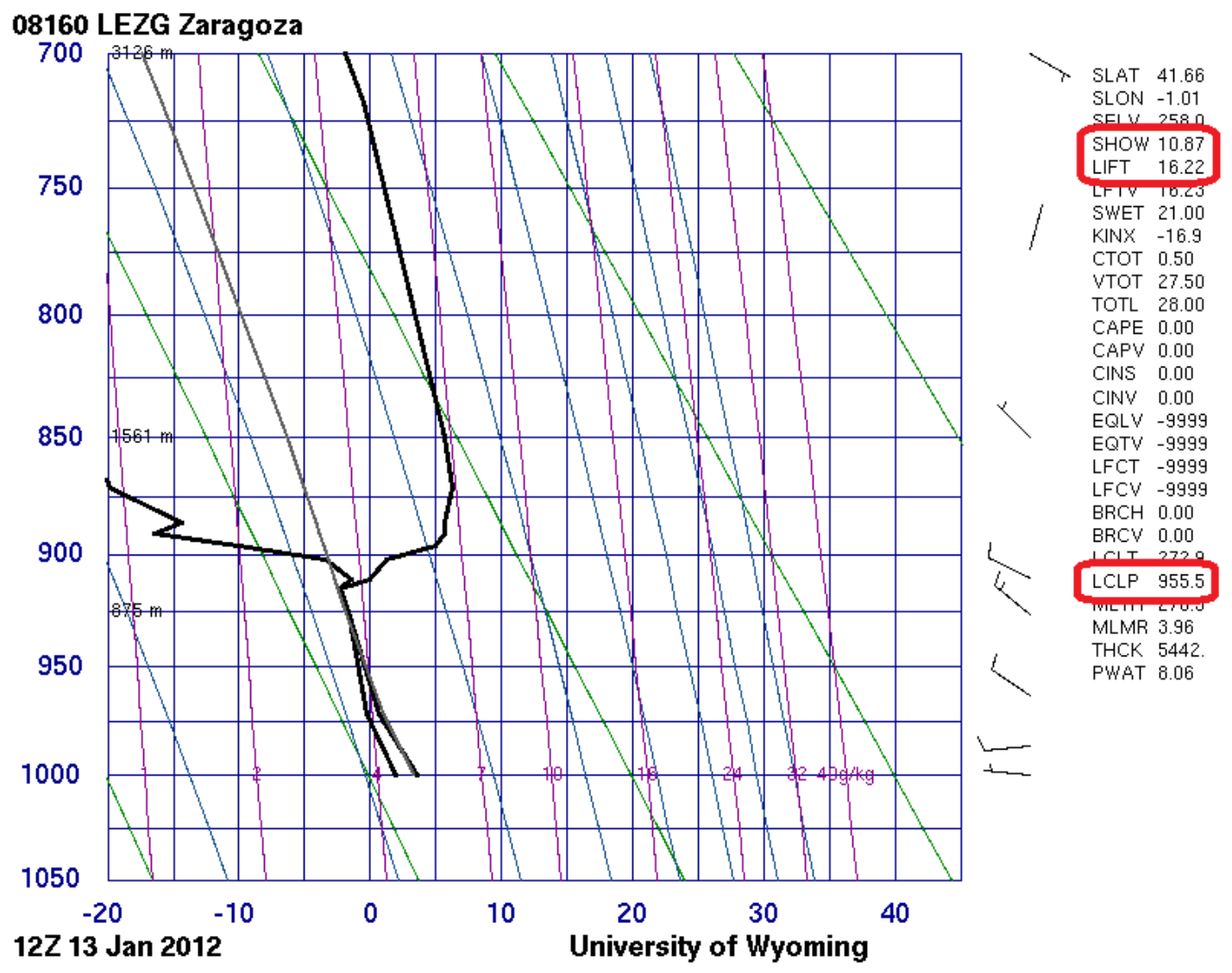

Figura 109: Radiosondeo de Zaragoza aeropuerto del 13 de enero del 2012 a las 12 horas. Fuente: http://weather.uwyo.edu/upperair/sounding.html.

En el mapa de presión correspondiente a dicha jornada una notable dorsal anticiclónica se sitúa sobre Europa Occidental. Esta dorsal subsidente agudiza los efectos provocados por la inversión térmica, potenciando los impactos de inmisión y reduciendo al máximo la dispersión de contaminantes (Fig. 110).

Página | 166 


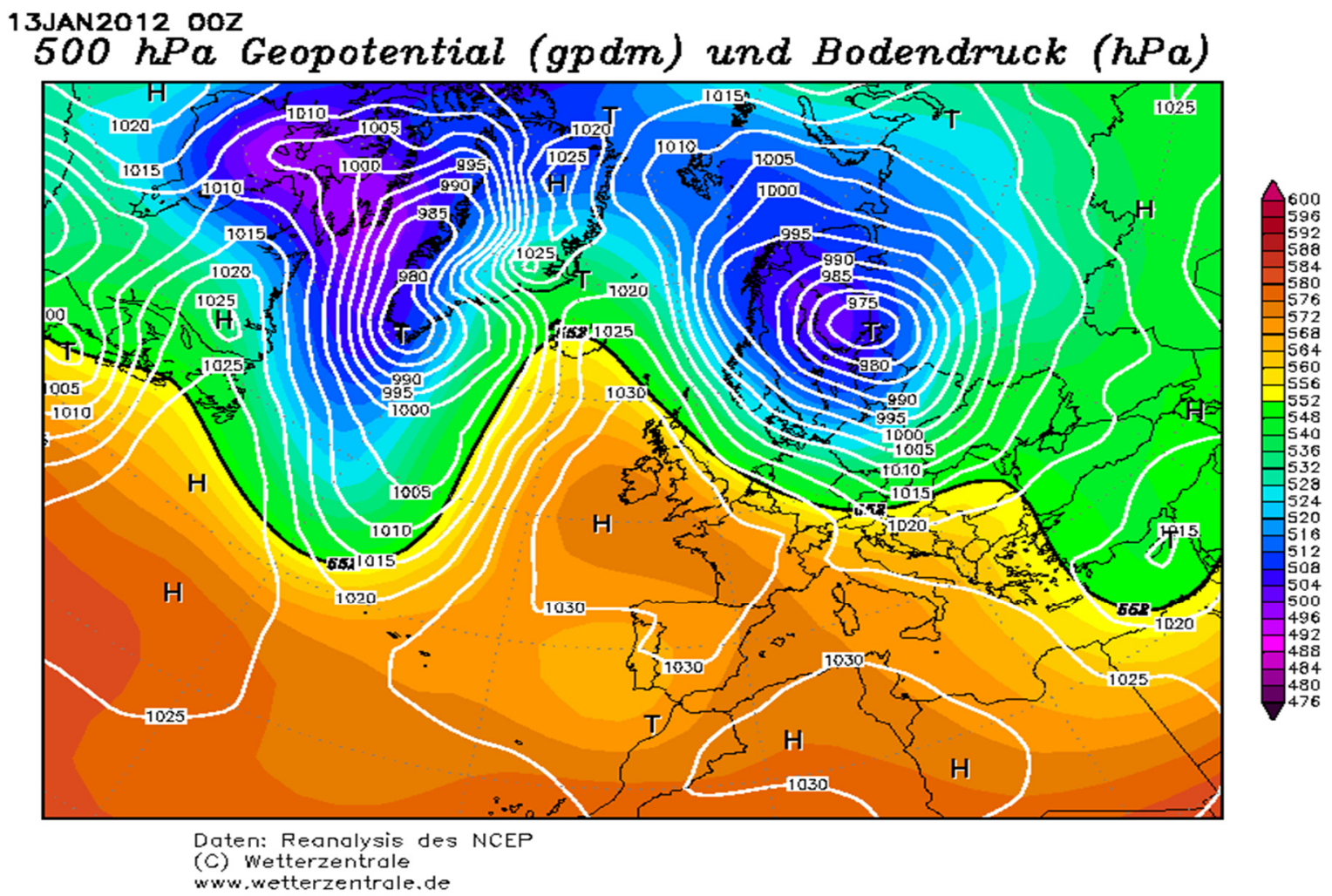

Figura 110: Reanálisis a 500 hPa del 13 de enero del 2012. Fuente: http://www.wetterzentrale.de/topkarten/fsreaeur.html.

Continuando con los picos de inmisión más recientes, analizamos ahora los correspondientes al año 2013 (Tabla 35).

Tabla 35: Tabla resumen de episodios horarios de mayor inmisión de $\mathrm{SO}_{2}$ durante el año 2013. Fuente: Red Valenciana de Vigilancia y Control de la Contaminación Atmosférica, http://www.habitatge.gva.es.

\begin{tabular}{|c|c|c|c|}
\hline Año & Fecha & Hora & Pico $\mathrm{SO}_{2}\left(\boldsymbol{\mu g} / \mathrm{m}^{3}\right)$ \\
\hline \multirow{4}{*}{2013} & $07 / 01 / 2013$ & $22 \mathrm{~h}$ & $\mathbf{2 3 6}$ \\
\cline { 2 - 4 } & $12 / 12 / 2013$ & $23 \mathrm{~h}$ & $\mathbf{1 8 6}$ \\
\cline { 2 - 4 } & $04 / 01 / 2013$ & $10 \mathrm{~h}$ & $\mathbf{1 7 0}$ \\
\cline { 2 - 4 } & $04 / 01 / 2013$ & $11 \mathrm{~h}$ & $\mathbf{1 3 4}$ \\
\cline { 2 - 4 } & $07 / 01 / 2013$ & $23 \mathrm{~h}$ & $\mathbf{1 1 5}$ \\
\cline { 2 - 4 } & $07 / 01 / 2013$ & $10 \mathrm{~h}$ & $\mathbf{1 0 6}$ \\
\hline
\end{tabular}

De nuevo los mayores picos de inmisión se producen en los meses de invierno, concretamente en diciembre y, especialmente, en enero. También en esta ocasión los registros de temperaturas máximas de las estaciones del monte Caro y de Fredes son clarificadores. Como podemos ver en la figura 111, nuevamente ambas curvas se cruzan coincidiendo con el momento en el que se operan los picos de contaminación. 


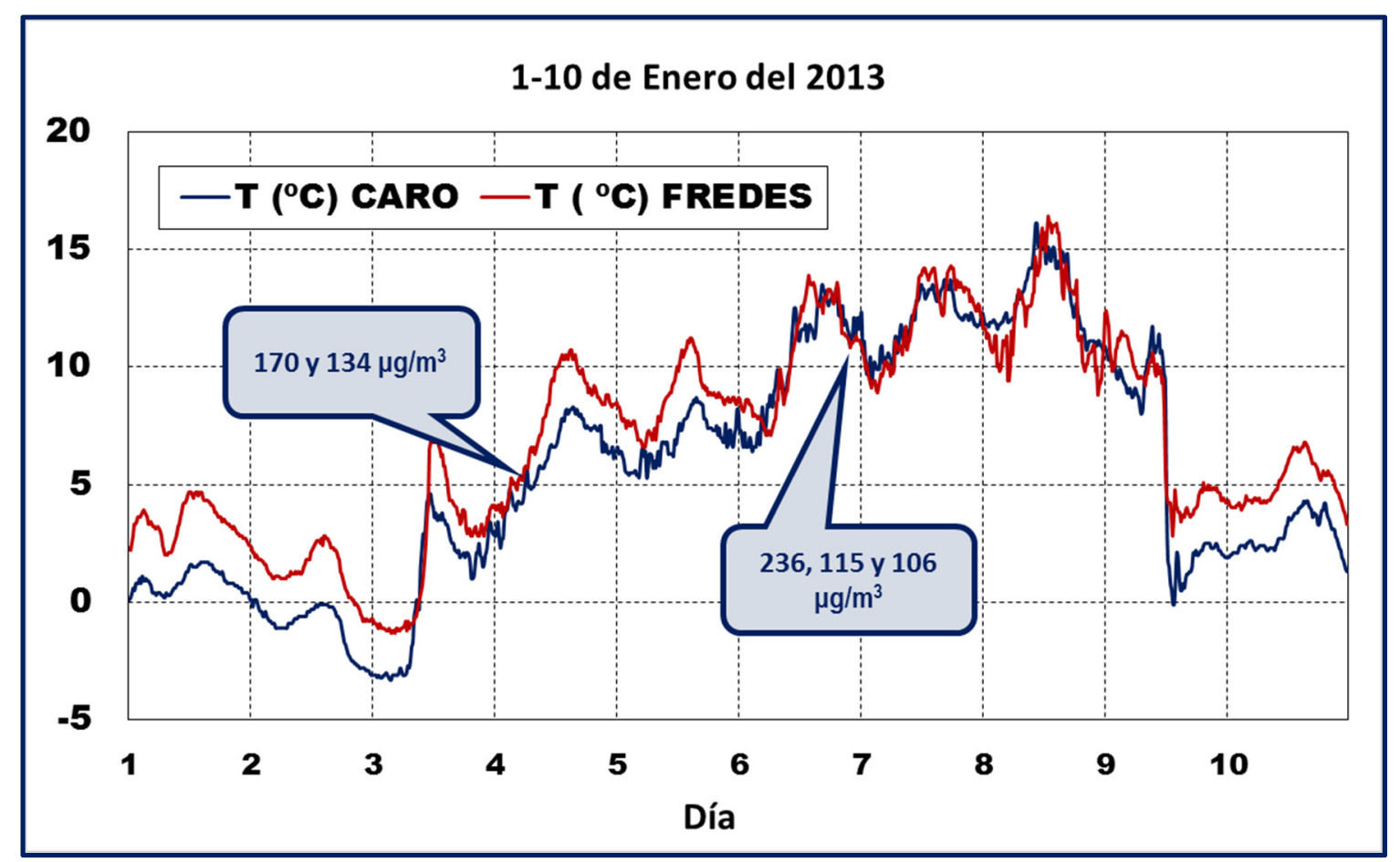

Figura 111: Registros de la temperatura, durante los días 1-10 del mes de enero del 2013, en los observatorios del monte Caro (1447 metros) y del pico Fredes (1235 metros). Fuente: elaboración propia, Laboratorio de Climatología de la Universitat Jaume I.

Como se puede comprobar, el día 7 de enero del 2013 registró el mayor pico horario de inmisión de ese año. También esta situación fue empleada en el capítulo III para validar el modelo gaussiano de dispersión de contaminantes. Durante esta jornada, y tal y como evidencian el radiosondeo (Fig. 112) y el mapa de presión (Fig. 113) correspondientes, de nuevo un notable anticiclón se sitúa sobre la vertical de la cuenca del Mediterráneo Occidental, potenciando los efectos de la inversión térmica. Vuelve a producirse así el escenario atmosférico idóneo para que se produzcan estos picos de inmisión de $\mathrm{SO}_{2}$. 


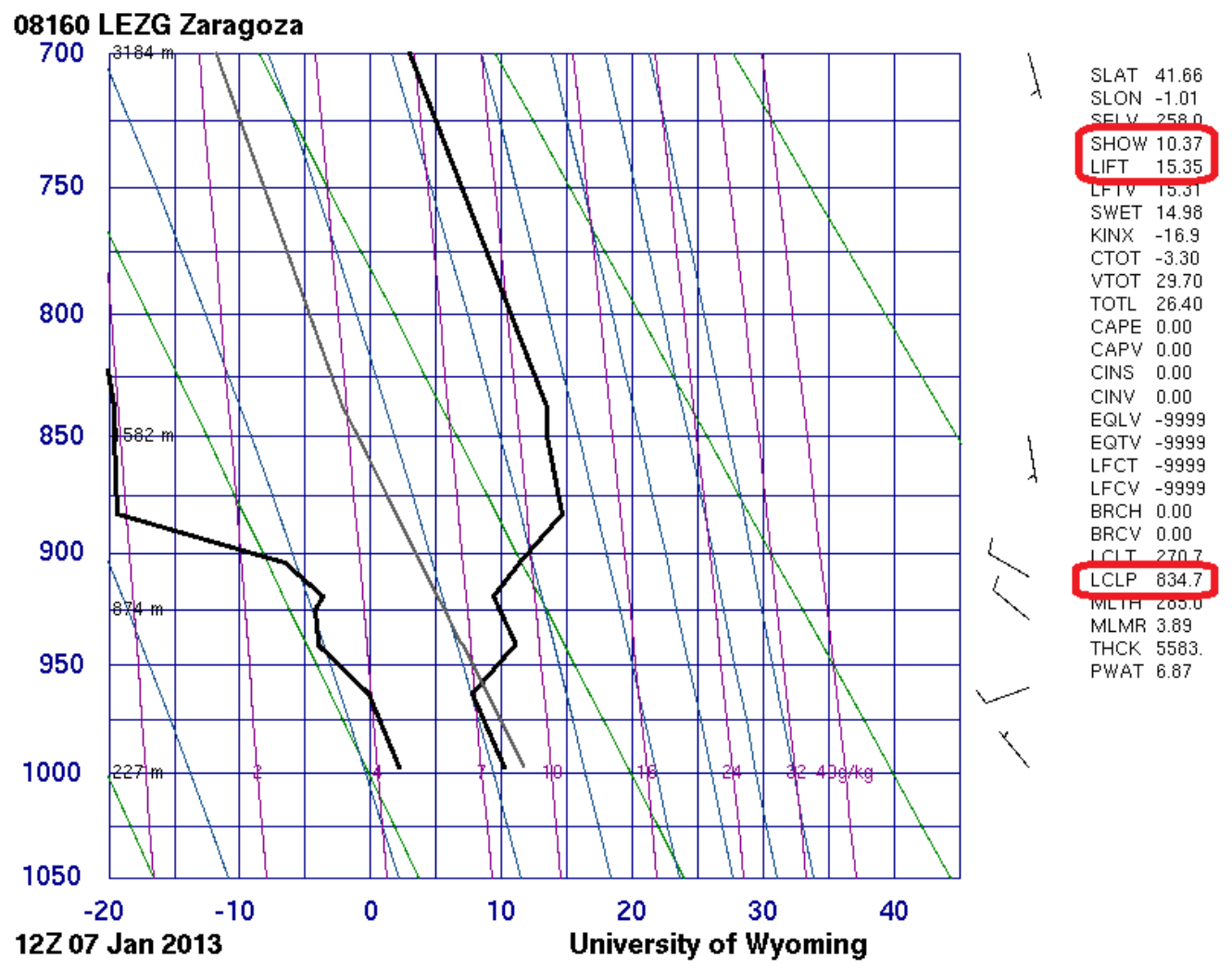

Figura 112: Radiosondeo de Zaragoza aeropuerto del 7 de enero del 2013 a las 12 horas. Fuente: http://weather.uwyo.edu/upperair/sounding.html.

\section{JAN2013 00Z}

\section{$850 \mathrm{hPa}$ Temperatur (Grad C)}
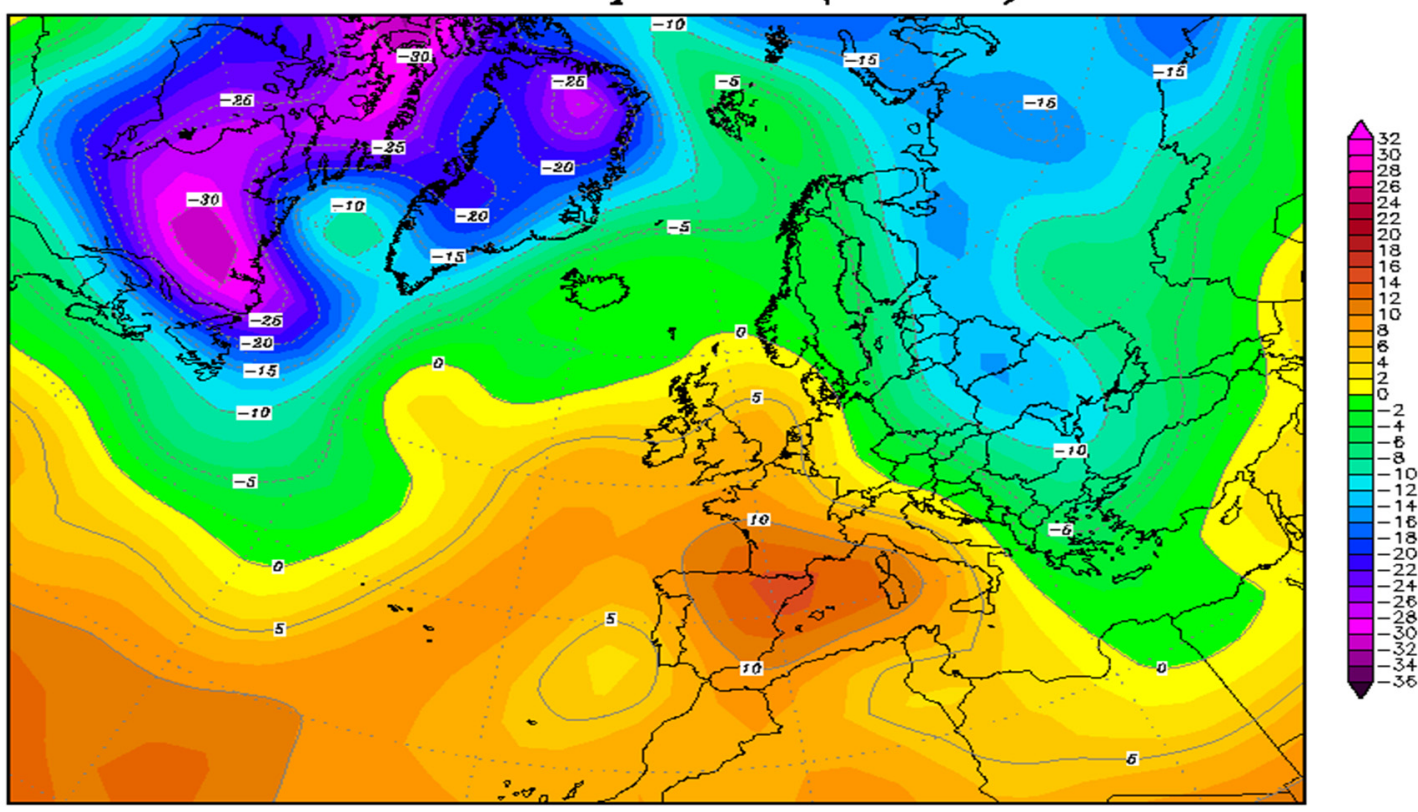

Daten: Reanalysis des NCEP

(C) Wetterzentrale

Figura 113: Reanálisis a $850 \mathrm{hPa}$ del 7 de enero del 2013. Fuente: http://www.wetterzentrale.de/topkarten/fsreaeur.html. 
Finalmente, analizamos las situaciones más recientes, correspondientes al año 2015. A pesar de que los picos registrados durante este año no son muy elevados, se sigue cumpliendo el mismo patrón de situación atmosférica potenciadora de estos episodios de mayor contaminación. Durante el 2015 se registraron 3 picos horarios que destacan sobre el valor medio anual de tan solo $5 \mu \mathrm{g} / \mathrm{m}^{3}$ (Tabla 36).

Tabla 36: Tabla resumen de episodios horarios de mayor inmisión de $\mathrm{SO}_{2}$ durante el año 2015. Fuente: Red Valenciana de Vigilancia y Control de la Contaminación Atmosférica, http://www.habitatge.gva.es.

\begin{tabular}{|c|c|c|c|}
\hline \multirow{2}{*}{ Año } & Fecha & Hora & Pico $\mathrm{SO}_{2}\left(\boldsymbol{\mu g} / \mathrm{m}^{3}\right)$ \\
\hline \multirow{3}{*}{2015} & $10 / 11 / 2015$ & $9 \mathrm{~h}$ & $\mathbf{1 1 9}$ \\
\cline { 2 - 4 } & $15 / 11 / 2015$ & $3 \mathrm{~h}$ & $\mathbf{1 1 4}$ \\
\cline { 2 - 4 } & $01 / 12 / 2015$ & $1 \mathrm{~h}$ & $\mathbf{1 0 7}$ \\
\hline
\end{tabular}

Como vemos, los casos más recientes de elevado pico horario acontecieron durante los meses de noviembre y diciembre del 2015. Los registros de la red meteorológica universitaria durante el mes de noviembre, en las estaciones del monte Caro y de Fredes, permiten constatar que la capa de inversión aparece formada por debajo de los 1250 metros (Fig. 114). Un techo para los movimientos ascendentes del aire y determinante de los picos de $\mathrm{SO}_{2}$.

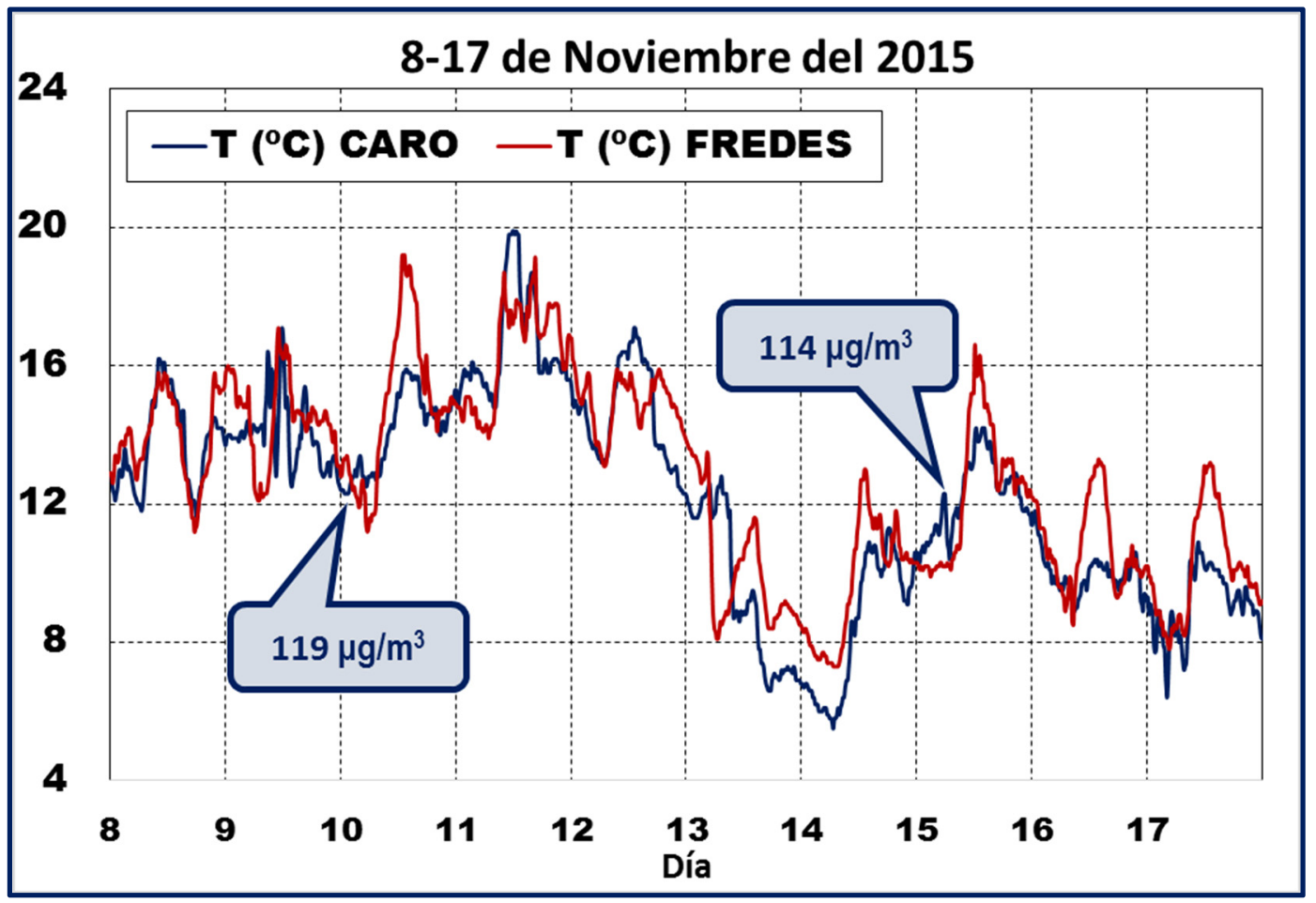

Figura 114: Evolución térmica en los observatorios del monte Caro (1447 metros) y Fredes (1235 metros) entre el 8 y el 17 de noviembre del 2015. Fuente: elaboración propia, Laboratorio de Climatología de la Universitat Jaume I. 
De este modo, los registros de la red meteorológica universitaria constituyen, en ausencia de un radiosondeo propio, la mejor técnica para la gestión ambiental de la calidad del aire en la región. La evolución de las temperaturas en la estación del monte Caro (1447 metros) y en la estación del pico de Fredes (1235 metros) traducen la estructura de esa capa crítica de la atmósfera regional en la que las inversiones térmicas actúan como tapadera de los movimientos verticales del aire. Las figuras analizadas muestran que, incluso en las recientes medidas de inmisión, los episodios más elevados de contaminación corresponden a esa estructura atmosférica. Esta es la situación sobrevenida en todas las situaciones analizadas del periodo 2007-2015 en las cuales los picos altos de contaminación se operan en momentos en que la capa de inversión cubre ese nivel de alturas sobre la región.

Como verificación de estas configuraciones atmosféricas potenciadoras de altas inmisiones, y estableciendo la antítesis, el escenario atmosférico regional muestra, y con mucha frecuencia, condiciones favorables a la dispersión en altura sobre la capa de mezcla o geográfica. Unas situaciones que, consecuentemente, comprenden valores mínimos o nulos de inmisión $\left(<5 \mu \mathrm{g} / \mathrm{m}^{3}\right)$. Estas situaciones aparecen vinculadas tanto a condiciones de inestabilidad como neutras.

Un claro ejemplo de estas situaciones inestables queda reflejado tanto en la figura 115, que muestra el radiosondeo correspondiente al día 24 de marzo del 2015, como en la tabla 37, correspondiente al registro de dicho radiosondeo. La inestabilidad es intensa y el nivel de condensación ascendente se alcanza a alturas sobre los 700 metros (925 hPa). El espesor de las nubes se eleva ya hasta alturas de 3000 metros. 


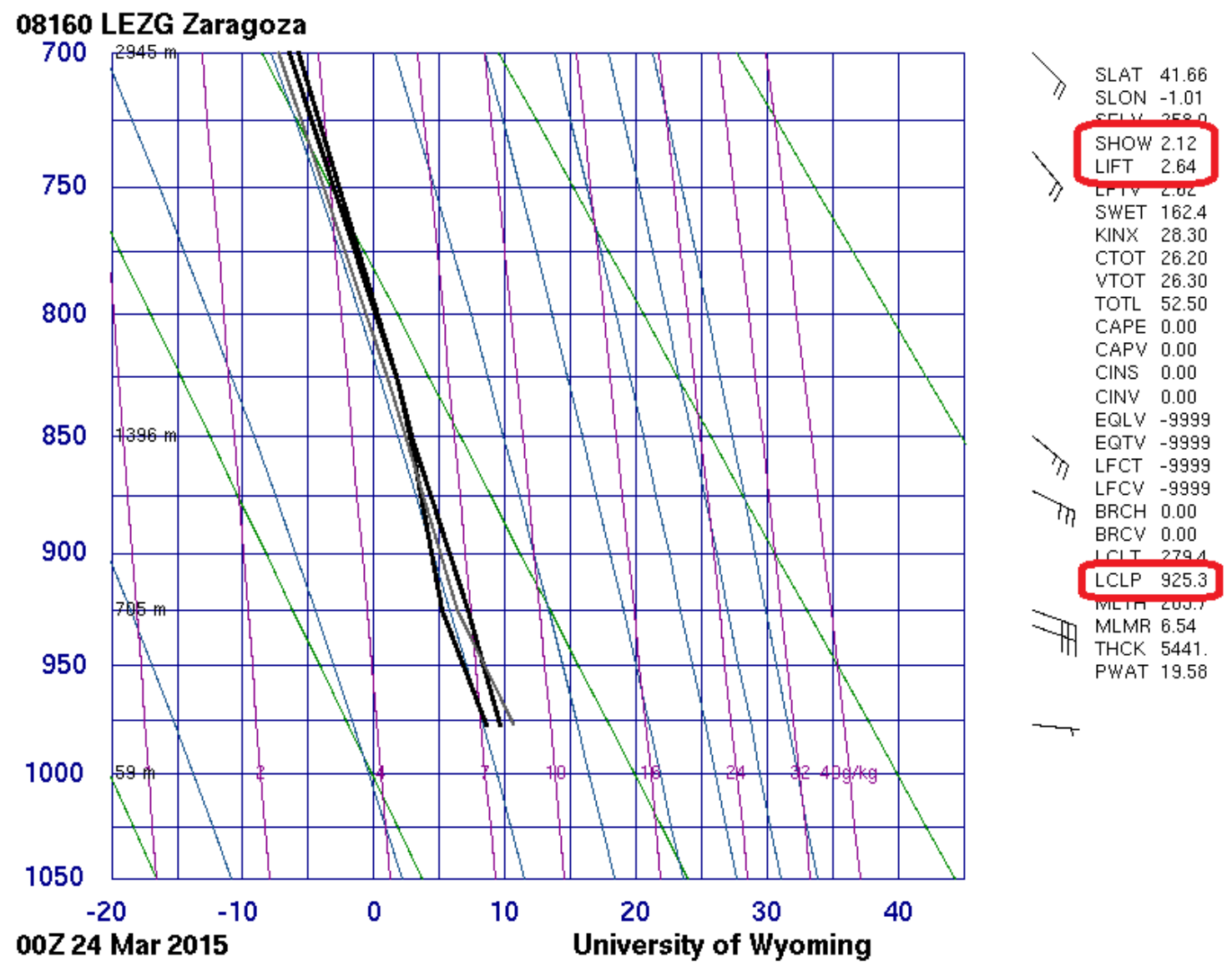

Figura 115: Radiosondeo de Zaragoza aeropuerto del 24 de marzo del 2015 a las 00 horas. Fuente: http://weather.uwyo.edu/upperair/sounding.html.

Tabla 37: Registro correspondiente al radiosondeo de Zaragoza del día 24 de marzo del 2015 a las 00 horas. Fuente: http://weather.uwyo.edu/upperair/sounding.html.

\begin{tabular}{|c|c|c|c|c|c|c|c|c|c|c|}
\hline PRES & HGHT & TEMP & DWPT & RELH & MIXR & DRCT & SKNT & THTA & THTE & THTV \\
\hline $\mathbf{h P a}$ & $\mathbf{m}$ & ${ }^{\mathbf{o}} \mathbf{C}$ & ${ }^{\mathbf{o}} \mathbf{C}$ & $\mathbf{\%}$ & $\mathbf{g} / \mathbf{k g}$ & $\mathbf{d e g}$ & $\mathbf{k n o t}$ & $\mathbf{K}$ & $\mathbf{K}$ & $\mathbf{K}$ \\
\hline 977,0 & 258 & 9,6 & 8,5 & 93 & 7,17 & 95 & 6 & 284,6 & 304,7 & 285,9 \\
\hline 932,0 & 643 & 7,5 & 5,7 & 88 & 6,18 & 110 & 30 & 286,4 & 303,9 & 287,4 \\
\hline 925,0 & 705 & 7,2 & 5,2 & 87 & 6,03 & 110 & 30 & 286,7 & 303,8 & 287,7 \\
\hline 873,0 & 1178 & 4,2 & 3,5 & 95 & 5,66 & 115 & 31 & 288,3 & 304,6 & 289,3 \\
\hline 850,0 & 1396 & 2,8 & 2,7 & 99 & 5,50 & 130 & 24 & 289,1 & 304,9 & 290,0 \\
\hline 849,0 & 1406 & 2,8 & 2,7 & 99 & 5,49 & 130 & 24 & 289,1 & 305,0 & 290,1 \\
\hline 827,0 & 1618 & 1,8 & 1,8 & 100 & 5,30 & 120 & 22 & 290,3 & 305,7 & 291,2 \\
\hline 737,0 & 2535 & $-3,4$ & $-3,9$ & 96 & 3,92 & 140 & 21 & 294,3 & 306,1 & 295,0 \\
\hline 700,0 & 2945 & $-5,7$ & $-6,4$ & 95 & 3,40 & 135 & 18 & 296,1 & 306,5 & 296,8 \\
\hline
\end{tabular}


Como se puede apreciar en la figura 116, correspondiente al mapa de presión en superficie para dicha jornada, la región aparece presidida por una notable columna de inestabilidad que favorece la dispersión de contaminantes. Esta situación atmosférica provocó que durante ese día los registros horarios de inmisiones en Coratxar no superaran los 3,6 $\mu \mathrm{g} / \mathrm{m}^{3}$, un valor muy bajo en comparación con los severos picos de inmisión estudiados anteriormente.

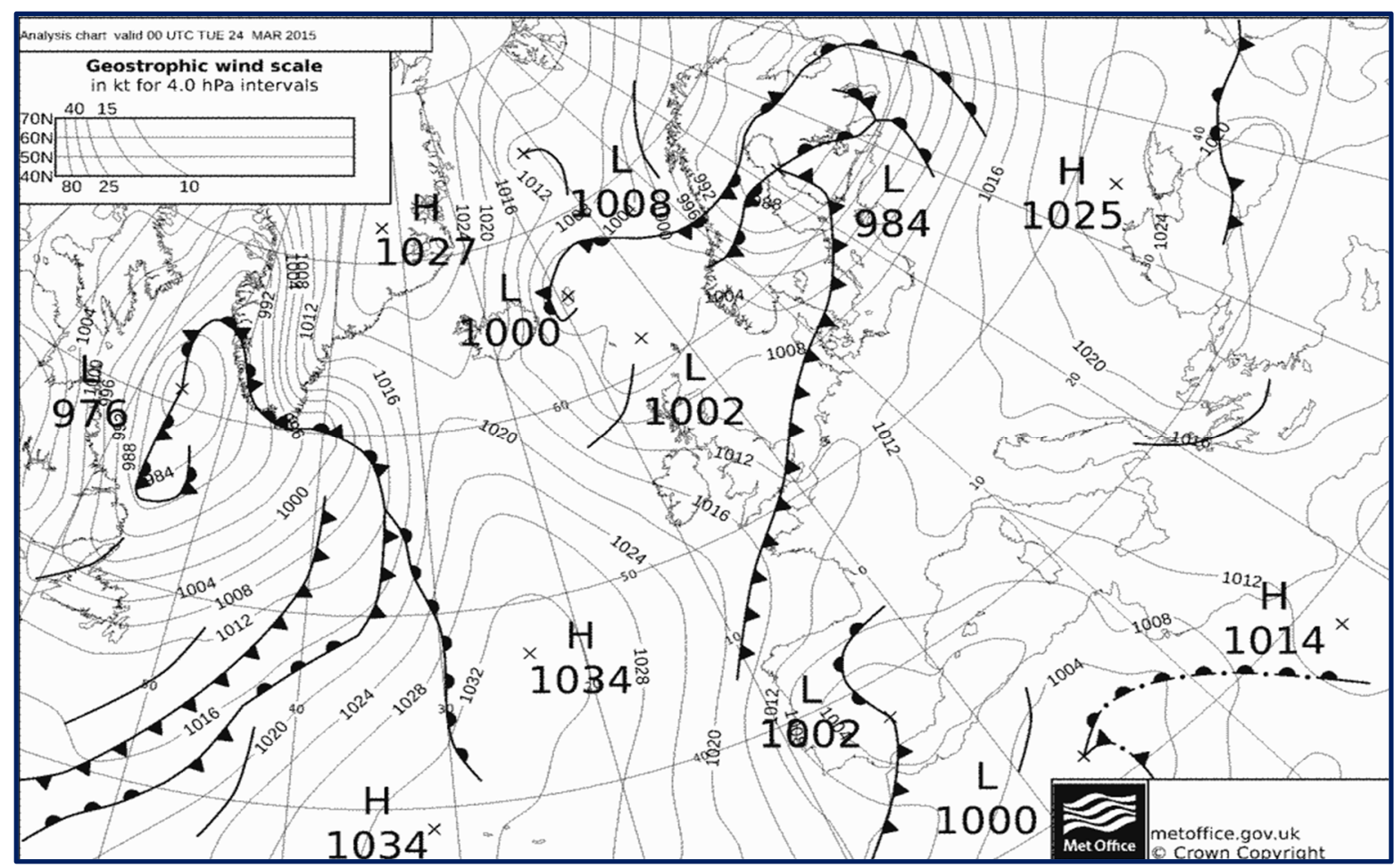

Figura 116: Mapa de superficie correspondiente al día 24 de marzo del 2015. Fuente:

http://www.wetterzentrale.de/topkarten/tkfaxbraar.html.

Del mismo modo, bajo situaciones de estabilidad, el escenario atmosférico regional puede favorecer la dispersión en altura. Ello se opera cuando el límite superior de la capa de mezcla se halla muy elevado. En estas situaciones, bajo condiciones de viento muy débil o calmas (vientos inferiores a 1,5 m/s), la dispersión del penacho sigue una ascendencia vertical sobre la chimenea, con impactos nulos o mínimos. Esta es la situación reflejada en la figura 117 y correspondiente al radiosondeo del día 5 de junio del 2015. En ella se aprecia la estructura de estabilidad donde el nivel de condensación ascendente (LCLP) se hallaría a una altura superior a los 3000 metros o 704,8 hPa. Una altura que supone un notable espesor en la capa de mezcla. 


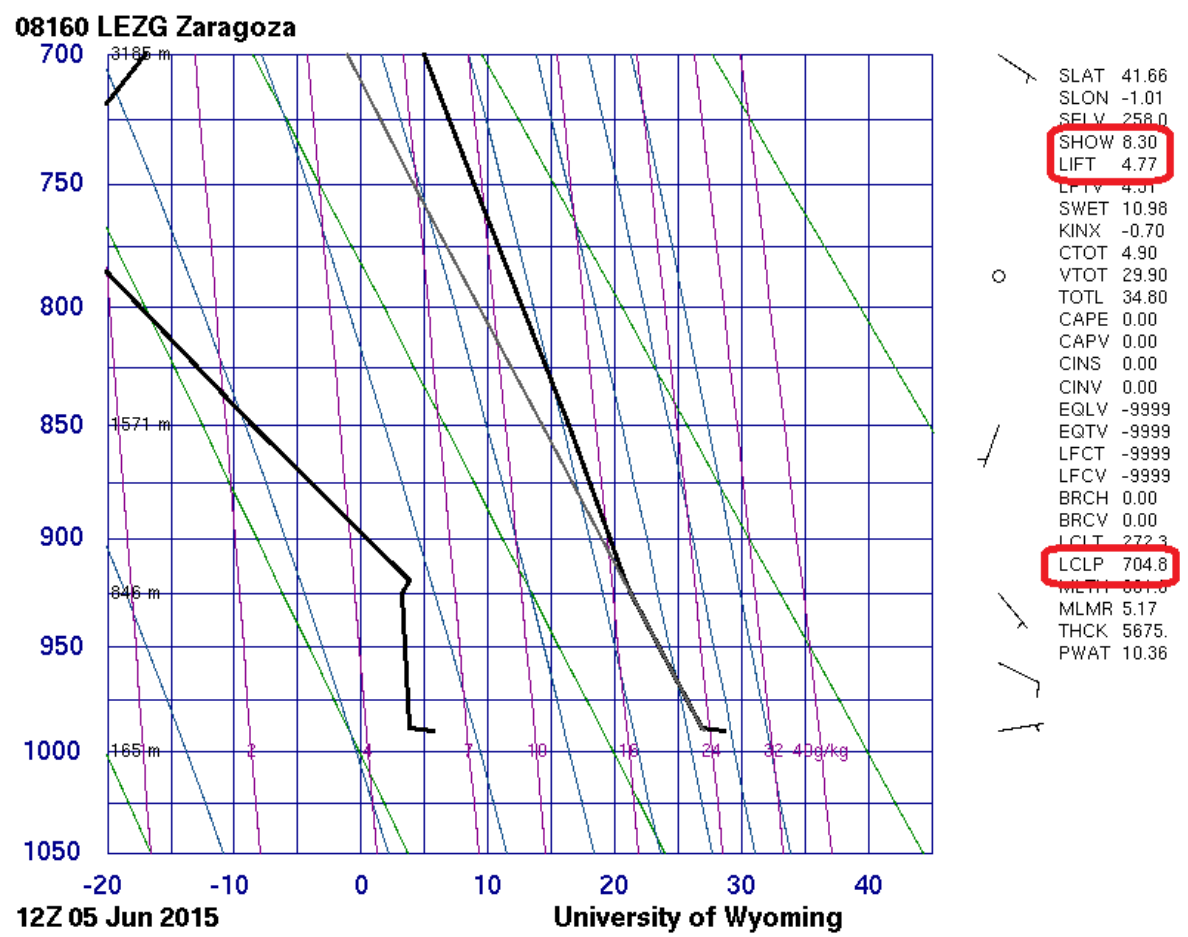

Figura 117: Radiosondeo de Zaragoza aeropuerto del 5 de junio del 2015 a las 12 horas. Fuente: http://weather.uwyo.edu/upperair/sounding.html.

El mapa de presión de superficie de esta jornada muestra la situación de ligera estabilidad, casi un collado, entre las dos áreas anticiclónicas de Centroeuropa y de Azores (Fig. 118).

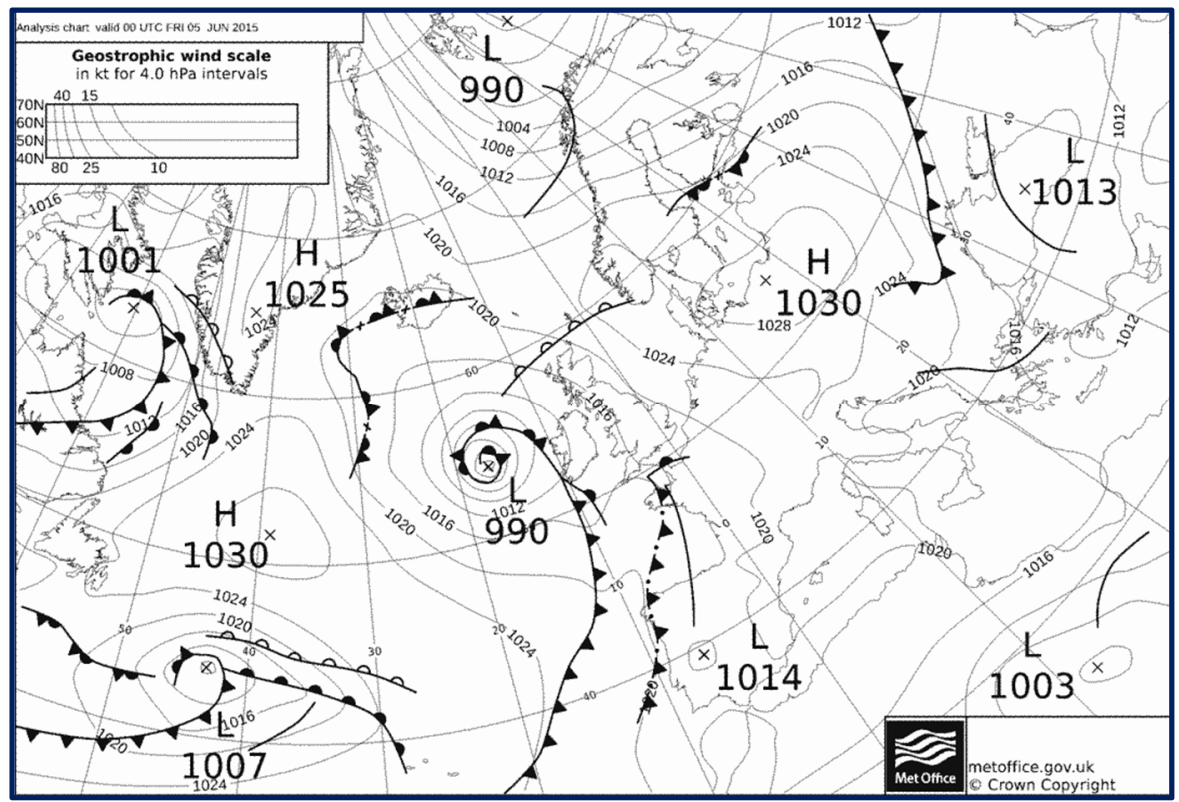

Figura 118: Mapa de presión de superficie del día 5 de junio del 2015. Fuente: http://www.wetterzentrale.de/topkarten/tkfaxbraar.html.

Página | 174 


\section{CONCLUSIONES Y SÍNTESIS DE LA ESTRUCTURA ATMOSFÉRICA EN LAS SITUACIONES DE IMPACTO SEVERO DE CONTAMINACIÓN}

En este capítulo IV se ha realizado un análisis de las situaciones atmosféricas en cuyo seno se han producido los procesos de máxima inmisión de $\mathrm{SO}_{2}$. El objetivo ha sido el de poner de manifiesto la importancia de tales situaciones atmosféricas en la potenciación o inhibición de los efectos contaminantes y, simultáneamente, identificar los patrones meteorológicos que ayuden a una más eficaz gestión del ecosistema.

Aplicando la metodología explicada al inicio del presente capítulo, se ha procedido a la determinación de los episodios de impactos severos de $\mathrm{SO}_{2}$ mediante el análisis de los registros de la base de datos de la Red de Vigilancia y Control de la Contaminación Atmosférica de la Generalitat Valenciana, durante el período 2000-2015. Así, se ha podido establecer una primera conclusión: globalmente las inmisiones severas del período 2000-2007, incluso superando en algunos años las 24 ocasiones de tolerancia señaladas en la actual legislación, contrastan con la sensible reducción que experimentan a partir de 2008, ya con los actuales sistemas de desulfuración funcionando a pleno rendimiento.

Por otra parte, el mero análisis estadístico de la serie de episodios identificados ya permite una aproximación a los procesos inherentes a su desarrollo. Tal es la configuración geográfica que muestran las inmisiones, así como su concentración estacional. Esa localización geográfica ya es expresiva de alineación con la dinámica aérea y con menores obstáculos orográficos. Asimismo, la concentración estacional muestra su vinculación a los meses de otoño e invierno, con un $86 \%$ del total de episodios concentrados en los meses de septiembre a enero. Esta concentración temporal viene a ser expresiva de su vinculación con períodos fríos en los que la interacción de factores geográficos y atmosféricos se intensifica.

En este orden analítico, se ha procedido a establecer la configuración atmosférica durante las situaciones con mayor severidad en los picos horarios y diarios de inmisión. En síntesis, se puede concluir que todos los episodios de fuerte contaminación se han desarrollado bajo un escenario atmosférico de marcada estabilidad, con viento muy débil o en calma. Una estructura atmosférica vertical presidida por una notable dorsal de aire cálido al nivel de 850 $\mathrm{hPa}$ que se corresponde con un acusado anticiclón en superficie, superior a los $1025 \mathrm{hPa}$. 
Tanto los radiosondeos de Zaragoza como los reanálisis a $850 \mathrm{hPa}$ muestran que son situaciones caracterizadas por la existencia de una capa de inversión térmica que limita los movimientos ascendentes del aire. Esta capa, aunque ocasionalmente haya sido prolongación de la inversión radiativa de superficie, tiene su origen en la subsidencia y compresión de la capa de aire situada sobre los 1000 metros de altura. Asimismo, puede apreciarse que la estabilidad es completa ya que a partir de los $850 \mathrm{hPa}$ (1550 metros) la estructura anticiclónica va intensificándose.

En síntesis, esta es la estructura atmosférica característica que se manifiesta en todas las situaciones de fuerte impacto ambiental. Unas situaciones predominantes durante el período invernal y que, como hemos definido en el capítulo II, resultan frecuentes en la región mediterránea. Básicamente vienen determinadas por el anticiclón de subsidencia que limita las inversiones radiativas de superficie, favoreciendo la aparición de capas de inversión en niveles más altos.

Los índices atmosféricos de Showalter, en todas las situaciones de grave impacto analizadas en este capítulo, oscilan entre los valores de 5 y 12 , significativos de gran estabilidad. Una significación que corrobora el Liftted Index, más apropiado a nuestro caso ya que la evolución adiabática se toma a 500 metros de altura, frente a los 1450 metros $(850 \mathrm{hPa})$ de Showalter. Los valores del Liftted Index oscilan entre 8 y 20, expresivos de gran estabilidad. Ello corresponde a un tipo de tiempo con estratificación estable y carencia, o gran limitación, de movimientos ascendentes. La flotabilidad de cualquier contaminante quedará detenida por la capa de inversión general que actúa como límite de la capa geográfica y, especialmente, por la capa de inversión regional que actúa como una tapadera de la capa activa o de mezcla.

La analítica, efectuada sobre la configuración y parámetros atmosféricos que sirven de escenario a los episodios de impacto severo en la inmisión regional de $\mathrm{SO}_{2}$, permite definir y establecer los modelos de las situaciones atmosféricas características. Unas situaciones en las que la estructura vertical de la atmósfera se revela determinante. Consecuentemente, el análisis y la previsión de tales estructuras o situaciones atmosféricas pueden constituir una importante aportación a los modelos de gestión ambiental. En este orden de prevención, es preciso partir de un buen conocimiento de las condiciones meteorológicas que pueden preceder a la formación de estas capas de inversión. Tanto los radiosondeos como, muy especialmente, los registros de la temperatura en niveles centrados en los $900 \mathrm{hPa}$ pueden aportar señales 
significativas. Las gráficas térmicas del observatorio del pico Fredes y de la cima del monte Caro son bien expresivas de este proceso, vinculado a la irrupción de una capa de aire cálido, compresiva por subsidencia, en esos niveles superiores a los afectados por los efectos geográficos. En definitiva, la conclusión es nítida: la existencia de una capa de inversión, cuya base se sitúa en niveles inferiores a 1200 metros, es el factor potenciador de los efectos de la contaminación regional. 

CAPÍTULO QUINTO

LAS SITUACIONES ATMOSFÉRICAS DE ACIDIFICACIÓN Y SU IMPACTO 



\section{METODOLOGÍA DE IDENTIFICACIÓN}

A tenor de la analítica desarrollada sobre todo el proceso de emisiones de $\mathrm{SO}_{2}$, y especialmente sobre sus episodios de máximo impacto de inmisión regional, es lícito interrogarse acerca de los efectos observados en el ecosistema. Tal y como hemos analizado, las condiciones atmosféricas superan, ocasionalmente, el diseño estructural de la chimenea de la CT, concebida en sus 343 metros para proyectar sus emisiones por encima de la capa geográfica o de mezcla. Esta ocasionalidad, inducida por la ocurrencia de escenarios meteorológicos que retienen las emisiones en el seno de la misma capa geográfica regional, ya permite explicar el carácter localizado de los efectos fitotóxicos observados en algunas de las masas forestales de la vertiente mediterránea del Sistema Ibérico.

No obstante, además de la rigurosa determinación del escenario meteorológico regional, hemos tratado de verificar si esa falta de generalización en las manifestaciones de efectos fitotóxicos podía estar en relación con procesos de acidificación del medio. En este orden de conocimientos, el fundamento de todo proceso de acidificación del medio viene constituido por la determinación de los procesos de lluvia ácida.

La metodología para establecer las situaciones de acidificación ambiental ha tenido como fundamento el registro del $\mathrm{pH}$ en el agua de lluvia. Este registro ha sido realizado mediante un analizador automático de lluvia ácida marca Kimoto, modelo AR-106 (Fig. 119).

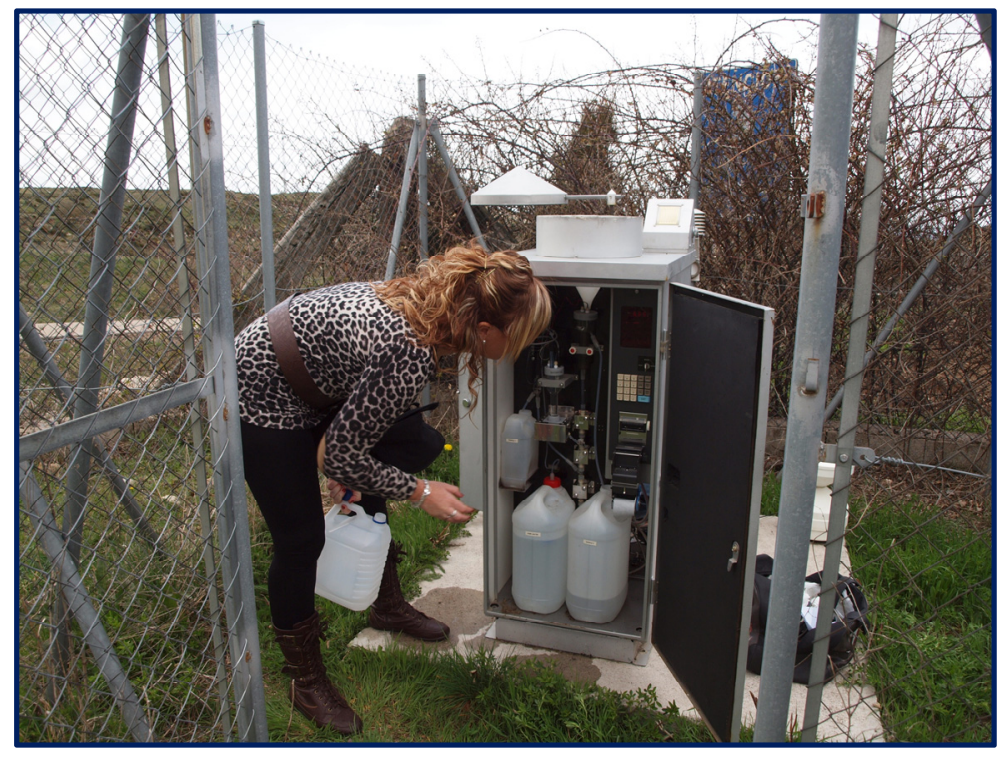

Figura 119: Control y calibrado del analizador automático de $\mathrm{pH}$ y conductividad en agua de lluvia, marca Kimoto, modelo AR-106 (Estación de Torre Miró, Morella). Fuente: archivo del Laboratorio de Climatología de la Universitat Jaume I. 
En total el analizador ha registrado, entre los años 2005-2014, más de tres mil medidas y análisis diezminutales en muestras de lluvia. A través de todas esas medidas ha sido posible extraer, con gran rigor, el valor medio del $\mathrm{pH}$ en el agua de lluvia. En el presente resumen se dan los promedios de todos aquellos episodios con precipitación continuada durante una hora. Asimismo, se han representado las analíticas correspondientes a los períodos más significativos por magnitud del pH y duración de la lluvia. El analizador ha estado ubicado en el altiplano de Torre Miró (1256 metros), en la linde de las provincias de Castellón y Teruel, ubicación escogida como ya se ha explicado en los capítulos precedentes a tenor de los flujos aéreos dominantes sobre la región (Fig. 120).

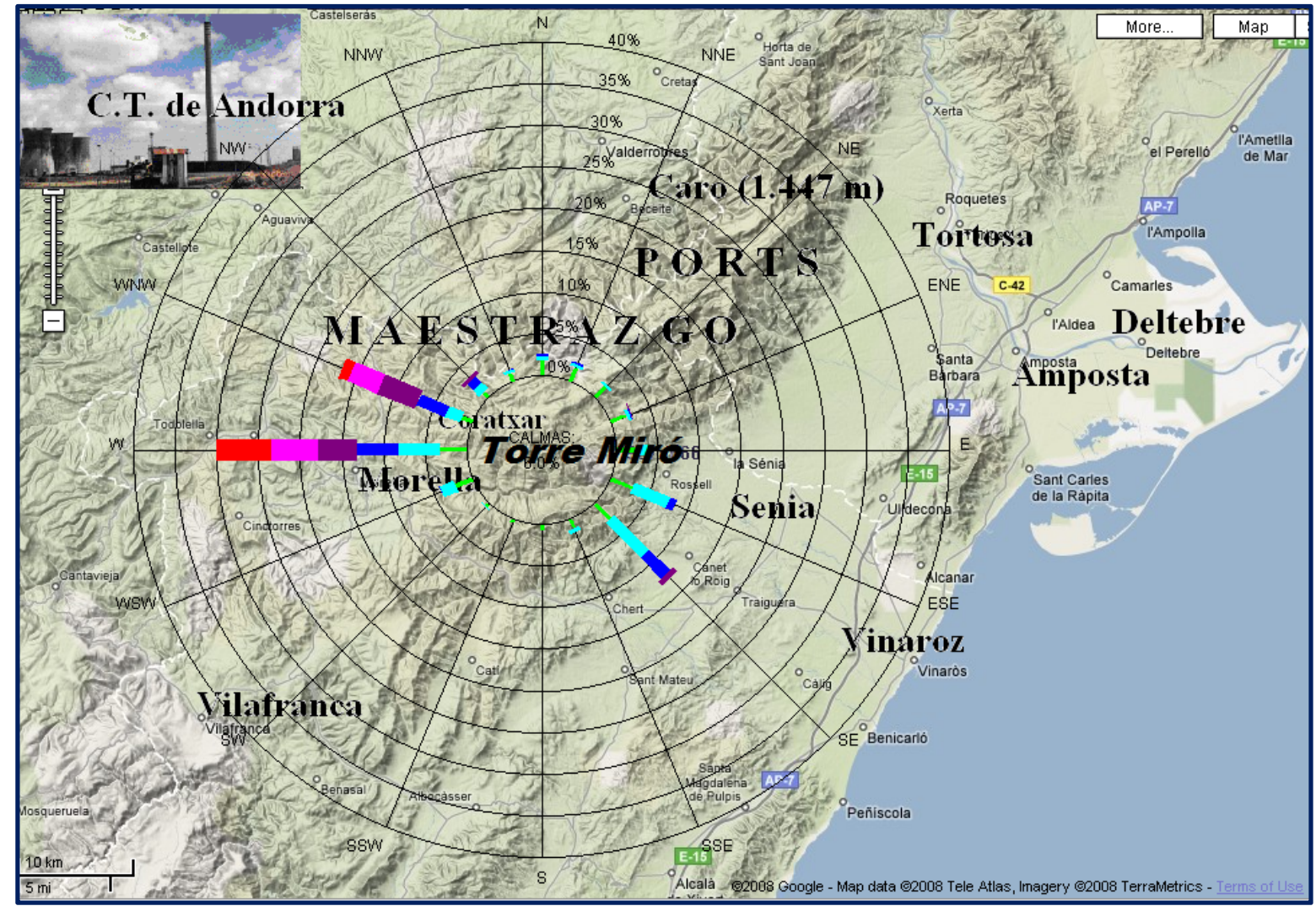

Figura 120: Ubicación del analizador Kimoto en el altiplano de Torre Miró (1256 metros). La rosa de vientos de Coratxar, refleja los flujos aéreos dominantes sobre la vertiente mediterránea del Sistema Ibérico en el nivel de 1200 metros. Fuente: archivo del Laboratorio de Climatología de la Universitat Jaume I.

La evolución global del pH a lo largo de los registros pluviométricos de los años 2005 a 2014 está representada en la figura 121. En ella aparecen las medidas correspondientes a los períodos más significativos por intensidad y duración de la lluvia (mínimo de seis registros diezminutales seguidos). 


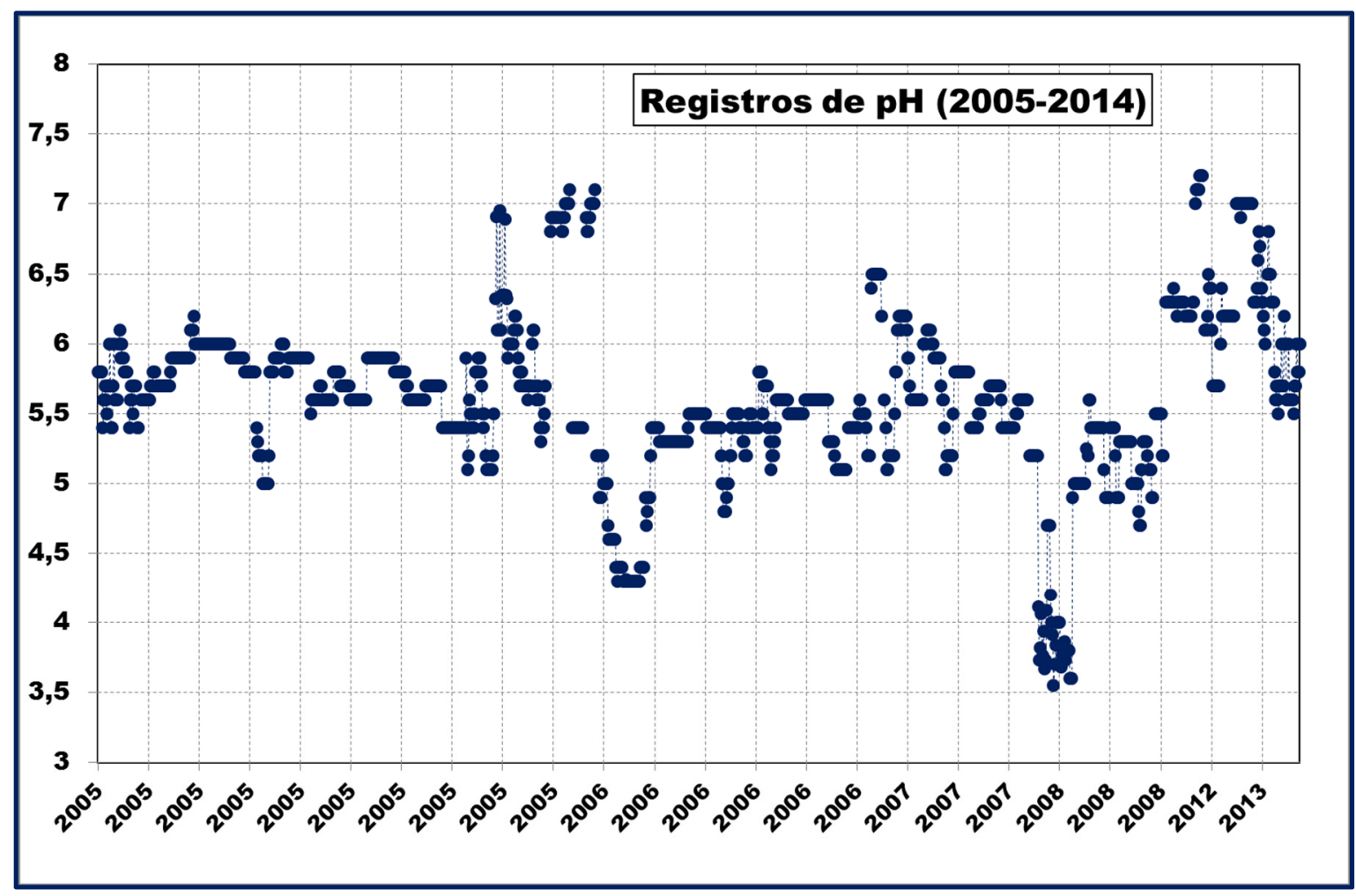

Figura 121: Valor del pH en el agua de lluvia precipitada en Torre Miró (2005-2014). Fuente: elaboración propia, Laboratorio de Climatología de la Universitat Jaume I.

La representación gráfica muestra una gran constancia en torno al valor medio de 5,6, si bien las desviaciones son acusadas. No obstante, es preciso señalar que la curva muestra la eficacia de las medidas de desulfuración de la CT en los registros realizados entre 2009 y 2014. Así, el valor medio del $\mathrm{pH}$ en el total de la serie ha sido de 5,6, mientras que si consideramos únicamente los registros más recientes, desde 2009 a 2014, han dado un valor medio algo superior, concretamente de 6,2.

Por otra parte, es conveniente destacar que el valor promedio de $\mathrm{pH}$ a lo largo del período 2005-2014 ha sido muy semejante al promedio que se obtuvo en la estación de Torre Miró en el período 1984-1992. Unos valores algo ácidos pero muy próximos a la neutralidad (ENDESA, 1993). En esa misma zona los valores en el periodo 1989-1991 fueron también semejantes con pH 5,54 (Carratalà et al., 1992). Estos valores son indicativos de una lluvia no contaminada y situada bajo la influencia, junto con la naturaleza del ecosistema, de los altos niveles de $\mathrm{CaCO}_{3}$ contenidos en los aerosoles africanos.

Consecuentemente, con la magnitud del valor de $\mathrm{pH}$, es posible concluir la existencia de una masa atmosférica con un nivel de aceptable calidad del aire. 
Asimismo, tal y como refleja también la figura 121, los parámetros de $\mathrm{pH}$ han mostrado, eventualmente, unos registros en los que los valores de acidez del agua de lluvia se sitúan ya dentro del umbral de acidificación $(\mathrm{pH}<5)$ y más ocasionalmente con valores acusados ( $\mathrm{pH}$ entre 4,3 y 4,5). Estos han sido precisamente los episodios que han servido para caracterizar las situaciones atmosféricas de baja calidad del aire con valores de neta acidificación. No obstante, igualmente podemos observar que el valor medio del $\mathrm{pH}$, a lo largo de la serie de observaciones, viene altamente condicionado por la existencia de picos y períodos de neta neutralización de la acidez.

De este modo la metodología meteorológica se ha aplicado, al igual que en el capítulo anterior, a caracterizar las situaciones extremas. Así se ha procedido a configurar el modelo atmosférico correspondiente a valores de neta acidificación y, como contraposición, el modelo que provoca las situaciones de neutralización de la acidez. Exponente de este trabajo, realizado en el seno de nuestro grupo de investigación, ha sido la publicación en 2014 del artículo "El escenario atmosférico como modelo de gestión ambiental en la vertiente mediterránea del Sistema Ibérico". En él figuran algunas de las situaciones más representativas de episodios de ambos procesos. 


\section{SITUACIONES ATMOSFÉRICAS DE ACIDIFICACIÓN}

El criterio selectivo ha sido configurar las situaciones atmosféricas correspondientes a episodios de lluvia con registros de $\mathrm{pH}$ inferior a 4. La configuración atmosférica característica de estas situaciones de neta acidificación viene representada por episodios como los acontecidos en enero de 2006 y febrero de 2008. En este orden de escenarios, la situación atmosférica más característica de estas lluvias ácidas $(\mathrm{pH}<4)$ viene asociada principalmente a la convergencia de tres factores:

- El primero es la afluencia sobre el Maestrazgo y Els Ports de vientos que aportan las mayores cantidades de contaminantes atmosféricos. Este factor de advección es determinante cuando, además de los contaminantes locales, se realiza un transporte transfronterizo de las emisiones de contaminantes generadas en las grandes centrales térmicas mediterráneas. Estas centrales constituyen un grandioso cinturón, especialmente de lignitos, que desde los Balcanes, Maritsa Iztok en Bulgaria y Turceni en Rumanía, alcanza nuestra región a través de Italia y Francia (Piombino y Fos Berre) (Millán y Sanz, 1993). No obstante, la ubicación geográfica de nuestra región respecto a la circulación atmosférica determina que esta llegada de emisiones extranjeras se produzca en ocasiones esporádicas (Olcina, 1994).

- El segundo factor es la existencia de una capa de inversión, situada entre 1,5 y 2,5 km, que atrapa las emisiones de contaminantes locales o transfronterizos.

- En tercer lugar se requiere la condensación de la humedad necesaria para la precipitación ácida. Esta precipitación puede proceder del efecto orográfico sobre vientos húmedos marinos que activan pluviométricamente situaciones de estabilidad condicionada.

Una de las situaciones atmosféricas más favorables a los impactos de acidificación es aquella en la que los vientos moderados y constantes del NW aportan los contaminantes sobre la zona. Esta es la situación meteorológica que se produjo en los primeros días del año 2006. Unos vientos que, simultáneamente, limpian de cualquier aerosol africano la atmósfera local determinando el $\mathrm{pH}$ real y sin enmascaramiento (Fig. 122). Los valores analizados de $\mathrm{pH}<4,5$ significan una neta acidificación del ecosistema. Una acidificación que se torna tanto más intensa en cuanto que estas situaciones desembocan frecuentemente, durante el invierno, en 
procesos de inversión térmica, con vientos calmados y con retención de los contaminantes en los niveles bajos.

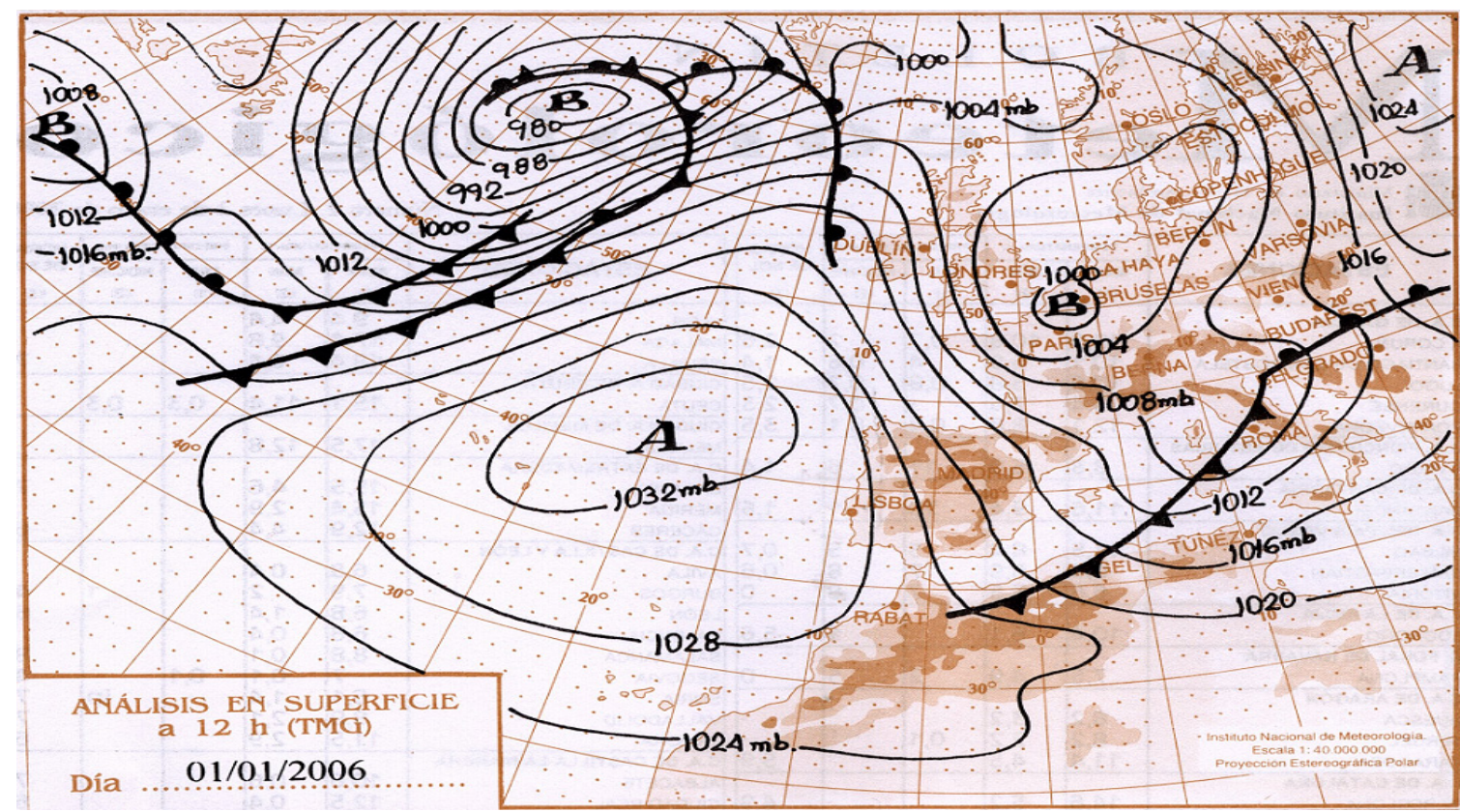

Figura 122: Situación en superficie del día 1 de enero del 2006. El campo bárico muestra la afluencia de flujos del NW. Fuente: Instituto Nacional de Meteorología, INM.

Como se puede apreciar en la figura 123, la estructura en ondas de las formaciones nubosas bajas evidencia el soplo de los vientos sobre una orografía de aristas montañosas. 


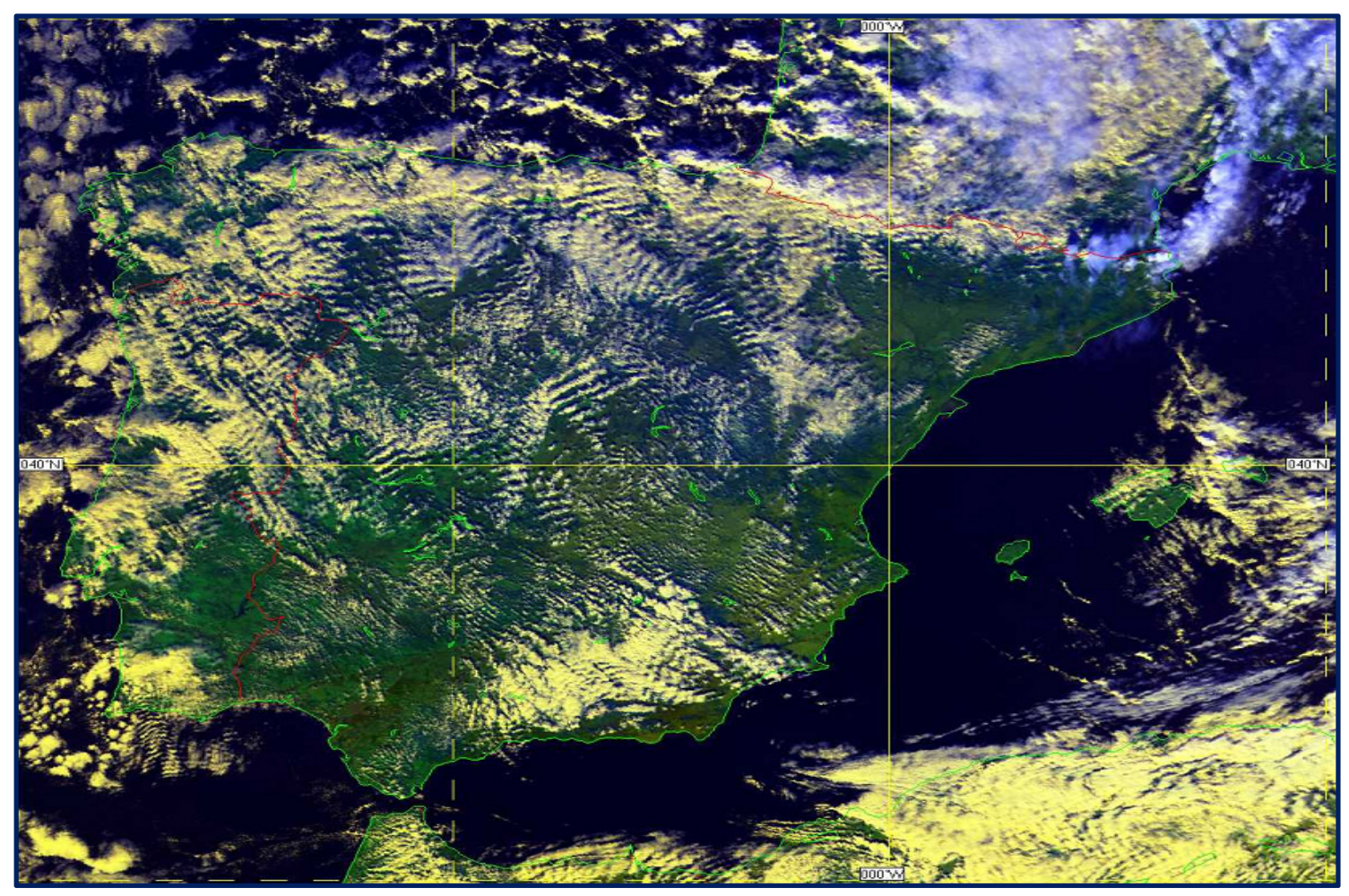

Figura 123: Imagen NOAA del 1 de enero del 2006. Fuente: archivo del Laboratorio de Climatología de la Universitat Jaume I.

Esta preparación desembocó en uno de los casos más intensos de acidificación, con valores analizados de $\mathrm{pH}$ de 4,5 (Fig. 124). El proceso es el acaecido en la situación correspondiente a los días 4 y 5 del mes de enero del 2006. 


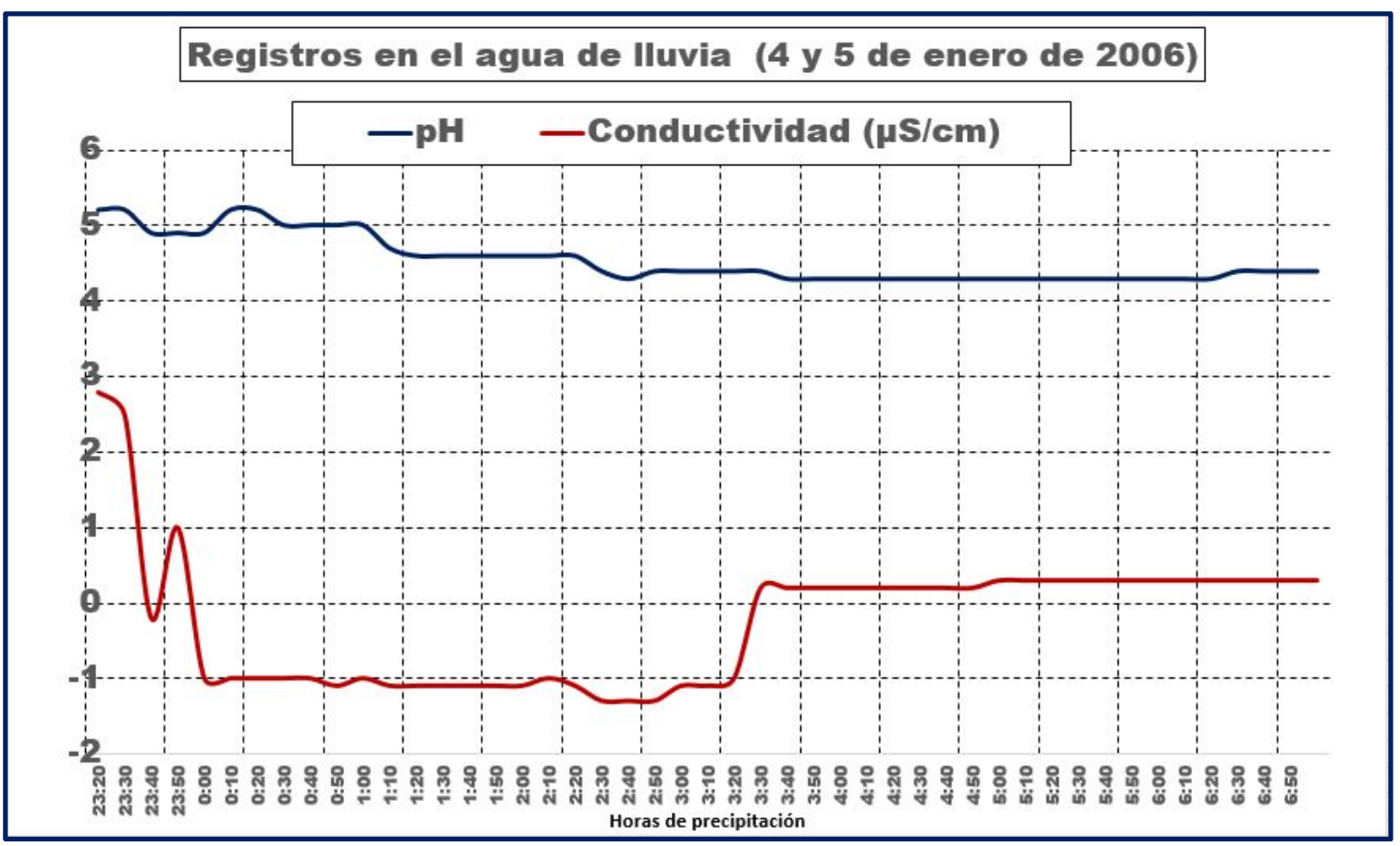

Figura 124: Valores de pH y conductividad en el agua de lluvia durante los días 4 y 5 de enero del 2006. Fuente: elaboración propia, Laboratorio de Climatología de la Universitat Jaume I.

La configuración atmosférica de este episodio de neta acidificación muestra claramente el primero de los factores reseñados: la contribución previa de vientos de limpieza y su sustitución por los aportes transfronterizos. Los vientos constantes del NE aportan los contaminantes transfronterizos sobre la zona. Como puede apreciarse en la figura 125, la disposición isobárica muestra una potente depresión sobre el mediterráneo central. Los vientos hacen de vectores de las grandes emisiones de contaminantes generadas en las grandes centrales térmicas mediterráneas, extendidas desde las orillas del mar Negro hasta nuestra región. 


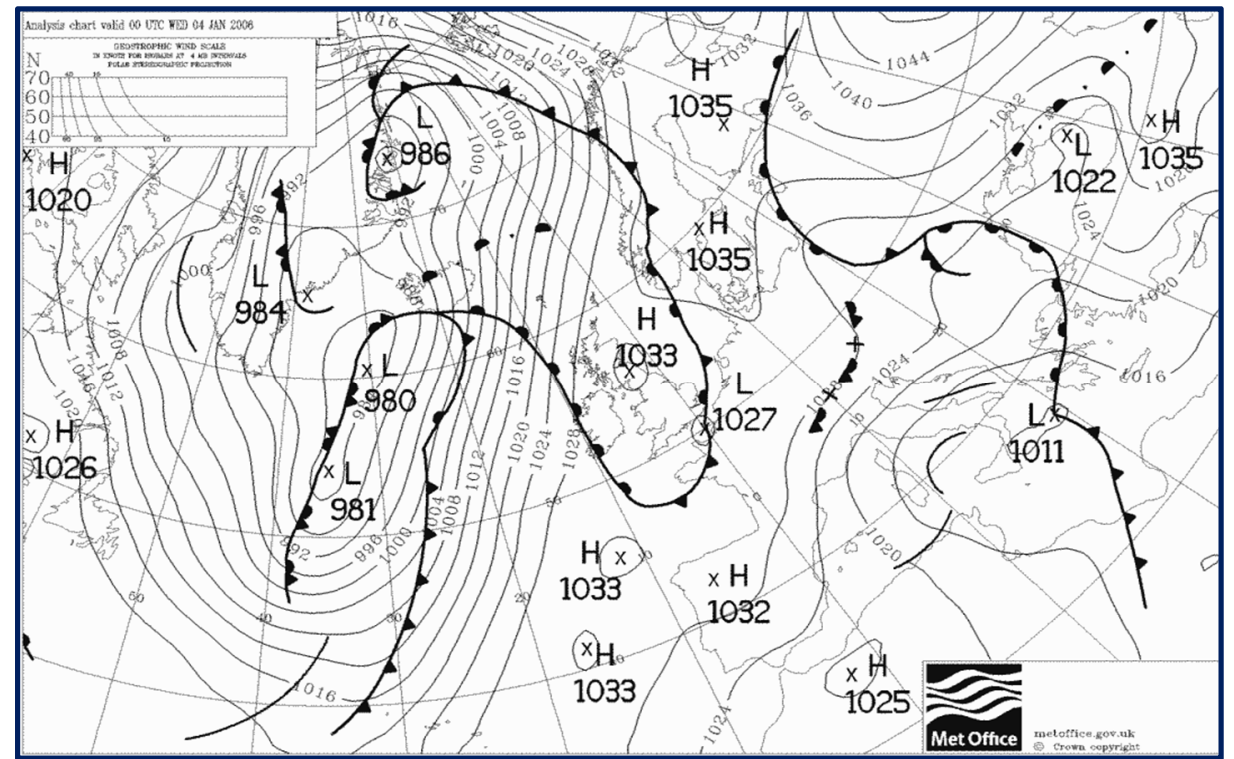

Figura 125: Situación en superficie del día 4 de enero del 2006. Fuente: http://www.wetterzentrale.de/topkarten/tkfaxbraar.htm.

En esta situación aérea viene a actuar el segundo de los factores señalados: la existencia de una capa de inversión. De este modo, los contaminantes aportados son atrapados bajo la capa de inversión térmica, situada a 1460-1520 metros, cuyos efectos se suman a la estabilidad condicionada presente en la capa geográfica (Fig. 126).

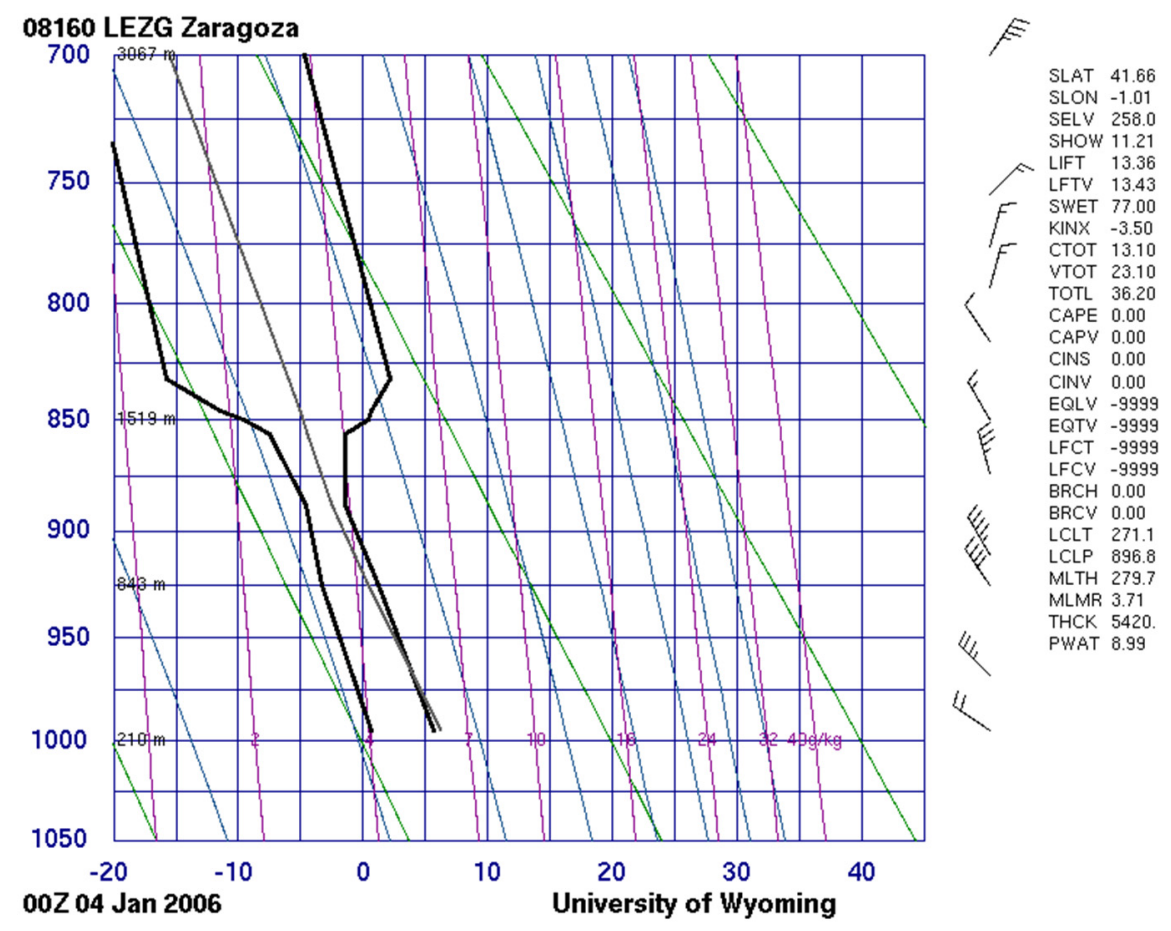

Figura 126: Radiosondeo de Zaragoza aeropuerto del 4 de enero del 2006 a las 00 horas. Fuente: http://weather.uwyo.edu/upperair/sounding.html. 
Idéntica configuración mostraba el episodio de acidificación acontecido en febrero de 2008. La estructura atmosférica de los días 12, 13 y 14 de febrero de 2008 vuelve a ser significativa. Precisamente esta estructura térmica vertical presidió uno de los episodios más agresivos de acidificación de todos los registrados. Los valores de $\mathrm{pH}$ son inferiores a 4, en un agua de lluvia cuya temperatura apenas supera los $0{ }^{\circ} \mathrm{C}$ (Fig. 127).

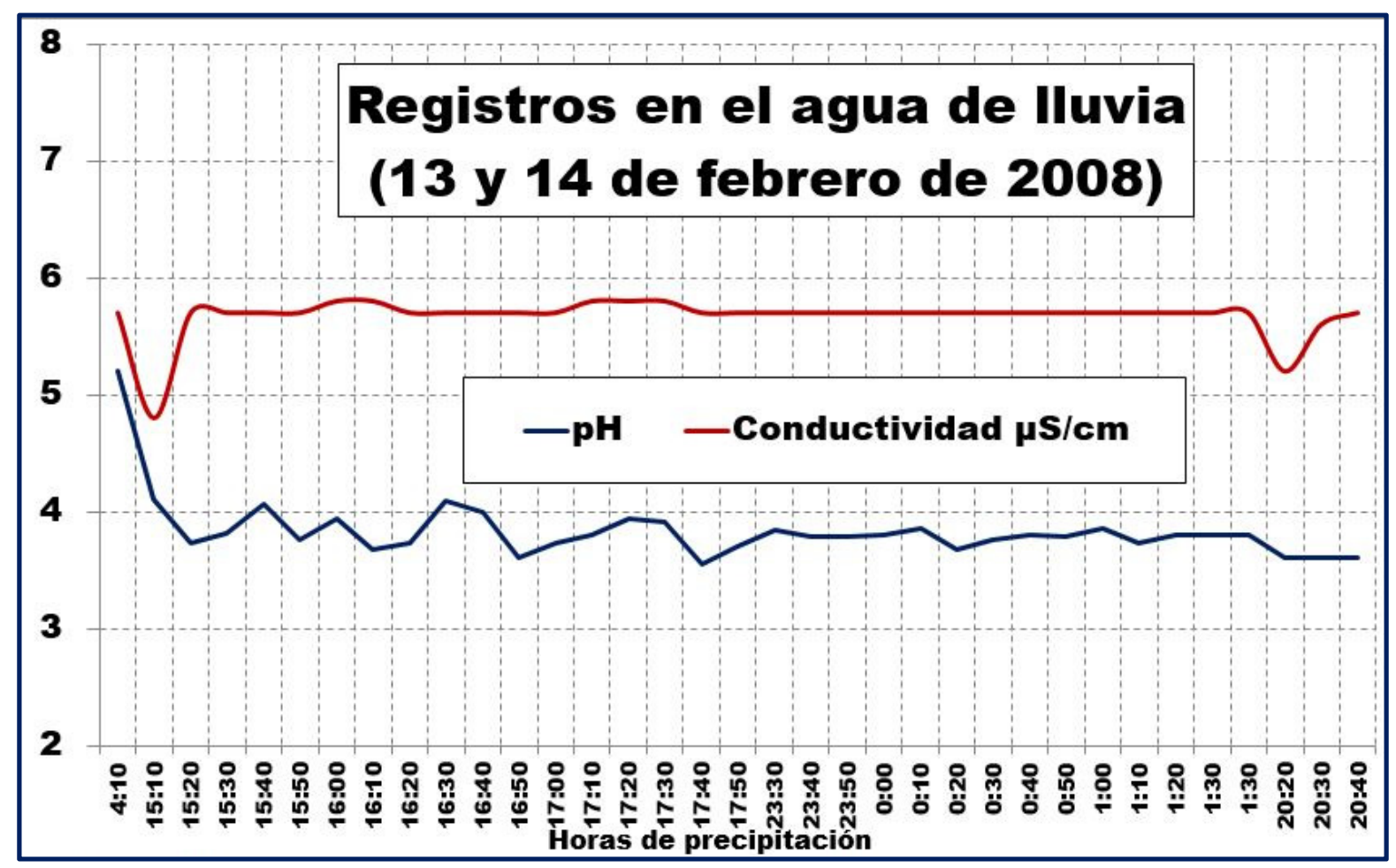

Figura 127: Registros de pH y conductividad en el agua de lluvia durante los días 13 y 14 de febrero del 2008. Fuente: elaboración propia, Laboratorio de Climatología de la Universitat Jaume I.

Esta situación comportaba vientos constantes del $\mathrm{E}$, a nivel de los $850 \mathrm{hPa}$, que actuaron como canalizadores de los contaminantes transfronterizos de larga distancia procedentes de las centrales térmicas europeas (Fig. 128). Estos aportes, junto con las emisiones propias de la CT, provocan episodios de acidificación sobre el Maestrazgo. 
14FEB2008 00Z

$850 \mathrm{hPa}$ Temperatur (Grad C)
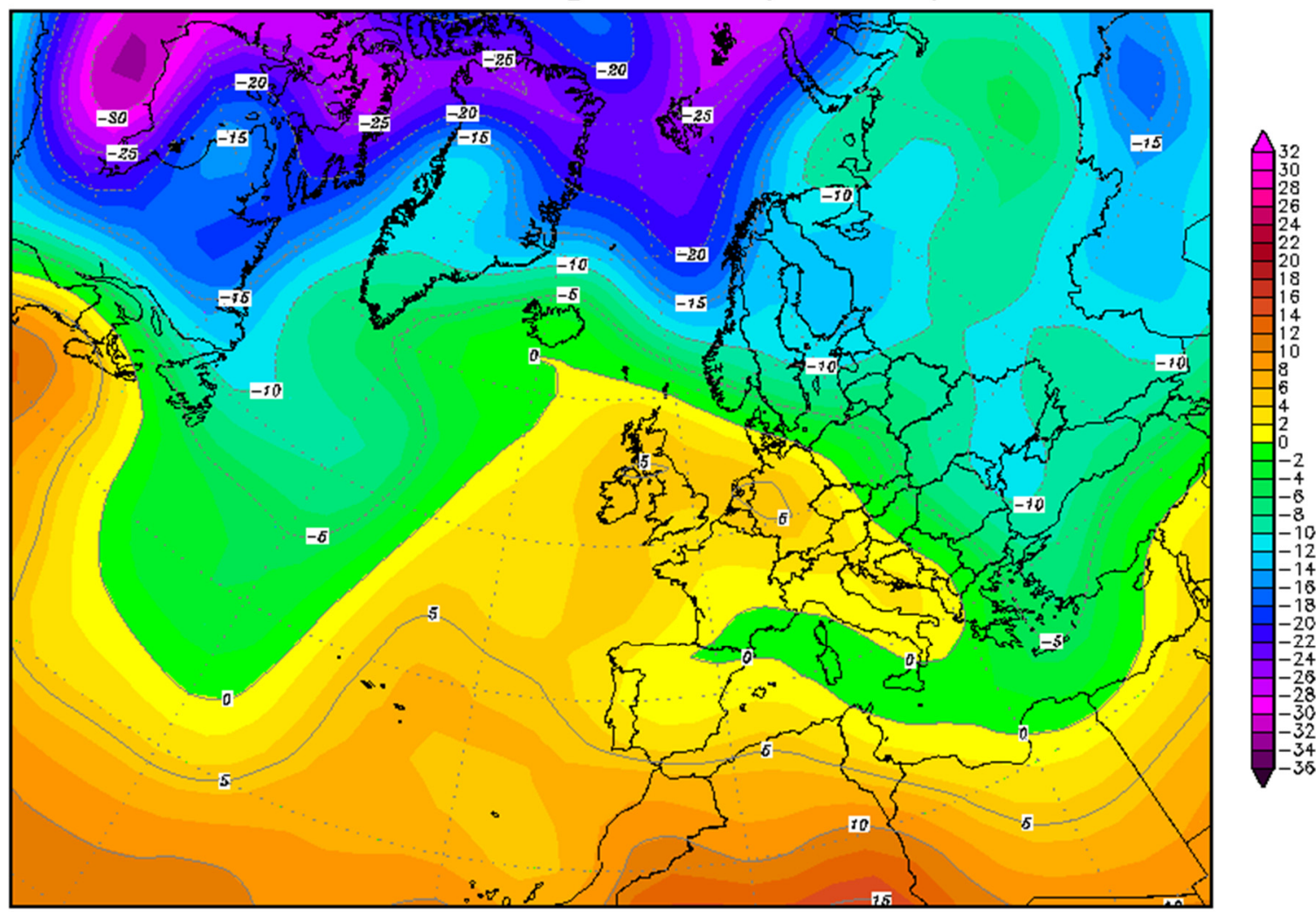

Daten: Reanolysis des NCEP

(C) Wetterzentrale

www,wetterzentrale.de

Figura 128: Situación atmosférica a $850 \mathrm{hPa}$ el día 14 de febrero del 2008. Nítida advección de aire frío en altura, nivel de 850 hPa. Fuente: http://www.wetterzentrale.de/topkarten/fsreaeur.html.

Estos flujos se observan nítidamente en el radiosondeo de la figura 129. A $940 \mathrm{hPa}$ se alcanza el LCLP sobre el cual la fuerza del viento supera los $50 \mathrm{~km} / \mathrm{h}$. Además, la capa de inversión térmica aparece sobre los 2500 metros. La constancia de la dirección ESE dirige los contaminantes transfronterizos sobre nuestra región. 


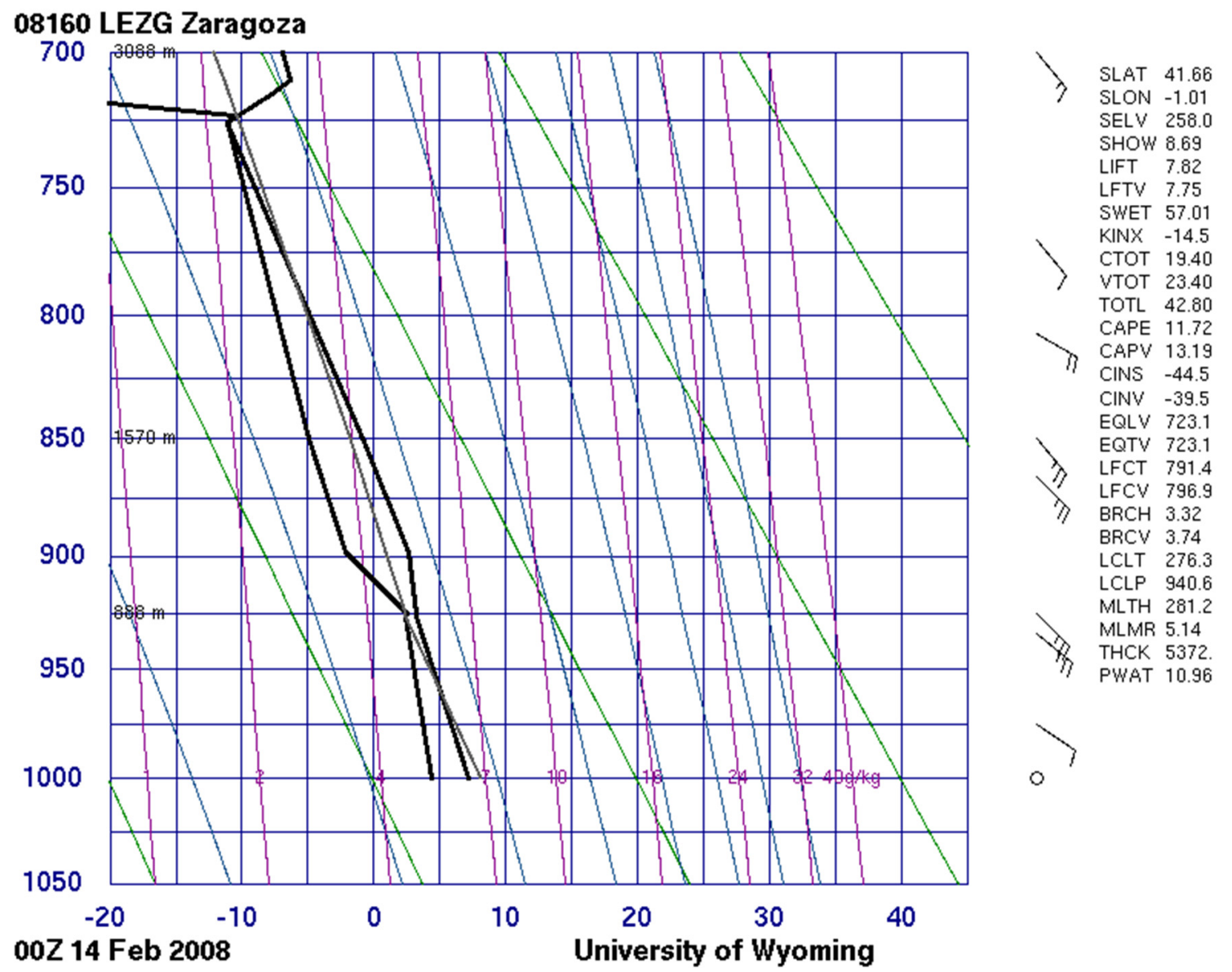

Figura 129: Radiosondeo de Zaragoza el día 14 de febrero del 2008 a las 00 horas. Fuente:

http://weather.uwyo.edu/upperair/sounding.html.

Las condiciones de temperatura y humedad regionales aparecen reflejadas en los registros de la estación de Torre Miró (Morella). Como se puede apreciar en la figura 130, la temperatura de rocío $\left(T_{d}\right)$ registrada en el nivel de condensación ascendente (NCA/LCLP), se mantuvo en los mismos valores de la temperatura del aire durante los días 13, 14 y 15 de febrero, provocando una situación de notable saturación. Ello desembocó en la formación de una tenaz niebla que dominó las cumbres del Maestrazgo y en cuyo seno tuvieron lugar las reacciones acidificantes. 


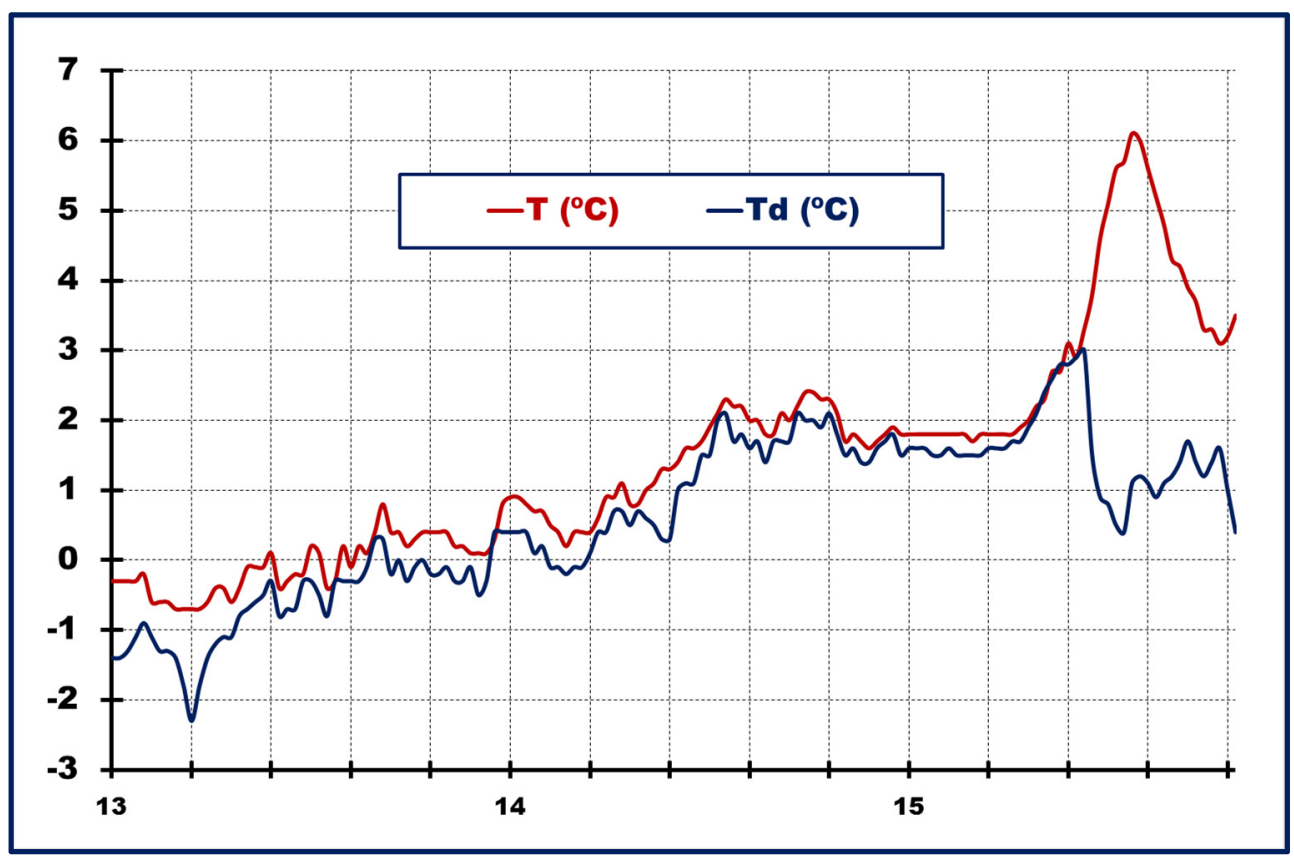

Figura 130: Evolución térmica $(T)$ y del punto de rocío $\left(T_{d}\right)$ en la estación de Torre Miró durante los días 13,14 y 15 de febrero del 2008. Fuente: elaboración propia, Laboratorio de Climatología de la Universitat Jaume I.

Asimismo, en la figura 131 se muestran los registros del viento de la estación de Torre Miró durante la jornada del 14 de febrero del 2008. En el gráfico se puede apreciar con claridad como los vientos soplaron constantemente del E y SE y la velocidad media se aproximaba a los $23 \mathrm{~km} / \mathrm{h}$.

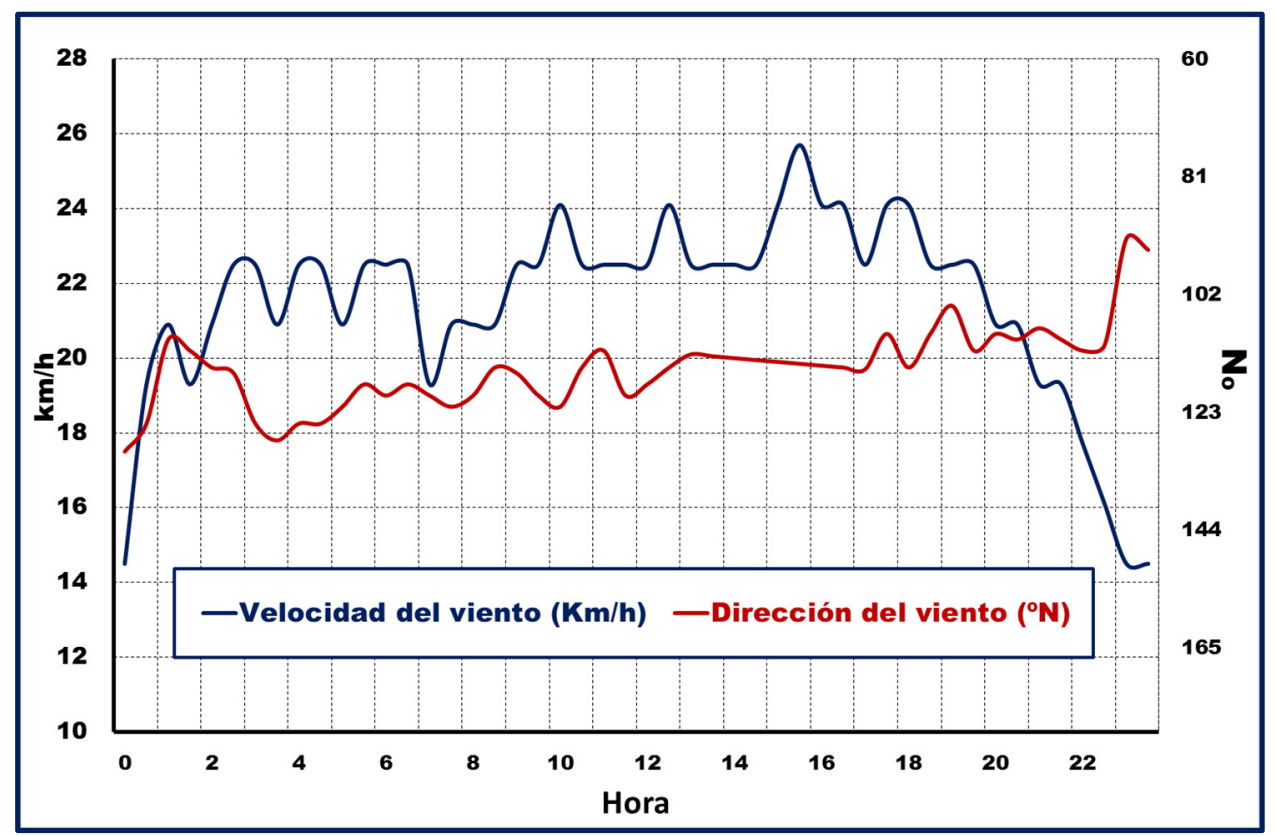

Figura 131: Régimen aéreo del día 14 de febrero del 2008 sobre la cima de Torre Miró (1256 metros). Fuente: elaboración propia, Laboratorio de Climatología de la Universitat Jaume I. 


\section{SITUACIONES DE NEUTRALIZACIÓN DE LLUVIA ÁCIDA}

En este punto de nuestro análisis, hemos de destacar que un factor determinante de las situaciones de neutralización de lluvia ácida es la existencia de aerosoles procedentes del Sahara que irrumpen, principalmente en periodos estivales, en la Cuenca Occidental del Mediterráneo (Westphal et al., 1988). Estos aerosoles, junto al carácter básico de la geología local, constituida esencialmente por terrenos calcáreos, son los causantes de los registros de $\mathrm{pH}$ superiores a 6 (Quereda y Olcina, 1994). Un exponente claro de este fenómeno de neutralización de la lluvia ácida es el análisis químico de dos grandes episodios de lluvia de tierra acontecidos los días 18 de septiembre de 1993 y 1 de junio de 1994. Dicho análisis fue realizado en el Instituto de Tecnología Cerámica (ITC) para nuestro grupo de investigación ofreciendo los siguientes resultados (Quereda et al., 1996):

Tabla 38: Tabla de análisis químico del agua de lluvia, promedio de los valores analizados durante el 18 de septiembre del 1993 y el 1 de junio del 1994. Fuente: Quereda et al., 1996.

\begin{tabular}{|c|c|}
\hline $\mathbf{p H}$ & 7,86 \\
\hline Calcio & $21,20 \mathrm{ppm}$ \\
\hline Magnesio & $0,60 \mathrm{ppm}$ \\
\hline Sodio & $3,30 \mathrm{ppm}$ \\
\hline Potasio & $6,10 \mathrm{ppm}$ \\
\hline
\end{tabular}

Un ejemplo de estos procesos viene representado por la situación atmosférica acontecida el día 4 de agosto del 2012. El factor determinante de la neutralización de las precipitaciones fue una frontólisis sobre el NW de la Península Ibérica (Fig. 132). 
04AUG2012 00Z

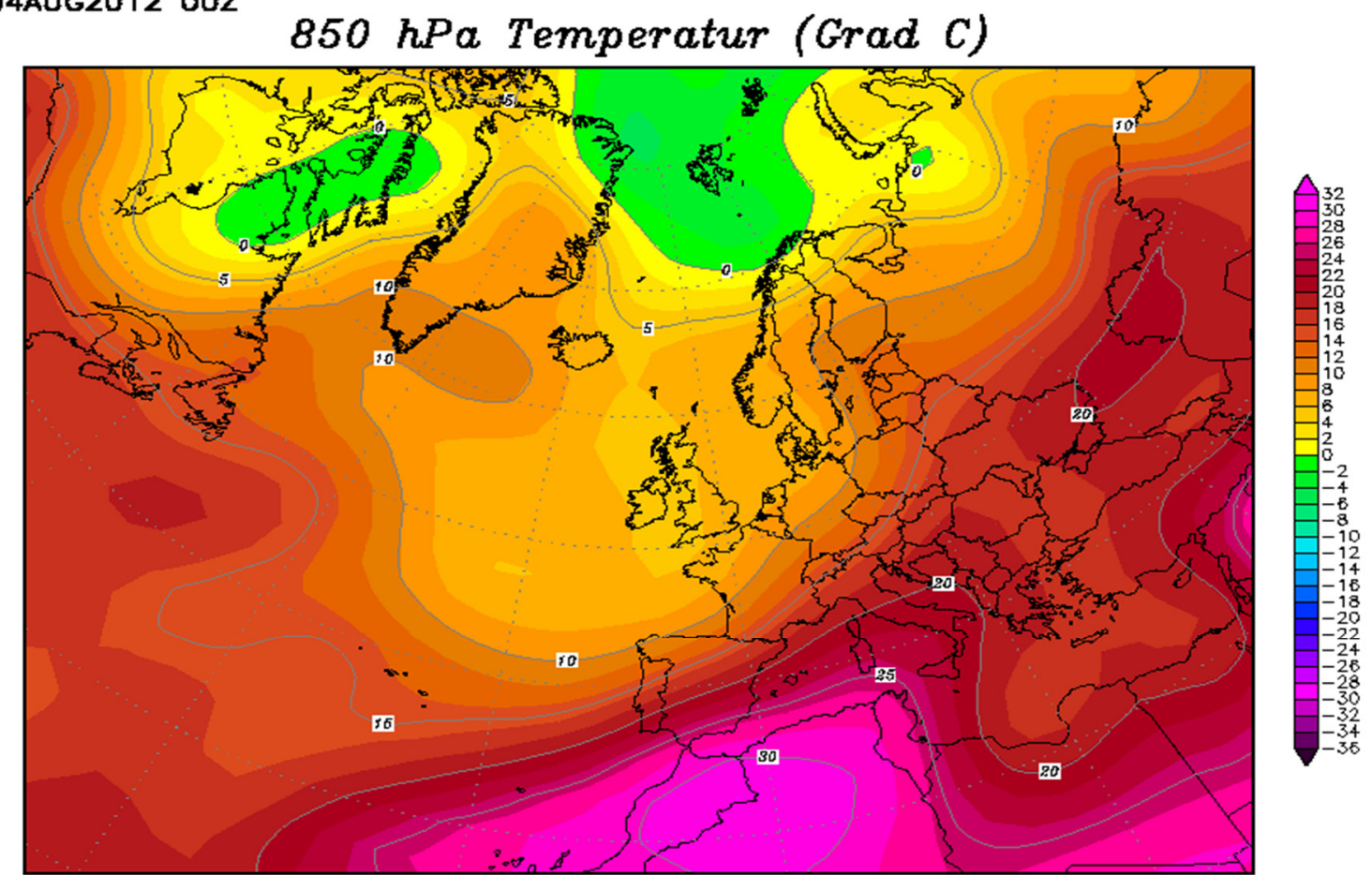

Daten: Reanalysis des NCEP

(C) Wetterzentrole

www.wetterzentrale.de

Figura 132: Situación atmosférica a 850 hPa del 4 de agosto del 2012. Aerosol africano sobre la Cuenca occidental del Mediterráneo y frontólisis sobre el NW de la Península Ibérica. Fuente: http://www.wetterzentrale.de/topkarten/fsreaeur.html.

El análisis de los registros de $\mathrm{pH}$ en el agua de lluvia precipitada el mismo día sobre Torre Miró aparece en la figura 133. Los valores de $\mathrm{pH}$ registrados durante este episodio alcanzan varios picos de $\mathrm{pH}=7$. Al final del episodio de precipitación, con la atmósfera ya lavada, se puede apreciar en la figura como los valores de $\mathrm{pH}$ comienzan a descender. 


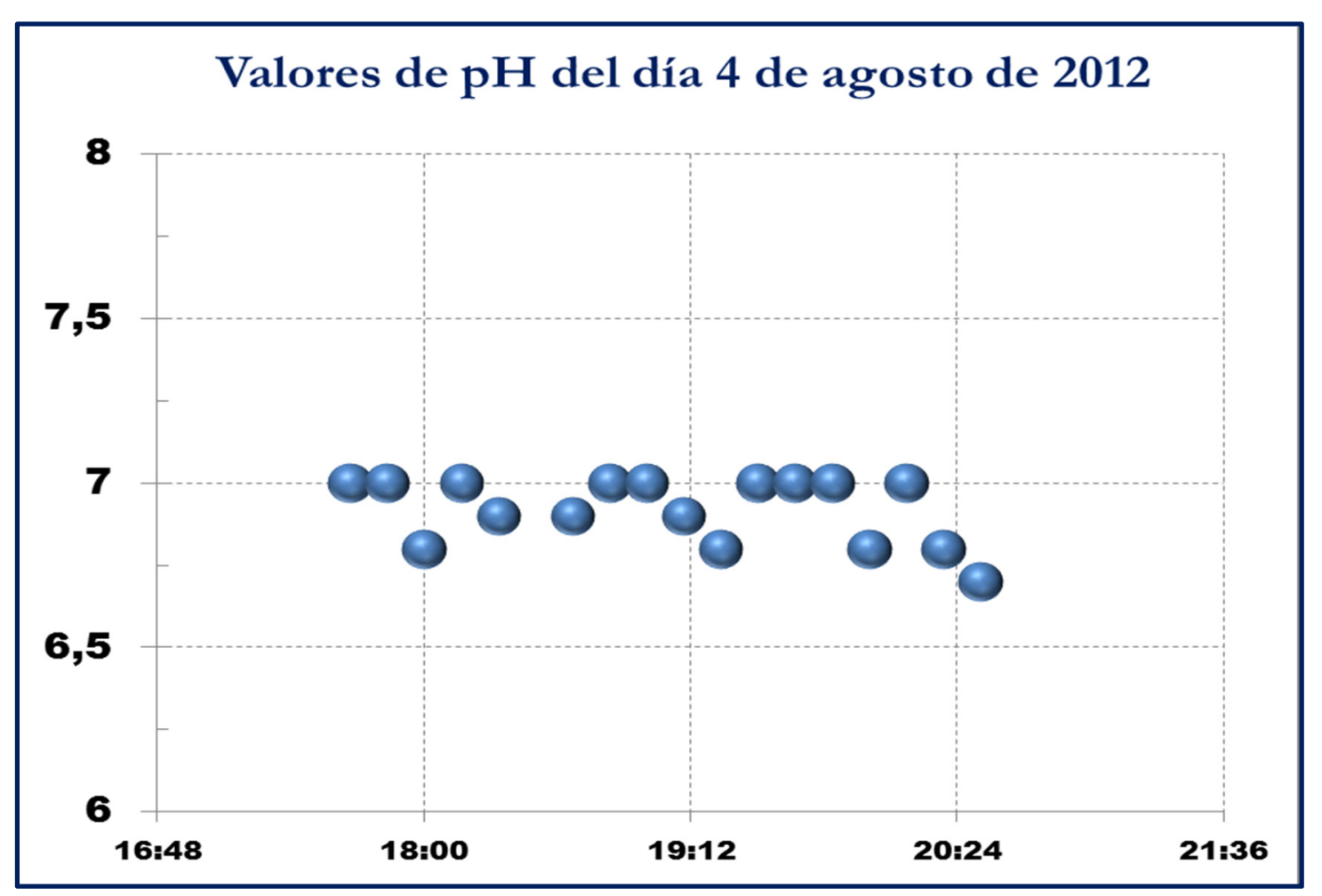

Figura 133: Análisis del agua de lluvia precipitada en Torre Miró durante el día 4 de agosto del 2012. Fuente: elaboración propia, Laboratorio de Climatología de la Universitat Jaume I.

Como se puede apreciar en la figura 134, la irrupción de un profundo aerosol africano sobre la Cuenca Occidental del Mediterráneo es la causante de la neutralización del valor del pH del agua de lluvia. El aerosol africano desborda sobre la región mediterránea española a través del mar de Alborán. 


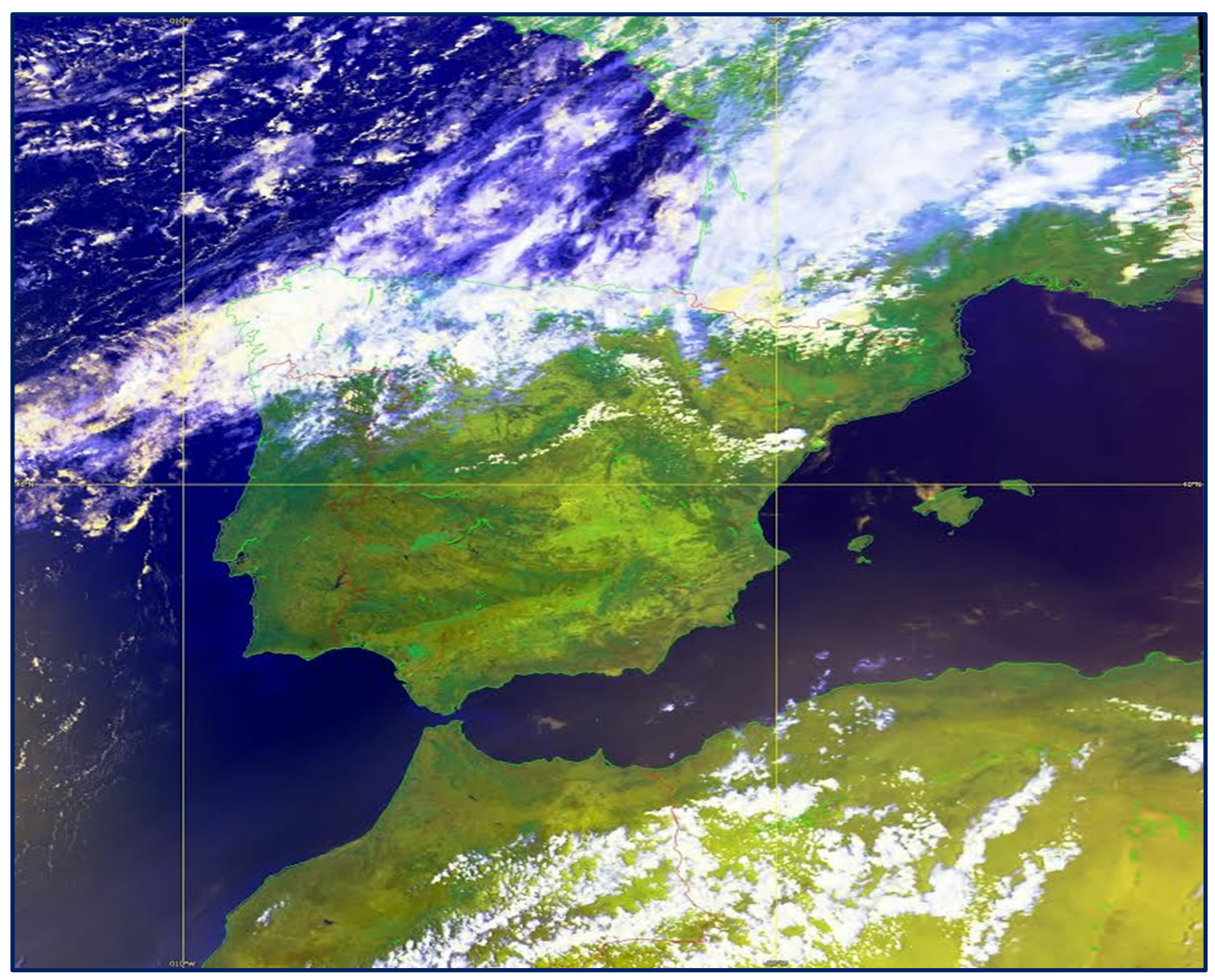

Figura 134: Imagen NOAA-AVHRR, VIS, correspondiente al día 4 de agosto del 2012. Fuente: archivo del Laboratorio de Climatología de la Universitat Jaume I.

El mismo fenómeno de enmascaramiento del $\mathrm{pH}$ del agua de lluvia se produjo durante la jornada del 9 de septiembre de 2012. En la figura 135 se puede observar la dorsal de aire cálido sobre la Península Ibérica y el pequeño embolsamiento de aire frío sobre el golfo de Cádiz, determinante de las ligeras precipitaciones. 


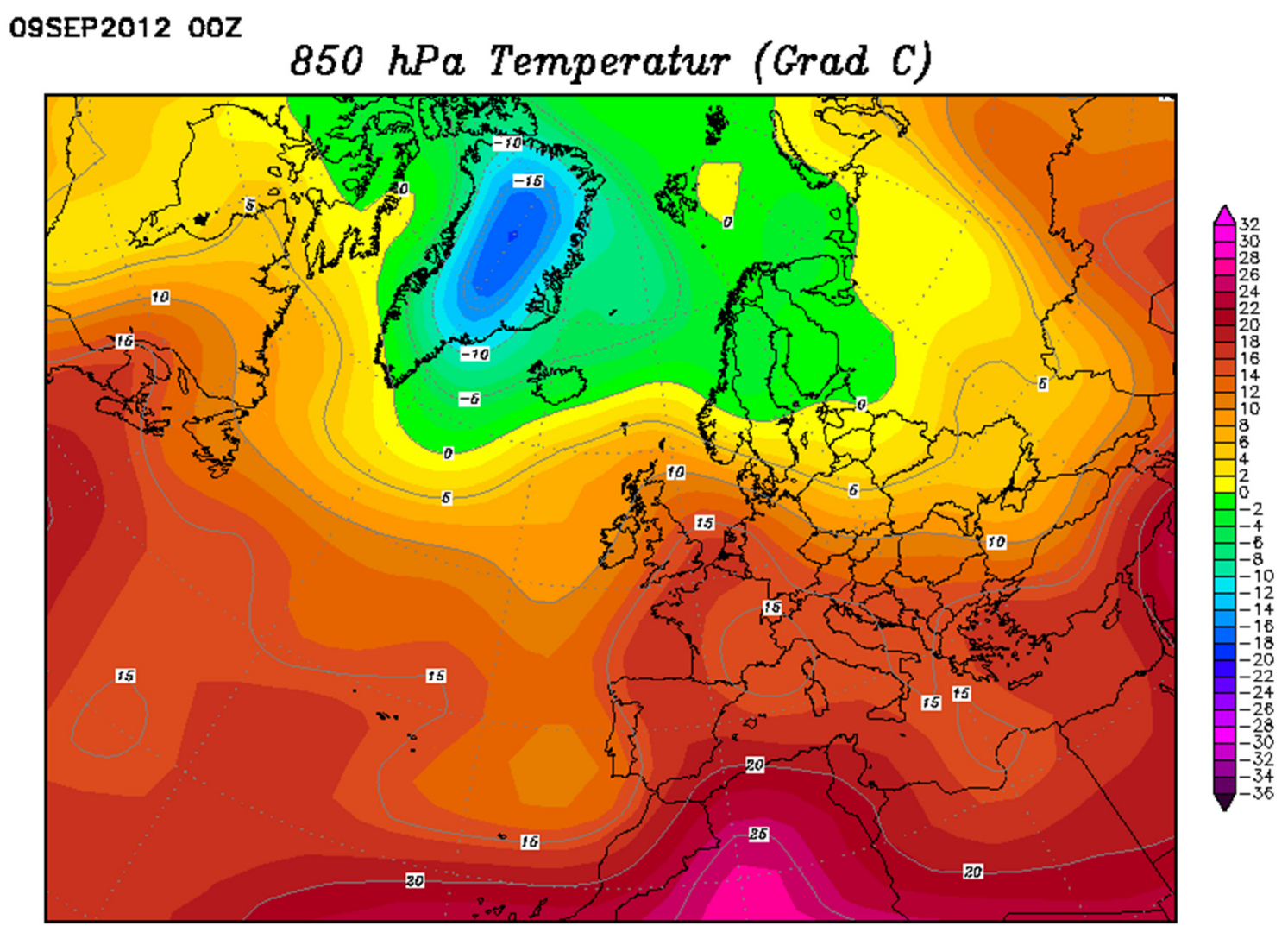

Daten: Reanalysis des NCEP

(C) Wetterzentrale

www. wetterzentrale.de

Figura 135: Situación atmosférica a 850 hPa del día 9 de septiembre del 2012. Fuente: http://www.wetterzentrale.de/topkarten/fsreaeur.html.

Asimismo, los registros de $\mathrm{pH}$ del agua de lluvia en Torre Miró durante este día muestran valores típicamente alcalinos al inicio de la precipitación de lluvia de tierra. Estos valores descienden progresivamente a medida que avanza la precipitación, produciéndose el efecto de lavado de la atmósfera (Fig. 136). 


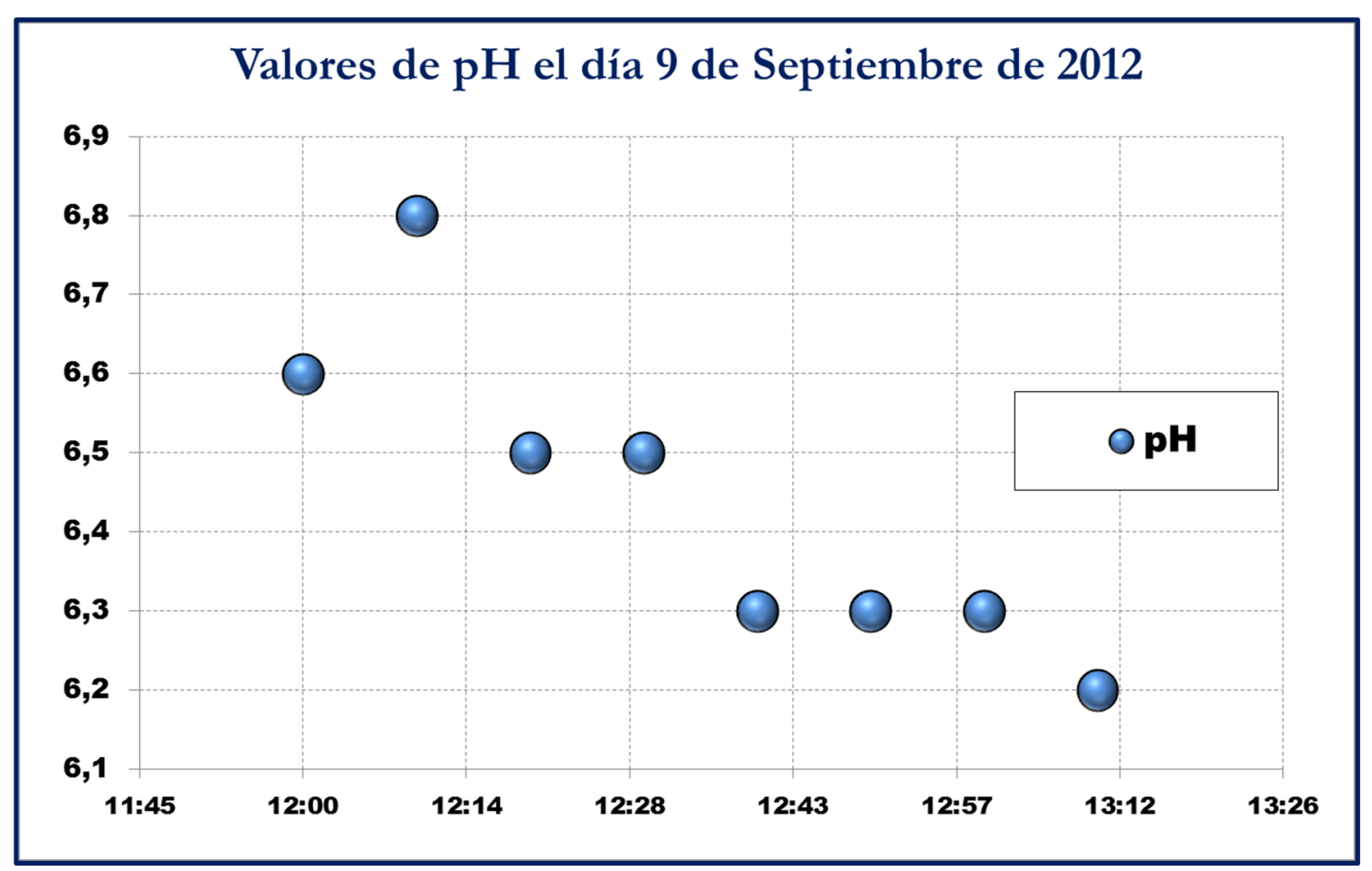

Figura 136: Registro de valores de pH durante el día 9 de septiembre del 2012. Fuente: elaboración propia, Laboratorio de Climatología de la Universitat Jaume I.

En la figura 137, tomada por el satélite NOAA-18, se aprecia nítidamente la coloración marrón de las nubes sobre el Mediterráneo, reflejo evidente de la aportación del aerosol africano. 


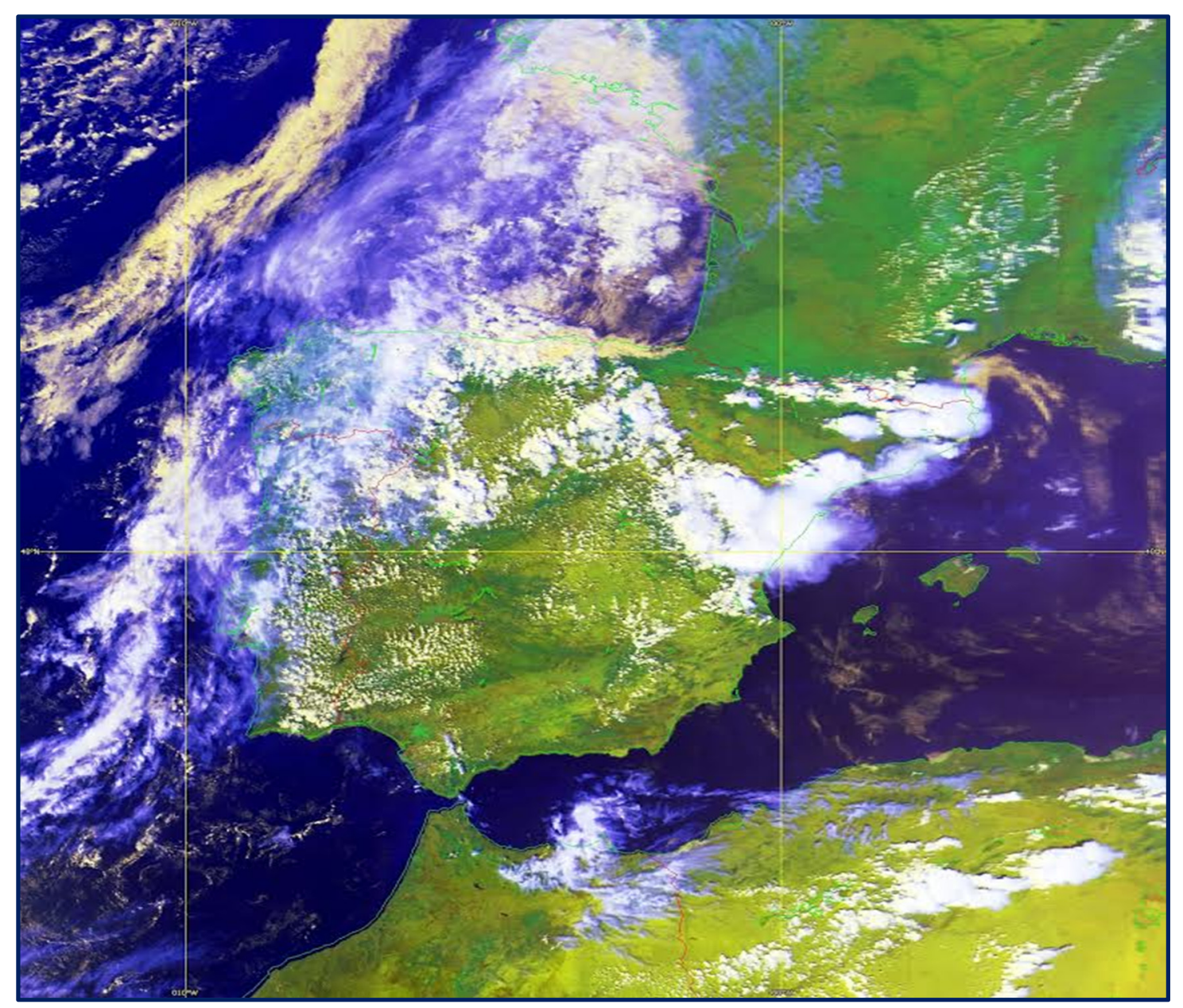

Figura 137: Imagen NOAA-AVHRR, VIS, correspondiente al día 9 de septiembre del 2012. Fuente: archivo del Laboratorio de Climatología de la Universitat Jaume I.

Una verificación reciente de estos procesos de neutralización de los bajos valores de pH en el agua de lluvia ha sobrevenido durante la última semana del mes de abril del 2016 con una extraordinaria persistencia. La imagen del NOAA-19 muestra la plena irrupción del aerosol africano sobre la Península Ibérica el día 20 (Fig. 138). En ella se observa como el notable aerosol, con origen en los grandes Ergs y salvando los relieves costeros norteafricanos del Atlas, cubre la Cuenca Occidental del Mediterráneo. 


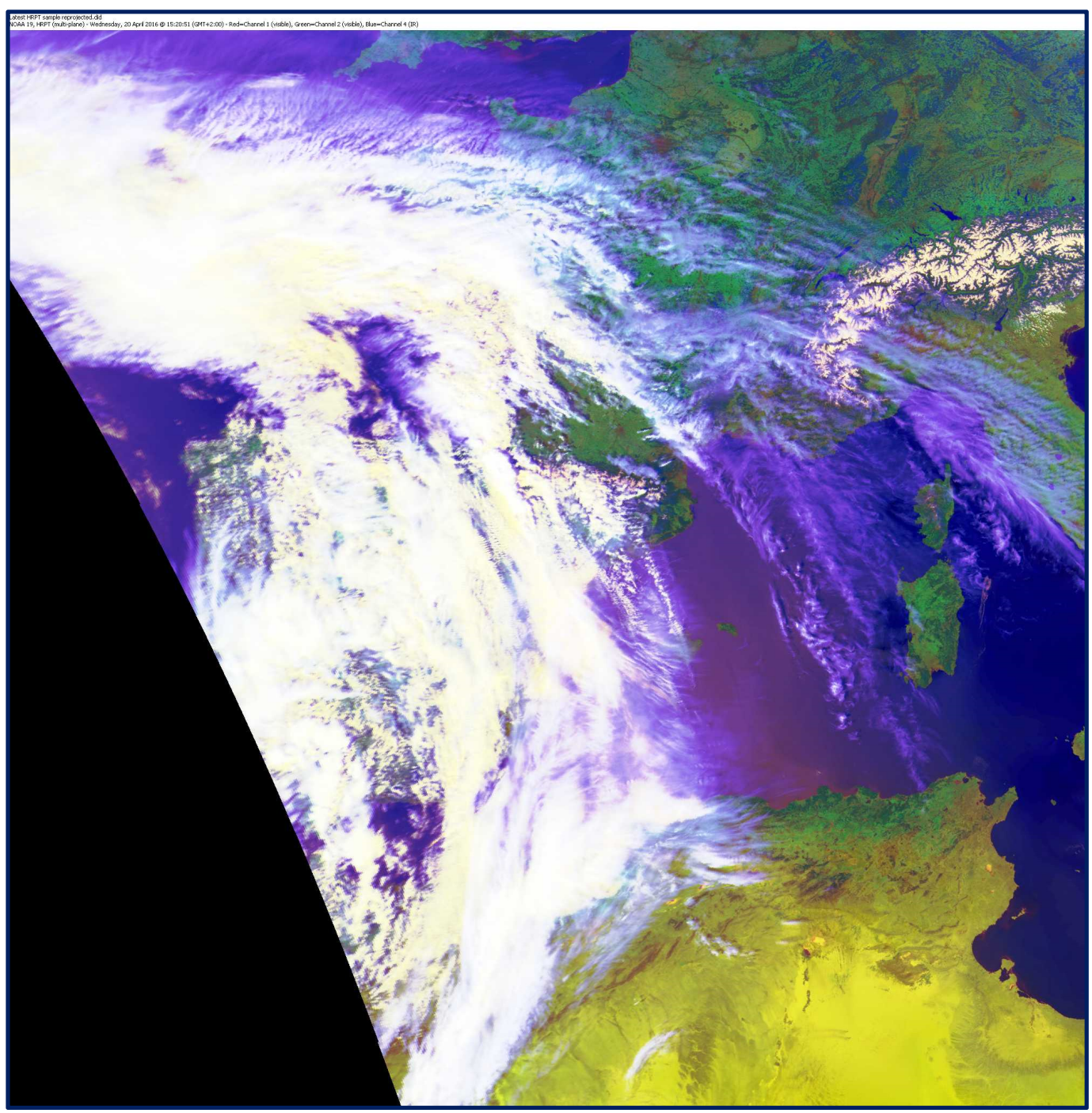

Figura 138: Imagen NOAA-19 HRPT del día 20 de abril del 2016. Fuente: archivo del Laboratorio de Climatología de la Universitat Jaume I. 
Como se puede apreciar en las figuras 139 y 140, la gran carga de barro todavía se conserva durante los días 27 y 29 de abril.

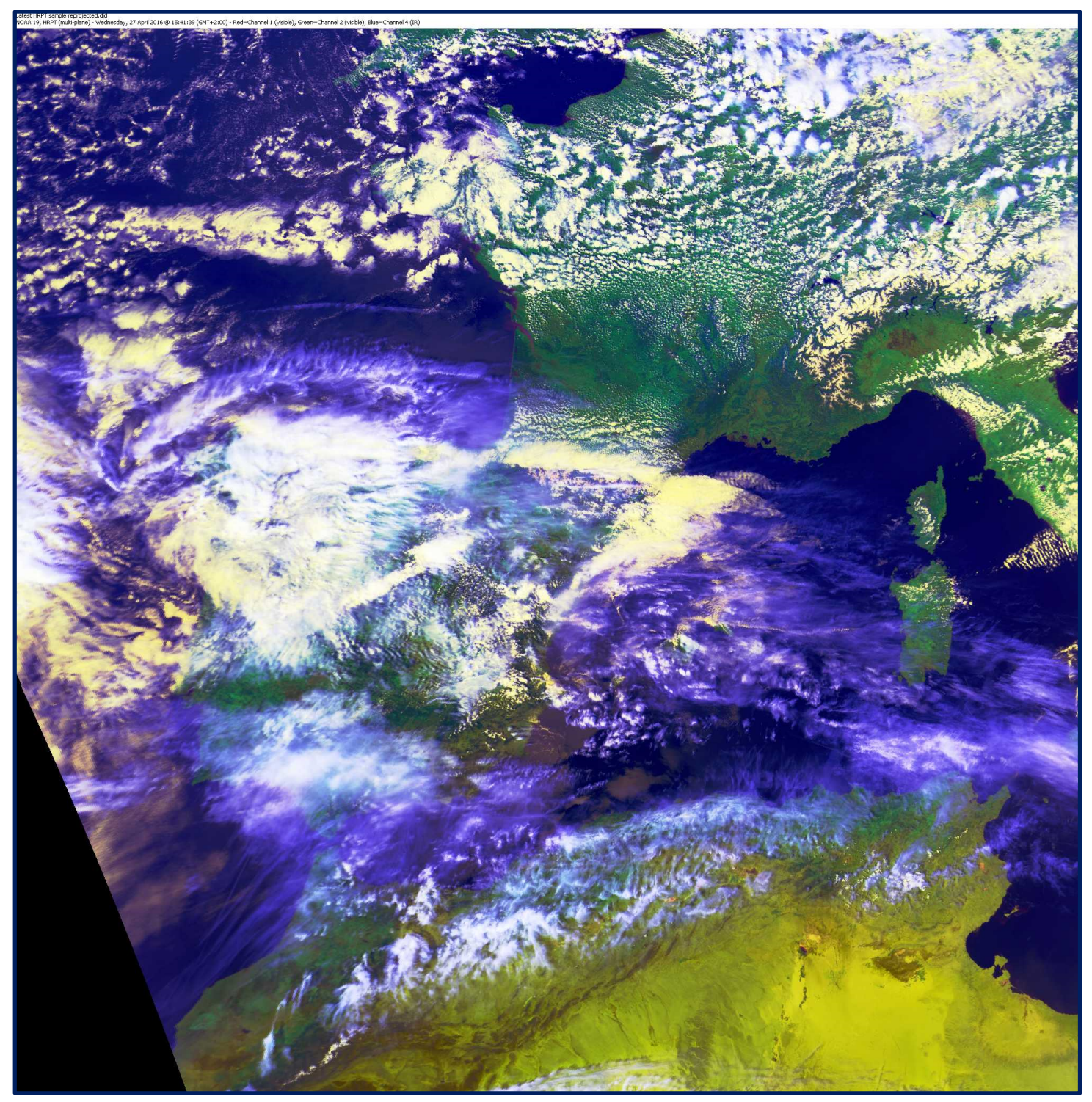

Figura 139: Notable carga de tierra sobre la Cuenca Occidental del Mediterráneo. Imagen NOAA-19 HRPT del 27 de abril del 2016. Fuente: archivo del Laboratorio de Climatología de la Universitat Jaume I. 


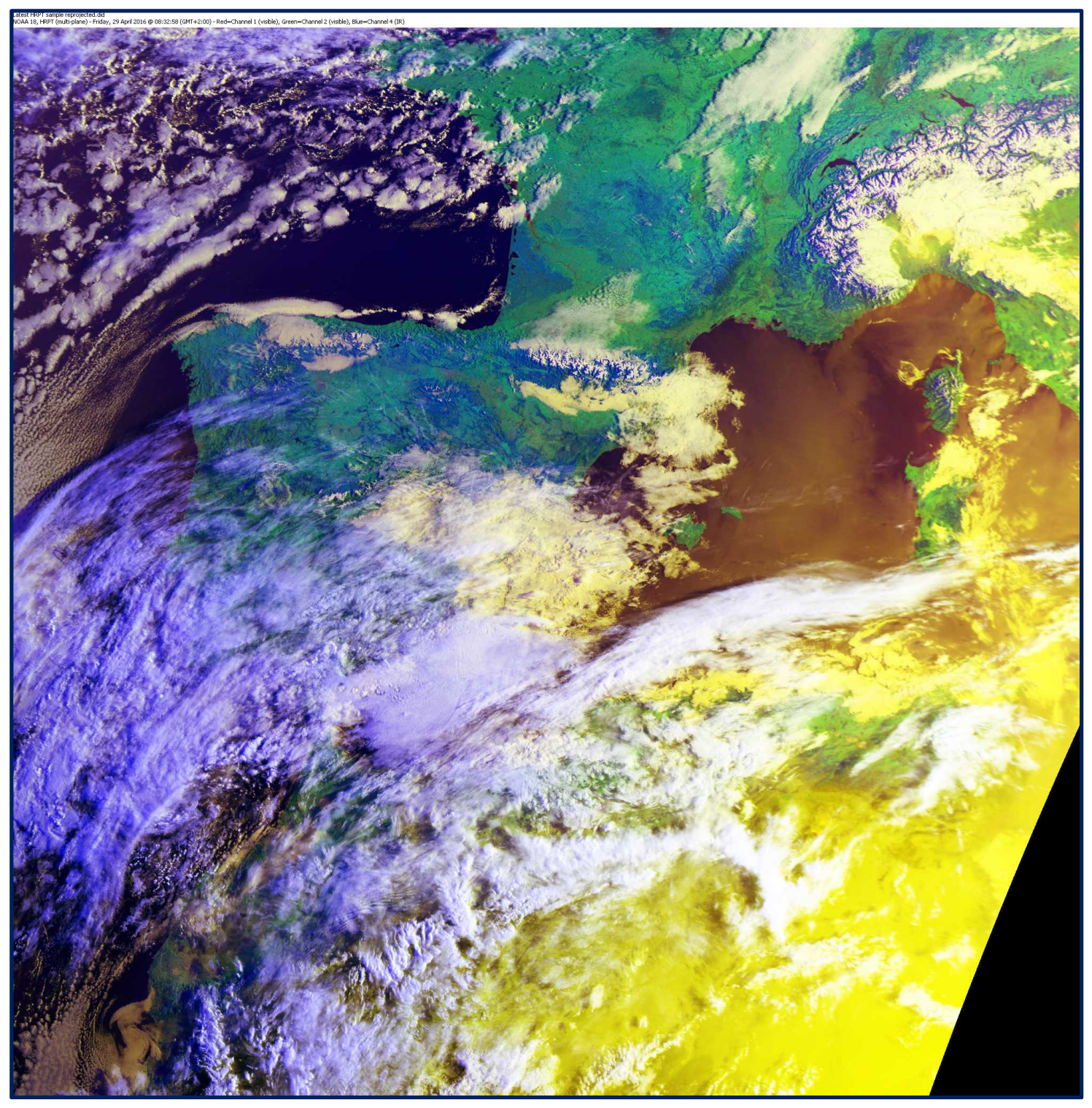

Figura 140: La imagen muestra la notable persistencia del aerosol que todavía cubre la Cuenca Occidental del Mediterráneo a finales del mes de abril. Imagen NOAA-19 HRPT del día 29 de abril del 2016. Fuente: archivo del Laboratorio de Climatología de la Universitat Jaume I.

La determinación del $\mathrm{pH}$, realizada con un pH-metro modelo PCE-PH 22, en las muestras de agua de lluvia recogida durante estas jornadas oscilaba escasamente entre 7,5 (27 de abril del 2016) y 7,7 (29 de abril del 2016). Todo ello consecuencia de una situación atmosférica que por su persistencia e intensidad es más propia de los meses de julio-agosto que del mes de abril. Toda una línea de investigaciones que suscita interrogantes decisivas para la previsión de nuestro próximo porvenir climático. 


\section{CONCLUSIONES SOBRE LA CALIDAD DEL AIRE}

Tal y como hemos analizado en el capítulo II, sobre el territorio de El Maestrazgo y de la reserva natural de Els Ports de Tortosa-Beseit, situados en la vertiente mediterránea del Sistema Ibérico, aparece una constante advección de vientos del oeste que coadyuva al transporte de los contaminantes gaseosos procedentes de las emisiones de la CT de Andorra. En este capítulo se analiza su posible impacto sobre la calidad del aire mediante el registro del pH en el agua de lluvia en la cima de Torre Miró (Morella), a 1256 metros de altitud, entre 2005 y 2014. Así, se ha determinado el valor medio de la calidad del aire y las situaciones atmosféricas características de fuerte acidificación o, por el contrario, de neutralización. En cuanto al valor medio de $\mathrm{pH}$, de 5,6, se ha observado un progresivo aumento en los últimos años que bien podría ser reflejo de las medidas de desulfuración adoptadas por la CT.

El análisis de las situaciones características de fuerte acidificación muestra la influencia de tres factores determinantes:

1. Un flujo previo de vientos del NW que transporta los contaminantes locales, al que se une un transporte transfronterizo de las emisiones de contaminantes generadas en las grandes centrales térmicas del sur de Europa.

2. La existencia de una capa de inversión situada entre 1,5 y 2,5 km que atrapa las emisiones de contaminantes.

3. La condensación de la humedad necesaria para la precipitación ácida. Esta precipitación puede proceder del efecto orográfico sobre vientos húmedos marinos que activan pluviométricamente situaciones de estabilidad condicionada.

Por otra parte, el análisis de las situaciones características de neutralización muestra la constante presencia, especialmente en verano, de aerosoles de procedencia africana que cubren gran parte de la Cuenca Occidental del Mediterráneo. Estos aerosoles básicos que desbordan sobre la región mediterránea y sustituyen la advección europea acidificante, son los máximos responsables del enmascaramiento o neutralización de la lluvia ácida. Sin ellos el valor promedio regional del $\mathrm{pH}$ podría ser inferior. 


\title{
CAPÍTULO SEXTO
}

\author{
ANÁLISIS DEL VALOR DE ACIDEZ Y DEL \\ CONTENIDO DE AZUFRE DE LOS SUELOS \\ EN LAS COMARCAS DE ELS PORTS DE \\ MORELLA Y LA TINENÇA DE BENIFASSÀ
}





\section{OBJETIVO DE LA ANALÍTICA DE SUELOS DESARROLLADA}

El análisis del valor del $\mathrm{pH}$ en el agua de lluvia ha permitido situar el valor medio de la serie en 5,6. Un valor que, especialmente por la tendencia ascendente de los últimos tres años, con un valor medio de 6,2, impide hablar de lluvia ácida. No obstante, al objeto de verificar este valor en el ecosistema regional, hemos procedido al análisis de la naturaleza edafológica comarcal. Una edafología que podría reflejarse en la manifestación de efectos fitotóxicos. No en balde, hay un cierto consenso, más o menos generalizado entre los especialistas, en atribuir a la acidificación de los suelos los principales daños forestales. Resulta evidente que los suelos, al tiempo que abastecen a las plantas de agua y nutrientes, le transfieren también los contaminantes retenidos en ellos. No obstante, en ocasiones, los suelos son capaces de neutralizar en mayor o menor grado esta acidificación actuando como tampón o "buffer" y dando lugar a las diferencias observadas en diferentes zonas forestales.

\section{PROTOCOLO DE TOMA DE MUESTRAS}

A tenor de este objetivo, en el transcurso del año 2013 se ha efectuado una toma de muestras de suelos en dos zonas forestales de las comarcas del Maestrazgo y de la Tinença de Benifassà, en el límite de la Reserva Natural dels Ports de Tortosa-Beseit. La elección de ambas zonas ha estado determinada por ser las que mayores efectos de degradación forestal presentaban en años anteriores. La primera de estas zonas ha sido la del monte de los Carrascales (Morella) (Fig. 141) y la segunda en la zona del monte Pereroles (Morella-Castell de Cabres) (Fig. 142), ya en la linde del parque natural de la Tinença de Benifassà. En este monte se han extraído muestras de una zona con efectos de degradación forestal más acusados, identificadas con código M, y otras de una zona menos deteriorada, con código B. Ambas zonas están separadas por un cortafuegos. La altura media de la exploración ha sido entre 1000 y 1200 metros. 


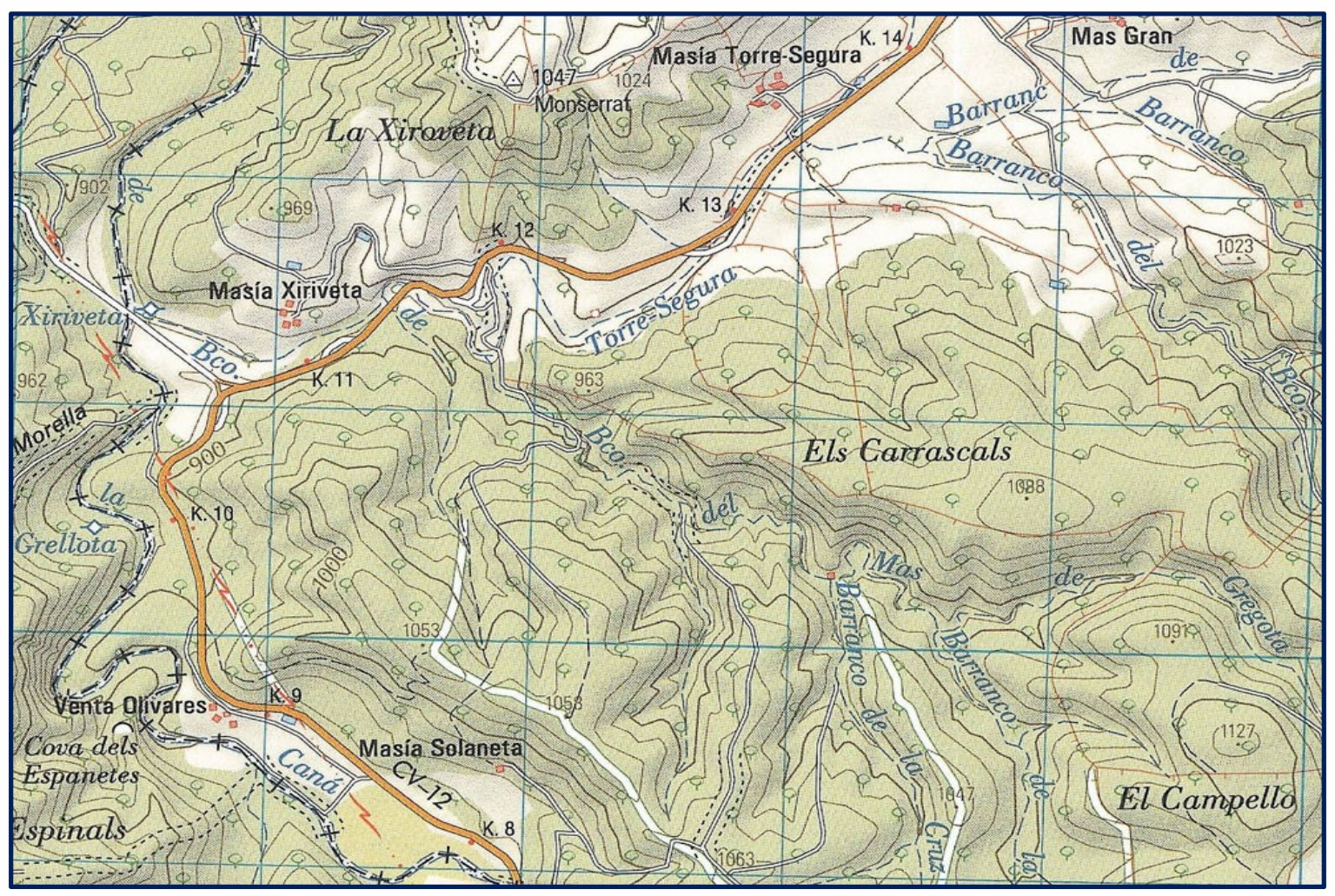

Figura 141: Mapa topográfico del monte de los Carrascales. La vertiente explorada corresponde a la orilla derecha del Barranco de Torre Segura, en cuyas aguas circulantes se efectuaron determinaciones de pH. Fuente: mapa topográfico nacional, MTN50, Hoja $\mathrm{N}^{\circ}$ 545, Morella.

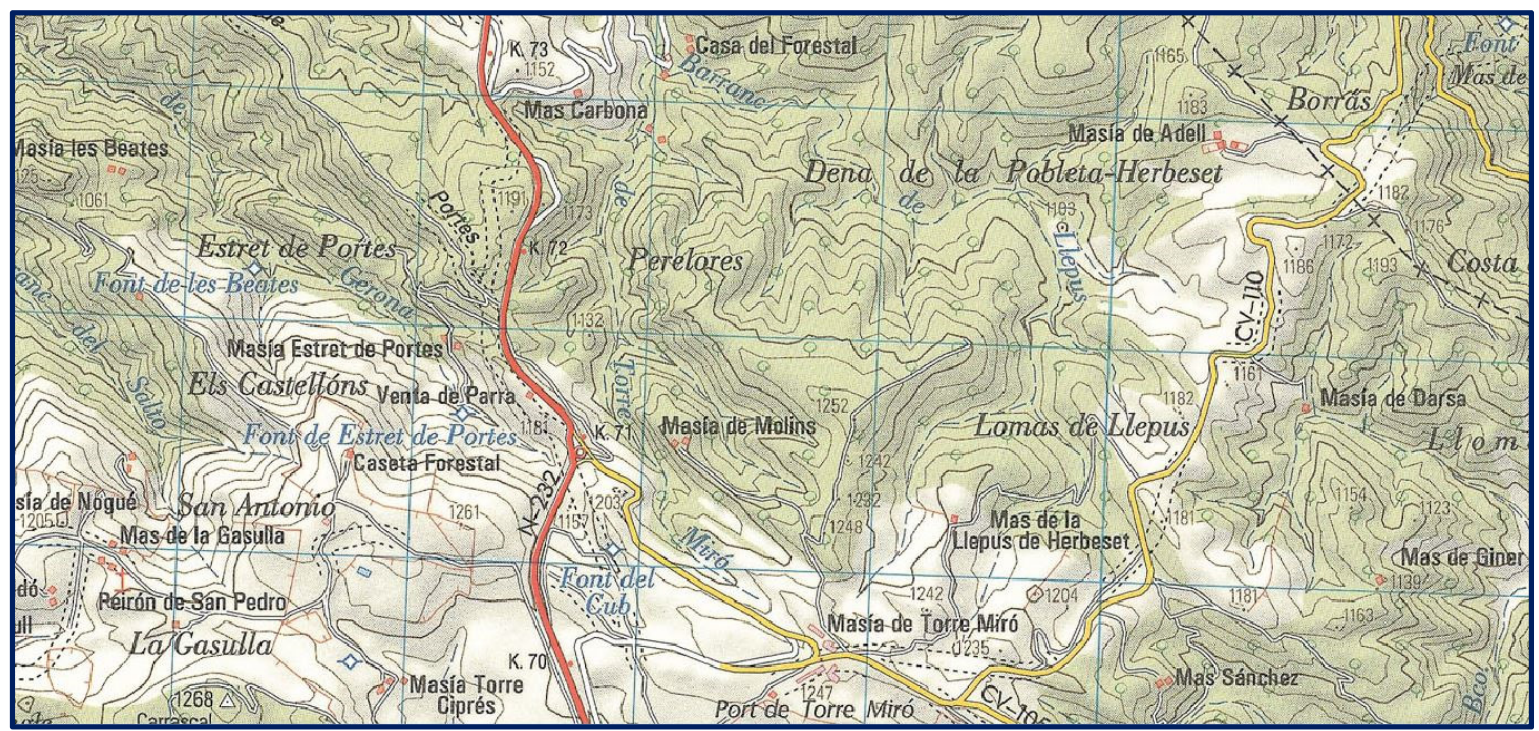

Figura 142: Masa forestal del monte Pereroles. Fuente: mapa topográfico nacional, MTN50, Hoja $\mathbf{N}^{\circ} 520$, Penyarroya de Tastavins.

La toma de muestras ha tratado de ser lo más representativa posible de la edafología que soporta a cada una de esas masas forestales. A tal efecto, las parcelas analizadas han sido objeto de una extracción de muestras en diversos puntos, siguiendo el esquema de zigzagueo

Página | 208 
sobre áreas de unos $5000 \mathrm{~m}^{2}$ en cada una de las dos masas forestales. La litología de la zona muestra un substrato de calizas, margas y areniscas (Fig. 143).

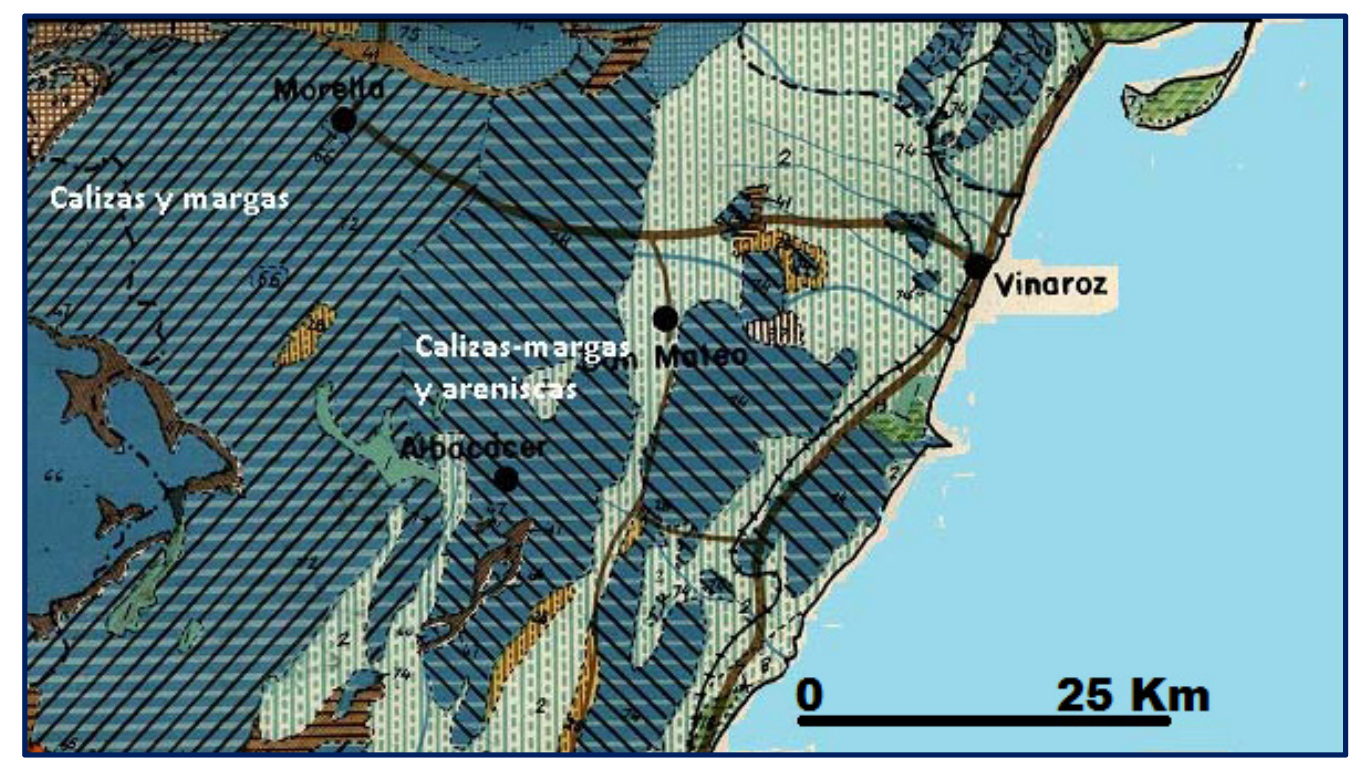

Figura 143: Litología de la zona. Fuente: Mapa litológico de España. Instituto Geológico y Minero de España. Hoja 2.

Sobre ella, y con gran semejanza en cada una de las dos áreas exploradas, se disponen unos suelos esqueléticos, o poco profundos, rendzinas, muy ricos en humus, lo que les confiere su color oscuro (Fig. 144).

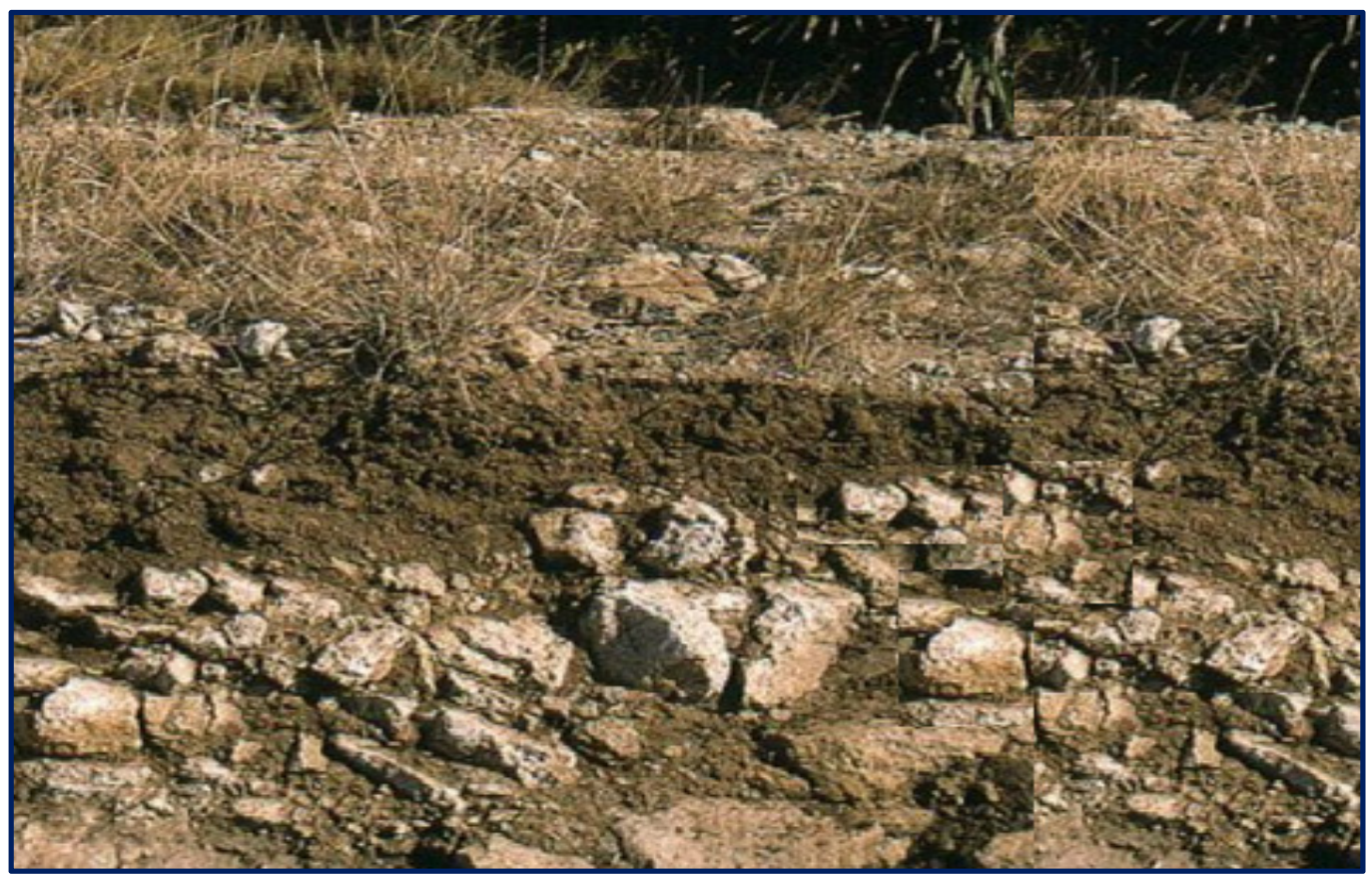

Figura 144: Tipología de los suelos explorados, rendzinas. Fuente: archivo del Laboratorio de Climatología de la Universitat Jaume 


\section{TÉCNICAS DE LA ANALÍTICA PRACTICADA}

Las muestras recogidas fueron analizadas en el Instituto de Tecnología Cerámica (ITC) donde se determinó el contenido en azufre así como el valor del pH de las diferentes muestras. El informe C123180 (Anexo II) corresponde a las muestras obtenidas en el monte Carrascales de Morella. El informe C130577 (Anexo III) corresponde a las muestras obtenidas en el monte Pereroles, en la linde de la Tinença de Benifassà.

\section{III.I. Determinación de azufre}

La determinación de azufre se ha llevado a cabo sobre pastillas prensadas de la muestra, usando como compactante una solución de n-butil metacrilato en acetona. Las pastillas fueron prensadas en una prensa hidráulica de la casa comercial CASMON y, a continuación, fueron medidas por espectrometría de fluorescencia de rayos $\mathrm{X}$ por dispersión de longitudes de onda, utilizando un espectrómetro de la casa comercial PANALYTICAL. Esta técnica permite analizar y cuantificar la composición química de una muestra de suelo irradiándola con Rayos $\mathrm{X}$. La radiación resultante del análisis se descompone en sus diferentes longitudes de onda o espectros característicos de cada uno de los elementos que componen la muestra. Para garantizar la trazabilidad de las medidas se utilizaron materiales de referencia.

\section{III.II. Determinación del pH en muestras sólidas}

La determinación del pH se ha realizado según la norma UNE 77305. Se preparó una suspensión de la muestra con cinco veces su volumen en agua y se sometió a agitación durante 5 minutos. Después se dejó en reposo durante dos horas y se midió el pH de la suspensión decantada con un pH-metro CRISON modelo 2002.C123180 2/3. 


\section{RESULTADOS DE LAS ANALÍTICAS}

\section{IV.I. Resultados Informe $\mathrm{n}^{\circ} \mathrm{C} 123180$ (monte Carrascales)}

Resultados de la determinación de $\mathrm{pH}$ y azufre de las dieciséis muestras tomadas en el monte Carrascales de Morella (Tabla 39):

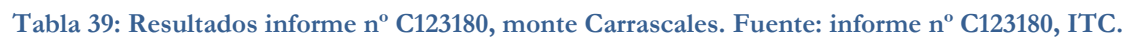

\begin{tabular}{|c|c|c|}
\hline Referencia & $\mathrm{pH}$ & S $(\%)$ \\
\hline MUESTRA 1 & 8,0 & 0,096 \\
\hline MUESTRA 2 & 8,1 & 0,044 \\
\hline MUESTRA 3 & 8,1 & 0,054 \\
\hline MUESTRA 4 & 7,9 & 0,088 \\
\hline MUESTRA 5 & 7,9 & 0,049 \\
\hline MUESTRA 6 & 7,8 & 0,063 \\
\hline MUESTRA 7 & 7,9 & 0,061 \\
\hline MUESTRA 8 & 8,4 & 0,059 \\
\hline MUESTRA 9 & 7,9 & 0,041 \\
\hline MUESTRA 10 & 7,5 & 0,094 \\
\hline MUESTRA 11 & 7,8 & 0,098 \\
\hline MUESTRA 12 & 8,1 & 0,066 \\
\hline MUESTRA 13 & 8,1 & 0,061 \\
\hline MUESTRA 14 & 7,9 & 0,056 \\
\hline MUESTRA 15 & 7,8 & 0,078 \\
\hline MUESTRA 16 & 8,0 & 0,088 \\
\hline VALOR MEDIO & 7,95 & 0,0685 \\
\hline
\end{tabular}




\section{IV.II. Resultados Informe $\mathbf{n}^{\circ} \mathrm{C} 130577$ (monte Pereroles)}

Resultados de la determinación de pH y azufre de las quince muestras tomadas en el monte Pereroles (Tabla 40):

Tabla 40: Resultados del informe $\mathrm{n}^{\circ} \mathrm{C} 130577$, monte Pereroles. Fuente: informe $\mathrm{n}^{\circ} \mathrm{C} 130577$, ITC.

\begin{tabular}{|c|c|c|}
\hline Referencia & $\mathrm{pH}$ & S $(\%)$ \\
\hline MUESTRA M - 1 & 7,43 & 0,038 \\
\hline MUESTRA M - 2 & 7,65 & 0,034 \\
\hline MUESTRA M - 3 & 7,59 & 0,036 \\
\hline MUESTRA M - 4 & 8,12 & 0,044 \\
\hline MUESTRA M - 5 & 8,04 & 0,046 \\
\hline MUESTRA M - 6 & 7,96 & 0,042 \\
\hline MUESTRA M - 7 & 7,95 & 0,037 \\
\hline VALOR MEDIO & 7,82 & 0,040 \\
\hline MUESTRA B - 1 & 6,87 & 0,031 \\
\hline MUESTRA B - 2 & 6,85 & 0,036 \\
\hline MUESTRA B - 3 & 7,10 & 0,041 \\
\hline MUESTRA B - 4 & 7,08 & 0,061 \\
\hline MUESTRA B - 5 & 7,26 & 0,047 \\
\hline MUESTRA B - 6 & 7,16 & 0,041 \\
\hline MUESTRA B - 7 & 7,32 & 0,033 \\
\hline MUESTRA B - 8 & 7,25 & 0,042 \\
\hline VALOR MEDIO & 7,11 & 0,042 \\
\hline
\end{tabular}




\section{CONCLUSIONES SOBRE EL ESTADO EDAFOLÓGICO DE LA REGIÓN ESTUDIADA}

Los resultados analíticos obtenidos, tanto en valor de $\mathrm{pH}$ como en contenido de azufre (S), permiten considerar que no se alcanzan valores que puedan ser significativos de contaminación por azufre y lluvia ácida.

Las muestras del informe C123180, correspondientes al monte Carrascales de Morella, han dado valores de $\mathrm{pH}$ entre 7,5 y 8,4. Estos valores, propios de suelos moderada o altamente básicos, son semejantes a los obtenidos en los análisis de aguas circulantes en el barranco de Torre Segura (Fig. 145) realizados "in situ” el mismo día de la toma de muestras de suelos mediante un pH-metro modelo PCE-PH 22.

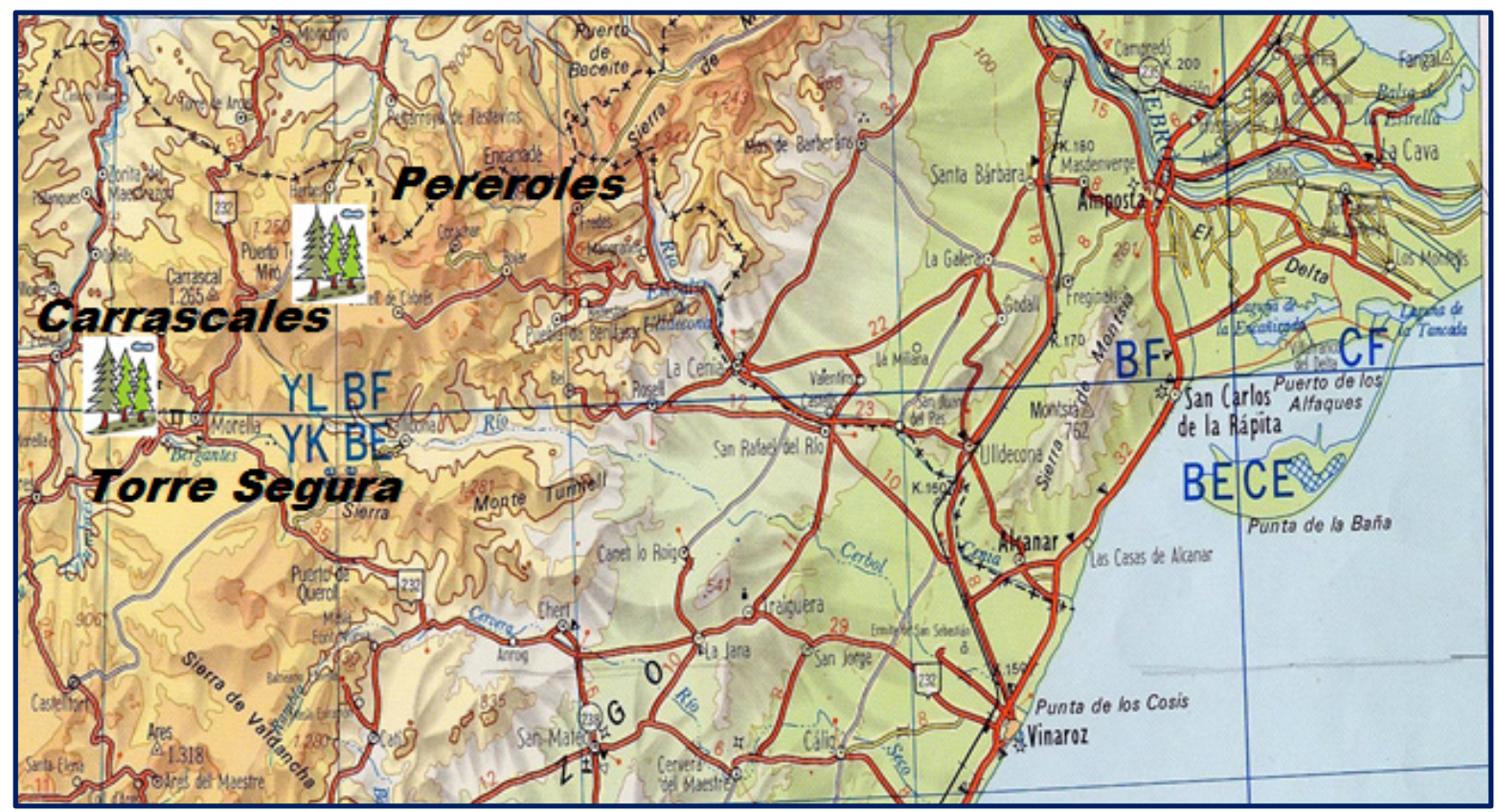

Figura 145: Zonas de análisis edafológico y de aguas. Fuente: mapa militar de España, escala 1:400000, hoja: Teruel 4-3.

Tan sólo en las muestras del monte Pereroles ha sido posible encontrar algunos valores de $\mathrm{pH}$ entre 6,85 y 6,87, que entrarían en la categoría de suelos neutros. Sin embargo, al margen de estos valores neutros, el resto de las muestras vuelve a situarse como suelos moderadamente básicos. No obstante, es preciso destacar que esos valores neutros han sido obtenidos de muestras extraídas de una sección parcelaria donde no se observan efectos de degradación forestal. Tales son las muestras referenciadas como B, frente a las M que son las de la zona con visibles deterioros. 
Por otra parte, la analítica de contenido en azufre (S) muestra asimismo que los valores distan de mostrar significación con respecto a deposiciones de compuestos sulfurosos emitidos por la CT. Tan sólo es destacable que, dentro de lo reducido del contenido en azufre, siempre entre $0,03 \%$ y $0,09 \%$, éste siempre es ligeramente inferior en las muestras de Pereroles que en las de Carrascales. En esta última masa forestal, los valores oscilan entre 0,04\% y 0,09\%. El valor medio se sitúa en 0,0685 . Un valor acorde con el rango normal de contenido de azufre en los suelos que oscila entre 0,02\% y 0,05\% llegando en los suelos de las regiones áridas hasta el 1\% (Navarro y Navarro, 2013).

En consecuencia, los valores obtenidos sobre el contenido en azufre y valor de $\mathrm{pH}$ de los suelos analizados permiten afirmar, a tenor de nuestro estudio, que no muestran valores significativos de una contaminación por partículas o lluvia ácida procedente de las emisiones de la CT de ENDESA o de otra fuente puntual de la región. 



\section{CONCLUSIONES FINALES Y FUTURAS LÍNEAS DE INVESTIGACIÓN}

Como se ha señalado al comienzo de este trabajo de investigación desarrollado en los capítulos precedentes, el tema propuesto tiene su fundamento en el reconocimiento de los efectos fitotóxicos de la contaminación atmosférica en las comarcas de El Maestrazgo y Els Ports en las provincias de Castellón, Tarragona y Teruel. Unos efectos de degradación forestal que han venido siendo objeto de diferentes estudios realizados por los miembros del Instituto Interuniversitario de Geografía. Estos estudios han sido concluyentes en la necesidad de caracterizar las diferentes y complejas situaciones atmosféricas del escenario meteorológico regional que actúan como potenciadoras o, en algunos casos, inhibidoras de los valores de riesgo ambiental. Necesidad que ya venía siendo señalada por los extensos estudios precedentes, realizados en una zona afectada por un acusado deterioro forestal. Deterioro que será observado casi simultáneamente a la puesta en funcionamiento de la CT de ENDESA en Andorra en 1979-1980 y a la que, inmediatamente, se hará responsable de todos los impactos ecológicos.

La larga controversia científica que desde hace más de treinta años se ha desarrollado sobre este problema en la región mediterránea del Sistema Ibérico, ha determinado el objetivo de estudio que sirve de título a nuestra tesis doctoral: "Escenarios atmosféricos de contaminación y lluvia ácida sobre la vertiente mediterránea del Sistema Ibérico”. En efecto, las principales investigaciones sobre el tema han venido planteando que todas las conclusiones alcanzadas dejaban sin respuesta cuestiones claves señalando que la causa de ello había radicado en la falta de conocimiento del medio atmosférico. Según el NILU, "se producen estructuras del viento complejas debido a las características topográficas y a circulaciones a media escala que exigirían estudios complementarios" (NILU, 1985a: 5). Tal vez por ello el informe encargado al Instituto Noruego de Investigaciones Atmosféricas (NILU, 1985a, 1985b, 1987a, 1987b), que realiza la modelización del penacho en función de unas breves experiencias durante la primera década de mayo de 1985 concluye que resulta muy poco probable su impacto a distancias mayores de $15 \mathrm{~km}$ y por ello el Maestrazgo no debería verse afectado. Esta conclusión errónea, como ha mostrado posteriormente la Red de Vigilancia Atmosférica de la GVA, tan sólo es mitigada cuando el informe final del NILU añade que la contaminación, a más de $15 \mathrm{~km}$, no debe descartarse totalmente. Un descarte que precisamente 
tan sólo podrá establecerse a medida que la circulación atmosférica regional sea mejor conocida y disponga de medios más adecuados. Una necesidad de conocimiento atmosférico que igualmente va a ser ratificada al conocerse los resultados del proyecto MECAPIP de la UE (1993). Las conclusiones del mismo aportan nueva luz sobre los ciclos de contaminantes observados sobre la costa mediterránea. En ellas se señala también la necesidad de una actualización cuidadosa de "los conocimientos sobre los procesos meso-meteorológicos en la cuenca mediterránea, en general, y en la Península Ibérica en particular” (Millán y Sanz, 1993: 50) y también la necesidad de "determinar los escenarios meteorológicos de difusión y transporte de contaminantes atmosféricos, específicos de las regiones del Maestrazgo y Els Ports de Castellón, incluyendo los de ámbito local, regional y sub-continental” (Millán y Sanz, 1993: 51). El insuficiente conocimiento de la circulación y estructura de la capa atmosférica activa de la región es la causa de la falta de conclusiones sobre la relación de las emisiones de la CT y los efectos fitotóxicos observados. Esta es igualmente una de las principales aseveraciones del dictamen científico elaborado por la comisión interuniversitaria coordinada por la Universitat Jaume I. Entre sus conclusiones se señala que "la caracterización del escenario meteorológico regional y de su evolución temporal es bastante confusa e incompleta" (Conde et al., 1993: 8). A mayor abundancia, expone el dictamen, "no existe especialmente en observaciones térmicas y anemocinemográficas, una red superficial de estaciones meteorológicas adecuada para conocer la difusión de contaminantes atmosféricos" (Conde et al., 1993: 8). Cuestiona así la validez de las hipótesis y conclusiones de alguno de los trabajos realizados.

Consecuentemente, ante tal reiteración de la falta de un mayor conocimiento atmosférico para alcanzar conclusiones válidas, el objetivo principal de la investigación no podía ser otro que el reconocimiento y elaboración de modelos de escenario atmosférico que, sin menoscabo de las emisiones contaminantes de la zona, potencien o inhiban los valores de inmisión y riesgo ambiental. Modelos de situación atmosférica que deben de servir como guías para una mejor y más eficaz gestión de nuestro medio-ambiente. De este modo, la tesis defendida en esta investigación es la verificación del determinante papel que las situaciones atmosféricas juegan en la potenciación o inhibición de los procesos de inmisión de los contaminantes atmosféricos. Una investigación que se aplica a la vertiente mediterránea del Sistema Ibérico, región geográfica sui géneris, cuyo escenario meteorológico presenta diferencias muy acusadas con los de otras regiones europeas con las que erróneamente se viene 
comparando. Paralelamente, el objetivo complementario de la investigación ha sido la verificación de la eficacia regional de las medidas de desulfuración de la CT de Andorra y, en consecuencia, la evaluación de la calidad del aire en la vertiente mediterránea del Sistema Ibérico.

Ante este reto nuestra investigación ha dispuesto ya de una red de observaciones ambientales y meteorológicas que, en gran parte, cubren las deficiencias resaltadas en todas las investigaciones anteriores a 1994. En este orden de cobertura ambiental, la metodología de calidad del aire planteada en la investigación ha partido del análisis de la base de datos de la Red de Vigilancia y Control de la Contaminación Atmosférica de la Generalitat Valenciana, creada por Decreto 161/2003 del Consell de la Generalitat. Los registros de esta red, utilizados en la investigación, corresponden básicamente a la estación de observación de Coratxar (La Pobla de Benifassà, 1200 metros). Esta metodología de calidad del aire se ha completado con el control del pH en el agua de lluvia mediante un analizador automático de lluvia ácida, ubicado en Torre Miró (Morella).

Este equipamiento forma parte del notable esfuerzo desarrollado para disponer de la tecnología meteorológica básica para el estudio de la capa atmosférica y de los mecanismos de la circulación atmosférica regional. Un equipamiento que ha consistido en la instalación y mantenimiento de una red meteorológica de quince estaciones automáticas entre las que destacan las dos estaciones que controlan el nivel superior de la capa activa regional entre los 1235 metros (pico de Fredes) y los 1447 metros (monte Caro). Asimismo, para una mejor identificación de los escenarios atmosféricos, la metodología aplicada ha contado con la imaginería de satélites meteorológicos del Laboratorio de Climatología de la Universitat Jaume I.

Sobre estas bases nuevas de infraestructura científica, nuestra investigación ha permitido conclusiones que hasta ahora habían quedado sin respuesta, tal y como reafirman los diversos estudios que se habían enfrentado a establecer la relación causa-efecto entre impactos fitotóxicos y emisiones de la CT. En este orden de investigación, los análisis desarrollados en los capítulos precedentes han permitido establecer las siguientes conclusiones:

I) El conocimiento del escenario atmosférico regional es clave para el establecimiento de cualquier modelización de las emisiones. Precisamente la insuficiencia de tales conocimientos, en los momentos en que surge la problemática, ha impedido dar 
respuesta a cuestiones trascendentes. Ciertamente que la base estructural de la atmósfera en la vertiente mediterránea estudiada viene definida por el radiosondeo (AEMET) de una estación, Zaragoza aeropuerto, situada a considerable distancia (85 $\mathrm{km})$. No obstante, esta limitación ha podido ser superada, desde 2003, por los registros térmicos y aerodinámicos de la red meteorológica universitaria. Especialmente dos estaciones, pico de Fredes y monte Caro, ubicadas en vértices orográficos, auténticas torres naturales, han constituido un radiosondeo continuo de la capa atmosférica crítica (1235-1447 metros) en donde se desarrollan los procesos de difusión y dispersión de las emisiones de la CT. Una conclusión que justifica no sólo las reiteradas lamentaciones de las investigaciones desarrolladas con anterioridad, sino también la necesidad de redes geográficas de observación para el estudio de los actuales procesos de contaminación ambiental. Simultáneamente, los numerosos análisis realizados sobre todos los casos de impacto en los que se registraron elevadas concentraciones de $\mathrm{SO}_{2}$ ha permitido lograr el objetivo esencial de nuestra tesis sobre los "Escenarios atmosféricos de contaminación y lluvia ácida sobre la vertiente mediterránea del Sistema Ibérico". Dicho estudio ha evidenciado la existencia de una capa de inversión térmica a niveles inferiores a 1200 metros, o nivel del pico de Fredes, que se erige como principal inductora de la potenciación de los impactos ambientales provocados por las emisiones gaseosas contaminantes de la CT.

II) Por otra parte, el análisis de las situaciones de impacto severo de contaminación, realizado en el capítulo IV, nos ha permitido establecer la configuración geográfica que muestran las inmisiones así como su concentración estacional. La localización geográfica es altamente expresiva de la alineación con la dinámica aérea y con menores obstáculos geográficos. En cuanto a la concentración estacional es destacable su vinculación a los meses de otoño e invierno, periodos fríos en los que la interacción de factores geográficos y atmosféricos se intensifica. Situaciones especialmente determinadas por el anticiclón de subsidencia que limita las inversiones radiativas de superficie, favoreciendo la formación de capas de inversión más altas. Asimismo, el análisis efectuado nos ha permitido concluir que todos los episodios de fuerte contaminación se han desarrollado bajo un escenario atmosférico de marcada estabilidad, con viento muy débil o en calma. Una estructura atmosférica vertical presidida por una notable dorsal de aire cálido, al nivel de $850 \mathrm{hPa}$, que se corresponde 
con un acusado anticiclón en superficie, superior a los $1025 \mathrm{hPa}$. Son situaciones caracterizadas por la existencia de una capa de inversión térmica que limita los movimientos ascendentes del aire.

III) La tercera conclusión, inherente a las dos primeras, es la verificación de la validez del modelo gaussiano para el estudio de los procesos de difusión y concentración de contaminantes en nuestra región. Las diferencias obtenidas, entre los valores calculados y los registrados en la Red de Vigilancia Atmosférica de la GVA, derivan precisamente de la utilización de los datos del radiosondeo de Zaragoza. Estos datos, a nivel de 900 $\mathrm{hPa}$, pueden ofrecer cierta fiabilidad en los valores térmicos, si bien, como hemos mostrado con los registros de Fredes y Caro, puede diferir en los valores aerodinámicos. En todo caso, las diferencias resultantes son poco significativas y todas ellas explicadas por la formación de capas de inversión térmica inferiores a 1200 metros, limitantes del espesor atmosférico en donde se operan los procesos de difusión y dispersión de los penachos.

IV) Esta validez de los modelos gaussianos aplicados, sobre un eje aerodinámico característico de la circulación regional $290-300^{\circ} \mathrm{N}$, ha permitido calcular que la dispersión y concentración de contaminantes puede ser seguida a distancias superiores a $50 \mathrm{~km}$. Una distancia que en los estudios iniciales se limitaba a $15 \mathrm{~km}$ y, por lo tanto, sin efectos sobre el Maestrazgo y Els Ports. Unos impactos que siempre han venido asociados a situaciones de estabilidad atmosférica y, como hemos dicho, a la formación de inversiones térmicas en alturas inferiores a los 1200 metros.

V) Todas estas conclusiones vienen fuertemente vinculadas a la consecución del objetivo principal de nuestra investigación: verificar la decisiva influencia de los factores atmosféricos como potenciadores o inhibidores de los procesos de contaminación atmosférica sobre la vertiente mediterránea del Sistema Ibérico. Una influencia que, al margen de su aplicación en los modelos teóricos de dispersión de contaminantes atmosféricos, condiciona igualmente la advección tanto de los procesos de lluvia ácida como de los procesos de neutralización de $\mathrm{pH}$.

En los procesos de lluvia ácida se ha observado la influencia determinante de un transporte transfronterizo de las emisiones de contaminantes procedentes de la Europa oriental y meridional así como la existencia de una capa de inversión situada entre 1,5 y 
2,5 km. En cuanto a los procesos de neutralización de $\mathrm{pH}$ se ha evidenciado la constante presencia de aerosoles de procedencia africana de carácter básico.

VI) Finalmente, a lo largo de los análisis efectuados sobre los procesos de difusión, se ha podido constatar que todos los valores de inmisión calculados y registrados, paralelamente a su respuesta a los procesos atmosféricos, han acusado, lógicamente, la evolución en las cargas de emisión de contaminantes $\left(\mathrm{SO}_{2}\right)$. Estos análisis han venido, consecuentemente, a mostrar la eficacia de los procesos técnicos específicos de desulfuración que ENDESA introdujo. Una eficacia cuya verificación habíamos propuesto como objetivo complementario de nuestra tesis y que viene reflejada en el actual estado de los suelos y aguas regionales como han mostrado las analíticas realizadas.

En la línea de trabajo que nos proponemos continuar, la investigación llevada a cabo constituye, sin duda, la mejor base para desarrollar un método que, con un buen conocimiento de la Capa Geográfica de la Troposfera, permita elaborar modelos de gestión energética y productiva altamente eficaces $\mathrm{y}$, simultáneamente, respetuosos con el medio ambiente. La decisión está tomada y nada podía ser mejor exponente de ello que la reciente instalación de una estación automática de meteorología en el vértice orográfico del Peñagolosa (1813 metros), la cima más elevada del Reino de Valencia en palabras de Sarthou Carreres, si bien con permiso del Cerro Calderón (1839 metros), ya en el enclave del Rincón de Ademuz. La visual, bajo cielos claros, entre la cima del Penyagolosa al norte, el Montgó y sierras de La Marina al sur y las mismas islas Columbretes, en el Mediterráneo, acentúan su simbolismo en la orografía valenciana. 
\begin{tabular}{l|l} 
ANEXos \\
\hline
\end{tabular} 



\section{ANEXO I: EPISODIOS DE INMISIÓN DE SO}

\section{Red Valenciana de Vigilancia y Control de la Contaminación Atmosférica (RVVCCA)}

Datos extraídos de: http://www.cma.gva.es/cidam/emedio/atmósfera/jsp/historicos.jsp Conselleria de Agricultura, Medio Ambiente, Cambio Climático y Desarrollo Rural, Generalitat Valenciana

\section{EXPORTACIÓN DE PROMEDIOS HORARIOS (2000-2015)}

\section{ESTACIÓN: Coratxar CÓDIGO: 12093004}

A continuación se detallan los episodios horarios de inmisión de $\mathrm{SO}_{2}$ que alcanzaron, al menos, el $75 \%$ del valor umbral $\left(350 \mu \mathrm{g} / \mathrm{m}^{3}\right)$ permitido por la legislación (Real Decreto 102/2011, BOE 29 de enero 2011 relativo a la mejora de la calidad del aire).

Tabla 41: Episodios horarios de inmisión de $\mathrm{SO}_{2}(>75 \%$ del umbral permitido) en Coratxar en el año 2000. Fuente: RVVCCA.

\begin{tabular}{|c|c|c|c|c|c|c|c|c|c|}
\hline \multirow{2}{*}{ Fecha } & \multirow{2}{*}{ Hora } & $\mathbf{S O}_{2}$ & Veloc. & Direc. & Temp. & H. Rel. & Pres. & R. Sol. & Precip. \\
\hline & & $\boldsymbol{\mu g} / \mathbf{m}^{3}$ & $\mathbf{m} / \mathbf{s}$ & grados & ${ }^{\circ} \mathbf{C}$ & \% H.R. & $\mathbf{m b}$ & $\mathbf{W} / \mathbf{m}^{2}$ & $\mathbf{1 / \mathbf { m } ^ { 2 }}$ \\
\hline $05 / 01 / 2000$ & 3 & 664 & 0,4 & 81 & 4,4 & 57 & 890 & 1 & 0 \\
\hline $06 / 01 / 2000$ & 22 & 499 & 5,1 & 334 & 4,9 & 69 & 890 & 1 & 0 \\
\hline $06 / 01 / 2000$ & 23 & 278 & 4,6 & 331 & 5,2 & 68 & 890 & 2 & 0 \\
\hline $08 / 01 / 2000$ & 19 & 607 & 3,8 & 324 & 5 & 66 & 889 & 1 & 0 \\
\hline $08 / 01 / 2000$ & 20 & 1542 & 4,1 & 324 & 4,8 & 77 & 888 & 0 & 0 \\
\hline $08 / 01 / 2000$ & 21 & 316 & 3,5 & 323 & 5,1 & 78 & 888 & 2 & 0 \\
\hline $08 / 01 / 2000$ & 22 & 414 & 1,6 & 332 & 4,8 & 79 & 888 & 2 & 0 \\
\hline $08 / 01 / 2000$ & 23 & 462 & 1,7 & 332 & 5,1 & 77 & 888 & 1 & 0 \\
\hline $09 / 01 / 2000$ & 0 & 793 & 3,4 & 326 & 5,4 & 76 & 888 & 1 & 0 \\
\hline $09 / 01 / 2000$ & 22 & 282 & 7,2 & 326 & $-0,6$ & 99 & 887 & 2 & 0 \\
\hline $10 / 01 / 2000$ & 14 & 274 & 2,7 & 354 & 0,5 & 99 & 891 & 142 & 0 \\
\hline $11 / 01 / 2000$ & 8 & 369 & 0,2 & 2 & -3 & 77 & 893 & 14 & 0 \\
\hline $11 / 01 / 2000$ & 9 & 272 & 0,2 & 334 & $-1,9$ & 75 & 894 & 127 & 0 \\
\hline $11 / 01 / 2000$ & 10 & 361 & 0,1 & 53 & $-0,2$ & 71 & 894 & 281 & 0 \\
\hline $11 / 01 / 2000$ & 11 & 413 & 0,1 & 91 & 1,6 & 67 & 895 & 410 & 0 \\
\hline $12 / 01 / 2000$ & 1 & 616 & 0,1 & 311 & 1,3 & 64 & 893 & 1 & 0 \\
\hline $12 / 01 / 2000$ & 2 & 1958 & 0,4 & 299 & 1 & 68 & 893 & 0 & 0 \\
\hline $12 / 01 / 2000$ & 10 & 362 & 4 & 336 & 3,3 & 58 & 892 & 291 & 0 \\
\hline $12 / 01 / 2000$ & 11 & 764 & 2,6 & 334 & 4,8 & 53 & 893 & 421 & 0 \\
\hline $12 / 01 / 2000$ & 12 & 500 & 3,3 & 331 & 5,3 & 51 & 893 & 503 & 0 \\
\hline $12 / 01 / 2000$ & 13 & 372 & 3,1 & 335 & 6,2 & 48 & 892 & 523 & 0 \\
\hline
\end{tabular}




\begin{tabular}{|c|c|c|c|c|c|c|c|c|c|}
\hline $13 / 01 / 2000$ & 11 & 337 & 2 & 299 & 3,1 & 73 & 885 & 419 & 0 \\
\hline $18 / 01 / 2000$ & 6 & 746 & 2,9 & 330 & 2,6 & 65 & 886 & 1 & 0 \\
\hline $18 / 01 / 2000$ & 7 & 361 & 7,1 & 325 & 2,9 & 62 & 886 & 1 & 0 \\
\hline $10 / 03 / 2000$ & 4 & 281 & 5,1 & 335 & 11,7 & 35 & 895 & 2 & 0 \\
\hline $17 / 03 / 2000$ & 5 & 282 & 3,8 & 326 & & 58 & 890 & 2 & 0 \\
\hline $17 / 03 / 2000$ & 6 & 336 & 2,8 & 330 & & 60 & 889 & 2 & 0 \\
\hline $17 / 03 / 2000$ & 7 & 277 & 2,9 & 328 & & 59 & 889 & 36 & 0 \\
\hline $17 / 03 / 2000$ & 9 & 951 & 3,9 & 334 & & 57 & 890 & 411 & 0 \\
\hline $17 / 03 / 2000$ & 10 & 396 & 3,9 & 332 & & 52 & 891 & 615 & 0 \\
\hline $13 / 06 / 2000$ & 6 & 334 & & 309 & 11,1 & 78 & & 29 & 0 \\
\hline $13 / 06 / 2000$ & 9 & 298 & & 341 & 14,6 & 71 & & 527 & 0 \\
\hline $05 / 09 / 2000$ & 3 & 404 & 0,4 & 85 & 11,8 & 84 & 890 & 1 & $\overline{0}$ \\
\hline $05 / 09 / 2000$ & 4 & 598 & 0,4 & 82 & 11,7 & 84 & 890 & 1 & 0 \\
\hline $05 / 09 / 2000$ & 5 & 1142 & 0,4 & 63 & 11,3 & 87 & 890 & 0 & 0 \\
\hline $05 / 09 / 2000$ & 6 & 353 & 0,7 & 23 & 10,9 & 92 & 890 & 6 & 0 \\
\hline $05 / 09 / 2000$ & 8 & 823 & 1,4 & 15 & 14,1 & 80 & 891 & 239 & 0 \\
\hline $07 / 09 / 2000$ & 8 & 337 & 7,5 & 316 & 17,8 & 44 & 887 & 217 & 0 \\
\hline $07 / 09 / 2000$ & 9 & 281 & 8,5 & 312 & 18,6 & 44 & 887 & 441 & $\overline{0}$ \\
\hline $08 / 09 / 2000$ & 8 & 296 & 0,2 & 94 & 20,3 & 55 & 888 & 235 & 0 \\
\hline $04 / 10 / 2000$ & 5 & 335 & 9,2 & 326 & 14,4 & 19 & 887 & 2 & 0 \\
\hline $04 / 10 / 2000$ & 6 & 369 & 9,6 & 330 & 14,6 & 15 & 887 & 2 & 0 \\
\hline $04 / 10 / 2000$ & 7 & 331 & 10,4 & 329 & 14,3 & 16 & 888 & 35 & 0 \\
\hline $04 / 10 / 2000$ & 8 & 547 & 10,8 & 330 & 14,6 & 16 & 888 & 167 & 0 \\
\hline $04 / 10 / 2000$ & 20 & 342 & 2,4 & 327 & 17,8 & 45 & 888 & 2 & 0 \\
\hline $04 / 10 / 2000$ & 21 & 383 & 1,7 & 305 & 17,1 & 47 & 888 & 2 & 0 \\
\hline $05 / 10 / 2000$ & 6 & 489 & 0,8 & 302 & 12,4 & 80 & 887 & 1 & 0 \\
\hline $05 / 10 / 2000$ & 7 & 338 & 0,5 & 8 & 12,4 & 86 & 887 & 34 & 0 \\
\hline $08 / 10 / 2000$ & 8 & 264 & 7,4 & 341 & 12,8 & 28 & 889 & 167 & 0 \\
\hline $08 / 10 / 2000$ & 9 & 286 & 7,2 & 343 & 13,7 & 26 & 889 & 271 & 0 \\
\hline $17 / 10 / 2000$ & 18 & 404 & 2,5 & 358 & 12,4 & 70 & 894 & 7 & 0 \\
\hline $17 / 12 / 2000$ & 7 & 1861 & 1,5 & 335 & 2,8 & 71 & 882 & 0 & 0 \\
\hline $17 / 12 / 2000$ & 10 & 950 & 0,8 & 41 & 6,5 & 60 & 884 & 222 & 0 \\
\hline $17 / 12 / 2000$ & 12 & 283 & 0,8 & 312 & 7,8 & 57 & 885 & 377 & 0 \\
\hline $17 / 12 / 2000$ & 13 & 263 & 1,1 & 297 & 9,1 & 52 & 885 & 385 & 0 \\
\hline
\end{tabular}




\begin{tabular}{|c|c|c|c|c|c|c|c|c|c|}
\hline \multirow{2}{*}{ Fecha } & \multirow{2}{*}{ Hora } & $\mathrm{SO}_{2}$ & Veloc. & Direc. & Temp. & H. Rel. & Pres. & R. Sol. & Precip. \\
\hline & & $\mu g / m^{3}$ & $\mathrm{~m} / \mathrm{s}$ & grados & ${ }^{\circ} \mathrm{C}$ & \% H.R. & $\mathrm{mb}$ & $\mathrm{W} / \mathrm{m}^{2}$ & $1 / \mathrm{m}^{2}$ \\
\hline $21 / 06 / 2001$ & 10 & 336 & 3,6 & 338 & 27,2 & 28 & 887 & 700 & 0 \\
\hline $28 / 06 / 2001$ & 9 & 270 & 6,2 & 337 & 16,5 & 39 & 888 & 567 & 0 \\
\hline $02 / 07 / 2001$ & 7 & 521 & 1,8 & 328 & 25,7 & 29 & 892 & 155 & 0 \\
\hline $21 / 07 / 2001$ & 4 & 301 & 0,4 & 296 & 14,8 & 54 & 889 & 0 & 0 \\
\hline $21 / 07 / 2001$ & 5 & 270 & 0,6 & 242 & 15,7 & 50 & 889 & 2 & 0 \\
\hline 03/08/2001 & 8 & 468 & 1,2 & 343 & 18,5 & 77 & 886 & 287 & 0 \\
\hline $10 / 08 / 2001$ & 6 & 313 & 1,7 & 338 & 14,4 & 79 & 890 & 20 & 0 \\
\hline $01 / 09 / 2001$ & 7 & 323 & 7,3 & 326 & 11,4 & 77 & 885 & 68 & 0 \\
\hline $02 / 09 / 2001$ & 4 & 392 & 0,1 & 321 & 12,3 & 73 & 886 & 0 & 0 \\
\hline $02 / 09 / 2001$ & 5 & 301 & 0,1 & 320 & 12,6 & 71 & 886 & 0 & 0 \\
\hline 06/09/2001 & 1 & 537 & 0,6 & 25 & 16,1 & 59 & 887 & 0 & 0 \\
\hline $06 / 09 / 2001$ & 8 & 296 & 0,6 & 346 & 13,4 & 78 & 886 & 217 & 0 \\
\hline $07 / 09 / 2001$ & 9 & 320 & 2,2 & 308 & 12,4 & 87 & 888 & 351 & 0 \\
\hline $08 / 09 / 2001$ & 6 & 812 & 0,2 & 150 & 12,2 & 94 & 889 & 4 & 0 \\
\hline $08 / 09 / 2001$ & 7 & 540 & 0,1 & 260 & 13,1 & 91 & 889 & 89 & 0 \\
\hline $08 / 09 / 2001$ & 8 & 895 & 0,1 & 20 & 15,8 & 79 & 889 & 246 & $\overline{0}$ \\
\hline 08/09/2001 & 9 & 477 & 0,2 & 40 & 18 & 73 & 889 & 405 & 0 \\
\hline 09/09/2001 & 20 & 299 & 6,4 & 351 & 17,6 & 72 & 885 & 0 & 0 \\
\hline 09/09/2001 & 21 & 428 & 7,3 & 346 & 16,3 & 77 & 885 & 0 & 0 \\
\hline $13 / 09 / 2001$ & 6 & 300 & 1,7 & 304 & 16,7 & 47 & 888 & 3 & 0 \\
\hline $13 / 09 / 2001$ & 7 & 1225 & 0,1 & 356 & 18,4 & 39 & 888 & 72 & 0 \\
\hline $13 / 09 / 2001$ & 8 & 418 & 0,7 & 241 & 21,4 & 40 & 888 & 225 & 0 \\
\hline $16 / 09 / 2001$ & 6 & 463 & 8,1 & 350 & 11,9 & 72 & 886 & 1 & 0 \\
\hline 16/09/2001 & 7 & 580 & 9,6 & 333 & 11,9 & 69 & 886 & 43 & 0 \\
\hline $24 / 09 / 2001$ & 10 & 318 & 6,1 & 331 & 10,6 & 96 & 881 & 58 & 1,5 \\
\hline $06 / 10 / 2001$ & 21 & 278 & 3,4 & 352 & 16,7 & 80 & 883 & 0 & 0 \\
\hline $24 / 10 / 2001$ & 20 & 362 & 2,4 & 340 & 12,1 & 74 & 896 & 0 & 0 \\
\hline $26 / 10 / 2001$ & 7 & 1059 & 0,1 & 265 & 13,3 & 77 & 888 & 8 & 0 \\
\hline $30 / 10 / 2001$ & 6 & 300 & 0,8 & 324 & 18,2 & 53 & 895 & 0 & 0 \\
\hline $21 / 11 / 2001$ & 23 & 300 & 0,8 & 13 & 3,5 & 92 & 891 & 5 & 0 \\
\hline $22 / 11 / 2001$ & 18 & 573 & 2,6 & 331 & 3,6 & 84 & 889 & 5 & 0 \\
\hline $22 / 11 / 2001$ & 19 & 467 & 4,1 & 336 & 3,4 & 80 & 889 & 5 & 0 \\
\hline $23 / 11 / 2001$ & 4 & 333 & 3,1 & 329 & 0,3 & 81 & 885 & 3 & 0 \\
\hline $25 / 11 / 2001$ & 9 & 264 & 4,7 & 320 & 2,9 & 91 & 883 & 110 & 0 \\
\hline $26 / 11 / 2001$ & 2 & 277 & 0,5 & 40 & 3,4 & 99 & 881 & 3 & 0 \\
\hline
\end{tabular}




\begin{tabular}{|c|c|c|c|c|c|c|c|c|c|}
\hline $26 / 11 / 2001$ & 3 & 1639 & 0,4 & 80 & 3,4 & 96 & 880 & 0 & 0 \\
\hline $26 / 11 / 2001$ & 4 & 355 & 3,3 & 321 & 3,6 & 95 & 880 & 2 & 0 \\
\hline $26 / 11 / 2001$ & 5 & 740 & 1,6 & 336 & 3,1 & 97 & 879 & 0 & 0 \\
\hline $26 / 11 / 2001$ & 6 & 431 & 1,2 & 18 & 2,9 & 96 & 879 & 2 & 0 \\
\hline $26 / 11 / 2001$ & 7 & 364 & 0,3 & 94 & 3,2 & 95 & 879 & 3 & 0 \\
\hline $01 / 12 / 2001$ & 10 & 828 & 4,5 & 337 & 13 & 48 & 887 & 265 & 0 \\
\hline $01 / 12 / 2001$ & 11 & 517 & 4 & 332 & 13,5 & 50 & 887 & 356 & 0 \\
\hline $02 / 12 / 2001$ & 22 & 278 & 0,3 & 341 & 9,6 & 57 & 887 & 2 & 0 \\
\hline $03 / 12 / 2001$ & 22 & 526 & 2,8 & 311 & 8,3 & 58 & 889 & 1 & 0 \\
\hline $03 / 12 / 2001$ & 23 & 274 & 3,2 & 324 & 9,1 & 65 & 889 & 2 & 0 \\
\hline $06 / 12 / 2001$ & 12 & 443 & 3,2 & 348 & 8,7 & 91 & 893 & 237 & 0 \\
\hline $06 / 12 / 2001$ & 13 & 348 & 3,7 & 341 & 10,1 & 85 & 892 & 391 & 0 \\
\hline $13 / 12 / 2001$ & 4 & 439 & 0,2 & 230 & 3,1 & 56 & 879 & 2 & 0 \\
\hline $15 / 12 / 2001$ & 16 & 289 & 5,6 & 337 & $-8,6$ & 87 & 875 & 19 & 0 \\
\hline $16 / 12 / 2001$ & 7 & 333 & 1,1 & 64 & $-5,9$ & 89 & 879 & 3 & 0 \\
\hline $16 / 12 / 2001$ & 8 & 283 & 1,4 & 138 & $-5,6$ & 87 & 880 & 19 & 0 \\
\hline $16 / 12 / 2001$ & 9 & 272 & 2,7 & 2 & $-4,9$ & 87 & 880 & 120 & 0 \\
\hline $16 / 12 / 2001$ & 11 & 844 & 3,1 & 312 & $-3,1$ & 80 & 881 & 320 & 0 \\
\hline $16 / 12 / 2001$ & 12 & 1043 & 1,1 & 26 & -1 & 70 & 881 & 367 & 0 \\
\hline $20 / 12 / 2001$ & 9 & 465 & 4,2 & 324 & 0,3 & 86 & 883 & 119 & 0 \\
\hline $20 / 12 / 2001$ & 14 & 269 & 5,7 & 331 & 2,2 & 81 & 883 & 340 & 0,7 \\
\hline $20 / 12 / 2001$ & 15 & 540 & 5,5 & 338 & 2,1 & 79 & 883 & 248 & 0,3 \\
\hline $20 / 12 / 2001$ & 17 & 294 & 7,4 & 327 & 0,8 & 85 & 883 & 20 & 0 \\
\hline $21 / 12 / 2001$ & 4 & 284 & 8,5 & 340 & -4 & 92 & 881 & 2 & 0 \\
\hline $21 / 12 / 2001$ & 11 & 295 & 5,1 & 323 & $-2,6$ & 85 & 883 & 324 & 0 \\
\hline $24 / 12 / 2001$ & 12 & 319 & 0,8 & 13 & -3 & 56 & 878 & 391 & 0 \\
\hline $24 / 12 / 2001$ & 13 & 265 & 0,1 & 360 & $-1,1$ & 54 & 877 & 410 & 0 \\
\hline $25 / 12 / 2001$ & 10 & 544 & 1,6 & 323 & $-0,9$ & 78 & 877 & 232 & 0 \\
\hline
\end{tabular}




\begin{tabular}{|c|c|c|c|c|c|c|c|c|c|}
\hline Fecha & Hora & $\mathrm{SO}_{2}$ & Veloc. & Direc. & Temp. & H. Rel. & Pres. & R. Sol. & Precip. \\
\hline Fecila & $1101 a$ & $\mu \mathrm{g} / \mathrm{m}^{3}$ & $\mathrm{~m} / \mathrm{s}$ & grados & ${ }^{\circ} \mathbf{C}$ & \% H.R. & $\mathrm{mb}$ & $\mathrm{W} / \mathrm{m}^{2}$ & $1 / \mathrm{m}^{2}$ \\
\hline $13 / 01 / 2002$ & 4 & 277 & 5,4 & 331 & 9,7 & 32 & 893 & 2 & 0 \\
\hline $28 / 01 / 2002$ & 6 & 448 & 3,1 & 329 & 9 & 64 & 893 & 1 & 0 \\
\hline $13 / 02 / 2002$ & 0 & 264 & 0,9 & 316 & 11,6 & 63 & 891 & 2 & 0 \\
\hline $13 / 02 / 2002$ & 1 & 811 & 0,5 & 171 & 11 & 65 & 890 & 0 & 0 \\
\hline $13 / 02 / 2002$ & 2 & 661 & 0,7 & 276 & 10,6 & 62 & 890 & 1 & 0 \\
\hline $13 / 02 / 2002$ & 3 & 343 & 0,2 & 102 & 10,7 & 57 & 890 & 2 & 0 \\
\hline $13 / 02 / 2002$ & 7 & 305 & 0,1 & 72 & 11,8 & 39 & 888 & 3 & 0 \\
\hline $30 / 03 / 2002$ & 9 & 318 & 2 & 308 & 3,2 & & 877 & 298 & 0,6 \\
\hline $03 / 04 / 2002$ & 9 & 268 & 1,5 & 310 & 4,8 & & 859 & 32 & 0 \\
\hline $03 / 04 / 2002$ & 10 & 436 & 2,1 & 303 & 5 & & 860 & 101 & 0,2 \\
\hline $30 / 06 / 2002$ & 4 & 369 & 0,1 & 306 & 9,7 & 96 & 872 & 0 & 0 \\
\hline $30 / 06 / 2002$ & 8 & 280 & 0,1 & 345 & 9,3 & 96 & 873 & 27 & 0 \\
\hline $18 / 07 / 2002$ & 4 & 388 & 0,9 & 273 & 15,1 & 31 & 871 & 0 & 0 \\
\hline $18 / 07 / 2002$ & 5 & 325 & 1,1 & 265 & 15,8 & 24 & 871 & 1 & $\overline{0}$ \\
\hline $23 / 07 / 2002$ & 7 & 381 & 3,5 & 316 & 15,6 & 40 & 871 & 128 & $\overline{0}$ \\
\hline $04 / 08 / 2002$ & 5 & 286 & 0,1 & 261 & 14,3 & 64 & 869 & $\overline{0}$ & $\overline{0}$ \\
\hline $07 / 08 / 2002$ & 5 & 437 & 0,5 & 84 & 10,3 & 65 & 874 & 0 & 0 \\
\hline $07 / 08 / 2002$ & 6 & 301 & 1,1 & 70 & 10,3 & 66 & 874 & 13 & 0 \\
\hline $07 / 08 / 2002$ & 8 & 512 & 1,2 & 351 & 12,9 & 55 & 874 & 253 & 0 \\
\hline $30 / 08 / 2002$ & 4 & 396 & 0,2 & 311 & 9,2 & 52 & & 0 & 0 \\
\hline $25 / 09 / 2002$ & 7 & 314 & 0,3 & 310 & 0,1 & 43 & & 59 & 0 \\
\hline $25 / 09 / 2002$ & 9 & 430 & 0,8 & 1 & 3,4 & 35 & & 321 & $\overline{0}$ \\
\hline $25 / 09 / 2002$ & 10 & 485 & 1,4 & 48 & $\overline{5,4}$ & 32 & & 435 & $\overline{0}$ \\
\hline $26 / 09 / 2002$ & 7 & 289 & 2,1 & 303 & 3,9 & 15 & & 56 & $\overline{0}$ \\
\hline $26 / 09 / 2002$ & 8 & 298 & 3,4 & 303 & 5,2 & 14 & & 184 & 0 \\
\hline $26 / 09 / 2002$ & 9 & 723 & 2,9 & 299 & 6,3 & 13 & & 326 & 0 \\
\hline $27 / 09 / 2002$ & 4 & 278 & 6,8 & 316 & 4,7 & 23 & & 0 & 0 \\
\hline $27 / 09 / 2002$ & 9 & 269 & 8,9 & 308 & 4,6 & 33 & & 316 & 0 \\
\hline $27 / 09 / 2002$ & 10 & 329 & 6,5 & 301 & 6 & 32 & & 449 & 0 \\
\hline $27 / 09 / 2002$ & 11 & 292 & 3,3 & 310 & 7,6 & 30 & & 543 & 0 \\
\hline $28 / 09 / 2002$ & 9 & 286 & 0,3 & 213 & 10,7 & 24 & & 307 & 0 \\
\hline $28 / 09 / 2002$ & 10 & 273 & 0,9 & 153 & 11,4 & 22 & & 439 & 0 \\
\hline $05 / 10 / 2002$ & 9 & 311 & 0,2 & 32 & 12,8 & 62 & 876 & 436 & $\overline{0}$ \\
\hline $07 / 10 / 2002$ & 2 & 265 & 5,5 & 314 & 11,2 & 33 & 867 & 0 & 0 \\
\hline
\end{tabular}




\begin{tabular}{|c|c|c|c|c|c|c|c|c|c|}
\hline \multirow{2}{*}{ Fecha } & \multirow{2}{*}{ Hora } & $\mathbf{S O}_{\mathbf{2}}$ & Veloc. & Direc. & Temp. & H. Rel. & Pres. & R. Sol. & Precip. \\
\cline { 3 - 11 } & & $\boldsymbol{\mu g} / \mathbf{m}^{\mathbf{3}}$ & $\mathbf{m} / \mathbf{s}$ & grados & ${ }^{\mathbf{C}} \mathbf{C}$ & $\mathbf{\%} \mathbf{H . R}$. & $\mathbf{m b}$ & $\mathbf{W} / \mathbf{m}^{\mathbf{2}}$ & $\mathbf{1 / \mathbf { m } ^ { \mathbf { 2 } }}$ \\
\hline $09 / 02 / 2003$ & 4 & 395 & 2,6 & 293 & 0,5 & 48 & 868 & 0 & 0 \\
\hline $28 / 02 / 2003$ & 10 & 263 & 1,9 & 313 & 4,9 & 42 & 877 & 560 & 0 \\
\hline $12 / 03 / 2003$ & 7 & 287 & 4 & 300 & 14,8 & 12 & 876 & 13 & 0 \\
\hline $06 / 04 / 2003$ & 6 & 462 & 9,4 & 278 & 6,8 & 40 & 866 & 3 & 0 \\
\hline $06 / 04 / 2003$ & 7 & 416 & 7,9 & 284 & 6,9 & 41 & 866 & 76 & 0 \\
\hline $06 / 04 / 2003$ & 8 & 265 & 11,1 & 283 & 7,7 & 39 & 866 & 228 & 0 \\
\hline $07 / 04 / 2003$ & 9 & 273 & 2,2 & 24 & 9,5 & 45 & 862 & 388 & 0 \\
\hline $01 / 08 / 2003$ & 9 & 289 & 4,3 & 305 & 24,5 & & 872 & 440 & 0 \\
\hline $13 / 09 / 2003$ & 6 & 292 & 0,4 & 7 & 16,8 & 44 & 885 & 1 & 0 \\
\hline $10 / 10 / 2003$ & 4 & 450 & 0,5 & 194 & 11,7 & 57 & 881 & 0 & 0 \\
\hline $04 / 11 / 2003$ & 0 & 353 & 0,3 & 65 & 11,1 & 41 & 884 & 0 & 0 \\
\hline $07 / 11 / 2003$ & 10 & 317 & 1,1 & 299 & 14,7 & 15 & 877 & 319 & 0 \\
\hline $07 / 11 / 2003$ & 11 & 323 & 0,5 & 291 & 15,9 & 14 & 876 & 408 & 0 \\
\hline $07 / 11 / 2003$ & 19 & 302 & 2,7 & 305 & 12,7 & 30 & 874 & 0 & 0 \\
\hline
\end{tabular}

Tabla 45: Episodios horarios de inmisión de $\mathrm{SO}_{2}$ (> 75\% del umbral permitido) en Coratxar en el año 2004. Fuente: RVVCCA.

\begin{tabular}{|c|c|c|c|c|c|c|c|c|c|}
\hline \multirow{2}{*}{ Fecha } & \multirow{2}{*}{ Hora } & $\mathbf{S O}_{2}$ & Veloc. & Direc. & Temp. & H. Rel. & Pres. & R. Sol. & Precip. \\
\cline { 3 - 11 } & & $\boldsymbol{\mu g} / \mathbf{m}^{3}$ & $\mathbf{m} / \mathbf{s}$ & grados & ${ }^{\circ} \mathbf{C}$ & \% H.R. & $\mathbf{m b}$ & $\mathbf{W} / \mathbf{m}^{2}$ & $\mathbf{1 / \mathbf { m } ^ { 2 }}$ \\
\hline $06 / 01 / 2004$ & 0 & 741 & 1,9 & 288 & 9,9 & 25 & 879 & 0 & 0 \\
\hline $06 / 01 / 2004$ & 1 & 961 & 2,1 & 283 & 10,3 & 24 & 879 & 0 & 0 \\
\hline $06 / 01 / 2004$ & 2 & 721 & 1,4 & 295 & 10,2 & 22 & 879 & 0 & 0 \\
\hline $06 / 01 / 2004$ & 3 & 1473 & 0,5 & 189 & 9,9 & 23 & 879 & 0 & 0 \\
\hline $06 / 01 / 2004$ & 7 & 347 & 0,1 & 171 & 10 & 18 & 878 & 0 & 0 \\
\hline $06 / 01 / 2004$ & 8 & 663 & 0,2 & 158 & 10 & 18 & 879 & 3 & 0 \\
\hline $06 / 01 / 2004$ & 9 & 345 & 0,3 & 225 & 12,2 & 13 & 879 & 82 & 0 \\
\hline $06 / 01 / 2004$ & 19 & 347 & 0,4 & 323 & 11,9 & 11 & 880 & 0 & 0 \\
\hline $05 / 02 / 2004$ & 7 & 1387 & & 253 & 12,5 & 42 & 892 & 0 & 0 \\
\hline $05 / 02 / 2004$ & 8 & 1447 & & 203 & 13,3 & 38 & 893 & 19 & 0 \\
\hline $05 / 02 / 2004$ & 9 & 325 & & 293 & 15,3 & 31 & 893 & 133 & 0 \\
\hline $08 / 02 / 2004$ & 22 & 275 & & 17 & 7,2 & 68 & 884 & 0 & 0 \\
\hline $09 / 02 / 2004$ & 8 & 339 & & 194 & 4,3 & 37 & 883 & 32 & 0 \\
\hline $11 / 02 / 2004$ & 9 & 286 & & 290 & 10 & & 883 & 150 & 0 \\
\hline $11 / 02 / 2004$ & 14 & 284 & & 287 & 13,2 & & 882 & 477 & 0 \\
\hline $24 / 04 / 2004$ & 2 & 282 & 3,2 & 249 & 8,6 & & 877 & 0 & 0 \\
\hline
\end{tabular}





\begin{tabular}{|c|c|c|c|c|c|c|c|c|c|}
\hline $12 / 02 / 2005$ & 2 & 335 & 9,5 & 289 & 7,1 & 34 & 887 & 0 & 0 \\
\hline $20 / 06 / 2005$ & 8 & 444 & 1 & 62 & 28,3 & 59 & 879 & 317 & 0 \\
\hline $05 / 07 / 2005$ & 8 & 336 & 5,9 & 297 & 15,9 & 64 & 878 & 317 & 0 \\
\hline
\end{tabular}

Tabla 47: Episodios horarios de inmisión de $\mathrm{SO}_{2}$ (> 75\% del umbral permitido) en Coratxar en el año 2006 . Fuente: RVVCCA.

\begin{tabular}{|c|c|c|c|c|c|c|c|c|c|}
\hline \multirow{2}{*}{ Fecha } & \multirow{2}{*}{ Hora } & $\mathrm{SO}_{2}$ & Veloc. & Direc. & Temp. & H. Rel. & Pres. & R. Sol. & Precip. \\
\hline & & $\mu \mathrm{g} / \mathrm{m}^{3}$ & $\mathrm{~m} / \mathrm{s}$ & grados & ${ }^{\circ} \mathrm{C}$ & \% H.R. & $\mathrm{mb}$ & $\mathrm{W} / \mathrm{m}^{2}$ & $1 / \mathrm{m}^{2}$ \\
\hline $12 / 01 / 2006$ & 6 & 309 & 2,6 & 188 & 4,3 & 60 & 883 & 0 & 0 \\
\hline $12 / 01 / 2006$ & 8 & 280 & 3,3 & 284 & $\overline{4,4}$ & 58 & 883 & 6 & 0 \\
\hline $23 / 01 / 2006$ & 10 & 369 & 3,6 & 182 & 5,7 & 49 & 880 & 233 & 0,2 \\
\hline $23 / 01 / 2006$ & 11 & 768 & 3,4 & 18 & 6,5 & 48 & 881 & 340 & 0,2 \\
\hline $26 / 01 / 2006$ & 12 & 354 & 3,4 & 341 & 2,5 & 51 & 867 & 406 & 0 \\
\hline $31 / 01 / 2006$ & 20 & 327 & 2,6 & 314 & 6 & 99 & 878 & & 0 \\
\hline $31 / 01 / 2006$ & 22 & 347 & 0,4 & 317 & 6 & 99 & 879 & & 0 \\
\hline $01 / 02 / 2006$ & 2 & 487 & 0 & 153 & 6,6 & 66 & 878 & & 0 \\
\hline $01 / 02 / 2006$ & 3 & 520 & $\overline{0}$ & 178 & 6,3 & 61 & 878 & & 0 \\
\hline $01 / 02 / 2006$ & 7 & 618 & 4,5 & 258 & 7,7 & 46 & 877 & & 0 \\
\hline $03 / 02 / 2006$ & 2 & 879 & 1,1 & 280 & 7,4 & 43 & 872 & 0 & 0 \\
\hline $06 / 02 / 2006$ & 5 & 373 & 4,6 & 249 & 0,4 & 53 & 876 & 0 & 0 \\
\hline $07 / 02 / 2006$ & 5 & 758 & 2,4 & 12 & 3,6 & 40 & 879 & 0 & 0 \\
\hline $07 / 02 / 2006$ & 6 & 375 & 1,2 & 140 & 2,6 & 42 & 879 & 0 & 0 \\
\hline $12 / 02 / 2006$ & 5 & 304 & 0,7 & 322 & 2,7 & 42 & 878 & 0 & 0 \\
\hline $15 / 02 / 2006$ & 7 & 303 & 4,8 & 213 & 7,3 & 42 & 877 & 1 & 0 \\
\hline $13 / 03 / 2006$ & 20 & 302 & & 256 & 12,9 & 53 & 875 & $\overline{0}$ & 0 \\
\hline $27 / 09 / 2006$ & 20 & 287 & 3,5 & 298 & 19,8 & 44 & 875 & 0 & 0 \\
\hline $21 / 12 / 2006$ & 11 & 273 & 5,8 & 236 & 1,6 & 57 & 882 & 272 & 0 \\
\hline
\end{tabular}


Tabla 48: Episodios horarios de inmisión de $\mathrm{SO}_{2}$ (> 75\% del umbral permitido) en Coratxar en el año 2007. Fuente: RVVCCA.

\begin{tabular}{|c|c|c|c|c|c|c|c|c|c|}
\hline \multirow{2}{*}{ Fecha } & \multirow{2}{*}{ Hora } & $\mathbf{S O}_{2}$ & Veloc. & Direc. & Temp. & H. Rel. & Pres. & R. Sol. & Precip. \\
\cline { 3 - 11 } & & $\boldsymbol{\mu g} / \mathbf{m}^{3}$ & $\mathbf{m} / \mathbf{s}$ & grados & ${ }^{\circ} \mathbf{C}$ & \% H.R. & $\mathbf{m b}$ & $\mathbf{W} / \mathbf{m}^{2}$ & $\mathbf{1} \mathbf{m}^{\mathbf{2}}$ \\
\hline $10 / 01 / 2007$ & 10 & 264 & 1,3 & 56 & 14,4 & 45 & 883 & 206 & 0 \\
\hline $10 / 01 / 2007$ & 12 & 296 & 1,8 & 53 & 15,4 & 43 & 883 & 308 & 0 \\
\hline $10 / 01 / 2007$ & 13 & 333 & 1,9 & 351 & 15,5 & 44 & 883 & 353 & 0 \\
\hline $04 / 06 / 2007$ & 17 & 309 & 2,5 & 0 & 14,3 & 83 & & 4 & 0 \\
\hline $03 / 08 / 2007$ & 8 & 323 & 0,4 & 330 & 18,7 & 34 & 885 & 261 & 0 \\
\hline $10 / 08 / 2007$ & 8 & 404 & 4,8 & 292 & 14 & 54 & 880 & 257 & 0 \\
\hline $01 / 09 / 2007$ & 2 & 301 & 0,1 & 341 & 12,9 & 75 & 885 & 0 & 0 \\
\hline $06 / 09 / 2007$ & 8 & 331 & 2,2 & 313 & 15,5 & 57 & 886 & 214 & 0 \\
\hline $07 / 09 / 2007$ & 9 & 445 & 2 & 305 & 17,1 & 62 & 885 & 342 & 0 \\
\hline $11 / 09 / 2007$ & 6 & 425 & 0,5 & 340 & 14,7 & 64 & 883 & 1 & 0 \\
\hline $19 / 09 / 2007$ & 8 & 592 & 0,9 & 4 & 11,7 & 55 & 885 & 68 & 0 \\
\hline $19 / 09 / 2007$ & 9 & 441 & 1 & 13 & 13,4 & 54 & 886 & 196 & 0 \\
\hline $04 / 11 / 2007$ & 1 & 401 & 0 & 154 & 10,8 & 59 & 882 & 0 & 0 \\
\hline $04 / 11 / 2007$ & 12 & 285 & 2,6 & 284 & 15,1 & 39 & 882 & 491 & 0 \\
\hline $06 / 11 / 2007$ & 8 & 297 & 1,3 & 168 & 6,4 & 69 & 888 & 87 & 0 \\
\hline $06 / 11 / 2007$ & 9 & 324 & 2,2 & 218 & 7,1 & 67 & 888 & 221 & 0 \\
\hline $13 / 11 / 2007$ & 1 & 277 & 8,8 & 296 & 5,1 & 82 & 880 & 0 & 0 \\
\hline $29 / 11 / 2007$ & 7 & 263 & 7,4 & 292 & 1,4 & 95 & 875 & 2 & 0 \\
\hline $30 / 11 / 2007$ & 23 & 288 & 3 & 291 & 7,2 & 83 & 879 & 2 & 0 \\
\hline $01 / 12 / 2007$ & 0 & 776 & 2,8 & 289 & 7,4 & 82 & 879 & 2 & 0 \\
\hline $14 / 12 / 2007$ & 6 & 327 & 0,3 & 182 & 1,1 & 55 & 885 & 0 & 0 \\
\hline $14 / 12 / 2007$ & 7 & 472 & 0,2 & 174 & 1,2 & 57 & 885 & 0 & 0 \\
\hline $14 / 12 / 2007$ & 8 & 365 & 0,1 & 193 & 1,3 & 55 & 885 & 13 & 0 \\
\hline $14 / 12 / 2007$ & 9 & 751 & 0,6 & 199 & 2,9 & 47 & 885 & 124 & 0 \\
\hline $14 / 12 / 2007$ & 20 & 353 & 6,4 & 302 & 4 & 35 & 882 & 0 & 0 \\
\hline $15 / 12 / 2007$ & 2 & 584 & 1,4 & 221 & 3,1 & 39 & 880 & 0 & 0 \\
\hline
\end{tabular}




\section{EXPORTACIÓN DE PROMEDIOS DIARIOS (2000-2015)}

\section{ESTACIÓN: Coratxar CÓDIGO: 12093004}

A continuación se detallan los episodios diarios de inmisión de $\mathrm{SO}_{2}$ que alcanzaron, al menos, el $75 \%$ del valor umbral $\left(125 \mu \mathrm{g} / \mathrm{m}^{3}\right)$ permitido por la legislación (Real Decreto 102/2011, BOE 29 de enero 2011 relativo a la mejora de la calidad del aire).

Tabla 49: Episodios diarios de inmisión de $\mathrm{SO}_{2}$ (> 75\% del umbral permitido) en Coratxar en el año 2000. Fuente: RVVCCA.

\begin{tabular}{|c|c|c|c|c|c|c|c|c|}
\hline \multirow{2}{*}{ Fecha } & $\mathbf{S O}_{\mathbf{2}}$ & Veloc. & Direc. & Temp. & H. Rel. & Pres. & R. Sol. & Precip. \\
\cline { 2 - 9 } & $\boldsymbol{\mu g} / \mathbf{m}^{\mathbf{3}}$ & $\mathbf{m} / \mathbf{s}$ & grados & ${ }^{\circ} \mathbf{C}$ & $\mathbf{\%} \mathbf{H . R}$. & $\mathbf{m b}$ & $\mathbf{W} / \mathbf{m}^{\mathbf{2}}$ & $\mathbf{1 / \mathbf { m } ^ { \mathbf { 2 } }}$ \\
\hline $02 / 01 / 2000$ & 97 & 2,3 & 311 & 3 & 93 & 891 & 60 & 0 \\
\hline $08 / 01 / 2000$ & 208 & 2 & 338 & 4,8 & 77 & 888 & 74 & 0 \\
\hline $11 / 01 / 2000$ & 110 & 0,3 & 30 & 0,6 & 68 & 894 & 123 & 0 \\
\hline $12 / 01 / 2000$ & 223 & 2,5 & 325 & 2,8 & 61 & 891 & 127 & 0 \\
\hline $17 / 03 / 2000$ & 119 & 4,5 & 335 & & 48 & 890 & 267 & 0 \\
\hline $05 / 09 / 2000$ & 177 & 1,4 & 120 & 17,3 & 73 & 891 & 222 & 0 \\
\hline $04 / 10 / 2000$ & 200 & 4,3 & 331 & 17,6 & 31 & 888 & 179 & 0 \\
\hline $05 / 10 / 2000$ & 139 & 3,7 & 345 & 15,1 & 74 & 888 & 148 & 0 \\
\hline $08 / 10 / 2000$ & 120 & 6,7 & 340 & 15,3 & 32 & 889 & 174 & 0 \\
\hline $17 / 12 / 2000$ & 186 & 3,2 & 333 & 5,3 & 64 & 884 & 86 & 0 \\
\hline
\end{tabular}

Tabla 50: Episodios diarios de inmisión de $\mathrm{SO}_{2}$ (> 75\% del umbral permitido) en Coratxar en el año 2001. Fuente: RVVCCA.

\begin{tabular}{|c|c|c|c|c|c|c|c|c|}
\hline \multirow{2}{*}{ Fecha } & $\mathbf{S O}_{\mathbf{2}}$ & Veloc. & Direc. & Temp. & H. Rel. & Pres. & R. Sol. & Precip. \\
\cline { 2 - 9 } & $\boldsymbol{\mu g} / \mathbf{m}^{\mathbf{3}}$ & $\mathbf{m} / \mathbf{s}$ & grados & ${ }^{\circ} \mathbf{C}$ & $\mathbf{\%} \mathbf{H . R}$. & $\mathbf{m b}$ & $\mathbf{W} / \mathbf{m}^{\mathbf{2}}$ & $\mathbf{1 / \mathbf { m } ^ { \mathbf { 2 } }}$ \\
\hline $01 / 09 / 2001$ & 94 & 5 & 340 & 15,1 & 66 & 886 & 231 & 0 \\
\hline $06 / 09 / 2001$ & 122 & 2,6 & 345 & 16,5 & 64 & 885 & 144 & 0 \\
\hline $07 / 09 / 2001$ & 94 & 5,2 & 331 & 15,3 & 75 & 888 & 216 & 0 \\
\hline $08 / 09 / 2001$ & 165 & 1,9 & 340 & 18,9 & 68 & 889 & 224 & 0 \\
\hline $09 / 09 / 2001$ & 106 & 7,2 & 334 & 17,2 & 67 & 885 & 231 & 0 \\
\hline $13 / 09 / 2001$ & 129 & 1,9 & 278 & 20,9 & 66 & 887 & 173 & 0 \\
\hline $16 / 09 / 2001$ & 103 & 6,5 & 335 & 15,8 & 58 & 886 & 212 & 0 \\
\hline $22 / 11 / 2001$ & 102 & 1 & 349 & 3,2 & 87 & 889 & 137 & 0 \\
\hline $23 / 11 / 2001$ & 95 & 9,4 & 325 & 3,1 & 91 & 885 & 65 & 0 \\
\hline $25 / 11 / 2001$ & 113 & 2,6 & 335 & 4,3 & 89 & 883 & 94 & 0 \\
\hline $26 / 11 / 2001$ & 207 & 2,8 & 335 & 4,9 & 91 & 879 & 70 & 0,6 \\
\hline $01 / 12 / 2001$ & 139 & 2,7 & 336 & 11,4 & 59 & 886 & 105 & 0 \\
\hline $06 / 12 / 2001$ & 106 & 4,3 & 347 & 8,3 & 91 & 891 & 72 & 0 \\
\hline
\end{tabular}




\begin{tabular}{|c|c|c|c|c|c|c|c|c|}
\hline $16 / 12 / 2001$ & 172 & 2,7 & 335 & $-2,9$ & 79 & 881 & 90 & 0 \\
\hline $20 / 12 / 2001$ & 123 & 4,8 & 323 & 0 & 89 & 883 & 87 & 1 \\
\hline $21 / 12 / 2001$ & 94 & 5,6 & 328 & $-1,4$ & 78 & 881 & 94 & 0 \\
\hline
\end{tabular}

Tabla 51: Episodios diarios de inmisión de $\mathrm{SO}_{2}$ (> 75\% del umbral permitido) en Coratxar en el año 2002. Fuente: RVVCCA.

\begin{tabular}{|c|c|c|c|c|c|c|c|c|}
\hline \multirow{2}{*}{ Fecha } & $\mathbf{S O}_{2}$ & Veloc. & Direc. & Temp. & H. Rel. & Pres. & R. Sol. & Precip. \\
\cline { 2 - 9 } & $\boldsymbol{\mu g} / \mathbf{m}^{\mathbf{3}}$ & $\mathbf{m} / \mathbf{s}$ & grados & ${ }^{\circ} \mathbf{C}$ & $\mathbf{\%}$ H.R. & $\mathbf{m b}$ & $\mathbf{W} / \mathbf{m}^{\mathbf{2}}$ & $\mathbf{1 / \mathbf { m } ^ { 2 }}$ \\
\hline $13 / 02 / 2002$ & 152 & 0,8 & 211 & 13,8 & 53 & 886 & 144 & 0 \\
\hline $07 / 08 / 2002$ & 97 & 1,7 & 28 & 15,3 & 52 & 873 & 140 & 0 \\
\hline $25 / 09 / 2002$ & 112 & 2,5 & 311 & 4,7 & 30 & & 177 & 0 \\
\hline $26 / 09 / 2002$ & 107 & 3 & 311 & 7,2 & 17 & & 184 & 0 \\
\hline $27 / 09 / 2002$ & 96 & 3,9 & 298 & 7 & 34 & & 181 & 0 \\
\hline
\end{tabular}

Tabla 52: Episodios diarios de inmisión de $\mathrm{SO}_{2}$ (> 75\% del umbral permitido) en Coratxar en el año 2004. Fuente: RVVCCA.

\begin{tabular}{|c|c|c|c|c|c|c|c|c|}
\hline \multirow{2}{*}{ Fecha } & $\mathbf{S O}_{2}$ & Veloc. & Direc. & Temp. & H. Rel. & Pres. & R. Sol. & Precip. \\
\cline { 2 - 9 } & $\boldsymbol{\mu g} / \mathbf{m}^{\mathbf{3}}$ & $\mathbf{m} / \mathbf{s}$ & grados & ${ }^{\circ} \mathbf{C}$ & $\mathbf{\%}$ H.R. & $\mathbf{m b}$ & $\mathbf{W} / \mathbf{m}^{\mathbf{2}}$ & $\mathbf{1 / \mathbf { m } ^ { \mathbf { 2 } }}$ \\
\hline $06 / 01 / 2004$ & 238 & 0,9 & 206 & 12,3 & 14 & 879 & 91 & 0 \\
\hline $05 / 02 / 2004$ & 148 & & 209 & 15,1 & 27 & 892 & 123 & 0 \\
\hline $24 / 11 / 2004$ & 165 & 1,1 & 323 & 11,7 & 25 & 882 & 98 & 0 \\
\hline $25 / 11 / 2004$ & 101 & 1,9 & 237 & 11,6 & 31 & 883 & 94 & 0 \\
\hline
\end{tabular}

Tabla 53: Episodios diarios de inmisión de $\mathrm{SO}_{2}(>75 \%$ del umbral permitido) en Coratxar en el año 2005. Fuente: RVVCCA.

\begin{tabular}{|c|c|c|c|c|c|c|c|c|}
\hline \multirow{2}{*}{ Fecha } & $\mathbf{S O}_{2}$ & Veloc. & Direc. & Temp. & H. Rel. & Pres. & R. Sol. & Precip. \\
\cline { 2 - 9 } & $\boldsymbol{\mu g} / \mathbf{m}^{\mathbf{3}}$ & $\mathbf{m} / \mathbf{s}$ & grados & ${ }^{\circ} \mathbf{C}$ & \% H.R. & $\mathbf{m b}$ & $\mathbf{W} / \mathbf{m}^{\mathbf{2}}$ & $\mathbf{1} / \mathbf{m}^{\mathbf{2}}$ \\
\hline $08 / 01 / 2005$ & 128 & 1,2 & 322 & 12,5 & & 888 & 95 & 0 \\
\hline $17 / 01 / 2005$ & 198 & 2,1 & 227 & 8,5 & & 882 & 97 & 0 \\
\hline
\end{tabular}

Tabla 54: Episodios diarios de inmisión de $\mathrm{SO}_{2}(>75 \%$ del umbral permitido) en Coratxar en el año 2006. Fuente: RVVCCA.

\begin{tabular}{|c|c|c|c|c|c|c|c|c|}
\hline \multirow{2}{*}{ Fecha } & $\mathbf{S O}_{2}$ & Veloc. & Direc. & Temp. & H. Rel. & Pres. & R. Sol. & Precip. \\
\cline { 2 - 9 } & $\boldsymbol{\mu g} / \mathbf{m}^{\mathbf{3}}$ & $\mathbf{m} / \mathbf{s}$ & grados & ${ }^{\circ} \mathbf{C}$ & \% H.R. & $\mathbf{m b}$ & $\mathbf{W} / \mathbf{m}^{\mathbf{2}}$ & $\mathbf{1 / \mathbf { m } ^ { \mathbf { 2 } }}$ \\
\hline $01 / 02 / 2006$ & 146 & 3,6 & 233 & 8,5 & 47 & 878 & & 0 \\
\hline $07 / 02 / 2006$ & 103 & 1,4 & 175 & 7,2 & 36 & 879 & 190 & 0 \\
\hline
\end{tabular}


Tabla 55: Episodios diarios de inmisión de $\mathrm{SO}_{2}$ (> 75\% del umbral permitido) en Coratxar en el año 2007. Fuente: RVVCCA.

\begin{tabular}{|c|c|c|c|c|c|c|c|c|}
\hline \multirow{2}{*}{ Fecha } & $\mathbf{S O}_{\mathbf{2}}$ & Veloc. & Direc. & Temp. & H. Rel. & Pres. & R. Sol. & Precip. \\
\cline { 2 - 9 } & $\boldsymbol{\mu g} / \mathbf{m}^{3}$ & $\mathbf{m} / \mathbf{s}$ & grados & ${ }^{\circ} \mathbf{C}$ & \% H.R. & $\mathbf{m b}$ & $\mathbf{W} / \mathbf{m}^{\mathbf{2}}$ & $\mathbf{1 / \mathbf { m } ^ { \mathbf { 2 } }}$ \\
\hline $04 / 11 / 2007$ & 2,2 & 97 & 314 & 11,9 & 57 & 882 & 132 & 0 \\
\hline $30 / 11 / 2007$ & 4,6 & 132 & 291 & 6,2 & 78 & 878 & 103 & 0 \\
\hline $14 / 12 / 2007$ & 2,5 & 169 & 325 & 3,4 & 39 & 884 & 99 & 0 \\
\hline
\end{tabular}




\section{EXPORTACIÓN DE PROMEDIOS HORARIOS (2000-2015)}

ESTACIÓN: Vallibona CÓDIGO: 12127002

A continuación se detallan los episodios horarios de inmisión de $\mathrm{SO}_{2}$ que alcanzaron, al menos, el $75 \%$ del valor umbral $\left(350 \mu \mathrm{g} / \mathrm{m}^{3}\right)$ permitido por la legislación (Real Decreto 102/2011, BOE 29 de enero 2011 relativo a la mejora de la calidad del aire).

Tabla 56: Episodios horarios de inmisión de $\mathrm{SO}_{2}$ ( $>75 \%$ del umbral permitido) en Vallibona en el año 2000. Fuente: RVVCCA.

\begin{tabular}{|c|c|c|c|c|c|c|}
\hline \multirow{2}{*}{ Fecha } & \multirow{2}{*}{ Hora } & $\mathbf{S O}_{2}$ & Veloc. & Direc. & Temp. & H. Rel. \\
\cline { 3 - 7 } & & $\boldsymbol{\mu g} / \mathbf{m}^{\mathbf{3}}$ & $\mathbf{m} / \mathbf{s}$ & grados & ${ }^{\circ} \mathbf{C}$ & \% H.R. \\
\hline $05 / 01 / 2000$ & 2 & 777 & 6,1 & 298 & 2,9 & 48 \\
\hline $05 / 01 / 2000$ & 3 & 445 & 6,2 & 326 & 3 & 46 \\
\hline $05 / 01 / 2000$ & 4 & 442 & 5,1 & 333 & 2,8 & 55 \\
\hline $05 / 01 / 2000$ & 5 & 941 & 4 & 351 & 2,7 & 54 \\
\hline $05 / 01 / 2000$ & 8 & 641 & 3 & 218 & 3,6 & 44 \\
\hline $08 / 01 / 2000$ & 21 & 467 & 3,1 & 330 & 4,2 & 52 \\
\hline $08 / 01 / 2000$ & 22 & 441 & 2,4 & 329 & 3,9 & 60 \\
\hline $09 / 01 / 2000$ & 0 & 466 & 2,7 & 318 & 3,6 & 65 \\
\hline $10 / 01 / 2000$ & 11 & 338 & 4,9 & 277 & -1 & 81 \\
\hline $10 / 01 / 2000$ & 12 & 446 & 5,1 & 160 & $-0,7$ & 81 \\
\hline $10 / 01 / 2000$ & 22 & 287 & 6,6 & 221 & $-1,7$ & 71 \\
\hline $11 / 01 / 2000$ & 1 & 354 & 5,1 & 289 & $-2,3$ & 68 \\
\hline $11 / 01 / 2000$ & 2 & 378 & 5,6 & 324 & $-2,7$ & 68 \\
\hline $11 / 01 / 2000$ & 6 & 306 & 5,8 & 313 & $-3,6$ & 65 \\
\hline $11 / 01 / 2000$ & 7 & 1128 & 5 & 342 & $-3,3$ & 64 \\
\hline $11 / 01 / 2000$ & 8 & 274 & 5,5 & 339 & -3 & 64 \\
\hline $11 / 01 / 2000$ & 9 & 541 & 5,3 & 340 & $-2,6$ & 63 \\
\hline $12 / 01 / 2000$ & 1 & 571 & 3,5 & 7 & 0,1 & 57 \\
\hline $12 / 01 / 2000$ & 2 & 284 & 3,9 & 344 & 0,4 & 57 \\
\hline $12 / 01 / 2000$ & 3 & 308 & 3,9 & 332 & 0,4 & 58 \\
\hline $07 / 04 / 2000$ & 0 & 488 & 0,1 & 23 & 3,9 & 64 \\
\hline $07 / 04 / 2000$ & 2 & 305 & 0,3 & 173 & 3,9 & 65 \\
\hline $28 / 07 / 2000$ & 6 & 381 & 8,4 & 299 & 15,2 & 84 \\
\hline $17 / 09 / 2000$ & 5 & 283 & 5,1 & 130 & 14,3 & 84 \\
\hline $17 / 09 / 2000$ & 6 & 328 & 4,8 & 325 & 14 & 85 \\
\hline $18 / 09 / 2000$ & 3 & 391 & 4,7 & 42 & 12,5 & 89 \\
\hline $05 / 10 / 2000$ & 5 & 266 & 5,8 & 329 & 11,5 & 71 \\
\hline $05 / 10 / 2000$ & 6 & 458 & 6,2 & 331 & 11,2 & 77 \\
\hline
\end{tabular}




\begin{tabular}{|l|c|c|c|c|c|c|}
\hline $05 / 10 / 2000$ & 8 & 393 & 6,5 & 335 & 10,8 & 82 \\
\hline $05 / 10 / 2000$ & 9 & 384 & 5,6 & 304 & 12 & 78 \\
\hline $05 / 10 / 2000$ & 10 & 453 & 4,7 & 95 & 14,5 & 71 \\
\hline $05 / 10 / 2000$ & 11 & 270 & 4,1 & 203 & 15,4 & 68 \\
\hline $17 / 10 / 2000$ & 19 & 303 & 2,3 & 327 & 9,9 & 74 \\
\hline $17 / 10 / 2000$ & 20 & 553 & 1,7 & 320 & 10,3 & 69 \\
\hline $17 / 10 / 2000$ & 21 & 746 & 3 & 327 & 10,8 & 66 \\
\hline $28 / 10 / 2000$ & 0 & 313 & 5,5 & 269 & 12,3 & 79 \\
\hline $15 / 12 / 2000$ & 9 & 358 & 10,8 & 179 & 1,2 & 101 \\
\hline $16 / 12 / 2000$ & 12 & 272 & 7,4 & 221 & 2,4 & 82 \\
\hline
\end{tabular}

Tabla 57: Episodios horarios de inmisión de $\mathrm{SO}_{2}$ (> 75\% del umbral permitido) en Vallibona en el año 2001. Fuente: RVVCCA.

\begin{tabular}{|c|c|c|c|c|c|c|}
\hline \multirow{2}{*}{ Fecha } & \multirow{2}{*}{ Hora } & $\mathrm{SO}_{2}$ & Veloc. & Direc. & Temp. & H. Rel. \\
\hline & & $\mu g / m^{3}$ & $\mathrm{~m} / \mathrm{s}$ & grados & ${ }^{\circ} \mathrm{C}$ & \% H.R. \\
\hline $01 / 06 / 2001$ & 2 & 385 & 5 & 339 & 16 & 75 \\
\hline $01 / 06 / 2001$ & 3 & 492 & 3,8 & 342 & 15,6 & 74 \\
\hline $01 / 06 / 2001$ & 4 & 282 & 2,6 & 328 & 15,1 & 77 \\
\hline $03 / 07 / 2001$ & 8 & 342 & 4 & 107 & 21,5 & 47 \\
\hline $03 / 07 / 2001$ & 9 & 422 & 4,1 & 265 & 23,6 & 43 \\
\hline $03 / 07 / 2001$ & 10 & 296 & 1,7 & 173 & 26,1 & 38 \\
\hline $07 / 07 / 2001$ & 3 & 817 & 5 & 326 & 11 & 83 \\
\hline $07 / 07 / 2001$ & 4 & 515 & 5,5 & 308 & 11,2 & 84 \\
\hline $03 / 08 / 2001$ & 2 & 558 & 9 & 65 & 16 & 88 \\
\hline $03 / 08 / 2001$ & 3 & 463 & 7,8 & 65 & 15,6 & 88 \\
\hline $03 / 08 / 2001$ & 4 & 730 & 7,4 & 55 & 15,4 & 89 \\
\hline $03 / 08 / 2001$ & 8 & 289 & 5,1 & 39 & 16,8 & 78 \\
\hline $10 / 08 / 2001$ & 4 & 267 & 5,9 & 85 & 12,5 & 82 \\
\hline $10 / 08 / 2001$ & 5 & 294 & 5 & 222 & 12,3 & 82 \\
\hline $06 / 09 / 2001$ & 2 & 656 & 4,3 & 326 & 13,7 & 60 \\
\hline $06 / 09 / 2001$ & 10 & 383 & 2,9 & 291 & 15,4 & 69 \\
\hline $06 / 09 / 2001$ & 11 & 263 & 1,6 & 268 & 17,7 & 67 \\
\hline $12 / 09 / 2001$ & 6 & 271 & 3,8 & 337 & 12,2 & 47 \\
\hline $12 / 09 / 2001$ & 7 & 683 & 2,7 & 28 & 13,4 & 39 \\
\hline $12 / 09 / 2001$ & 8 & 314 & 2,2 & 277 & 14,4 & 42 \\
\hline $14 / 09 / 2001$ & 5 & 457 & 8,1 & 207 & 13 & 64 \\
\hline $14 / 09 / 2001$ & 6 & 332 & 8,1 & 222 & 12,2 & 76 \\
\hline $21 / 11 / 2001$ & 1 & 277 & 5,8 & 226 & 0,5 & 101 \\
\hline
\end{tabular}




\begin{tabular}{|c|c|c|c|c|c|c|}
\hline $21 / 11 / 2001$ & 5 & 328 & 4,1 & 210 & 0,4 & 101 \\
\hline $21 / 11 / 2001$ & 8 & 329 & 3,2 & 216 & 0,1 & 101 \\
\hline $21 / 11 / 2001$ & 9 & 336 & 2,2 & 159 & 1,7 & 91 \\
\hline $22 / 11 / 2001$ & 0 & 573 & 3,6 & 118 & 1,8 & 101 \\
\hline $28 / 11 / 2001$ & 12 & 285 & 9,3 & 125 & 3,9 & 78 \\
\hline $01 / 12 / 2001$ & 12 & 370 & 2,8 & 94 & 12,9 & 53 \\
\hline $16 / 12 / 2001$ & 2 & 448 & 9,1 & 346 & $-6,9$ & 100 \\
\hline $16 / 12 / 2001$ & 3 & 326 & 7,5 & 347 & $-7,2$ & 99 \\
\hline $16 / 12 / 2001$ & 8 & 297 & 7,7 & 346 & -7 & 88 \\
\hline
\end{tabular}

Tabla 58: Episodios horarios de inmisión de $\mathrm{SO}_{2}$ (> 75\% del umbral permitido) en Vallibona en el año 2002. Fuente: RVVCCA.

\begin{tabular}{|c|c|c|c|c|c|c|}
\hline \multirow{2}{*}{ Fecha } & \multirow{2}{*}{ Hora } & $\mathbf{S O}_{2}$ & Veloc. & Direc. & Temp. & H. Rel. \\
\cline { 3 - 7 } & & $\boldsymbol{\mu g} / \mathbf{m}^{\mathbf{3}}$ & $\mathbf{m} / \mathbf{s}$ & grados & ${ }^{\circ} \mathbf{C}$ & \% H.R. \\
\hline $12 / 01 / 2002$ & 4 & 365 & 2.3 & 169 & 3.8 & 80 \\
\hline $12 / 01 / 2002$ & 5 & 323 & 2.2 & 307 & 3.9 & 73 \\
\hline $12 / 01 / 2002$ & 6 & 545 & 2 & 304 & 4.2 & 64 \\
\hline $04 / 02 / 2002$ & 9 & 811 & 5.3 & 343 & 5.5 & 81 \\
\hline $13 / 02 / 2002$ & 7 & 291 & 3.8 & 333 & 9.4 & 58 \\
\hline $13 / 02 / 2002$ & 8 & 352 & 3.6 & 259 & 10.7 & 46 \\
\hline $25 / 02 / 2002$ & 2 & 306 & 6.8 & 305 & 4.1 & 89 \\
\hline $10 / 03 / 2002$ & 8 & 489 & 6.1 & 352 & 2.8 & 93 \\
\hline $10 / 03 / 2002$ & 9 & 423 & 3.3 & 352 & 4.6 & 85 \\
\hline $17 / 04 / 2002$ & 0 & 304 & 3.1 & 317 & 5.8 & 51 \\
\hline $17 / 04 / 2002$ & 1 & 347 & 3.7 & 349 & 6.3 & 51 \\
\hline $24 / 06 / 2002$ & 8 & 300 & 4.8 & 310 & 15.3 & 65 \\
\hline $01 / 07 / 2002$ & 22 & 332 & 4 & 112 & 16.1 & 61 \\
\hline $18 / 07 / 2002$ & 4 & 676 & 2.6 & 118 & 17.2 & 29 \\
\hline $30 / 07 / 2002$ & 7 & 461 & 5.9 & 194 & 16.3 & 61 \\
\hline $04 / 08 / 2002$ & 5 & 290 & 2.5 & 156 & 15.5 & 66 \\
\hline $29 / 08 / 2002$ & 23 & 350 & 6 & 65 & 13.7 & 66 \\
\hline $30 / 08 / 2002$ & 3 & 497 & 3.5 & 69 & 12.8 & 69 \\
\hline $30 / 08 / 2002$ & 4 & 812 & 2.1 & 63 & 13.3 & 65 \\
\hline $25 / 09 / 2002$ & 8 & 654 & 4.5 & & 5 & 59 \\
\hline $26 / 09 / 2002$ & 5 & 622 & 4.9 & & 7.5 & 42 \\
\hline $26 / 09 / 2002$ & 6 & 355 & 5.1 & & 7.5 & 42 \\
\hline $26 / 09 / 2002$ & 7 & 639 & 5.5 & & 9.2 & 31 \\
\hline $05 / 10 / 2002$ & 8 & 902 & 2.6 & 88 & 11.6 & 73 \\
\hline
\end{tabular}




\begin{tabular}{|c|c|c|c|c|c|c|}
\hline $11 / 11 / 2002$ & 14 & 296 & 6.7 & & 11.1 & 65 \\
\hline $25 / 11 / 2002$ & 18 & 288 & 11.4 & 325 & 3.4 & 90 \\
\hline
\end{tabular}

Tabla 59: Episodios horarios de inmisión de $\mathrm{SO}_{2}$ (> 75\% del umbral permitido) en Vallibona en el año 2003. Fuente: RVVCCA.

\begin{tabular}{|c|c|c|c|c|c|c|}
\hline \multirow{2}{*}{ Fecha } & \multirow{2}{*}{ Hora } & $\mathrm{SO}_{2}$ & Veloc. & Direc. & Temp. & H. Rel. \\
\hline & & $\mu \mathrm{g} / \mathrm{m}^{3}$ & $\mathrm{~m} / \mathrm{s}$ & grados & ${ }^{\circ} \mathrm{C}$ & \% H.R. \\
\hline $13 / 01 / 2003$ & 23 & 411 & 8.3 & 310 & -3.4 & 58 \\
\hline $14 / 01 / 2003$ & 1 & 493 & 8.4 & 311 & -3.3 & 50 \\
\hline $14 / 01 / 2003$ & 9 & 435 & 4.7 & 310 & -.4 & 34 \\
\hline $14 / 01 / 2003$ & 10 & 505 & 3.9 & 310 & 0.2 & 34 \\
\hline $14 / 01 / 2003$ & 11 & 291 & 3.9 & 322 & 0.9 & 34 \\
\hline $07 / 02 / 2003$ & 0 & 343 & 4.4 & 294 & 0.8 & 90 \\
\hline $07 / 02 / 2003$ & 2 & 396 & 3.3 & 304 & 0.8 & 93 \\
\hline $07 / 02 / 2003$ & 3 & 292 & 2.4 & 300 & 0.7 & 92 \\
\hline $07 / 02 / 2003$ & 5 & 263 & 3.1 & 212 & 0.4 & 94 \\
\hline $09 / 02 / 2003$ & 5 & 443 & 5.6 & 310 & 2.2 & 65 \\
\hline $24 / 09 / 2003$ & 9 & 354 & 0.5 & 305 & 15.9 & 65 \\
\hline $07 / 10 / 2003$ & 6 & 296 & 7.7 & 319 & 4.9 & 85 \\
\hline $25 / 10 / 2003$ & 2 & 306 & 5.5 & 312 & -.7 & 54 \\
\hline $25 / 10 / 2003$ & 6 & 383 & 2.4 & 332 & 0.5 & 35 \\
\hline $07 / 11 / 2003$ & 9 & 585 & 4.6 & 316 & 12.6 & 24 \\
\hline $18 / 11 / 2003$ & 9 & 515 & 5.1 & 316 & 4.5 & 59 \\
\hline $18 / 11 / 2003$ & 10 & 332 & 5.7 & 320 & 4.4 & 62 \\
\hline $16 / 12 / 2003$ & 6 & 272 & 4.7 & 311 & 2.9 & 50 \\
\hline $16 / 12 / 2003$ & 7 & 299 & 4.6 & 308 & 3.6 & 41 \\
\hline
\end{tabular}

Tabla 60: Episodios horarios de inmisión de $\mathrm{SO}_{2}$ (> 75\% del umbral permitido) en Vallibona en el año 2004. Fuente: RVVCCA.

\begin{tabular}{|c|c|c|c|c|c|c|}
\hline \multirow{2}{*}{ Fecha } & \multirow{2}{*}{ Hora } & $\mathbf{S O}_{\mathbf{2}}$ & Veloc. & Direc. & Temp. & H. Rel. \\
\cline { 3 - 7 } & & $\boldsymbol{\mu g} / \mathbf{m}^{\mathbf{3}}$ & $\mathbf{m} / \mathbf{s}$ & grados & ${ }^{\circ} \mathbf{C}$ & \% H.R. \\
\hline $06 / 01 / 2004$ & 19 & 364 & & 153 & 9,5 & 27 \\
\hline $06 / 01 / 2004$ & 20 & 395 & & 28 & 9,4 & 27 \\
\hline $03 / 02 / 2004$ & 21 & 860 & 2,6 & 298 & 8,7 & 74 \\
\hline $03 / 02 / 2004$ & 22 & 794 & 2,1 & 306 & 8,6 & 74 \\
\hline $04 / 02 / 2004$ & 7 & 590 & 3,4 & 311 & 9 & 77 \\
\hline $09 / 02 / 2004$ & 6 & 687 & 6,9 & 318 & $-0,2$ & 87 \\
\hline $09 / 02 / 2004$ & 7 & 876 & 6,6 & 315 & $-0,1$ & 83 \\
\hline
\end{tabular}




\begin{tabular}{|c|c|c|c|c|c|c|}
\hline $13 / 02 / 2004$ & 5 & 368 & 2,2 & 318 & 5 & 62 \\
\hline $14 / 02 / 2004$ & 21 & 264 & 3 & 327 & 6,4 & 54 \\
\hline $18 / 02 / 2004$ & 3 & 289 & 5,9 & 325 & -2 & 96 \\
\hline $03 / 03 / 2004$ & 5 & 601 & 6,7 & 313 & $-0,5$ & 42 \\
\hline $03 / 03 / 2004$ & 7 & 376 & 5,2 & 310 & 0 & 39 \\
\hline $03 / 03 / 2004$ & 8 & 458 & 4,2 & 314 & 2 & 35 \\
\hline $03 / 03 / 2004$ & 10 & 493 & 3,5 & 298 & 4,4 & 32 \\
\hline $09 / 03 / 2004$ & 5 & 309 & 2,9 & 315 & $-0,1$ & 70 \\
\hline $09 / 03 / 2004$ & 6 & 539 & 1,2 & 327 & 0,7 & 65 \\
\hline $12 / 06 / 2004$ & 7 & 419 & 1,9 & 313 & 19,4 & 63 \\
\hline $01 / 07 / 2004$ & 5 & 286 & 5,9 & 326 & 13,5 & 85 \\
\hline $01 / 07 / 2004$ & 6 & 361 & 5,9 & 320 & 14,7 & 78 \\
\hline $30 / 09 / 2004$ & 11 & 266 & & 22 & 23,2 & 46 \\
\hline $06 / 11 / 2004$ & 4 & 281 & & 315 & 4,9 & 100 \\
\hline $12 / 11 / 2004$ & 7 & 267 & & 315 & & 99 \\
\hline $23 / 11 / 2004$ & 6 & 324 & & 330 & 7,8 & 68 \\
\hline $23 / 11 / 2004$ & 8 & 285 & & 310 & 8,4 & 58 \\
\hline $23 / 11 / 2004$ & 20 & 266 & & 319 & 6,1 & 68 \\
\hline $23 / 11 / 2004$ & 21 & 559 & & 317 & 6,1 & 70 \\
\hline $23 / 11 / 2004$ & 22 & 1150 & & 307 & 6,2 & 77 \\
\hline $23 / 11 / 2004$ & 23 & 272 & & 307 & 7,6 & 67 \\
\hline $26 / 11 / 2004$ & 18 & 386 & & 319 & 6,6 & 71 \\
\hline $26 / 11 / 2004$ & 19 & 377 & & 304 & 6,6 & 66 \\
\hline $27 / 11 / 2004$ & 1 & 1450 & & 303 & 5,6 & 79 \\
\hline $24 / 12 / 2004$ & 5 & 371 & & 319 & 2,4 & 100 \\
\hline
\end{tabular}

Tabla 61: Episodios horarios de inmisión de $\mathrm{SO}_{2}$ ( $>75 \%$ del umbral permitido) en Vallibona en el año 2005. Fuente: RVVCCA.

\begin{tabular}{|c|c|c|c|c|c|c|}
\hline \multirow{2}{*}{ Fecha } & \multirow{2}{*}{ Hora } & $\mathbf{S O}_{2}$ & Veloc. & Direc. & Temp. & H. Rel. \\
\cline { 3 - 7 } & & $\boldsymbol{\mu g} / \mathbf{m}^{\mathbf{3}}$ & $\mathbf{m} / \mathbf{s}$ & grados & ${ }^{\circ} \mathbf{C}$ & \% H.R. \\
\hline $07 / 01 / 2005$ & 6 & 336 & & 313 & 4,1 & 92 \\
\hline $07 / 01 / 2005$ & 7 & 388 & & 298 & 4,8 & 78 \\
\hline $08 / 01 / 2005$ & 23 & 591 & & 323 & 7,6 & 28 \\
\hline $09 / 01 / 2005$ & 0 & 619 & & 357 & 7,5 & 28 \\
\hline $10 / 01 / 2005$ & 20 & 263 & & 325 & 7 & 18 \\
\hline $10 / 01 / 2005$ & 21 & 295 & & 320 & 7,2 & 13 \\
\hline $11 / 01 / 2005$ & 3 & 430 & & 321 & 5,2 & 19 \\
\hline $17 / 01 / 2005$ & 0 & 402 & & 299 & 6,5 & 69 \\
\hline
\end{tabular}




\begin{tabular}{|c|c|c|c|c|c|c|}
\hline $10 / 02 / 2005$ & 7 & 480 & & 313 & 1,4 & 82 \\
\hline $18 / 05 / 2005$ & 23 & 309 & & 284 & 8,1 & 77 \\
\hline $19 / 05 / 2005$ & 8 & 573 & & 285 & 13,6 & 47 \\
\hline $14 / 08 / 2005$ & 4 & 291 & 2,6 & 250 & 25 & 31 \\
\hline $16 / 09 / 2005$ & 4 & 486 & 6 & 288 & 22,3 & 49 \\
\hline $21 / 09 / 2005$ & 2 & 290 & 9 & 309 & 15,3 & 65 \\
\hline $06 / 11 / 2005$ & 5 & 305 & 15,1 & 295 & 10,6 & 63 \\
\hline $07 / 12 / 2005$ & 8 & 271 & & & 7,8 & 88 \\
\hline $19 / 12 / 2005$ & 2 & 370 & 3,7 & 52 & 7,1 & 81 \\
\hline
\end{tabular}

Tabla 62: Episodios horarios de inmisión de $\mathrm{SO}_{2}$ (> 75\% del umbral permitido) en Vallibona en el año 2006. Fuente: RVVCCA.

\begin{tabular}{|c|c|c|c|c|c|c|}
\hline \multirow{2}{*}{ Fecha } & \multirow{2}{*}{ Hora } & $\mathbf{S O}_{\mathbf{2}}$ & Veloc. & Direc. & Temp. & H. Rel. \\
\cline { 3 - 7 } & & $\boldsymbol{\mu g} / \mathbf{m}^{\mathbf{3}}$ & $\mathbf{m} / \mathbf{s}$ & grados & ${ }^{\circ} \mathbf{C}$ & \% H.R. \\
\hline $26 / 01 / 2006$ & 10 & 382 & 3 & 301 & 6,2 & 89 \\
\hline $26 / 01 / 2006$ & 11 & 297 & 2,4 & 308 & 7,1 & 80 \\
\hline $29 / 01 / 2006$ & 11 & 350 & 3,7 & 285 & 4,5 & 60 \\
\hline $01 / 02 / 2006$ & 2 & 269 & 2,4 & 276 & 10,9 & 76 \\
\hline $03 / 02 / 2006$ & 0 & 296 & 1,9 & 311 & 12,1 & 70 \\
\hline $03 / 02 / 2006$ & 1 & 707 & 1,9 & 311 & 12,5 & 64 \\
\hline $07 / 02 / 2006$ & 3 & 299 & 3,9 & 297 & 7,4 & 64 \\
\hline $07 / 02 / 2006$ & 4 & 288 & 4 & 295 & 7,2 & 65 \\
\hline $15 / 02 / 2006$ & 4 & 272 & 2,1 & 278 & 11 & 63 \\
\hline $23 / 02 / 2006$ & 9 & 354 & 3,7 & 296 & 5,5 & 97 \\
\hline $15 / 03 / 2006$ & 23 & 295 & 1,2 & 299 & 16,5 & 34 \\
\hline $27 / 09 / 2006$ & 22 & 362 & & & 17,9 & 36 \\
\hline $10 / 11 / 2006$ & 20 & 345 & & 346 & 12,3 & 72 \\
\hline
\end{tabular}

Tabla 63: Episodios horarios de inmisión de $\mathrm{SO}_{2}(>75 \%$ del umbral permitido) en Vallibona en el año 2007. Fuente: RVVCCA.

\begin{tabular}{|c|c|c|c|c|c|c|}
\hline \multirow{2}{*}{ Fecha } & \multirow{2}{*}{ Hora } & $\mathbf{S O}_{2}$ & Veloc. & Direc. & Temp. & H. Rel. \\
\cline { 3 - 7 } & & $\boldsymbol{\mu g} / \mathbf{m}^{\mathbf{3}}$ & $\mathbf{m} / \mathbf{s}$ & grados & ${ }^{\circ} \mathbf{C}$ & \% H.R. \\
\hline $28 / 01 / 2007$ & 4 & 538 & 2,8 & 321 & $-4,2$ & 77 \\
\hline $28 / 01 / 2007$ & 5 & 312 & 2,2 & 325 & $-3,7$ & 73 \\
\hline $31 / 07 / 2007$ & 6 & 287 & 2,7 & 336 & 20,5 & 22 \\
\hline $17 / 08 / 2007$ & 6 & 310 & 5 & 335 & 10,1 & 67 \\
\hline $14 / 12 / 2007$ & 8 & 497 & 4,2 & 338 & 0,4 & 50 \\
\hline $14 / 12 / 2007$ & 11 & 269 & 4,4 & 337 & 2,1 & 42 \\
\hline
\end{tabular}




\section{EXPORTACIÓN DE PROMEDIOS DIARIOS (2000-2015)}

ESTACIÓN: Vallibona CÓDIGO: 12127002

A continuación se detallan los episodios diarios de inmisión de $\mathrm{SO}_{2}$ que alcanzaron, al menos, el $75 \%$ del valor umbral $\left(125 \mu \mathrm{g} / \mathrm{m}^{3}\right)$ permitido por la legislación (Real Decreto 102/2011, BOE 29 de enero 2011 relativo a la mejora de la calidad del aire).

Tabla 64: Episodios diarios de inmisión de $\mathrm{SO}_{2}$ (> 75\% del umbral permitido) en Vallibona en el año 2000. Fuente: RVVCCA.

\begin{tabular}{|c|c|c|c|c|c|}
\hline \multirow{2}{*}{ Fecha } & $\mathbf{S O}_{2}$ & Veloc. & Direc. & Temp. & H. Rel. \\
\cline { 2 - 6 } & $\boldsymbol{\mu g} / \mathbf{m}^{\mathbf{3}}$ & $\mathbf{m} / \mathbf{s}$ & grados & ${ }^{\circ} \mathbf{C}$ & \% H.R. \\
\hline $05 / 01 / 2000$ & 159 & 3,8 & 254 & 5,1 & 48 \\
\hline $10 / 01 / 2000$ & 101 & 5,6 & 226 & $-1,1$ & 78 \\
\hline $11 / 01 / 2000$ & 155 & 3,1 & 330 & $-0,1$ & 57 \\
\hline $12 / 01 / 2000$ & 98 & 4,7 & 325 & 2 & 51 \\
\hline $05 / 10 / 2000$ & 140 & 5 & 285 & 13,6 & 72 \\
\hline $17 / 10 / 2000$ & 131 & 4,5 & 297 & 9,6 & 73 \\
\hline
\end{tabular}

Tabla 65: Episodios diarios de inmisión de $\mathrm{SO}_{2}$ (> 75\% del umbral permitido) en Vallibona en el año 2001. Fuente: RVVCCA.

\begin{tabular}{|c|c|c|c|c|c|}
\hline \multirow{2}{*}{ Fecha } & $\mathbf{S O}_{2}$ & Veloc. & Direc. & Temp. & H. Rel. \\
\cline { 2 - 6 } & $\boldsymbol{\mu g} / \mathbf{m}^{\mathbf{3}}$ & $\mathbf{m} / \mathbf{s}$ & grados & ${ }^{\circ} \mathbf{C}$ & \% H.R. \\
\hline $03 / 08 / 2001$ & 119 & 3,8 & 121 & 18,7 & 79 \\
\hline $06 / 09 / 2001$ & 124 & 4,4 & 297 & 14,9 & 65 \\
\hline $12 / 09 / 2001$ & 106 & 2,8 & 222 & 16,2 & 73 \\
\hline $21 / 11 / 2001$ & 136 & 2,6 & 162 & 2,4 & 95 \\
\hline $22 / 11 / 2001$ & 99 & 5,3 & 172 & 1,8 & 89 \\
\hline
\end{tabular}

Tabla 66: Episodios diarios de inmisión de $\mathrm{SO}_{2}$ (> 75\% del umbral permitido) en Vallibona en el año 2002. Fuente: RVVCCA.

\begin{tabular}{|c|c|c|c|c|c|}
\hline \multirow{2}{*}{ Fecha } & $\mathbf{S O}_{2}$ & Veloc. & Direc. & Temp. & H. Rel. \\
\cline { 2 - 6 } & $\boldsymbol{\mu g} / \mathrm{m}^{3}$ & $\mathrm{~m} / \mathrm{s}$ & grados & ${ }^{\circ} \mathbf{C}$ & $\%$ H.R. \\
\hline $26 / 09 / 2002$ & 115 & 4.3 & & 12.1 & 41 \\
\hline
\end{tabular}

Tabla 67: Episodios diarios de inmisión de $\mathrm{SO}_{2}$ (> 75\% del umbral permitido) en Vallibona en el año 2003. Fuente: RVVCCA.

\begin{tabular}{|c|c|c|c|c|c|}
\hline \multirow{2}{*}{ Fecha } & $\mathbf{S O}_{2}$ & Veloc. & Direc. & Temp. & H. Rel. \\
\cline { 2 - 6 } & $\boldsymbol{\mu g} / \mathbf{m}^{\mathbf{3}}$ & $\mathbf{m} / \mathbf{s}$ & grados & ${ }^{\circ} \mathbf{C}$ & \% H.R. \\
\hline $14 / 01 / 2003$ & 157 & 3.3 & 335 & 1.4 & 36 \\
\hline $17 / 11 / 2003$ & 96 & 7.6 & 319 & 2.5 & 96 \\
\hline
\end{tabular}


Tabla 68: Episodios diarios de inmisión de $\mathrm{SO}_{2}$ (> 75\% del umbral permitido) en Vallibona en el año 2004. Fuente: RVVCCA.

\begin{tabular}{|c|c|c|c|c|c|}
\hline \multirow{2}{*}{ Fecha } & $\mathbf{S O}_{2}$ & Veloc. & Direc. & Temp. & H. Rel. \\
\cline { 2 - 6 } & $\boldsymbol{\mu g} / \mathbf{m}^{\mathbf{3}}$ & $\mathbf{m} / \mathbf{s}$ & grados & ${ }^{\circ} \mathbf{C}$ & \% H.R. \\
\hline $03 / 02 / 2004$ & 106 & 2,7 & 301 & 9,1 & 67 \\
\hline $03 / 03 / 2004$ & 123 & 5,8 & 315 & 4 & 38 \\
\hline $23 / 11 / 2004$ & 157 & & 315 & 9,1 & 60 \\
\hline
\end{tabular}

Tabla 69: Episodios diarios de inmisión de $\mathrm{SO}_{2}$ (> 75\% del umbral permitido) en Vallibona en el año 2005. Fuente: RVVCCA.

\begin{tabular}{|c|c|c|c|c|c|}
\hline \multirow{2}{*}{ Fecha } & $\mathbf{S O}_{2}$ & Veloc. & Direc. & Temp. & H. Rel. \\
\cline { 2 - 6 } & $\boldsymbol{\mu g} / \mathrm{m}^{3}$ & $\mathrm{~m} / \mathrm{s}$ & grados & ${ }^{\circ} \mathbf{C}$ & $\%$ H.R. \\
\hline $11 / 01 / 2005$ & 95 & & 184 & 7,4 & 24 \\
\hline
\end{tabular}




\section{EXPORTACIÓN DE PROMEDIOS HORARIOS (2000-2015)}

ESTACIÓN: Morella CÓDIGO: 12080007

A continuación se detallan los episodios horarios de inmisión de $\mathrm{SO}_{2}$ que alcanzaron, al menos, el $75 \%$ del valor umbral $\left(350 \mu \mathrm{g} / \mathrm{m}^{3}\right)$ permitido por la legislación (Real Decreto 102/2011, BOE 29 de enero 2011 relativo a la mejora de la calidad del aire).

Tabla 70: Episodios horarios de inmisión de $\mathrm{SO}_{2}$ ( $>75 \%$ del umbral permitido) en Morella en el año 2000. Fuente: RVVCCA.

\begin{tabular}{|c|c|c|c|c|c|c|c|c|c|}
\hline \multirow{2}{*}{ Fecha } & \multirow{2}{*}{ Hora } & $\mathbf{S O}_{2}$ & Veloc. & Direc. & Temp. & H. Rel. & Pres. & R. Sol. & Precip. \\
\cline { 3 - 11 } & & $\boldsymbol{\mu g} / \mathbf{m}^{\mathbf{3}}$ & $\mathbf{m} / \mathbf{s}$ & grados & ${ }^{\circ} \mathbf{C}$ & $\mathbf{\%}$ H.R. & $\mathbf{m b}$ & $\mathbf{W} / \mathbf{m}^{\mathbf{2}}$ & $\mathbf{1 / \mathbf { m } ^ { \mathbf { 2 } }}$ \\
\hline $08 / 01 / 2000$ & 14 & 309 & 3 & 302 & 6,6 & 64 & 885 & 278 & 0 \\
\hline $17 / 09 / 2000$ & 5 & 516 & 6,5 & 336 & 15,8 & 76 & 880 & 0 & 0 \\
\hline $05 / 10 / 2000$ & 10 & 382 & 4,4 & 328 & 13,7 & 72 & 885 & 507 & 0 \\
\hline
\end{tabular}

Tabla 71: Episodios horarios de inmisión de $\mathrm{SO}_{2}$ (> 75\% del umbral permitido) en Morella en el año 2001. Fuente: RVVCCA.

\begin{tabular}{|c|c|c|c|c|c|c|c|c|c|}
\hline \multirow{2}{*}{ Fecha } & \multirow{2}{*}{ Hora } & $\mathbf{S O}_{2}$ & Veloc. & Direc. & Temp. & H. Rel. & Pres. & R. Sol. & Precip. \\
\cline { 3 - 12 } & & $\boldsymbol{\mu g} / \mathbf{m}^{3}$ & $\mathbf{m} / \mathbf{s}$ & grados & ${ }^{\circ} \mathbf{C}$ & \% H.R. & $\mathbf{m b}$ & $\mathbf{W} / \mathbf{m}^{\mathbf{2}}$ & $\mathbf{1 / \mathbf { m } ^ { \mathbf { 2 } }}$ \\
\hline $01 / 06 / 2001$ & 0 & 352 & 8,3 & 345 & 17,8 & 69 & 885 & 0 & 0 \\
\hline $01 / 06 / 2001$ & 1 & 510 & 6,2 & 334 & 17,1 & 71 & 885 & 0 & 0 \\
\hline $01 / 06 / 2001$ & 2 & 440 & 4,2 & 328 & 16,6 & 70 & 884 & 0 & 0 \\
\hline $27 / 06 / 2001$ & 8 & 321 & 7,4 & 325 & 14,3 & 81 & 881 & 362 & 0 \\
\hline $05 / 08 / 2001$ & 4 & 270 & 3,3 & 342 & 15,4 & 55 & 889 & 0 & 0 \\
\hline $05 / 08 / 2001$ & 5 & 273 & 4,4 & 333 & 15,2 & 57 & 889 & 0 & 0 \\
\hline $05 / 08 / 2001$ & 7 & 503 & 1,5 & 338 & 15,3 & 65 & 889 & 148 & 0 \\
\hline $05 / 08 / 2001$ & 8 & 344 & 0,3 & 331 & 16,6 & 64 & 889 & 377 & 0 \\
\hline $06 / 08 / 2001$ & 5 & 263 & 6 & 345 & 16,4 & 66 & 889 & 0 & 0 \\
\hline $06 / 08 / 2001$ & 7 & 427 & 8 & 343 & 15,4 & 80 & 889 & 150 & 0 \\
\hline $09 / 08 / 2001$ & 23 & 301 & 9,9 & & 16,5 & 66 & 886 & 0 & 0 \\
\hline $06 / 09 / 2001$ & 2 & 740 & 2,5 & 1 & 14,7 & 54 & 883 & 0 & 0 \\
\hline $06 / 09 / 2001$ & 3 & 552 & 0,6 & 290 & 14,4 & 54 & 882 & 0 & 0 \\
\hline $06 / 09 / 2001$ & 4 & 270 & 1,6 & 333 & 13,8 & 55 & 882 & 0 & 0 \\
\hline $06 / 09 / 2001$ & 9 & 301 & 4,3 & 324 & 12,9 & 74 & 882 & 469 & 0 \\
\hline $12 / 09 / 2001$ & 7 & 513 & 3,4 & 335 & 13,4 & 41 & 884 & 115 & 0 \\
\hline $04 / 10 / 2001$ & 3 & 413 & 3 & 1 & 11,4 & 97 & 883 & 0 & 0 \\
\hline $04 / 10 / 2001$ & 4 & 359 & 1 & 352 & 11,5 & 96 & 883 & 0 & 0 \\
\hline
\end{tabular}




\begin{tabular}{|c|c|c|c|c|c|c|c|c|c|}
\hline \multirow{2}{*}{ Fecha } & \multirow{2}{*}{ Hora } & $\mathbf{S O}_{2}$ & Veloc. & Direc. & Temp. & H. Rel. & Pres. & R. Sol. & Precip. \\
\cline { 3 - 11 } & & $\boldsymbol{\mu g} / \mathbf{m}^{\mathbf{3}}$ & $\mathbf{m} / \mathbf{s}$ & grados & ${ }^{\mathbf{C}}$ & $\mathbf{\%} \mathbf{H . R}$. & $\mathbf{m b}$ & $\mathbf{W} / \mathbf{m}^{\mathbf{2}}$ & $\mathbf{1 / \mathbf { m } ^ { \mathbf { 2 } }}$ \\
\hline $09 / 03 / 2002$ & 10 & 292 & 6.3 & 323 & 5.4 & 83 & 882 & 259 & 0 \\
\hline $09 / 03 / 2002$ & 11 & 469 & 5 & 318 & 6.6 & 76 & 882 & 450 & 0 \\
\hline $09 / 03 / 2002$ & 12 & 339 & 4.5 & 324 & 8.2 & 69 & 883 & 589 & 0 \\
\hline $09 / 03 / 2002$ & 13 & 287 & 4 & 341 & 10.1 & 63 & 883 & 663 & 0 \\
\hline $10 / 03 / 2002$ & 9 & 313 & 5.2 & 345 & 3.9 & 82 & 880 & 147 & 0 \\
\hline $24 / 06 / 2002$ & 2 & 310 & 6 & 359 & 16.8 & 68 & 884 & 0 & 0 \\
\hline $24 / 06 / 2002$ & 3 & 366 & 8.1 & 352 & 15.7 & 71 & 884 & 0 & 0 \\
\hline $24 / 06 / 2002$ & 4 & 378 & 8.8 & 353 & 14.8 & 74 & 884 & 0 & 0 \\
\hline $24 / 06 / 2002$ & 5 & 341 & 9.7 & 345 & 14.1 & 76 & 884 & 1 & 0 \\
\hline $24 / 06 / 2002$ & 9 & 323 & 3.4 & 314 & 16 & 69 & 885 & 533 & 0 \\
\hline
\end{tabular}

Tabla 73: Episodios horarios de inmisión de $\mathrm{SO}_{2}$ (> 75\% del umbral permitido) en Morella en el año 2003. Fuente: RVVCCA.

\begin{tabular}{|c|c|c|c|c|c|c|c|c|c|}
\hline \multirow{2}{*}{ Fecha } & \multirow{2}{*}{ Hora } & $\mathbf{S O}_{2}$ & Veloc. & Direc. & Temp. & H. Rel. & Pres. & R. Sol. & Precip. \\
\cline { 3 - 11 } & & $\boldsymbol{\mu g} / \mathbf{m}^{\mathbf{3}}$ & $\mathbf{m} / \mathbf{s}$ & grados & ${ }^{\circ} \mathbf{C}$ & \% H.R. & $\mathbf{m b}$ & $\mathbf{W} / \mathbf{m}^{\mathbf{2}}$ & $\mathbf{1 / \mathbf { m } ^ { \mathbf { 2 } }}$ \\
\hline $14 / 01 / 2003$ & 9 & 334 & 2.5 & 342 & -.4 & 23 & 889 & 131 & 0 \\
\hline $14 / 01 / 2003$ & 10 & 472 & 1.2 & 334 & 0.3 & 25 & 890 & 261 & 0 \\
\hline $14 / 01 / 2003$ & 11 & 389 & 0.5 & 333 & 2.2 & 24 & 890 & 356 & 0 \\
\hline $05 / 09 / 2003$ & 21 & 296 & 2.9 & 314 & 18.1 & 49 & 887 & 0 & 0 \\
\hline $24 / 09 / 2003$ & 8 & 333 & 1.3 & 337 & 12.1 & 65 & 885 & 195 & 0 \\
\hline $16 / 12 / 2003$ & 8 & 305 & 1 & 334 & 5 & 46 & 882 & 16 & 0 \\
\hline $16 / 12 / 2003$ & 9 & 329 & 1.4 & 291 & 6.2 & 44 & 882 & 120 & 0 \\
\hline
\end{tabular}

Tabla 74: Episodios horarios de inmisión de $\mathrm{SO}_{2}$ (> 75\% del umbral permitido) en Morella en el año 2004. Fuente: RVVCCA.

\begin{tabular}{|c|c|c|c|c|c|c|c|c|c|}
\hline \multirow{2}{*}{ Fecha } & \multirow{2}{*}{ Hora } & $\mathbf{S O}_{2}$ & Veloc. & Direc. & Temp. & H. Rel. & Pres. & R. Sol. & Precip. \\
\cline { 3 - 11 } & & $\boldsymbol{\mu g} / \mathbf{m}^{\mathbf{3}}$ & $\mathbf{m} / \mathbf{s}$ & grados & ${ }^{\circ} \mathbf{C}$ & \% H.R. & $\mathbf{m b}$ & $\mathbf{W} / \mathbf{m}^{\mathbf{2}}$ & $\mathbf{1 / \mathbf { m } ^ { \mathbf { 2 } }}$ \\
\hline $06 / 01 / 2004$ & 19 & 332 & 1,7 & 7 & 10,7 & 23 & 882 & 0 & 0 \\
\hline $11 / 02 / 2004$ & 10 & 267 & 4,7 & 321 & 8,5 & 27 & 886 & 350 & 0 \\
\hline $14 / 02 / 2004$ & 19 & 301 & 5,3 & 353 & 8,7 & 48 & 882 & 0 & 0 \\
\hline $03 / 03 / 2004$ & 9 & 507 & 5,5 & 328 & 2,9 & 36 & 885 & 305 & 0 \\
\hline $31 / 05 / 2004$ & 7 & 283 & 4,1 & 330 & 13 & 85 & 884 & 100 & 0 \\
\hline $02 / 07 / 2004$ & 2 & 362 & 4,1 & 348 & 15,9 & 66 & 884 & 0 & 0 \\
\hline $02 / 07 / 2004$ & 5 & 281 & 4,7 & 347 & 13,5 & 72 & 883 & 1 & 0 \\
\hline $17 / 10 / 2004$ & 2 & 367 & 3,4 & 298 & 6,6 & 82 & 874 & 0 & 0 \\
\hline
\end{tabular}




\begin{tabular}{|c|c|c|c|c|c|c|c|c|c|}
\hline $12 / 11 / 2004$ & 7 & 273 & 6,7 & 318 & 1,2 & 96 & 873 & 0 & 0 \\
\hline $21 / 11 / 2004$ & 4 & 1027 & 0,1 & 339 & 11,3 & 55 & 884 & 0 & 0 \\
\hline $21 / 11 / 2004$ & 5 & 1293 & 0,1 & 332 & 10,9 & 57 & 884 & 0 & 0 \\
\hline $21 / 11 / 2004$ & 6 & 585 & 0,1 & 282 & 10,7 & 56 & 884 & 0 & 0 \\
\hline $21 / 11 / 2004$ & 7 & 442 & 0,1 & 253 & 10,8 & 56 & 884 & 0 & 0 \\
\hline $21 / 11 / 2004$ & 8 & 964 & 0,1 & 171 & 11,6 & 53 & 885 & 35 & 0 \\
\hline $21 / 11 / 2004$ & 9 & 867 & 1 & 146 & 12,9 & 51 & 885 & 148 & 0 \\
\hline $23 / 11 / 2004$ & 17 & 298 & 1,8 & 300 & 10 & 64 & 886 & 18 & 0 \\
\hline $23 / 11 / 2004$ & 18 & 483 & 5 & 339 & 8 & 68 & 886 & 0 & 0 \\
\hline $23 / 11 / 2004$ & 19 & 1030 & 5 & 340 & 7,8 & 72 & 886 & 0 & 0 \\
\hline $23 / 11 / 2004$ & 20 & 839 & 3,8 & 338 & 7,5 & 69 & 886 & 0 & 0 \\
\hline $23 / 11 / 2004$ & 21 & 531 & 3,4 & 331 & 7,6 & 72 & 887 & 0 & 0 \\
\hline $26 / 11 / 2004$ & 18 & 943 & 4,3 & 350 & 8 & 66 & 887 & 0 & 0 \\
\hline $26 / 11 / 2004$ & 19 & 339 & 5,1 & 329 & 7,9 & 56 & 887 & 0 & 0 \\
\hline
\end{tabular}

Tabla 75: Episodios horarios de inmisión de $\mathrm{SO}_{2}$ (> 75\% del umbral permitido) en Morella en el año 2005. Fuente: RVVCCA.

\begin{tabular}{|c|c|c|c|c|c|c|c|c|c|}
\hline \multirow{2}{*}{ Fecha } & \multirow{2}{*}{ Hora } & $\mathbf{S O}_{2}$ & Veloc. & Direc. & Temp. & H. Rel. & Pres. & R. Sol. & Precip. \\
\cline { 3 - 11 } & & $\boldsymbol{\mu g} / \mathbf{m}^{3}$ & $\mathbf{m} / \mathbf{s}$ & grados & ${ }^{\circ} \mathbf{C}$ & \% H.R. & $\mathbf{m b}$ & $\mathbf{W} / \mathbf{m}^{2}$ & $\mathbf{1 / \mathbf { m } ^ { 2 }}$ \\
\hline $08 / 01 / 2005$ & 21 & 284 & & 35 & 9,2 & 22 & 891 & 0 & 0 \\
\hline $04 / 02 / 2005$ & 4 & 266 & & 338 & 0,1 & 90 & 881 & 0 & 0 \\
\hline $01 / 07 / 2005$ & 3 & 289 & 10,2 & 340 & 14,4 & 83 & 881 & 0 & 0 \\
\hline $21 / 12 / 2005$ & 16 & 289 & 3,6 & 330 & 8,1 & 43 & 886 & 110 & 0 \\
\hline
\end{tabular}

Tabla 76: Episodios horarios de inmisión de $\mathrm{SO}_{2}$ (> 75\% del umbral permitido) en Morella en el año 2006. Fuente: RVVCCA.

\begin{tabular}{|c|c|c|c|c|c|c|c|c|c|}
\hline \multirow{2}{*}{ Fecha } & \multirow{2}{*}{ Hora } & $\mathbf{S O}_{2}$ & Veloc. & Direc. & Temp. & H. Rel. & Pres. & R. Sol. & Precip. \\
\cline { 3 - 11 } & & $\boldsymbol{\mu g} / \mathbf{m}^{\mathbf{3}}$ & $\mathbf{m} / \mathbf{s}$ & grados & ${ }^{\circ} \mathbf{C}$ & \% H.R. & $\mathbf{m b}$ & $\mathbf{W} / \mathbf{m}^{\mathbf{2}}$ & $\mathbf{1 / \mathbf { m } ^ { 2 }}$ \\
\hline $26 / 01 / 2006$ & 9 & 350 & 4,1 & 330 & $-0,4$ & 92 & 869 & 53 & 0 \\
\hline $29 / 01 / 2006$ & 13 & 302 & 1,8 & 336 & 1,7 & 55 & 870 & 423 & 0 \\
\hline $03 / 02 / 2006$ & 0 & 374 & 1,4 & 359 & 9,2 & 65 & 875 & 0 & 0 \\
\hline $07 / 02 / 2006$ & 3 & 427 & 6,2 & 330 & 3,2 & 63 & 882 & 0 & 0 \\
\hline $13 / 10 / 2006$ & 4 & 266 & 7,9 & 347 & 10 & 77 & 884 & 0 & 0 \\
\hline
\end{tabular}


Tabla 77: Episodios horarios de inmisión de $\mathrm{SO}_{2}$ (> 75\% del umbral permitido) en Morella en el año 2007. Fuente: RVVCCA.

\begin{tabular}{|c|c|c|c|c|c|c|c|c|c|}
\hline \multirow{2}{*}{ Fecha } & \multirow{2}{*}{ Hora } & $\mathbf{S O}_{\mathbf{2}}$ & Veloc. & Direc. & Temp. & H. Rel. & Pres. & R. Sol. & Precip. \\
\cline { 3 - 11 } & & $\boldsymbol{\mu g} / \mathbf{m}^{\mathbf{3}}$ & $\mathbf{m} / \mathbf{s}$ & grados & ${ }^{\circ} \mathbf{C}$ & $\mathbf{\%} \mathbf{H . R}$. & $\mathbf{m b}$ & $\mathbf{W} / \mathbf{m}^{\mathbf{2}}$ & $\mathbf{1} \mathbf{m}^{\mathbf{2}}$ \\
\hline $28 / 01 / 2007$ & 4 & 311 & 2,4 & 332 & $-1,5$ & 73 & 886 & 0 & 0 \\
\hline $28 / 01 / 2007$ & 8 & 488 & 2 & 326 & $-0,9$ & 77 & 886 & 15 & 0 \\
\hline $16 / 05 / 2007$ & 7 & 297 & 10,1 & 331 & 8,4 & 75 & 881 & 84 & 0 \\
\hline $18 / 07 / 2007$ & 7 & 470 & 3,1 & 346 & 17,4 & 79 & 881 & 75 & 0 \\
\hline $28 / 10 / 2007$ & 22 & 267 & 4,6 & 336 & 11,2 & 58 & 882 & 0 & 0 \\
\hline
\end{tabular}




\section{EXPORTACIÓN DE PROMEDIOS DIARIOS (2000-2015)}

\section{ESTACIÓN: Morella CÓDIGO: 12080007}

A continuación se detallan los episodios diarios de inmisión de $\mathrm{SO}_{2}$ que alcanzaron, al menos, el $75 \%$ del valor umbral $\left(125 \mu \mathrm{g} / \mathrm{m}^{3}\right)$ permitido por la legislación (Real Decreto 102/2011, BOE 29 de enero 2011 relativo a la mejora de la calidad del aire).

Tabla 78: Episodios diarios de inmisión de $\mathrm{SO}_{2}(>75 \%$ del umbral permitido) en Morella en el año 2000. Fuente: RVVCCA.

\begin{tabular}{|c|c|c|c|c|c|c|c|c|}
\hline \multirow{2}{*}{ Fecha } & $\mathbf{S O}_{2}$ & Veloc. & Direc. & Temp. & H. Rel. & Pres. & R. Sol. & Precip. \\
\cline { 2 - 9 } & $\boldsymbol{\mu g} / \mathbf{m}^{\mathbf{3}}$ & $\mathbf{m} / \mathbf{s}$ & grados & ${ }^{\circ} \mathbf{C}$ & $\mathbf{\%}$ H.R. & $\mathbf{m b}$ & $\mathbf{W} / \mathbf{m}^{\mathbf{2}}$ & $\mathbf{1 / \mathbf { m } ^ { \mathbf { 2 } }}$ \\
\hline $05 / 08 / 2001$ & 97 & 3,4 & 176 & 19,4 & 67 & 889 & 286 & 0 \\
\hline $06 / 09 / 2001$ & 108 & 4,9 & 329 & 15,1 & 62 & 882 & 157 & 0 \\
\hline
\end{tabular}

Tabla 79: Episodios diarios de inmisión de $\mathrm{SO}_{2}(>75 \%$ del umbral permitido) en Morella en el año 2002. Fuente: RVVCCA.

\begin{tabular}{|c|c|c|c|c|c|c|c|c|}
\hline \multirow{2}{*}{ Fecha } & $\mathbf{S O}_{2}$ & Veloc. & Direc. & Temp. & H. Rel. & Pres. & R. Sol. & Precip. \\
\cline { 2 - 9 } & $\boldsymbol{\mu g} / \mathbf{m}^{\mathbf{3}}$ & $\mathbf{m} / \mathbf{s}$ & grados & ${ }^{\circ} \mathbf{C}$ & \% H.R. & $\mathbf{m b}$ & $\mathbf{W} / \mathbf{m}^{\mathbf{2}}$ & $\mathbf{1 / \mathbf { m } ^ { \mathbf { 2 } }}$ \\
\hline $24 / 06 / 2002$ & 125 & 5.3 & 19 & 18.6 & 61 & 886 & 293 & 0 \\
\hline
\end{tabular}

Tabla 80: Episodios diarios de inmisión de $\mathrm{SO}_{2}$ (> 75\% del umbral permitido) en Morella en el año 2003. Fuente: RVVCCA.

\begin{tabular}{|c|c|c|c|c|c|c|c|c|}
\hline \multirow{2}{*}{ Fecha } & $\mathbf{S O}_{2}$ & Veloc. & Direc. & Temp. & H. Rel. & Pres. & R. Sol. & Precip. \\
\cline { 2 - 9 } & $\boldsymbol{\mu g} / \mathbf{m}^{3}$ & $\mathrm{~m} / \mathbf{s}$ & grados & ${ }^{\circ} \mathbf{C}$ & \% H.R. & $\mathrm{mb}$ & $\mathbf{W} / \mathbf{m}^{\mathbf{2}}$ & $1 / \mathbf{m}^{\mathbf{2}}$ \\
\hline $14 / 01 / 2003$ & 103 & 2.4 & 333 & 2.2 & 22 & 890 & 106 & 0 \\
\hline
\end{tabular}

Tabla 81: Episodios diarios de inmisión de $\mathrm{SO}_{2}$ (> 75\% del umbral permitido) en Morella en el año 2004. Fuente: RVVCCA.

\begin{tabular}{|c|c|c|c|c|c|c|c|c|}
\hline \multirow{2}{*}{ Fecha } & $\mathbf{S O}_{2}$ & Veloc. & Direc. & Temp. & H. Rel. & Pres. & R. Sol. & Precip. \\
\cline { 2 - 9 } & $\boldsymbol{\mu g} / \mathbf{m}^{\mathbf{3}}$ & $\mathbf{m} / \mathbf{s}$ & grados & ${ }^{\circ} \mathbf{C}$ & \% H.R. & $\mathbf{m b}$ & $\mathbf{W} / \mathbf{m}^{\mathbf{2}}$ & $\mathbf{1 / \mathbf { m } ^ { \mathbf { 2 } }}$ \\
\hline $21 / 11 / 2004$ & 255 & 1,9 & 160 & 11,1 & 71 & 885 & 91 & 0 \\
\hline $23 / 11 / 2004$ & 211 & 3,8 & 328 & 7,9 & 70 & 885 & 45 & 0 \\
\hline
\end{tabular}




\section{EXPORTACIÓN DE PROMEDIOS HORARIOS (2000-2015)}

\section{ESTACIÓN: Zorita CÓDIGO: 12141002}

A continuación se detallan los episodios horarios de inmisión de $\mathrm{SO}_{2}$ que alcanzaron, al menos, el $75 \%$ del valor umbral $\left(350 \mu \mathrm{g} / \mathrm{m}^{3}\right)$ permitido por la legislación (Real Decreto 102/2011, BOE 29 de enero 2011 relativo a la mejora de la calidad del aire).

Tabla 82: Episodios horarios de inmisión de $\mathrm{SO}_{2}$ (> 75\% del umbral permitido) en Zorita en el año 2000. Fuente: RVVCCA.

\begin{tabular}{|c|c|c|c|c|c|c|c|c|}
\hline \multirow{2}{*}{ Fecha } & \multirow{2}{*}{ Hora } & $\mathbf{S O}_{\mathbf{2}}$ & Veloc. & Direc. & Temp. & H. Rel. & R. Sol. & Precip. \\
\cline { 3 - 9 } & & $\boldsymbol{\mu g} / \mathbf{m}^{\mathbf{3}}$ & $\mathbf{m} / \mathbf{s}$ & grados & ${ }^{\circ} \mathbf{C}$ & $\mathbf{\%} \mathbf{H . R}$. & $\mathbf{W} / \mathbf{m}^{\mathbf{2}}$ & $\mathbf{1 / \mathbf { m } ^ { \mathbf { 2 } }}$ \\
\hline $20 / 07 / 2000$ & 11 & 316 & 2,3 & 357 & 30,1 & 47 & 884 & 0 \\
\hline $08 / 09 / 2000$ & 10 & 668 & 0,4 & 50 & 26,8 & 30 & 688 & 0 \\
\hline $08 / 09 / 2000$ & 11 & 302 & 1,2 & 24 & 29 & 28 & 805 & 0 \\
\hline $16 / 09 / 2000$ & 14 & 348 & 3 & 357 & 34,1 & 19 & 777 & 0 \\
\hline $17 / 09 / 2000$ & 10 & 395 & 1 & 334 & 24,1 & 47 & 490 & 0 \\
\hline $17 / 09 / 2000$ & 11 & 411 & 1,6 & 22 & 25,5 & 45 & 722 & 0 \\
\hline $17 / 09 / 2000$ & 12 & 419 & 2,4 & 18 & 27,2 & 41 & 775 & 0 \\
\hline $03 / 10 / 2000$ & 18 & 278 & 2,2 & 358 & 24,2 & 16 & 47 & 0 \\
\hline
\end{tabular}

Tabla 83: Episodios horarios de inmisión de $\mathrm{SO}_{2}$ ( $>75 \%$ del umbral permitido) en Zorita en el año 2001. Fuente: RVVCCA.

\begin{tabular}{|c|c|c|c|c|c|c|c|c|}
\hline \multirow{2}{*}{ Fecha } & \multirow{2}{*}{ Hora } & $\mathbf{S O}_{2}$ & Veloc. & Direc. & Temp. & H. Rel. & R. Sol. & Precip. \\
\cline { 3 - 9 } & & $\boldsymbol{\mu g} / \mathbf{m}^{\mathbf{3}}$ & $\mathbf{m} / \mathbf{s}$ & grados & ${ }^{\circ} \mathbf{C}$ & \% H.R. & $\mathbf{W} / \mathbf{m}^{\mathbf{2}}$ & $\mathbf{1 / \mathbf { m } ^ { \mathbf { 2 } }}$ \\
\hline $27 / 06 / 2001$ & 13 & 263 & 3,2 & 23 & 26,7 & 34 & 672 & 0 \\
\hline $11 / 09 / 2001$ & 15 & 373 & 2,3 & 19 & 26,6 & 27 & 643 & 0 \\
\hline $12 / 09 / 2001$ & 11 & 283 & 1 & 9 & 24,7 & 30 & 697 & 0 \\
\hline $12 / 09 / 2001$ & 16 & 293 & 2,7 & 17 & 28,8 & 22 & 505 & 0 \\
\hline $29 / 10 / 2001$ & 13 & 283 & 0,5 & 324 & 31,1 & 25 & 521 & 0 \\
\hline $05 / 11 / 2001$ & 15 & 283 & 1,1 & 9 & 14,1 & 67 & 83 & 0 \\
\hline $05 / 11 / 2001$ & 16 & 278 & 0,7 & 20 & 14,3 & 64 & 68 & 0 \\
\hline
\end{tabular}

Tabla 84: Episodios horarios de inmisión de $\mathrm{SO}_{2}(>75 \%$ del umbral permitido) en Zorita en el año 2002. Fuente: RVVCCA.

\begin{tabular}{|c|c|c|c|c|c|c|c|c|}
\hline \multirow{2}{*}{ Fecha } & \multirow{2}{*}{ Hora } & $\mathbf{S O}_{2}$ & Veloc. & Direc. & Temp. & H. Rel. & R. Sol. & Precip. \\
\cline { 3 - 9 } & & $\boldsymbol{\mu g} / \mathbf{m}^{\mathbf{3}}$ & $\mathbf{m} / \mathbf{s}$ & grados & ${ }^{\circ} \mathbf{C}$ & $\boldsymbol{\%}_{\mathbf{0}}$ H.R. & $\mathbf{W} / \mathbf{m}^{\mathbf{2}}$ & $\mathbf{1 / \mathbf { m } ^ { \mathbf { 2 } }}$ \\
\hline $28 / 01 / 2002$ & 13 & 290 & 2.1 & 31 & 18.1 & 42 & 425 & 0 \\
\hline $28 / 09 / 2002$ & 15 & 288 & 2.3 & 348 & 26.9 & 26 & 527 & 0 \\
\hline $07 / 10 / 2002$ & 17 & 319 & 0.5 & 343 & 23.7 & 31 & 125 & 0 \\
\hline
\end{tabular}


Tabla 85: Episodios horarios de inmisión de $\mathrm{SO}_{2}$ (> 75\% del umbral permitido) en Zorita en el año 2003. Fuente: RVVCCA.

\begin{tabular}{|c|c|c|c|c|c|c|c|c|}
\hline \multirow{2}{*}{ Fecha } & \multirow{2}{*}{ Hora } & $\mathbf{S O}_{2}$ & Veloc. & Direc. & Temp. & H. Rel. & R. Sol. & Precip. \\
\cline { 3 - 9 } & & $\boldsymbol{\mu g} / \mathbf{m}^{\mathbf{3}}$ & $\mathbf{m} / \mathbf{s}$ & grados & ${ }^{\circ} \mathbf{C}$ & $\mathbf{\%}$ H.R. & $\mathbf{W} / \mathbf{m}^{\mathbf{2}}$ & $\mathbf{1 / \mathbf { m } ^ { \mathbf { 2 } }}$ \\
\hline $14 / 01 / 2003$ & 14 & 291 & 0.2 & 115 & 15.2 & 21 & 419 & 0 \\
\hline $14 / 03 / 2003$ & 16 & 272 & 2.3 & 8 & 22.8 & 31 & 390 & 0 \\
\hline $21 / 03 / 2003$ & 11 & 334 & 0.9 & 6 & 17.7 & 29 & 501 & 0 \\
\hline $25 / 08 / 2003$ & 12 & 361 & 1.4 & 21 & 31.2 & 33 & 742 & 0 \\
\hline
\end{tabular}

Tabla 86: Episodios horarios de inmisión de $\mathrm{SO}_{2}$ (> 75\% del umbral permitido) en Zorita en el año 2004. Fuente: RVVCCA.

\begin{tabular}{|c|c|c|c|c|c|c|c|c|}
\hline \multirow{2}{*}{ Fecha } & \multirow{2}{*}{ Hora } & $\mathbf{S O}_{\mathbf{2}}$ & Veloc. & Direc. & Temp. & H. Rel. & R. Sol. & Precip. \\
\cline { 3 - 9 } & & $\boldsymbol{\mu g} / \mathbf{m}^{\mathbf{3}}$ & $\mathbf{m} / \mathbf{s}$ & grados & ${ }^{\circ} \mathbf{C}$ & $\mathbf{\%}$ H.R. & $\mathbf{W} / \mathbf{m}^{\mathbf{2}}$ & $\mathbf{1 / \mathbf { m } ^ { \mathbf { 2 } }}$ \\
\hline $29 / 06 / 2004$ & 9 & 353 & 0,7 & 30 & 28,7 & 45 & 390 & 0 \\
\hline $01 / 07 / 2004$ & 10 & 278 & 2,2 & 29 & 24,3 & 40 & 532 & 0 \\
\hline $06 / 12 / 2004$ & 17 & 350 & 0,7 & 338 & 6,2 & 89 & 0 & 0 \\
\hline
\end{tabular}

Tabla 87: Episodios horarios de inmisión de $\mathrm{SO}_{2}$ (> 75\% del umbral permitido) en Zorita en el año 2005. Fuente: RVVCCA.

\begin{tabular}{|c|c|c|c|c|c|c|c|c|}
\hline \multirow{2}{*}{ Fecha } & \multirow{2}{*}{ Hora } & $\mathbf{S O}_{2}$ & Veloc. & Direc. & Temp. & H. Rel. & R. Sol. & Precip. \\
\cline { 3 - 9 } & & $\boldsymbol{\mu g} / \mathbf{m}^{\mathbf{3}}$ & $\mathbf{m} / \mathbf{s}$ & grados & ${ }^{\circ} \mathbf{C}$ & \% H.R. & $\mathbf{W} / \mathbf{m}^{\mathbf{2}}$ & $\mathbf{1 / \mathbf { m } ^ { 2 }}$ \\
\hline $21 / 12 / 2005$ & 16 & 360 & 1,6 & 8 & 9,7 & 44 & 132 & 0,2 \\
\hline
\end{tabular}

Tabla 88: Episodios horarios de inmisión de $\mathrm{SO}_{2}$ (> 75\% del umbral permitido) en Zorita en el año 2006. Fuente: RVVCCA.

\begin{tabular}{|c|c|c|c|c|c|c|c|c|}
\hline \multirow{2}{*}{ Fecha } & \multirow{2}{*}{ Hora } & $\mathbf{S O}_{2}$ & Veloc. & Direc. & Temp. & H. Rel. & R. Sol. & Precip. \\
\cline { 3 - 9 } & & $\boldsymbol{\mu g} / \mathbf{m}^{\mathbf{3}}$ & $\mathbf{m} / \mathbf{s}$ & grados & ${ }^{\circ} \mathbf{C}$ & $\mathbf{\%}$ H.R. & $\mathbf{W} / \mathbf{m}^{\mathbf{2}}$ & $\mathbf{1 / \mathbf { m } ^ { \mathbf { 2 } }}$ \\
\hline $14 / 02 / 2006$ & 14 & 298 & 2,4 & 13 & 13,6 & 38 & 644 & 0 \\
\hline $14 / 02 / 2006$ & 15 & 264 & 2,2 & 4 & 14,5 & 33 & 539 & 0 \\
\hline $14 / 02 / 2006$ & 16 & 691 & 1,8 & 3 & 14,3 & 35 & 371 & 0 \\
\hline $14 / 02 / 2006$ & 17 & 372 & 2 & 1 & 13,3 & 38 & 185 & 0 \\
\hline $24 / 03 / 2006$ & 13 & 405 & 4,4 & 280 & 18,9 & 35 & 805 & 0 \\
\hline
\end{tabular}

Tabla 89: Episodios horarios de inmisión de $\mathrm{SO}_{2}$ ( $>75 \%$ del umbral permitido) en Zorita en el año 2007. Fuente: RVVCCA.

\begin{tabular}{|c|c|c|c|c|c|c|c|c|}
\hline \multirow{2}{*}{ Fecha } & \multirow{2}{*}{ Hora } & $\mathbf{S O}_{2}$ & Veloc. & Direc. & Temp. & H. Rel. & R. Sol. & Precip. \\
\cline { 3 - 9 } & & $\boldsymbol{\mu g} / \mathbf{m}^{\mathbf{3}}$ & $\mathbf{m} / \mathbf{s}$ & grados & ${ }^{\circ} \mathbf{C}$ & $\mathbf{\%} \mathbf{H . R}$. & $\mathbf{W} / \mathbf{m}^{\mathbf{2}}$ & $\mathbf{1 / \mathbf { m } ^ { \mathbf { 2 } }}$ \\
\hline $24 / 08 / 2007$ & 9 & 313 & 0,9 & 45 & 17,1 & 67 & 324 & 0 \\
\hline $24 / 08 / 2007$ & 10 & 272 & 0,9 & 196 & 18,6 & 60 & 571 & 0 \\
\hline
\end{tabular}



ANEXO II: INFORME NC123180

Sede Central

Campus Universitario Riu Sec

Av. Vicent Sos Baynat s/
12006 Castellón (Spain)

\section{Sede Alicer}

12003 Castellón (Spain) www.itc.uji.es

info@itc.uji.es

T. +34964342424

F. +34964342425

\section{Determinación del pH y de azufre en} muestras de suelos

Informe no C123180

№ de páginas 3

INSTITUTO INTERUNIVERSITARIO DE GEOGRAFÍA

Castellón, 11 de diciembre de 2012 


\section{Antecedentes}

Con fecha 16 de noviembre de 2012 se recibieron en el Instituto de Tecnología Cerámica (ITC) dieciséis muestras, suministrada por la firma INSTITUTO INTERUNIVERSITARIO DE GEOGRAFÍA, e identificadas con las siguientes referencias:

- Muestra 1:MUESTRA 1

- Muestra 2:MUESTRA 2

- Muestra 3:MUESTRA 3

- Muestra 4:MUESTRA 4

- Muestra 5:MUESTRA 5

- Muestra 6:MUESTRA 6

- Muestra 7:MUESTRA 7

- Muestra 8:MUESTRA 8

- Muestra 9:MUESTRA 9

- Muestra 10:MUESTRA 10

- Muestra 11:MUESTRA 11

- Muestra 12:MUESTRA 12

- Muestra 13:MUESTRA 13

- Muestra 14:MUESTRA 14

- Muestra 15:MUESTRA 15

- Muestra 16:MUESTRA 16

Se solicitó la determinación del pH según norma UNE 77305 y la determinación de azufre en dichas muestras.

\section{Ensayos realizados}

\subsection{Determinación de azufre}

La determinación de azufre se ha llevado a cabo sobre pastillas prensadas de la muestra usando como compactante una solución de n-butil metacrilato en acetona. Las pastillas fueron prensadas en una prensa hidráulica de la casa comercial CASMON y a continuación fueron medidas por espectrometría de fluorescencia de rayos $X$ por dispersión de longitudes de onda utilizando un espectrómetro de la casa comercial PANALYTICAL. Para garantizan la trazabilidad de las medidas se utilizaron materiales de referencia.

\subsection{Determinación del pH en muestra sólidas}

La determinación del pH se ha realizado según la norma UNE 77305. Se preparó una suspensión de la muestra con cinco veces su volumen en agua y se sometió a agitación durante 5 minutos. Después se dejó en reposo durante dos horas y se midió el pH de la suspensión decantada con un pHmetro CRISON modelo 2002. 


\section{Resultados}

\subsection{Determinación de pH y azufre}

\begin{tabular}{|l|l|l|}
\hline Referencia & pH & s (\%) \\
\hline MUESTRA 1 & 8,0 & 0,096 \\
\hline MUESTRA 2 & 8,1 & 0,044 \\
\hline MUESTRA 3 & 8,1 & 0,054 \\
\hline MUESTRA 4 & 7,9 & 0,088 \\
\hline MUESTRA 5 & 7,9 & 0,049 \\
\hline MUESTRA 6 & 7,8 & 0,063 \\
\hline MUESTRA 7 & 7,9 & 0,061 \\
\hline MUESTRA 8 & 8,4 & 0,059 \\
\hline MUESTRA 9 & 7,9 & 0,041 \\
\hline MUESTRA 10 & 7,5 & 0,094 \\
\hline MUESTRA 11 & 7,8 & 0,098 \\
\hline MUESTRA 12 & 8,1 & 0,066 \\
\hline MUESTRA 13 & 8,1 & 0,061 \\
\hline MUESTRA 14 & 7,9 & 0,056 \\
\hline MUESTRA 15 & 7,8 & 0,078 \\
\hline MUESTRA 16 & 8,0 & 0,088 \\
\hline
\end{tabular}


El presente informe $\mathrm{n}^{\circ} \mathrm{C} 123180$ expedido a petición de la firma INSTITUTO INTERUNIVERSITARIO DE GEOGRAFÍA, consta de una portada y 3 páginas.

Castellón, 11 de diciembre de 2012
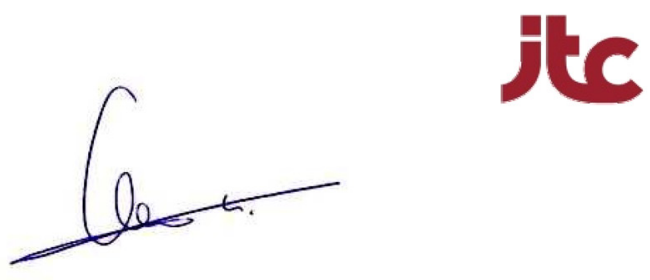

Dra. Ma Fernanda Gazulla Barreda

Responsable del Área de Análisis y Ensayos

Documento firmado digitalmente mediante firma electrónica legal. Este documento se considera original siempre que no pierda la firma electrónica debido a la alteración de su integridad. Toda reproducción en papel se considera copia.

\section{Cláusulas de responsabilidad}

Los resultados, conclusiones y/o recomendaciones contenidos en este informe se han obtenido a partir de los ensayos realizados y/o de la información suministrada por el peticionario.

No se admite ninguna responsabilidad referente a la exactitud y representatividad del muestreo a menos que éste haya sido efectuado bajo nuestra propia supervisión. Salvo mención expresa, las muestras y sus referencias han sido elegidas libremente por el peticionario.

Reservados todos los derechos. El contenido de este informe goza de la protección que le otorga la ley. No podrá ser comunicado, transformado, reproducido o distribuido públicamente en todo o en parte, sin la autorización expresa del Instituto de Tecnología Cerámica - AICE. La reproducción de este informe solamente está autorizada bajo forma de facsímil íntegro fotográfico, para el envío puntual y no masivo a clientes y/o proveedores del peticionario, con el único objetivo de informar y siempre citando la autoría del Instituto de Tecnología Cerámica -AICE.

El Instituto de Tecnología Cerámica - AICE no se hace responsable del uso que el peticionario u otra persona o entidad haga de los datos o indicaciones contenidos en el presente informe, en perjuicio o en beneficio de las marcas comerciales que el peticionario haya podido citar como identificación de las muestras sometidas a estudio.

Este informe tiene carácter exclusivamente comercial y no podrá ser utilizado en cualquier procedimiento judicial o administrativo, ni como dictamen pericial ni como prueba documental, salvo autorización expresa del Instituto de Tecnología Cerámica - AICE. La autorización por parte de ITC-AICE estará condicionada, cuando así se requiera, al abono por parte del cliente, incluso con carácter previo, de los fondos necesarios para cubrir los gastos asociados a la defensa de este informe. ITC-AICE se reserva el derecho de tomar las oportunas acciones legales en caso de incumplimiento de esta cláusula.

El Instituto de Tecnología Cerámica - AICE podrá incluir en sus informes análisis, comentarios o cualquier otra valoración que juzgue necesaria, aun cuando ésta no hubiese sido expresamente solicitada.

El Instituto de Tecnología Cerámica - AICE garantiza la confidencialidad del contenido del presente informe. 
ANEXO III: INFORME N $^{\circ} \mathrm{C} 130577$

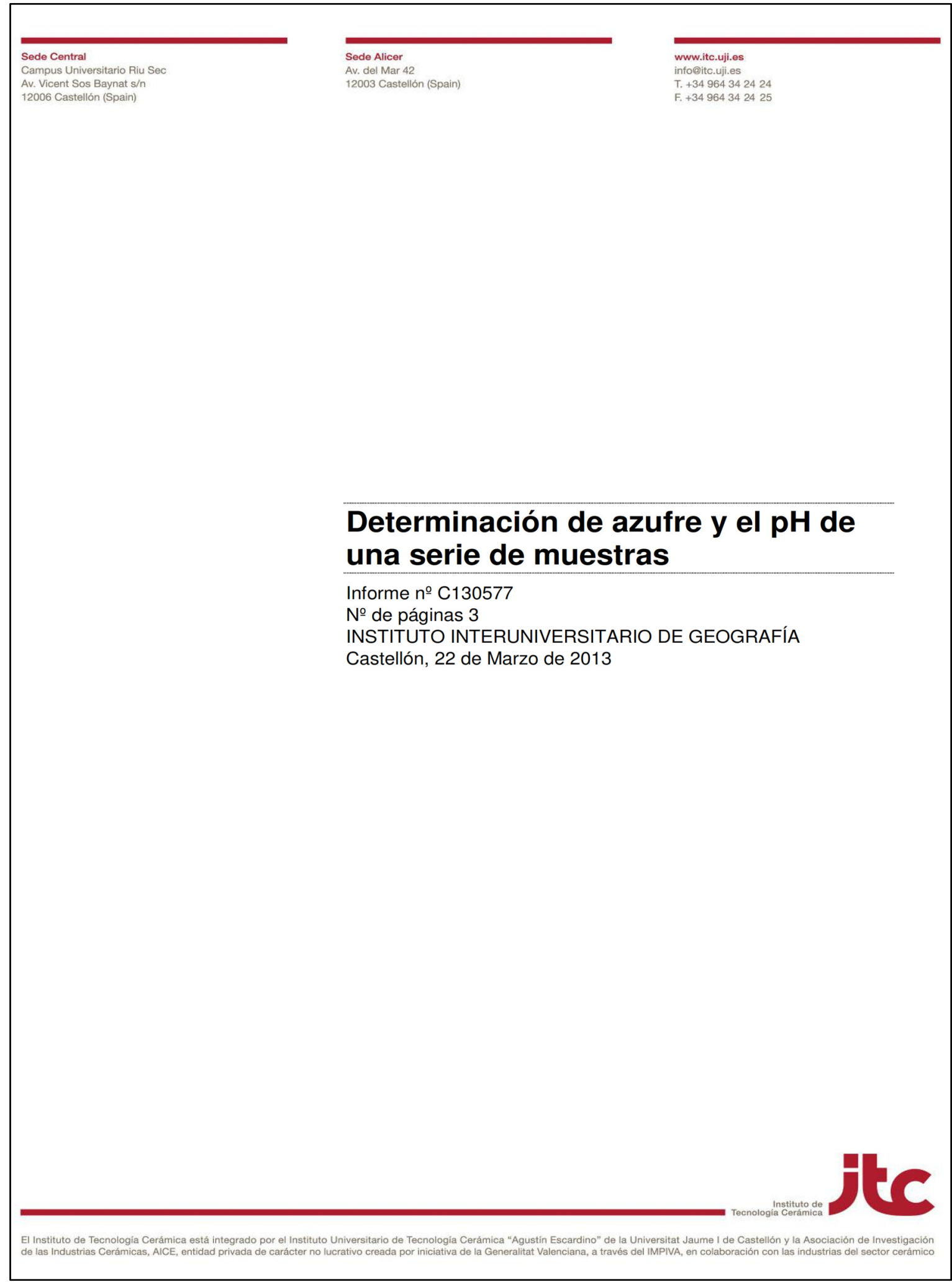

Página | 257 


\section{Antecedentes}

Con fecha 18 de febrero de 2013 se recibieron en el Instituto de Tecnología Cerámica (ITC) quince muestras, suministradas por la firma INSTITUTO INTERUNIVERSITARIO DE GEOGRAFÍA, e identificadas con las siguientes referencias

- Muestra 1:M-1

- Muestra 2:M-2

- Muestra 3:M-3

- Muestra 4:M-4

- Muestra 5:M-5

- Muestra 6:M-6

- Muestra 7:M-7

- Muestra 8: B-1

- Muestra 9: B-2

- Muestra 10: B-3

- Muestra 11: B-4

- Muestra 12: B-5

- Muestra 13: B-6

- Muestra 14: B-7

- Muestra 15: B-8

Se solicitó la determinación de azufre y pH en dichas muestras.

\section{Ensayos realizados}

\subsection{Determinación de azufre}

La determinación de azufre se ha llevado a cabo sobre pastillas prensadas de la muestra usando como compactante una solución de n-butil metacrilato en acetona. Las pastillas fueron prensadas en una prensa hidráulica de la casa comercial CASMON y a continuación fueron medidas por espectrometría de fluorescencia de rayos $X$ por dispersión de longitudes de onda utilizando un espectrómetro de la casa comercial PANALYTICAL. Para garantizan la trazabilidad de las medidas se utilizaron materiales de referencia.

\subsection{Determinación del pH en muestra sólidas}

La determinación del pH se ha realizado según la norma UNE 77305. Se preparó una suspensión de la muestra con cinco veces su volumen en agua y se sometió a agitación durante 5 minutos. Después se dejó en reposo durante dos horas y se midió el pH de la suspensión decantada con un pHmetro CRISON modelo 2002. 


\section{Resultados}

\subsection{Determinación de pH y azufre}

\begin{tabular}{|c|c|c|}
\hline Referencia & pH & S (\%) \\
\hline$M-1$ & 7,43 & 0,038 \\
\hline$M-2$ & 7,65 & 0,034 \\
\hline$M-3$ & 7,59 & 0,036 \\
\hline$M-4$ & 8,12 & 0,044 \\
\hline$M-5$ & 8,04 & 0,046 \\
\hline$M-6$ & 7,96 & 0,042 \\
\hline$M-7$ & 7,95 & 0,037 \\
\hline
\end{tabular}

\begin{tabular}{|c|c|c|}
\hline Referencia & pH & s (\%) \\
\hline B - 1 & 6,87 & 0,031 \\
\hline B - 2 & 6,85 & 0,036 \\
\hline B - 3 & 7,10 & 0,041 \\
\hline B - 4 & 7,08 & 0,061 \\
\hline B - 5 & 7,26 & 0,047 \\
\hline B - 6 & 7,16 & 0,041 \\
\hline B - 7 & 7,32 & 0,033 \\
\hline B - 8 & 7,25 & 0,042 \\
\hline
\end{tabular}


El presente informe no C130577 expedido a petición de la firma INSTITUTO INTERUNIVERSITARIO DE GEOGRAFÍA, consta de una portada y 3 páginas.

Castellón, 22 de Marzo de 2013
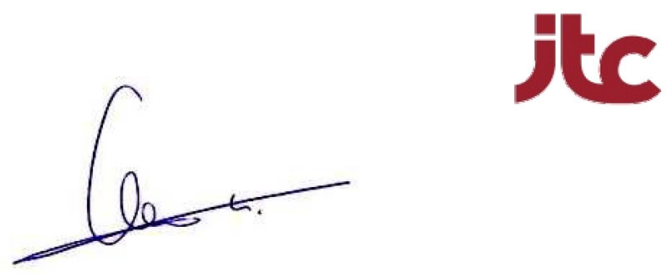

\section{Dra. Mª Fernanda Gazulla Barreda}

Responsable del Área de Análisis y Ensayos

Documento firmado digitalmente mediante firma electrónica legal. Este documento se considera original siempre que no pierda la firma electrónica debido a la alteración de su integridad. Toda reproducción en papel se considera copia.

\section{Cláusulas de responsabilidad}

Los resultados, conclusiones y/o recomendaciones contenidos en este informe se han obtenido a partir de los ensayos realizados y/o de la información suministrada por el peticionario.

No se admite ninguna responsabilidad referente a la exactitud y representatividad del muestreo a menos que éste haya sido efectuado bajo nuestra propia supervisión. Salvo mención expresa, las muestras y sus referencias han sido elegidas libremente por el peticionario.

Reservados todos los derechos. El contenido de este informe goza de la protección que le otorga la ley. No podrá ser comunicado, transformado, reproducido o distribuido públicamente en todo o en parte, sin la autorización expresa del Instituto de Tecnología Cerámica - AICE. La reproducción de este informe solamente está autorizada bajo forma de facsímil íntegro fotográfico, para el envío puntual y no masivo a clientes y/o proveedores del peticionario, con el único objetivo de informar y siempre citando la autoría del Instituto de Tecnología Cerámica -AICE.

El Instituto de Tecnología Cerámica - AICE no se hace responsable del uso que el peticionario u otra persona o entidad haga de los datos o indicaciones contenidos en el presente informe, en perjuicio o en beneficio de las marcas comerciales que el peticionario haya podido citar como identificación de las muestras sometidas a estudio.

Este informe tiene carácter exclusivamente comercial y no podrá ser utilizado en cualquier procedimiento judicial o administrativo, ni como dictamen pericial ni como prueba documental, salvo autorización expresa del Instituto de Tecnología Cerámica - AICE. La autorización por parte de ITC-AICE estará condicionada, cuando así se requiera, al abono por parte del cliente, incluso con carácter previo, de los fondos necesarios para cubrir los gastos asociados a la defensa de este informe. ITC-AICE se reserva el derecho de tomar las oportunas acciones legales en caso de incumplimiento de esta cláusula.

EI Instituto de Tecnología Cerámica - AICE podrá incluir en sus informes análisis, comentarios o cualquier otra valoración que juzgue necesaria, aun cuando ésta no hubiese sido expresamente solicitada

El Instituto de Tecnología Cerámica - AICE garantiza la confidencialidad del contenido del presente informe. 


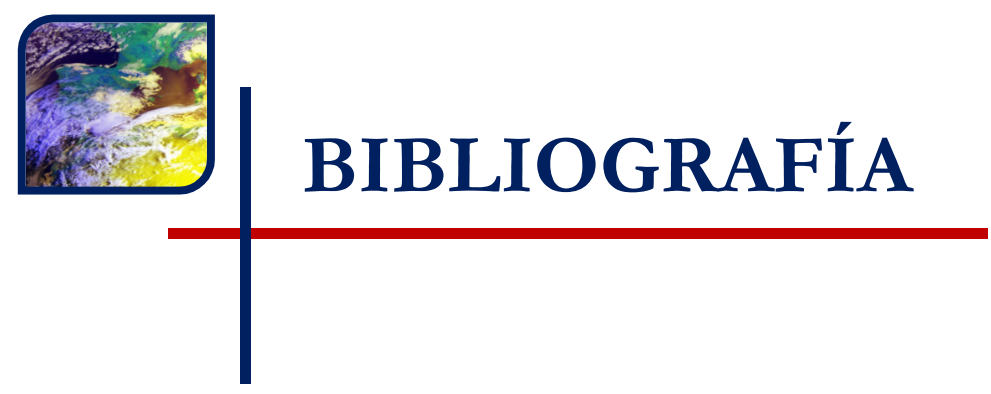





\section{BIBLIOGRAFÍA}

\section{Referencias Bibliográficas}

AMBIO, S. A. (Gabinete de estudios y planificación del medio ambiente, entidad colaboradora del MIE, Ministerio de Industria y Energía) (1991): “Análisis de los valores obtenidos en la red de inmisión del Maestrazgo desde su puesta en marcha (1984-1991)”. Memoria ENDESA.

AMBIO, S. A. (Gabinete de estudios y planificación del medio ambiente, entidad colaboradora del MIE, Ministerio de Industria y Energía) (1992 a): "Campaña de seguimiento de las masas forestales de El Maestrazgo y Els Ports. Año 1991”.

AMBIO, S. A. (Gabinete de estudios y planificación del medio ambiente, entidad colaboradora del MIE, Ministerio de Industria y Energía) (1992 b): “Caracterización bioclimática en el área de El Maestrazgo”. Memoria de 1992.

AMBIO, S. A. (Gabinete de estudios y planificación del medio ambiente, entidad colaboradora del MIE, Ministerio de Industria y Energía) (1984): "Estudio de inmisión atmosférica en El Maestrazgo". Memoria anual 1984.

AMBIO, S. A. (Gabinete de estudios y planificación del medio ambiente, entidad colaboradora del MIE, Ministerio de Industria y Energía) (1985): "Estudio de inmisión atmosférica en El Maestrazgo". Memoria anual 1985.

AMBIO, S. A. (Gabinete de estudios y planificación del medio ambiente, entidad colaboradora del MIE, Ministerio de Industria y Energía) (1986): "Estudio de inmisión atmosférica en El Maestrazgo". Memoria anual 1986.

AMBIO, S. A. (Gabinete de estudios y planificación del medio ambiente, entidad colaboradora del MIE, Ministerio de Industria y Energía) (1987): "Estudio de inmisión atmosférica en El Maestrazgo". Memoria anual 1987.

AMBIO, S. A. (Gabinete de estudios y planificación del medio ambiente, entidad colaboradora del MIE, Ministerio de Industria y Energía) (1988): "Estudio de inmisión atmosférica en El Maestrazgo". Memoria anual 1988. 
AMBIO, S. A. (Gabinete de estudios y planificación del medio ambiente, entidad colaboradora del MIE, Ministerio de Industria y Energía) (1989): "Estudio de inmisión atmosférica en El Maestrazgo". Memoria anual 1989.

AMBIO, S. A. (Gabinete de estudios y planificación del medio ambiente, entidad colaboradora del MIE, Ministerio de Industria y Energía) (1990): "Estudio de inmisión atmosférica en El Maestrazgo". Memoria anual 1990.

ARYA, S. P. (2001): Introduction to micrometeorology. Academic Press. San Diego. 415 pp.

BARRENO, E. et al. (1990): "Seguimiento de la calidad atmosférica en las comarcas de Els Ports y Maestrazgo mediante bioindicadores vegetales (líquenes, briófitos, vasculares)”. Primera campaña Junio 1989. ENDESA. Universidad de Valencia.

BARRENO, E. et al. (1991): "Seguimiento de la calidad atmosférica en las comarcas de Els Ports y Maestrazgo mediante bioindicadores vegetales (líquenes, briófitos, plantas vasculares)". Segunda campaña. Junio 1990. ENDESA. Universidad de Valencia.

BARRENO, E. et al. (1992 a): "Seguimiento de la calidad atmosférica en las comarcas de Els Ports y Maestrazgo mediante bioindicadores vegetales (líquenes, briófitos, plantas vasculares)". Tercera campaña. Junio 1991. ENDESA. Universidad de Valencia.

BARRENO, E. et al. (1992 b): "Visible symptoms of injury on lichens related to high levels of photooxidants in the eastern Coast of Spain". Second International Association for Lichenology Symposium, Sweden.

BARRENO, E., et al. (1993): "Seguimiento de la calidad atmosférica en las comarcas de Els Ports y Maestrazgo mediante bioindicadores vegetales (líquenes y briófitos)". Grupo de liquenología y briología. Informe final y campaña 1992. ENDESA. Universidad de Valencia.

BARTHELMIE, R. J. (1999): "The effects of atmospheric stability on coastal wind climates". Meteorological Applications, 6. Pp. 39-47.

BEYCHOK, M. R. (2005): Fundamentals of Stack Gas Dispersion. Author published. Newport Beach, CA. 193 pp. 
BOSANQUET, C. H. et al. (1950): "Dust Deposition from Chimney Stacks" Proceedings of the Institution of Mechanical Engineers, 162. Pp. 355-367.

BRIGGS, G. A. (1965): “A plume rise model compared with observations”. Journal of the Air Pollution Control Association, 15. Pp. 433-438.

BRIGGS, G. A. (1969): Plume rise. Air Resources Atmospheric Turbulence and Diffusion Laboratory Environmental Science Services Administration. US Atomic Energy Commission. Division of Technical Information. Oak Ride, Tennesse. 82 pp.

BRIGGS, G. A. (1972): "Discussion on Chimney Plumes in Neutral and Estable Surroundings". Atmospheric Environment, 6. Pp. 507-510.

BRIGGS, G. A. (1973): "Diffusion estimation of small emissions". Atmospheric Turbulence and Diffusion Laboratory Contribution, 79. Pp. 83-145.

BRIGGS, G. A. (1974): "Plume rise from multiple source", Procedings of cooling tower environment held at University of Maryland. ERDA Symposium Series. College Park, Maryland. Pp. 161-179.

BRIGGS, G. A. (1975): "Plume rise predictions", Lectures on air pollution and environmental impact analyses. Workshop Proceedings. American Meteorological Society. Boston, Massachusetts. Pp. 59-111.

BRIGGS, G. A. (1982): "Similarity forms for ground source surface layer diffusion”. Boundary-Layer Meteorology, 23. Pp. 489-502.

BRUMMAGE, K. G. et al. (1966): "The calculation of atmospheric dispersion from a stack". CONCAWE publication. The Hague, The Netherlands. 57 pp.

BUSINGER, J. A. (1973): “Turbulence Transfer in the Atmospheric Surface Layer. Workshop in Micrometeorology", American Meteorological Society, 45. Beacon St., Boston, MA. Pp. 67-100.

BUSINGER, J. A. et al. (1971): "Flux profile relationships in the atmospheric surface layer". Journal of Atmospheric Science, 28. Pp. 181-189. 
BUSINGER, J. A. y ARYA, S. (1974): "The height of the mixed layer in the stably stratified planetary boundary layer". Advances in geophysics, 18(A). Pp. 73-92.

CARRATALÀ, et al. (1992): “Composición química del agua de lluvia en la Comunidad Valenciana: resultados preliminares de una red para el control de la calidad ambiental". Tecnología del agua XII, 101. Pp. 17-23.

CASTRO, M. (2004): "Modelos de contaminación atmosférica”, en MARTÍNEZ, E. y DÍAZ, Y. (ed.): Contaminación atmosférica. Colección Ciencia y Técnica, 45. Ediciones de la universidad de Castilla la Mancha. Murcia. 286 pp.

CASTRO, M. et al. (1991): "Parametrización de la capa límite atmosférica en los modelos numéricos de pronóstico meteorológico". Física de la Tierra, 3. Ed. Universidad Complutense de Madrid. Pp. 103-138.

CONDE, C. et al. (1993): "Dictamen sobre la información aportada y conclusiones obtenidas por los estudios realizados sobre la incidencia ambiental de la Central Térmica de ENDESA en Andorra (Teruel)”. Universitat Jaume I. Castellón. 33 pp.

CRESPI, S. N. et al. (1995): "Synoptic classification of the mixed-layer evolution". Journal of Applied Meteorology, 27. Pp. 1382-1394.

DAVENPORT, A. G. (1963): The relationship of wind structure to wind loading. International Conference on the Wind Effects on Buildings and Structures. National Physical Laboratory. Teddington. Middlesex. England. 51 pp.

DE VISSCHER, A. (2013): Air dispersion modeling. Foundations and applications. Wiley. Hoboken, New Jersey. 634 pp.

DOMÍNGUEZ, S. (2009): La fisica de un indice predictivo de riesgo de incendios forestales. Colección Vitor, 237. Ed. Universidad de Salamanca. Salamanca. 1167 pp.

DRAXLER, R. R. (1976): "Determination of atmospheric diffusion parameters". Atmospheric Environmet, 10. Pp. 99-105.

ENDESA (1993): "Red de Control de la Contaminación Atmosférica. Central Térmica de Teruel”. Memoria año 1992.

Página | 266 
ESCRIG, J. (1999): Dendrocronología y contaminación ambiental. El impacto de la contaminación atmosférica en el crecimiento forestal de las comarcas de El Maestrazgo y Els Ports de Morella. Tesis Doctoral Inédita. Universitat Jaume I. Castellón. 191 pp.

ESPERT, V. y LÓPEZ, P. A. (1998): Contaminación atmosférica. Módulo: Dispersión de contaminantes. Publicaciones Universidad de Valencia. Valencia. 160 pp.

GALLEGO, A. et al. (2012): Contaminación atmosférica. Universidad Nacional a Distancia. Madrid. 441 pp.

GIFFORD, F. A. (1961): "Uses of routine meteorological observations for estimating atmospheric dispersion". Nuclear Safety, 2, 4. Pp. 47-51.

GIL, A. (2009): “Clima e hipótesis de cambio climático en la región geográfica del Sureste Ibérico”. Investigaciones Geográficas, 49. Universidad de Alicante. Pp. 5-22.

GIL, A. y OLCINA, J. (1997): Climatología general. Editorial Ariel Geografía. Barcelona. 579 pp.

GREEN, A. E. S. et al. (1980): “Analytic Extensions of the Gaussian Plume Model". Journal of the Air Pollution Control Association, 30: 7. Pp. 773-776.

HANNA, S. R. et al. (1982): Handbook on atmospheric diffusion. Technical Information Center US Department of Energy. Springfield, Virginia. 102 pp.

HELLMANN, G. (1915): "Über die Bewegung der Luft in den untersten Schichten der Atmosphäre”. Meteorologische Zeitschrift, 32. Pp. 1-16.

HOLZWORTH, G. C. (1972): Mixing Heights, wind speeds, and potential for urban air pollution throughout the contiguous United States. Office of Air Programs. EPA Publication $N^{\circ}$ AP-101. Research Triangle Park, NC. 118 pp.

HUFTY, A. (1984): Introducción a la climatología. Ariel Geografía, S. A. Barcelona. 100 pp.

ICONA (1984 a): "Informe sobre las masas forestales de la comarca de Els Ports (Castellón)". ICONA, Instituto para la Conservación de la Naturaleza. MAPA, Ministerio de Agricultura, Pesca y Alimentación. 
ICONA (1984 b): "Situación de los pinares en gran parte de la comarca de Els Ports”. ICONA, Instituto para la Conservación de la Naturaleza. MAPA, Ministerio de Agricultura, Pesca y Alimentación.

ICONA (1986): "Proceso de datos y análisis de resultados para la estimación de las pérdidas de crecimiento de las masas de pino de Els Ports y El Maestrazgo en relación a la central térmica de Andorra (Teruel)". ICONA, Instituto para la Conservación de la Naturaleza. MAPA, Ministerio de Agricultura, Pesca y Alimentación.

ICONA (1988 a): "Resumen de las defoliaciones de los puntos de Castellón". ICONA, Instituto para la Conservación de la Naturaleza. MAPA, Ministerio de Agricultura, Pesca y Alimentación.

ICONA (1988 b): "Resumen de resultados del estudio de daños en los montes de Teruel, Castellón y Tarragona mediante interpretación de fotograma color infrarrojo". ICONA, Instituto para la Conservación de la Naturaleza. MAPA, Ministerio de Agricultura, Pesca y Alimentación.

ICONA (1991): "Información diversa de ICONA sobre la situación de las masas forestales de la comarca de Els Ports (Castellón)". ICONA, Instituto para la Conservación de la Naturaleza. MAPA, Ministerio de Agricultura, Pesca y Alimentación.

IRWIN, J. S. (1979): “A Theoretical Variation of the Wind Profile Power-Law Exponent as a Function of Surface Roughness and Stability". Atmospheric Environment, 13. Pp. 191-194.

IRWIN, J. S. (1985): "Modeling the diurnal variation of meteorological variables within the boundary layer. Preliminary comparison results". Air Pollution Modeling and Its Application V. Plenum Publishing Corporation. New York. Pp. 195-210.

JOHNSON, A. H. y SICCAMA, T. G. (1983): “Acid deposition and forest decline”. Environmental Science and Technology, 17. Pp. 294-305.

KALNAY et al. (1996): “The NCEP/NCAR 40-year reanalysis project”. Bulletin of the American Meteorological Society, 77. Pp. 437-470. 
LUCAS, D. H. et al. (1963): “The rise of hot plumes from chimneys”. International Journal of Air and Water Pollution, 7. Pp. 473-500.

MARTIN, J. y OLCINA, J. (1996): Tiempos y climas mundiales. Climatología a través de mapas del tiempo e imágenes de satélite. Oikos-tau. Barcelona. 320 pp.

MASTERS, G. M. y ELA, W. P. (2008): Introducción a la ingeniería medioambiental. Pearson, Prentice hall. Madrid. 752 pp.

MILLÁN, M. (2009): El ozono troposférico en el sur de Europa: aspectos dinámicos documentados en proyectos europeos. Fundación Centro de Estudios Ambientales del Mediterráneo (CEAM). 156 pp.

MILLÁN, M. et al. (1993): "Meso-meteorological Cycles of Air Pollution in the Iberian Peninsula, (MECAPIP PROJECT)". Air Pollution Research Report, 44, DirectorateGeneral for Science, Research and Development (DG XII/E). Comission of the European Communities. Brussels. 219 pp.

MILLÁN, M. et al. (1997): "Photo-oxidant dynamics in the Mediterranean basin in summer: results from European Research projects. Journal of Geophysical Research, 102. Pp. 8811-8823.

MILLÁN, M. et al. (2000): “Ozone Cycles in the Western Mediterranean Basin: Interpretation of Monitoring Data in Complex Coastal Terrain". Journal of Applied Meteorology, 39. Pp. 487-508.

MILLÁN, M. y SANZ, M. J. (1993): La contaminación atmosférica en la Comunidad Valenciana; estado de conocimientos sobre los problemas en El Maestrazgo y Els Ports de Castellón. Centro de Estudios Ambientales del Mediterráneo (CEAM). Valencia. 151 pp.

MOLLÀ, B. (2007): La decodificación dendroclimática en la vertiente mediterránea del Sistema Ibérico. Siglos XIX y XX. Tesis Doctoral Inédita. Universitat Jaume I. Castellón. 177 pp.

MONIN, A. S. y OBUKHOV, A. M. (1954): "Basic laws of turbulent mixing in the surface layer of the atmosphere". Trudy Geofizicheskogo Instituta, Akademiya Nauk SSSR, 24. Pp 163-187. 
NAVARro, G. y NAVARRO, S. (2013): Química Agrícola. Química del suelo y de los nutrientes esenciales para las plantas. Ediciones Mundiprensa. Madrid. Pp. 508.

NIEUWSTADT, F. (1978): "The computation of the friction velocity $\mathrm{u} *$ and the temperature scale $\mathrm{T} *$ from temperatute and wind velocity profiles by least-square methods". Boundary Layer Meteorology, 14. Dordrecht, Holland. Pp. 235-246.

NILU (Instituto Noruego de Investigación Atmosférica) (1985 a): "Resumen de los datos de los experimentos con trazador $\mathrm{SF}_{6}$ efectuados en la central térmica de Andorra (Teruel)". Informe final. MOPU, Ministerio de Obras Públicas y Urbanismo.

NILU (Instituto Noruego de Investigación Atmosférica) (1985 b): "Resolución sobre standards de calidad de aire para la protección de los bosques". MOPU, Ministerio de Obras Públicas y Urbanismo.

NILU (Instituto Noruego de Investigación Atmosférica) (1987 a): "Resultados del informe del Instituto Noruego para la protección del Medio Ambiente". MOPU, Ministerio de Obras Públicas y Urbanismo.

NILU (Instituto Noruego de Investigación Atmosférica) (1987b): "Modelización del penacho de la Central Eléctrica de Andorra (Teruel)". MOPU, Ministerio de Obras Públicas y Urbanismo.

NUÑEZ, S. (2004): Altura de la capa de mezcla: caracterización experimental y aplicación de un modelo meteorológico para el estudio de su evolución diurna. Tesis doctoral. Recuperado el 14 de marzo del 2016 de http://eprints.ucm.es/4622/1/T25482.pdf.

OLCINA, J. (1994): Riesgos climáticos en la Península Ibérica. Acción Divulgativa, S. L. Madrid. 440 pp.

OLIVER, A. (2015): Local Scale Air Quality Model System For Diagnostic And Forecasting Simulations Using The Finite Element Method. Doctoral Thesis. Departament de Matemàtica Aplicada III. Universitat Politécnica de Catalunya. 103 pp. Recuperado el 21 de febreo del 2016 de http://futur.upc.edu/17382680.

PASQUILL, F. (1961): "Estimation of the dispersion of windborne material". Meteorological Magazine, 90. Pp. 33-49. 
PASQUILL, F. (1979): “Atmospheric Dispersion Modeling”. Journal of the Air Pollution Control Association, 29. Pp. 117-119.

PASQUILL, F. y SMITH, F. B. (1983): Atmospheric Diffusion. 3rd Edition. Ellis Horwood (John Wiley \& Sons). New York. 437 pp.

PEY, J. (2007): Caracterización físico-química de los aerosoles atmosféricos en el Mediterráneo Occidental. Memoria de Tesis. Universidad Politécnica de Cataluña. 315 pp. Recuperado el 17 de octubre del 2015 de http://www.tdx.cat/handle/10803/6992.

PUIGCERVER, M. y CARRASCAL M. D. (2008): El medio atmosférico: meteorología y contaminación. Publicacions Universitat de Barcelona. Barcelona. 248 pp.

QUEREDA, J. (1985): “Ciclogénèse et convection dans le Levant Spagnol”, La Météorologie, Societée Météorologique de France, SMF, VII, 6. Toulouse, France. Pp. 6-10.

QUEREDA, J. (1987): “Les vents sur la côte orientale de l'Espagne”. Met-mar, Météorologie maritime, Direction de la Météorologie, 136. Boulogne-Billancourt, France. Pp. 24-29.

QUEREDA, J. (2005): Curso de climatología general. Col·lecció Universitas. Publicacions Universitat Jaume I. Castellón. 264 pp.

QUEREDA, J. et al. (1992): “Evolución y régimen del dióxido de carbono en Castellón (1987-1990)". En aportaciones en Homenaje al Profesor Luis Miguel Albentosa, Universidad de Tarragona. Tarragona. Pp. 305-319.

QUEREDA, J. et al. (1996): "Red dust rain within the Spanish Mediterranean Area". Climatic Change, 32. Pp. 215-228.

QUEREDA, J. et al. (2004): "La circulación aérea en el límite de la capa de fricción”, en Historia, clima y paisaje, Estudios geográficos en memoria del profesor Don Antonio López Gómez: Publicacions de la Universitat de València. València. Pp. 397-410.

QUEREDA, J. et al. (2009): Evaluación del cambio climático y de su impacto sobre los recursos hídricos en la Cuenca del Júcar. Fundación Agua y Progreso, Generalitat Valenciana. 165 pp. 
QUEREDA, J. et al. (2012): Climatología aeronáutica del aeropuerto de Castellón. Col·lecció Medi Ambient 9. Publicacions de la Universitat Jaume I. Castellón. 182 pp.

QUEREDA, J. et al. (2014): “El escenario atmosférico como modelo de gestión ambiental en la vertiente mediterránea del Sistema Ibérico”, en OLCINA, J. y RICO, A, M. (Ed.): Libro jubilar en homenaje al profesor Antonio Gil Olcina. Publicaciones de la Universidad de Alicante. Alicante. Pp. 107-123.

QUEREDA, J. y MONTÓN, E. (1996): “Dióxido de carbono y clima en el litoral mediterráneo". Investigaciones Geográficas, 16. Universidad de Alicante. Pp. 5-20.

QUEREDA, J. y OBIOL, E. (1986): “Incendios forestales y clima en la provincia de Castellón". Revista de Estudios Agrosociales, Ministerio de Agricultura, Alimentación y Medio Ambiente, 136. Madrid. Pp. 297-309.

QUEREDA, J. y OLCINA, J. (1994): "Incremento de lluvias de barro en la fachada mediterránea de la península Ibérica. ¿Un signo de cambio atmosférico?”, en Cambios y variaciones climáticas en España. Actas de la I reunión del grupo de climatología de la asociación de geógrafos españoles. Universidad de Sevilla. Fundación El Monte. Sevilla. Pp. 235-258.

QUEREDA, J. y TORRES, R. (1989): "Blocage et goutte froide sur le Levant Espagnol”. La Météorologie, Societée Météorologique de France, SMF, VII, 27. Toulouse, France. Pp. 2-7.

Red de Vigilancia y Control de la Calidad atmosférica de la Generalitat Valenciana. (2005-2015): Informes anuales. Disponibles en: http://www.habitatge.gva.es/web/calidadambiental/evaluacion-de-la-calidad-del-aire-informes-anuales.

SAN JOSÉ, R. et al. (1984): Torres meteorológicas y determinación de parámetros turbulentos. Universidad de Valladolid. 87 pp.

STULL, R. B. (1988): An Introduction to Boundary Layer Meteorology. Kluwer Academic. $666 \mathrm{pp}$.

SUTTON, O. G. (1932): "A theory of eddy diffusion in the atmosphere". Proceedings of the Royal Society of London, Series A, 135. Pp. 143-165. 
TECMENA, S. L. (Técnicas del Medio Natural) (1990): “Seguimiento de daños por la contaminación atmosférica en las masas forestales de la comarca de Els Ports (Castellón)” Informe final. Octubre-89/Marzo-90.

TECMENA, S. L. (Técnicas del Medio Natural) (1991): "Seguimiento de daños por la contaminación atmosférica en las masas forestales de la comarca de Els Ports (Castellón)" Informe final. Diciembre-90/Enero/Febrero-91.

TECMENA, S. L. (Técnicas del Medio Natural) (1992): "Seguimiento de daños por la contaminación atmosférica en las masas forestales de la comarca de Els Ports (Castellón)" Informe final. Septiembre-90/Febrero-92.

TURNER, D. B. (1970): Workbook of Atmospheric Dispersion Estimates. PHS Publication No. 999 AP-26. US Department of Health, Education and Welfare. National Air Pollution Control Administration, Cincinnati, Ohio. 84 pp.

TURNER, D. B. y SCHULZE, R. H. (2007): Practical Guide to Atmospheric Dispersion Modeling. Trinity Consultants. Inc., Dallas, TX, and Air and Waste Management Association, Pittsburgh. 408 pp.

VILLARRUBIA, M. (2012): Ingeniería de la energía eólica. Colección nuevas energías, 5. Marcombo, S. A. Barcelona. 283 pp.

WESTPHAL, D. L. et al. (1988): “A case study of mobilization and transport of Saharan dust". Journal of the Atmospheric Sciences, 45. Pp. 2145-2175.

ZILITINKEVICH, S. S. (1972): "On the determination of the height of the Ekman boundary layer". Boundary-Layer Meteorology. Volume 3, No 2. Pp. 141-145.

ZILITINKEVICH, S. S. (1975): "Resistance Laws and Prediction Equations for the Depth of the Planetary Boundary Layer". Journal of the Atmospheric Sciences, 32. Pp. 741 752 


\section{Referencias Webgráficas}

Biblioteca virtual de desarrollo sostenible y salud ambiental. Centro Panamericano de Ingeniería Sanitaria y Ciencias del Ambiente (CEPIS). Conceptos básicos sobre meteorología de la contaminación del aire: http://www.bvsde.paho.org/cursoa_meteoro/prologo.html.

NCEP Reanalysis data provided by the NOAA/OAR/ESRL PSD, Boulder, Colorado, USA: http://www.esrl.noaa.gov/psd.

Red Valenciana de Vigilancia y Control de la Contaminación Atmosférica (RVVCCA): http://www.habitatge.gva.es/web/calidad-ambiental/red-valenciana-de-vigilancia-y-controlde-la-contaminacion-atmosferica.

University of Wyoming. Departament of Atmospheric Sciences. Soundings: http://weather.uwyo.edu/upperair/sounding.html.

Modelo GFS (Global Forecast System). Wetterzentrale:

http://www.wetterzentrale.de/topkarten/fsreaeur.html.

http://www.wetterzentrale.de/topkarten/tkfaxbraar.htm. 


\section{Legislación: Decretos y Directivas}

DECRETO 161/2003, de 5 de septiembre, del Consell de la Generalitat, por el que se designa el organismo competente para la evaluación y gestión de la calidad del aire ambiente en la Comunidad Valenciana y se crea la Red Valenciana de Vigilancia y Control de la Contaminación Atmosférica. [2003/X10029] Publicado en: «DOCV» núm. 4588 de 16 de septiembre de 2003, páginas 23226 a 23228 (3 pp) Disponible en:

http://www.docv.gva.es/datos/2003/09/16/pdf/2003_X10029.pdf

DIRECTIVA (UE) 2015/2193 del Parlamento Europeo y del Consejo, de 25 de noviembre de 2015, sobre la limitación de las emisiones a la atmósfera de determinados agentes contaminantes procedentes de las instalaciones de combustión medianas. Publicado en: «DOUE» núm. 313, de 28 de noviembre de 2015, páginas 1 a 19 (19 pp) Departamento: Unión Europea Referencia: DOUE-L-2015-82361 Disponible en:

http://www.boe.es/diario_boe/txt.php?id=DOUE-L-2015-82361.

REAL DECRETO 102/2011, de 28 de enero de 2011. Publicado en: «BOE» núm. 25, de 29 de enero de 2011, páginas 9574 a 9626 (53 pp). Relativo a la mejora de la calidad del aire. Disponible en: https://www.boe.es/boe/dias/2011/01/29/pdfs/BOE-A-2011-1645.pdf. 
